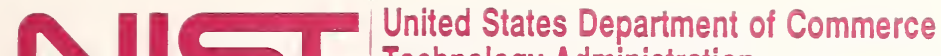 Technology Administration \\ National Institute of Standards and Technology \\ NIST SPECIAL PUBLICATION 854
}

\section{Report of the 78th National Conference on Weights and Measures}

1993

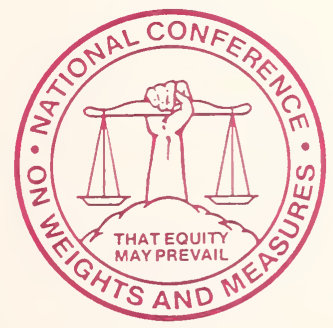




\section{Report of the \\ 78th National Conference on Weights and Measures}

Sponsored by the National Institute of Standards and Technology

Attended by Officials from the Various States, Counties, and Cities, and Representatives from U.S. Government, Industry, and Consumer Organizations

Kansas City, Missouri July 18-22, 1993

Report Editors: Carroll S. Brickenkamp, Ph.D.

Ann H. Turner

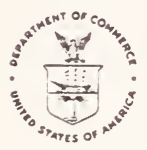

U.S. Department of Commerce

Ronald H. Brown, Secretary

Technology Administration

Mary L. Good, Under Secretary for Technology

National Institute of Standards and Technology

Arati Prabhakar, Director

Issued October 1993

Natl. Inst. Stand. Technol. Spec. Publ. 854, 422 pages (Oct. 1993)

CODEN:NSPUE2

U.S. GOVERNMENT PRINTING OFFICE

WASHINGTON: 1993

For sale by the Superintendent of Documents, U.S. Government Printing Office, Washington, DC 20402-9325 


\begin{abstract}
The 78th Annual Meeting of the National Conference on Weights and Measures (NCWM) was held July 18 through 22, 1993, at the Ritz-Carlton Hotel, Kansas City, Missouri. The theme of the meeting was "Excellence Through Standards."

Reports by the standing and annual committees of the Conference comprise the major portion of this publication, along with the addresses delivered by Conference officials and other authorities from government and industry.

Special meetings included those of the Metrologists, the Associate Membership Committee, the Retired Officials Committee, the Scale Manufacturers' Association, the American Petroleum Institute, the Industry Committee on Packaging and Labeling, the regional weights and measures associations, and the National Association of State Departments of Agriculture Weights and Measures Division, and the National Council on State Metrication.
\end{abstract}

Key words: legal metrology; motor-fuel dispensers; railroad track scales; safety; specifications and tolerances; training; type evaluation; uniform laws and regulations; weights and measures.

Library of Congress Catalog Card Number 26-27766.

Note: The policy of the National Institute of Standards and Technology is to use metric units of measurement in all of its publications; in this publication, however, recommendations received by the NCWM technical committees have been printed as they were submitted and, therefore, may contain references to inch-pound units. Opinions expressed in non-NIST papers are those of the authors and not necessarily those of the National Institute of Standards and Technology. Non-NIST speakers are solely responsible for the content and quality of their material. 


\section{Contents}

Abstract

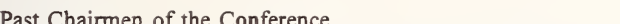

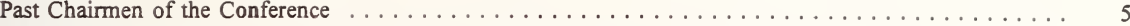

State Representatives . . . . . . . . . . . . . . . . . . . . . . . . . . . . 6

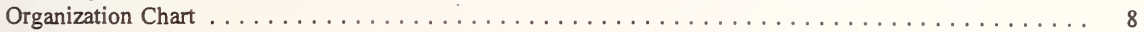

\section{General Session}

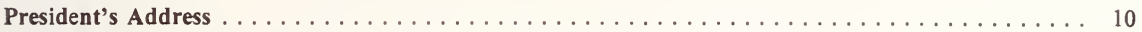

Dr. Arati Prabhakar, Director, National Institute of Standards and Technology

Chairman's Address . . . . . . . . . . . . . . . . . . . . . . . . . . . . 19

Alan M. Nelson, Director of Weights and Measures, Connecticut Dept. of Consumer Protection

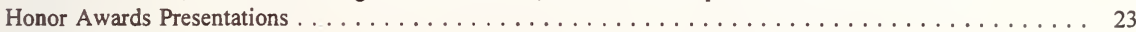

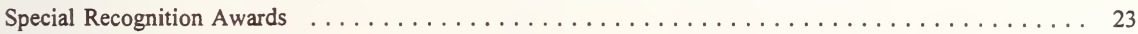

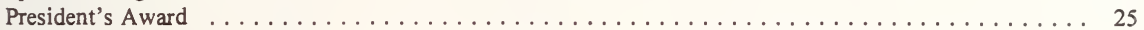

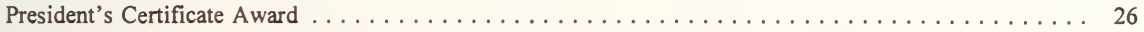

\section{Other Technical Presentations}

How A Regulatory Jurisdiction Implements The Use Of

The National Type Evaluation Program (NTEP) and Why - James C. Truex . . . . . . . . . 27

Technical Committee On National Type Evaluation - John J. Elengo . . . . . . . . . . . . . 30

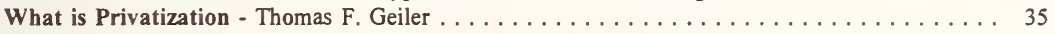

Excellence in OIML Recommendations -

Excellence Through OIML Recommendations - A Step Forward . . . . . . . . . . . . . . . 39

Bernard Athané and Kristine French

Harmonization and Mutual Recongition - Robert Bruce . . . . . . . . . . . . . 42

\section{Standing Committee Reports}

Report of the Executive Committee . . . . . . . . . . . . . . . . . . . . . . 45

Report of the Laws and Regulations Committee . . . . . . . . . . . . . . . . . . . . . . . . 209

Report of the Specifications and Tolerances Committee . . . . . . . . . . . . . . . . . . . 283

Report of the Committee on Education, Administration, and Consumer Affairs . . . . . . . . . . . . . 343

Metrology Working Group Report $\ldots \ldots \ldots \ldots \ldots \ldots \ldots \ldots \ldots \ldots \ldots$

\section{Annual Committee Reports}

Report of the Resolutions Committee $\ldots \ldots \ldots \ldots \ldots \ldots \ldots \ldots \ldots \ldots \ldots$

Report of the Nominating Committee . . . . . . . . . . . . . . . . . . . . . . . . 383

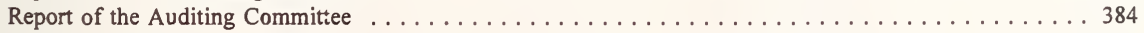

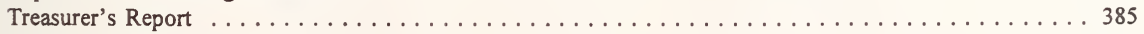

New Chairman's Address $\ldots \ldots \ldots \ldots \ldots \ldots \ldots \ldots \ldots \ldots \ldots \ldots$

Thomas F. Geiler, Director of Consumer Affairs, Barnstable, MA

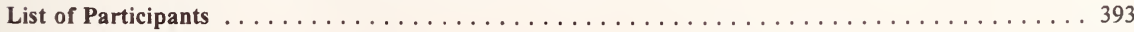




\section{Past Chairmen of the Conference}

\section{CONFERENCE YEAR CHAIRMAN}

\begin{tabular}{lll} 
43rd & 1958 & J. P. McBride, MA \\
44th & 1959 & C. M. Fuller, CA \\
45th & 1960 & H. E. Crawford, FL \\
46th & 1961 & R. E. Meek, IN \\
47th & 1962 & Robert Williams, NY \\
48th & 1963 & C. H. Stender, SC \\
49th & 1964 & D. M. Turnbull, WA \\
50th & 1965 & V. D. Campbell, OH \\
51st & 1966 & J. F. True, KS \\
52nd & 1967 & J. E. Bowen, MA \\
53rd & 1968 & C. C. Morgan, IN \\
54th & 1969 & S. H. Christie, NJ \\
55th & 1970 & R. W. Searles, OH \\
56th & 1971 & M. Jennings, TN \\
57th & 1972 & E. H. Black, CA \\
58th & 1973 & George L. Johnson, KY \\
59th & 1974 & John H. Lewis, WA \\
60th & 1975 & Sydney D. Andrews, FL \\
61st & 1976 & Richard Thompson, MD \\
62nd & 1977 & Earl Prideaux, CO \\
63rd & 1978 & James F. Lyles, VA \\
64th & 1979 & Kendrick J. Simila, OR \\
65th & 1980 & Charles H. Vincent, TX \\
66th & 1981 & Edward H. Stadolnik, MA \\
67th & 1982 & Edward C. Heffron, MI \\
68th & 1983 & Charles H. Greene, NM \\
69th & 1984 & Sam F. Hindsman, AR \\
70th & 1985 & Ezio F. Delfino, CA \\
71st & 1986 & George E. Mattimoe, HI \\
72nd & 1987 & Frank Nagele, MI \\
73rd & 1988 & Darrell A. Guensler, CA \\
74th & 1989 & John J. Bartfai, NY \\
75th & 1990 & Fred A. Gerk, NM \\
76th & 1991 & N. David Smith, NC \\
77th & 1992 & Sidney A. Colbrook, IL \\
& & \\
\hline
\end{tabular}




\section{State Representatives}

The following designated State representatives were present and voted on reports presented by the Conference standing and annual committees:

\begin{tabular}{|c|c|c|}
\hline State & Representative & Alternate \\
\hline Alabama & Don. E. Stagg & Charles A. Burns, Jr. \\
\hline Alaska & Aves D. Thompson & None \\
\hline American Samoa & None & None \\
\hline Arizona & Sharon S. Rhoades & None \\
\hline Arkansas & James M. (Mike) Hile & Bill Sullivant \\
\hline California & Darrell A. Guensler & Barbara Bloch \\
\hline Colorado & David Wallace & None \\
\hline Connecticut & Allan M. Nelson & Raymond Kalentkowski \\
\hline Delaware & William Lagemann & None \\
\hline District of Columbia & Jeffrey X. Mason & Richard Siegel \\
\hline Florida & Maxwell H. Gray & Jack Jeffries \\
\hline Georgia & Curtis P. Williams & James H. Wilson, Jr. \\
\hline Guam & None & None \\
\hline Hawaii & James E. Maka & None \\
\hline Idaho & Glen H. Jex & Tom Schafer \\
\hline Illinois & Sidney A. Colbrook & Rich Philmon \\
\hline Indiana & Michael A. Horan & Charles E. Critzer \\
\hline lowa & Darryl L. Brown & None \\
\hline Kansas & DeVern H. Phillips & Charles "Bud" Frieze \\
\hline Kentucky & Danny R. Willis & Randy Wise \\
\hline Louisiana & None & None \\
\hline Maine & Clayton F. Davis & Stanley Millay \\
\hline Maryland & Louis E. Straub & Constantine V. Cotsoradis \\
\hline Massachusetts & Charles H. Carroll & None \\
\hline Michigan & Edward C. Heffron & Celeste Bennett \\
\hline
\end{tabular}




\begin{tabular}{|c|c|c|}
\hline State & Representative & Alternate \\
\hline Minnesota & Michael F. Blacik & Mark V. Buccelli \\
\hline Mississippi & None & None \\
\hline Missouri & Lester H. Barrows & None \\
\hline Montana & None & None \\
\hline Nebraska & Steven A. Malone & Richard C. Suiter \\
\hline Nevada & None & None \\
\hline New Hampshire & Michael F. Grenier & Richard Cote \\
\hline New Jersey & Herbert Sehgel & None \\
\hline New Mexico & Gary D. West & None \\
\hline New York & John J. Bartfai & Ross Andersen \\
\hline North Carolina & N. David Smith & Ronald D. Murdock \\
\hline North Dakota & None & None \\
\hline Ohio & John Steinberger, Jr. & Jim Truex \\
\hline Oklahoma & Charles Carter & Ken Fraley \\
\hline Oregon & Ken Simila & None \\
\hline Pennsylvania & Dean F. Ely & A. Courtney Yelle \\
\hline Puerto Rico & Juan Rodriguez & None \\
\hline Rhode Island & None & None \\
\hline South Carolina & Carol P. Fulmer & None \\
\hline South Dakota & Michael Kumm & None \\
\hline Tennessee & Robert G. Williams & Cathryn Pittman \\
\hline Texas & Ed Price & James H. Eskew \\
\hline Utah & David O. McKay & None \\
\hline Vermont & Bruce Martell & None \\
\hline Virginia & J. Alan Rogers & G. Wes Diggs \\
\hline Virgin Islands & Clement Magras & Joycelyn Encarnacion \\
\hline Washington & Bob Arrington & None \\
\hline West Virginia & None & None \\
\hline Wisconsin & Alan J. Porter & Jim Akey \\
\hline Wyoming & Vic Gerber & None \\
\hline
\end{tabular}


Operating Committees

\begin{tabular}{|c|}
\hline \multicolumn{1}{|c|}{ Auditing Committee } \\
\hline Chairman: E. Hanish, Laporte Co., IN (1) \\
Members: J. H. Eskew, TX (3) \\
R. Gunja, Kansas City, KS (2) \\
Coordinator: J. Mindte, NIST \\
\hline
\end{tabular}

\begin{tabular}{|c|}
\hline Resolutions Committee \\
\hline Chairman: G. Jex, ID (1) \\
Members: C. Fulmer, SC (3) \\
M. Grenier, NH (1) \\
R. Gunja, Kansas City, KS (1) \\
W. Lagemann, DE (3) \\
B. Martell, VT (3) \\
R. Philmon, IL (3 \\
E. Price, TX (1) \\
A. Thompson, AK (1) \\
Coordinator: J. Mindte, NIST
\end{tabular}

\begin{tabular}{|c|}
\hline Sergeants-At-Arms \\
\hline $\begin{array}{l}\text { John Albert, MO } \\
\text { John Shephard, MO }\end{array}$ \\
\hline
\end{tabular}

Standing Committees

\begin{tabular}{|c|c|}
\hline \multicolumn{2}{|c|}{$\begin{array}{c}\text { Specifications \& Tolerances } \\
\text { Committee }\end{array}$} \\
\hline Chairman: & C. Carroll, MA (1) \\
\hline Members: & $\begin{array}{l}\text { J. Jeffries, FL (2) } \\
\text { R. Kelley, NYC, NY (5) } \\
\text { R. Suiter, NE (3) } \\
\text { G. West, NM (4) }\end{array}$ \\
\hline Tech Advisors: & $\begin{array}{l}\text { T. Butcher, NIST } \\
\text { R. Marceau, Canada } \\
\text { H. Oppermann, NIST }\end{array}$ \\
\hline Liaison Rep: & J. Lacy USDA, P\&SA (2) \\
\hline
\end{tabular}

\begin{tabular}{|c|c|}
\hline \multicolumn{2}{|c|}{$\begin{array}{l}\text { Education, Administration, \& } \\
\text { Consumer Affairs Committee }\end{array}$} \\
\hline Chairman: & R. Kalentkowski, CT (1) \\
\hline Members: & $\begin{array}{l}\text { B. DeSalvo, OH (4) } \\
\text { M. Gray, FL (3) } \\
\text { J. Harnett, Orange Co., CA (2) } \\
\text { E. Price, TX (5) }\end{array}$ \\
\hline \multicolumn{2}{|c|}{$\begin{array}{l}\text { Tech Advisor: J. Koenig, NIST } \\
\text { Llaison Rep: C. Davis, ME (3) }\end{array}$} \\
\hline \multicolumn{2}{|c|}{ NCWM Safety Liaison } \\
\hline Chairmar & C. Gardner, Suffolk Co., NY \\
\hline
\end{tabular}
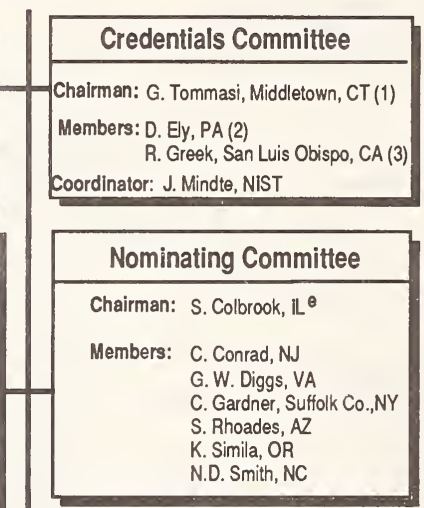

\begin{tabular}{|l|}
\hline Budget Review Committee \\
\hline Chairman: \\
A. Nelson, CT \\
Members: S. Colbrook, IL \\
H. Lodge, Dunbar \\
N. David Smith, NC \\
C. Gardner, Suffolk Co., NY \\
C. Brickenkamp, NIST ${ }^{\theta}$ \\
\hline
\end{tabular}

Laws and Regulations
Committee

\begin{tabular}{|ll|}
\hline Chairman: & F. Clem, Columbus, $\mathrm{OH}(1)$ \\
Members: & B. Bloch, CA (2) \\
& S. Millay, ME (5) \\
& S. Rhoades, AZ (3) \\
& L. Straub, MD (4) \\
Tech Advisors: & K. Butcher, NIST \\
& G. Vinet, Canada \\
Llaison Reps: & L. Barrows, MO (4) \\
& W. Braun, \\
& WHB Resources (5)
\end{tabular}

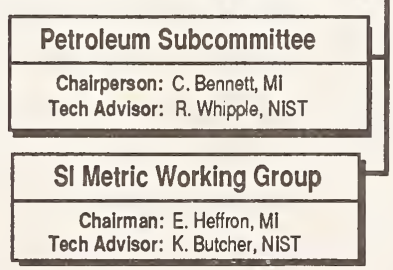
and NTEP Board of Governors

Chairman! A. Nelson, CT

Chairman-Eiect: T. Geiler, Barnstable, MA

Past Chairman: ${ }^{e}$

BoG Cha irman: S. Colbrook, IL

Treasurer: ${ }^{e} \quad$ C. Gardner, Suffolk Co., NY

One Year: R. Andersen, NY

P. Nichols, Alameda Co., CA

Two Years: D.Guensler, CA

S. Malone, NE

Three Years: J. A. Rogers, VA

J. Truex, $\mathrm{OH}$

President: ${ }^{n, e}$ NIST Director

Executive Secretary ${ }^{n, e}$ C. Brickenkamp, NIST

Technical Advisor: ${ }^{\text {n }}$ R. Bruce, Canada

(Exec. Cmte. Only)

Liaison Rep: A. Thompson, AK

Weights and Measures Coordinator

A. Turner, NIST
Liaison Committee Coordinator
K. Newell, NIST

\begin{tabular}{|l|}
\hline \multicolumn{1}{|c|}{ Other Elected Officers } \\
\hline Vice-Chairmen: \\
M. Gray, FL \\
R. Greek, San Luis Obispo, CA \\
R. Kelley, NYC, NY \\
D. Phillips, KS \\
\hline
\end{tabular}

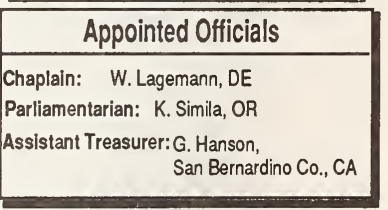

\begin{tabular}{|l|l|}
\hline \multicolumn{1}{|c|}{$\begin{array}{l}\text { Privatization } \\
\text { Work Group }\end{array}$} \\
\hline Chairman: & T. Geiler, Barnstable, MA \\
Members: & S. Colbrook, IL \\
J. Colman, FMi \\
D. Guensle, CA \\
R. Hutton, Winn-Dixie \\
N. D. Smith, NC \\
T. Stabler, Mettler-Toledo \\
D. Tonini, SMA \\
- R. Tucker, Tokheim \\
Technical Advisor: C. Brickenkamp, NIST \\
\hline
\end{tabular}

Revised: April 1993 


\section{National Conference on Weights and Measures}

\section{Associate Membership} Committee

Chairman: D. Quinn, Fairbanks Scales Vice Chairman: C. Guay, Procter \& Gamble Secretary: B. Peterson, API

Treasurer: T. Stabler, Mettler-Toledo, Inc.

Members: I. Bell, Coca-Cola Company W. Braun, WHBraun Resources R. Davis, James River Corp.

T. James, Cardina//Detecto C. Kloos, Hunt-Wesson Foods D. Walker, Marathon Petrol. Co.

\begin{tabular}{|c|}
\hline Belt Conveyor Scales Sector \\
\hline Chairman: \\
(to be named) \\
\hline Technical Advlsor: R. Whipple, NIST \\
\hline Public Members \\
\hline C. Bertand, Canada \\
C. Cotsoradis, MD \\
R. Miller, CO \\
H. Oppermann, NIST \\
O. Warnlof, NIST
\end{tabular}

Private Sector

W. Brasher, Southern Co. Services, Inc. G. Burger, Consultant

M. Casanova, Ramsey Tech., Inc.

P. Chase, Envirotech

D. Cockrell, Consultant

R. Dietrich, Kaskaskia Valley Scale Co.

R. DeSollar, Central IL Public Service Co.

S. Gibson, ABC Scale

N. Johnson, Merrick Corp.

T. Johnson, Sensortronics

K. Knapp, Milltronics

F. Joe Loyd, CSX Transportation

J. MacFarlane, CST AutoWeigh Co.

J. Oliver, Virginia Power

N. Ortyl, III, Dresser Industries

R. Penner, Riede Systems

J. Robinson, Assoc. of American Railroads

P. Sanford, Thayer Scale

D. Tonini, Scale Manufacturers Assoc.
National Type Evaluation

Technical Committee

Chairman: J. Elengo, Jr.,

Revere Transolucers

Checkweigher Working Group

Chairman: Dennis Johannes, CA

Tech Advlsor: K. Butcher, NIST

\begin{tabular}{|c|}
\hline Weighing Sector \\
\hline $\begin{array}{r}\text { Chairman: J. Elengo, Jr., Revere } \\
\text { Transducers } \\
\text { Technical Advisor: T. Butcher, NIST }\end{array}$ \\
\hline Public Members \\
\hline $\begin{array}{ll}\text { R. Andersen, NY } & \text { R. Pforr, USDA-FGIS } \\
\text { C. Bertrand, Canada } & \text { H. Oppermann, NIST } \\
\text { C. Conrad, Jr., NJ } & \text { J. Truex, OH } \\
\text { C. Cotsoradis, MD } & \text { O. Warnlof, NIST } \\
\text { D. Guensler, CA } & \text { K. Yee, NIST } \\
\text { J. Lacy, USDA-P\&SA } & \end{array}$ \\
\hline Private Sector \\
\hline $\begin{array}{l}\text { M. Adams, Fairbanks Scales } \\
\text { J. Antkowiak, Hottinger Baldwin Msmts. } \\
\text { W. Goodpaster, Cardinal/Detecto } \\
\text { K. Haker, BLH Electronics } \\
\text { T. Johnson, Sensortronics } \\
\text { D. Krueger, NCR Corp. } \\
\text { G. Lameris, PMI Food Equipment } \\
\text { H. Lockery, Lockery Assoc. } \\
\text { J. MacDonald, Chronos Richardson } \\
\text { J. Robinson, Assoc. of Am. Railroads } \\
\text { T. Stabler, Mettler-Toledo, Inc. } \\
\text { D. Tonini, Scale Manufacturers Assoc. } \\
\text { J. Wang, A\&D Engineering, Inc. }\end{array}$ \\
\hline
\end{tabular}

\section{ISO 9000 Task Force}

Industry Members:

R. Calkins, Rice Lake Weighing Systems

Regional Public Members

M. Dyni, CT

J. Everhart, EG\&G

Mound Applied

Technologies

M. Kline Troemner, Inc

R. Weber, $3 M$

Technlcal Advisor. Georgia Harris, NIST

$$
\text { Legend }
$$

$n$ - Non-Voting e - Ex-Officio

Numbers in parentheses refer to years remaining to

serve on committees.

State and local government officials are identified by

their State abbreviations.

USDA - U.S. Department of Agriculture

P\&SA - Packers \& Stockyards Administration

FGIS - Federal Grain Inspection Service

OIML - International Organization of Legal Metrology

NIST - National Institute of Standards and Technology

\begin{tabular}{|c|}
\hline Measuring Sector \\
\hline $\begin{array}{l}\text { Chairman: N. Alston } \\
\text { Daniel Flow Products, Inc. }\end{array}$ \\
\hline Technical Advisor: T. Butcher, NIST \\
\hline Public Members \\
\hline $\begin{array}{l}\text { R. Andersen, NY } \\
\text { C. Cotsoradis, MD } \\
\text { D. Guensler, CA } \\
\text { J. Jeffries, FL } \\
\text { S. Malone, NE } \\
\text { D. Morgan, Canada } \\
\text { R. Murdock, NC } \\
\text { H. Oppermann, NIST } \\
\text { J. Truex, OH } \\
\text { O. Warnlof, NIST } \\
\end{array}$ \\
\hline Private Sector \\
\hline $\begin{array}{l}\text { F. M. Belue, Belue Associates } \\
\text { R. Fonger, Bennett Pump } \\
\text { M. Hankel, Liquid Controls } \\
\text { F. Holland, Schlumberger Technologies } \\
\text { G. Johnson, Gilbarco } \\
\text { M. Keilty, Micro Motion, Inc. } \\
\text { D. Krueger, NCR Corp. } \\
\text { C. Kunkel, EMARK Corp. } \\
\text { L. Murray, Dresser Industries, Inc. } \\
\text { R. Rall, Texaco Refining Co. } \\
\text { T. Scott, Brooks Instrument Co. } \\
\text { J. Skuce, Smith Meter, Inc. } \\
\text { D. Smith, William M. Wilson's Sons } \\
\text { R. Tucker, Tokheim, Corp. }\end{array}$ \\
\hline
\end{tabular}

Grain Moisture Meter Sector and

Near Infrared Protein Analyzer Sector

Chairman: L. Hill, Univ. of Illinois Technical Advisor: R. Pierce, USDA-FGIS

\section{Public Members}

Canadian Grain Commission

R. Burns, AR

T. Butcher, NIST

D. Funk, FGIS

H. Oppermann, NIST

J. Rothleder, CA

C. Tew, NC

R. Wittenberger, MO

R. Wotthlie, MD

Private Sector

J. Bair, Millers National Federation

J. W. Barber, Dickey-John Corp.

A. Butler, Perten Instruments

M. Emori, Kett Electric Laboratory

C. Hurburgh, Jr., lowa State University

D. Kaminsky, Trebor

J. McClenethan, Growmark, Inc.

T. McLain, Sartorius Instruments

T. O'Connor, Natl. Grain \& Feed Assn.

A. Pflug, CSC Scientific

T. Runyon, Seedboro Equipment $\mathrm{Co}$.

F. Seeber, Shore Sales Co., Grain Elevator and Processors Society

C. Watson, Stein Labs, Perstorp Analytical, Foss Foods

(Grain Moisture Meter Sector only) 
Editor's Note: Dr. Arati Prabhakar, Director of the National Institute of Standards and Technology was unable to attend the 78th Annual Meeting of the National Conference on Weights and Measures. As a result of her last minute inability to participate in the Conference, Dr. Edward Heffron, Director, Food Division, Michigan Department of Agriculture, and a member of the NIST Visiting Committee, delivered the following remarks in her behalf.

Dr. Heffron:

Dr. Prabhakar sends her regrets that she could not visit with you or address you today. She is testifying on Capitol Hill today, as part of her effort to obtain the biggest budget increase in NIST's history, during a time of reduced resources throughout the nation. NIST has tightened its belt for almost a generation in its base programs, and this budget is meant to revitalize these programs, including NIST's investment in weights and measures. So she hopes that you understand: her job is to get money to operate. She is transmitting the same vision she was going to present in her speech here about the overall plans for technology outreach to Congress today. We all hope it "plays well."

Arati is impressed with the history of weights and measures in this country and the roles both NIST and the States have played in legal metrology. She also wants to provide you graphical descriptions of the size of the job that needs accomplishing in our economy. You all have copies of her speech, and I will only paraphrase what she has told me and the substance of what we should focus upon. 


\title{
Partnerships for the Future
}

\author{
Arati Prabhakar \\ Director, National Institute of Standards and Technology
}

I am honored to greet you today as the new Director of the National Institute of Standards and Technology and, accordingly, the new President of the National Conference on Weights and Measures.

I want to use this opportunity to describe for you our vision of the future - for NIST, for NCWM, and for our nation. To do that, let's set the NCWM into the context of the new roles and tasks of NIST.

When Congress passed the Omnibus Trade and Competitiveness Act in 1988, the National Bureau of Standards was renamed the National Institute of Standards and Technology, because the Administration and the Congress had a vision of the future for NIST. However, I suspect that from your perspective, nothing much seemed to happen for several years, other than "Standards" becoming our middle name instead of our last. But in fact, NIST is at a turning point in an evolution, as is much of the Federal government generally. NIST is improving its services in response to its customers. In many instances, we have formed partnerships with our customers, and, in a real sense, given them a stake in the outcome of our work. Vice President Gore has called this part of the process "reinventing government."

This partnership concept is not entirely new: NIST has been deeply concerned with customer feedback and collaborations since its founding. We continue to adhere to our founding mission, which includes (and I quote) "cooperation with other government agencies and with private organizations in the establishment of standard practices, incorporated in codes and specifications..." The NCWM has certainly been successful with this cooperative approach - having given citizens a stake in the outcome for nearly 90 years.

However, the future must always build on a dynamically changing past. If our plans for technology investment become a reality, as we hope and expect that they will, the NIST and national weights and measures programs will be reinvigorated and strengthened. Although the NIST Office of Weights and Measures will then represent a much smaller percentage of a greatly increased overall program, it will be no less important. Let me elaborate:

The Federal government provides $45 \%$ of the total research and development investment in the United States, which amounts to $\$ 150$ billion per year. At the present time, $60 \%$ of the Federal government investment is for defense, and only $0.5 \%$ for industrial development. The Administration plans to:

- invest in civilian technology, an increasingly important role for NIST;

- drive the defense investment toward dual use -- both military and civilian -- of technologies invented for defense applications; and

- transfer more technology from government laboratories into the private industrial and business sectors.

In President Clinton's "Vision of Change for America," which accompanied his State of the Union message, the President stated his intention to establish a program at NIST with "over 100 manufacturing extension centers nationwide by 1997 to assist manufacturers to modernize their production capability." This new program is a mechanism to help get technology to the 350,000 small and medium-sized manufacturers that are such a vital part of our industrial base. NIST calls this program the "Manufacturing Extension Partnership" (MEP).

\section{Manufacturing Technology Centers}

One part of the MEP is the Manufacturing Technology Centers program or MTC, created by the 1988 Omnibus Trade and Competitiveness Act. The MTC objective is to improve the competitiveness of U.S.-based small and medium-sized manufacturers by advancing their levels of technology utilization. One of the seven centers is right next door in Overland Park, Kansas. At these centers, companies can get in-depth assessments of their manufacturing and business operations. As an outgrowth, many companies have subsequently established partnerships with NIST. They have licensed federal 
technologies, designed new processes, and introduced new products into the marketplace as a direct result of this program.

\section{Other Components of the Manufacturing Extension Partnership}

Thirty-four States have participated in the State Technology Extension Program (STEP), which provides technical assistance and funding to States for planning and implementing a State-based industrial extension infrastructure. If the President's Budget is passed, Manufacturing Outreach Centers will be established to serve areas of the nation that do not have heavy concentrations of industry, or to serve as MTC satellites. In addition, all of the modernization service providers and the sources of technology will be linked together using modern computer networks.

\section{Advanced Technology Program}

The major area of growth in NIST's partnerships is the Advanced Technology Program (ATP), which is designed to accelerate the development and commercialization of technology and refine manufacturing practices. ATP features a competitive process for funding partnerships for successful business ventures. Manufacturing projects are already under way with a variety of companies and consortia.

The President calls for the NIST outreach programs to grow enormously in the next few years. They will soon exceed the size of the internal programs at NIST.

Having said this, however, neither NIST -- nor even the Federal government as a whole -- can meet all of the current and future challenges alone. Thus, I want to emphasize other partnerships for our future, not just in our outreach programs, but in our laboratory and technology services programs as well.

The economic future of every one of us in this nation hangs in a balance of our own manufacture (puns intended). We must cooperate with each other, forming and strengthening partnerships -- putting an end to the divisiveness and adversarial relationships that have been so common among regulatory agencies and the industries they regulate. This is but one of the reasons that impelled me to come here: to learn from the success of the National Conference on Weights and Measures in bringing erstwhile adversaries together.

I want to reassure you of our commitment to the values and history upon which both NIST and the NCWM were founded. As the philosopher Santayana said, those who do not learn from history are doomed to repeat it. For this reason, I have chosen for my inaugural NCWM address a review of some of this history. This will become the basis for establishing a vision for our future joint successes. Our shared history with NCWM and other successful standardsdevelopment partnerships can help us design future solutions as well as addressing today's problems. Let us reduce the total effort needed by government and industry to achieve common goals, and increase our efficiency and effectiveness in solving our problems.

\section{Laboratory Standards}

Many of you already know that the Office of Weights and Measures (OWM) predates the National Bureau of Standards. The OWM was established because of our Nation's desperate need for standards! OWM was established in 1836 as part of the Treasury Department with the objective of constructing a set of weights and measures (and balances to intercompare them) for each State and customhouse "...to the end that a uniform standard of weights and measure may be established throughout the United States." This momentous work was begun by, and directly the result of, intercomparisons made years earlier by Ferdinand Rudolph Hassler, when he was the Superintendent of the Coast Survey.

As more stars were added to the U.S. flag, sets of standards and balances were constructed and presented to the new States until 1893, when a national depression precluded further presentations. However, this program became the basis for what metamorphosed into the "new" State Standards Program. Begun in the 1960's, the State Standards Program is a very real partnership between NIST and the States.

In return for providing a suitable laboratory environment and full-time metrologist, NIST provided each State training for its metrologists, a set of mass, length, and volume standards, and instruments to intercompare the standards with unknowns. Since the initiation of the program in 1966, States have gone on to add to their repertoire in liquid-in-glass thermometry, frequency, motor fuel quality, and moisture measurements. The program now encompasses continuing 
education at advanced levels of expertise, regional measurement metrology groups with industry, laboratory assessment, and accreditation. As you know, the State laboratories are an integral part of our legal metrology system, providing thousands more calibrations than NIST can provide, in 50 (of a potential 55) accredited laboratories. We have been successful in transferring technology to the States, and they have been found an indispensable part of technological services to their businesses and industry.

I am pleased to report that, contingent on passage by Congress of the President's Budget for Fiscal Year 1994, the NIST Office of Weights and Measures will establish a very-high-precision mass calibration capability to assist NIST OWM's partners, the State Weights and Measures Laboratories. They will then be better able to respond to their customers and partners, including other government agencies, local businesses and industry. I understand that Georgia Harris, NIST's manager of the State Standards Program, has already begun to prepare for this growth by training private laboratory and State metrologists to use the NIST Mass Code Software to analyze mass calibration data. She works with a rather large network of metrologists across the country. These metrologists are building quality into the measurement services they provide to industry and government by partnering with NIST, with private industry, and with each other.

\section{The National Conference on Weights and Measures}

I am very impressed that we have achieved the level of uniformity of quantities and trading standards we all take for granted in our everyday life because of the voluntary contributions and sacrifices of individuals at State and local agencies, businesses, and NIST, in the consensus committee process that is the National Conference on Weights and Measures.

I was intrigued to learn how closely the development of the National Bureau of Standards (NBS) and the NCWM are intertwined. NBS was founded by Congress in March of 1901. At that time, there was only a name, a director, Samuel Wesley Stratton from the University of Chicago, and the Office of Weights and Measures (made famous by Hassler). The OWM and its director, Louis A. Fischer, were transferred from Treasury as the core unit of NBS. Thus, the National Bureau of Standards grew from the Office of Weights and Measures in much the same way as the National Institute of Standards and Technology grew from the National Bureau of Standards.

Within weeks of NBS' founding in the spring of 1901, Mr. Fischer visited New York and questioned State and city officials about their inspection of commercial weights and measures. The answers prompted him to compile the weights and measures laws of all the States. As R.C. Cochrane's book "Measures for Progress" relates, Fischer found (and I again quote) "a hopeless tangle of regulations, as remarkable for their variety as for their inadequacy." As a result of Fischer's findings, Dr. Stratton, NBS Director, proposed to the State Governors, as early as 1903, a meeting of State "sealers of weights and measures." It was not until January 1905, however, that the first meeting could be held, and then representatives of only seven States and the District of Columbia met. It is most interesting, however, that an industry representative also came to this meeting, from Fairbanks Scales, still a vital company and strong leader in the National Conference today. That individual contributed as much to the discussions as any other delegate. This obviously set the tone for cooperation and collaboration that has persisted ever since.

Due to the need expressed by those present at that first meeting, the new National Bureau of Standards agreed to host further meetings to discuss means to secure uniform laws and inspection of commercial weights and measures. The very next year, in April 1906, it was decided to set up a permanent organization of State officials. Thus, the 1905 gathering has been dubbed the "First Annual Meeting" of the National Conference on Weights and Measures.

Among the first objectives of the Conference was the development of a model weights and measures law to be offered for adoption by all the States. That law was drafted by Louis Fischer and unanimously adopted by the National Conference. More was required, however, to inspire States to adopt it. With a special

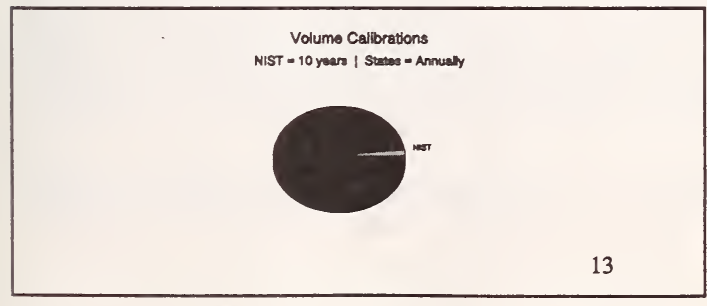
Congressional appropriation of $\$ 10,000$, Bureau inspectors visited every State between 1909 and 1911, testing more than 30,000 scales, weights, and measures in more than 3000 retail shops. Nearly half of the scales, $20 \%$ of the weights, half the dry measures and 


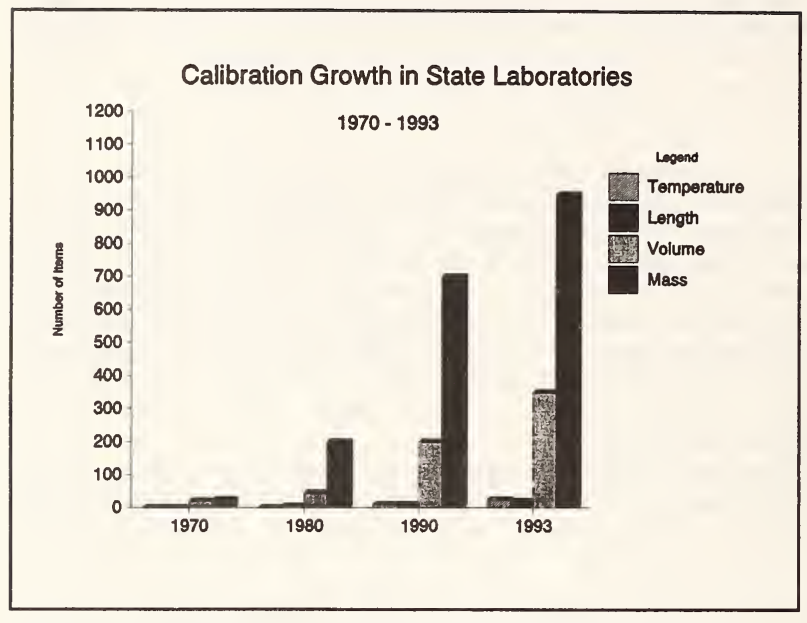

$25 \%$ of the liquid measures were not only grossly inaccurate, but also in the favor of the shopkeeper. The Bureau estimated that consumers lost more than $\$ 8$ million from short weight butter alone! Reports of these tests and disclosures in the press initiated a crusade soon joined by the States and major cities: New Jersey adopted the new NCWM model weights and measures law in 1911, and all the States eventually established weights and measures inspection agencies. The partnership with State and local governments thus began in earnest.

The needs of the marketplace were not fully satisfied by testing and regulating retail small capacity sales. Another special appropriation from Congress, in 1913, allowed the

State Laboratory Customer Base

1970 Workload

1993 Wonkload
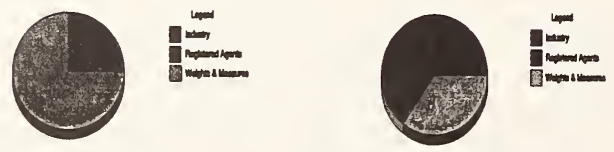

Bureau to construct a special railway scale test car to assist the Interstate Commerce Commission. The car was designed to transport mass standards to determine whether railroad, elevator, grain-hopper and other large capacity scales used to determine freight charges in interstate shipments were accurate. This again further strengthened the partnership with device manufacturers: A.H. Emery Company built the special test car for NBS.

Testing uncovered overwhelming problems: between 75 and $80 \%$ of the tested track scales were found to be grossly in error. Few States were willing to initiate inspection of railroad weighing, even if they could afford the equipment. Unannounced testing was impossible since the railroads had to move the test equipment. However, the railroads were more than willing to work with the Bureau (and I quote from "Measures for Progress") to "...'get right' with the public again." A railroad "master scale" testing program was begun and continues to this day, now funded by the Association of American Railroads and the U.S. Department of Agriculture's Federal Grain Inspection Service, to which agency the program was transferred from NIST in the 1970's. This history is especially pertinent in light of the major issues on coupled-in-motion weighing on the agenda this week.

In 1918, NBS conducted a similar investigation of scales upon which the wages of coal miners were based; they found that all scales read beyond allowable errors. One scale with a capacity of $2000 \mathrm{lb}$ was found with an error of $616 \mathrm{lb}$. The Bureau again investigated scale accuracy in 1936, this time for truck-weighing scales. In the first year, the Bureau found that $80 \%$ of the 400 commercial scales exceeded allowable tolerances, usually resulting in dangerously overloaded trucks and badly abused highway surfaces. By 1941, all the then 48 States had been visited and their weights and measures agencies supplied with inspection data and specifications for test equipment and procedures for testing truck scales.

Today, as a result of the partnerships forged at these early activities and nurtured through nearly 90 years of cooperation, all 50 States and every territory and possession have a weights and measures law modeled after the latest recommendation 
of the NCWM at the time of its adoption by the jurisdiction. Every jurisdiction has adopted NIST Handbook 44 "Specifications, Tolerances, and Other Technical Requirements for Weighing and Measuring Devices," as its regulation, generally setting performance standards for measuring devices used in commercial transactions.

NIST is justly proud of its role in weights and measures, and of the States' successes in adopting and enforcing fair and equitable national standards of performance for commercial measurements. We intend to renew and strengthen our partnerships with business and with Federal, State, and local governments in weights and measures as we head toward the next century.

\section{The NCWM Partnership}

The National Conference on Weights and Measures in the United States is a model partnership. It is also complex, interacting with the State and local weights and measures agencies, other State and local agencies, NIST, and businesses, including packagers, retailers, wholesalers, commercial measuring device manufacturers, device installers and service companies, device purchasers and users (including supermarkets, shippers, manufacturers, and other service providers, for example). Increasingly, other Federal agencies have been joining these partnerships. They find that the NCWM recommendations are valuable for defining the limits of error in real-world commercial applications under Federal jurisdiction, such as for grain export, or in meat or poultry processing plants. The Federal Grain Inspection Service, the Food Safety and Inspection Service (FSIS), and the Packers and Stockyards Administration of the U.S. Department of Agriculture have all adopted NIST Handbook 44. The FSIS has adopted NIST Handbook 133, "Checking the Net Contents of Packaged Goods."

It is essential to recognize these new partnerships in the goals and objectives of the National Conference. Industry needs uniformity for fairness in the regulatory standards it must meet at Federal and State and local levels. True national standardization can only be achieved when Federal and State regulations are harmonized with each other. This harmonization will come naturally when Federal and State agencies bring their unique resources into the commercial trade arena. State and local agencies have the human resources to enforce requirements; Federal agencies have the ability to set national standards as requirements to avoid the confusion and inefficiencies that local differences may generate.

\section{Contributions to Public Good}

Two key elements make the partnership between NCWM and various levels of government, and between government and private sectors, concrete: finance and operations. The NCWM is now a dues-paying membership organization, open to any individual; representing government agencies, businesses, industry or even the individual him or herself. It has grown from 1200 to more than 3000 dues-paying members since the initiation of dues in 1983. Membership fees support the meetings, publications, and other business of the NCWM, now contributing about a quarter of a million dollars to the total costs of the Conference. NIST still pays the lion's share of NCWM costs (more than one million dollars) by supplying most of the Conference's technical advisors and by writing and publishing NCWM standards and related documents. NIST has encouraged partnerships in its traditional role of technical advisor, and Dr. Rich Pierce is now the technical advisor for the Grain Moisture and Protein Analyzer Sectors; Ms. Nathalie Dupuis-Desormeaux of Canada's Legal Metrology Branch is technical advisor for the Solid Volume Measuring Devices Work Group. I am proud of the efforts our Office of Weights and Measures has made to meet the needs of the marketplace using every resource available. The NIST Office of Weights and Measures will have to take on more responsibility to meet our economic and trading challenges, and we must all support its key position at the national and international level in this regard.

The organization chart of the NCWM tells the story of the operational element: not counting the several hundred members of the Metric Working Group and the Handbook 133 Working Group, 85 State and local government representatives and 87 industry representatives work together as members of standards committees, subcommittees, work groups, and task forces. They correspond with the 25,000 persons or organizations on the NCWM mailing list. Their work encompasses motor fuel quality regulatory programs for the laboratory and the field; criteria and test methods for prototype measuring devices; minimum performance standards for new commercial measurement technologies; and optimizing the legal metrology system at all levels of government and for the nation's private industry. NCWM develops consensus on laws, regulations, tests, and enforcement procedures by assigning a committee to produce the policy, procedures, laws, regulations, and even the rationale for adopting these standards. The resulting standards are recommended to the States and local government entities to adopt as their own requirements. NCWM is the only technical legal metrology standards-development organization in which: 
each State has a vote (in the NCWM House of State Representatives);

each regulatory official has a vote (in the House of Delegates);

each regulated business has a voice and a vote in subcommittees, task forces, and work groups.

NCWM is a model of true participative management. The NIST Office of Weights and Measures is committed to this process and its health. It brings the various "sides" of any issue together and helps all sides understand each other's needs and each other's priorities: consumer and business; device user, whether government or private business, and device manufacturer; device owner and device servicer; retailer and wholesaler; State, local and Federal government; buyer and seller. NIST and NCWM are partners in achieving the most useful standards and their associated systems for our nation.

Even though the Conference has an impressive list of accomplishments, it may be that the checks and balances in the system are still not enough to achieve true national uniformity. For example, only 37 States automatically adopt NIST Handbook 44. Some States are as much as 5 years out of date in the edition of Handbook 44 that they enforce. Only 5 States automatically adopt the Uniform Regulation for the Method of Sale of Commodities. The vote of 45 other States determines what becomes the regulation in only 5 States!

The partnership in weights and measures between regulated industry and Federal and State and local government must evolve to increase the effectiveness and efficiency of the programs that we must maintain in these days of limited fiscal resources. We can no longer afford to waste critical private sector resources meeting differing - and sometimes conflicting - requirements in different States. Congress sent this message to the States when they passed the Nutrition Labeling and Education Act of 1990. States may no longer impose any requirement that is not identical to the Food and Drug Administration's regulations for food products.

The NCWM is the best hope of the States in meeting this challenge of potential preemption. We must be serious about the standards recommended in this forum. Moreover, if States do not adopt the NCWM consolidated recommendations, there is increased likelihood of Federal preemption.

Government agencies can improve U.S. competitiveness in the world's marketplace by working toward uniformity in requirements and enforcement of these requirements.

\section{Improving U.S. Competitiveness}

Are you asking yourself how weights and measures government agencies can improve U.S. competitiveness? The linkage to improving our nation's competitive position in the global marketplace derives from the fact that business and industry fuel our economic engine. And it is weights and measures regulation that ensures marketplace equity, so that businesses can compete fairly. Most States have been doing a good job at this. However, States must look beyond their borders, and focus on the imperative for adopting national standards to give their businesses leverage nationally and internationally. State and local agencies also need to enforce national standards uniformly. Then, businesses can target what could be the largest single market in the world, instead of diverting resources to meeting conflicting regulations in weights and measures. National businesses today take a risk when they work within the NCWM to establish high national standards, if their more local competitors are not held to the same high standards by the State and local weights and measures enforcement agency.

We inust strive to eliminate those situations in which businesses must meet different requirements in different States. An example of this is the level of adoption of the National Type Evaluation Program. This places an unacceptable burden on business, and the cost of meeting different or extra requirements from State to State is passed along to the consumer.

What else can weights and measures do to improve U.S. competitiveness? We can reduce the cost of necessary government by increasing efficiency and effectiveness in government operations at all levels. We can combine our resources better administratively by using common testing procedures and common reporting forms, electronically linked for immediate data sharing across the nation. Businesses will appreciate equality in treatment and quick, fair enforcement against unfair competitors. 
How can national standards be enforced uniformly? Through education, not only for beginning staff but throughout our careers. Administrators, managers, weights and measures regulatory staff, device service company staff, regulated businesses, and especially the public, deserve full information and thoughtful discussions with their public servants. We cannot afford divisiveness because of lack of communication and education about our roles and responsibilities, why the laws and regulations exist, and how they protect our way of life. Obviously, until there is national uniformity, there cannot be much improvement in efficiency and effectiveness. Standardization, however, will permit greater ease in maintaining national uniformity in test procedures, forms, electronic data collection and interpretation. This will, in turn, permit establishing real-time communications on a wide-area computer network, sharing data and inspection resources, quick business and consumer complaint response, and immediate guidance, and alerts.

Improving our nation's competitiveness has also meant forming new partnerships -- a hallmark of this organization since its founding.

\section{The International Marketplace}

I am pleased that the United States is working with Canada to mutually recognize type evaluations done by either nation using either nation's test criteria and test protocols. I hope that you will consider becoming an Issuing Authority under the certificate system recently established by the International Organization for Legal Metrology (OIML). It is in the area of the National Type Evaluation Program that I believe we can have great leverage. Not only is the Conference working on mutual recognition of type evaluation with Canada, there have been ground-breaking efforts for an expanding partnership base across national boundaries.

Groups have been established, having Canadian participation, to develop standards for motor-fuel quality enforcement point-of-pack inspection of packaged goods, agricultural grain quality measurements, and shipping industry device standards, among many others.

\section{Running Lean and Mean}

How can we maintain and improve government and industry effectiveness with reduced resources? Government must oversee and audit (i.e., "govern") both government and private sectors. In the weights and measures area, this means an audit of some portion of all commercial transactions in order to assure fairness in the marketplace

for device users;

for device service companies;

for retailers and wholesalers; and

for buyers and sellers.

This is an enormous task if you are a local official and you believe that you must test every device annually. What do you do if you have only enough staff to test $10-20 \%$ of the population? Having to compete in a particular technology in which there are no standards of performance, or where the standards are design-oriented and stifle innovation, can be enormously unproductive for our businesses. The NCWM needs your help to resolve these issues. Weights and measures agencies can only treat their customers fairly and with concern about the competitive forces when enforcing weights and measures standards in an equivalent means and manner from one jurisdiction to another. Businesses in the community can help weights and measures agencies to maintain equivalence by partnering with the agencies. Cut-backs in government and business at every level demand creative collaborations. The consumer brochure, "Getting What You Pay For" is an excellent example of informing the ordinary consumer of what it takes to be a savvy shopper, in concert with honest businesses, and the local weights and measures agency. Perhaps something similar needs to be developed for the local business community, explaining their rights, and responsibilities to the public, with respect to weights and measures.

You are being asked at this meeting to begin the process of determining what your long term direction will be in education and training. Keep in mind, as you deliberate, that we should be drawing upon each other's strengths, private and public sector alike, to maintain our standard of living - but not at our neighbor's expense. We are each other's customers. There are too many in government service at all levels from Federal to local to ignore what they contribute positivcly and negatively to our nation's productivity. Lend your ideas as private citizens to your governments to improve their efficiency and effectiveness. 
Unfortunately, there is a natural human tendency to relax our standards when no one places any real priority (and often this means enforcement resources) on them. Evenhanded we must be. When we focus on a particular trading arena, we should have strong reasons for pursuing it at the risk of disregarding other arenas.

Weights and measures standards have grown broader than just those that can be enforced by a State or local weights and measures official! Commercial transactions requiring measurements are part of the fabric of our society. We have a broader customer base, with this perspective, than we have ever had before. Priorities must be set as to what is most important to accomplish first, and we should collectively reevaluate these priorities on a frequent basis. NIST and the NCWM have mutually set goals for many decades. We stand ready to work with you to reaffirm our goals and select from our priorities those we mutually agree will contribute to our greatest success!

The Office of Weights and Measures staff stands ready to continue this process of setting priorities with you. Both our organizations have much larger objectives and real responsibilities for leadership than they have ever had before. We can leverage the funds in both organizations by working together to "pull ourselves up by our bootstraps, " and by using the same principles of self-help and self-motivation that have made those we honor in history so justly admired. Let's symbolically tip our hats to Hassler, Stratton, Fischer, and their counterparts in State and local government and business, and get on with our work - focussed, goal-oriented, and in partnership with each other, for the next generation. Thank you.

Reference:

Rexmond C. Cochrane, 1966, "Measures for Progress, A History of the National Bureau of Standards, " National Bureau of Standards. 


\title{
Chairman's Address \\ To The \\ 78th Annual Meeting Of The \\ National Conference On Weights And Measures
}

\author{
Allan M. Nelson \\ Director of Weights and Measures \\ Connecticut Department of Consumer Protection
}

It is my privilege to welcome you to the 78th Annual Conference on Weights and Measures. I thank you for being here and allowing me the opportunity to appear before you. I am disappointed that Dr. Prabhakar is unable to join us today. However, I am looking forward to the continued support of the National Institute of Standards and Technology (NIST) that we enjoyed under the leadership of former director John Lyons, and I am certain that this cooperation between the Director's office at NIST and NCWM will continue to grow under Dr. Prabhakar's leadership.

As a weights and measures official, I have just completed the best year of my working career. It has been an honor and a pleasure to represent you, the members of this great Conference, at so many meetings throughout our country and abroad. Our organization, NCWM, is held in the highest esteem by so many people and organizations that we touch in carrying out our daily activities. I truly thank you for giving me the opportunity to serve as chairman. It has been an experience that I will always remember and cherish, and I would not have missed it for the world. I hope I have served you well.

Our outreach program, with Congress, continued this past year with members of the Executive Committee meeting with members of Congress and their key staff people to obtain funding for NIST and the Office of Weights and Measures (OWM). In addition, we visited with Dr. John Lyons asking for his continued support of the Conference and OWM. We were successful in preventing further staff reductions within OWM.

I had intended to inform Dr. Prabhakar that she could be expecting a visit from the Conference leadership in the very near future, for I believe the transfer of technology to the States is suffering due to OWM's lack of sufficient staff - not their quality, just their quantity. The Conference is making demands and growing faster in areas of standards development than OWM can stretch to meet. Let me cite two examples: one is the mutual recognition with Canada and the other is the Solid Volume Measuring Device Working Group. In both instances we have had to rely on our Canadian counterparts to carry much of the load. In mutual recognition, Bob Bruce has committed one full-time person for 1 year. Our NTEP labs, represented by Steve Cook (California) and Jim Truex (Ohio), are filling in for the United States. However, the U.S. National lab can only meet its domestic responsibilities, and can only provide minimal technical assistance. In the Solid Volume Measuring Device Working Group, Canada is supplying the technical advisor, rather than NIST, and NCWM is paying travel and per diem expenses. As you can see, the Conference is more than willing to assist in whatever way possible, but we need NIST's assistance in providing for staff and resources in OWM.

The most gratifying experience I have had during these past 2 years has been my participation in the four regional Conferences. It is always so meaningful to get out and meet the regional delegates. Conference issues are thoroughly discussed and regional positions are established. It is remarkable how uniformity is achieved from region to region. The regional conferences have done more to eliminate floor debates on voting day because the delegates have thoroughly had the opportunities to understand the issues at their regional meetings and come to the Conference much better prepared. It is also a pleasure to see regional leaders being developed and then take their place at the national level.

As I look back over this past year, I find that there are many things I want to share with you concerning Conference activities relative to the development of standards. As you know, I chose as a Conference theme, "Excellence Through Standards," and as Tom Geiler, Chairman-elect, and I traveled around to the regions, we hosted either a breakfast and/or a lunch to talk about adopting Conference standards, and how we as a Conference could better assist the individual directors in adopting the most recent standards. The Conference this past year has been so very active in standards 
development. The SI working group for Handbook 130, under the leadership of Ed Heffron, presented a workshop at the end of last year's Conference which was very well attended and received by both weights and measures officials and industry. This working group, so ably supported by Ken Butcher, has represented the Conference and OWM, by working with the FDA to make sure our concerns were addressed in their regulations implementing the metric revisions in the Federal Fair Packaging and Labeling Act. Ken has done such a great job that this working group was able to do all of its work through the mail. This working group is comprised of over 200 members. This may be somewhat out of order, but I will just use one of the few perks the Conference Chairman has left and ask Ken Butcher to stand and accept a round of applause from the members of the Conference for a job well done.

The Petroleum Subcommittee to the Laws and Regulations Committee, chaired by Celeste Bennett (Michigan), has met twice since our last meeting and is doing excellent work in developing new standards to be compatible with ASTM motor fuel standards.

The Working Group on Handbook 133, chaired by Barbara Bloch (California), had its first meeting in June. This working group, which has 90 members, is studying the moisture loss issues and working with the FDA and USDA in hopes that the FDA will adopt Handbook 133 as an official document for testing packages in the marketplace - just as USDA has already done. The working group is also planning to work with the Education Committee in rewriting NCWM Training Module 10 on checking the net contents of packaged goods and also has agreed to develop test procedures for scanning devices.

The metrologists Task Force on ISO 9000 met last December and they are meeting again at this Conference. They are writing and assessing a laboratory quality manual and developing self-assessment criteria and checklists, along with on-site assessment using the team approach. In addition, I would like to thank the following metrologists for pitching in and giving Georgia Harris a helping hand in training their fellow metrologists: Martin Coile from Georgia, José Torres Ferrer from Puerto Rico, L.F. Eason from North Carolina, Joe Rothleder from California, Ken Fraley from Oklahoma, Tom Schafer from Idaho, and Kelley Moody from Arizona. If I have missed anyone, I apologize. To quote, "in today's world, too many people are anxious to give advice, when what you really need is help." Again, much thanks from the Conference for your help. It was greatly appreciated.

A new NTEP committee on in-motion weighing and checkweighers has also been formed and has met once this spring. These technical committees play such a major role in the Conference and NTEP. These technical committees also involve so many more representatives of industry and gives them a vote at the sector meetings. To the members of these committees and the Conference as a whole - I thank you for sharing your knowledge and volunteering so much of your time.

I have saved the next two working groups until last. They are the U.S./Canada Mutual Recognition Working Group and the Privatization Working Group. The U.S./Canada Mutual Recognition Working Group is moving ahead at a very rapid pace. "Things are happening" faster than I could ever imagine. For instance, Jim Truex and Steve Cook were in Ottawa the first week in June conducting type evaluations on bench and floor scales and indicators with their Canadian counterparts. It is my understanding that the testing went better than anyone ever anticipated. This working group has set a date of April 1994 to sign a memorandum of understanding between our two countries. This type of cooperation is exciting, and Bob Bruce, I publicly want to thank you for your cooperation and for dedicating your resources to this working group.

The Privatization Working Group has held two meetings this past year and is made up of a dynamic group of individuals. This working group has helped two weights and measures programs successfully defend themselves against efforts to eliminate their activities by shifting testing responsibilities to the private sector without government oversight, and has found that no State has yet given the responsibility for approving devices to the private sector. Two States have required businesses to obtain annual testing of their devices and have called it "privatization." One State has not provided enough resources to oversee the marketplace under these conditions.

I personally believe privatization can be avoided if a good weights and measures program is in place. The taxpayer is getting a fair return on the money spent to administer the program, and business and industry are both benefitting from a level playing field. Essentially, the burden of the program rests on the shoulders of the State director. Strong programs are not in trouble at the present time. State directors need to be active in promoting their programs, looking for new 
avenues of work and adopting NCWM standards. There is an old Yankee saying -- "responsibility is like old age in that it is not possible to escape from either of them."

I would like to leave you with some thought-provoking ideas and decisions that I believe the Conference needs to make in the very near future.

Looking back 3 years ago, incoming Chairman N. David Smith gave us his vision of where weights and measures officials would be in the twenty-first century. Because of David, who prefers to be known as a "good ol' country boy," or as I prefer to think of him, as a "redneck yuppie," we have had many meetings trying to prepare the Conference for the twentyfirst century. These meetings have been most successful.

In some areas of the country, I believe we need to look at the concept of regional laboratories. Just as all State metrology laboratories could not be NTEP laboratories, I believe the same holds true for those wishing to participate with the more sophisticated calibrations systems utilizing the mass package, for which N. David paved the way with his famous letter to Dr. Lyons. This letter shook the foundation of the Administration Building at NIST. However, there are some of us who could support regional laboratories that would have the capabilities to certify standards to nearly the same order as NIST. I do not want to imply that a State should give up its laboratory. Because without an accredited laboratory to do at least tolerance testing, you literally have nothing. The metrology laboratory is the heart of any weights and measures program.

More States need to become involved with the quality of motor fuel. This is a high visibility area -- a program which provides service to the citizens of your State -- a program that keeps your entire weights and measures program in the minds of legislators. As an example of the good things that can come from a motor fuel quality program, some of you must have seen the NBC dateline program which aired on June 29th. One segment was based on the quality of gasoline. As a direct result of this program, the two AAA clubs in Connecticut have contacted me and want to become involved in our program. Their involvement will be in the form of a monetary contribution so that we can obtain and have tested additional samples of motor fuel. With this example in mind, I believe there are all kinds of opportunities available for our programs if we, as State directors, are willing to be creative and go after them.

One of the most important concepts for strengthening our programs, which I believe the Conference needs to explore and seriously consider, is an accreditation program for weights and measures jurisdictions. This will steer us towards standards uniformity and adequate training that we so desperately need. An accredited weights and measures program would have to be somewhat like our laboratory programs where metrologists are certified and their laboratories then become accredited. Such a program would be administered by both NCWM and OWM. Inspectors would have to complete a series of training modules and a jurisdiction would need to have minimum amounts of field standards and other equipment. These programs would be evaluated and certified by areas of inspection. For instance, a jurisdiction would need a 1,500gallon prover to test rack meters or 24,000 pounds of certified weights to check vehicle scales.

As I look around, I see beautiful banners for States that have 100 percent membership in NCWM and these States are to be congratulated for their achievement. However, the day that we can display just as many banners, or better yet flags representing accredited jurisdictions, is the day we can be most proud. For then we will have journeyed into the twentyfirst century armed with the knowledge and the tools of our trade -- truly making a level playing field for all participants involved in commercial measurement.

I have been asked by a number of people during this past year how Bill Slamon is doing. For those of you who don't know Bill, he is the Assistant Director in Connecticut. In fact, the real question I am asked is, "is Bill Slamon still the Director in Connecticut?" That really worries me, and tells me it's time to go home. I guess now I will have to apply for active membership in Fred Gerk's "Has-been Club."

I want to publicly thank my staff in Connecticut for doing an outstanding job in my absence this past year. Bill Slamon is the person who has held our program together. Supervisors Ray Kalentkowski and Peter Wilson contributed beyond the call of duty working on new programs for licensing and registration. Mike Dynia just continued to do his usual good job running our laboratory program. To my former secretary, Ann Marie Costello, who left to accept a promotion in another agency - and who now tells me she is bored, and also my present secretary, Jean Colleoni who not only keeps my calendar up to date, makes my travel arrangements and keeps my boss and the Commissioner informed of my travel 
schedule, but also kept the office running, I thank you. In addition, I would like to thank the Commissioner of Consumer Protection, Gloria Schaffer, who has supported me 100 percent and has given me all of the time I needed away from the office. Commissioner Schaffer really understands the importance of NCWM and the contributions and benefits that come from supporting this Conference. To my immediate boss, Kathy Curry, thank you for the understanding and support you have given me these past two years.

I would also like to thank the staff at NIST for their assistance this past year, particularly Stan Warshaw, Director of the Office of Standards Services, and Sam Chappell and Otto Warnlof of the Standards Management Program. The OWM staff for their invaluable support this past year - Henry Oppermann, Ken Butcher, Tina Butcher, Joan Koenig, Karl Newell, Dick Whipple, Georgia Harris, Joan Mindte, Elizabeth Loveless, Terry Grimes, and Carlitta Foster.

Special thanks to Ann Turner, Conference Coordinator and money person. This past year, Ann has taken on the added responsibility of keeping the lid on the Conference chairman and chairman-elect's expenses. Ann refers to Tom and me as "double trouble." However, I do believe we have earned the title and given Ann a good run for the money -- no pun intended.

As Executive Secretary of the Conference, Carroll Brickenkamp has been a blessing. She has guided me through some very difficult issues, participated in many long telephone conversations, personally provided transportation to and from airports to meeting sites and through it all never lost her patience or got out of sorts. It's been a real pleasure, Carroll.

Last and certainly not least, I want to thank Tom Geiler for sharing this past year with me. Tom has been there every step of the way. Tom certainly made the travel enjoyable and it's been a pleasure working with him this year. I was very fortunate as chairman-elect to learn the ropes from Sid Colbrook, who included me in all matters, and I was able to pass this openness on to Tom. Tom, I wish you a very successful year and it goes without saying -- but I feel compelled to say it anyway -- if there is anything I can do for you next year, please do not hesitate to ask.

This has been an incredible year for me. I sincerely enjoyed serving as Chairman of the 78th Annual Conference on Weights and Measures. As I leave you, it is comforting to know that the Conference won't miss a beat. The Conference will be in able hands and I look forward to Tom's and Jim's leadership. We are fortunate to have an endless supply of good leaders for years to come.

Thank you for the cooperation and kindness you have all shown me this past year. 


\title{
Honor Award Presentations
}

\author{
10 years \\ Robert Bruce, Canadian Consumer and Corporate Affairs \\ Melvin Hankel, Liquid Controls Corp. \\ Kathleen Thuner, San Diego County, CA \\ Richard Tucker, Tokheim Corp. \\ Sy Fienland, Pitney Bowes, Inc. \\ Joan Koenig, National Institute of Standards and Technology \\ Paul Peterson, USDA Packers \& Stockyards Administration \\ Ken Fraley, State of Oklahoma \\ Forrest Joe Loyd, Jr., CXS Transportation, Inc.
}

\section{5 years}

N. David Smith, State of North Carolina

J. Herb Eskew, State of Texas

\section{0 years}

Carroll Brickenkamp, National Institute of Standards and Technology

\section{Special Recognition Awards}

The success of this Conference is the result of the dedication and hard work of many of its members. The work of these members is not complete until the official closing of the 78th Annual Meeting on Thursday. However, we would like to recognize them at the general session for the hard work over the past year within the respective committees and for their contributions to the National Conference in general.

\section{Executive Committee}

Ross Andersen, State of New York

Pat Nichols, Alameda County, California

\section{Standing Committees}

\section{Laws and Regulations Committee}

Fred Clem, Columbus, Ohio

\section{Specifications and Tolerances Committee}

Charles Carroll, State of Massachusetts

George Shefcheck, State of Oregon, who had to resign because of health concerns.

\section{Education, Administration, and Consumer Affairs}

Ray Kalentkowski, State of Connecticut 


\section{Liaison Committee}

Aves Thompson, State of Alaska

\section{Budget Review Committee}

N. David Smith, State of North Carolina

Harvey Lodge, Cargotec, Inc.

\section{Associate Membership Committee}

Dave Quinn, Fairbanks Scales

\section{Annual Committees}

\section{Resolutions Committee}

Glen Jex, State of Idaho

Michael Grenier, State of New Hampshire

Robert Gunja, Kansas City, Kansas

Ed Price, State of Texas

Aves Thompson, State of Alaska

\section{Credentials Committee}

Guy Tommasi, Middletown, CT

\section{Auditing Committee}

Ed Hanish, Laporte County, Indiana

\section{Nominating Committee}

Sid Colbrook, State of Illinois

Carl Conrad, State of New Jersey

G. Wes Diggs, State of Virginia

Charles Gardner, Suffolk County, New York

Sharon Rhoades, State of Arizona

Ken Simila, State of Oregon

N. David Smith, State of North Carolina

Carl Conrad, Jr., Resigning from the National Type Evaluation Technical Committee Weighing Sector on the occasion of his retirement.

Charles Gardner for 9 years as Treasurer.

Special thank you to the Liaison Committee: Kathleen Thuner, Aves Thompson, Rich Davis, John Lacy (retired), Bill Braun, Clayton Davis, and Karl Newell, and to Tina Butcher and Joan Koenig, NIST, for their work on the consumer brochure, "Getting What You Pay For." The National Conference on Weights and Measures was awarded the National Association of Consumer Affairs Administrators' (NACAA) Recognition of Excellence Award - First Place Business and Industry - 1993 for this brochure. 


\title{
President's Award
}

This is the eighth annual presentation of the President's Award. This award is given for two levels of achievement. First is a banner presented to those directors representing States that have 100 percent membership, both State and local, of their weights and measures officials in the National Conference on Weights and Measures for the first time in the membership year July 1, 1992 through June 30, 1993.

Those States that repeat with 100 percent membership are awarded a streamer for their banner. A streamer is presented for each year the State qualifies.

The second level of the President's Award is a certificate presented to a State in which all of the weights and measures officials from the State office are members of the Conference.

\section{Award for First Year Banner}

Territory of the U.S. Virgin Islands

\section{Streamer Award for Second Year}

Commonwealth of Puerto Rico

\section{Streamer Award for Third Year}

State of Colorado

State of West Virginia

\author{
Streamer Award for Fourth Year \\ State of Montana \\ State of Oregon \\ State of Utah \\ State of Washington \\ State of Wyoming
}

\section{Streamer Award for Fifth Year}

State of Arizona

State of Hawaii

State of Michigan

State of New Hampshire

State of Vermont

State of Virginia

There are No Awards for Sixth Year 


\title{
Streamer for Seventh Year
}

\author{
State of Alaska \\ State of Delaware \\ State of Idaho \\ State of Kansas \\ State of New Mexico \\ State of South Dakota

\section{Streamer for Eighth Year} \\ State of Arkansas \\ State of Nebraska

\section{President's Certificate}

Five States qualify for the President's Certificate, with $100 \%$ of their State office staff members for the 1992-93 conference year:

\author{
First Year Award \\ State of Indiana \\ State of Massachusetts \\ State of Tennessee \\ Second Year Award \\ State of Illinois \\ Fourth Year Awards \\ State of Maine \\ State of New York \\ State of Wisconsin
}




\title{
How A Regulatory Jurisdiction Implements The Use Of The National Type Evaluation Program (NTEP) And Why
}

\author{
James C. Truex \\ W\&M Inspection Manager, Ohio Division of Weights \& Measures
}

\section{Background \& Purpose}

Ohio was not a type approval State until very recently. Thus, we did not have the opportunity to just let NTEP take over our State type approval program. We started from block one and very diligently moved ourselves into a position of improving the quality of the commercial weighing and measuring devices being installed in the State of Ohio.

We have been asked to share our plans and experiences with other weights and measures (W\&M) jurisdictions, hoping that it may assist them with their goal to implement NTEP in their jurisdiction. The title given to this presentation is "How a Regulatory Jurisdiction Implements the Use of the National Type Evaluation Program and Why." First, l'd like to cover "why" and then we'll look at "how," or at least how we went about the task in our State.

Why

Let me try to answer this question with a few questions directed to the regulatory officials in this room. How many of you have been asked these types of questions?

I'm a salesperson. I have a customer that needs a legal for trade scale. Can you send me a list of scales that meet your requirements? or

I'm opening up a market. I know my scales must be tested by W\&M. What scale or scales should I buy? or

I haven't been on the job long and I just came across a weight classifier for the first time. I'm lost and I don't understand the features of the device. Has anybody else seen these yet? Has anybody looked at this model for compliance with Handbook 44? or, (my personal favorite), I own a gas station. I've got a chance to pick up these model ABC dispensers from manufacturer XYZ pretty cheap. Are they okay? (Note that in this case: you are being asked this question over the phone; you have never inspected this model of dispenser; and, you have never even heard of the manufacturer.)

I doubt that there is a W\&M inspector or administrator in this country that has not been asked one or more of these questions. These questions are all good reasons to implement an NTEP requirement in your jurisdiction. The use of NTEP will help you answer every one of the questions? We know that each device, NTEP evaluated or not, must be installed properly and stands on its own so NTEP can't solve every question. But it certainly helps.

Additionally, let's not forget that W\&M has a responsibility to promote equity in the marketplace. From a device manufacturer and distributor's point of view this means a level playing field for all. They have a very legitimate request in asking for our help in promoting and preserving a level playing field. 
How

If your State is not and never has been a type approval State and you are faced with the adoption and use of NTEP, it is a scary feeling. Questions immediately come to mind. What is the first step? How will we do it? In Ohio, we have been in that situation. The steps we took, and we'll look at now, may assist you in your endeavor.

\section{Steps In The Implementation Of NTEP In A State}

I. Adopt the "Uniform Regulation for National Type Evaluation" which gives the director the authority to require NTEP devices.

II. Discuss the NTEP and the NTEP Certificate of Conformance (CC) with W\&M officials within the State. Discuss devices currently being installed in the State and the impact of the NTEP requirement on current practices. Consider the following:

A. Which device categories should be covered under the NTEP requirement.

B. Listings of devices with an NTEP CC (NCWM Publication 5) need to be in the hands of W\&M officials, distributors, salespeople, installers, etc. in the State. How will this be accomplished?

C. The NTEP requirement obviously can only apply to new and modified installations in the State. What defines a new installation? What defines a modified installation in the State?

D. What will the State policy be concerning used devices which have been sealed for years that are resold and moved to a new location? Will there be special consideration given in these cases?

III. Schedule a meeting with scale companies, manufacturers, meter companies, distributors, service agency representatives, interested buyers, and any others in the W\&M community that may be affected by the NTEP requirement. Discuss all the considerations stated in step II and report any decisions or plans the State has made. Explain how NTEP will be beneficial to the manufacturers, sellers, installers, buyers, users, and consumers in the State.

IV. Study and discuss the information and comments gathered carefully when deciding the best course of action for the State.

V. Insure listings of devices with NTEP CCs are available for all necessary parties.

VI. Notify the W\&M community in the State of the effective date of the requirement. If necessary, schedule another meeting with the community to explain details. Be sure to include information about:

A. Which device categories are included in the requirement,

B. The State's definition of a modified type of device,

C. Any other State policies to be used in the enforcement of the requirement (exemptions, field enforcement policies, etc.).

VII. Training must be offered by the State for interested individuals in the State's W\&M community. Training topics should include; NTEP policies (parameters, modifications, use of different elements, one-of-a-kind devices, etc.), main elements and the marrying of elements, proper use and meaning of terms and abbreviations of terms $\left(n, n_{\max }, d, e, e_{\min }, V_{\min }, C L C\right.$, etc.), single load cell applications and formulas, multiple load cell applications and formulas, etc.

VIII. Implement NTEP in the State.

There is help to establish the use of NTEP in your jurisdiction. Don't be afraid to ask. We're all in this business together. In Ohio, we found that it was necessary and useful to provide tables and worksheets to our inspectors and servicepeople. We're sharing two worksheets with you today. 


\section{Sources for Help and Information}

1. NCWM

2. NIST/Office of Weights \& Measures

3. Other NTEP States

4. Scale Manufacturers Association (SMA)

5. Other industry associations \& manufacturers.

6. "WHAT IS HANDBOOK 44 AND WHAT IS NTEP?", a booklet by Tom Leahy, Rice Lake Weighing Syst.

7. Ohio Weights \& Measures and Jim Truex 


\title{
Technical Committee On National Type Evaluation
}

\author{
John J. Elengo, Committee Chairman \\ Revere Transducers
}

\begin{abstract}
Good Morning. I am John Elengo, Chairman of the Technical Committee on National Type Evaluation. I am here to provide you with information regarding the background, objectives, accomplishments, and plans of the Technical Committee on National Type Evaluation (TCNTE).
\end{abstract}

\section{National Type Evaluation Program:}

The National Type Evaluation Program is a cooperative effort between the National Institute of Standards and Technology (NIST), the National Conference on Weights and Measures (NCWM), the States, and the private sector for determining, on a uniform basis, the conformance of a particular model of a measurement system, instrument, element, or field standard to the relevant provisions of:

NIST Handbook 44 - "Specifications and Tolerances for Measuring and Weighing Devices"; or

NIST Handbooks 105-1 through 105-3 - "Specifications and Tolerances

for Reference Standards and Field Standards"; or any other special requirement that might be applicable.

\section{Device Evaluations:}

Device evaluation testing is conducted by a participating Federal or State Measurement Laboratory which has been authorized to do so by NIST, acting in conjunction with the NCWM. Such authorized laboratories are called Participating Laboratories. However, not all Participating Laboratories have full capability. NIST is the central coordinator and will assist in the selection of the most appropriate Laboratory. NIST is the final review and approval agency and the point of issue or withdrawal of all NTEP Certificates of Conformance.

The Participating Laboratories currently include:

$\begin{array}{ll}\text { NIST } & \text { USDA/FGIS } \\ \text { Alabama } & \text { California } \\ \text { Kansas } & \text { New York } \\ \text { Maryland } & \text { North Carolina } \\ \text { Ohio } & \text { Oregon }\end{array}$

\section{NTEP Board of Governors:}

A Board of Governors oversees NTEP activities on behalf of the NCWM. The Board is chaired by the immediate past Conference Chairman and consists of members of the NCWM's Executive Committee. The Board is empowered to judge ard resolve the appeal of any party in disagreement with an NTEP action.

\section{Technical Committee on National Type Evaluation and its Sectors:}

The Technical Committee on National Type Evaluation reports to the NTEP Board of Governors and is responsible for the development of specific test criteria and procedures for use in the evaluation process by the Participating Laboratories. The Committee is organized into Sectors according to measurement technology. The current Sectors are: 


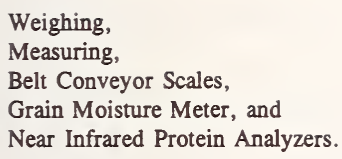

Each Sector has its own Chairman and meets one or more times annually, usually for two-day sessions, dependent on workload.

The Technical Committee draws its members from both the public and private sector. Each member is appointed by the Conference Chairman for a one-year renewable term. Most members provide regular and ongoing service to the Committee. This results in excellent continuity. The Committee's balanced makeup of interested regulators, manufacturers, and users assures that the issues are dealt with in an equitable manner. Meetings are open to all interested parties.

During the course of its deliberations, each Sector:

- establishes new, or revises existing, test criteria and procedures based on code changes;

- develops guidelines to be used when making judgmental decisions relating to device evaluations;

- establishes technical policies relating to the appropriateness and extent of device evaluation;

- provides guidance to Participating Laboratories when clarification is required; and

- due to its professional and wide ranging membership base, is often called upon to serve as a "sounding board" within the NCWM regarding other substantive issues before various Committees of the NCWM.

The Committee favors the use of the consensus process. The consensus process requires general agreement and as such goes beyond simple majority rule. When a consensus is not possible, the issue is resolved by majority vote in which case the minority has the option to place a dissenting opinion in the record.

The output of the Technical Committee on National Type Evaluation effort appears in NCWM Publication 14, Administrative Procedures, Technical Policy, Checklists, and Test Procedures. This publication is reprinted periodically. In the interim period between new publication dates, the output of the Committee is recorded in the individual Sector Meeting Minutes. In addition to being circulated to attendees, the minutes are regularly published in the Executive Committee/NTEP Board of Governor Report portion of NCWM Interim Meeting and Annual Conference documents. Also, key issues are often given formal Executive Committee Report Items status in order to increase awareness prior to adoption. Refer to Executive Committee Items 102-1 through 102-11. These issues include:

- the funding of NTEP by means of an annual Certificate maintenance fee system;

considerations regarding the verification that production meets type; and

- the impact of U.S./Canada trade agreement on evaluation testing.

The following are items of interest regarding the activities of the various Technical Committee Sectors:

Weighing Sector:

This Sector primarily deals with scales, scale systems, load receivers, weighing instruments, and load cells. It has been in existence since the initiation of NTEP. Initially, Participating Laboratories shared their existing State evaluation procedures and checklists with NIST in an attempt to become coordinated. A single uniform set of checklists was produced and submitted to the Sector for review. Following adoption by the Sector, these uniform procedures and 
checklists, along with those of the Measuring Sector, became the foundation for NCWM Publication 14.

In order to allow more efficient scheduling of attendance by members whose interest may vary, the Sector first deals with Load Cell issues and then Scale Issues. In the load cell area, the Sector is keeping abreast with the existing and planned load cell test equipment facilities within NTEP. The Committee has established technical policy relative to the extent of coverage for a Certificate granted to a particular load cell model family with different capacities within it. It has also set policy for handling circumstances where existing NTEP test facilities are too limited to enable a full evaluation. In the scale area, the Sector deals with a number of different issues. Recent activity has included:

- guideline development regarding suitability of required markings;

- setting evaluation policy for remanufactured devices;

- clarifying permanence test requirements for floor scales and weigh bridges;

- setting guidelines regarding acceptable indications of zero associated with "sleep mode" equipped devices;

- the establishment of a working group to review automatic weighing systems used in meat and poultry plants; and

- the establishment of a working group to review Class III L vehicle scale testing.

The next meeting of the Sector will take place in the Fall. Current agenda items include reviewing the effect on evaluation procedures as a result of:

- the decision made at this Conference concerning audit trails as a substitute for physical seals, and

- the output of the U.S./Canada task force for mutual recognition of type evaluation tests.

\section{Weighing Sector - Automatic Weighing Systems Working Group:}

This Working Group has only recently been organized and is new. Originally referred to as Checkweighing, it has adopted a title change to become the Automatic Weighing System Working Group. The group will deal with the evaluation of automatic weighing systems used in meat and poultry plants. An automatic weighing system is a device that in combination with other hardware and/or software components automatically weighs discreet items dynamically. Examples include but are not limited to weigh/price labelers and checkweighers. Although static weighing devices have been routinely submitted to and evaluated by NTEP, no automatic weighing systems have been evaluated because test methods have not yet been adopted. The Working Group has initiated discussions toward the development of evaluation policies, checklists and test procedures. The next meeting will take place in the fall. At this meeting the Working Group will concentrate on a review of draft proposals relative to evaluation testing.

\section{Weighing Sector - Class III L Vehicle Scale Test Working Group:}

This Working Group was established to review test procedures for Class III L vehicle scales and to develop new, more efficient, and technically correct ways of conducting tests. When possible, other heavy capacity scale tests will be considered. The Working Group is in the process of organizing itself. The next meeting will take place in the fall. At this meeting the Working Group will review the issues and develop its work plan.

\section{Measuring Sector:}

This Sector primarily deals with liquid measuring devices of various types, vehicle tank meters, retail motor-fuel dispensers, and gas measuring devices. It too has been in existence since the initiation of NTEP and has developed in parallel with the Weighing Sector. The Sector has produced a number of well developed evaluation and checklist procedures. Recent activity has included:

- attempts to classify liquids to try to establish liquid groups by viscosity in order to minimize the number of meter acceptance tests required for approval;

- the review of compressed natural gas standards, metering devices, and test methods; and

- the establishment of policy for use of compact provers in type evaluation testing. 
The next meeting of the Sector will take place in the fall. Current agenda items include:

- continuation of liquid classification activities;

- review of the decision made at this Conference concerning audit trails as a substitute for physical seals;

- compressed natural gas meter testing requirements; and

- impact of a normalization of U.S. and Canadian standards on meter accuracy and repeatability and reciprocal testing requirements.

\section{Belt Conveyor Scales Sector:}

This Sector was established a few years ago as an outgrowth of the Weighing Sector to deal specifically with the evaluation of belt conveyor scales. The Sector initially concentrated on the development of procedures and checklists to be used during evaluation. Following this development, NTEP initiated device evaluations. With evaluation experience having now been gained, the Sector is in the process of refining procedures and checklists. Recent activity has included:

- the elimination of static testing, performing dynamic testing only;

- the reduction of dynamic test period from 230 to 146 minutes;

- a sequence change to perform the overload test after temperature testing;

- providing an allowance to use refrigerated trailers during temperature testing; and

- requiring more than one flow rate at field test of 1 or 2 idler belt conveyor scales.

Lacking significant unresolved issues to warrant the expense of meeting, the Sector is currently awaiting additional input prior to establishing its next meeting date. Three minor changes have been accomplished via mail ballot. They include:

- a sequence change to perform the voltage test before temperature testing;

- a clarification to definition of thermal "soak period"; and

- addition of requirement to identify the maximum rate of temperature change when changing between test temperatures.

\section{Grain Moisture Meter Sector:}

This sector was established approximately two years ago and deals specifically with the evaluation of grain moisture meters. NTEP evaluations have yet to be conducted on these devices. The Sector is still in the process of finalizing evaluation procedures and checklists. However, during this process, it became evident that existing Handbook 44 specification and tolerance requirements might be in need of updating. The Sector has presented its recommendations to the NCWM's Specification and Tolerance Committee for adoption at this conference.

The next meeting of the Sector will take place in late summer. At this meeting the Sector will:

- review the effect of Conference decisions with regard to the Grain Moisture Meter Code on evaluation procedure and checklist with the intent of finalizing them;

- assess readiness to initiate NTEP testing in the fall; and

- consider methods to source funds to enable evaluation to expand from an initial scope of 3 grains (corn, soy, hard red winter wheat) to an eventual total of 17 or more different grains.

\section{Near Infrared Protein Analyzer Sector:}

This Sector was established one year ago as an outgrowth of the Grain Moisture Meter Sector and both Sectors generally consist of the same members. The Sector has the responsibility to develop necessary evaluation procedures and checklists for the eventual NTEP evaluation of Near Infrared Protein Analyzers. Before this can be done, specifications and tolerances are required. Thus, the Sector is currently concentrating on the development of a recommended code for the NCWM Specification and Tolerance Committee to consider. Thus, the Sector's activity is somewhat parallel to that of 
the Grain Sector, but lagging by one year.

The next meeting of the Sector will take place in late summer. At this meeting the Sector will continue to develop a recommendation for a Near Infrared Protein Analyzer Code for Handbook 44.

\section{Conclusion:}

For more details concerning any of the above Sectors or their current and planned activity, contact the Sector Chairman or Technical Advisor. Their names, along with the names of all current Sector members, appears in the NCWM Organization Chart which appears in the first few pages of the Conference's Program and Committee Reports for the 78th Annual Meeting, NCWM Publication 16. 


\title{
What Is Privatization?
}

\author{
Thomas F. Geiler \\ Director, Barnstable Consumer Affairs, MA \\ NCWM Chairman-elect
}

Last year, Chairman Allan Nelson established a working group on Privatization as a result of one of the recommendations of the Task Force on Planning for the 21 st Century. The issue of privatization was identified as a major issue in the near term future of weights and measures in the United States. The members of the working group are:

Chair: Tom Geiler

Public Members:

Southern:

Western:

Northeastern:

Central:
N. David Smith, N.C. Darrell Guensler, CA

Al Nelson, CT

Sid Colbrook, IL
Private Members:

Daryl Tonini, Scale Manufacturers Association

Rich Tucker, Gas Pump Manufacturers Association

Jennifer Colman, Food Marketing Institute

Tom Stabler, Mettler Toledo

Randy Hutton, Winn-Dixie

Technical Advisor: Carroll Brickenkamp, NIST

What is privatization? There are probably many answers to this question; however privatization is generally understood to be a shifting of responsibility, or ownership, from government to the private sector. Examples of privatization could include garbage pickup where government either contracts with the private sector to provide the service, or simply stops providing the service and allows the private sector to contract directly with the public for service.

Deregulation, such as that which occurred in the airline and banking industry, could be considered a form of privatization. In some cases government may shift the responsibility for testing to the private sector. Automobile emission testing is an example of this. Some States have government officials test auto emissions, and others authorize the private sector to conduct the tests. An overall objective of privatization is to save government revenues for other purposes.

The privatization working group has members representing both the public and private sector. Any privatization of weights and measures functions will affect both the public and private sectors. The business community is aware that without government controls, the lowest common denominator will prevail. Without reasonable government controls, business will pay more and the public will pay more. Both business and government share the same objectives of achieving a fair marketplace and a level, competitive playing field.

What privatization is occurring in weights and measures? One State explored the possibility of selling off weights and measures test equipment to the private sector. A State that does not provide enough resources to oversee the marketplace, while at the same time maintaining marketplace laws and regulations, is exercising a form of deregulation. Two States have mandated annual service of devices, while at the same time authorizing registered service agencies to affix private agency approval seals. No State has yet to contract out weights and measures testing. No State has yet given the responsibility for rejecting a device to the private sector.

Frequently, government agencies reviewing weights and measures services with an eye toward budget reductions do not fully understand the regulatory responsibility of weights and measures, nor are they aware of the cost benefit of weights and measures programs. One State review agency suggested that weights and measures regulatory services duplicated and competed with private device service and repair agencies. Many businesses, like private citizens in general, take the level playing field secured by weights and measures for granted. They both tend to assume that measurement representations are accurate because the government is guaranteeing the accuracy through laws and regulations. They may not even know which government agency is responsible for weights and measures enforcement. Nevertheless, confidence in the accuracy of stated measurement representations is very high today. What would the impact on the marketplace be if that confidence was severely eroded. 
How can weights and measures prove the need for regulation of the marketplace? One way is a marketplace audit. In the 1950's NIST conducted such an audit in Arkansas which at the time had no formal State weights and measures program. The marketplace errors detected by that audit established the need for the current Arkansas weights and measures program.

How can weights and measures prove its worth today? The State of Washington Office of Financial Management has completed a draft of their report of weights and measures services in the State. The draft report compares the cost to consumers and retailers of the actual errors found in the marketplace with the cost of providing the weights and measures services. While the report is based on very limited data, it can be a valuable resource to us all in identifying the type of data that should be collected by weights and measures officials and how that data can be managed to justify a program.

Weights and measures programs today compete for available dollars with health, safety, and education programs which have considerably more public support, or at least visible support, than weights and measures. How can we compete with these services for budget dollars? We must develop vocal customers who will demand weights and measures services. Consumers and retailers alike must be educated to understand the value of the services and the impact on them of lost or reduced weights and measures services. Without outside support for budget requests we will not survive the battle of the budget gods.

We must develop better means of telling our customers who we are and what we do for them. Through contact with consumer and retailers, this goal is achievable. The consumer pamphlet developed by the Liaison Committee is a good example of useful educational material. We must be prepared to explain what is weights and measures. The goal of equity in the marketplace needs to be further explained in order that business and consumers understand that weights and measures services allow businesses to compete fairly and provide consumers with fair treatnent in transactions involving measurement.

We must be able to clearly articulate why government is involved in weights and measures. It is not enough to simply state that weights and measures is a regulatory function. We should be prepared to explain the need to provide impartial regulatory services by an objective third party without any conflict of interest and be able to institute enforcement actions.

Government today provides a process to adopt, administer, and enforce laws and regulations concerning commercial trade practices and measurement to form a basis for equity in trade.

What is the potential result of deregulation of the marketplace? No government oversight would lead to uncontrolled cheating, unfair competition, false advertising, the inability to account for goods and services by individuals, and an eventual mistrust by all citizens of business and government alike.

In order to begin to tell the weights and measures story, we must understand the basic components of a weights and measures program. Those include a metrology function in the form of traceability from national and international standards to standards used in and for commerce to maintain accuracy for legal purposes. The device inspection further includes the regulation of measurement devices used in commerce and the design requirements, test procedures, tolerances, and use requirements. Registration of service agencies is also a part of this function.

Regulation of measurement practices in commerce in cooperation with the business community include full disclosure laws, method of sale uniform requirements, and packaging and labeling requirements that provide appropriate consumer information without restricting the producer's ability to market in a world economy.

Weights and measures programs must provide effective means to respond to and investigate complaints and assist the business community and the public in achieving compliance. Each element of a weights and measures program has both a regulatory and service component. Let's examine each element and attempt to describe why it is needed.

Why should we provide traceability from national standards to commercial standards? Maintenance of accuracy is basic to all regulatory decisions. We must be able to verify accuracy of government and private sector standards so that legal claims of accuracy or inaccuracy are irrefutable. The service component of this function includes consultation on measurement standards and their use. The service function will frequently be funded by the assessment of user fees. 
Why regulate devices? Integrity in trade and commerce depends on accurate measurement representations in direct buying and selling by quantity, as well as in controlling measurements in preparation for buying or selling goods and services. Assuming honest behavior and the elimination of human error, the most direct control of accuracy is to test the accuracy of devices used to measure in commerce. Accuracy alone cannot be the only requirement. Suitability of equipment is an important consideration as well. Equipment must be suitable for its intended use. You cannot weigh letters on a truck scale accurately. It is important that standards of design and performance be available and utilized in the inspection process. This is accomplished during the evaluation of prototypes of devices for compliance, as well as during initial verification of a device when first placed in service and its actual use is determined, and also in subsequent verification after the device has been in use for a period of time.

Why regulate measurement practices in commerce? Fair marketplace exchanges require more than accurate devices. The device must be used correctly. The weight of packaging material (tare) must be deducted. Statements of quantities on products must be accurate and the prices paid by the consumer must be the same as the product prices posted or advertised.

Complaint response and investigation, as well as consulting services to business entities and individuals, are responsibilities that help gain voluntary compliance and head off problems or violations before they happen.

What are the components of a State metrology program? The main component required is a NIST accredited laboratory, including fully trained personnel, following standard operating procedures, using appropriate equipment in an appropriate environment. A metrology program must also maintain a quality control measurement system and participate in proficiency tests on an annual basis. Minimum resources are needed in all aspects of weights and measures service delivery.

What is needed to regulate commercial devices? The first requirement is to adopt the uniform laws and regulations developed by the NCWM; for example, the State Weights and Measures Law should be modeled after the Uniform Weights and Measures Law in NIST Handbook 130. States should also adopt the regulations in Handbook 130, such as the Uniform Regulation for National Type Evaluation requiring an NTEP certificate for any device sold for commercial purposes and the Uniform Regulation for the Registration of Servicepersons and Service Agencies for Commercial Weighing and Measuring Devices. In addition, States should adopt the current version of NIST Handbook 44.

What else is needed? Fully trained personnel. How many? Enough personnel to test all devices annually (at least in order to obtain baseline data on businesses, devices, repair history). Some devices require inspection more frequently, some less. Personnel should receive training appropriate to their responsibilities. NCWM training modules are intended for beginning inspectors; updated training should be provided at least annually. Personnel should be NCWM certified in those areas for which certification is offered. Equipment and field standards should be sufficient to test the accuracy of commercial devices. Examples, $40,000 \mathrm{lb}$ of known test weights on a truck with gross vehicle weight of $80,000 \mathrm{lb}$ to test large capacity scales; 1,500 gal truck-mounted volumetric prover to test large capacity meters; Liquid Propane Gas Prover; 5 th wheel for taximeter testing, etc. Fully equipped general duty inspectors with field standard test weight kits, volumetric measures, electronic balances; notebook computer, etc., funds to allow undercover buying and selling.

What else is needed? Electronic database containing, for example: location of all businesses selling by weight or measure, devices used, type, history of measurement accuracy of any commercial device, history of complaints, investigations.

What is needed to regulate measurement practices? National standards adopted as regulations: Uniform Regulations contained in Handbook 130, fully trained personnel, certified by the NCWM, equipment, data on retailers, wholesalers, packagers, compliance levels, training and education program.

Some aspects of what is traditionally considered WEIGHTS AND MEASURES may be provided by private agencies: This has been called "privatization." For example, Kansas used to test devices on about a 4-year cycle, and adjust those devices. Their compliance level for scales was about $60 \%$. Kansas now requires that all commercial device owners get their devices annually tested. Device repair firms are licensed to test, and apply seals that they have tested; they do not have the power to reject or condemn. Businesses should have had their devices annually tested under earlier programs, but many businesses did not do so because (1) weights and measures adjusted devices, and (2) rural locations make annual tests expensive, (3) they had not been required to. 
Kansas still operates a testing program, testing on about a 4-year cycle. However, they no longer adjust devices, and compliance level has risen to $90 \%$ for scales. In the scale area, Kansas did not save any money. The State saved money by cross training their inspectors and reducing other agricultural programs. Training needs are larger under this type of program and are difficult for Kansas to provide to their own inspectors and to private repair firms. Government must oversee and audit all aspects in order to monitor the marketplace. Kansas is doing so. This is not an example of privatization in the way most people think of it. Businesses were further regulated by being required to obtain annual maintenance and testing.

What should you do? Visit your constituents and make them your customers. Find out what they understand your job is, explain what is your job, and how it helps your customer. Find out how you can serve your customers better, more effective, more efficient, cheaper, implement improvements and let customers know, keep them informed. Remember, your legislature, your governor, and your businesses are your customers.

Data collection and management can be your most effective tool in establishing the value of your program. The Washington State study, as I mentioned earlier, clearly shows the value of compiling the information that will provide an unbiased comparison of the value of the program and the cost of the program. For most of us this will mean a dramatic change in the type of information we record on inspection forms and input into our data base system. The NCWM should play a role in developing uniform model data collection standards so that jurisdictions can utilize similar systems and be comparing apples with apples when looking at information from other jurisdictions for comparison purposes.

Information on pass/fail results without the recording of the amount of error and the direction of errors does not provide adequate information to reach any conclusion from the data alone. I urge you to obtain a copy of the Washington State report and see for yourself the value of this approach and how you may benefit from improvements in the record keeping process. 


\title{
Excellence In OIML Recommendations Excellence Through OIML Recommendations... A Step Forward
}

\author{
Bernard Athané, Directeur \\ Bureau International De Métrologie Légale \\ and \\ Kristine French, Responsable de la Communication
}

\section{Voyage towards international harmonization}

We're here today because Kansas City happened to be on our road towards international harmonization in the field of metrology. This Conference is all about excellence through standards. Before continuing on our journey, we'd like to share with you our own pursuit of excellence through a special category of international standards, the OIML Recommendations.

But first, did you know that OIML and the NCWM have many things in common? The NCWM defines itself as a standard writing organization for weights and measures regulatory agencies of the States, counties, and cities, of the United States.

We too develop model regulations for use by the legal metrology services of the 51 nations which make up OIML, plus the 38 other nations registered as Corresponding Members.

We too bring together government officials, manufacturers and users of measuring instruments, and representatives of other interested parties.

The NCWM and OIML work towards the same ends: NCWM strives to produce weights and measures model standards for voluntary implementation in the United States; OIML's activities aim at formulating legal metrology model recommendations which are also voluntarily accepted by our members and transformed into national laws and regulations. Therefore, OIML and the NCWM are both concerned with weights and measures. But there is much more to legal metrology than weights and measures!

Measurement credibility in the field of trade is of essential importance and is the main priority of the NCWM; of course, work in this field is also an important responsibility for OIML.

But there are other fields, such as the environment, health, and safety, in which credibility in measurement is essential as well.

American agencies such as the Food and Drug Administration and the Environmental Protection Agency are responsible for developing the relevant Federal regulations. Insofar as measuring instruments are concerned, there is a role to be played by OIML for internationally harmonizing the applicable metrological requirements.

Complementary to the regulatory activity that applies to metrological performances of measuring instruments, there may be a need for a more general standardization activity.

International institutions such as ISO or IEC and American bodies such as ANSI or ASTM, are responsible for this activity. There is a need for close coordination between standardization and legal metrology and we will address this later.

The question is: How can OIML reach its ambitious destination of international harmonization in legal metrology?

\section{Excellence through OIML Recommendations}

An OIML Recommendation is a model regulation that specifies the necessary metrological performances for particular 
measuring instruments. It also provides the methods for testing conformity, and the format for reporting the test results.

OIML Recommendations are the necessary tools for building the pillars of an international environment in which all interests can be served. Whose interests are we referring to? Those of the legal metrology officials since they are charged with the development and the implementation of regulations; those of the users of instruments because of their reliance on the measurement accuracy.

We are also referring to the interests of the manufacturers of measuring instruments. Certain regions, such as North America or the European Economic Area, are introducing new directives that would affect the free circulation of products if they were not based on common international recommendations. What American manufacturer would not see the interest in contributing to the establishment of metrological requirements beyond the U.S. borders?

The importance of this vantage point was expressed in March of this year during the annual conference of the American National Standards Institute in Washington, DC. John Kinn, consultant and retired Vice President of the Electronic Industries Association, expressed that:

The recognition of the need to become globally competitive by U.S. manufacturers is a positive step towards the ultimate development of single worldwide standards. However, in this process of internationalization, steps must be taken to assure that regional viewpoints (North American for example), continue to be developed and provided while at the same time minimizing the cost of development of international standards to industry.

(Quoted from the ANSI Reporter, May 1993)

So an OIML Recommendation can be one of the tools for increasing global competitiveness. But how?

Allow us to cite the ANSI Reporter as our source for the following:

To compete in today's global marketplace, American businesses must: create synergies with former competitors; effectively participate in the definition of standards which will determine rules for international competition; and anticipate potential new standards and determine their impact on technology and markets.

Ronald Saporita

Grace Specialty Chemical Co.

American experts can indeed determine the rules by participating in OIML work through active contribution to the technical committees and subcommittees. Their expertise and regional views can help mold the formulation of the Recommendations. And since these Recommendations are usually implemented through the national regulations of OIML Member States, U.S. manufacturers would have a significant role in preventing potential commercial barriers.

U.S. experts can contribute to OIML's pursuit of excellence in Recommendations with their experience and know-how; as a result, they would permit U.S. manufacturers to have unlimited access to international markets, through these Recommendations.

The OIML Certificate System constitutes an expressway to international markets. We know that general information on this system has been given to the NCWM through our Vice President, Dr Samuel E. Chappell from NIST; so we can be brief on this topic.

At present, the System applies to a limited number of instrument types: mainly the nonautomatic weighing instruments. Soon, it will apply to load cells, automatic weighing instruments and later, to gasoline pumps or other liquid meters. The System became operational last year and, at present, six certificates have been issued. At least one country has accepted an instrument on the sole basis of the OIML certificate and some developing countries have already decided to favor the importation of certified instruments. Therefore, we believe that it is worthwhile for U.S. manufacturers to apply for these certificates: either through NIST or when applying for a European pattern approval. The additional cost of obtaining the OIML certificate is low compared to the added value that it will have for export of the instrument. 
The finishing touch of excellence in OIML Recommendations will result from our efforts to base these Recommendations not only on expertise, but also on intercomparisons that clearly demonstrate the value of the requirements and test methods.

This exercise may be difficult and costly. However, some tentatives in fields such as the humidity of cereals, load cells and nonautomatic weighing instruments have already proven their value.

\section{Perhaps you haven't heard yet... So let us tell you about OIML's need to communicate}

OIML is re-defining its long-term policies and objectives and the importance of developing an efficient communication network between the various partners in legal metrology has not been overlooked.

The field of legal metrology is increasingly interconnected with other domains such as accreditation, certification, and quality assurance. In fact, in many countries, the classical legal metrology service is no longer the only body responsible for performing all the tasks associated with the control of measuring instruments. Other accredited bodies may be charged with such tasks.

These evolutions and the appearance of new actors on the scene influence OIML's global strategy. This is why we feel it is necessary to expand the scope of our communications to respond to the growing diversity of interests in metrology.

You have received a brochure that describes one of our organization's channels for transmitting information: the OIML Bulletin.

We encourage you to contact us at BIML for a free copy of our next double issue of the OIML Bulletin which will feature the new orientations of our communication strategy.

We are convinced of the value of OIML's international leadership in legal metrology. That is why we intend to reach out to those of you working in areas ranging from legal metrology to standardization; government to industry; and verification to accreditation and certification. OIML can give you access to the road that will take you in the right direction. And we plan on doing this, in part, by fine-tuning our instruments of communication.

\section{En route towards intemational harmonization - Co-existence - There's room for everyone on the roads!}

There is not just one road to international harmonization. And since it is a highly sought-after destination, there are, of course, many different travelers heading in the same direction.

This leads us to our final point. We encourage the peaceful co-existence of the international and regional bodies concerned with legal metrology and standardization. It is necessary not only for assuring compatibility between the legal metrology and standardization provisions, but also to save time and resources in our pursuit of international harmonization. There are international agreements that permit an appropriate distribution of responsibilities, mutual references, and joint activities. Therefore, you can participate in OIML work AND standardization activities and remain confident that the benefits will be shared in both domains.

Come with us on our journey to international harmonization of measuring instruments. Gain speed by participating in OIML's technical activities. Of course you'll need a road map which you'll find in the OIML Bulletin and an OIML certificate will serve as your international driving permit! We are confident that you won't even consider turning back! Thank you and we'll see you on the road ahead. 


\title{
Harmonization And Mutual Recognition
}

\author{
Robert Bruce \\ Chief of Weights and Measures \\ Canadian Consumer and Corporate Affairs \\ Canada
}

It is my pleasure to be asked again to speak regarding some of the work that we are carrying out together. Last year, I focused on the Weights and Measures program in Canada and some opportunities that I believe exist to work together to protect consumers and to enhance the prosperity and competitiveness of businesses in both of our countries.

This year, I wish to focus on work we have accomplished since this time last year and my expectations for future work between the Weights and Measures communities in both countries, but most of all I would like to discuss the notion of harmonization and mutual recognition and how it may affect us.

What is harmonization? Although the term "harmonization" is used commonly these days in government and business circles, it is not clear that everyone is talking and thinking about the same thing.

The Oxford English Dictionary defines harmonization as "the process of bringing about harmony, bringing about a state of consonance or accord so as to form a consistent and orderly whole." From music, we know that harmony is not a single note, but rather a combination which, when played together, produces a sound that can be more pleasing than any note individually.

The important point here is that harmony is not taken to mean complete uniformity; diversity is preserved.

Why is harmonization important and on the policy agenda of both of our countries?

In many ways, the world is becoming more tightly wound together, like the elastic bands in a golf ball. To be more precise, lower transportation and labour costs, ease of capital transfers, innovative production methods, as well as products and services, all have a dramatic impact on consumption and production. Consumption baskets in many Western countries have a significant percentage of imports. Production inputs are sourced globally. As consumers demand the greater choices offered by globalization, their incomes increasingly depend on globalization as well. The greater economic interdependence between countries makes once exclusively domestic policies international. Harmonization is the logical outcome of the shift from domestic to global markets.

Where do the pressures to harmonize come from? The pressures for harmonization come from two main and interrelated sources. The first is economic. The second area of pressure is institutional. The GATT and the Free Trade Agreement between your country and mine, as well as membership in organizations such as OIML, ISO, OECD and G7 and so on, all have as part of their mandate some aspect of harmonization. Partly as a result of pressures from various marketplace players, partly through GATT and the Free Trade Agreement, we are committed, perhaps irrevocably, to the harmonization of standards for weights and measures.

The Free Trade Agreement, for example, has provisions respecting non-discriminatory treatment, standards related measures that are unnecessary obstacles to trade, conformance to international standards and the manner of conformity assessment used by parties to assess compliance with standards. Nevertheless, this agreement also permits either party to establish the level of protection that it considers appropriate to fulfill its legitimate objectives in matters relating to consumers. Again, the right of diversity is preserved, where warranted.

What needs to be harmonized? The first focus is usually the laws and codes that regulate products and services. While they need not be equivalent they should be compatible. Because accurate and fair measurement is a universal concern, between our countries at least, the conception of weights and measures laws are relatively similar. 
If we choose to have even more compatible laws and codes we must decide what standards to adopt. The Free Trade Agreement requires that we consider international standards as a basis for these laws and codes except where such standards would be an ineffective or inappropriate means to fulfill legitimate objectives.

The second focus is on the methods we use to ascertain compliance with our laws and codes. In the case of Weights and Measures, this involves well-defined technical procedures and systems of product approval that ensure weighing and measuring devices are designed and constructed to meet our requirements.

Notwithstanding the difficulties inherent in this process, any agreement on harmonization must be for the mutual benefit of both parties. A lot of work has gone on over the last few years in an effort to achieve some form of harmonization.

During the last three to four years, my colleagues and I have actively participated in NCWM committee meetings in an attempt to acquire a good understanding of your requirements and of the philosophy that sustains the development of the requirements and the policies for the enforcement of your programs. Conversely, weights and measures representatives from your country have attended Canadian technical meetings. This mutual collaboration has provided both parties with an invaluable opportunity to better understand the differences and similarities between the Canadian and the U.S. Weights and Measures requirements, procedures and policies, and to appreciate industry concerns related to these differences. This mutual collaboration has also allowed both parties to work toward the adoption of more consistent requirements and policies for new device types, such as mass flow meters and solid volume measuring devices.

In the spring of 1992, representatives from both countries met to discuss the feasibility of full harmonization of the requirements applicable to weighing and measuring devices. A working group was set up and a workplan was established. Priorities were directed to non-automatic weighing devices. An intercomparison document of U.S. and the Canadian requirements was drafted in the summer of 1992. This document was intended to be the beginning of a process of regulatory review, negotiations, and the development of common Canadian/U.S. specifications for nonautomatic weighing devices and liquid-metering devices.

Since this time last year we have accomplished a good deal more on the harmonization front. I must say, however, that my views of harmonization have been re-oriented significantly. In December 1992, the National Institute of Standards and Technology hosted a meeting with U.S. industry and weights and measures officials from both countries. The dominant positions that emerged from the discussions at this meeting are that:

Harmonization efforts should place highest priority on type evaluation test procedures rather than on the U.S. scale code. Your scale industry did not consider differences in requirements to be trade barriers; however, they did consider the type evaluation process to constitute a trade barrier.

Both countries should work together to achieve mutual recognition of each other's type evaluation process, not an exact conformance of documents or the format of those documents.

Mutual recognition of type evaluations would require the harmonization of test requirements between the two nations or require both nations to conduct the evaluation test of the other nation. In any case, a device would only require testing in one laboratory to receive approval in both Canada and the United States.

It is my view that this is a reasonable approach to minimizing irritants to the trading of weigh scales between Canada and the United States. This view is also held by industry that we consulted in my country.

In January 1993, the Executive Committee of your Conference unanimously adopted an objective with respect to the harmonization initiative. The objective states that:

With respect to weights and measures devices, the parties agree that the most effective means to remove barriers to free trade is to achieve mutual recognition of device type evaluation testing. This will necessarily involve the comparative analysis of type evaluation codes and test procedures together with the intent of 
streamlining and minimizing differences in so far as possible so as to enable efficient device evaluation while preserving the technical capability and competence of their mutual laboratories.

It is important to note that this objective no longer considers full harmonization of the codes as the main concern but rather the mutual recognition of device approvals. We will only harmonize laws and codes where we consider it to be in our mutual best interests.

Work is already underway to achieve this objective. A working group with representatives from the NCWM, all NTEP Laboratories and the Canadian Legal Metrology Branch, along with industry representatives from both countries, have established a plan that will implement a mutual approval program for selected device types in less than 10 months from now.

The first devices targeted for mutual recognition in type evaluation are bench and floor scales up to a capacity of $500 \mathrm{~kg}$ and digital indicators that may be used with bench and floor scales and vehicle scales. Specialized software features intended for specific applications are excluded from this initial effort.

The working group plans to review and develop a single checklist by identifying similarities and differences in type evaluation requirements and test procedures, combining the various requirements into this single checklist (which will contain the different requirements for each country), and determining if a single test procedure can be used to satisfy two different, but related, requirements. The group is to develop recommendations to harmonize requirements whenever this action appears reasonable. Other work that needs to be done includes an applicant's guide; a common type evaluation application for the devices; an instruction manual for the laboratories; and common work sheets and report forms to aid in evaluating the test results.

Extensive training of laboratory staff by representatives of the other country is anticipated to achieve a mutual understanding of requirements and test procedures. In addition, an ongoing training program will have to be established.

Finally, each country will issue its own certificate based on the test data provided by the participating laboratory.

I believe that the work we are pursuing will provide a number of tangible benefits.

Firstly, the review of device codes and methods for conformity assessment that is inherent in this process should provide all parties with an opportunity to re-evaluate our requirements. This should only lead to improved device codes. In Canada, we have already decided to adopt several of your codes found in Handbook 44, simply because they make good sense.

Mutual recognition of device approvals, and where we choose, more compatible device codes, should enhance trade opportunities. These initiatives should be of particular benefit to small manufacturers of devices who cannot readily afford to have devices evaluated for approval in both countries.

This work will afford us an opportunity to share expertise and to share equipment and facilities for the evaluation of devices.

The time and cost to manufacturers for the approval of devices should be reduced as there will be more participating laboratories where testing and evaluation may be conducted.

Lastly, we should be able to reduce government expenditures or reduce resources because we will be able to share the work.

For these reasons, I expect our work will not only better protect consumers but it will enhance the prosperity and competitiveness of business in both of our countries. I hope that you share this belief. Thank you. 
Table A (Continued)

Reference

Key No. Title of Item

Page

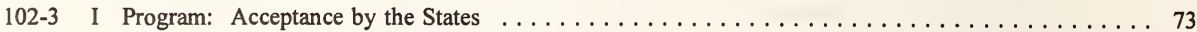

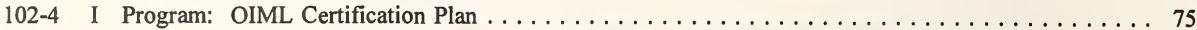

102-5 I Program: NTETC Sectors on Grain Moisture Meters and Protein Analyzers $\ldots \ldots \ldots \ldots$

102-6 I Program: Participating Laboratories/Evaluation Report . . . . . . . . . . . . . . . . . 79

102-7 I Program: NTETC Weighing, Measuring, and Belt-Conveyor Scale Sector and Work groups ... . . 81

102-8 I Policy: Recognition of Witness Testing as an Alternative to Type Evaluation for Load Cells by NIST

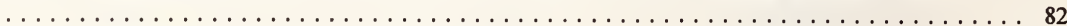

102-9 I Policy: Extensions of Existing Vehicle Scales $\ldots \ldots \ldots \ldots \ldots \ldots \ldots$

102-10 I Policy: Clarification of "One-of-a-Kind" Devices . . . . . . . . . . . . . . . . . . . 83

102-11 I Policy: Repaired and Remanufactured Scales . . . . . . . . . . . . . . . . . . 84

Table B

Appendices

\begin{tabular}{llc}
\hline Appendix & Title & Reference Key No. Page \\
\hline
\end{tabular}

A NCWM Annual Report 1992

B NCWM Committee Roles and Responsibilities

101-1

89

C Letters from and to Central W\&M Association

$101-2 \mathrm{a}$

$101-3 a$

E Letter to the Interstate Commerce Commission

$101-3 b$

102

F U.S.-Canada Mutual Recognition of Type Evaluations

$101-5$

101-8

G Privatization Work group

H ISO 9000 Task Force

$101-9$

I Composition of NCWM Mailing List

101-10

101-12

J Budget for 1993

101-13

K ASTM Report

101-16

1993 NCWM Plans

101-19

N Weighing, Measuring, and Belt Conveyor Scale Sector Reports

$102-7$

\section{Table C Voting Results}

\begin{tabular}{lcclll}
$\begin{array}{l}\text { Reference } \\
\text { Key No. }\end{array}$ & \multicolumn{2}{l}{ House of State Representatives } & \multicolumn{2}{l}{ House of Delegates } & Result \\
\hline & Yes & No & Yes & No & \\
& & & & & Passed \\
$102-1$ (as amended) & 44 & 1 & 60 & 0 & Passed \\
$102-2$ (as amended) & 46 & 0 & 70 & 0 & Passed \\
100 (in entirety) & 45 & 0 & 71 & 0 & \\
\hline
\end{tabular}




\section{Part I - Executive Committee}

\section{1-1 I Organization: Appointments and Assignments, Status Report}

The National Conference on Weights and Measures continues to grow in terms of (1) its national impact and status, and (2) the number of projects and products for which the National Conference has assumed responsibility and leadership. As a result of the Interim Meetings, new work groups were formed under the Laws and Regulations and the Specifications and Tolerances Committees (see Items 101-4 and 101-5). The organizational structure for the 1992/1993 membership year is depicted below and on the next page:

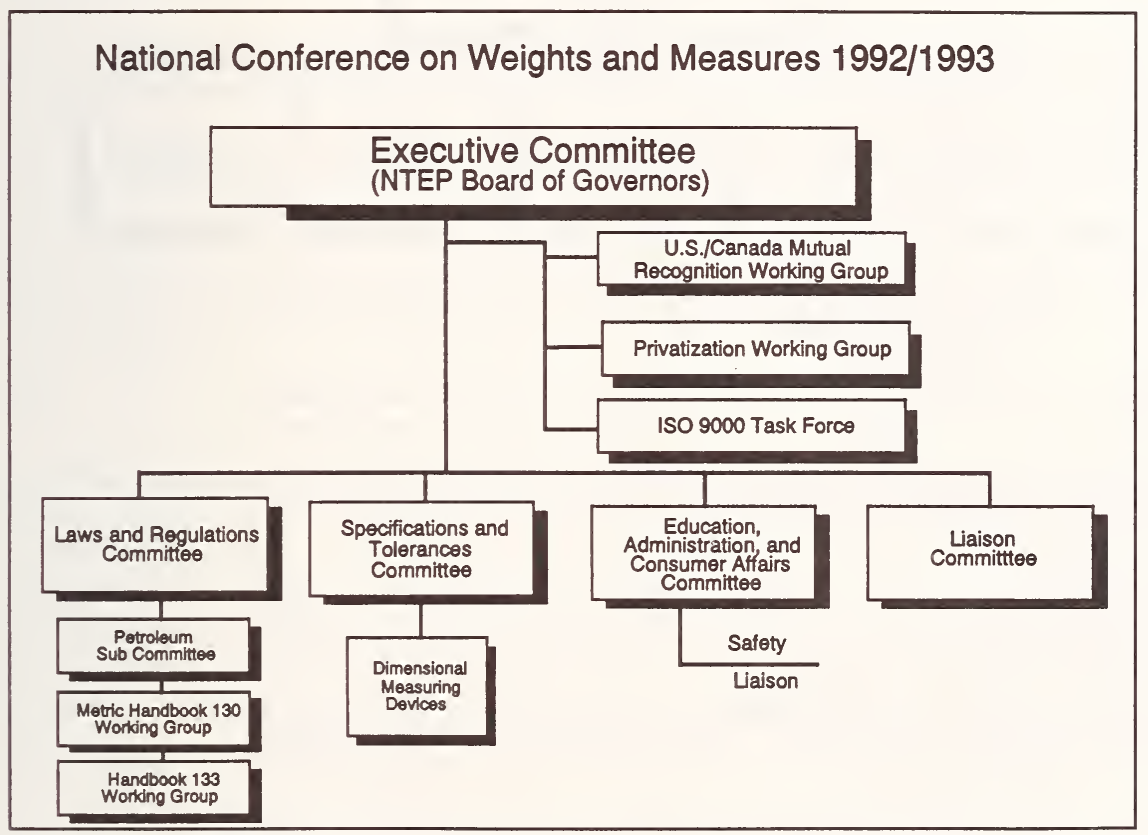

An annual report of products and progress of the NCWM was provided by the Executive Secretary (see Appendix A). Mr. Nelson reported on appointments that have been made since the 77th Annual Meeting.

\section{Specifications and Tolerances Committee}

Due to illness, two Specifications and Tolerances Committee members could not attend the Interim Meeting. Mr. Nelson appointed "interim" replacements from appropriate regions in order to maintain the geographical balance needed in this committee's critical discussions and decisions. Gary West, NM, chairperson of the Western Specifications and Tolerances Committee replaced George Shefcheck, OR, for this one meeting. Ron Murdock, NC, chairperson of the Southern Specifications and Tolerances Committee replaced Jack Jeffries, FL. It is a tribute to the expertise and experience of both the missing members and the "interim" members, and the excellent communications of the national with the regional associations, that these relatively "last minute" assignments and the resulting decisions were successful and productive. The Executive Committee congratulates all who were involved in the complex issués and administrative arrangements, including the "interim" members' employer States. Mr. Shefcheck and Mr. Jeffries hoped to be able to rejoin the 


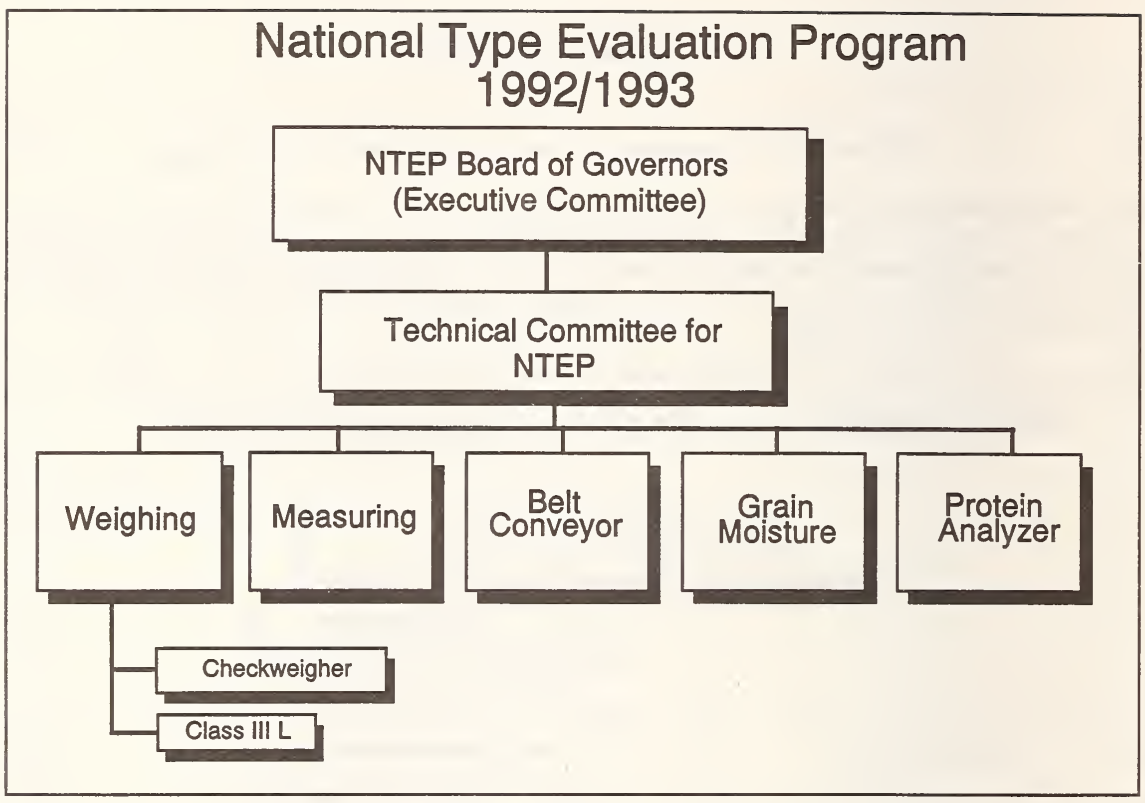

committee at the 78th Annual Meeting. See the discussions under Item 101-5 (the S\&T Committee) for further appointments subsequent to the Interim Meeting.

\section{Auditing Committee}

The Chair appointed G. W. Diggs, VA, and Carl Conrad, NJ, to replace Robert Gunja, Kansas City, KS, and Herb Eskew, TX, two members of the Auditing Committee who were not able to attend the Interim Meeting and audit the 1992 books of the NCWM Treasurer.

\section{Appointments Made After the Interim Meeting}

Additional appointments made by Chairman Allan Nelson since the Interim Meeting include:

Gary D. West, New Mexico, Specifications and Tolerances Committee, replacing George Shefcheck, Oregon, who had to resign for health reasons;

G. Wes Diggs, Virginia, National Type Evaluation Technical Committee (NTETC) Weighing Sector;

John Reimer, Weigh-Tronix, NTETC Weighing Sector;

Paul Peterson, Packers \& Stockyards Administration, U.S. Department of Agriculture, NTETC Weighing Sector; Jerry Wang, A \& D Engineering, Inc., NTETC Weighing Sector;

Michael J. Keilty, Micro Motion, Inc., NTETC Measuring Sector;

Norman Johnson, Merrick Corp., Chair, NTETC Belt-Conveyor Scales Sector;

W. D. Brasher, Southern Company Services, Inc., NTETC Belt-Conveyor Scales Sector;

Dennis Johannes, California, Chair, Automatic Weighing Work group, reporting to the Weighing Sector;

Christopher Dyson, Public Citizen, Petroleum Subcommittee; and

Fairman Thompson, South Point Ethanol, Petroleum Subcommittee.

The names of other appointees and the goals, objectives, and charge from the Executive Committee are reported as part of the summary of work under each committee. 


\section{1-2a I Quality Improvement: Role and Responsibilities of Committee Members}

Decision: Appendix B contains the substance of a presentation on committee roles given at the Interim Meeting. The Executive Secretary will send this document to all new appointees when they accept an appointment. In addition, the document will become part of Publication 3, NCWM Policy, Interpretations and Guidelines. The Committee does not intend to repeat this session at any Interim Meeting upcoming in the near term.

Background: An orientation session for new members is held at the Annual Meeting. Each new committee member appointed by the NCWM Chair is brought into the work process by the technical advisor of that committee. Until now, no standards or objectives were explicitly provided to new members as to what their overall roles should be within their regions, or how they might maximize the benefit of committee membership and the perspectives that they bring to the Conference operations.

In order to provide information to assist committees to work more effectively during the Interim Meeting and throughout their service, Chairman Nelson conducted a short orientation session for new and veteran committee members. This familiarization session was held with all committee members to review their roles, responsibilities, and authorities within the National Conference and the regional conferences in order to maximize the efforts of the organization. Committee members do not always realize when they accept a committee appointment that their service extends beyond attendance at the Interim and Annual Meetings. For example, since regional representation is one of the selection criteria for any committee, committee members are expected to canvass their regions for input on committee issues. They are also expected to communicate the national committee's position and the reasons for that position to their peers in their region. If committee members understand how they can participate and assist, they can contribute more effectively to promote national uniformity. Any additional guidelines that can be added to Appendix B would be greatly appreciated. Please forward any remarks or additions to the Executive Secretary.

\section{1-2b I Organization: Roles and Terms of Public Sector (Active) and Private Sector (Associate) Members}

The Executive Committee adopted an interim policy that clarifies the voting status and the terms of individuals appointed to subgroups within the NCWM. The term limits, if any, of the members of the Petroleum Subcommittee have not yet been determined. The Executive Committee will consider whether or not to incorporate the final policy, when developed, into the Constitution and Bylaws.

As the Constitution and Bylaws defines the terms, "Active" members are State or local government weights and measures officials, also known as public sector members in Conference reports. "Associate" members are representatives of industry, business, educational, and trade associations or organizations; they are also termed private sector members in many Conference reports. "Advisory" members are Federal agency representatives or persons retired from "Active" membership status.

The Executive Committee decided on the following interim policy:

\section{POLICY ON APPOINTMENTS TO WORK GROUPS, TASK FORCES, SUBCOMMITTEES, AND THE NATIONAL TYPE EVALUATION TECHNICAL COMMITTEE}

Unless otherwise indicated, all meetings of the National Conference on Weights and Measures are open meetings, and NCWM members are encouraged to participate or observe, whether or not appointed to a particular work group, task force, etc.

1. SHORT TERM GROUPS. Appointments of Active, Associate, or Advisory members to work groups or task forces are for the duration of the project(s) to meet the objective(s); the NCWM Chair will appoint the members when the group is formed. The issues and tasks of these groups are self-limiting in nature; the work groups will be disbanded when the tasks are completed and the objectives met. All members have voting rights. The NCWM Chair appoints the members with the advice of the committee to which the group will report. 
2. NTETC SECTORS. The membership and voting status of the National Type Evaluation Technical Committee will be as follows:

a. ASSOCIATE MEMBERS. The NCWM Chairperson will appoint new Associate members on the advice of the sector chairperson and technical advisor. There is no fixed term for this representation; the Associate member will serve until removed by the NCWM Chairperson, by the sponsoring company, or when the member resigns. If one company owns another, or if two companies are owned by the same parent company, only one vote per parent company will be permitted. The company(ies) involved will decide who will vote.

b. ACTIVE MEMBERS.

PARTICIPATING LABORATORY REPRESENTATION. The NCWM Chairperson will appoint a representative from every NTEP Participating Laboratory conducting complete evaluations in the particular device sector. (Those performing only field tests will not necessarily be appointed.) There will be no fixed term for this representation.

S\&T COMMITTEE REPRESENTATION. If funds are available, the NCWM Chairperson will appoint a representative from the S\&T Committee, based on the recommendation of the S\&T Committee. The term of this member will be concurrent with his/her membership on the S\&T Committee.

OTHER ACTIVE MEMBER REPRESENTATION. Additional Active members may be appointed by the NCWM Chairperson with the advice of the technical committee sector chairperson and technical advisor. If financially feasible, the NCWM will underwrite their participation to provide additional weights and measures perspective.

c. ADVISORY MEMBERS. The NCWM Chairperson will appoint appropriate representation from Federal agencies with the advice of the chairperson of the sector and its technical advisor. The Executive Secretary will appoint the technical advisor. Advisory members have voting rights within the sector.

Although the Chairperson will appoint members, an appointed representative may designate an alternate with full voting rights whenever necessary.

A 5-year term for the Active members who do not represent a Participating Laboratory or the S\&T Committee is being considered at this time. The Sector chairpersons and technical advisors will be consulted before a final determination is made. The Petroleum Subcommittee will also be asked to advise on the appropriateness of term limitations for the Associate, Advisory, and Active members on that subcommittee.

Background: Standing committee members are appointed for terms of 3 years (Executive; Auditing; Credentials; Resolutions) 5 years (Specifications and Tolerances; Laws and Regulations; Education, Administration, and Consumer Affairs; and Liaison), or 2 years (Budget Review). Annual Committees (Nominating; Associate Membership) are appointed by the incoming Chair for the term of the Chair. The terms of appointments to other groups were considered, in order to provide both the technical expertise that each group needs and the freshness of new perspectives. The NCWM Constitution and Bylaws have no firm policy on terms of appointment for subgroups except for task forces, which have a maximum 2-year life specified. At some point after the National Type Evaluation Technical Committee (NTETC) sectors were first formed, the Chair annually reappointed all the members by formal letter. Under the new policy, the Chair will no longer annually reappoint the membership of the sectors or other work groups and subcommittees.

It is important to note that all votes in the standing committees, except for the Liaison Committee, are held by Active members only. Although the technical advisor of each Standing Committee is a full member and will participate in all sessions, including executive (closed) sessions, the technical advisor of a standing committee is a nonvoting member. The other work groups, subcommittees, and NTETC and its sectors have been operating with voting membership from all classes of membership: Active, Associate, and Advisory. Only Active members have the vote for standing committee recommendations (excluding Liaison) because their final recommendations may be intended for adoption and enforcement as regulations. The recommendations of the work groups, Petroleum Subcommittee, and the NTETC Sectors are made 
in part by Associate members and Advisory members because their recommendations funnel upward through a standing committee, so that only regulatory officials make the final decision.

At the present time, there is no limit to the number of members or the length of a member's term on a work group, sector, or subcommittee, nor is there a limit to the number of observers or participants at any meeting of these groups. Since almost all Associate and Advisory members' participation is underwritten by the member's employer, the large number of competing manufacturers and users does not permit setting term limits easily while maintaining fairness (if the number of Associate members vastly outnumbers the Active membership on any given group). Any volunteer is welcome in any capacity. The NCWM Chair will appoint Active (public sector) members; NCWM will indicate those it can fund; others may be appointed, but at their own expense. If a State or local agency can underwrite the participation of a weights and measures official, the NCWM Chairperson may appoint that official. Active members may volunteer and participate as full members of any group.

Since some companies own subsidiaries, several of which may be represented on one NTETC Sector, voting rights have been clarified when more than one representative from the same parent company participates in a subcommittee or sector. Only one vote per parent company will be permitted when more than one representative participates in a meeting of an NCWM group in which a vote is taken.

A member's technical expertise, experience, and the rarity of that particular expertise, overrides the need for a "fresh point of view," in the opinion of the Committee. The necessity of developing experience, technical knowledge, and an historical perspective by Active members is just as important as for Associate members (there is no limit on Associate member's terms). Generally, there are too few Active members to permit term rotations (as is done in the Standing Committees) in subcommittees, sectors, and work groups; therefore, the sectors and subcommittees will be consulted concerning the appropriateness of terms for Active members whose participation is underwritten by the Conference. The Executive Committee has set no limits on their terms at the present time.

\section{1-3a I Quality Improvement: Role of the NIST OWM and Technical Advisors}

Decision: The Executive Committee acknowledged that Conference success is highly dependent upon the organizational skills and expertise of the technical advisors for the Conference committees and other groups. They expressed a preference for technical advisors drawn from OWM, which is not a regulatory agency, whose staff understands the constraints and needs of regulatory agencies in terms of resources, personnel, political pressures, and especially the need for methods to verify compliance with any recommended rules for commerce. The technical advisor maintains the integrity of the NCWM by providing long range vision for the future and the historical memory of why certain decisions were made. OWM operates under standards of practice and quality that enhance the integrity of the NCWM. Representatives of the NCWM spoke to Dr. John Lyons, Director of the NIST, advising against possible further cutbacks in OWM budget and staffing. Dr. Lyons assured the NCWM representatives that he did not want to see any further program reductions in OWM and had directed his staff to cover any anticipated shortfalls in budget this fiscal year. Letters from and to the Central Weights and Measures Association are appended (Appendix C) substantiating Dr. Lyons' position.

Background: In order to prepare committee members who may not have a thorough technical background in subjects they are asked to address, someone must analyze the issue, seek technical input on both sides of the issue, translate the issue into understandable language, determine and explain the costs and benefits of issue resolution and potential solutions, and ensure that all parties with a stake in the issue have an opportunity to express their differences and seek an agreeable solution. In order to communicate the logic of the discussions, alternatives, rationale, and final decisions to all interested parties who did not participate, meeting reports must be written (together with supporting documentation and data), published, and circulated before a final consensus can be generated.

The integrity of the NCWM depends upon the quality of this background work as well as the quality of the final decisions made by the committee members. NIST Office of Weights and Measures (OWM) staff members have typically provided this technical support, translating problems and needs into issues that the committees can address. NIST OWM staff members aiso organize meeting agendas, advertise meetings in order to get as much participation as possible, assist the committee chairperson to lead the meeting, and document committee and work group decisions and meeting results.

Many high priority tasks have been slowed in their accomplishment and others have been delayed in their initiation owing to lack of OWM staff resources. In 1991, a technical advisor was provided by other than NIST OWM: FGIS contributed 
Dr. Richard Pierce's time as technical advisor for the two NTETC sectors underwritten by that agency to establish type evaluation standards for grain measuring equipment. When considering the number of committees and work groups requiring technical advisors ( 5 standing committees, one subcommittee, three other NTETC sectors, and at least four work groups - privatization, metric, checkweighers, and U.S./Canadian mutual recognition), it is clear that the Conference needs additional technical staff to support this national standardization process. For its part, NIST OWM will continue to identify other agencies and organizations that share its objectives in particular areas and which might provide additional technical advice and, perhaps, contribute a technical advisor. The Committee will consider other sources of staffing for projects, such as industry and government volunteers and contracting with technical experts for services. The NCWM can offer only financial support (rather than technical personnel) because its members are volunteers whose employers are also constrained by limited staff and other resources to meet their own priorities. Although these employers, States, Federal agencies, and businesses often share priorities with the NCWM, it is necessary to combine several resources, technical, administrative, and financial, in order to execute a satisfactory plan and project.

\section{1-3b I Organization: Revision of the NCWM Constitution and Bylaws to Explicitly Recognize Voting Rights of Various Groups and Individuals Within the Conference}

Background: Review of NCWM Publication 1, Constitution and Bylaws shows the need to clarify and revise the operating rules under which the NCWM operates in order to:

- explicitly acknowledge the voting rights of work groups, task forces, subcommittees, and sectors (incorporating item 101-2b);

- explicitly acknowledge the roles and responsibilities of the NCWM Office of Weights and Measures staff; and

- revise certain committees from annual to standing.

See Appendix D for proposed revisions. These revisions will be discussed at the next Interim Meeting. See item 101-2b for the interim policy.

\section{1-4 I Organization: Laws and Regulations Committee}

Discussion: The Executive Committee believes that great progress has been made on certain long-standing issues under the Laws and Regulations Committee, which has organized and is managing two new groups: the Petroleum Subcommittee and the SI Work group on NIST Handbook 130. The L\&R Committee requested authority to establish another work group on revising Handbook 133. The Executive Committee authorized this group, and Chairman Nelson appointed the members.

\section{Petroleum Subcommittee}

At the 77th Annual Meeting outgoing Chairman Colbrook, in concert with incoming Chairman Nelson, appointed Celeste Bennett, MI, as Chairperson of the Subcommittee on Petroleum; Randy Jennings (TN); Barbara Bloch (CA); Eric Hamilton (FL); Charles Gardner (Suffolk Co., NY); Ron Hayes (MO); N. David Smith (NC); Jose Torres-Ferrer (PR); Bill Butterbaugh (National Propane Gas Assn.); Marilyn Herman (Herman \& Assoc.); Bob Reynolds (Downstream Alternatives); William Scheller (Scheller \& Assoc.); Dan Moenter (Marathon Oil Co.); Jim Williams (API); Lew Gibbs (Chevron); Jim Peeples (Clean Fuels Devel. Coalition); Robert Furey (General Motors); and Sydney Andrews (Consultant) as members. Dick Whipple, NIST, serves as technical advisor. The Subcommittee reported on the progress at its first meeting November 12-14 in Raleigh, NC. Chairperson Bennett charged four work groups with (1) expanding the Uniform Law; (2) expanding the Uniform Regulation; (3) revising the guidelines for a minimum engine fuel quality laboratory; and (4) initiating guidelines for field sampling and testing. Handbook 130 contains versions of (1), (2), and (3). A field guide (4) is a totally new project. The first three work groups have agreed to draft documents; the fourth work group drafted an outline of objectives and what must be included in a field guide. Chairman Nelson appointed two other members to the Subcommittee in the late spring, Mr. Christopher Dyson representing Public Citizen and Mr. Fairman Thompson from South Point Ethanol. The Subcommittee held another meeting in April 1993. A draft of their report is available upon request. 


\section{SI Work group on NIST Handbook 130}

Dr. Ed Heffron reported on the progress made by the SI Work group that has grown to over 250 participants [Editor's note, now 300 corresponding members]. The group was charged with revision of Handbook 130 laws and regulations to encourage the use of metric units in commercial trade and, in particular, to recognize and coordinate the Uniform Packaging and Labeling Regulation with the SI revisions to the Federal Fair Packaging and Labeling Act (1992). This group met at the 77th Annual Meeting and conducted the rest of its reviews by mail. The technical advisor is Ken Butcher, OWM. See the L\&R Committee Report for specific recommendations as a result of their review.

\section{H133 Work Group}

As a result of further discussions with the Committee during the Interim Meeting, another Work Group was formed on Revisions to NIST Handbook 133 and Module 10. The objective is to achieve consensus by both Federal and State agencies on a fourth edition of $\mathrm{H} 133$ by 1994 . Issues to be resolved include the delineation of sampling plans, such as the suggested combination of Plans A and B, the updating of the MAV's, and the standardization of methodology for establishing gray areas for moisture loss. Their conclusions will be used to update the training module in package checking. They are asked to act as part of the U.S. National Work group for OIML Recommendation 87 - Net Content on Packages, and Recommendation 79 - Information on Package Labels.

The Work Group is chaired by Barbara Bloch, CA, Laws and Regulations Committee. Representing the four regions are Ross Andersen, NY, (Northeastern); Tom Coleman, MD, (Southern); Barbara DeSalvo, OH, (Central); and Pat Nichols, Alameda County, CA (Western). This group met in the spring of 1993. Technical advisors are Ken Butcher and Carroll Brickenkamp, NIST.

\section{Other Work Groups}

Just as the NTEP Board of Governors uses the National Type Evaluation Technical Committee Sectors as its subcommittees in the development and discussion of technical issues, and as the L\&R Committee now has a Subcommittee on Petroleum, there appears to be a need to establish more subcommittees or work groups under L\&R in the areas of (1) quality assurance and assessment programs for processes and products (such as registration in ISO 9000 series standards), (2) registration and accreditation of service agencies (such as a few States are piloting in their own registration requirements), (3) licensing of commercial measurement equipment users (an extension of public weighmaster requirements), and (4) development of moisture loss test methods and collection of data on packaging process variability; all require in-depth technical knowledge and consultations which is ordinarily done by a group's technical advisor. The L\&R Committee technical advisor has been inundated with technical and managerial work in the area of moisture loss, for example. The problem of adequate staff support with technical advisory services must also be addressed. As a result of fortuitous circumstances, Mrs. Diane Lee, MD Weights and Measures Laboratory, is assisting OWM on a half-time basis with moisture loss issues and measurements. She is an Intergovernmental Personnel Act staff acquisition for one year; we anticipate establishing State laboratory moisture determinations as a traceable measurement as a result of her work. There are no other financial or technical resources that can be dedicated to these other needs at this time.

\section{1-5 I Organization: Specifications and Tolerances Committee}

Decision: When the National Type Evaluation Technical Committee Sectors develop type evaluation test procedures and other technical material, they must consider the technical standards developed by the S\&T Committee. In this regard, the NTETC Sectors follow H44 and therefore could be considered subgroups to serve as a technical resource to aid in the development of S \& T issues under the S\&T Committee. The Executive Committee believes that the sectors should not limit their discussions to type evaluation standards if time permits.

Discussion: If the number of issues managed by the S\&T Committee compared with the workload of other committees, is any indication, there may be a need to further prioritize (and delay work on) the requests coming to this Committee and thereby reduce the number of items addressed by the Committee and/or consider subcommittees or work groups for specific work projects under this Committee. For example, some high priority work might be resolved faster if it could be delegated to a subcommittee. The Executive Committee discussed with the S\&T Committee the latter's priorities, how they fit into the NCWM priorities as a whole, and how the NCWM can assist the S\&T Committee to meet its priorities. Again, the problem of sufficient technical advisory services must be addressed. However, the S\&T Committee advised the Executive Committee that its workload looked manageable after the very high priority issues of railroad coupled-inmotion weighing and audit trails were addressed. 
The task of greatest interest to the majority of members is the establishment and clarification of standards for devices. This is the task of the Specifications and Tolerances Committee through its responsibility over the maintenance of NIST Handbook 44, "Specifications, Tolerances, and Other Technical Requirements for Weighing and Measuring Devices." This committee provides the technical leadership to the rest of the Conference on questions and issues concerning devices.

Due to its workload, it had been suggested that the S\&T Committee be split into two parts - one committee for weighing and another for measuring. In further discussions at the 77th Annual Meeting, however, the Executive Committee agreed to maintain a single S\&T Committee (after all, the General Code applies to all devices) and to explore subcommittees or work groups to develop specific issues. The S\&T Committee now has joint technical advisors: Henry Oppermann and Tina Butcher of the OWM, NIST.

\section{Solid Volume Measuring Devices Work group}

The S\&T Committee reported that many industry members expressed great interest in establishing a work group to develop standards for devices that measure the volume of packages and their individual weights and compute a shipping charge based on weight or volume. The users, such as UPS and Federal Express, as well as the device manufacturers, are anxious to move forward with standards-setting for these commercial devices. The S\&T Committee described the effort as mainly involving the users and device manufacturers. One member of the S\&T Committee and an OWM representative from the government arena would be involved. Although only a small NCWM financial commitment is needed, the problem is to obtain a technical advisor. The OWM is investigating potential sources for this role outside of OWM itself; Mr. Bruce, Chief of the Legal Metrology Branch of Canada has agreed to assign a technical staff person from his group to serve as technical advisor. Mr. Carl Skonberg, United Parcel Service, will serve as Chairperson of the group. A meeting was held before the July Annual Meeting. Two more meetings will probably be necessary to provide a final recommendation for the S\&T Committee to provide to the Conference for voting next July, 1994.

Thanks to the financial assistance of the National Conference on Weights and Measures, and to Canada's Legal Metrology Branch, the Executive Secretary named Ms. Nathalie Dupuis-Desormeaux, engineer with Canada's Legal Metrology Branch to act as Technical Advisor to the Solid Volume Measuring Devices Work group under the Specifications and Tolerances Committee. Their first meeting was held in June, 1993. A draft report is available upon request.

\section{Interstate Commerce Commission}

The S\&T Committee alerted the Executive Committee about a problem faced by the State of Maryland. Maryland will not permit a freight company to use forklift truck scales as the means to charge for moving goods because those scales do not meet $\mathrm{H} 44$ performance requirements for Class III. Nevada, Florida, and California are also pursuing this issue. The freight company requested the Interstate Commerce Commission to preempt the States in this regard. The Executive Secretary wrote the Interstate Commerce Commission. A copy of that letter appears in Appendix D; the letter may be of assistance to other States in their enforcement programs. [Editor's note: letters were transmitted from several States, industries, the NCWM, as well as NIST. They are available upon request from the OWM, NIST.]

\section{1-6 I Organization: Education, Administration, and Consumer Affairs Committee}

The Executive Committee believes that the National Training Program should be expanded to encompass the coordination of a national training delivery system (see below), specific measurable inspector certification criteria, service agency registration criteria based on training, and continuing certification and registration dependent upon specific continuing education requirements. Subcommittees in the areas of (1) education delivery, (2) inspector and repair agency certification, (3) trainer certification, and (4) administration of weights and measures programs are needed to work on various elements of the expanded program; however, no technical advisors are available to staff the subcommittees. Unfortunately, NIST cannot at present provide more than one technical advisor to assist the Education Committee. The Executive Committee will work with the Office of Weights and Measures to seek additional resources for the expansion of the training program.

Discussions with the Education Committee at the Interim Meeting centered around the following issues:

- Keeping the modules up to date when handbooks are revised annually. It was suggested that States presenting modules could obtain electronic copies of the module on floppy discs and incorporate their updates as first draft revisions for the Education Committee. 
- Module 23 Weights and Measures Administration, Part II, is on hold until another contractor is found to complete its development. The Executive Committee was asked to assist in seeking an appropriate contractor.

Besides the difficult national economic situation, one of the reasons for a decline in module training and a decrease in the number of CEU's awarded is that many weights and measures inspectors have taken more than one version of the modules and CEU's have up until this time been given to a student only once per specific module. With major changes having been made to some modules,

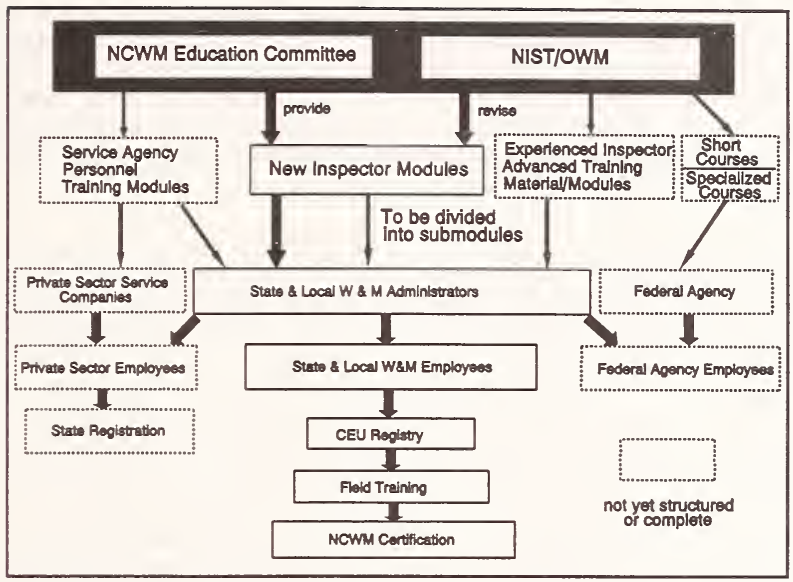
the Education Committee sees merit in providing additional CEU's to students who retake significantly revised modules. This will encourage students to update their knowledge about a particular subject by attending and receiving credit for formal training. The Education Committee intended to put this before the voting membership in July, but the Executive Committee felt that the Education Committee, in its managerial capacity for training for the NCWM, could implement the policy as soon as feasible without waiting for a formal vote from the NCWM membership. This policy change posed no disadvantages to the NCWM members. The Education Committee was asked, therefore, to proceed with its plans.

\section{1-7 I Organization: Liaison Committee}

Decision: The Liaison Committee met on Sunday, July 18, and decided to recommend abolition of the Liaison Committee by formal action of the National Conference at the next Annual Meeting. They further recommend:

1. Assign general liaison responsibility to each of the standing committees;

2. Assign issue-specific outreach to each of the standing committees;

3. Include a strong reference to liaison responsibilities to each standing committee duty descriptions;

4. Request that each regional weights and measures association report on their activities and projects to the Executive Committee; and

5. Assign Weights and Measures Week, the consumer brochure, and consumer group outreach to the Committee on Education, Administration, and Consumer Affairs.

The Liaison Committee also recommended that the Executive Committee take immediate action to allow the Conference to operate as if the Liaison Committee had been abolished. This will save approximately $\$ 3,000$ in travel expenses for the upcoming Interim Meeting. The Executive Committee voted to adopt the Liaison Committee's recommendations.

Action on changes to the Constitution and Bylaws will be initiated at the Interim Meeting of 1994.

Background: The Task Force on Planning for the 21st Century recommended that liaison with other organizations be incorporated into the work of every group within the Conference, not just the Liaison Committee. It was recommended that liaison is important enough to be highlighted as an objective of every standing committee. After discussing the Task Force recommendations, the Liaison Committee met with the Executive Committee at the 1992 Annual Meeting and proposed that each member of the Liaison Committee be assigned to another standing committee in order to bridge the gap between their roles as liaison experts and the work of the other committees. The Liaison Committee members were asked to emphasize and transfer the task of liaison in the context of each committee's work at the Interim Meeting. Aves Thompson, chairperson of the Liaison Committee, was invited to participate in the rest of the Executive Committee deliberations at the Annual Meeting. 
The long term future of this committee was discussed with Liaison Committee members. With the technical advisor of the Liaison Committee reassigned to other duties at NIST (as a result of budgetary restrictions), and with other issuespecific responsibilities of high priority (Petroleum Subcommittee; Grain Moisture and Protein Analyzer Type Evaluation Sectors; keeping the modules up-to-date; etc.), the Executive Committee considered revising the standing committee structure within the NCWM, deleting the Liaison Committee as a separate standing committee. The Liaison Committee recommended to the Executive Committee that it be abolished as such, and that a four-person liaison advisory group be established.

The four person advisory group should consist of a chairperson and three other members. The chairperson should be a weights and measures official appointed to a 3-year term who will serve as the liaison advisor to the Executive Committee. The other three members should be appointed to 3-year terms and assigned as liaison advisors to each of the other three standing committees. Two of these other three members should not be weights and measures officials. The liaison advisors are not to be voting members of the committees to which they are assigned. The major responsibility of the liaison advisor is to provide support to the committee chairperson when outreach or input is needed on an issue before the committee. The liaison advisor will prepare a report on the liaison activities of the committee for the standing committee chairperson, which will become a part of the annual report for that standing committee. The liaison advisor to the Executive Committee will also prepare an executive summary report of the activities of all the liaison advisors to be included in the annual report of the Executive Committee. The chairperson of the liaison advisory group will also convene the group at both the Interim and the Annual Meetings to discuss liaison activities of each of the advisors, activities that may cross committee lines, items of general interest to the Conference and any other pertinent issues. The intent of the group is to provide a valuable liaison resource to committee chairpersons by which the conference can lead, educate, and inform others outside the field.

The recommendations of the Liaison Committee were discussed. These recommendations were followed at the Interim Meeting and were reviewed at the Annual Meeting. The arguments for and against continuing the Liaison Committee either as a work group or standing committee long term are as follows:

For: An extra non-voting committee member could conduct liaison activities that often fall through the cracks when decisions are being made by the committee.

A committee member would be available who is familiar with interacting with other agencies and organizations and familiarizing them with the goals and objectives of the National Conference on Weights and Measures.

Notice and reminders to jurisdictions to prepare for Weights and Measures Week, and maintenance of the Consumer Brochure "Getting What You Pay For" can continue to be under the purview of the Liaison Committee or Liaison Work group.

Against: The Conference could save money by disbanding the Liaison Committee and transferring full responsibility for liaison activities to the other Standing Committees. The money saved could be used for new projects.

The other standing committees have established liaisons with outside groups as needed. Once the former Liaison Committee members transfer their knowledge and insights to the other committees, there should be no reason why they cannot assume full responsibility for liaison.

For Associate members from the Liaison Work group, no single industry representative can represent the entire packaging, device manufacturing, and user business population on any given committee.

As reported in Item 101-2b, work groups are formed for delimited objectives, short term in nature, (but not necessarily for 1 or 2 years as is a task force). The proposal of the Liaison Committee, unless it is to transfer the experience of the existing Liaison Committee to the other standing committees, is not specifically short term in all aspects.

Additional reasons for not maintaining the Liaison Committee:

- Other Standing Committees have mentioned the need for more interaction with other Federal agency representatives, perhaps making them members of the committees, rather than just "keeping them informed." Some now attend meetings: the Canadian government representatives are titled "technical advisors." Alternatively, these individuals might 
be appointed as non-voting members. There may be alternative ways to add Federal agency membership, such as a Food and Drug Administration or Federal Trade Commission representative to the L\&R Committee.

- S\&T, L\&R, and Education Committees each have 5 Active members; Executive has 10 Active members. Executive's work is principally liaison. Another nonvoting member from the Active membership and therefore representing the same constituency as the other members, is an additional cost that can be saved by not adding a liaison member.

Incorporating the responsibilities of the Liaison Committee into the other standing committees' functions and abolishing the Liaison Committee will require revising Publication 1, NCWM Constitution and Bylaws, BYLAWS as given in Appendix E. This action was postponed until the committees reported on the success of transfer of liaison activities, and whether further Liaison Work group actions are needed for an extended duration. Action will be taken by the Executive Committee per the recommendations of the Liaison Committee.

\section{1-8 I Organization: U.S. - Canadian Mutual Recognition Work group}

The Executive Committee unanimously adopted the following policy with respect to the two parties (the United States and Canada):

With respect to weights and measures devices, the parties agree that the most effective means to remove barriers to free trade is to achieve mutual recognition of device type evaluation testing. This will necessitate the comparative analysis of type evaluation codes and test procedures together with the intent of streamlining and minimizing differences insofar as possible to enable efficient device evaluation while preserving the technical capability and competence of their mutual laboratories.

A U.S.-Canada Mutual Recognition Work group was formed with representation from Canada's Legal Metrology Branch, four NTEP participating laboratories, and NIST OWM. Its first meeting was held April 14-16, at the Clarion Hotel in Rockville, MD so that the group could tour the NIST Force Group load cell testing facilities and the Maryland Type Evaluation Participating Laboratory. The goal set at this meeting was to mutually recognize type evaluations between the U.S. and Canada for bench/floor scales and weighing/load receiving elements, with a capacity up to $500 \mathrm{~kg}$ (1000 lb), and digital indicators by April of 1994. In order to establish mutual recognition for simpler devices as soon as possible, specialized software features intended for specific applications, price computing scales, complex devices, and new technologies are all excluded from this initial effort. A summary of points from the meeting including the proposed work plan was distributed in May to those attending the meeting, and is appended to this report as part of Appendix F.

Technical representatives met in Ottawa June 7-10 to review both nations' type evaluation test procedures and criteria and to devise a dual checklist for scales and for digital indicators. The next milestone is to complete the combined checklist, test procedures, and any recommendations for harmonizing requirements in time for review by LMB and the NTETC Weighing Sector. An application guide and a single application form are also being drafted. The next meeting of the full Work group will be held in Ottawa September 8 and 9 in order to review drafts of all products before transmittal to the Weighing Sector, which is expected to meet in November.

Type evaluation interpretations may be endorsed or modified by the Weighing Sector as long as the interpretations are in harmony with Handbook 44 requirements. If recommendations for harmonizing requirements require changes to Handbook 44 and are supported by the Weighing Sector, they will be forwarded to the S\&T Committee for consideration and will be accorded the appropriate due-process procedures in Canada. A jointly-agreed program statement will be prepared for the 1994 Interim Meeting by Mr. Robert Bruce, Canada LMB, and the Executive Secretary, describing the objectives and operation of this first programmatic implementation for review by the Executive Committee. If all milestones are met, training of laboratory personnel and joint evaluations can begin in February in order to commence the program by April 1994.

Background: On November 9 and 10, 1992, NIST hosted a preliminary meeting with U.S. industry and NCWM representatives to discuss the extent to which industry and weights and measures officials believed harmonization with Canada or with OIML should be pursued. Representatives of the scale industry were present. It was concluded at that meeting that: 
1. Although the impact of OIML recommendations may be important to the U.S. legal metrology system, and more immediately to U.S. businesses, the National Conference on Weights and Measures should place a higher priority on U.S. - Canadian interactions in weights and measures.

2. Harmonization efforts should place highest priority on type evaluation test procedures rather than on the base requirements in Handbook 44. The scale industry member present did not consider differences in design requirements to be trade barriers; they did consider the type evaluation process to constitute a trade barrier.

3. This group proposed defining harmonization as compatibility or mutual recognition of each nation's type evaluation, not necessarily exact conformance of documents or the format of those documents.

Two alternatives were considered at that time:

a. Conduct additional tests to verify compliance with the other nation's criteria if requirements are not the same; or

b. Agree to conduct a single test for the same point that will satisfy the more stringent requirement of the two countries.

4. U.S. - Canadian harmonization or reciprocity of type evaluation tests was important enough to establish an NCWM Work group reporting to the Executive Committee.

A meeting with U.S. scale industry representatives, NCWM representatives, NIST staff, and Canadian officials was held on December 10 and 11. The meeting focussed on exploring with Canada whether reciprocity of type evaluation tests could be a mutual priority for both nations. A report of that meeting is contained in Appendix F. Robert Bruce, chief of Canada's Legal Metrology Branch (LMB), met with the Executive Committee and other NCWM members and organizations at the Interim Meeting to further explore the issue.

Robert Bruce informed the Executive Committee that he expected that harmonization efforts with the Conference will assist the LMB in reforming Canada's device codes, as well as fulfilling obligations under the U.S. - Canada Free Trade Agreement, by minimizing standards related measures that impede trade.

He stated that the higher priority is to reform device codes in Canada. The government of Canada is committed to adopting codes only when there is a risk of real problems; government intervention is justified; benefits clearly outweigh costs; and when device codes are the best alternative to minimizing inaccurate measurement. He informed the Committee that some of Canada's device codes have outlived their intended purpose and have been outpaced by technology. Any revised codes will be less prescriptive and lean more heavily on performance requirements, rather than prescribing the manner of device design and installation.

The process for establishing device codes in Canada was presented in brief. This process includes full opportunity for public and business consultation and participation, and for an impact assessment.

Mr. Bruce stated that the harmonization effort between Canada and the United States should provide opportunities to enhance trade, share expertise, equipment and facilities, reduce costs for device manufacturers, and reduce government expenditures.

In conclusion, he informed the Committee that the LMB fully supports harmonization through the mutual recognition of each nation's type evaluation process. He has recently requested the support of Canada stakeholders in this initiative and plans to form a Canadian Work group at the earliest opportunity to prepare for negotiations related to this matter.

\section{1-9 I Organization: Privatization Work Group}

Chairman-Elect Tom Geiler, who is also Chair of the Privatization Work Group, reported on the group's first meeting in Richmond, VA, and a subsequent meeting with the Washington State Task Force investigating the privatization of Washington Weights and Measures. Their report is contained in Appendix G. 
the Iowa Legislature to clarify that privatization should not be attempted in a State without strong regulatory oversight of the system; such oversight requires State government investment and might not be a major cost savings to the State. In addition, the issue of conflict of interest is an area that the Privatization Work group has not been able to resolve. The Work Group will meet in Topeka, KS, in June, to learn from a State that is strongly committed to its implementation of a privatized weights and measures program.

At the meeting in Richmond, VA, the Work group preliminarily determined that a great deal of service and routine device testing had been and could be further shifted from government employees to private agencies and companies. It did not appear possible, however, that government agencies could absent themselves from oversight of the marketplace to ensure maintaining faimess among all parties. The State of New Hampshire's program has no follow-up inspection of private service agencies and does not appear workable. Therefore, when the lowa Legislature proposed deleting funding for its weights and measures agency, reducing lowa weights and measures staff from 19 to 5 and adding repair firm registration to its duties, the NCWM sent a small delegation to oppose Iowa's approach and was able to convince the lowa Legislature to continue to fund a weights and measures program.

The Work Group wanted to investigate the problem that, if all testing were to be turned over to private companies, the Work Group knows of no private company that does not also sell or service devices for profit. Therefore, conflicts of interest appear likely without some sort of check or balance for companies assigned to review their own work or to require adequate service or replacement of devices when it could be interpreted as work for their own profit. The Work Group decided that discussions with State governments and businesses that favored privatization and had implemented such privatization was necessary to determine what checks and balances might have been or are planned to be instituted to avoid this significant problem; it asked whether it could visit Kansas, a state widely advertising its weights and measures program as "privatized."

The Work group understands that Kansas is not only happy with its approach to weights and measures regulation, but has made significant overtures to other States that this is the approach of the future for weights and measures regulation that other States should copy. Unfortunately, if the lowa situation is any indication, the message of cost savings is being heard, but not the need to retain at least minimal control over the marketplace. The State of Kansas, for example, does not have a skeleton staff enforcing its weights and measures requirements. This is one of the reasons several members of the Work Group have significant reservations about the advisability of the Kansas approach without adding significant training, accreditation, and legal enforcement capabilities, which add significant costs to privatization. The Work Group therefore met with Kansas weights and measures management and staff and regulated industries to explore how Kansas manages its authorities and responsibilities in the marketplace.

A meeting of the Work Group was held in Topeka, KS, June 3-5, 1993, in order to study what Kansas and others have called privatization of weights and measures. The Work Group is very appreciative of the hospitality and openness accorded the group by the Kansas Department of Agriculture and Weights and Measures management and staff, as well as the several businesses which sent representatives to the meeting or met with representatives of the Work group in their offices.

Chairman Tom Geiler reported in the Technical Session held at this Annual Meeting on Tuesday morning, the Work Group has the following information.

\section{Has Kansas "Privatized"?}

Using the definition of privatization as the shifting of tasks or responsibilities from government to the private sector, then the answer is negative for the weighing device area, but positive for the motor fuel volumetric measurement area.

- Kansas has not cut back on the government oversight given to commercial weights and measures in the weighing area. Kansas' test cycle was approximately once every 4 years before programmatic changes were made, and remains once per 4 years today. Approximately the same number of full time equivalent hours is spent in today's program as before. Kansas decided that this frequency of testing was not adequate to provide a fair marketplace.

- Kansas Department of Agriculture did save resources by reducing time and effort in other areas, including egg and fertilizer programs, combining these duties with weights and measures small and medium capacity weighing device inspection, and creating general duty inspectors.

- Kansas Weights and Measures, prior to what is called "privatization," did not have responsibility for motor fuel dispenser testing. That program was transferred to them, and the number of inspectors and frequency of test were 
both reduced. Kansas used to test dispensers approximately twice per year and have reduced testing to about every 2 years.

\section{What Did Kansas Do That It Calls "Privatization"?}

Kansas legislated that all businesses with commercial weighing or measuring devices have their devices tested annually by State-licensed private service companies or obtain a license to test their own devices. These companies apply a sticker to the device, but do not "reject" a device.

Kansas has shifted to the private sector the annual testing responsibility held by many State and local governments. Prior to this legislative action, Kansas did not have the resources to perform annual testing in the weighing device area; Kansas was able to maintain the same level of resources with higher compliance rates after their law was enacted. In the volume measuring device area, the State was able to save substantial resources by reducing the number of inspectors and frequency of testing.

\section{What Has the Effect of Requiring Annual Testing Been?}

According to statistics collected by Kansas, when Kansas Weights and Measures inspectors test devices as found, the compliance level is much higher than before. It is difficult to determine how much higher the compliance level has risen because:

(1) In the motor fuel area, the standard the former agency used as the basis for compliance was tighter than Handbook 44 standards now applied. Without realizing that they were not comparing compliance with the same standard, Kansas claimed to have increased compliance of motor fuel dispensers from $60 \%$ to $90 \%$ after initiating the new program requiring annual testing by private companies.

(2) In the weighing device area, general duty inspectors have test guidelines in the form of notebooks for those procedures with which they are less familiar. It was not possible to determine whether the tests that are now performed are the same as, less stringent, or more stringent than those used before this new program was devised because the earlier procedures were never recorded. There is no question, however, that the data indicate that compliance levels have risen.

Costs to businesses have generally remained the same (if they were already getting annual testing) or have risen (if they were not already buying annual testing services). It can be argued that the overall costs for such a program to the taxpayer has risen, since the costs of testing are passed along to the consumer. However, it can also be argued that, generally speaking, testing should have been obtained by businesses on an annual basis, as a cost of doing business. Additional costs above an annual testing program operated by a government agency may have occurred for multipurpose retailers that had depended on government testing to tell them when they needed service, and which now must contract with several service agencies, one specialized in volume measuring for motor fuel dispensers and another one for small capacity scales, for example.

One significant concern expressed by the Work Group before visiting Kansas could not be addressed: what is the extent of conflict of interest issues in the Kansas milieu?

\section{Present and Future Products of the Work Group}

The greatest risk weights and measures agencies face today is that governments at every level must reduce costs and when considering eliminating weights and measures agencies do not know of (1) the regulatory responsibilities of weights and measures; (2) the cost/benefit of weights and measures programs; nor (3) any improvements that can reduce costs in regulatory efforts and increase benefits. The State of Washington's legislature had planned to eliminate weights and measures enforcement in that State. Instead, they agreed to fund a one-year study to determine whether weights and measures had substantial benefits as compared with the costs. The Chairperson and one member of the Work Group met with the Washington survey team, and several members of the Work Group corresponded with the team throughout the project. Although one might question some aspects of the study, the benefits as measured were many times the costs. The question remaining from the study was not whether to retain the program, but how to pay for it.

The Work Group has attacked several problems so far. (1) Members have met with and written State and local agencies, legislatures, and other managers to explain the need for retaining weights and measures oversight as a government responsibility. (2) The Work Group developed a set of overhead transparencies and slides available to all to explain either their own programs and why needed, or of what a complete program should consist. These efforts are directed at developing vocal customers who, in turn, demand government regulation of the marketplace. 
Quantitative measurements of the effectiveness of a program or of changes to a program are of little value if the same standards are not used to evaluate the effects over time. Therefore, the Work Group would like to clarify data that would be useful to collect without too much effort, and that can be used to measure programmatic effectiveness. Illinois and Ohio, for example, have both reported that they were able to show a direct correlation between frequency of device inspection and compliance level. All jurisdictions should be collecting, for example, quantitative data on device error at the time of test, rather than only recording whether the device was "in" or "out" of tolerance.

Recognizing economic realities, the Work Group has outlined what is an effective program, but also realizes that government rarely has the resources to deliver that complete program. The Work Group therefore plans to explore in more depth how industry can play a more effective role in delivering the most effective program possible. Some areas to be explored include: minimum training; evaluating the tests performed by the testing agent; how to fund package testing and undercover buying and selling; an accreditation system for weights and measures programs including their private company licensees.

At the Open Hearing of the Committee, the Scale Manufacturers Association read a statement about privatization that the Executive Committee incorporates in its report:

SMA supports the principle that weights and measures enforcement by states and subordinate jurisdictions is an indispensable function of government.

Although other options may exist, SMA is concerned that such options would:

1. Create an unprecedented opportunity for conflict of interest in enforcement.

2. Fall short of the basic requirement of equity in the marketplace.

3. Not serve to improve/enhance the quality and effectiveness of experienced weights and measures professionals in enforcement vs. private sector service technicians who lack training in Handbook 44.

4. Fail to provide the administrative continuity to insure competent supervision and field inspection.

\section{1-10 I Organization: ISO 9000 Task Force}

Georgia Harris, NIST, provided a report on progress towards ISO Guide 25 accreditation (equivalent to ISO 9002 registration) of State and private company mass and volume calibration laboratories. She also discussed progress towards development of a NVLAP accreditation program in mass and volume calibrations at a higher level of accuracy and precision than currently available at State laboratories, as requested by State Weights and Measures Directors, using the expertise and collaborations of State Weights and Measures Laboratories. Her report is contained in Appendix H.

At the Annual Meeting, Ms. Harris addressed the concern that conformance to ISO quality standards is being increasingly demanded of State laboratories, service agencies, weights and measures manufacturers. Moreover, the NTEP Participating Laboratories must consider these standards for conformance with the OIML Certificate system. She recommended continuing the Task Force as a Work group, and adding the objective of developing criteria and documentation not only for the State weights and measures laboratories but also for the NTEP Participating Laboratories. The Executive Committee agrees with her assessment of the importance of this Task Force and reauthorizes the funding of this group to develop documentation to conform with ISO 9000 , Guide 25, and Guide 38 standards.

\section{1-11 I Publications: Status Report}

Discussions on improvements to the publications distribution and marketing are summarized below.

- It is difficult to impose a November 1 deadline for agenda topics and still produce the Interim Meeting agenda and mail it by December 5-10. Many industries take extended holidays near the end of the year, hence do not receive copies of the agenda until after the new year, only a week before the Interim Meeting itself. The task of researching the agenda topic, reviewing it with each committee, and documenting the logic for potential NCWM participants takes the entire time between November 1 and 25. The Thanksgiving holiday, deters printing companies from printing and mailing the agenda before the end of the first week of December without paying overtime. Therefore, unless the NCWM can afford double printing costs, the only alternative is to move the deadline for agenda topics back to October 15 . This was rejected because many meetings are held just prior to the November 1 deadline in order to reach consensus on items to be forwarded to the NCWM as agenda topics. The Committee 
therefore decided to make no changes to the November 1 deadline for agenda issues for the standing committees' Interim Meetings.

- Another alternative is to hold the Interim Meeting at a different time in January, say after January 20 or the Martin Luther King holiday. Several Executive Committee members pointed out that State legislatures resume meetings on Weights and Measures budgets immediately after the King holiday, so that would prevent many State directors from attending the Interim Meeting. Therefore, no change will be made to the date of the Interim Meeting.

- Order forms for the Handbook 133 series will be clarified to explain what a full set is (that it is the 3rd Edition (1988), plus 3 supplements $(1990,1991$, and 1992)), and what is necessary to have up to date standards documents for package checking.

- The Interim and Final reports will be announced on the NCWM Bulletin Board, and the reports will be made available for downloading. The handbooks, however, will be available in electronic form only with specific permission; they will not be available from the Bulletin Board until a subscription service is devised.

Following is a summary of NIST publications, the writing, printing, and distribution paid for by NIST, and distributed during calendar years 1991 and 1992 at no charge to NCWM members (membership year July 1 through June 30):

\begin{tabular}{|c|c|c|}
\hline $\begin{array}{l}\text { Title of NIST Publication } \\
\text { (Total Cost Paid by NIST) }\end{array}$ & $\begin{array}{c}1991 \\
(3,093 \text { total membership) }\end{array}$ & $\begin{array}{c}1992 \\
(2,996 \text { total membership as of } \\
1-8-93)\end{array}$ \\
\hline $\begin{array}{l}\text { Handbook 44, "Specifications, Tolerances, and Other Technical } \\
\text { Requirements for Weighing and Measuring Devices" }\end{array}$ & $\begin{array}{lr}\text { Distributed: } & 2,479 \\
\text { Printing: } & \$ 6,500\end{array}$ & $\begin{array}{lr}\text { Distributed: } & 2,740 \\
\text { Printing: } & \$ 7,000\end{array}$ \\
\hline Handbook 130, "Uniform Laws and Regulations" & $\begin{array}{ll}\text { Distributed: } & 2,144 \\
\text { Printing: } & \$ 4,500\end{array}$ & $\begin{array}{lr}\text { Distributed: } & 2,374 \\
\text { Printing: } & \$ 5,000\end{array}$ \\
\hline $\begin{array}{l}\text { Handbook 133, "Checking the Net Contents of Packaged } \\
\text { Goods" and Supplements }\end{array}$ & $\begin{array}{lc}\text { Distributed: } & 1,171 \\
\text { Printing: } & \$ 1,400\end{array}$ & $\begin{array}{lc}\text { Distributed: } & 1,864 \\
\text { Printing: } & \$ 6,524\end{array}$ \\
\hline $\begin{array}{l}\text { NIST Special Publication } 816 \text {, "Report of the } 76 \text { th National } \\
\text { Conference on Weights and Measures" }\end{array}$ & $\begin{array}{lc}\text { Distributed: } & 2,676 \\
\text { Printing: } & \$ 10,000\end{array}$ & $\begin{array}{lr}\text { Distributed: } & 2,996 \\
\text { Printing: } & \$ 6,000\end{array}$ \\
\hline
\end{tabular}

Selected NCWM publications have been sent at no charge to members as follows:

\begin{tabular}{|c|c|c|}
\hline Title of NCWM Publication & $\begin{array}{c}1991 \\
(3,093 \text { total membership) }\end{array}$ & $\begin{array}{c}1992 \\
(2,996 \text { total membershap as of } 1-8-93)\end{array}$ \\
\hline $\begin{array}{l}\text { Publication } 2 \text {, Membership Directory (sent to all } \\
\text { requesting members and as complimentary incentive } \\
\text { to "brand new" } 1993 \text { members) }\end{array}$ & $\begin{array}{lr}\text { Distributed: } & 2,676 \\
\text { Printing: } & \$ 5,780\end{array}$ & $\begin{array}{l}\text { Distributed: } \quad 493 \\
\text { Printing: } \quad \$ 1,060 \\
\text { Distribution to new members only (those not } \\
\text { previously participating in NCWM). } \\
\text { A new edition will be sent to } 1992 / 93 \\
\text { members who selected it about June } 1993 \text {. }\end{array}$ \\
\hline Publication 15, Interim Meeting Agenda & $\begin{array}{lr}\text { Distributed: } & 2,812 \\
\text { Printing: } & \$ 4,780\end{array}$ & $\begin{array}{lr}\text { Distributed: } & 2,996 \\
\text { Printing: } & \$ 4,800\end{array}$ \\
\hline Publication 16, Program and Committee Reports & $\begin{array}{lc}\text { Distributed: } & 3,093 \\
\text { Printing: } & \$ 6,186\end{array}$ & $\begin{array}{l}1993 \text { edition to publication in March; to be } \\
\text { mailed May 1, 1993 } \\
\text { Est. Distribution: } \quad 3,200 \\
\text { Printing Estimate: } \quad \$ 6,720\end{array}$ \\
\hline
\end{tabular}


Other NCWM publications have been offered for sale to members and nonmembers contained in the NCWM database. The following reflects that activity:

Publication 12, "Examination Procedure Outlines"

\begin{tabular}{|c|c|c|c|c|}
\hline $\begin{array}{c}\text { Unit Price } \\
\text { Member/Nonmember }\end{array}$ & Quantity Sold & Income & Printing Cost & Net Income \\
\hline $1991: \$ 10 / \$ 20$ & 190 & $\$ 2,025$ & $\$ 800$ & $\$ 1,220$ \\
\hline $1992: \$ 12 / 24$ & 315 & $\$ 3,780$ & $\$ 2,047$ & $\$ 1,733$ \\
\hline
\end{tabular}

Publication 5, "Index of Device Evaluations" (Not Available in 1992)

\begin{tabular}{||c|c|c|c|c||}
\hline 1991: \$20/\$35 & 162 & $\$ 3,300$ & $\$ 1,275$ & $\$ 2,025$ \\
\hline \multicolumn{5}{|c|}{ Publication 5A, "Index of Device Evaluations" (Not Available in 1992) } \\
\hline 1991: \$15/30 & 77 & $\$ 1,600$ & $\$ 676$ & $\$ 924$ \\
\hline \multicolumn{7}{|c|}{ NCWM Publication 5B, "Index of Device Evaluations" (Not Avallable in 1991) } \\
\hline $1992: \$ 15 / \$ 30$
\end{tabular}

\begin{tabular}{|c|c|c|}
\hline \multicolumn{2}{|c|}{ Summary of NCWM Publication Sales in 1991 and 1992} \\
\hline Total Gross Income & Total Printing Costs & Total Net Income \\
\hline$\$ 17,025$ & $\$ 7,290$ & $\$ 9,735$ \\
\hline
\end{tabular}

\section{1-12 I Membership: Status Report}

A report was given on the current level of membership, its growth over time, and the additional services being provided. See Appendix I for a complete breakdown on the NCWM mailing list database.

\section{NCWM Membership}

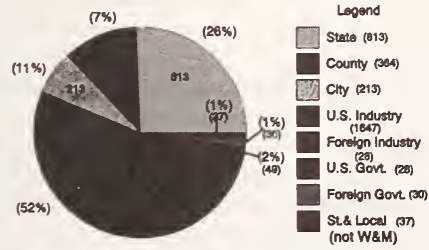

Types of Members - July 1, 1992 - June 30, 1993

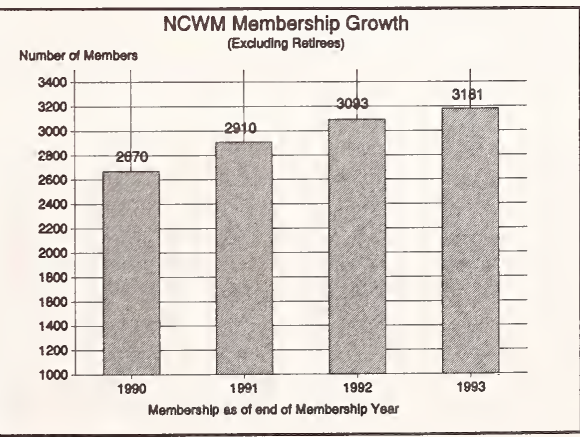


For the last 2 years, a count was kept of retirees who did not pay dues and this number was added into the overall totals. An effort was made during this past year to determine whether retirees want to be kept on our mailing list and continue to receive the W\&M Today newsletter. As a result of this effort, the number of retiree members dropped from 350 to 130. The graph and chart above do not show the number of retirees over the years, either before or after deleting disinterested retirees. As of March 5, 1993, membership was 3,137 members. This compares with 2,981 members in March of 1992 , a 5 percent rise in members from last year.

\section{1-13 I Finances: Treasurer's Report}

Decision: The Executive Committee voted meeting registration fees as follows:

1. Raise the registration fee of the Annual Meeting from $\$ 100$ to $\$ 150$; and

2. Raise the registration fee of the Interim Meeting from $\$ 50$ to $\$ 150$ for industry and from $\$ 50$ to $\$ 100$ for government officials. [Based on a comment raised at the Annual Meeting questioning the two-tiered registration fee, the Executive Committee met after the Annual Meeting and set the Interim Meeting registration fee at $\$ 125$ for all members.]

The 1994 budget is shown in Appendix J.

Background: A complete report was given at the Interim Meeting of actual expenses incurred in calendar year 1992 versus the budgeted amounts. In addition, the budget for calendar year 1993 was revised. See the Treasurer's Report for the final accounts and financial situation at the end of the calendar 1992 year. In order to fund the NCWM mission, priorities were set and funding sources, such as training tuition, and raising membership and meeting registration fees, studied. One significant standards development program that is entirely underwritten by membership dues is that of the National Type Evaluation Program (NTEP) test procedures and checklist development, and other NTEP operations, such as the Board of Governor's meeting to resolve appeals outside of the normal schedule of meetings. In 1992, NTEP expenses amounted to about $\$ 40,000$. Therefore, a maintenance fee for NTEP Certificates is proposed. See Item $102-1$.

The budget for FY 93 was projected in light of current expenses. The Executive Secretary warned that only one more year is available to the NCWM for which expenses at the current rate can exceed income.

The Budget Review Committee met July 7 and 8 to address the budget proposed by the Executive Secretary. After intensive budgetary reductions of over $\$ 40,000$, the Budget Review Committee was still not able to balance income with expenses. However, the number of projects requested by the customers of the Conference could not be reasonably reduced further. In 1993, groups are working in the following areas:

Privatization

U.S./Canada Mutual Recognition of Type Evaluation

Handbook 133/OIML/Price Verification/Module 10

SI Metric Work group

ISO 9000 Task Force

Checkweigher Type Evaluation Criteria and Test Procedures

Petroleum Subcommittee

Five sectors under the National Type Evaluation Program Technical Committee

Solid Volume Measuring Devices under the S\&T Committee.

The NCWM has become a standards-development organization of considerable note. All of these standardization work objectives were considered significantly high enough in priority that individuals in industry and government asked that the NCWM sponsor work groups to develop standards in these areas. This work has grown very significantly in the last 2-4 years. NCWM funds support the participation of public sector representation that would otherwise be unavailable to provide balance to the private sector interests and provide the weights and measures perspective to the standards development process. Only one group, the SI Metric Work group under the Laws and Regulations Committee, has been able to do their work entirely by mail, phone, and facsimile, because of the extraordinary work of their Technical Advisor, Ken Butcher. All other groups have needed at least one meeting, and many groups required two meetings in the calendar year, to meet their objectives and complete their tasks. Budgeted costs have been significantly trimmed from the initial budget proposed by the Executive Secretary. In spite of this, income does not meet expenses. The Conference has been drawing from a surplus for the last two years that has been predicted to shrink to a minimum of $\$ 25,000$ by January of 1994. If the Conference votes to authorize a maintenance fee for NTEP Certificates of Conformance, (1) this 
fee is specifically authorized to cover NTEP costs only, and (2) there will still be a shortfall between income and expense. Two options were explored after significant cost cutting: raising dues and/or raising registration fees.

It was noted that income for the Interim and Annual Meetings (see Appendix J in the Interim Report, accounts 411.1 and 411.2 in 1992 amounted to $\$ 35,850$ ) does not nearly pay for the expenses of these meetings (accounts 511 and 512 in 1992 amounted to $\$ 66,362.47$ ). The income from the Interim is far and away much smaller than the expense of this meeting. The income from the Annual Meeting is closer to paying for the cost of the meeting, but about $1 / 3$ short. The $\$ 50$ and $\$ 100$ registration costs are not in synchrony with today's costs and economy. The Committee decided to raise registration fees for the two major meetings of each year.

A new income account 483, and expense account 583, will be created if the NTEP maintenance fee is adopted and approved at the July 1993 Annual Meeting. [It was adopted.] Subaccounts are shown under each of these accounts. A new bank account 113 titled "European American - NCWM Associate" was established with a carry-over asset of $\$ 8,878.35$ at the beginning of 1993 .

\section{1-14 I Finances: Associate Membership Fees}

A status report was provided by the Conference Coordinator and Treasurer. As of December 31, 1992, an additional $\$ 22,635.00$ had been raised by increasing the Associate member fee to $\$ 50$ from $\$ 35$ for the membership year July 1 , 1992 to June 30, 1993. This represented 1,509 Associate members as of the end of the 1992 calendar year.

A separate bank account was set up in January 1993 in order to separate the income and expenses associated with the $\$ 15$ per Associate member which are under the control of the Associate Membership Committee. This account will earn its own interest and will be charged separately for any bank expenses. The policy adopted by the Executive Committee in concert with the Associate Membership Committee for this bank account is as follows:

1. Checks cannot be written, nor funds transferred to other accounts, without written authorization from the Associate Membership Committee's Chairman and Treasurer, as listed in the Annual Meeting Report.

2. The NCWM Associate Membership Account will be used to pay for the Annual Associate Membership's Outing, which may or may not be a joint outing with the NCWM general membership. Joint does not imply nor is it intended to mean $\mathbf{5 0 - 5 0}$ cost sharing.

3. After monies to cover the outing have been disbursed, any balance over $\$ 2,500$ at the end of the calendar year will be transferred to the NCWM by written authorization from the Associate Membership Committee's Chairperson and Treasurer. The decision of how to distribute these excess funds will be the sole responsibility and authority of the Associate Membership Committee. The only stipulation is that the monies must go into NCWM accounts. The distribution decision of monies by the Associate Membership Committee will be based on, but not limited to, a list of funding needs identified by the Executive Committee and submitted to the Associate Membership Committee Chairperson after each Interim Meeting. The Associate Membership Committee will disburse and announce its disbursal at its own discretion.

The Associate Membership Committee is invited to contribute a report of its actions, activities, issues, etc. to be included in the Executive Report.

\section{1-15 I Finances: Auditing Committee}

The Auditing Committee normally meets at the Annual Meeting. Now that the NCWM fiscal year corresponds to the calendar year, the Auditing Committee was asked to examine the NCWM finances and books at the Interim Meeting, since this is close to the end of the 1992 NCWM fiscal year. Their report is provided separately in this publication and will be repeated in the Annual Report of the Conference.

\section{1-16 I Meetings: Networking with Other Organizations}

Meetings with NIST management, and various other groups and individuals of importance to the National Conference on Weights and Measures, were held on Wednesday, January 13, 1993. 


\section{NIST Visiting Committee}

Dr. Ed Heffron, MI, was named a member of the NIST Visiting Committee in 1988 when the Omnibus Trade and Competitiveness Act gave new technology transfer objectives to the then National Bureau of Standards and renamed it as the National Institute of Standards and Technology. He has been asked to serve an additional year since he completed his term in the fall of 1992. Dr. Heffron reported to the Executive Committee on the importance of making the NIST management aware of the weights and measures constituency at every opportunity, and that he shared in the assessment of the importance to meet with the NIST Director during the Interim Meetings. He noted that the organization has concentrated recently on facilities upgrade and manufacturing technology transfer. Dr. Heffron gave the Annual Meeting President's presentation for the new NIST Director, Dr. Arati Prabhakar, who was called at the last minute to testify before Congress.

\section{ASTM}

Past Chairman Sid Colbrook asked N. David Smith, NC, to serve as liaison between the American Society for Testing and Materials (ASTM) Committee D-2 on Petroleum Products and Lubricants and the NCWM. ASTM is a not-for-profit organization that provides a forum for producers, users, ultimate consumers, and those having a general interest (representatives of government and academia) to meet on common ground and write standards for materials, products, systems, and services. The membership of ASTM is approximately 33,000 and there are 134 standards writing committees. The committee most familiar to NCWM members is D-2 and it is one of the largest in ASTM with a membership of 1,300. Committee D-2 has 27 subcommittees. Two of the subcommittees, A on Gasoline and J on Aviation Fuels, are the primary subjects of Mr. Smith's report on the Committee's last meeting, December 6-11, 1992, in San Jose, CA. Please see Appendix K for this report. Mr. Smith is expected to become the next chairperson of ASTM Committee D-2.

\section{ASHRAE}

Mr. Pat Nichols, Alameda County, CA, was chairperson of the Task Force on Energy Allocation Systems for the NCWM. One of the objectives of that task force was to provide the recommendations and information it had collected to a standards-writing organization with greater technical depth in the area of heating and cooling for home and office. The Task Force was able to pass its work along to the American Society of Heating and Air Engineers. The former chairperson of the task force was asked to participate to provide continuity between the NCWM and ASHRAE. He has worked over the past 2 years on ASHRAE Guideline 8P, part of a standards development committee under the direction of Martha Hewett, Director of Technical Projects, Center for Energy and the Urban Environment in Minneapolis. The NCWM "Recommended Regulation for Energy or Utilities Allocation Systems" was drawn upon heavily in the guideline, as well as standards of European countries and draft CEN standards. A meeting in February is expected to conclude the ASHRAE work; the Committee congratulates Mr. Nichols for his shepherding this project to a successful product.

\section{Meetings with NIST Director and Staff at the U.S. Capitol}

Three delegations from the Executive Committee visited with (1) Sally Chadbourne, staff member of Congressman Neal Smith, IA, Chairperson of the Subcommittee on Commerce, Justice, State, and Judiciary; (2) Carol Pompliano, staff member of Congressman George Brown, CA, Chairperson of the Committee on Science, Space, and Technology, and (3) Dr. John Lyons, Director of the National Institute of Standards and Technology. Their purpose was to introduce themselves to the congressional staff whose committees are critical to NIST appropriations and authorizations and to let them know how critical NIST is to the weights and measures national infrastructure and how vital its support of the NCWM is to the State, Federal, and industrial weights and measures system. Their purpose in visiting Dr. Lyons was to explore with him the possibility of reprogramming OWM staff to cover budgetary shortfalls and the necessary tasks that would go undone if reprogramming were to occur. Dr. Lyons assured the group of his support, later transmitted in writing to Mr. Bruce Adams, President of the Central Weights and Measures Association. The Committee intends to continue its visits with the NIST Director and members of Congress.

\section{1-17 I Meetings: Annual and Interim, Work Schedule and Technical Sessions}

\section{Interim Meeting Work Schedule}

Meetings were held with all the standing committees to determine the level of financial support and other assistance the Executive Committee can allocate to their priorities and to the NCWM members. Further discussions were also held exploring improvements to the Interim Meeting process and work sessions. 
For example, in order for committees to begin their meetings on time, special registration for committee members will be held 30 minutes prior to official opening of the registration desk at both the Annual and Interim Meeting.

\section{Annual Meeting}

Chairman Nelson asked that Mr. Bruce, LMB Canada, provide another presentation on his plans for future involvement with the United States and OIML at the 78th Annual Meeting. Mr. Bernard Athane, Director of the Bureau of International Legal Metrology, Paris, requested the opportunity to address the Conference concerning the OIML certificate system. An invitation from the Executive Secretary was extended to Mr. Athane. His and Ms. Kristine French's joint presentation was very well received.

A presentation on metric labeling was given as part of the Laws and Regulations Meeting. Open hearings for all the committees will be held on Monday of the Annual Meeting Week, to allow more time for the committees to prepare their addendum sheets for voting on Wednesday afternoon and Thursday morning. Technical presentations on NTEP issues, package checking, and privatization were held on Tuesday morning prior to the General Session.

The Committee discussed shortening the awards ceremony, traditionally held at the General Opening Session on Tuesday afternoon of the Annual Meeting week, by changing the way the awards are announced and presented. Attendance awards for 15 or more years are given in 5 year increments. Until now, the NCWM Chairperson read the name of each awardee, the NIST Director and NCWM President presented a framed certificate to each person, and a photographer took separate photographs of each person with the NIST Director. The Executive Committee decided to ask OWM to provide the attendance certificates as part of each delegate's registration materials and to ask the NIST Director to read the names without each person coming to the podium to accept the award. A group photograph of the awardees was to be taken with the Director and Chairperson; unfortunately, the Director could be present. Banner and ribbon awards will be displayed the entire Annual Meeting week, rather than just on Tuesday, and the President's awards will be announced formally on Tuesday. The State representatives were asked to come to the podium to receive the banner or ribbon and stay for a group photograph.

\section{1-18 I Meetings: Annual and Interim, Future}

\section{8th NCWM}

The Associate Membership Committee Chairman, Dave Quinn, and the Conference Coordinator presented a report concerning the Conference Outing in Kansas City. A rodeo, barbecue, and hoe-down and square dance were held at the Benjamin Ranch on Wednesday, July 21. The Associate Membership provided the entire "shindig" at the ranch, with the NCWM general accounts covering the bus transportation.

\section{9th NCWM}

Reports on possible sites, including Denver, Palm Springs, and Orange County, CA, were given. Mrs. Ann Turner, NCWM Conference Coordinator, visited 25 sites distributed in Irvine, CA (one hour from Los Angeles); Denver, CO; and San Diego, CA. As a result of her analysis and report, the Executive Committee decided to hold the Annual Meeting at the Doubletree Inn, San Diego, July 17-21, 1994.

\section{Future Annual Meeting Sites}

Decisions: The Holiday Inn in Portland, ME, has been selected as the site of the 80th Annual Meeting in 1995. The Hyatt Regency in Bethesda, MD, has been selected as the site of the 1994 and 1995 Interim Meetings. No contracts have yet been signed for the 1995 meetings.

Background: Mr. Clayton Davis, ME, suggested to the Committee that Portland, ME, would have adequate facilities to host the 1995 Annual Meeting, scheduled for the northeastern region. After the Interim Meeting, the Conference Coordinator traveled to Portland. There are no hotels large enough to book enough sleeping rooms so that all the Conference delegates could reside at the same location. The only hotel with enough meeting room facilities has no other hotel convenient to it for delegates who could not book reservations in the main hotel. Unfortunately, at this time neither Vermont, New Hampshire, nor Maine have urban areas where a single hotel has enough sleeping rooms for which it is willing to contract. The Chairman and Chairman-Elect reviewed the Conference Coordinator's recommendations, visited the Portland site, and recommended to the Executive Committee that the location outweighed the hotel accommodation issues. The Executive Committee decided unanimously to select the Portland site. The main hotel is on the waterfront and part of the quaint city of Portland. Many restaurants and shops fill the streets. Fishing trawlers and other water craft 
moor in the busy harbor. The secondary hotel is within one block of the main hotel. The meeting will be close to our Canadian neighbors, so the Committee hopes to attract many business and weights and measures representatives from north of the border.

The Executive Committee welcomes proposals from any jurisdiction that thinks its location would be suitable for an Annual Meeting. Provided below are minimum specifications for Annual Meeting sites. Please note that the host jurisdiction does not have to concern itself with the additional burden of support and technical personnel when an Annual Meeting is held in its vicinity; the Conference hires support personnel for report generation and registration from temporary oftice services and Convention Bureaus.

\section{Annual Meeting Minimum Specificanons}

1. The Annual Meeting will rotate among the 4 regions in the following order: 1990 - Washington DC; 1991 Northeastern; 1992 - Southern; 1993 - Central; 1994 - Western; 1995 - Northeastern, etc.

2. Large full service hotel (at least 500 rooms), minimum AAA 4-diamond or Mobil 4-star rating (to ensure an appropriate number of meeting and conference staff), with complete meeting room facilities, i.e.:

a. General Sessions set for 400 classroom style with head podium for 12 .

b. Ten (10) breakout rooms for simultaneous meetings throughout the week.

3. Active and supportive Convention Bureau for registration desk and cashier personnel, and access to a temporary office agency for typing and report assistance.

4. Downtown area with ample restaurants and safe for walking in the evening.

5. Several printing firms within one to four blocks from hotel.

6. A variety of optional events and outings from which to choose.

7. Full service airport for connections from all 50 states (small connector airlines not desirable.) Transportation to and from the airport should be ample, either by host hotel or airport transportation system.

8. Final selection made by the Executive Committee, concurred by the Executive Secretary and the Conference Coordinator.

\section{Regional Association Reports}

A meeting had been planned at the Interim Meeting with representatives from each of the regional weights and measures associations concerning their priorities, how they can better interact with the National Conference, and what each organization needs to maximize their effectiveness. Other scheduled meetings that required longer time than had been originally planned prevented the conduct of the meeting, and discussion of this issue. The Liaison Committee turned this responsibility over to the Executive Committee at the 1993 Annual Meeting.

\section{1-19 II Program: OWM and NIST}

The Long Range Plan of OWM was presented (available on request from the Office of Weights and Measures). The Executive Secretary provided a status report on staffing OWM can provide to the Conference. Dr. Edward Heffron, Director of the Food Division, MI Department of Agriculture, former Chairman of the NCWM, and currently a member of the NIST Visiting Committee, discussed the status of the National Institute of Standards and Technology, and the Federal agency perspective in light of the transition to President-Elect Clinton's administration. Plans for the 1993 calendar year in support of the National Conference by the NIST Office of Weights and Measures are presented in Appendix L.

Dr. Arati Prabhakar was sworn in as the tenth Director of the National Institute of Standards and Technology in the spring of 1993. She was not able to attend the 78th Annual Meeting because she was called to testify before Congress 
at the last minute. She sent her regrets and asked Dr. Ed Heffron, MI, a member of the NIST Visiting Committee, to make a few remarks on her behalf at the Annual Meeting Opening Session.

\section{1-20 I Program: International Organization of Legal Metrology}

Dr. Sam Chappell, NIST, updated the Committee on the work and plans of OIML as they affect the NCWM. There is a significant reorganization of the structure of OIML in progress. The United States has maintained its leadership of technical committees in the areas of metrological control, packages, mass and density, pressure and force, and pollution. See Dr. Chappell's report in Appendix M. Mr. Bernard Athane, Director of the Bureau of International Legal Metrology, addressed the Conference on July 20, 1993.

\section{Part II - NTEP Board of Governors}

$102-1$

\section{Finances: NTEP Operations and Funding}

(This item was adopted.)

Recommendation: Revise NCWM Publication 1 "Constitution and Bylaws" Constitution, Article VII - Fees and Dues as follows:

The annual membership fees ${ }_{2}$ the registration fees for meetings, fees for the National Type Evaluation Program (NTEP) shall be established (and may be revised) by a majority vote of the Executive Committee at any official meeting of that Committee.

Revise Bylaws, Section 5 - Duties and Fields of Operation of Committees, A. Executive Committee

The Executive Committee, subject to the overriding authority of the Conference itself:

(No change to items 1, 2, 3, and 4.) Add the following:

5. fixes the annual maintenance fee for retaining a National Type Evaluation Program Certificate of Conformance. These fees will go solely for the NCWM support of the National Type Evaluation Program.

Revise NCWM Publication 14, "National Type Evaluation Program Administrative Procedures, Technical Policy, Checklists, and Test Procedures"; Part I, Subpart D as follows:

To obtain a type evaluation, the applicant shall:

(no change to parts 1,2 , and 4)

3. authorize the billing of all associated costs incurred by NIST administration, NCWM maintenance of the Certificate, and the Participating Laboratory conducting the evaluation.

Revise Subpart K. Period of Validity of Certificate of Conformance, as follows

K. Poritititus of Certificate of Conformance

1. Active Status. Devices are being manufactured or remanufactured for commercial applications under an NTEP Certificate of Conformance.

2. Inactive Status. Devices are no longer being manufactured or remanufactured for commercial applications. However, devices already manufactured, installed or in inventory, but not yet sold, may be used, sold, repaired, and resold, under an Inactive Certificate of Conformance.

3. Declaration of Status by Certificate Holder. The Certificate holder, usually the manufacturer or remanufacturer, declares intent to continue to manufacture or remanufacture the device by paying an 
annual maintenance fee for the Certificate. If the maintenance fee is not paid (or if other outstanding bills have not been paid or arranged to be paid for the issuance of a Certificate), the Certificate is "inactive."

\title{
4. Withdrawn Status. The Certificate of Conformance remains valid unless withdrawn as the result of a

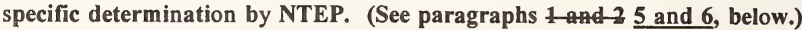

\section{5. Withdrawal of Certificate of Conformance.}

\author{
Apporthe Certificate of Conformance may be withdrawn for deficiencies in the type. \\ aetion-of last resort.
}

Renumber 2. Feedback to item 6 . No further changes.

The Executive Committee has determined that a maintenance fee of $\$ 100$ per certificate will be assessed. These fees will be devoted only to NTEP.

General administrative plans are to bill all existing CC holders on September 15, with a due date of November 1, for payment of $\$ 100$ per CC. If the maintenance fee is not paid until after November 1 , reminders will be sent. Any CC for which a maintenance fee has not been paid by December 1 will be listed as inactive in the next Publication 5. Any manufacturer that decides to continue to produce commercial devices under a $\mathrm{CC}$ for which the maintenance fee has not been paid by January 1 will have to apply for a new CC. An update of Publication 5 will be issued by February 1, 1994, in order to notify all authorities of the status of all CC's. Quarterly Publication 5 addenda are being considered to list changes in status of existing CC's and the issuance of new CC's. The 1994 issue of Publication 5 will contain copies of all certificates of conformance issued after May 1, 1993. Copies of all certificates issued before May 1, 1993 are contained in the 1993 Publication 5.

The Executive Committee authorizes that the NCWM administration of NTEP coordinate its maintenance fee assessment with NIST and the Participating Laboratories so that when a maintenance fee is assessed, all outstanding bills for the issuance of an NTEP Certificate of Conformance must be paid for the Certificate to remain "active."

Discussion: The Board continues to implement its plans to cover the developmental cost and maintenance of the National Type Evaluation Program by means other than general membership dues. The Executive Secretary reported on NTEP expenditures for calendar year 1992 to assist the Board of Governors in determining the level of funding necessary. This item concerns the need to support ongoing standardization activities of NTEP. This item does not deal with the funding of a program to determine whether or not production devices meet type; costs for testing production devices are more difficult to assess since NTEP fees apply up front, and not to subsequent production, and since many verification costs for complete devices can be minimized by using information from State regulatory agencies.

Instead of using funds from general membership dues, the Executive Committee recommends recovering NCWM costs related to participation in National Type Evaluation Program (NTEP) standards development and maintenance (including such costs as public sector member participation at meetings of the Participating Laboratories and NTETC Sectors) by charging NTEP Certificate of Conformance (CC) holders an annual maintenance fee. The costs of providing and improving services provided to the NTETC Sectors, such as technical advice, administration and documentation of the meetings, and documentation of the type evaluation checklists and policy will continue to be absorbed by NIST as part of its support of the NCWM; these services are not currently billed to NTEP customers and it is not anticipated that these costs will be billed to them in the future. (Services for evaluating types and for preparing and distributing CC's are billed to individual CC applicants by the NTEP Participating Laboratory and by NIST.)

If the maintenance fee recommendation passes in July 1993, CC holders will be assessed an annual fee per CC in the late fall of 1993 valid from January 1, 1994 to December 31, 1994. CC holders who are no longer producing devices under a given CC will not have to pay the annual fee. These CC's will be termed "INACTIVE." When a manufacturer chooses to cease manufacturing the device and therefore not pay a maintenance fee, the CC is not "withdrawn" (which would mean that it is no longer valid). It is "inactive," indicating that the Certificate is valid only for those devices already installed or in the distribution pipeline. 
Enforcement of NTEP CC requirements by State and local officials will be critically important in this scheme. Under the maintenance fee program, NCWM intends that a CC holder who chooses not to renew a CC will no longer manufacture devices covered by the inactive CC. Further production of devices formerly covered by a now inactive CC, will no longer be acceptable, and the weights and measures jurisdictions should not permit those newly manufactured devices to be installed in commercial applications. However, devices in existing installations or already in the distribution system should still be recognized under the inactive $\mathrm{CC}$. Weights and measures should permit these devices to be used. A complete listing of all CC's, including inactive CC's, will be made available to all weights and measures jurisdictions to provide the needed information. The Board proposes that used devices under inactive CC's may be resold. Weights and measures jurisdictions should alert the Board if their individual policies for addressing used equipment with inactive CC's differ from this proposal and why.

A question asked at the Annual Meeting, 1993, was how this maintenance fee applied to "remanufactured" (by the original manufacturer) devices. "Remanufactured" devices are also subject to a maintenance fee if the remanufacturer intends to continue to remanufacture devices to which the $\mathrm{CC}$ applies.

Background: The cost of developing test methods and checklist standards by the NTETC Sectors (i.e., meeting room expenses, Active member participation, etc.) is currently underwritten by general Conference membership fees. The costs of convening the Board of Governors and the Participating Laboratory technical staff have also been borne by the Conference. Other administrative costs of NTEP continue to increase, including developing, printing, and distributing CC's and publications listing current CC's. When appeals were lodged in the area of load cells, NIST purchased the load cells in question; NIST can no longer afford to do this. Manufacturers currently pay the NTEP Participating Laboratory for conducting an evaluation and reimburse NIST for the administrative cost of issuing a Certificate of Conformance.

In the opinion of the Board of Governors, the NCWM is assuming, or should assume, the costs of checklist development and refinement, conducting appeals, and keeping Participating Laboratory personnel uniform in evaluation outcome, but these costs should not be borne by the general membership.

The Board therefore agreed that the Constitution and Bylaws should be amended to permit the Board of Governors to assess an annual NTEP CC maintenance fee. Of course, all affected parties will be notified and given an opportunity to comment on any proposed fee changes. This fee would finance the conduct of all NTEP operations other than those direct services separately billed by Participating Laboratories or by NIST for issuing specific CC's. These NTEP operations include reimbursement of public sector participation in the NTETC Sector meetings, meetings of the Participating Laboratory staff, and Board of Governor meetings called for appeals, as well as testing associated with appeals.

The magnitude of an annual NTEP CC maintenance fee will depend upon (1) the costs associated with the standardsdevelopment process within NTEP, and (2) the size of the population of CCs. The amount of funding needed to operate other aspects of NTEP is estimated in account 583 in the 1994 NCWM budget shown in Appendix J. These costs include: Board of Governors meeting for appeals; National Type Evaluation Technical Committee Sector meetings, including the Checkweigher Work Group; the U.S. - Canada Mutual Recognition Work Group; a meeting of the Participating Laboratory staff to ensure that all laboratories apply checklists uniformly, particularly with U.S. - Canada mutual recognition to go into effect in April of 1994. Additional administrative costs for the maintenance fee are estimated at $\$ 22,000$. Publication costs are estimated at $\$ 12,000$ for both Publication 5 and 14. The sum of these projected expenses is $\$ 87,500$. NTEP management reports that, of the approximately 1,800 Certificates issued since 1985, about 1,200 are unique and still valid; that is, (1) about 600 amendments or revisions have been issued and (2) only 14 of the 127 CC's issued in 1985 are still valid due to the influence factors requirement that went into effect in 1986 . Since one model of any device is generally produced over a period of 3 to 5 years, only some $850-900$ of the 1200 total CC's apply to devices or components still in production. The Executive Committee therefore decided to assess each CC holder $\$ 100$ per certificate.

No annual maintenance fee can go into effect until the Constitution and Bylaws are revised to give the Executive Committee the authority to set NTEP fees. If the recommendation passes, an annual fee will be assessed, beginning for 1994, of all CC holders who wish to continue production of the models of devices currently covered by CCs. Those CC holders who no longer produce or sell devices under a given Certificate will not have to pay that annual fee. Those CC holders who allow their Certificates to lapse by not paying the maintenance fee thereby certify to NTEP that they will not, after January 1, 1994, produce the device(s) for which the Certificate applies as commercial equipment. State and local 
weights and measures jurisdictions should permit existing installed devices to continue to be legally used for commercial purposes, and to allow devices in the distribution pipeline to be sold and installed, but devices manufactured under an inactive CC, after January 1, 1994, may not thereafter be installed for commercial use. States might allow a "grace period" to device sales personnel of perhaps 3 months between the lapse of a CC and the time when enforcement action will be taken due to the inactive status of the CC.

\section{2-2 V Program: Verification that Production Meets Type}

\section{(This item was adopted.)}

Recommendation: The Committee recommends revising NCWM Publication 14, "National Type Evaluation Program Administrative Procedures, Technical Policy, Checklists, and Test Procedures"; Subpart K. Period of Validity of Certificate of Conformance, as follows (recommendations from Item 102-1 are also shown):

\section{Withdrawal of Certificate of Conformance}

The Certificate of Conformance Approval may be withdrawn (a) for deficiencies in the type, (b) when production devices do not meet type, buty-anty-

Revise Subpart M. Certificate of Conformance, 6. Post-Evaluation - Responsibility of Manufacturer, as follows:

As a result of requesting an evaluation and accepting the Certificate of Conformance, the manufacturer implicitly asserts that all devices manufactured as the type referenced in the Certificate of Conformance are the same type. If a production device is found with a model number corresponding to that referenced in the Certificate of Conformance but which does not conform to the type, the Certificate of Conformance may be withdrawn.

Questions regarding the conformance of manufactured devices to the "type" for which a Certificate of Conformance was issued will be addressed using the existing verification system based on the following premises:

a. existing NTEP policies are sufficient to address production devices;

b. NTEP is limited to the initial type evaluation of devices but is intended to work with existing enforcement programs to provide feedback and validation of type (a Certificate may be withdrawn because production is not equivalent to the type) (see Part K. 2. Feedback);

c. the field enforcement process and verification of production using NTEP administrative resources is responsible for ensuring that production devices comply with Handbook 44 (this may include obtaining production devices or components and subsequent evaluation of these devices or components); and

d. if (i) the field verification process reveals a history of abnormally high device failure; or (ii) the field verification process reveals that production devices do not match the type for which the Certificate was issued; or (iii) subsequent laboratory evaluation of the device or component reveals that it does not comply with the influence factors requirements specified in Handbook 44, this information may be used in withdrawing a Certificate of Conformance for cause.

Further Action: The Board will:

- transmit its concern to all jurisdictions that commercial floor scales (particularly those with 5000 scale divisions) may not meet type, (particularly with respect to accuracy) and request that thorough performance testing be conducted at ambient temperature during field inspections. Existing Examination Procedure Outlines should be used. The need to test the devices to full capacity will be reinforced. NIST OWM will send the EPO's to all State and major local 
jurisdiction directors. The jurisdictions will be asked to transmit their findings to the NTEP Board of Governors, for consideration and action.

- formulate additional policy and recommendations concerning the misuse of the NTEP Certificate and the NTEP logo in marketing and sales brochures;

- ask the Weighing Sector to address NTEP and field tests of large-capacity scales that better simulate use;

- seek assistance from the Weighing Sector and S\&T Committee to study whether or not more useful definitions for concentrated load capacity might be formulated; and

- investigate the potential for contracting certain tests to private laboratories to verify that production meets type.

Background: The Board has determined that the policy that production devices and load cells must comply with the original type must be clarified in order to preserve NTEP integrity. As the NTEP Administrative Procedures states:

The physical and metrological characteristics of copies of a type submitted for evaluation under NTEP are expected to be representative of production devices.

The Board believes that a more refined system is needed to ensure that production devices and components match the original types. The original intent was that State enforcement agencies provide that assurance. As Publication 14, Subpart K.2. Feedback reads:

The evaluation process under NTEP can generate only limited data. The data gathered during the initial and subsequent verifications of a larger number of devices of a given type will, when systematically analyzed, often yield information not available from the type evaluation. Such feedback can be used as the basis for revising the conditions of approval when the situation so warrants.

Depending on circumstances, experience gained during verifications may justify later changes in the Certificate of Conformance; in extreme cases, it may dictate reevaluation of the type.

The Board of Governors discussed what action should be taken to monitor the compliance of both scales and load cells in production with the influence factors requirements. It was agreed that compliance with the influence factor requirements cannot be determined by ordinary field enforcement testing. There have been reports that some devices in the field do not match the designs and performance (even at ambient temperature) of those devices given NTEP CCs.

\section{2-3 I Program: Acceptance by the States}

Mr. Daryl Tonini of the Scale Manufacturers Association (SMA) updated the Board of Governors on the status of the SMA drive to assist States in adopting the Uniform Regulation for National Type Evaluation (URNTE). The SMA has conducted sessions at each of the regional weights and measures association annual meetings. The first cycle of meetings focussed on panel discussions that explained, from manufacturer, user, and regulator points of view, why adoption of URNTE was a necessary part of State weights and measures regulation. This year's meetings at the regionals have been breakfast workshops to disseminate information and to discuss issues States must confront when they require NTEP CC's.

Mr. Tonini reported that there has been less progress in terms of the number of States adopting URNTE since he last addressed the Board; however, a letter from the Michigan State Attorney General supports the interpretation made by Michigan Weights and Measures that Michigan can require a National Type Evaluation Program Certificate of Conformance as the only proof that the temperature requirements in Handbook 44 have been met. Louisiana Weights and Measures reports that it makes the same interpretation.

Two more breakfasts will be held at the regional weights and measures associations annual meetings in 1993. SMA will distribute the guidelines prepared by Ohio and Illinois for use by their field staff and registered service agencies. SMA 
will also follow up on areas that indicate a need for standardization, such as the policy a State follows on whether or not to require a $\mathrm{CC}$ for resale of a used device. Another area needing standardization is how to test devices that States determine to be one-of-a-kind. Manufacturers often feel that they can save the cost of an NTEP evaluation if they convince a local jurisdiction or State that their device is one-of-a-kind. California charges for the initial evaluation of a one-of-a-kind device because, if it has not been tested under NTEP, a more thorough initial evaluation of the device must be conducted. For example, several trucks of field weights have to be scheduled to a single location in order to test a large capacity scale to as close to its capacity as possible.

Most States that have adopted the URNTE report the necessity for repair and service agency registration and for training programs. More information is needed than NCWM Publication 5 "NTEP Certificate Index" provides. For example, a quarterly updated publication designed for Ohio regulatory and registered service personnel provides more information. This document, prepared by Jim Truex, $\mathrm{OH}$, is available for $\$ 3$ from Ohio Weights and Measures. [Editor's note: NCWM Pub 5 will be revised in 1993 to include copies of all active CC's in order to provide the information needed by field inspectors but not available either in the current version of Publication 5 or in Ohio's index.]

At the Annual Meeting, Mr. Tonini, SMA, provided an update on its work to encourage States to adopt NTEP and the Uniform Regulation for the Voluntary Registration of Service Persons and Service Agencies. It is printed below.

I appreciate this opportunity to report on progress which has been made on the NCWM/SMA effort to encourage states to adopt the Uniform Regulation for National Type Evaluation (URNTE). Since our meeting last year in Nashville, two states, Michigan and Louisiana, have obtained a ruling from their Attorney General's office that, by virtue of adoption of Handbook 44, the weights and measures director has the authority to require NTEP certificates of conformance on equipment placed in service in the state. For state jurisdictions which have held back the adoption of the URNTE because of procedural concerns, the Michigan and Louisiana experience suggests that a favorable ruling from the Attorney General's office on NTEP certificates (based on H44 adoption) may be a way to avoid the pitfalls of seeking new legislation or conducting open hearings.

In addition to Michigan and Louisiana, Wyoming has announced that effective July 1, 1993, it will also require CCs on equipment placed in service. In the letter announcing this, the state director noted that NTEP adoption was pushed along by recognition that the state was becoming a "dumping ground" for non-NTEP equipment. Three states--Minnesota, South Carolina and New Mexico--are on the way to the NTEP adoption. Adoption by each is expected within a year. In addition, Washington, Nevada, and Florida have stated their intention to adopt NTEP at some future time. It should be noted that the non-NTEP jurisdictions are becoming islands in a sea of NTEP adoptions. It should come as no surprise that Wyoming's experience in becoming a popular destination for nonNTEP quality equipment will be repeated as more states adopt the NTEP regulation.

I am pleased to report that the popular NTEP Directors Breakfast program has been funded for another year. These activities have proven to be an excellent forum for NTEP information sharing and a good source of ideas on weights and measures NTEP administration. A very important document--NCWM Publication 5, Index of Device Evaluations, has just been released. It should be of considerable value to administrators and field officials. It joins the Ohio "Green Book" as another aid to better NTEP enforcement. 


\section{2-4 I Program: OIML Certification Plan}

\section{Reciprocity}

A device manufacturer requested that data from test reports accompanying an OIML certificate be accepted by NTEP in lieu of tests by NTEP. Based on the status of information available at the time of the Annual Meeting (see the discussion below under the same heading), the Board determined that the consensus of the NCWM appears to be:

\section{NTEP should seek to become the Issuing Authority for OIML for Non-automatic Weighing Devices (R 76.)}

2. NTEP is not prepared at this time to accept OIML certificate test results as a substitute for NTEP evaluation without further work and clarification. The United States should determine what the evaluation is that the Netherlands (NMi) must make to accept U.S. OIML Certificate test data, and work closely with Canada in this effort.

The NTEP Board of Governors decided that the data submitted with the OIML certificate from the Netherlands not be accepted.

Status Report for OIML Load Cell Testing: At the Interim Meeting, Mr. Ken Yee, the automation expert at NIST who assisted the Force Group in automating their dead-weight testers, discussed the additional tests and modifications that are necessary to conduct an OIML test (and issue an OIML certificate) for load cells. Manufacturers of load cells, scales, and motor fuel dispensers were requested to provide their input concerning their willingness to explore with OIML "issuing authorities" (national type evaluation laboratories) whether they will consider type evaluation against OIML standards, or an OIML certificate issued by the United States, on their device or load cell as providing adequate proof for accepting the device or load cell into other nations.

A small amount of additional test equipment is necessary (a temperature/humidity chamber is needed for all load cells not marked "NH" - not hermetically sealed). The software that controls the test sequence automatically in the manner and order prescribed by NTEP has to be modified to run a sequence of tests in the order and prescribed test protocol for an OIML test. In addition, the data analysis program requires modification, to average 3 runs, to eliminate the $4000 \mathrm{v}$ step in class $\mathrm{C}$ (OIML) and to add the repeatability requirement and creep requirement, MDLO, and humidity requirements.

Unfortunately, the OIML tests cannot be combined with the NTEP tests in an efficient manner, so two separate tests will have to be conducted to provide a requester with both an NTEP certificate and an OIML certificate; this would double the cost. No load cell manufacturer expressed an interest at this time to explore obtaining an OIML test performed by NIST in lieu of a test performed in countries that declare that an OIML test is sufficient for marketing within their borders. No reciprocal agreement exists between the U.S. and any other country accepting a U.S. test to OIML requirements. NIST OWM is exploring with other national type evaluation laboratories the possibility of mutual recognition and what tests might be performed to provide assurance in the equivalence of examinations conducted by different laboratories, similar to detailed discussions with Canada.

Simone Yaniv, head of the NIST Force Group reported that NIST will be capable of providing tests against OIML R60 by October 1993.

OIML Weighing Device Status Report: Tests for electromagnetic interference and electrical bursts must be added for non-automatic weighing devices. The issue of who is qualified to conduct the electromagnetic interference tests also has to be settled.

\section{Reciprocity}

The National Type Evaluation Program (NTEP) was contacted by a scale manufacturer concerning a Class II balance for which they wished to obtain an NTEP Certificate of Conformance. The company asked whether NTEP would be willing to accept data from an International Organization of Legal Metrology (OIML) Certificate they had obtained from the Netherlands. Where there are criteria for a Class II device under Handbook 44, these criteria are the same as those in the OIML R 76 standard (the OIML standard contains additional criteria that is not in Handbook 44). The scale company requested recognition of this test data since both the United States and the Netherlands were treaty members of the OIML 
and since the scale had been evaluated against the same performance criteria under the OIML standards as it would have under Handbook 44.

It was explained to the company that the Weighing Sector had recommended and the Board of Governors set policy that

"NTEP would not accept a certificate from another country as the basis for issuing an NTEP certificate. The basis of the decision was that there is no formal agreement among countries to accept each other's certificates.... The discussions on accepting data from a national laboratory focussed on whether or not the [load cell] manufacturer had access to test equipment to monitor production and the need for reciprocity between countries before accepting data from another national laboratory as a basis for issuing a full Certificate of Conformance."(Page 136, Report of the 76th National Conference on Weights and Measures, 1991, Weighing Sector Report of 1989.)

Although this statement of policy specifically references load cells, NTEP management applies it to all devices under NTEP. Since the policy was enunciated before there was an OIML Certificate System, the NCWM and NTEP were asked to revisit these issues.

The scale company representatives agreed to discuss the reciprocity issue with the Netherlands authorities. The scale company submitted to the NTEP manager, Henry Oppermann, all the documentation and test results upon which the OIML Certificate was based and, in addition, transmitted the attached letter from the Nederlands Meetinstituut (NMi), the recognized type approval body for the Netherlands. This letter verifies that OIML Certificate test data from the U.S. will be recognized by NMi.

A review by NTEP of the Class II device against the NTEP checklist indicates that it meets all NTEP Handbook 44 requirements in addition to the performance criteria that the OIML test data verifies. The scale company has requested an NTEP CC for a family of scales that extends from this Class II device into Class III. If the OIML test data from the Netherlands were considered acceptable to NTEP, all that would be required would be to reevaluate the data with respect to the Handbook 44 tolerances. Appropriate data were submitted to evaluate.

A letter was sent to NMi requesting clarification of its first memorandum. To quote from part of this letter from NTEP to NMi:

We understand your letter to agree to reciprocity with the United States as long as the United States fulfilled the requirements for the OIML Certificate System and issued an OIML certificate. We have two questions:

1. Will the data from an OIML certificate from the United States be accepted in lieu of testing by the Netherlands for EC certification?

2. Will data from tests conducted by the United States that do not constitute an entire OIML test, but only part of an OIML test be accepted in lieu of that part of the OIML test repeated by your laboratory?

NMi answered our letter (some abbreviations used; U.S. editorial comments in brackets):

"1. As representative for the Netherlands in OIML, the NMi will accept an OIML Certificate of Conformity for a nonautomatic weighing instrument if the issuing authority of the OIML certificate involved has fulfilled all the requirements stated in the OIML document "OIML Certificate System for Measuring Instruments." [This includes conformance with ISO Guide 25.]

"It is possible that some (small) additional testing for the EC type-approval examination involved [will be] necessary because there is some (editorial) difference between the OIML R76-1 and the European standard EN45501.

"...when a Notified Body...issues an EC type-approval certificate...based on (parts of) test results gathered by another laboratory or by the manufacturer..., the Notified Body is responsible for the "quality" of these test 
results....the NMi only accepts test results from other parties when the facilities, personnel involved etc. from these other...laboratories... are positively evaluated by the NMi.

"Due to the above mentioned we have some questions...

- Which OIML tests will be performed by NIST?

- Which laboratories are normally designated by the NIST to perform the OIML tests of conformity?

- Does the NIST accept test results from the manufacturer involved? If the answer is yes, on what conditions?

"2. Because parts of tests are not covered by the OIML Certificate System, the NMi...only accepts test results of specific complete test(s) that constitute part of a complete OIML examination gathered by another party if this party for this/these specific test(s) is evaluated by the NMi."

A "straw poll" of the Executive Committee and the National Type Evaluation Technical Committee was conducted by the Executive Secretary in anticipation of a meeting of the NTEP Board of Governors at the Annual Meeting. That meeting was held July 18. The Executive Committee discussed the fact that correspondence from NMi did not mention the NCWM or NTEP. Rather, it referred to a U.S. OIML certificate which is yet to be developed or issued. The Executive Committee discussed the need to study the issue and establish a foundation for possible OIML Certificate issuance in the U.S. This effort should be coordinated with NIST prior to considering agreement with other countries. This section is consistent with the work of the US/Canada Mutual Recognition Committee going on now.

\section{2-5 I Program: NTETC Sectors on Grain Moisture Meters and Protein Analyzers}

The Technical Advisor for these sectors, Dr. Richard Pierce, of the U.S. Department of Agriculture, Federal Grain Inspection Service (FGIS), updated the Board on the progress of the sectors. The S\&T Committee has revisions to the grain moisture meter code for its consideration. The proposed revisions include nonretroactive requirements that will apply to NTEP evaluations immediately if the requirements are adopted this July. These nonretroactive requirements will have the effect of phasing out nonautomatic meters for commercial purposes over a period of 10 years.

In the scheme devised by the sector, type evaluation of grain moisture meters will take place in two phases. Phase I tests will include examination of the submitted device against "basic instrument" tests (including the current requirements as well as the proposed specification and user requirements, which demand automatic display of moisture content results) and a test of the calibration of the device over a limited range of grains and moisture contents. Successful completion of Phase I will qualify the meter as eligible for enrollment in Phase II, the National Calibration Program. Phase II will be required for continued approval and use of the meter in commercial grain exchange. Phase II will also be used to add approvals for additional grains for any particular meter. Therefore, the calibration status of a given meter will be indicated on the CC by a listing of the specific grains and moisture content ranges along with a designation of "approved," "pending approval," or "not approved" for each range.

If the S\&T Committee determines that the revisions are appropriate for recommendation to the voting membership at the Annual Meeting this July, the FGIS will be prepared to announce its readiness to accept applications for NTEP evaluation of grain moisture meters in Phase I by the Fall, 1993. The costs of Phase I are intended to be covered entirely by the meter manufacturer. Although FGIS can charge a manufacturer for Phase I evaluation, the accuracy of the moisture measurement over the lifetime of the meter depends on the calibration of these meters over their lifetime routinely using a wide variety and range of moisture contents of actual grain samples. The costs of Phase II will be as much or more annually than the one-time costs of Phase I for any given model of moisture meter; the issue of who will be responsible for the costs of maintaining the ongoing calibration program has not yet been resolved.

The Board of Governors discussed the issue of supporting an ongoing calibration monitoring program required for grain moisture meters. The calibration cannot yet be simulated with unchangeable standard reference materials. Only grain acts like grain in grain moisture meters. Thus, the accuracy of the calibration is dependent upon adequate monitoring using actual grain samples from a wide variety of sources, with a wide range of moisture contents, and with other characteristics associated with each year's actual crops. The accuracy also depends on revision of the software or calibration charts with 
such data to modify the final moisture calibration as often as annually, or at least every 2 to 5 years; however, annual monitoring would still be required. Thus, there is a critical need not only to address the hardware used in grain moisture determinations, but also to coordinate an ongoing national program using State and Federal resources to monitor and maintain the accuracy of the calibrations over time.

Although an equipment manufacturer can be expected to pay for an initial prototype evaluation of the design and performance of a grain moisture meter, the manufacturer cannot be expected to underwrite the rather large costs of obtaining grain from all over the nation to monitor the calibration of a particular model of meter over the lifetime of that model. In other words, although a meter can be determined to give accurate moisture content results by a type evaluation in a given year, the meter cannot be expected to maintain accuracy without calibration adjustment in subsequent harvest years as crop variety, climate, geography, and harvesting practices vary over time. An ongoing system of monitoring and adjusting the calibration of commercial meters with a lifetime of 20 or more years must be devised. The possibilities include:

(a) Charging the meter manufacturer not only the initial instrument evaluation, but an annual instrument calibration service charge, perhaps $\$ 10,000$ or more annually for each model of meter.

(b) Charging the meter purchaser and user in one of several ways:

(1) The States could charge an annual inspection fee; part of the inspection fee could be used to underwrite calibration maintenance.

(2) The States could charge an annual user fee specifically intended to maintain the calibration and to maintain the validity of the NTEP CC.

(3) NTEP could charge a fee for annual calibration (and NTEP certificate) maintenance; again, this fee would be assessed of the meter owner.

(c) Federal funding might be sought for calibration maintenance.

It does not seem reasonable for calibration maintenance charges to be borne by device manufacturers because it is difficult to determine initially whether the device warrants the investment to maintain calibration over the lifetime of their devices or over the period that the user considers to be the lifetime of the device. If owners of the 10,000 to 15,000 commercial devices were assessed a fee for the monitoring and upkeep of the system, through existing State regulations (which are varied at present and may have to be modified on a State-by-State basis), there might be inconsistent rules, enforcement, and assessment among the States. If individual meter owners were assessed an annual maintenance fee, the cost of administration might be more than the amount used to maintain calibration accuracy by FGIS and the States.

FGIS conducts fee-supported programs as much as possible, but the ultimate beneficiaries of a national calibration monitoring system are the meter users themselves, a highly heterogeneous clientele. The argument in favor of Federal funding is that calibration maintenance is required for the official (FGIS) system and the rest of the commercial system could in a sense "piggy-back" on the required official calibration maintenance, with only a small increase in the costs to the official calibration maintenance program.

NIST sponsors the NCWM, manages the NTEP, and certifies State weights and measures laboratories (which requires that State grain moisture meter testing programs trace their moisture measurements back to standards maintained by the FGIS), but does not currently certify grain moisture labs. If Federal funds were specifically available for monitoring and upkeep of commercial and official moisture meters as a cooperative venture for NIST, FGIS, and the States, there would be the combination of technical, administrative, and field enforcement resources to maintain and monitor the calibrations.

A national collaborative approach can correct a problem encountered with the existing grain moisture meter programs operated by State Departments of Agriculture, namely the difference between the samples that FGIS collects and uses to evaluate meters and the samples that States collect and use. By incorporating the State samples collected and used for field testing into the sample pool of FGIS, a better mix and system for verification of calibration and test would be 
available. (Calibrations developed by individual States should be discontinued once a national sample set is the basis for a national calibration.)

Dr. Pierce explained that one of the incentives for designers and manufacturers of new devices or existing models that could meet Phase I requirements to become involved with NTEP, would be to access a national grain sample pool for calibration purposes. It is the consensus of the sector that most of the meters currently used in the marketplace should not be permitted into Phase II of the NTEP system (the calibration program) for two reasons: (1) manufacturers participate in the NTEP prototype system in part to incorporate the calibration data collected by FGIS in their existing software or hardware to update the calibration, and many no longer provide any support to the devices currently in the field; and (2) most existing moisture meters are so susceptible to human operating error that they should be phased out of the commercial marketplace no more than 5 to 10 years (hence the reason for Phase I evaluations); it would take at least 3 to 5 years to evaluate calibrations provided as part of existing meter systems before their calibrations could be upgraded. In other words, the cost of monitoring these moisture meters under the calibration program is not justified. Companies should be required to design meters that are less susceptible to human operating error than existing devices before calibration maintenance is considered as a publicly underwritten program. The Board will continue to explore the alternatives for calibration maintenance in the coming year.

To date, the sector has concentrated its work on the Handbook 44 code and the type evaluation criteria and test procedures for grain moisture meters, so that Phase I of the proposed NTEP program might be instituted in 1993. Work on a code for protein analyzers will take priority at future meetings of the sector, the first scheduled for March 1993.

The Board of Governors congratulates the Sectors and their Technical Advisor, Dr. Richard Pierce, for their leadership, technical expertise, and the speed with which they achieved their objectives.

\section{2-6 I Program: Participating Laboratories/Evaluation Report}
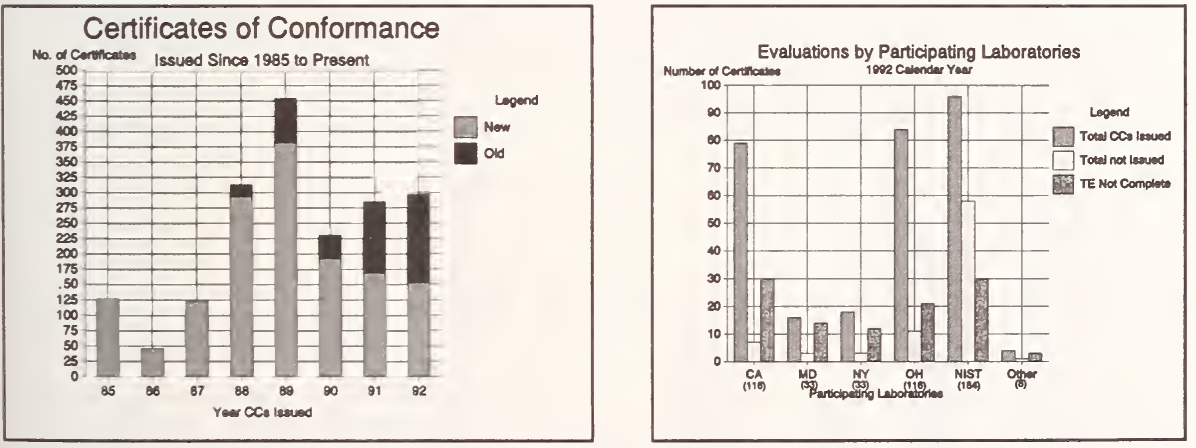

In the figure on the left, "Old" means that amendments or other modifications were made to an existing Certificate. In the figure to the right, "Total CCs Issued" refers to Certificates that were completed and distributed. "Total Not issued" means that Certificate numbers have been assigned and are in effect for use by the manufacturer, but some element of the paperwork has not been completed. "TE Not Complete" means that a type evaluation has been assigned to the particular participating laboratory, but the evaluation has not resulted in a Certificate number being assigned. (Many evaluations are delayed because modifications of the design are required on the part of the manufacturer and not because of work backlog on the part of the participating laboratory.)

Due to the discontinuation of NTEP Provisional CC's for load cells wherever possible, a large number of load cell provisional certificates were converted to full status. 


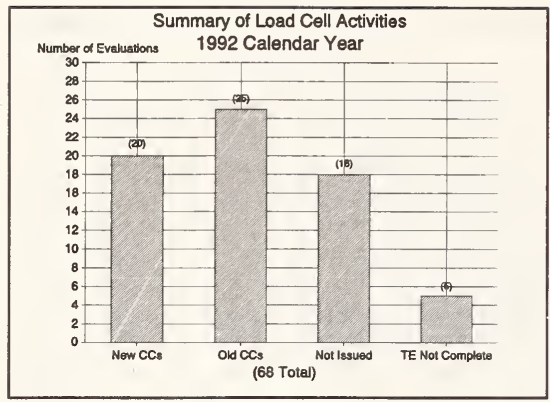

The Executive Secretary reported on the work of the Participating Laboratories, including their workload and plans for addition of capabilities to conduct evaluations. NIST has added capability to test load cells from $200 \mathrm{lbf}-500 \mathrm{lbf}$ in tension and compression with a minimum dead load of $10 \mathrm{lb}$. With NIST assistance, CA Division of Measurement Standards has established test capability for load cells in tension below the 200-lbf range using hand weights. See further information in the reports of the Weighing Sector in Appendix N.

\section{Improvements in NTEP Process}

In November and December 1992, the NCWM and NTEP management met with device manufacturers at meetings of the Measuring and Weighing Sectors of the NTETC to discuss customer needs. Based on the recommendations made at these meetings and NTEP's internal reviews, NTEP established a number of near-term goals, priorities to meet these goais, and the following policies:

1. NTEP's highest priority will be to establish two more participating laboratories in the liquid-measuring device area. Mr. Will Wotthlie from the State of Maryland has joined the NIST Office of Weights and Measures for half of his time in order to prepare Maryland to become a Participating Laboratory for liquid-measuring devices by the end of 1993. This will provide four Participating Laboratories for liquid-measuring devices: NIST, California, North Carolina, and Maryland. Other Participating Laboratories have expressed an interest but have a shortage of personnel at this time, as does NIST, in order to provide the training.

2. NTEP will take additional measures to improve turn-around time in providing draft CCs and issuing final CCs. A 1993 objective is to reduce the time between assignment of a CC number and the distribution of a CC to 2 months or less. (More than 50 percent of the 1992 CCs took more than 2 months to complete and distribute.) Many internal efficiencies and changes in procedure are being implemented to accomplish this objective.
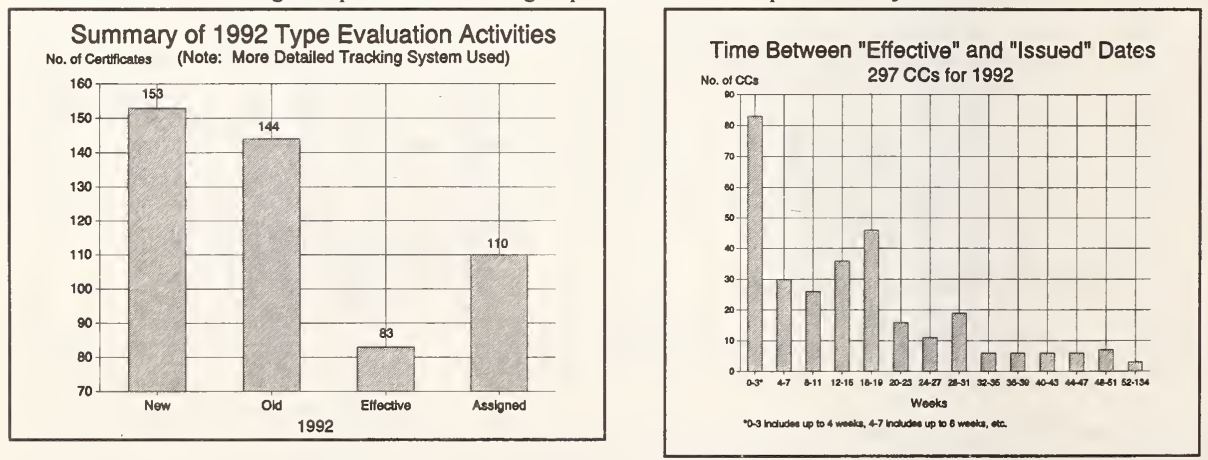

3. Billing has been modified, so that type evaluation costs for NIST staff evaluating devices in laboratory or field tests are now sent with the CC. Administrative costs will continue to be issued by NIST Accounting, and do not appear to be greatly delayed from the delivery date of the $\mathrm{CC}$ to the $\mathrm{CC}$ holder.

4. Updated checklists and test procedures to be included in NCWM Publication 14 will be circulated at least annually to the NTETC Sectors. 


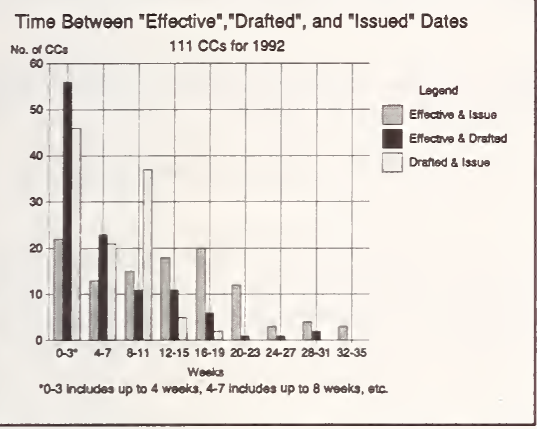

5. Reports from Sector meetings will be made available within 2 months of each meeting.

The costs of services to the NTETC Sectors, such as for the time necessary to provide adequate technical advice and full documentation of all meetings, will continue to be absorbed by NIST; these services are not currently billed to NTEP customers and are not anticipated to be billed in the future.

An announcement that NIST's administrative fees will be increased was made at the Interim Meeting. A letter was sent to State directors and past NTEP CC holders announcing this fee increase:

As of February 15, 1993, all National Institute of Standards and Technology (NIST) charges in connection with the administration of the National Type Evaluation Program (NTEP) CC's will be increased. The cost of processing a CC generated by a Participating Laboratory other than NIST will increase from $\$ 125$ to $\$ 300$. The cost of generating a CC exclusively at NIST will increase from $\$ 250$ to $\$ 550$. The new fees will apply only to applications submitted after February 15; fees for the processing of applications received prior to the effective date will not change.

NIST is taking this step because fees have not been raised since 1988, but the current costs of managing the program exceed program income. In addition, plans are underway to significantly improve NTEP services in response to customer requests; more NIST staff time will be devoted to NTEP in order to achieve these improvements.

Simone Yaniv, NIST Force Group Leader, informs NTEP that NIST will be fully capable of performing a complete OIML R 60 evaluation of load cells by October 1993.

\section{2-7 I Program: NTETC Weighing, Measuring, and Belt-Conveyor Scale Sector and Work groups}

The Board was updated on the status of the work of each of these sectors. Appendix $\mathrm{N}$ contains reports of the last meetings of the three sectors. Manufacturer feedback has become part of the meetings since the participating labs and major manufacturers are then present.

\section{Checkweigher Work group}

A new work group on checkweighers reporting to the Weighing Sector of the NTETC was appointed by Chairman Nelson. Dennis Johannes, CA, was appointed Chairperson; regional representation underwritten by the NCWM will be Jim Truex, $\mathrm{OH}$, Constantine Cotsoradis, MD, and Ross Andersen, NY, who each represent NTEP Participating Laboratories expected to evaluate these types of devices for the U.S. Department of Agriculture. Also participating in the first meeting were:

Paul Chase, Envirotech

Martin Lymn, Loma North America

John Gould, American Meat Institute

Oscar Lorenzo, USDA, Food Safety \& Inspection Service

Richard Walker, B.C.E. Technologies, Inc.

Richard D. Roberts, A\&D Engineering, Inc.

Paul Peterson, USDA, Packers \& Stockyards Admin.

Dale Farr, Taylor Packaging Co., Inc.
David Musselman, Hatfield Quality Meats, Inc.

Ronald Easterday, John Morrell \& Co.

Max C. Casanova, Ramsey Technology, Inc.

David R. Nathaniel, Hi-Speed Checkweigher Co, Inc.

Harry W. Willmott, Hormel

Otto K. Warnlof, NIST, Standards Management Program

Daryl Tonini, Scale Manufacturers Association

Roger Suttle, AZ Weights and Measures 
Ken Butcher, OWM, is the Technical Advisor for the work group. The first meeting was held February 1-2, 1993 in Bethesda; its report is available upon request.

\section{2-8 I Policy: Recognition of Witness Testing as an Alternative to Type Evalua- tion for Load Cells by NIST}

Determination: The Board of Governors unanimously decided that the policy to require NTEP Participating Laboratory testing of load cells will continue.

Discussion: In August of 1991, the Board of Governors announced that NIST load cell testing facilities had expanded sufficiently that they believed it timely to discontinue the "Interim Procedure" of witness testing in lieu of complete load cell evaluation; as a result, all bearers of Provisional load cell Certificates were to submit their load cells to NIST in order to upgrade their Certificates to Full, or else their Provisional Certificates would expire. The deadline for this action was August 1992.

Another NTEP load cell policy stated that round-robins with other laboratories would be initiated "to assure that private laboratory results agree with NIST results." On February 26, 1992, the Board of Governors balloted and announced that they were going to discontinue this policy, which promised work to recognize other facilities as a substitute for NTEP testing at NIST, due to the lack of NIST adequate resources to explore this issue at this time. The change in policy was a natural outgrowth of the decision to use NIST load cell testing facilities whenever possible; different test facilities do not produce equivalent results, and NIST is the only independent laboratory (not owned by the load cell manufacturer) capable of testing most of the load cells to be evaluated.

Sensortronics had expected to be recognized as an equivalent test site when the policy of provisional load cell certification based on witness testing at the manufacturer's laboratory was discontinued in August of 1991; it therefore protested the change in policy. Sensortronics requested that its laboratory be recognized for witness testing, arguing that the additional costs of preparing a test mounting rig for NIST are unnecessary and would not have to be incurred if its lab were recognized as equivalent for type evaluation tests.

Mr. Ken Yee, NIST, pointed out that witnessing a test cannot determine systematic errors: one can only observe that proper procedures have been followed and that the weights have been calibrated. One cannot measure the errors inherent in the test machine. Some form of round robin is required to show agreement between test machines. In order to run a round robin among various test machines, decisions have to be made concerning the capacities of cells to cover the range of test equipment, the type of cells to cover a range of fixturing and machine-cell interactions, the number of cells to show effects of experimental variation and, most importantly, what constitutes "agreement." Unfortunately, due to the incidence of "borderline cases" (cells that barely pass or barely fail), agreement must be fairly complete for all tests: load cycle, creep, and TEMDLO (Temperature Effect on Minimum Dead Load Output). It would be necessary to specify the maximum number of cases in which the laboratory in question would pass what NTEP/NIST would fail.

The concerns of the Board of Governors center around fairness and objectivity. Witness testing is only a small part of a full load cell type evaluation test, and all other tests are those of the manufacturer for the manufacturer. The Board of Governors unanimously decided that the policy to require NTEP Participating Laboratory testing of load cells will continue. In order to provide more complete coverage of the range of load cells NTEP can test, the California NTEP participating laboratory has equipped itself to test load cells with capacities less than $200 \mathrm{lb}$ that NIST cannot. California is an NTEP Participating Laboratory, and does not cover any of the load cell test range that NIST covers. The laboratory will operate with NIST consultative advice. 
Determination: The Board of Governors requested that at its next meeting the Weighing Sector revisit the issue of extension kits that are mass produced. As a minimum, the sector is asked to write an ad hoc testing procedure to be used with different combinations and applications addressing mechanical and electronic separately. The sector might also consider including guidelines in NCWM Publication 14 for jurisdictions to use in field evaluations of combinations of scales and extension kits, whether or not the kit has been type evaluated.

Background: This item deals with adding an "extension kit" to a previously certified scale. The Board determined that extensions are subject to type evaluation if they are "kits"; that is, more than a single unit of the extension is manufactured. The NTETC-Weighing Sector took up this issue at its June 1992 meeting. The Sector was divided on the issue, some clearly disagreeing with the Board decision. Some supported the requirement for a separate certificate; others felt that the use of kits had been normal practice and consider the field test at initial evaluation as sufficient to determine compliance. The Sector decided to inform the Board of its concerns and ask that the issue be reviewed again.

The discussion at the Interim Meeting with John Elengo, Chairman of the NTETC and Chairman of the NTETC Weighing Sector, centered around extension kits that are mass-produced and should therefore be subject to type evaluation. Two different situations were envisioned:

1. An extension kit is produced specifically and only for the extension of a scale by the original equipment manufacturer (OEM). In this case, the scale manufacturer, under certain conditions, might be able to get such an extension added to an existing NTEP CC if the size of the scale plus extension is already included in the range of sizes and capacities provided in the certificate. The Board noted that NTEP policy requires additional review or test when an OEM kit would extend a scale beyond the concentrated load capacity limits established by the existing certificate.

2. An extension kit is produced by other than the OEM. The kit manufacturer must declare the types, brands, etc., of scales for which the kit is intended; otherwise, the kit manufacturer must prove compatibility with any scale to which it is added.

It is the second situation for which the Board most sought advice from the Weighing Sector, as to how many and what combinations of scales and kit must be evaluated.

At the very least, if a kit manufacturer chooses to indicate that the combination of extension and scale is a custom, one-ofa-kind device, the State should test the kit and scale combination wherever it is installed in the State with the same diligence and extent that a National Type Evaluation test would include. The State will therefore incur costs equivalent to those incurred in NTEP evaluations. This may not be a problem for States that charge for initial verification costs (such as those States requiring type evaluation by the State when an NTEP CC is not available), but may be for those States that do not.

\section{2-10 I Policy: Clarification of "One-of-a-Kind" Devices}

The Board of Governors adopted the following policy as developed by the Weighing Sector of the National Type Evaluation Technical Committee:

If a device manufactured for sale has been categorized and tested as a "one-of-a-kind" device and the manufacturer then decides to manufacture an additional device or devices, the device will no longer be considered as "one-of-a-kind." This applies to a device that has been determined to be a "one-of-a-kind" device by a weights and measures jurisdiction in one State and the manufacturer decides to manufacture the device and install it in another State. In this case, the manufacturer must request an NTEP evaluation on the device through the normal application process unless NTEP has already deemed that such an evaluation will not be conducted. 
Note that indicators and load cells in all "one-of-a-kind" installations must have an NTEP CC.

The Board will send a memo to the States to request that they communicate by fax with NTEP or use the NCWM computer bulletin board when they determine that a "one-of-a-kind" device is in place in their jurisdiction, so that this information may be disseminated to other jurisdictions in order to determine whether NTEP policy is being followed. NTEP will enter this information in a publicly available file on the NCWM bulletin board so States will be able to access the most current information.

Discussion: The National Type Evaluation Technical Committee Weighing Sector developed the following policy guidelines for consideration by the Board and entry into NCWM Publication 14:

1. If a scale company converts an existing structure, such as a hopper, into a weighing device in an existing installation or retrofits an existing scale, the device can be considered to fall into the "one-of-a-kind" category under NTEP policy. In this case, an NTEP CC is not required and the device should be evaluated for compliance with Handbook 44 by the individual weights and measures jurisdiction. This does not apply to equipment purchased by the scale company for the conversion and installation into a new location, (which falls into the category of "remanufactured."

2. If a device manufactured for sale has been categorized and tested as a "one-of-a-kind" device and the manufacturer then decides to manufacture an additional device or devices, the device will no longer be considered as "one-of-akind." This applies to a device that has been determined to be a "one-of-a-kind" device by a weights and measures jurisdiction in one State and the manufacturer decides to manufacture the device and install it in another State. In this case, the manufacturer must request an NTEP evaluation on the device through the normal application process unless NTEP has already deemed that such an evaluation will not be conducted.

Note that, for all "one-of-a-kind" installations, the weights and measures jurisdictions should require the device to use an indicator and load cells with an NTEP CC.

In discussion with the Weighing Sector Chairman, John Elengo, and Technical Advisor, Tina Butcher, the Board of Governors decided to adopt only item 2 of the recommended policy, and that it should become general policy, not applying just to scales and weighing systems. There was disagreement among the Board members about the advisability of recommending item 1 at this time due to differing enforcement policies in the separate States. Some members were opposed to forcing the jurisdiction to completely test devices when the conversion of a hopper of a given design into a weighing device might be equivalent to a series of conversions by the same company resulting in the same final design. In other words, there may be instances when conversions might not create unique "one-of-a-kind" devices. Other Board members both disagreed and agreed with item 1 because of their experience with conversions that are occurring. Disagreement with item 1 is based on the fact that field conversions are being made into a weighing system with equipment never intended to weigh, and that the resulting weighing systems should not even be allowed. Agreement with item 1 is based on the fact that States can test these "one-of-a-kind" systems to the equivalent extent as NTEP; it just requires a great deal more resources in time, equipment, and effort to do so. It is unfortunate, but necessary. In order to get these systems to perform, there is a great deal of custom manufacture and assembly. Because some of the equipment is old and some new and some manufactured on site, the initial installation should be thoroughly tested; an NTEP certificate would not provide as much confidence to the inspector as for devices mass produced.

\section{2-11 I Policy: Repaired and Remanufactured Scales}

Decision: The Board of Governors was not able to discuss this item in the detail that it deserves. The Weighing and Measuring Sectors are requested to discuss the issue and provide more guidance to the Board, which is prepared to accept the interpretation and guidance of the Office of Weights and Measures if there is no opposition. The Measuring Sector is especially asked to suggest how the NTEP principles should be applied to repaired and remanufactured measuring devices and systems. The weights and measures community is asked to study this issue, discuss it in the regional meetings, at trade association meetings, and when considering State policy on repaired and remanufactured devices, not just scales. Please call or write with your input on this critical issue. As States move to require NTEP CCs, OWM has received 
inquiries regarding how NTEP policy should apply to repaired and remanufactured equipment. The inquiries address devices that are assembled from used parts of the same make and model of device, from used parts taken from different models made by the same scale manufacturer.

Remanufactured equipment is defined as the overhaul or replacement of parts to enable a device to be installed in a new location. Repair is defined as the maintenance or replacement of parts for a device remaining in the same location.

Discussion: Henry Oppermann sent a memorandum on November 9, 1992, to summarize current policy and to state the OWM position regarding issues where definitive policy has not been established. That memorandum serves as the basis for policy development through the NTETC Sectors and the NTEP Board of Governors. The memorandum focusses on scales; many aspects of it are applicable to all commercial devices.

\section{Current NTEP Policy}

1. An NTEP CC applies to the specified design (type or family) for a specific manufacturer. The parameters for a particular family of devices are often defined through NCWM Publication 14.

2. If a company copies the design of a device made by another company that has a CC for the device, the $\mathrm{CC}$ does not apply to the "copy." The company that copied the scale must get an evaluation on its "type" because critical aspects of the manufacturing process and quality control may have a significant effect on the performance of the copied device. These aspects may not be evident in the finished product and may not be incorporated in the process used to manufacture the "copy."

3. Scales Code performance requirements under T.N.8. Influence Factors Requirements apply to electronic devices. If an electronic scale had a type evaluation before 1986, the type must (or had to) be resubmitted for an appropriate form of type evaluation to determine compliance with the influence factors requirements. Small scales had to be submitted for testing over a temperature range. Larger capacity scales that had a CC or an OWM Report of Test prior to 1986 had to be modified by using load cells and an indicator with NTEP CCs to obtain an updated NTEP CC for the scale.

4. Mechanical scales (excluding belt-conveyor scales because of the belt) are not considered to be affected by temperature changes. Consequently, the original CC or OWM Report of Test is still valid and no additional testing is required.

5. Virtually all weighbridge designs must have their own type evaluation. At the June 1992 meeting of the Weighing Sector, it was concluded that concrete and steel weighbridges (load-receiving element) for the same weighing element design and produced by the same manufacturer must each receive its own type evaluation. A memorandum dated January 3,1991, provides more detail regarding the type evaluation of weighing elements.

6. NTEP recognizes "one-of-a-kind" devices, designed or customized for a specific application in a specific installation. This concept does not permit multiple devices of the same device to be installed in different States (although there may be only one per State) and still be classified as one of a kind. When a "unique" design becomes a standard product, in that multiple devices are subsequently manufactured, then the device must be submitted for type evaluation and a CC issued before it can be accepted in those States that require an NTEP CC.

7. Replacement of "metrologically-significant" mechanical parts with parts of a different design (e.g., the replacement of levers with levers of a different design) invalidates the original CC.

8. If a company buys NTEP load cells and an NTEP indicating element and then manufactures a scale from the parts, the complete scale must be submitted for type evaluation to assess its performance characteristics for compliance with Handbook 44.

9. If load cells are repaired by other than the original manufacturer or the manufacturer's authorized agent, then the CC for the load cell does not apply to the repaired load cells. 
In June 1992, the Weighing Sector of the Technical Committee on National Type Evaluation discussed the remanufacture of scales and which devices must be submitted for type evaluation. Remanufactured equipment is defined as the overhaul or replacement of parts to enable a device to be installed in a new location. The eriteria are listed below.

(1) If a device with an existing NTEP CC is remanufactured by the original equipment manufacturer (OEM) or authorized agent using OEM parts, no additional evaluation is required, and the original CC applies, provided that the remanufacturing process does not modify the design of the device.

If a device without an existing NTEP CC is remanufactured by the OEM or authorized agent, the device must be submitted to NTEP for evaluation in order to be recognized on an NTEP CC.

(2) If a device with or without an existing NTEP CC is remanufactured by a company other than the OEM or authorized agent, it must be marked with the remanufacturer's name, model designation, non-repetitive serial number, and the qualifier for the serial number as required by G-S.1., General Code of Handbook 44.

The device must be submitted to NTEP for evaluation, and the device submitted to NTEP for evaluation should be a device considered by the remanufacturer to be a "typical" example of the remanufactured devices overhauled by the remanufacturer.

(3) Remanufactured deviees will be evaluated in the same manner using the same test procedures and criteria as newly manufactured devices. No test results obtained for the original equipment will be accepted in lieu of actual testing.

(4) The same guidelines for including parameters of a device on a CC that apply to newly manufactured equipment shall apply to remanufactured equipment.

Repair is defined as the maintenance or replacement of parts for a device remaining in the same location. The guidelines for the repair and replacement of seale parts are as follows.

(1) The repair of a mechanical seale with parts consistent with the design and quality of the original parts does not invalidate the $\mathrm{CC}$.

(2) Except for the substitution of load cells identified earlier, the policy regarding the repair of electronic scales by replacing various electronic components has not been agreed upon. The replacement of electronic components that affect the analog-to-digital converter, gain eircuitry, and dead load may affect compliance with the influence factors of Handbook 44.

\section{Basic Principles}

Specific issues have been raised regarding the repair, remanufacture, and replacement of parts, particularly in mechanical scales. It is necessary to reference some basic principles that ean be applied to provide guidance in the areas where definitive poliey does not exist. Some of the repair issues have been diseussed on at least two occasions by the Weighing Sector. Agreement was not reached on all issues because many companies or service ageneies repair scales of different manufacturers, consequently the ramifications of restricting "minor" repairs would be extremely disruptive to the maintenance of equipment. The following basic prineiples form the basis for NTEP policy and practices:

1. A manufacturing site may be moved, but the manufacturer has the responsibility to manufacture the device consistent with the original type, regardless of where it is manufactured. It is assumed that the manufacturer will apply the same quality control procedures regardless of location.

2. A CC does not apply to a similar device made by another company, even if the design was "copied" from a device with a CC, because the quality control aspects and any specialized manufacturing techniques may not be part of the manufacturing process of the other company. Consequently, any company that is not authorized by the OEM to manufacture or install the device must demonstrate through a suceessful type evaluation that the device model is eapable of complying with Handbook 44 . 
3. Metrologically equivalent parts may be substituted for parts produced by the OEM. The criteria for metrologically equivalent load cells have been developed, but the details of metrological equivalence for other equipment or parts remains undefined. This is similar to the situation where NTEP must make judgments of when a device has undergone a significant modification. (See Section I of the Administrative Procedures for NTEP in NCWM Publication 14.)

4. Superficial differences (differences that are not metrologically significant) among devices are permitted.

5. The OEM may authorize a distributor to sell the manufacturer's product (equivalent to the device originally type evaluated) but with the distributor's name and model designation. The original manufacturer remains responsible for ensuring that the model sold by the distributor is equivalent to the original design. This process does not work in reverse. For example, if a device is manufactured by a company but is submitted for type evaluation by a distributor, the distributor can obtain a CC for the device, but another CC cannot be issued at a later date to the original manufacturer without a new type evaluation because the distributor does not control the manufacturing process. The distributor specifies the criteria for the product, consequently the distributor cannot ensure that the device marketed by the device manufacturer is the same as what the distributor receives.

\section{Responses to Specific Issues}

Several questions have been raised regarding repair practices and devices routinely encountered in weights and measures enforcement. Several States have requested guidance regarding the position they should take when requiring that only NTEP devices be installed in their jurisdiction. The positions of the Office of Weights and Measures are reported below.

1. The repair or replacement of weighbridges has not been addressed by the NTEP Weighing Sector and is not addressed by NTEP policy. However, if the replacement weighbridge is consistent in design, material, and strength of material, then it seems that the new weighbridge is metrologically equivalent to the original. In this case, the original manufacturer will probably not assume responsibility for the repaired device (which is in a sense equivalent to voiding a manufacturer's warranty), but the metrological characteristics of the device have not been changed. In this case, the original CC would still apply. If the weighbridge design is modified, then the metrological characteristics may have changed and the original CC does not apply.

2. Replacement parts for mechanical scales, such as pivots and bearings, are not type evaluated. NTEP has avoided component testing and restricted its activities to main elements, such as indicating elements, weighing/load-receiving elements, and "intelligent" recording elements (printers). By necessity, load cells are evaluated because NTEP is unable to test the complete weighing/load-receiving element in an environmental chamber. Consequently, to determine compliance with influence factors for medium and large capacity scales, it is necessary to test load cells separately.

In terms of replacement parts for mechanical scales, the business of manufacturing replacement parts by companies other than the OEM, was well established before type evaluations were initiated through NTEP. Consequently, the practice and acceptance of the replacement of "metrologically equivalent" mechanical parts is in place. In principle, the substitution of metrologically equivalent parts does not invalidate the CC.

The replacement of circuit boards using rebuilt boards will not be apparent to weights and measures inspectors. Replacement of some electronic parts will certainly affect compliance with the influence factors requirements. Replacement of electronic parts that affect compliance with influence factors requirements will void the original CC, but there is no policy regarding how to address this type of repair.

Care must be taken regarding the repair and replacement of parts for mechanical scales to be sure that manufacturers do not become overzealous by attempting to restrict the source of parts to repair a scale to the original manufacturer, to the exclusion of equivalent parts manufactured by competent companies. The point at which this occurs is not defined. Weights and measures officials must use judgment to make these decisions. 
3. The appropriateness of assembling a scale from used parts by other than the OEM has not been specificaliy addressed. It is the opinion of the Office of Weights and Measures that the original CC does not apply to the reassembled device because the quality control of parts by the original manufacturer and the control over the assembly process may not apply to the reassembled scale. It is unlikely that the original manufacturer would assume responsibility for the reassembled product, so it becomes the product of the remanufacturer. NTEP does not have a policy addressing devices assembled from used parts.
A. Nelson, Connecticut, Chairman
T. Geiler, Barnstable, MA, Chairman-Elect
S. Colbrook, Illinois, Past Chairman
R. Andersen, New York
D. Guensler, California
P. Nichols, Alemeda County, California
S. Malone, Nebraska
J.A. Rogers, Virginia
J. Truex, Ohio
C. Gardner, Suffolk County, NY, Treasurer
C. Brickenkamp, NIST, Executive Secretary

A. Thompson, Alaska, Chairman, Liaison Committee

R. Bruce, Canada Legal Metrology Branch, Advisor when meeting as Executive Committee

\section{Executive Committee}




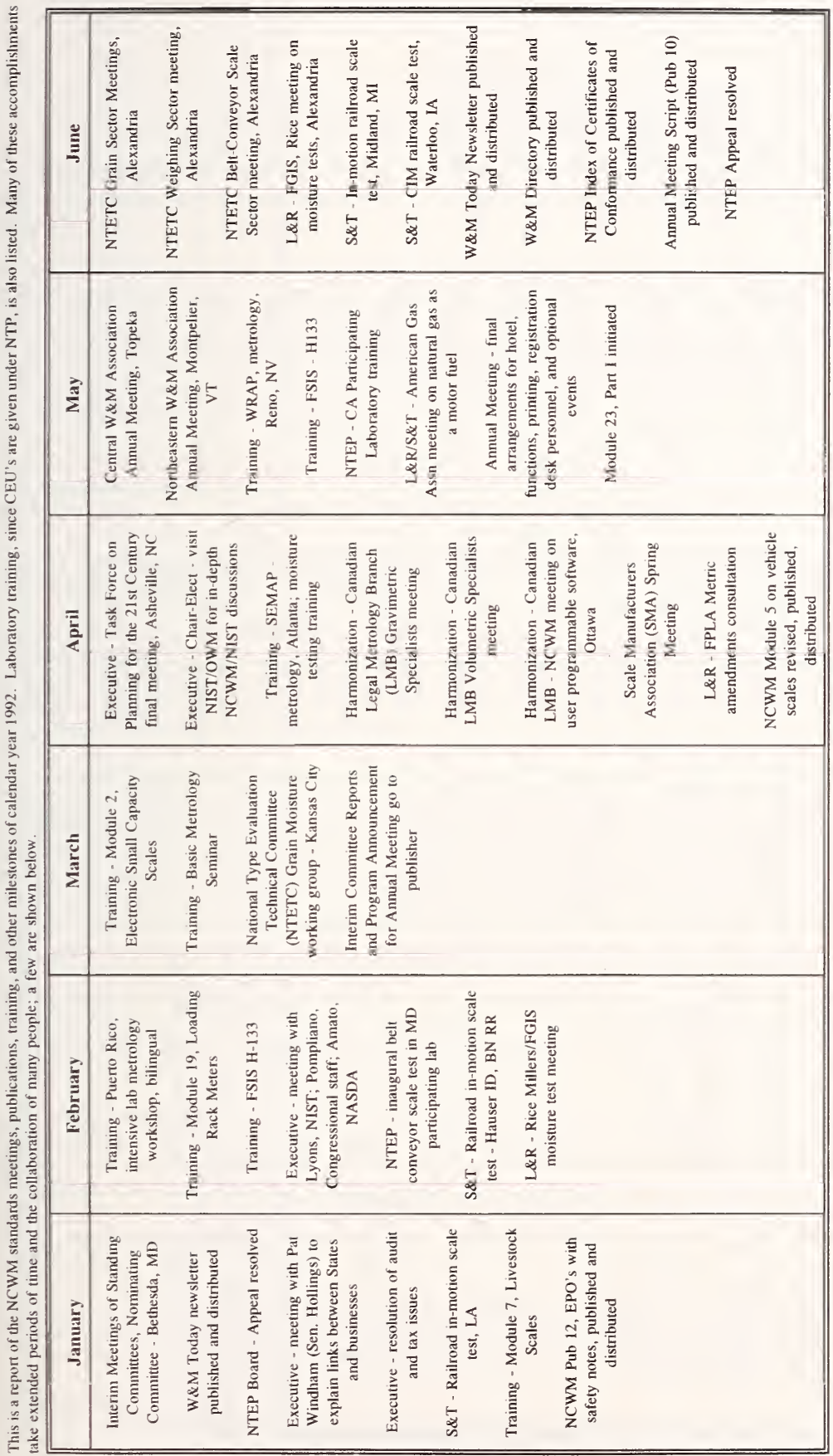




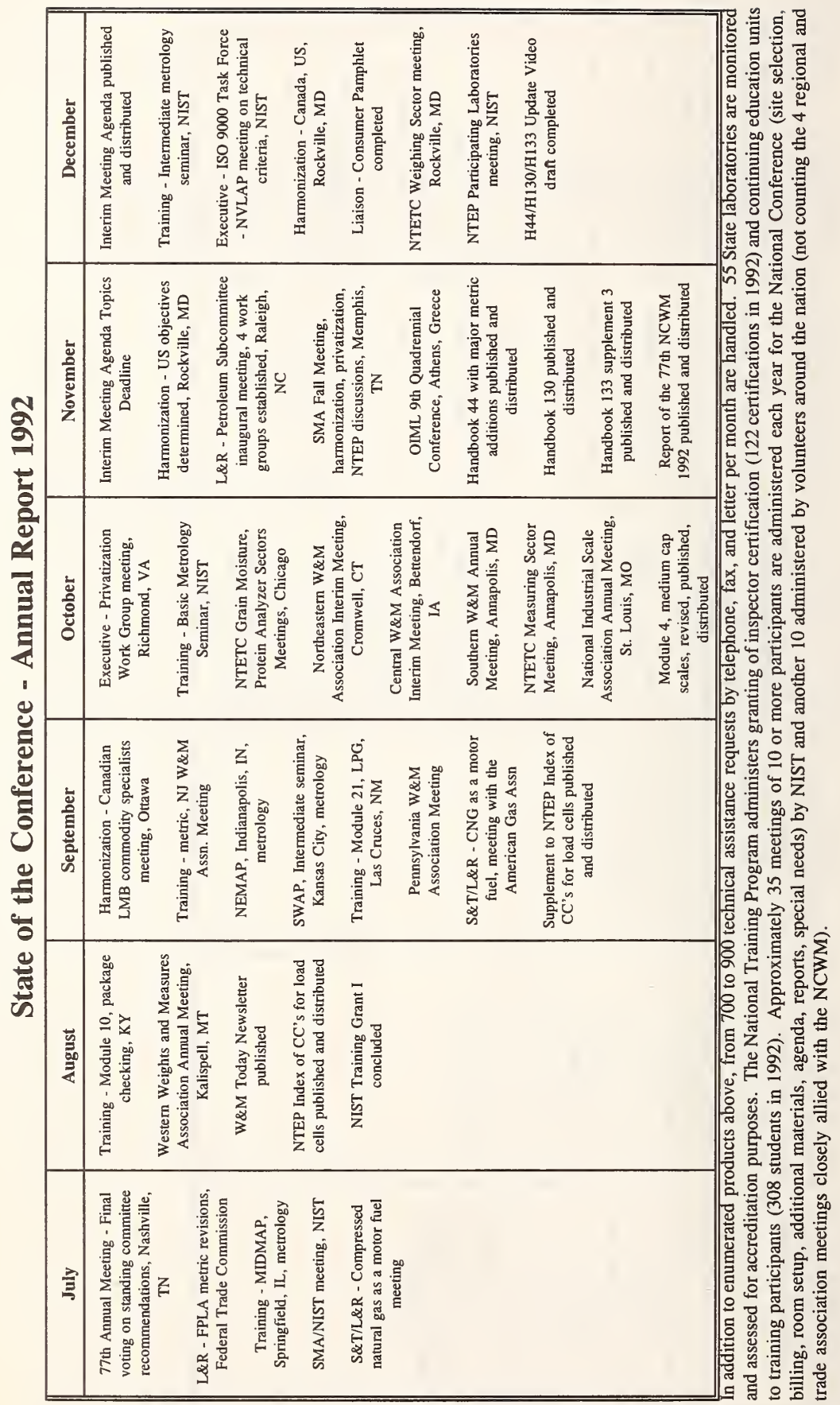




\section{Appendix B}

\section{NCWM Committee Authorities and Responsibilities}

At our Annual Meeting, the first order of business on Monday is an orientation session for those who have never attended an Annual Meeting, describing the structure of the conference, and the responsibilities of the voting and non-voting delegates.

\section{Purpose of this document}

This is an orientation for all new committee members concerning the internal operations of the NCWM, its committees, and its goals. Some of the information we present will be obvious to many of us, but it is reasonable that we should review the information and examine our performance on each element, and consider how we can meet our responsibilities in the coming work year. Since the only way the Conference can meet its objectives and goals is through the efforts of its numerous committees, subcommittees, and work groups, that is, through YOU, it is important to review our roles and responsibilities on all committees.

There is a structure to the NCWM organizational maze that is difficult to perceive when the organization chart listing all the members is shown; however, we will try to make sense of it for us all so that we can work more efficiently and effectively together. Your dedication to weights and measures is obvious by your accepting appointment to a committee.

What we want to do is to provide as much assistance and guidance to make your enthusiasm lead to progress and success in meeting the Conference's goals and objectives.

\section{Which groups meet at the Interim Meetings and why}

Not every group that is part of the National Conference meets at either the Interim or Annual Meetings. The highest level of management, called the "Standing Committees" (and not all of them - there are also the Finance and Credentials Standing Committees) meets at the Interims in order to recommend policy and standards for the voting membership to accept, reject, or modify at the Annual Meeting.

The items voted upon by the Active Membership in July include policies in the NCWM Constitution and Bylaws (NCWM Publication 1), NTEP Policy and Administrative Procedures (NCWM Publication 14), NCWM Policy, Interpretations, and Guidelines (NCWM Publication 3) as recommended by the Executive Committee, uniform laws and regulations contained in NIST Handbook 130 and package checking procedures contained in NIST Handbook 133 recommended by the Laws and Regulations Committee, device regulations contained in NIST Handbook 44 and enforcement practices for NCWM Publication 3 recommended by the Specifications and Tolerances Committee, additions and modifications to the National Training Program including new and revised training modules recommended by the Education, Administration, and Consumer Affairs Committee, and the slate of officers as recommended by the Nominating Committee. This last committee, the Nominating Committee, is not a standing committee, but an annual committee, appointed each year by the incoming Chairman. Since its recommendations affect the long term leadership of the Executive Committee, and thus of the Conference, it too convenes at the Interim Meetings in order to deliberate on this most important issue. Since the Conference fiscal year now ends at the end of the calendar year, the Auditing Committee is also meeting this week to review and close the books on the 1992 fiscal year finances.

\section{Other Conference groups}

Other Conference groups generally meet at other times throughout the year and funnel their reports and recommendations through one of the standing committees. For example, the Petroleum Subcommittee held its inaugural meeting this fall; its chairman, Celeste Bennett, from Michigan is here with us this week, but the subcommittee is not meeting. The chairman of the Metric Working Group, Ed Heffron, also from Michigan, is with us this week. In general, however, the National Type Evaluation Technical Committee's various sectors, the Privatization Work Group, etc., do not meet during the Interim week.

These other groups have active, associate, and advisory membership, and all types of members have a vote within these groups. Of the Standing Committees, only the Liaison Committee has other than active members on it. When the Liaison Committee members advise the other standing committees, the Liaison member is a non-voting participant.

Other related organizations

Other groups that are meeting during this week in conjunction with the Interim Meetings include the American Petroleum 
Institute, the Gasoline Pump Manufacturers Association, the Scale Manufacturers Association, the Industry Committee on Packaging and Labeling, the National Industrial Scale Association and the National Working Groups for OIML PS7/RS2 on electronic weighing instruments and PS5D/RS10 on mass flow meters. None of these other groups are part of the National Conference, but each shares a close relationship to the Conference in collaboration, cooperation, and purpose.

\section{Authority of Each Committee}

The authorities of each standing committee and the other committee meeting this week, the Nominating Committee, as are contained in the Constitution and Bylaws, a copy of which you all should have. This should assist you in determining when and whether to conduct meetings or seek advice from other committees, depending upon your committee's objectives on any given issue:

\section{Executive Committee}

The Executive Committee, subject to the overriding authority of the Conference itself:

1. selects the place, dates, and headquarters, and fixes the registration fee for each meeting of the Conference;

2. fixes the annual membership fee;

3. may, at its option, fill any vacancy in any elective office of the Conference caused by death, resignation, or retirement from active official regulatory service; and

4. advises the Executive Secretary with respect to the programs for the meetings of the Conference and its committees, and makes recommendations to the Conference, the Conference officers, and the committee chairmen.

The Executive Committee, in the interval between meetings of the Conference:

1. authorizes Interim Meetings of Conference committees as needed;

2. authorizes committee and other contingent expenditures (including travel and subsistence expenses of committee members and the Conference Chairman), and

3. acts for the Conference in all routine or emergency situations that may arise.

Questions before the Executive Committee are decided, whether by voice vote or ballot, on the basis of the majority of votes cast.

\section{The Executive Committee:}

1. serves as the Board of Governors for the National Type Evaluation Program (NTEP);

2. utilizes the technical committees of the NCWM to resolve technical issues regarding NTEP;

3. utilizes the industry members of the Technical Committee on National Type Evaluation, who will comprise the NTEP Advisory Committee and who will represent the interest of industry, in advising the Board of Governors.

The Committee serves as a policy and coordinating body in matters of national and international significance which may include such areas as metrication, International Organization of Legal Metrology (OIML), American National Standards Institute (ANSI), International Organization for Standardization (ISO), American Society for Testing and Materials (ASTM), National Conference of Standards Laboratories (NCSL), and such internal matters as may be required. 
The Committee annually presents a report to the Conference on its activities, which are subject to Conference ratification.

It should now be apparent to you why the Executive Committee has scheduled a meeting with each of the other standing committees. Please plan to discuss your objectives, within the context of expenses that you foresee in the coming work year (meetings over and above the Interim Meetings, work projects, the formation of additional work groups under your authority, technical or political issues that the Executive Committee should be familiar with, and presentations, panels, or other discussions that might be educational and informative for the Annual Meeting).

\section{Committee on Laws and Regulations}

The Committee on Laws and Regulations annually presents a report for Conference action.

Its scope embraces all matters within the area of weights and measures supervision including:

1. the development and interpretation of uniform laws and regulations;

2. the study and analysis of bills for legislative enactment; and

3. the establishment and maintenance of published guidelines and other effective means of encouraging uniformity of interpretation and application of weights and measures laws and regulations.

\section{Committee on Specifications and Tolerances}

The Committee on Specifications and Tolerances annually presents a report for Conference action.

Its scope embraces all matters dealing with:

1. specifications, tolerances, and technical requirements of any kind relating to scales, weights, measures, and weighing and measuring devices and accessories, including interpretation of such material whenever necessary,

2. standards and testing equipment for weights and measures officials, and

3. procedures for testing commercial equipment.

\section{Committee on Education, Administration, and Consumer Affairs}

The Committee on Education, Administration, and Consumer Affairs annually presents a report for Conference action.

Its scope embraces all matters dealing with the:

1. education and training of weights and measures officials,

2. promotion of weights and measures principles and techniques among the general public and the users of weighing and measuring devices,

3. development and recommendation of administrative procedures and public relations programs, and

4. identification of commercial weights and measures practices and problems that are of concern to consumers. 


\section{Committee on Liaison}

The Committee on Liaison annually presents a report for Conference action. Its mission is divided into two categories as follows:

\section{Liaison with Federal Agencies.}

Intergovernmental (with NIST/USDA/FDA/FTC/DOD/Postal Service, etc.) contacts and relations on behalf of the Conference. This role involves explaining, advocating, and coordinating Conference positions, recommendations, and needs before Federal Government agencies and promoting uniformity among those agencies and with the NCWM.

\section{Liaison with Other Groups or Organizations and Agencies.}

This role involves public liaison with consumer groups, the associate NCWM membership, the retiree membership, domestic and international standards organizations, industry, trade associations, and others.

The goals are to provide and solicit information, develop a spirit of cooperation, and promote uniformity with the activities of the NCWM.

As you may be aware, the Conference Liaison Committee has agreed with the recommendation of the Task Force on Planning for the 21 st Century that its responsibilities are so important that they should be specifically added to the responsibilities of all the other standing committees that meet at the Interim Meetings, and has assigned its members to specific standing committees to transfer its liaison responsibilities to the other committees. The Executive Committee will meet with the Liaison Committee today to discuss its long term objectives and how these objectives can be met within the resources of the Conference.

\section{Nominating Committee}

The Nominating Committee annually presents a slate of nominees for all elective offices. The names of these nominees shall appear in the report of the Nominating Committee and be published in Conference Announcement Book (NCWM Publication 16).

\section{Hierarchy of the Conference Organization}

Now we can graphically describe the organization of the Conference and its major committees in the following way.

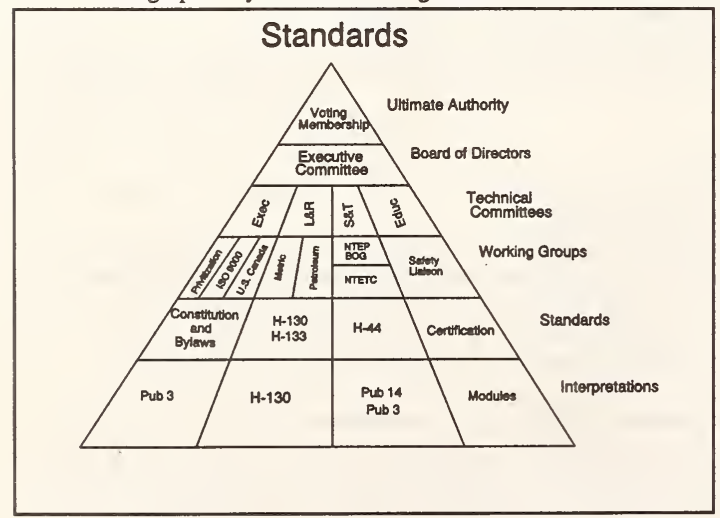
As you can see, since everything must be ultimately ratified by the active members, they are the ultimate authority. Since the Executive Committee acts for the Conference whenever the active members are not convened in an Annual Meeting, and since they have financial authority over work projects and subgroups, the next level of management is the Executive Committee. Then, the next level is the standing committees; they study and recommend standards of law, regulation, and practice. Then the next level is work groups, subcommittees, task forces, etc. that report to the standing committees. They expand and develop work and proposals for the standing committees. 
Annual Meeting and Financial Operations

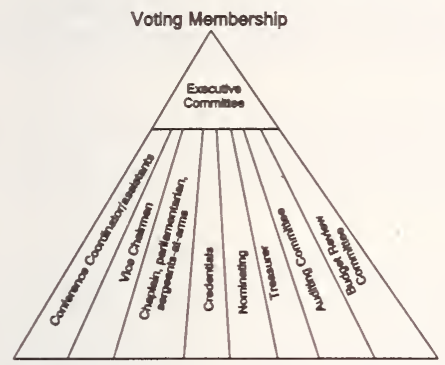

On a second drawing is shown the various annual committees and other officers that are so essential for the conduct of our Annual Meeting.

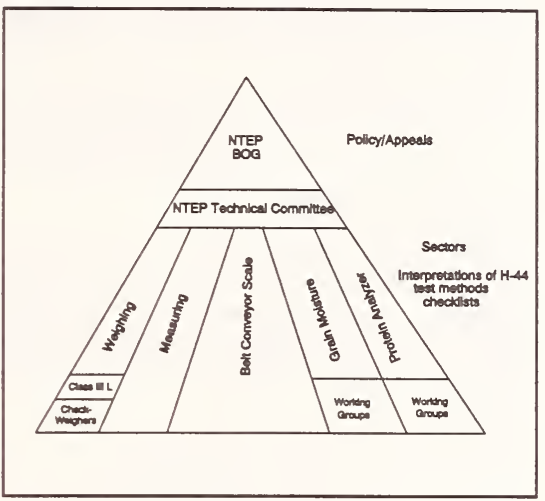

To the right, we show the lines of authority within the National Type Evaluation Program, and the various ways that policy and procedures are developed and implemented.

These drawings are all drafts of NCWM descriptions that I hope we will all study, critique, and recommend clarifications, modifications, and efficiencies.

We are proud of our heritage and history in weights and measures in the United States; however, we have a fiduciary responsibility to operate as leanly as the individuals, jurisdictions and businesses that support us do. We welcome your input on what we have outlined here, and the information yet to be provided.

\section{Goal of the Conference and How the Committees Meet This Goal}

The National Conference on Weights and Measures (NCWM) is a standards-development organization. The goal of the NCWM is to develop, through its various committees, subcommittees, task forces, and working groups, documented standards of practice or test that maintain or improve equity in commercial measurement practices at a reasonable cost, and that represent a consensus of its members. These standards are intended for States and other government entities to adopt as their own standards; thus only government officials may vote on the recommended standards.

What is a "consensus"? Consensus is not unanimity, but it is more than a majority. To have achieved a consensus means that most participants agree to the approach, the recommendation, or other product or process developed by the group, but that a few participants may disagree. When a vote is taken, a simple majority usually rules (except for matters concerning motions from the floor or votes on the Constitution and Bylaws); however, a vote is taken within the committee only when the issue does not seem to be resolving itself in a consensus fashion. For this reason, it is important to document as far as possible the participants at each working session, the alternatives the group considered, the arguments in favor and in opposition to each alternative, as well as the final decisions reached by the group. Let us caution, however, if a consensus cannot be reached within the committee, it is unlikely to have been developed and explained enough to achieve a consensus or even a majority on the floor of the Annual Meeting voting session (only a majority in most cases is required). In years gone by, it was typical for a committee to decide an issue the same year that the problem was described. The weights and measures community was smaller, and the problems were less complex. Now the time needed to explain the complexities to the regulatory and business community may be longer than the period between January and July; for this reason, do not feel compelled to decide every issue the first year it comes before the committee. Secondly, priorities should be set, and the Committee's time should be apportioned to the highest level priorities first; this may mean that some issues may have to be delayed in their study and resolution. Finally, it is critically important to attempt to achieve a consensus; this does not mean that a consensus is mandatory. However, it does mean that the NCWM customer is not just the weights and measures regulatory official; the proposed solution should be amenable to business and industry implementation at reasonable cost. Thus, consensus among all affect parties should 
be sought, if not always achieved; ultimately, the weights and measures regulators must make the call, and be willing to enforce the standards they develop in the Conference forum.

The discussion on each item should lead to a general agreement on the approach, special wording, or other decision of the committee. In general a vote will not be needed on every issue; but the final decision should be clarified in order to assure that agreement has been reached. As explained earlier, when a vote must be taken on any issue, majority rules apply.

\section{Committee Members Roles and Responsibilities:}

\section{Committee Members}

\section{Active Committee Members}

Public sector weights and measures government members are called active members; their participation at the Interim Meeting is ordinarily underwritten by the NCWM; their participation at the Annual Meeting is expected to be underwritten by their employer. They are responsible for representing their region, not just their State or local jurisdiction, at NCWM meetings and they are responsible for representing the NCWM at regional weights and measures meetings.

Each committee member should strive to:

- determine the needs of those they represent by canvassing fellow State and local regulatory officials, related industries, and the general public, including consumers and device users, for input on NCWM committee issues before the committee meetings and after tentative recommendations are made to determine how the proposal would impact the public they serve;

- get regional peers to develop as far as possible each new issue (for example, disseminate NCWM Form 15 to all state and local directors in the region) (see attached form);

- record regional committee discussions and hearings including arguments in favor or and in opposition to positions, and proponents of and against positions;

- disseminate regional committee results to the NCWM committee;

- present regional positions and supporting arguments on issues at NCWM committee meetings;

- participate in the Committee discussions and meetings to arrive at a consensus on the issues, priorities, and objectives of the committee (don't become locked into regional position; be open to new data and information);

- consider the cost and benefit of proposals and alternative solutions to problems;

- take notes of the discussions at the committee meetings in order to compose or review the information contained in the committee report;

- commit resources to gather data or collect information on any issue;

- assist in composing wording, arguments in support and in opposition, review, suggest revisions, and approve tentative and final reports;

- disseminate committee work to the State directors in the committee member's region and to the regional association;

- explain and argue for support of NCWM committee positions at regional meetings;

- adopt NCWM recommendations in the member's own jurisdiction;

- encourage adoption of NCWM recommendations in the other jurisdictions in the member's region; and 
- work to change NCWM recommendations within the due-process structure of the Conference, if the member can't live with them; and

show peers in other jurisdictions how to change NCWM recommendations within the due-process structure of the Conference, if the peer has problems accepting these recommendations.

Although the only standing committee currently formed with voting associate membership is the Liaison Committee, (the Finance Committee associate member is nonvoting), the following responsibilities and roles apply to all the technical sectors, working groups, and subcommittee work for which there are associate membership.

\section{Associate Committee Members}

Private sector members are known as associate members; the costs of their attendance must be specifically approved by the Chairman of the NCWM. Associate committee members should:

- canvass trade and professional peers for input on NCWM committee issues before the committee meetings, including the industry's customers;

- get peers in the member's organization or peer organizations to develop each new issue (for example, disseminate NCWM Form 15 to all members in the organization);

- disseminate the member's organizational position(s) on committee issues to the NCWM committee;

present the member's organizational positions and supporting arguments on issues at NCWM committee meetings;

participate in the committee discussions and meetings to arrive at a consensus on the issues, priorities, and objectives of the committee;

take notes of the discussions at the committee meetings in order to compose parts of the committee's report or to review the information contained in the committee report;

commit resources to gather data or collect information on any issue, including information that will provide estimates of cost and benefit;

- disseminate committee work to the organization that the member represents;

- explain and argue for NCWM committee positions to the member's organization;

recommend adoption of NCWM recommendations by regulatory agencies in the member's regional area; and

work to change NCWM recommendations within the due-process structure of the Conference, if the represented organization can't live with them.

\section{Committee Chair}

In addition to the responsibilities that are shared by all members, as listed above:

Prior to each meeting: Approve meeting scheduling, other special arrangements, and agenda. Assist in composing letters of invitation and other correspondence notifying individuals and organizations of planned meetings, draft proposals, etc.

At each meeting: Lead the meetings, determine priorities with the committee members, keep the group on the agenda, keep the discussion on track with respect to the objectives, summarize the points made both pro and con, conduct the vote, if one is necessary, and summarize the agreement reached at conclusion of each subject discussion. Assign specific tasks such as witnessing tests, collecting cost/benefit data, composing portions of a report, or other duties as appropriate. The Committee's technical advisor will assist in all these duties, as requested. 
After each meeting: Compose letters of appreciation for assisting the committee to appropriate individuals.

Overall responsibility: Ensure that the committee determines needs, sets objectives, prioritizes work to meet established objectives and ensure that action items are completed. Provide summary oral reports and represent the committee at other meetings.

\section{Technical Advisor}

The technical advisor is a non-voting member of each standing committee. Except for the Technical Committee on National Type Evaluation Grain Moisture and Protein Analyzer Sectors, the Executive Secretary has assigned NIST Office of Weights and Measures staff to act as technical advisors.

Prior to each meeting: Recommend to the Chair and committee a list of priorities. Develop and disseminate preliminary and final agendas and reports of the committee for publication. Develop and analyze issues with respect to their impact on the general community, including cost and benefit, impact on weights and measures regulatory authorities, and related and regulated industries. Locate experts, request their participation, and coordinate contributions of experts and other participants. Schedule and make other arrangements for meetings, and notify committee members of logistics. Compose and record mail ballots and record voice ballots, if necessary.

Additionally, the Technical Advisor will:

- seek groups that may be affected by an NCWM decision and encourage their participation in the forum;

- prepare questions so that as many sides of an issue as can be imagined are considered by the committee and document these positions in light of the final decision;

- take notes of and/or record the discussions at the committee meetings that will provide a sense of what the depth of the discussion is on each item; who supports and who opposes the proposal; what are the arguments for and against each item;

- develop alternative solutions, as well as pros and cons to each alternative;

- identify gaps in information and devise methods for filling those gaps (this may require devising test methods, field testing procedures, collecting data, etc. by NIST staff or by outside volunteers);

- monitor assignments made to committee members or other interested parties for their completion;

- document committee positions either as part of committee reports or in communications from the NIST Office of Weights and Measures; author or co-author the reports if parts are assigned to other committee members; disseminate reports to all committee members, committee mailing list, State Weights and Measures Directors, and other NCWM members as appropriate;

- compose final addendum sheets for standing committee to present to active members at the Annual Meeting; and

- ballot committee members on their acceptance or recommended revision to tentative and final reports, and addenda sheets.

\section{Summary}

We all appreciate to the utmost the sacrifices each of you have made to be here because of your dedication to maintain and improve marketplace fairness and equity. Thank you for accepting these responsibilities, and I wish us all success! 


\section{Appendix C}

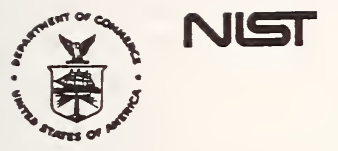

UNITED RTATEB OEPARTMENT OF COMMERCE National Inattute of Btandarda and Technology Geithersburg. Maryland 20899 OFFICE OF THE DIRECTOR

January 11, 1993

Mr. Bruce A. Adams

Chair CWMA

Minn Metrology Lab

2277 Highway 36

Rosevilie, MN 55113

Dear Mr. Adams:

Thank you for your letter of December 18, 1992. I share your views of the OWM program and recognize its importance in working with the states to attain common objectives that are important to insure equity in trade.

I have no intention of cutting back OWM services and am committed to insure that they are maintained. However, you must recognize that our ability to expand these services will depend on the availability of additional resources.

We look forward to your continued support and trust that the NIST OWM program will continue to serve the needs of your members.

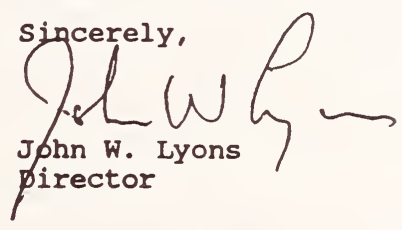

cc: S. Kramer

8. Warshaw 

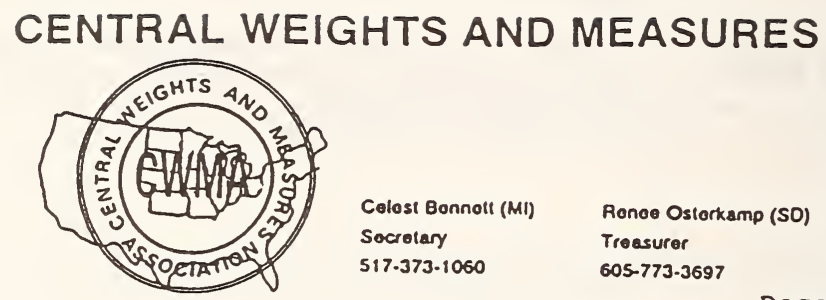

ASSOCIATION

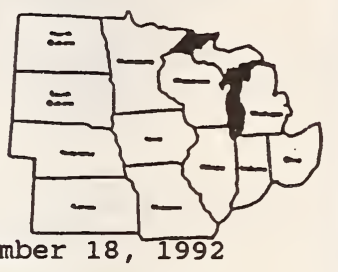

Bruce A. Adams

Chair CWMA

Minn Metrology Lab

2277 Highway 36

Roseville, MN 55113

Dr. John $W$ Lyons

Director NIST

Administration Building

National Institute of Standards and Technology

Gaithersburg, MD 20899

Dear Dr. Lyons,

I am writing to you on behalf of the Central Weights and Measures Association (CWMA). Since its inception, CWMA has been a strong supporter, as well as an active user of the services of the NIST Office of Weights and Measures (OWM). CWMA has actively worked to improve training, and transfer of knowledge and practices, to all our members and associates. We have, as a group and individually, made significate strides in staff improvement and education as a result of support and assistance from OWM in the training and education areas as well as the technical support area.

This association and its members have invested a substantial amount of time and funds to sponsor and participate in educational programs developed by the National conference on Weights and Measures (NCWM) with grant funds and technical and administrative assistance provide by NIST. These programs benefit our members by enabling them to better serve their clients in the public and private sectors. It is our view that it would be very unfortunate if the benefits from the investments made by NIST and the states to provide quality training and technical support were lost due to a short term lack of support staff to adequately maintain the training programs. Even a short term gap will cause a loss of momentum in the forward direction. 


\section{CENTRAL WEIGHTS AND MEASURES ASSOCIATION}

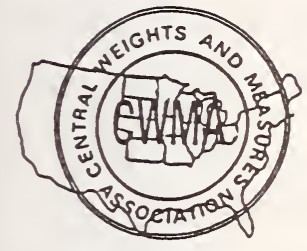

Celost Bonnoll (MI) Socrolary 517.373 .1060
Ronee Oslorkamp (SO)

Treasurer

$605-773-3697$

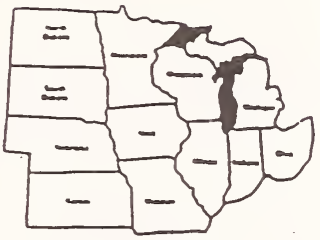

We have heard that a lack of funding may result in a transfer of OWM staff to other areas. This transfer would result in a curtailment or elimination of certain programs and services presently available. We are concerned because OWM has been operating at reduced staff levels already, and any further reductions would seriously disrupt one or more of the basic programs on which we rely, for example, the training program, type evaluation program, development of uniform laws and regulations, and state laboratory training and assistance programs, as well as NCWM operational functions. Members of the CWMA Fducation Committee and other members of the Association present at our interim meeting were, in particular concerned about any near term cuts in the educational services area. We were very glad to hear during the meeting that funding for Joan Koenig's position had been continued, at least for the present.

We are painfully aware of the funding difficulties in government at all levels. From our view we have seen much progress, and think that there is such promise, in the education programs and modules that are produced through the direction of OWM and with the cooperation of all interested parties, that we would be dismayed to see a halt or hold to this progress. The work by the OWM, the direction provided by the NCWM, and the conscientious efforts by many people have laid a fine foundation on which to build. We urge you not lay aside the plans to build for the future.

As a member of the CWMA Education Committee, a charter member of the Association, and weights and measures official who has used and gained from the educational and technical programs provided through NIST, I as an individual, also ask that continued support be made available to OWM so that those involved may continue to better and more efficiently serve the clients needs.

If there is anything that I or the members of the Central Weights and Measures Association can do to encourage additional funding for NIST or OWM please let us know.

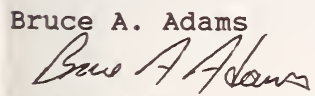

Chair CWMA 


\section{Appendix D}

\section{CONSTITUTION}

\section{ARTICLE I - GENERAL}

This Association shall be known as "The National Conference on Weights and Measures" and is sponsored by the National Institute of Standards and Technology (NIST) under the authority of that portion of the Organic Act (U.S. Code, Title 15, Chapter 7, Section 272) authorizing the NIST to undertake "cooperation with the States in securing uniformity in weights and measures laws and methods of inspection".

\section{ARTICLE II - Goal and OBJECTIVES}

The goals of the National Conference on Wetghts and Measures are to ensure equity in the marketplace between buyer and seller and provide and enhance the fairmess of the commercial trading environment by meeting the objectives given below.

The objectives of The National Conference on Weights and Measures are:

A. Forum. To provide a national forum for the discussion of all questions related to weights and measures administration as carried on by officials of the Federal Government and regulatory officials of the States, Commonwealths, Territories, and Possessions of the United States, their political subdivisions, and the District of Columbia for the following purposes:

B. Mechanism. To provide a mechanism to establish policy and coordinate activities within the Conference on matters of national and international significance pertaining to legal metrology.

C. Consensus. To develop a consensus on uniform laws and regulations, specifications, and tolerances for weighing and measuring devices, and on testing, enforcement, and administrative procedures.

D. Uniformity. To encourage and promote uniformity of requirements and methods among jurisdictions.

\section{E. Cooperation. To foster cooperation among} regulatory officers themselves and between them and all of the many manufacturing, industrial, business, and consumer interests affected by their official activities.

\section{ARTICLE III - MEMBERSHIP}

Membership consists of three classes: active, advisory, and associate.

ACTIVE MEMBERSHIP. - Active membership is limited to weights and measures or measurement officers actively engaged in regulatory service and in the employ of or under contract to Wederat govem. ment, States, Commonwealths, Territories, or Possessions of the United States, their political subdivisions, or the District of Columbia.

ADVISORY MEMBERSHIP. - Advisory membership is open to (1) representatives of agencies of the Federal Government who are not directy molved in regulatory activities, (2) representatives of State and local governments other than weights and measures officials, (3) foreign government officials, and (4) persons who have retired from Federal, State, county, or city weights and measures employment who are concerned in any way with regulatory weights and measures officers or their official activities or who are interested in the objectives and activities of the Conference. (Amended 1990)

ASSOCIATE MEMBERSHIP. - Associate membership comprises representatives of manufacturers, industry, business, consumers, and other persons who are interested in the objectives and activities of the Conference.

\section{ARTICLE IV - OFFICERS}

\section{SECTION 1 - EX OFFICIO OFFICERS}

A. President. - The Director of the National Institute of Standards and Technology is, ex officio, the President of the Conference.

B. Executive Secretary. - The Director of the National Institute of Standards and Technology designates a senior member of the Institute staff, who is thoroughly conversant with weights and measures nationally, to serve the Conference as its Executive Secretary. 


\section{SECTION 2 - ELECTIVE OFFICERS}

The Elective Officers of the Conference shall be: Chairman-Elect,

4 Vice-Chairmen,

Treasurer, and

6 members-at-large to serve on the Executive

Committee.

The consecutive reelection of a Chairman-Elect is prohibited; the Chairman-Elect shall not serve on any standing committee other than the Executive Committee. Should the Chairman-Elect for any reason be unable or unwilling to be installed as Chairman, his/her successor shall be elected in the manner prescribed. In this event, the newly elected Chairman-Elect shall be installed as Chairman.

\section{A. Eligibility}

1. Any active member in good standing shall be eligible to hold any office provided that the individual meets the other requirements set forth in the Constitution and Bylaws.

2. The Chairman-Elect will be elected at the Annual Meeting one year prior to the term of service as Conference Chairman. After serving one year as Chairman-Elect, the incumbent will succeed to the office of Conference Chairman.

\section{B. Nominations and Elections \\ 1. Nominating Committee}

a. The Chairman shall appoint a Nominating Committee consisting of the most recent active Past Chairman as Committee Chairman and six (6) active members, to include at least one (1) member representing each of the four Regions.

(Amended 1986)

\section{Nominations}

a. The Nominating Committee shall submit one name for each elective office and present its recommendation as a slate in its report to the Conference.

b. Additional nominations for officers may be made from the floor at the Annual Meeting provided that prior consent of the nominee has been obtained in writing and presented to the presiding officer at the time of the nomination.

\section{Elections}

Officers shall be elected during a designated session of the Annual Meeting by a formal recorded vote of the members in attendance and eligible to vote on Conference motions.

See Bylaws, Article VI - Voting System

4. Terms of Office

a. The Chairman, Chairman-Elect, Past Chairman, Vice Chairmen, and Treasurer, shall serve for a term of one year or until their successors are respectively elected or appointed and qualified.

b. The six Executive Committee members-at-large shall serve for 3-year terms; two elected each year.

c. All officers shall take office immediately following the close of the Annual Meeting at which they were elected.

\section{Filling Vacancies}

In case of a vacancy in any of the elective offices, the Executive Committee shall fill the office by appointment.

\section{ARTICLE V - APPOINTIVE OFFICIALS}

\section{SECTION 1 - OFFICIALS, SPECIFIC}

The Conference Chairman will appoint the following officials:

Chaplain

Parliamentarian

Assistant Treasurer

\section{SECTION 2 - OFFICIALS, OTHER}

\section{A. Appointment}

The Conference Chairman shall appoint other officials to conduct Conference activities. See Bylaws, Article IV - Duties of the Officers, and Article V - Committees.

The Exectitive Secretary thall appoin Iechnical atvisors

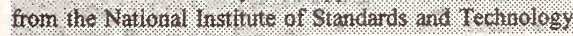
or other stitable organization.

\section{B. Assumption of Office}

All appointive officials shall take office immediately following appointment and will serve through the 
subsequent Annual Meeting of the Conference unless otherwise specified by the Conference Chairman.

\section{ARTICLE VI - MEETINGS OF THE CONFERENCE}

Unless otherwise indicated, all meetings of the Nattonat Conferratce or. Weights and Measures are open ineetings, and NCWM menbers are encouraged to partictpate or observe whether or thot appotinted to a particifar notking group, task force, etc.

\section{A. Annual Meeting}

The Annual Meeting of members shall be held each year at the Annual Conference. The agenda for this meeting shall include the election of officers, reports from the various committees, task forces, study groups, and treasurer, and other items pertinent to the Conference.

The Annual Meeting may include the presentation of technical papers, discussions, displays, entertainment, or other events at the discretion of the Executive Committee.

\section{B. Interim Meetings}

The Interim Meetings of the Executive Committee and those Standing Committees designated by the Chairman shall be held annually, approximately six months prior to the Annual Meeting in order to develop the agenda and committee recommendations to be presented to and acted on by the membership at the Annual Meeting.

\section{Special Meetings}

1. The Conference Chairman is authorized to order a meeting of the Executive Committee at any time such a session is deemed by the Chairman to be in the best interest of the Conference.

2. Other Committees of the Conference are authorized to hold meetings at times other than the Annual Meeting or Interim Meeting provided that:

a. such meeting or meetings have been provided for in the Conference budget approved by the Executive Committee, or

b. such meeting or meetings are approved by the Chairman and funding is available within the approved budget, or

c. such meeting or meetings are approved by the Chairman and the Executive Committee including agreement to increase the budget to cover the cost of the meeting.

3. A quorum shall consist of a majority of the eligible voters.

\section{Rules of Order}

The rules contained in Robert's Rules of Order shall govern the Conference in all cases to which they are applicable, and in which they are not inconsistent with the Constitution or Bylaws or the special rules of the Conference.

\section{ARTICLE VII - FEES AND DUES}

The annual membership fees and the registration fees for the Annual Meeting shall be established (and may be revised) by a majority vote of the Executive Committee at any official meeting of that Committee.

\section{ARTICLE VIII - AMENDMENTS TO THE CONSTITUTION}

This Constitution may be amended, added to, or repealed at any Annual Meeting of the membership under normal Conference procedures. Proposed changes must be included in the Agenda of the Executive Committee for the Interim Meetings, published in the recommendations of the Executive Committee in its Tentative Report (contained in the Announcement Book of the Annual Meeting, NCWM Publication 16), and discussed at the general session of the Executive Committee at the Annual Meeting at which said changes will be voted on. Amendments to the Constitution must be approved by a minimum of a two-thirds vote in both the House of State Representatives and the House of Delegates.

\section{ARTICLE IX - BYLAWS}

\section{SECTION 1 - SUPPLEMENTATION OF CONSTI- TUTION}

This Constitution shall be supplemented by Bylaws which shall detail the methods of operation of the Conference. Such Bylaws shall not be inconsistent with the provisions of the Constitution.

\section{SECTION 2 - AMENDMENTS, ADDITIONS, AND REPEALS OF BYLAWS}

The Bylaws may be amended, added to, or repealed in the same manner as prescribed for the Constitution (See Article VIII). 


\section{SECTION 3 - RENUMBERING}

The Executive Secretary is authorized to renumber the Articles and Sections of the Constitution or Bylaws to accommodate any changes made.

\section{BYLAWS}

\section{ARTICLE I - APPLICATION FOR MEMBERSHIP}

\section{SECTION 1 - FORM OF APPLICATION}

Each application for membership in this Conference shall be in the form prescribed by the Executive Committee.

\section{SECTION 2 - SUBMISSION OF APPLICATION}

Each application for membership shall be submitted to the Executive Secretary of his/her designate. The application shall be accompanied by the membership fee. Applications received by the Executive Secretary will be processed. The new applicant's name will be added to the Conference membership mailing list.

\section{ARTICLE II - FEES, MEMBERSHIP RECORDS}

\section{SECTION 1 - FEE}

The fee for annual membership, as well as the registration fee for the Annual Meeting, are established and subject to revision by the Executive Committee.

\section{SECTION 2 - MEMBERSHIP YEAR}

Annual membership shall be payable by July 1 of each year and covers the period July 1 to June 30 of the following year.

\section{SECTION 3 - BILLING}

The Executive Secretary's designate shall bill each member for yearly dues 2 months prior to the expiration of the current membership year.

\section{SECTION 4 - EVIDENCE OF MEMBERSHIP}

Membership certificates and cards of suitable design, bearing the seal of the Conference, shall be issued to members. The Executive Secretary's designate shall advise the Treasurer of the count of new members and will forward the membership monies for deposit in the Conference account.

\section{SECTION 5 - WAIVER OF REGISTRATION AND MEMBERSHIP FEES}

Individuals who have retired after ten or more years of weights and measures employment in either the public or private sectors, and who have attended at least one Annual meeting, shall not be subject to the payment of the registration and membership fees.

The spouses of retired members shall enjoy the same privileges as spouses of active members.

(Added 1986; Amended 1987)

\section{ARTICLE III - USE OF THE INSIGNIA}

The insignia of the Conference may be used or displayed only by members of the Conference, unless expressly authorized in writing by the Conference.

\section{ARTICLE IV - DUTIES OF THE OFFICERS}

\section{SECTION 1 - CHAIRMAN}

The Conference Chairman is the principal presiding officer at the meetings of the Conference and of the Executive Committee, makes appointments to the several standing and annual committees, and appoints other Conference officials to serve during his or her term of office.

\section{SECTION 2 - CHAIRMAN-ELECT}

The Chairman-Elect will:

A. serve as acting Conference Chairman in the event that the Chairman is unable to carry out the duties of that office,

B. perform other duties assigned by the Conference Chairman,

C. Serve on the Executive Committee.

\section{SECTION 3 - VICE CHAIRMEN}

The Conference Vice Chairmen preside over sessions of the meetings of the Conference as assigned by the Conference Chairman and assist the Chairman in the discharge of his or her duties.

\section{SECTION 4 - EXECUTIVE SECRETARY}

The Executive Secretary acts as the executive officer of the Conference, the secretary and executive officer of the Executive Committee, and the non-voting secretary 
to each standing committee; handles all details in connection with the arrangements for and the programs of the meetings; keeps the records of the proceedings of the meetings; manages the Conference administration and finances as prescribed in its Administrative Procedures; and certifies to the Treasurer the correctness of bills submitted to the Conference for payment.

\section{SECTION 5 - TREASURER}

The Treasurer receives and accounts for all monies collected and pays all Conference bills certified by the Executive Secretary as correct.

\section{SECTION 6 - CHAPLAIN}

The Chaplain performs the customary duties of that office.

\section{SECTION 7 - ASSISTANT TREASURER}

The Assistant Treasurer shall assist the Treasurer in the discharge of his or her duties.

\section{SECTION 8 - PARLIAMENTARIAN}

The Parliamentarian shall assist in assuring meetings of the Conference are conducted according to Robert's Rules of Order and any special rules adopted by the Conference.

\section{9 - PAST CHAIRMAN}

The most recent still-active Past Chairman will serve as: (1) Chairman of the Executive Committee when it sits as the Board of Governors for the National Type Evaluation Program and also as (2) Chairman of the Nominating Committee.

(Added 1991)

\section{ARTICLE V - COMMITTEES}

\section{SECTION 1 - ANNUAL COMMITTEES}

The Annual Committees consist of the following:

A. Nominating Committee. The Nominating Committee shall consist of seven members.

B. Resolutions Committee. The Resolutions Committee shall consist of seven members. Whis 15 operatus as a 3 ved commttee)

C. Auditing Committee. The Auditing Committee shall consist of three members. (This 8 iton operating

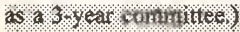

D. Associate Membership Committee. The Associate Membership Committee shall consist of not less than five nor more than ten members, appointed by the Conference Chairman from the associate membership. This Committee shall represent a cross-section of interests within the associate membership. Who 6 s operating as a standing (cotrnttie -

\section{SECTION 2 - STANDING COMMITTEES}

The standing committees are:

Executive Committee;

Committee on Specifications and Tolerances;

Committee on Laws and Regulations;

Committee on Education, Administration, and

Consumer Affairs;

Committee-en-Liaisen;

Finance Committee; and

Credentials Committee.

A. Membership (other than Executive, Finance, and Credentials Committees)

The membership of each of the standing committees is a normal complement of five members appointed by the Conference Chairman from the active membership (except that the mentors of the cammitter on Linson may be appointed from the active a d tsoly, or assoctate mermbershin) on a rotating basis for five-year terms, or until a successor is appointed. Hact, stanting commiftee

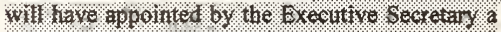

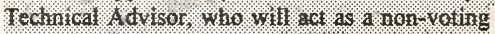
meriber of that cominitec

When it is necessary to make an appointment to any of the standing committees to fill a vacancy caused by the death, resignation, or retirement from active service by a committee member, the appointment is for the unexpired portion of the member's term.

Except as noted, each standing committee annually selects one of its members, preferably its senior member, to serve as its chairman.

At his or her option, the Chairman designates one or more advisory or associate members as consultants to a standing committee.

\section{B. Executive Committee}

The Executive Committee consists of the President, Executive Secretary, the Conference Chairman, the Chairman-Elect, the most recent still active Past Chairman, the Treasurer, and six members elected at large from the active membership, the latter to serve 3-year staggered terms. 
The President and Executive Secretary do not have votes on matters before the Executive Committee.

Insofar as possible, the Nominating Committee, in recommending candidates for the Executive Committee, shall consider regional representation.

The term of the Executive Committee runs from the adjournment of the Annual Meeting at which its members are elected through the succeeding Annual Meeting of the Conference.

\section{Finance Committee/Budget Review Camaittee}

The Finance Committee, which shall also serve as the Budget Review Committee, shall be appointed by the Conference Chairman. It shall consist of him/her as Chairman, two weights and measures officials as voting members (each with a two-year term), and the Treasurer and Executive Secretary as ex-officio voting members. One associate member shall serve in an advisory capacity, without vote.

\section{Credentials Committee}

The Credentials Committee shall consist of three members all of whom are appointed by the Conference Chairman from the active membership, and shall consist of one member each from a State, county, and city jurisdiction, serving on a rotating basis for 3-year terms (a new member appointed each year to replace the member whose term expires). The senior member serves as Committee Chairman.

\section{SECTION 3 - SPECIAL COMMITTEES, TASK FORCES, AND STUDY GROUPS}

Special committees, task forces, working groups, and study groups are appointed by the Conference Chairman from the active, advisory, or associate membership, in any combination, as the need arises or the Conference requests. These groups watz be given directions and an operating line of authority to one of the standing committees within the Conference.

\section{SECTION 4 - SUBCOMMITTEES}

Upon recommendation of a committee, the Conference Chairman may appoint a subcommittee(s) to assist the committee in carrying out its responsibilities.
SECTION 5. APPOLNTMENS TO WORKWG GROUPS, TASK FORCES, SURCOMMITTEES, AND TEE NATIONAL TYPE EVALUATION TECHNICAL. COMMITTER

1. Shart Tema Groups. Appointments of Active. Associate, or Adyisory members to working grotups or task forces are for htie furation of the project(s) to meet the obfective(s), the NOWM Chairman will appoint the nembers witer the group is fommed. The isstres and casks of these groups are self-fimiting in nature, the working grotips willt be ditsbarded when the tasks are completed and the ofjectives met. Aff members have voting rights. The NCWM Chatman appoints the members with the advice of the committee to whish the group will report

2. NTETC Sectors. The membershep and voting status of the National Type Evaluation Technical Committee watl be as follows:

a. Associate Members. The NOWMI Chaiman walf appoint new Associate members on Ite advice of the sector chamman and technical advisor. There is no fixed term for this representation; the associate member wi珜 serve untiz removed by the Chairnan. by the sponsoring company, or when the nember resignts, If one company owns another, of if two companies are owned by the same parent company, only one vote per parent company watl be permitted. The company (ies) involved witf decide who witf vole

b. Active Members.

(1) Participating Laboratory Representation. The NCWM Chairman will appoint a representative from every NTEP Pattcipating Laboratory contucting evaluations in the particular device sector. There wall be no fixed ferm for this representation.

(2) S\&T Committee Representation. The NCWM Chatman will oppoint a reptesentative froat the S\&T Committee, based on the fecommentation of the S\&r Commitee. Whe term of this member will be concurrent with hisher membership on the S.8T Comonitree.

(3) Other Active Member Representation Additional active members may be appointes by the NCWM Chamman with the advice of the technical committee sector Chair and cechnical advisor. If financially feastble, the NCWM will undenwrite thetr participation to 
provide additional weights and measures perspective.

c. Advisury Members. The NCWM Chasmman will appoint appropriate representation from Federat agencies with the idvice of the Chair of the sector and is ledhical advisor. Ite Exectitive Secretary will appoint a lechnical advisor. Advisory menbers have voling rights within the sector

Allough the chaiman well appoint nenbers, an appointed representative may destgnate an alternate with fill yoting rights witenever aecessary:

\section{SECTION 56 - DUTIES AND FIELDS OF OPERA- TION OF COMMITTEES}

\section{A. Executive Committee}

The Executive Committee, subject to the overriding authority of the Conference itself:

1. selects the place, dates, and headquarters, and fixes the registration fee for each meeting of the Conference;

\section{2. fixes the annual membership fee; See Item 1021}

3. may, at its option, fill any vacancy in any elective office of the Conference caused by death, resignation, or retirement from active official regulatory service; and

4. advises the Executive Secretary with respect to the programs for the meetings of the Conference and its committees, and makes recommendations to the Conference, the Conference officers, and the committee chairmen.

The Executive Committee, in the interval between meetings of the Conference:

1. authorizes Interim Meetings of Conference committees as needed;

2. authorizes committee and other contingent expenditures (including travel and subsistence expenses of committee members and the Conference Chairman), and

3. acts for the Conference in all routine or emergency situations that may arise.

Each newly constituted Executive Committee joins the new chairmen of standing committees in a breakfast meeting (as guests of the Conference) on the last day of the Conference, for general discussion and for transaction of business by the Executive Committee.

Questions before the Executive Committee are decided, whether by voice vote or ballot, on the basis of the majority of votes cast.

The Executive Committee:

1. serves as the Board of Governors for the National Type Evaluation Program (NTEP);

2. utilizes the technical committees of the NCWM to resolve technical issues regarding NTEP;

3. utilizes the industry members of the Technical Committee on National Type Evaluation, who will comprise the NTEP Advisory Committee and who will represent the interest of industry, in advising the Board of Governors.

The Committee serves as a policy and coordinating body in matters of national and international significance which may include such areas as metrication, International Organization of Legal Metrology (OIML), American National Standards Institute (ANSI), International Organization for Standardization (ISO), American Society for Testing and Materials (ASTM), National Conference of Standards Laboratories (NCSL), and such internal matters as may be required.

The Committee annually presents a report to the Conference on its activities, which are subject to Conference ratification.

\section{B. Committee on Laws and Regulations}

The Committee on Laws and Regulations annually presents a report for Conference action.

Its scope embraces all matters within the area of weights and measures supervision including:

1. the development and interpretation of uniform laws and regulations;

2. the study and analysis of bills for legislative enactment; and

3. the establishment and maintenance of published guidelines and other effective means of encouraging uniformity of interpretation and application of weights and measures laws and regulations.

4. liaison with Federal agencies, State agencies, and other groups or organizations on issues within the purview of the Committee. This role involves ex- 
plaining, advocating, and coordinating Conference positions, recommendations, and needs before Federal Government agencies, consumer groups, the associate NCWM membership, the retiree membership, domestic and international standards organizations, industry, trade associations, and others. The goals are to provide and solicit information, develop a spirit of cooperation, and promote uniformity with the activities and standards of the NCWM.

\section{Committee on Specifications and Tolerances}

The Committee on Specifications and Tolerances annually presents a report for Conference action.

Its scope embraces all matters dealing with:

1. specifications, tolerances, and technical requirements of any kind relating to scales, weights, measures, and weighing and measuring devices and accessories, including interpretation of such material whenever necessary,

2. standards and testing equipment for weights and measures officials, and

3. procedures for testing commercial equipment.

4. liaison with Federal agencies, State agencies, and other groups or organizations on issues within the purview of the Committee. This role involves explaining, advocating, and coordinating Conference positions, recommendations, and needs before Federal Government agencies, consumer groups, the associate NCWM membership, the retiree membership, domestic and international standards organizations, industry, trade associations, and others. The goals are to provide and solicit information, develop a spirit of cooperation, and promote uniformity with the activities and standards of the NCWM.

D. Committee on Education, Administration, and Consumer Affairs

The Committee on Education, Administration, and Consumer Affairs annually presents a report for Conference action.

Its scope embraces all matters dealing with the:

1. education and training of weights and measures officials,

2. promotion of weights and measures principles and techniques among the general public and the users of weighing and measuring devices,
3. development and recommendation of administrative procedures and public relations programs, and

4. identification of commercial weights and measures practices and problems that are of concern to consumers.

5. liaison with Federal agencies, State agencies, and other groups or organizations, especially consumer groups, on issues within the purview of the Committee. This role involves explaining, advocating, and coordinating Conference positions, recommendations, and needs before Federal Government agencies, consumer groups, the associate NCWM membership, the retiree membership, domestic and international standards organizations, industry, trade associations, and others.

The goals are to provide and solicit information. develop a spirit of cooperation, and promote uniformity with the activities and standards of the NCWM.

E. Committee-on-Liaisen-

The-committeo-on-Liaicon-annully presents-a-report for Conforenco-action. Its mission is divided into-two gategorios as follows:

1. Liaisen-with-Foderal-Agencies.

Intergovental-(with NISTAUS-

DA/FDA/FTCADOD/Postal Service,-otc) centacts and relations-on behalf of the-Conference. This role involves-oxplaining, advocating, and-coordinating Conference-pesitions, rocommendations, and neods before-Foderal Government-agencies-and promoting uniformity among those-agencies and-with the NGWM4.

2. Liaisen-with-Other-Groups-or-Organizations-and Agencies.

This rolo-involves public liaison-with-consumer groups, the-asseciate NCWAM membership, the retiree memberchip, demestic and international-standards organizations, industry, trado-asseciations, and-others.

The-goals aro to provide-and-solicit infomation, dovelop-a-spirit-of cooperation, and premete-uniformity with the activities of the NCWA.

\section{F. Nominating Committee}

The Nominating Committee annually presents a slate of nominees for all elective offices. The names of these nominees shall appear in the report of the Nominating Committee and be published in Conference Announcement Book (NCWM Publication 16). 


\section{G. Resolutions Committee}

The Resolutions Committee annually presents for Conference action such resolutions as it has been directed by the Conference to prepare, and such additional resolutions as are deemed appropriate by the Committee.

\section{H. Auditing Committee}

The Auditing Committee annually audits the books of the Treasurer and reports its findings to the Conference.

\section{Credentials Committee}

The Credentials Committee administers the Conference voting system, makes decisions conceming disputed rights of designated representatives, and approves or certifies representatives to the House of State Representatives.

\section{J. Finance Committee/Budget Revtew Coramiloe}

The Finance Committee oversees the financial responsibilities of the Conference and serves as the Budget

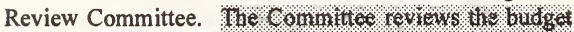
proposed by the Exectitice Secretang and nolkes

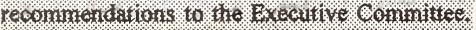

\section{K. Associate Membership Committee}

The Associate Membership Committee annually reports on its activities and makes recommendations to the Executive Committee.

The Committee provides coordination and participation of associate members in all business and social affairs of the Conference.

\section{ARTICLE VI - VOTING SYSTEM}

All questions before a meeting of the Conference that are to be decided by a formal recorded vote of the active members are voted on in accordance with the following voting structures and procedures.

\section{SECTION 1 - HOUSE OF STATE REPRESENTA- TIVES}

\section{A. Official Designation}

This body of officials shall be known as the "House of State Representatives."

\section{B. Composition}

Each State is authorized one official to serve as its representative at the Annual Meeting of the NCWM. The State weights and measures director, or his or her designee (State or local government official), is the State representative.

The District of Columbia and the U.S. Commonwealths and Territories that have weights and measures programs similar to those of the States (for example, have followed the uniform laws and regulations and have adopted Handbook 44) are also allowed representatives.

\section{Method of Designation}

Each representative is specified annually to the Credentials Committee 30 days before the NCWM annual meeting. Accommodation may be made for exceptions to this deadline. An alternate should be named prior to the NCWM annual meeting in case the designated representative cannot attend.

\section{SECTION 2 - HOUSE OF DELEGATES}

\section{A. Designation}

All other State and local weights and measures regulatory officials (those not sitting in the House of State Representatives) are grouped as a body known as the "House of Delegates."

\section{B. Requirements}

No other special requirements apply.

\section{SECTION 3 - MINIMUM VOTES}

\section{A. House of State Representatives}

A minimum of 27 votes in favor of, or 27 votes in opposition to, an issue must be cast for the vote to be considered official. If 54 or more votes are cast in the House of State Representatives, a majority of the total votes is required to pass or defeat the issue.

\section{B. House of Delegates}

A minimum of 27 votes in favor of, or 27 votes in opposition to, an issue must be cast for the vote to be considered official. If more than 54 total votes are cast, a simple majority rules. Should a tie vote occur, or if the minimum votes in support or opposition are not cast, the issue is decided by the vote of the House of State Representatives. 


\section{SECTION 4 - VOTING RULES}

\section{A. Proxy Votes}

Proxy votes are not permitted. Since issues and recommendations in the committees' interim reports are often modified and amended at the Conference, the attendance of officials at the NCWM Annual Meeting and voting sessions is vital.

\section{B. Method}

All voting is by a show of hands, standing vote, or machine (electronic). There shall be no voice voting. No abstentions are permitted.

\section{Timing}

Voting by both Houses is simultaneous.

\section{Recording}

The voting system is designed to record the votes of the State representatives whether an electronic system, show of hands, or standing vote is used.

\section{E. Applicability}

These procedures (rules) apply only to the plenary (general) sessions of the NCWM.

\section{SECTION 5 - COMMITTEE REPORTS}

Alternatives that may be used in voting on the reports:
A. vote on the entire report,
B. vote on grouped items or sections calfed the "Consent Calendar", or

C. vote on individual items; according to

1. committee discretion, or

2. on request by a voting delegate, with the support of 10 others.

\section{SECTION 6 - FLOOR AMENDMENTS}

\section{A. Amendments}

Committee chairmen are allowed to offer amendments on the day of voting to make editorial changes in their final reports.

\section{B. Changes}

Substantive changes can be made at the request of weights and measures officials only, and:

1. a majority of the voting delegates of each House must vote favorably before a proposed amendment can be accepted for debate.

2. A two-thirds favorable vote of each House on the amendment is required for passage (the requirement for a minimum vote of 27 in both Houses also applies).

\section{SECTION 7 - SEATING}

\section{A. Arrangement}

The seating arrangement for voting sessions is shown in Figure 1.

\section{B. Supervision}

The members of the Credentials Committee will count votes and control placement and movement of delegates.

\section{SECTION 8 - VOTING}

At the conclusion of debate (if authorized) on a motion, there shall be a call for the vote by a show of hands, standing, or electronic count.

\section{A. Motion Accepted If:}

1. a minimum of 27 members of the House of State Representatives votes Yea.

And If

2. a majority of the members of the House of Delegates votes Yea (a minimum of 27 Yea votes required); ${ }^{1}$

\section{B. Motion Rejected If:}

1. a minimum of 27 members of the House of State Representatives votes Nay

And If

2. a majority of the members of the House of Delegates votes Nay (a minimum of 27 Nay votes required); ${ }^{2}$

'If the minimum number of votes required to pass or fail an issue is not cast in the House of Delegates, the issue will be determined by the vote of the House of State Representatives.

${ }^{2}$ If the minimum number of votes required to pass or fail an issue is not cast in the House of Delegates, the issue will be determined by the vote of the House of State Representatives. 
C. Split Vote:

When the two Houses split on an issue or the minimum number of votes supporting or opposing an issue is not obtained in the House of State Representatives, the issue is returned to the standing committee for further consideration.

The committee may drop the issue or reconsider it for submission the following year. The issue cannot be recalled for another vote at the same Annual Meeting.

\section{SECTION 9 - PROCEDURES}

The Conference officers and committees observe in all of their procedures the principles of due process -- the protection of the rights and interests of affected parties; specifically, they (a) give reasonable advance notice of contemplated committee studies, items to be considered for committee action, and tentative or definite recommendations for Conference action, for the information of all parties at interest, and (b) provide that all interested parties have an opportunity to be heard by committees and by the Conference.

\section{SECTION 10 - CHANGES IN ORGANIZATION AND PROCEDURE}

Proposals for changes in organization or procedure of the Conference are not acted upon until the Annual Meeting of the Conference following the Annual Meeting at which such proposals are made.

\section{Front of Room}

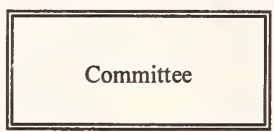

Credentials

Committee
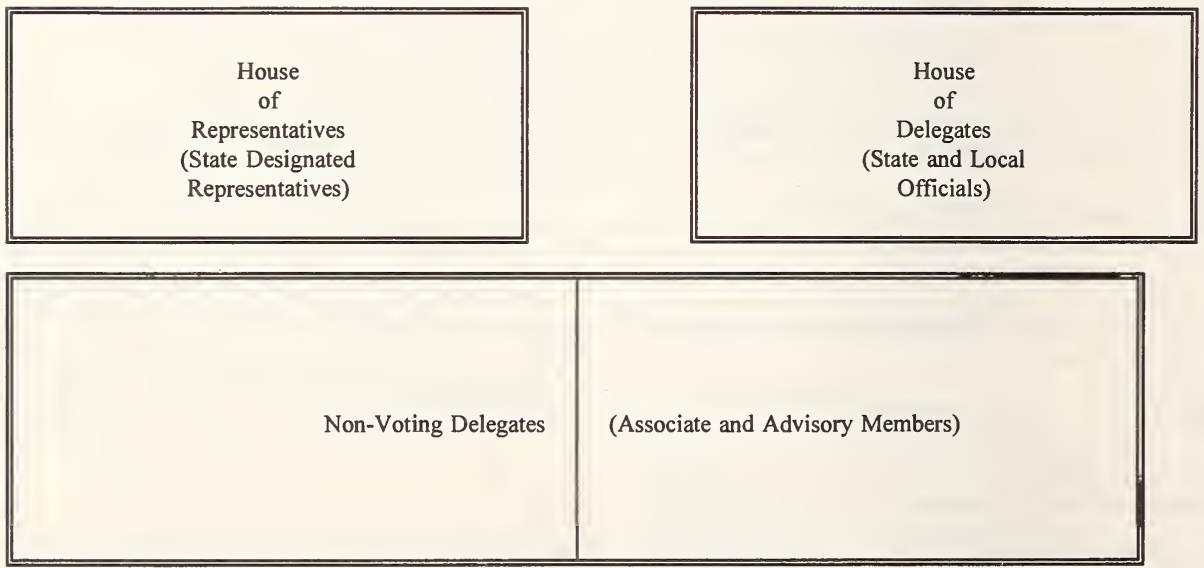

Figure 1. Seating Arrangement. 


\section{Appendix E - Letter to the Interstate Commerce Commission}

Interstate Commerce Commission

Applications Unit

Washington DC 20423

Sirs:

This letter concerns the Petition for Declaratory Order filed on behalf of Yellow Freight System Inc. of Indiana, Docket No. 40853.

\section{The National Conference on Weights and Measures}

The National Conference on Weights and Measures (NCWM) is a standards development organization founded in 1905 and sponsored by the National Institute of Standards and Technology (NIST) (formerly the National Bureau of Standards) and representatives of public and private organizations and citizens that comprise the 3100 NCWM members.

\section{National Standards for Commercial Weighing Accuracy}

The standards of accuracy for commercial and other weighing devices contained in NIST Handbook 44 "Specifications, Tolerances, and Other Technical Requirements for Weighing and Measuring Devices," referred to by Yellow Freight's petition, have been adopted by all fifty States, the District of Columbia, and all U.S. territories, several Federal agencies, including the Federal Grain Inspection Service, the Food Safety and Inspection Service, and the Packer and Stockyards Administration of the U.S. Department of Agriculture, and many national associations including the Association of American Railroads. Thus, the NCWM contends that the standards applied are not an undue burden on interstate commerce, because all States and many Federal agencies regulating marketplace equity apply the same standards. Vehicle on-board weighing systems, which include forklift scales have been addressed by the NCWM over the past 2 years and specific requirements adopted to apply to these devices (see enclosure).

\section{States Do Not Contest Practices or Fees; They Do Contest Use of Inaccurate Devices for Commercial Purposes}

The States object to the Yellow Freight request that "Scales used for verification purposes will be accurate within a $1 \%$ tolerance and need not be certified as 'Legal for Trade'." The States do not challenge or contest the practice to reweigh, the fees set for reweighing, or any other terms or conditions under which Yellow Freight weighs any shipment upon request or at its own discretion.

Any measuring device used to set charges are defined as commercial, not just those "held out to the public for usage in trade." Yellow Freight uses their forklift scales to set charges.

Yellow Freight says the forklift scales are "capable of calibration to $1 \%$ "; they do not say what the company's practices are to determine that even this accuracy is maintained; many States have found that these scales do not meet the $1 \%$ claimed tolerance.

The States do not require that Yellow Freight use a public weighmaster, which ICC references that freighters may use wherever available. What the States and Federal Agencies require is to use devices which meet commercial accuracy requirements to determine the weights upon which charges will be assessed. These requirements apply to whatever the means of freight movement might be - trucks, vans, railroads, airplanes, etc. 
The States do not contest the use of forklift scales by Yellow Freight for determining which shipper's loads need reweighing on a commercially accurate scale in order to reassess the freight charges. These commercial scales (usually "floor scales") are in place in locations of competitors of Yellow Freight, many of which work out of physically smaller shipping facilities.

Shippers assume a fair and equitable marketplace where measurements made for service charges are accurate enough for the purposes. All competing freight movers must comply with the accuracy requirements of commercial weighing devices. If different accuracy requirements apply to different freighters, the confusion that will result and the free license to operate with whatever the freighter believes is "fair" is inimical to businesses being able to take for granted the fairness of competing services. The States ensure that measuring equipment meet applicable standards by inspecting the equipment. No other agency, Federal or State, has the resources to assure such compliance. If the ICC preempts the States, who will assure that the freight companies comply with whatever standards ICC adopts?

\section{The NCWM Welcomes the Opportunity to Work with the ICC to Address This Issue}

If the ICC or freight companies believe commercial tolerances are too tight, the NCWM has due process mechanisms to publicly work with all affected parties to adjust the standards. Yellow Freight's forklift scale supplier, WeighTronix, advised Yellow Freight to provide justification for a larger tolerance for the entire freight industry. The NCWM Specifications and Tolerances Committee reviewed this issue in 1992 (see enclosed reports). As the reports suggest, since equipment is available that can meet commercial weighing standards, they were not persuaded that larger tolerances for a single type of weighing technology should be allowed for commercial service fee determination. We welcome, however, your input and advice on this matter, so that your interests, as well as the interests of other Federal agencies, competitor freight companies, shippers, device manufacturers, and the public can be heard.

State weights and measures agencies have the only field enforcement staff in the nation to assure that national standards of accuracy and performance for commercial measuring equipment are met. They share concurrent jurisdiction with Federal Agencies in many Federal laws, including the Federal Fair Packaging and Labeling Act, the Nutrition Labeling and Education Act, the Wholesome Meat Act, and the Wholesome Poultry Products Act. Rather than Federal preemption without means to enforce your agency's standards and thus to provide a fair marketplace in which freight companies can equitably compete, we recommend that the ICC and/or freight companies work with the NCWM to develop new standards or to affirm existing standards which are fair to all affected parties.

We welcome any comment or advice the ICC would care to provide; we urge you to work within the national standards development process provided by the NCWM, as the ICC has done in the past. Thank you.

Sincerely,

Carroll S. Brickenkamp, Ph. D.

Executive Secretary, NCWM

Chief, Office of Weights and Measures, NIST

cc: Mr. Sidney L. Strickland, Jr., Secretary, ICC

Mr. Lawrence W. Bierlein, Esq., Shaw, Pittman, Potts \& Trowbridge

Mr. Jerry C. Bowlin, Managing Attorney, Yellow Freight System, Inc. of Delaware

Mr. Constantine V. Cotsoradis, Weights and Measures, Maryland Department of Agriculture

Mr. Robert Gronowski, Division of Plant Industry, Nevada Department of Agriculture

Mr. Bill Murphy, Field Operations, Weigh-Tronix, Inc.

Mr. Allan M. Nelson, Chairman, NCWM

Executive Committee, NCWM

Specifications and Tolerances Committee, NCWM

Liaison Committee, NCWM 


\section{Appendix F \\ U.S. - Canada Mutual Recognition Meetings \\ Meeting on Harmonization for U.S. Interests \\ November 9/10, 1992}

The NCWM held a meeting to ascertain the direction and extent that public and private sector members of the NCWM desired to go in working with Canada in the area of legal metrology.

Background: Representatives of the Legal Metrology Branch (LMB) Canada had participated in and observed the process of the NCWM for several years.. LMB Canada staff had contributed substantively to ongoing work of the Specifications and Tolerances (S\&T) and the Laws and Regulations (L\&R) Committees. Representatives of NIST's Office of Weights and Measures (OWM) had attended meetings of LMB Canada specialists in weighing, measuring, and package testing.

In 1989, the Executive Secretary of the NCWM and the Chief of Canada's LMB sent out coordinated memoranda to their respective weighing and measuring industries asking what were the "irritants" that prevented easy trade across U.S. and Canadian borders. A set of letters loosely termed "harmonization" issues set the agenda for the S\&T Committee for the next 2 years. The approach taken was to study the particular requirement in Handbook 44 and in the parallel Canadian document and determine whether a single requirement could be devised that would eliminate the "irritant." Nine items were discussed in the S\&T 1992 Report related to these identified irritants. Because the industry had set the agenda, the NCWM had presupposed that the S\&T approach was endorsed by the private sector. It became clear at the 1992 Annual Meeting. That the membership (1) did not see the several issues as related and part of the overall agenda set by disparate private sector suggestions of what were trade irritants (even though the S\&T Interim Report introduced each issue as resulting from discussions with LMB Canada; and (2) was unwilling to adopt the committee recommendation on one issue which affected field enforcement techniques (the shift test). Discussions with different segments of industry also confirmed that they did not understand that they had been asked to set the agenda for the S\&T Committee. The NCWM therefore decided to specifically determine direction on the "harmonization" issue and the objectives of international cooperative work.

\section{Objectives and Conclusions:}

1. To formulate NCWM objectives with respect to discussions with Canada.

The U.S. scale industry and leaders of the NCWM were present at this meeting, but no representatives of the metering industry.

2. Should U.S. and Canadian device requirements be harmonized?

The industry present at this meeting did not consider differences between scale requirements in the United States and Canada to be a trade barrier; the differences are not of sufficient importance to justify harmonization (elimination of conflicting or different requirements). Five letters were submitted by those who did not attend the meeting: all but one of these letters favored harmonization of the device requirements. These letters did not have a significant impact on the final positions.

Entering the market of another country is purely a business decision on the part of the device manufacturer. Difference in device requirements are simply part of the business decision.

The industry considers the type evaluation process to be a trade barrier. Ideally, the United States and Canada should seek to develop harmonized type evaluation tests. The United States and Canada should at least develop reciprocal testing recognition so that a Canadian test can be performed in the United States and a United States test performed in Canada.

A formal statement of purpose and objectives should be the outcome of the next meeting with Canada in December.

3. Should harmonization with OIML recommendations or with other nations be included in the discussions? 
The industry present stated that U.S. requirements are already harmonized with OIML as far as is necessary for the United States, but the United States should still work on influencing OIML recommendations with respect to their philosophy and practice. In light of the North American Free Trade Agreement, Mexico should be involved as early as possible in the discussions. It was suggested that users of weighing devices want to be able to buy one type of scale that would be accepted for use in all countries in which international users operate.

A second meeting with representatives of LMB Canada was scheduled to determine whether the U.S. objectives would serve the purposes of Canada, and whether work between both nations had enough priority to both to pursue.

\section{List of Participants:}

Carroll Brickenkamp, NIST Office of Weights and Measures, NCWM Executive Secretary, chair

Public Sector:

Tina G. Butcher, NIST Office of Weights and Measures Samuel E. Chappell, NIST, Standards Management Program

Tom Geiler, Hyannis, MA, NCWM Chairman-Elect

John Lacy, USDA Packers \& Stockyards, NCWM Liaison Committee

Allan Nelson, Connecticut, NCWM Chairman

Henry Oppermann, NIST, Office of Weights and Measures

Louis E. Straub, Maryland, NCWM L\&R Committee

Otto Warnlof, NIST, Standards Management Program
Private Sector:

Norm Brucker, B.N. Railroad, AAR

R.T. Brumbaugh, Systems Associates Inc Roger Hadaway, MTA Group Terry James, Cardinal Scale Mfg

Kenneth J. Knapp, Milltronics Inc

David Quinn, Fairbanks Scales

Robert A. Reinfried, Scale Manufacturers Assn

Tom Stabler, Mettler Toledo

Daryl E. Tonini, Scale Manufacturers Assn 


\section{U.S. - Canada Meeting}

December $9 / 10,1992$

The objective of this meeting was to determine the extent to which Canada and the United States legal metrology communities were willing to explore reduction of trade barriers between them. Both the U.S. and Canadian representatives agreed to the objective of achieving mutual recognition of type evaluation tests performed either by U.S. NTEP Participating Laboratories or by LMB Canada. An NCWM U.S. - Canada Working Group on Mutual Recognition of Type Evaluation will be established of representatives of LMB Canada, NTEP Participating Laboratories, the S\&T Committee, and NIST Office of Weights and Measures. NCWM Industry members will be sent agenda and reports of the meetings, and will be encouraged to observe and participate. A meeting will be held in the spring of 1993 and another meeting at least to report the status and progress at the Annual Meeting. The group agreed on the following:

With respect to weights and measures devices, the parties agree that the most effective means to remove barriers to free trade is to achieve mutual recognition of device type evaluation testing. This will necessarily involve the comparative analysis of type evaluation test procedures together with the intent of streamlining and minimizing differences insofar as possible to make efficient device evaluation possible while preserving the technical capability and competence of their mutual laboratories.

The meeting concluded with a brief exploration of the technical issues that would have to be addressed in future meetings.

Background: An extensive review of Canadian priorities was presented by Mr. Robert Bruce, Chief, Legal Metrology Branch of Canada. LMB Canada is in the midst of work to reform their regulations pertaining to weighing and measuring devices. Canada is also working to fulfill its obligations under the U.S./Canadian Free Trade Agreement. Canada, too, wants to enhance trading opportunities, not only with the United States but with other nations. If wants to influence standards developments, share expertise, equipment, and facilities, reduce costs and time for device manufacturers, and reduce government expenditures, while at the same time, each nation maintains its level of expertise.

\section{Type Evaluation Tests or the Codes on Which They Are Based}

One major concern was how the United States and Canada could have compatible type evaluation test procedures without compatible base requirements. This rationale was used by the S\&T Committee in its recommendations to the NCWM this past year. However, the industry present indicated that difference in codes is not the barrier to trade, but that type evaluation is a barrier. Individuals pointed out that certain national requirements might appear to be identical on paper, but that, if the tests to determine compliance are not compatible or coherent, there is still a substantial trade barrier. It was generally conceded that the regulations themselves would have to be part of the discussion and work, but the overall goal should not be the harmonization of documented requirements, but the equivalence of type evaluation tests by the different nations.

Both the U.S./Canada Free Trade Agreement and the North American Free Trade Agreement (the latter including Mexico) require that

no party shall adopt, maintain, or apply any standards-related measure that will create an unnecessary obstacle to trade between the parties;

each party shall use, as a basis of standards-related measures, international standards except where they would be an ineffective means to fulfill legitimate objectives [for example, the climatic factors in Canada.]

For this reason, LMB Canada and the United States had earlier discussed the OIML requirements when the two nations had differed with respect to the issues before the S\&T Committee last year. Although the S\&T Committee had recommended a few changes to Handbook 44 as a result of these discussions, and Canada had agreed to make even more changes, the process for change in Canada is more involved, usually taking about 5-6 years. Parliament must change the law, the ministers must adopt regulations to implement the law, and the executive agency can implement policy with due process protected through publication and review of the policies. Even if the nations would agree to harmonization of base requirements, such as the $\mathrm{H} 44$ Scales Code, some mechanism would be needed to keep them harmonized, since the NCWM reviews and revises H44 annually and Canada follows a different revision process. 


\section{Joint Resources and Canada's Unique Capabilities}

Canada has an extensive executive agency in legal metrology, however, with professional engineers at headquarters, 15 approval technologists, 5 regional offices, 25 district offices, and approximately 160 field personnel receiving a minimum of 9 weeks formal basic training. Even with this enforcement staff, instead of annual device inspection, Canada operates a targeted inspection program, depending upon the history of compliance. It has extensive resources which it is prepared to share in the work of type evaluation mutual recognition. However, Canada cannot afford to lose the expertise it has developed if type evaluation business is diverted to the United States, and so a minimum amount of work must be guaranteed for the Canadians in any resulting work sharing.

\section{Exploration of Technical Issues}

The following discussions were held in order to get a perspective on what had to be done, not to make definitive decisions.

Basic Tolerance Structure. Canada would like to adopt a step tolerance like OIML and the United States. Why did the United States adopt an extra step, called Class IIIL? Daryl Tonini (SMA) responded that the United States felt that the load cell technology at the time OIML adopted its tolerance structure would not have permitted more than a $3000 \mathrm{~d}$ load cell. The United States believed that it was just a matter of time before $5000 \mathrm{~d}$ cells would be available and the United States wanted to recognize this technology. Henry Oppermann (NIST) commented that marketing and manufacturing forces confused resolution with accuracy, and that they demanded a 10,000d load cell. Due to temperature and return to zero requirements, load cell manufacturers simply couldn't deliver such a cell, but the marketplace already had it in place in the United States Canada would limit the capacity of large scales because OIML places limits on the maximum number of divisions, or else would make device manufacturers unhappy because they will not be able to provide very large capacity scales with very small division sizes. These are the trade-offs. The OIML steps are a trade off and a compromise, too. However, we assume that the Canadian marketplace is more like that of the United States than Europe. Moreover, it is hard to convince weights and measures regulatory agencies that Class IIII is legal for trade.

However, it is generally said that OIML tolerances are more stringent than U.S., and this is not true for $10000 \mathrm{~d}$ load cells. The return to zero test and the temperature susceptibility tests are very severe and few load cells can meet these U.S. requirements.

Temperature Testing. Testing scales and load cells over a range wider than -10 to $40^{\circ} \mathrm{C}$ was discussed in an effort to cover a wider range of outdoor environments in the northern U.S. and Canada. The industry indicated that the temperature range of -10 to $40^{\circ} \mathrm{C}$ was based upon European weighing practices, but it represents the range of temperatures needed to satisfy most commercial and industrial applications. To lower the cold temperature range to -20 or $-30{ }^{\circ} \mathrm{C}$ would cause costs to go up significantly. It was stated that it may be impossible (but, if not impossible, certainly more expensive) for conventional load cells to perform over the entire temperature range within the tolerances specified in OIML and Handbook 44. Any change to the temperature range should be assessed based on the need to correct measurement problems in comparison to the additional costs that would be incurred.

Electromagnetic Interference (EMI). The procedure of using hand-held transceivers to test for EMI susceptibility is known to lack repeatability and generates varying EMI field strengths around the scale that is subject to the test. There are many sources of EMI in the environment, and the number of sources increases daily. The field strength of EMI is also increasing. Scales must be able to withstand EMI.

The industry reported that designing equipment to meet the OIML standard at a field strength of $3 \mathrm{mV} / \mathrm{V}$ is difficult. However, the $3 \mathrm{mV} / \mathrm{V}$ field strength is a reasonable reflection of the "real world" environment. Manufacturers realize that equipment must resist EMI, but agree that there is great inconsistency in the test results from one laboratory to another, even if the tests are conducted in an anechoic chamber. The lack of correlation is due to the many variables that can affect the susceptibility of equipment. The lack of correlation in test results among sophisticated laboratories has led to the industry conclusion that the tests are not controllable or repeatable among different laboratories. Consequently, the industry does not support establishing a sophisticated EMI laboratory, because the results will not be conclusive for environments outside the EMI chamber in which the tests were conducted. The scale manufacturer must correct problems that occur in the field even if devices have passed the laboratory test.

Electrostatic Discharge and Electrical Bursts. Electrostatic discharge (ESD) usually results in the operational failure of a device. While continuous ESD pulses can affect the accuracy of a device, this is not a "real world" condition and is not significant enough to justify the test. 
Electrical bursts simulate lighting strikes in the vicinity of the scale installation. Electrical bursts usually result in a loss of memory in the microprocessors and interrupts scale operation. Typically, these are temporary failures. This test is important a country has a poor power supply. This test may be justified in Europe, but is not considered necessary for the United States at this time.

$$
\text { Canada - United States Meeting }
$$

December 10-11, 1992

\begin{tabular}{|c|c|c|c|}
\hline Participants Names & Affiliations & Address & Telephone \& Fax \\
\hline Steven Cook & $\begin{array}{l}\text { California Division of } \\
\text { Measurement Services }\end{array}$ & $\begin{array}{l}8500 \text { Fruitridge Rd. } \\
\text { Sacramento, CA }\end{array}$ & $\begin{array}{l}\text { (916) } 387-4241 \\
(916) 387-4260\end{array}$ \\
\hline Claude Bertrand & Canada LMB & $\begin{array}{l}\text { Standards Bldg Tunney's } \\
\text { Past, Ottawa }\end{array}$ & $\begin{array}{l}(613) 952-3529 \\
(6130952-5405\end{array}$ \\
\hline Renald Marceau & Canada LMB & 301 Laurier Ottawa & (613) 952-2629 \\
\hline Henry Oppermann & NIST & $\begin{array}{l}\text { 101/A617 Gaithersburg, } \\
\text { MD }\end{array}$ & $\begin{array}{l}(301) \text { 975-4008 } \\
(301) 926-0647\end{array}$ \\
\hline Garry Nolan & Federal Express & $\begin{array}{l}2828 \text { Business Park Dr. } \\
\text { Memphis, TN }\end{array}$ & (901) 375-6566 \\
\hline Marty Scanlon & Federal Express & $\begin{array}{l}2828 \text { Business Park Dr. } \\
\text { Memphis, TN }\end{array}$ & (901) $375-6315$ \\
\hline Patrick Nichols & $\begin{array}{l}\text { Alamedia County, } \\
\text { Weights \& Measures }\end{array}$ & $\begin{array}{l}333 \text { 5th Street } \\
\text { Oakland, CA } 94607\end{array}$ & $\begin{array}{l}(510) \\
268-7343 \\
(510) \\
444-3879\end{array}$ \\
\hline Jim Truex & Ohio Weights \& Measures & $\begin{array}{l}8995 \text { East Main Street } \\
\text { Reynoldsburg, OH } 43062\end{array}$ & $\begin{array}{l}(614) 866-6361 \\
(614) 866-4174\end{array}$ \\
\hline Bob Reinfried & SMA & $\begin{array}{l}932 \text { Hungerford Dr. } \\
\text { Rockville, MD } 20850\end{array}$ & $\begin{array}{l}\text { (301) 738-2448 } \\
\text { (301) } 738-0076\end{array}$ \\
\hline Charles H. Carroll & $\begin{array}{l}\text { Massachusetts Weights \& } \\
\text { Measures }\end{array}$ & $\begin{array}{l}\text { One Ashburton Place } \\
\text { Boston, MA }\end{array}$ & (617) $727-3480$ \\
\hline Michael Adams & Fairbanks Scales & St. Johnsbury, VT & $\begin{array}{l}(802) 748-5111 \\
(802) 748-5216\end{array}$ \\
\hline Ted Johnson & Sensortronics & $\begin{array}{l}677 \text { Arrow Grand Circle } \\
\text { Covina, CA } 91722\end{array}$ & $\begin{array}{l}(818) 331-0502 \\
(808) 332-3418\end{array}$ \\
\hline Gary Lameris & Hobart Corp. & $\begin{array}{l}701 \text { Ridge Avenue } \\
\text { Troy, OH } 45374\end{array}$ & $\begin{array}{l}(513) 332-3053 \\
(513) 332-3007\end{array}$ \\
\hline John Steinberger & $\begin{array}{l}\text { Chief, Division of } \\
\text { Weights \& Measures Ohio }\end{array}$ & $\begin{array}{l}8995 \text { East Main Street } \\
\text { Reynoldsburg, OH } 43086\end{array}$ & $\begin{array}{l}(614) 866-6361 \\
(614) 866-4174\end{array}$ \\
\hline John Lacy & Packers \& Stockyards & USDA Washington, DC & $\begin{array}{l}\text { (202) } 720-3140 \\
(202) 690-2173\end{array}$ \\
\hline David Quinn & Fairbanks Scales & Meridian, MS & (601) 483-4311 \\
\hline John Davidson & $\begin{array}{l}\text { Canadian Assoc. of Scale } \\
\text { Manufacturers }\end{array}$ & Toronto Canada & (416) $447-6432$ \\
\hline Tom Geiler & $\begin{array}{l}\text { Barnstable Consumer } \\
\text { Affairs }\end{array}$ & $\begin{array}{l}230 \text { South Street } \\
\text { Hyannis, MA } 02601\end{array}$ & $\begin{array}{l}(508) 790-6251 \\
(508) 790-6454\end{array}$ \\
\hline
\end{tabular}




\section{Executive Committee}

\begin{tabular}{|c|c|c|c|}
\hline Participants Names & Affiliations & Address & Telephone \& Fax \\
\hline Ray Lloyd & SMA & Rockville, MD & (301) 738-2448 \\
\hline R. T. Brumbaugh & Systems Assoc. Inc. & Libertyville, IL & (708) $367-6650$ \\
\hline John Elengo & Revere Transducers & Wallingford, CT & $\begin{array}{l}\text { (203) } 284-5102 \\
\text { (203) } 284-5136 \\
\end{array}$ \\
\hline John W. Reimer & Weigh-Tronix & Santa Rosa, CA & $\begin{array}{l}(707) 527-5555 \\
(707) 527-5517\end{array}$ \\
\hline Tina G. Butcher & NIST & $\begin{array}{l}\text { 101/A617 Gaithersburg, } \\
\text { Md }\end{array}$ & $\begin{array}{l}\text { (301) } 975-2196 \\
\text { (301) } 926-0647\end{array}$ \\
\hline Daryl Tonini & SMA & Rockville, MD & (301) 738-2448 \\
\hline Allan M. Nelson & State of CT & Hartford, CT & (203) 566-5230 \\
\hline Bob Bruce & Canada LMB & Ottawa, Canada & (613) 952-2625 \\
\hline Carroll Brickenkamp & NIST/NCWM & $\begin{array}{l}\text { 101/A617 Gaithersburg, } \\
\text { MD }\end{array}$ & $\begin{array}{l}(301) \text { 975-4005 } \\
\text { (301) } 926-0647\end{array}$ \\
\hline
\end{tabular}




\author{
First Meeting of the \\ U.S. - Canada Mutual Recognition Working Group \\ April 1993 \\ Summary of Decisions
}

1. The Working Group reaffirmed the objective for the mutual recognition of each other's type evaluations and to harmonize requirements and procedures whenever possible. The NCWM policy statement summarizes the objectives. The mandate of the U.S./Canada Working Group is defined as:

With respect to weights and measures devices, the parties agree that the most effective means to remove barriers to free trade is to achieve mutual recognition of device type evaluation testing. This will necessarily involve the comparative analysis of type evaluation codes and test procedures together with the intent of streamlining and minimizing differences in so far as possible so as to enable efficient device evaluation while preserving the technical capability and competence of their mutual laboratories.

2. Mexico is interested in the progress of the Working Group, but does not have a type evaluation program, hence, Mexico is not actively participating in the meetings.

3. The first devices targeted for mutual recognition in type evaluation are bench/floor scales up to a capacity of $500 \mathrm{~kg}$ and digital indicators that may be used with bench/floor scales and vehicle scales. However, specialized software features intended for specific applications are excluded from this initial effort. The objective is to establish mutual recognition for some devices as soon as possible. Price computing scales were excluded from this initial effort because the numerous special features would impede progress toward mutual recognition on more simple devices. Complex devices and new technologies are not subject to the mutual recognition agreement.

4. The Working Group is to review and develop (if practical and feasible) a single checklist by identifying similarities and differences in type evaluation requirements and test procedures, combining the various requirements into a single checklist (which will contain the different requirements for each country), and determining if a single test procedure can be used to satisfy two different, but related, requirements. The Group is to develop recommendations to harmonize requirements whenever this action appears reasonable.

The combined checklist, test procedures, and recommendations to harmonize requirements will be reviewed by LMB and the NTETC Weighing Sector. Type evaluation interpretations and procedures can be changed by decisions of the Weighing Sector, provided they do not conflict with Handbook 44 . Changes to Handbook 44 must go through the Specifications and Tolerances Committee for changes supported by the Weighing Sector. Conversely, modifications to the Canadian Weights and Measures Regulations and Specifications will have to be made in consultation with their Weights and Measures Specialists and the Canadian industry.

5. A jointly agreed program statement describing the initial objectives and operation of this initial effort will be prepared by January 4, 1994.

6. A second generation work plan was developed which outlined tasks and products to be generated and established a time table for the work (attached). The objective is to have an operating, mutual-recognition program for bench/floor scales with a capacity up to $500 \mathrm{~kg}$ and digital indicators by the end of April 1994.

7. Products to be produced include an applicant's guide; a common type evaluation application for the devices being addressed; an instruction manual for the laboratories; a single, combined checklist for use by both countries; and common work sheets and report forms to aid in evaluating the test results.

8. The laboratory that performs the tests should address, with the device manufacturer, any deficiencies of the device that are clearly defined in the checklist. When questionable issues arise, the managing staff of the affected country (or countries) should be consulted. Complex features or devices, and devices with new features and new technology will probably have to be evaluated by both countries. The final decision regarding compliance with each country's requirements will be made by the representatives of each country, based on the complete checklist and appended data. If a device manufacturer chooses to challenge a decision made by a type evaluation laboratory, the appeal of the laboratory's decision must be directed to the country whose requirement is the basis for the decision being challenged. 
If the decision being appealed is founded on equivalent requirements for both countries, the appeal will have to be directed separately to both countries.

9. Each country will issue its own certificate based on the test data provided by the participating laboratory.

10. The laboratory managers are responsible for assuring the quality and correctness of the work of their staff.

11. If necessary, quotas are likely to be used to assure that Canada retains a sufficient workload to maintain expertise and a viable type evaluation operation. This is a prime condition to maintain the agreement.

12. Applications for type evaluation are to be submitted to both countries whenever mutual recognition of the type evaluation is requested.

13. Technical policy must be reviewed as to which device(s) must be submitted for type evaluation and the range of devices that will be included on the type evaluation certificate.

14. Extensive training of laboratory staff by representatives of the other country is anticipated to achieve a mutual understanding of requirements and test procedures. In addition, an on-going training program will have to be established.

15. Test procedures and some specific differences were discussed to identify the probable actions needed to establish mutual recognition. These discussions identified numerous topics that must be researched in preparation for the June meeting of technical experts in Ottawa.

\section{U.S./Canada Mutual Recognition of Type Evaluation Proposed Work Plan}

\begin{tabular}{|c|c|c|}
\hline Date & Activity & Objective \\
\hline April 1993 & Meeting of Full Working Group & $\begin{array}{l}\text { Defined mandate, objectives, and priorities. Adopt } \\
\text { work plan. Initial device types to be included are } \\
\text { defined. Begin review of test procedures, equipment } \\
\text { needs. Tasks defined and assigned. }\end{array}$ \\
\hline \multirow[t]{5}{*}{ May } & NTEP Pub 14 & Update to be completed by $6 / 1$ (Henry and Tina) \\
\hline & Draft laboratory instruction manual & $\begin{array}{l}\text { Define laboratory activities and responsibilities as } \\
\text { step-by-step process with time frames (Jim). Due to } \\
\text { Renald by } 5 / 24 \text { in electronic form. }\end{array}$ \\
\hline & $\begin{array}{l}\text { Review of laboratory instruction } \\
\text { manual }\end{array}$ & $\begin{array}{l}\text { Expand and incorporate LMB considerations (LMB). } \\
\text { Update due by } 6 / 7\end{array}$ \\
\hline & Draft Applicant's Guide & OWM to draft by $6 / 1$. Include "punch list" \\
\hline & Draft Application Form. & $\begin{array}{l}\text { LMB to review NTEP application form and modify } \\
\text { to incorporate what they need. LMB to provide } \\
\text { copies of their Certificates of Approval to inform US } \\
\text { of information needed for inspectors. Due } 6 / 1 \text {. }\end{array}$ \\
\hline
\end{tabular}




\begin{tabular}{|c|c|c|}
\hline Date & Activity & Objective \\
\hline June & $\begin{array}{l}\text { Meeting of technical representatives } \\
\text { in Ottawa } 6 / 7-10\end{array}$ & $\begin{array}{l}\text { Participants expected to be Jim, Steve, Renald, Dave, } \\
\text { Eric, and LMB lab metrologist. Tasks will be to do } \\
\text { a detailed review of type evaluation test procedures } \\
\text { and device criteria to (1) identify similarities and } \\
\text { differences, (2) identify the best means to determine } \\
\text { compliance with the criteria, and (3) identify and } \\
\text { recommend long term changes to regulations, H44, } \\
\text { type evaluation criteria as best resolution of conflicts } \\
\text { where changes appear appropriate. Objective is to } \\
\text { establish foundation for drafting a dual checklist for } \\
\text { both bench/floor scales and digital indicators that can } \\
\text { be used by both countries. Examine worksheets with } \\
\text { the objective of drafting common worksheets. }\end{array}$ \\
\hline July & Update on progress at the NCWM & \multirow{2}{*}{$\begin{array}{l}\text { U.S. and Canada divide work and draft dual checklist } \\
\text { and test procedures. Due } 8 / 1 \text {. Distribute the drafts } \\
\text { to the Working Group in advance of the September } \\
\text { meeting. Draft worksheets for dual checklist. Due } \\
9 / 1 \text {. }\end{array}$} \\
\hline August & & \\
\hline September & $\begin{array}{l}\text { Meeting of full Working Group in } \\
\text { Ottawa (Sept. 8-9) }\end{array}$ & $\begin{array}{l}\text { Review, revise draft checklist, criteria, worksheets. } \\
\text { Review recommendations for long-term changes to } \\
\text { base requirements to determine if support exists to } \\
\text { move toward uniformity of some requirements. } \\
\text { Resolve technical issues not readily resolved by the } \\
\text { technical representatives. Review timetable and } \\
\text { objectives. }\end{array}$ \\
\hline October & Update dual checklist by $11 / 1$ & Incorporate revisions addressed by Working Group. \\
\hline November & $\begin{array}{l}\text { Review of the dual type evaluation } \\
\text { checklist and procedures by NTEP } \\
\text { Weighing Sector. }\end{array}$ & $\begin{array}{l}\text { Establish agreement on changes that can be made } \\
\text { immediately to U.S. type evaluation process to } \\
\text { facilitate mutual recognition of type evaluation. } \\
\text { Review long term proposed changes to H44 to } \\
\text { promote uniformity of requirements as recommended } \\
\text { by the full Working Group. }\end{array}$ \\
\hline December & Develop MOU/program agreement. & Carroll and Bob will develop. \\
\hline January 1994 & Review of program agreement. & $\begin{array}{l}\text { NCWM Executive Committee to review and endorse } \\
\text { objectives. }\end{array}$ \\
\hline February & Training & \multirow{2}{*}{$\begin{array}{l}\text { Training of lab personnel. Exchange of experts to } \\
\text { provide training to laboratory staff. Joint } \\
\text { evaluations. }\end{array}$} \\
\hline March & Training & \\
\hline April & Implementation & $\begin{array}{l}\text { Mutual recognition of type evaluations for } \\
\text { bench/floor scales, weighing/load-receiving elements, } \\
\text { and digital indicators. }\end{array}$ \\
\hline
\end{tabular}




\section{Attendees:}

Ross Andersen, State of New York

Carroll Brickenkamp, NIST

Robert Bruce, Legal Metrology Branch, Canada

Robert Brumbaugh, Systems Associates, Inc.

Tina Butcher, NIST

Steve Cook, State of California

Constantine Cotsoradis, State of Maryland

John Davidson, Canadian Association of Scale Manufacturers

Eric Klawis, Weights and Measures, Canada

Gary Lameris, Hobart Corporation

Ray Lloyd, Scale Manufacturers Association

Renald Marceau, Legal Metrology Branch, Canada

Dave Morgan, Legal Metrology Branch, Canada

Allan Nelson, State of Connecticut and Chairman, NCWM

Henry Oppermann, NIST

John Reimer, Weigh-Tronix

Frank Sekela, Mettler Toledo, Canada

Daryl Tonini, Scale Manufacturers Association

Jim Truex, State of Ohio 


\title{
Appendix G Privatization Work Group
}

\author{
October 9 and 10, Richmond, VA
}

Chairman: Tom Geiler

Darrell Guensler

N. David Smith

Sidney Colbrook

Allan Nelson

Daryl Tonini

\author{
Jennifer Colman \\ Rich Tucker \\ Randy Hutton \\ Carroll Brickenkamp \\ also present for short period: Wes Diggs \\ absent: Tom Stabler
}

\section{Executive Summary:}

The following is a report of the first meeting of the work group. The comments are for information only, and not to be construed as the position or recommendation of the group. Upon occasion, a preliminary position of the group will be noted as such. The draft report is in the process of circulation to the other jurisdictions mentioned in the report for clarification and correction. The draft was sent to them very recently (2/25/93); when returned (requested by Mar 10 ), a final draft will be sent to the Executive Committee and submitted for publication in their Interim Report.

The surge towards privatization of functions and services traditionally provided by government stems from severe shortages of government resources and unwillingness to levy additional taxes to pay for traditional services. Therefore, government managers, legislators, governors, etc., (1) prioritize what services they will provide with the limited tax revenues (police, welfare usually rank highest); (2) institute licensing and fee programs (a form of taxation targeted to specific users); and (3) transfer services to the private sector (such as turning over public golf courses and garbage pickup to private, for-profit companies). The basic reason for "privatization" is government's inability to provide expected services with available revenues. Our society believes that private companies can provide services better and cheaper than government agencies, although this sweeping generalization is not always true. The push to privatize will not diminish. To respond to this trend, weights and measures agencies must:

clarify the necessity of government involvement in weights and measures;

maximize resources to provide for an equitable marketplace environment by using the private sector as effectively as possible; and

examine alternative sources for funding the weights and measures system.

The Privatization Work Group decided to use the present situation in Washington State as a test case or pilot study to determine whether anyone from outside the State could be effective in convincing the State to maintain minimal regulatory oversight. The Work Group also decided that the efforts to analyze why weights and measures government services were under siege in Washington would prove useful to any jurisdiction, whether State or local, when questions of funding, maintaining, or even providing weights and measures services arise. An analysis of the Washington case was made and a plan for implementation was formulated. The Work Group decided to (1) prepare arguments concerning the necessary nature of government involvement in marketplace regulation; (2) work by telephone with the weights and measures representative (Kristie Anderson, Everett, WA) on a task force authorized by the WA State Legislature to get entre to the other task force members by telephone or, ideally, in person to explain why government cannot leave weights and measures entirely to the private sector; and (3) to stay involved with both technical and political contacts to establish credibility and trust in defense and support of weights and measures.

The objective of the Work Group was the practical application of material they prepared; however, the group determined that it would not consider its work a failure if it is not able to report success with Washington State government since: (1) the decision makers in the State may have already decided what they will or won't do and made agreements that cannot be at this point renegotiated; that is, local politics may have determined the general outcome no matter what a Task Force recommends; (2) the material presented to the Task Force might have been more effective if officials could have had the information provided and they, in turn, had provided it to decision makers in the State several years ago, before erosion of the program led to the present situation. 
The Work Group will investigate whether private organizations can be delegated police powers, what the impressions of private service companies and retailers are in those jurisdictions that have in some significant way privatized, and whether those organizations that have privatized can participate in a dialogue with the Work Group at its next meeting.

\section{What is Privatization?}

Any shift of what is ordinarily provided by government to the private sector is a form of privatization. There are many degrees of privatization. For example, many years ago, it was required that State or local government officials test all commercial devices after repair or installation. It is now routine for most States to permit registered repair firms to place new or repaired devices into service without immediate government testing. Registered service agencies should be perceived as an extension of weights and measures with the same responsibilities to apply the laws, test methods, and so on. This should be emphasized as a form of privatization that has already taken place across most of the nation. State and local weights and measures officials continued to attempt to test every commercial device in their jurisdictions at least annually. Many State laws require annual testing. Some jurisdictions were able to test small retail scales and motor fuel dispensers more often. In the 1960 's, Wisconsin weights and measures shifted to a program that sampled the device population rather than testing every device annually. The principle reason, as

Privatization
What is it?
1.Having services traditionally performed by
government provided by the private sector
Examples: private contracts for trash removal;
registered service agents may place newly
installed devices into service
2.Shifting costs of government from general
taxation to user fees
Examples: motor fuel tax; charges for laboratory
calibration by the hour
presented by D.E. Konsoer (Report of the 55th NCWM 1970, p. 185), was to shift responsibility for keeping the device accurate from the inspector to the owner/user. The record does not indicate that Wisconsin required annual maintenance and inspection by private companies, although it does indicate that there was a rapid growth in the number of repair firms and the amount of equipment they used. Wisconsin instituted a registration program for repair firms 8 years after dropping annual inspection; in addition, the report indicates that they took many more court actions than when conducting annual inspection. Unfortunately, it appears that a steady erosion of resources for weights and measures may have resulted at the State level in Wisconsin. Other local jurisdictions (some California counties, for example) refined and adopted the Wisconsin "variable frequency of inspection" program. Even in those jurisdictions that require annual inspection, we do not know the ratio of government testing to that tone by private firms: is it 1 to 10 ? 1 to 100 ? Weights and Measures may be far more "privatized" than many people think. Perhaps the placed-in-service reports could provide part of the data to indicate the number of devices per year that are installed and repaired and placed back in service.

It is unreasonable to discredit variable frequency of inspection programs due to this one example at the State level; however, they must be carefully managed to succeed. Inspection is targeted based upon the existing compliance level with annual inspection. Initially, variable frequency programs take more resources to implement properly: many businesses must be shown that enforcement will occur when they don't comply. In fact, the basic weights and measures law may need modification to permit strong enforcement, especially the use of civil penalties. The Task Force should determine the success rate of these other jurisdictions employing variable frequency of inspection programs and whether they have been able to maintain minimal services.

The marketplace has changed. In earlier times, a person on the other side of the counter weighed out the meat or beans. Now, an electronic indicating device does the measurement; electricity won't cheat the buyer or seller, or so the public believes. Our impersonal economy demands confidence in the marketplace. If businesses lose the public's confidence, there will be mayhem in the commercial marketplace. Consumer confidence and trust is the cornerstone of the grocery business, for example. Many weights and measures jurisdictions have found that grocery supermarkets take good care of their prepackaging scales; a comment was made that stores may not have as much incentive to keep the scale at checkout in such good working order. More money is made over the prepack scale and more packages or product will be called off-sale if the package sample is found short weight. If the checkout scale is found out of tolerance, the product sold has already gone out the door; there may not be as much incentive in some businesses to keep it in good order. An alternative 
explanation may be that inspectors have not received enough training to keep up with new front-end technology.

In the last few years, some jurisdictions have lost so many resources, inspectors, equipment, etc., that they have also lost the capability to test every device, especially large capacity devices, annually. Two States, Kansas and New Hampshire, in order to close the gap between State resources and inspection needs, added requirements that all commercial devices be tested annually by private service companies. These two States have become known as "privatized." Kansas had very few resources to devote to weights and measures about 10 years ago and changed its law to require device owners to purchase annual inspection from local service companies in order to bridge the gap. Now the State of Kansas employs more inspectors than its near-neighbor Iowa, which has not privatized. New Hampshire also requires annual inspection by private agencies. Kansas spends its government resources sampling the service agencies' work after they have serviced and inspected devices. New Hampshire weights and measures have no resources to sample the effectiveness of their device service and repair requirements. Neither State has resources to determine the level of compliance before service agencies test and adjust devices. The level of resources expended by either State on package inspection is not known; businesses may have accurate scales, but not take tare and sell short weight.

Tom Geiler and Bruce Martell visited New Hampshire last year as part of their work for the Task Force for Planning for the 21 st Century. Although the State weights and measures management expressed satisfaction with its program, the scale repair firms were not happy because they had invested considerably in equipment, anticipating additional business that did not materialize. The rural retailers expressed unhappiness at their expenses, because they now had to pay for several different companies to service different brands or types of equipment at their one retail location. The retailers had no idea whether the quality of work they were buying was good; New Hampshire weights and measures had no resources to test and verify the quality of private company services.

By shifting responsibility, privatization does not necessarily shift or reduce the cost. For example, garbage collection by private companies will still cost the homeowner whether billed by the private company or through tax payments if the jurisdiction contracts the service to private business.

The Washington State legislature was lobbied by trade groups that annual weights and measures government inspection duplicated of private company testing; the legislature originally planned to give device owners the choice of using private companies or State agency. The program adopted by the State legislature provides for fees, but only when devices are found in compliance. This was the status when the Work Group met in October.

\section{Other Input}

The Work Group received letters from Tom Stabler, Mettler Toledo, and from Bill McHale, Kenawha Valley Scale, concerning their perceptions on privatization and what should be done about it. Their letters are attached. Both emphasized that government regulation of the marketplace was mandatory. Mr. McHale's letter indicated that private service agencies might be forced to fill the gap if State or local agencies do not see the importance of government oversight.

The Food Marketing Institute represents a large percentage of the retail grocers in the United States. The Work Group representative (Colman) sent a survey to its members. There was a 2 to 1 consensus that privatized weights and measures functions, or removing government oversight from retail trade, should not be one. The response indicated that certain functions could be privatized, and that differences in services from State to State should be made uniform. In those States where retailers understand that weights and measures provides equity and fairness in the marketplace (and where some 
thought that the weights and measures inspectors calibrated and adjusted their scales); supermarket retailers didn't want privatization. They thought they were getting this from their taxes. These States appeared to be in the Northeast, Mid Atlantic, including NY, VT, and FL, and the western states of CA and NV. It would be interesting to compare these States' budgets and funding in comparison with those States that might be perceived as less responsive or "invisible" to their businesses.

In those States where weights and measures did not appear to provide a service, or where the service was not understood, the retailers thought that weights and measures could be privatized. This may indicate geographic areas where no resources are expended to educate the business population about the services weights and measures provides. According to the FMI survey, PA and TX, for example, appeared to get mixed reviews. Oregon retailers thought there were two groups, one government and one private, adjusting their devices. Weights and measures agencies are uniquely qualified to educate.

Some State food and drug inspectors are also responsible for small scale and package inspection. Weights and measures activities may be given less emphasis in these jurisdictions. It is possible that weights and measures may be confused with services provided by a scale company, since such jurisdictions may not test the device in a complete, professional manner, but only put a few weights on a scale. The sanitation question comes up because county health department share inspection authority with State food and drug inspectors. If the State food and drug inspector performs inspections similar to those of the county inspector, many businesses may feel that inspections are duplicated. Even if weights and measures is performed only by the State inspector, the store manager simply lumps everything together when asked to express an opinion. Florida passed a bill to combine State and local inspections to eliminate the duplication of store inspections; now only one inspector visits retailers. Georgia also duplicates county and State inspections (or so it seems to retailers.)

The necessity of weights and measures assuring a fair marketplace appears to be understood by many retail supermarkets; however, the lack of uniformity and the duplication of inspection frustrates retailers in many States. Winn-Dixie (Hutton) is in 13 southern States; its concerns are the lack of consistency by local inspectors in interpreting and enforcing their own laws; for example, what can be sold by count or by weight; whether shrink for moisture loss will be allowed or not. This inconsistency is worth eliminating, even if it means eliminating the government agency itself. Winn Dixie agrees that weights and measures regulation is needed, but weights and measures is a service for the general public, not just for the retail businesses.

The Work Group asked whether retail grocery chains inspect and repair their own scales. Many inspect or audit their own devices and practices. One of the 13 States in which Winn-Dixie operates forbids the chain to repair its own devices. However, retail grocers do not want to expose themselves to bad publicity if short weight is found. The press could have a field day: they might imply collusion with the scale repair firm; and perhaps destroy a firm.

However, the Work Group notes that lack of quality in weights and measures services destroys the credibility of the entire profession. Uniformity and quality is needed across the country in order to ensure the long term health of weights and measures regulation. The Work Group believes that NCWM must eventually accredit or certify jurisdictions. A jurisdiction that merely just checks devices and affixes seals is vulnerable. We need to advocate better management in government and the private sector. Scale Manufacturers' Association (SMA) members believe there would be no way to avoid conflict of interest, even among those who have service companies, if transaction verification were the responsibility of private companies. There would be a need to establish a type of business that does not now exist, a testing bureau, such as utilities and railroads operate. The Work Group could not say whether such weighing bureaus were successful in terms of avoiding conflicts of interest. It is not likely that weights and measures can convince their legislatures that general tax revenues should be the only way to finance weights and measures. A fee system will probably be needed, and this has the benefit of reminding the user that this service costs money. What the relative contributions of fees should be with respect to taxes is debatable, but there are no "free lunches" in any mix of funding to support a viable program.

SMA recommends that NCWM choose to accept a grass roots role to assist States in improving their services and entering the 21 st Century. NCWM should use its powers to come in to a State's Department of Agriculture or other departmental head, sit down, and share its vision of the future and what standards the State should be setting for its citizenry. The NCWM should take an active role to influence States adopt better regulations and control the damage done by deteriorating programs. For example, SMA representatives went to lowa in the past year to convince the management not to privatize the weights and measures program. 
Scale Manufacturers Association members communicated with their Work Group representative that privatization might be "in vogue" as needed to fill a vacuum, that is, that there are real or perceived deficiencies in what is being provided by the current weights and measures structure in many areas of the nation. One load cell manufacturer noted that, in the broadest sense, privatization should not be a dirty word. The Netherlands type evaluation laboratory is a private sector organization. In the aerospace industry, Boeing set the standards and the industry polices itself. However, the Work Group noted that the issue of customer safety does not allow any failures in the aerospace community, whereas no one loses life when a business shaves a little off full weight when buying and selling in commerce. The load cell manufacturer added in its comments that NIST tests are competitive with the Dutch; that they are a good value for the dollar.

The Gas Pump Manufacturers Association membership is amazed that privatization is taken seriously. This association cannot imagine Tokheim, for example, servicing Gilbarco devices as an objective business without any profit motive. Whatever the mix of taxes, fees, or licensing that fund weights and measures programs, some part should be general taxation; the general public derives benefit and should pay. GPMA members caution that shifting from government to private cannot be accomplished without following a step-by-step plan. An audit must first be conducted to measure the improvement or the cost of any benefits of privatizing. GPMA is opposed to privatizing weights and measures. Most small weights and measures jurisdictions already depend and rely on manufacturers and repair firms. They only do spot checking, already; rarely do they conduct $100 \%$ annual inspection of devices.

\section{Objectives of Work Group}

The Work Group does not consider its objectives to be job preservation for weights and measures government officers. Its objective is to provide ideas of how "to do more with less." The Privatization Work Group believes that the NCWM must take an honest, hard look at the advantages and disadvantages of shifting responsibilities to the private sector. Weights and measures has already made some steps toward privatization by using private service agencies to place new or repaired commercial measuring devices into service without requiring the presence of weights and measures government inspectors.

The Work Group does not oppose shifting responsibilities of good measurement and quality control practices as much as possible to the private sector; it advocates good programs no matter the public - private mix. However, government oversight must be maintained.

\section{Is Registration of Repair Firms Enough?}

Unfortunately, States that have registered repair firms cannot rely on the quality of the services provided by registrants. For example, in the large capacity scale area, IL finds $20 \%$ of the devices that have been rejected and serviced are still not correct after service. This may be because many of these firms do not carry more than $10,000 \mathrm{lb}$ of weights, whereas the State carries 21,000 lb of weight and strain loads the scales to $42,000 \mathrm{lb}$. Registered service agencies should be required to pass the same examinations as weights and measures inspectors.

\section{What is the Reason for Weights and Measures?}

Legislators, governors, secretaries of agriculture often have little idea what weights and measures government services are or do. If they ask supermarket retailers, they will often be told that the government representative comes in to the store to check the retail scales, and sometimes the scales in the packaging area, and sometimes the packages. Many weights and measures jurisdictions have done little to inform and educate the retailers why they test the scales, or how their test differs from those that are provided by the private scale company. They do not explain that checking the net weights on packages ensures that the full packaging process, not just the scale, was accurate. They have not explained to retailers their responsibility to keep their equipment in good repair, which is why service agencies are hired; and that weights and measures government oversight, whether by testing package net weights or by testing the measuring devices, is to verify that the service agencies and the retailers have done their jobs and that the marketplace is fair and equitable. In other words, the responsibility of weights and measures government regulation is to preserve and provide an equitable marketplace for honest businesses to be able to compete fairly with each other. It is vitally important to stress the regulatory aspects of weights and measures in the jurisdiction. It is also important to stress that if the government regulatory functions are to be contracted to private agencies, it must be to agencies that do not now exist; that is, these private agencies must have no conflict of interest. They cannot sell equipment, repair it, or service it. They must maintain complete objectivity with respect to any given brand of equipment; they must direct businesses to get equipment repaired when necessary, but they should not be able to repair the devices, because they may be accused of "drumming up business." 


\section{Making Decision Makers Aware of Weights and Measures}

A primary problem in weights and measures is the lack of public awareness even by regulated businesses as to what is "weights and measures." Several suggestions were made to improve public awareness. (1) Write articles in W\&M Today targeted for State legislators and local governing bodies, such a county councils, city boards, etc., that explain the essential nature of weights and measures government involvement. (2) Sid Colbrook reported some success with a "Fact Sheet" that ostensibly was tied to the subject of motor fuel since the Illinois legislature is principally interested in motor fuel; however, he incorporated broad information about general weights and measures regulation. The advice here is to use every interest of the decision makers and those who control the purse strings as a means to tell them about weights and measures.

IL plans to create an advisory board, with representation from various associations to get them more involved and informed about weights and measures. It will educate an important segment of the business community. A brochure should be produced for the supermarket industry, another targeted for the scale service industry, and another for the legislature, to better inform the public of the necessity of weights and measures government oversight.

\section{Why Should Businesses Want Weights and Measures Protection?}

One of the most difficult tasks, if a government agency has not been doing it all along, is to explain what the agency does and why. This difficult task takes constant reinforcement and repetition; the task is never done, since business persons and decision makers change, need reminding, and need re-education. Businesses do not like regulation. They do see it as a service to honest business to keep their dishonest competitors at bay: this point must be reinforced with actual examples over and over again. As Winn-Dixie store managers said individually, "make sure all my competitors are treated the same as I am." Build on that fairness concept. An article in the Washington Post about 10 years ago noted Montgomery County winning a case against both Safeway and Giant Food, there both pleaded nolo contendere to short weight charges, because their competitors were allowed to undercut them and they found they all had to discontinue deducting the tare weight in order to remain competitive.

Everyone is for privatization until discovering that it may not be cheaper. The tales Tom Geiler and Bruce Martell were told in New Hampshire concerning the costs of testing to a rural businessman with many devices were one aspect of the issue; however, weights and measures officials should not be perceived as service agents by businesses in order to justify their jobs. The cost of annual maintenance is a legitimate cost of doing business; if businesses perceive weights and measures officials as device maintenance companies, they must have their perceptions changed to recognize the necessity for taking responsibility for service, and for the government to verify that the service was adequate and that their devices are accurate.

\section{Licensing and Fee Systems}

Maryland conducted an extensive survey about one to two years ago in anticipation of having to recoup funding for regulatory services through instituting some kind of licensing or fee-based program. The Work Group will obtain and distribute the results of this data. It has long been the position of the National Conference and NIST Office of Weights and Measures to defend weights and measures as being a general taxation-supported program, since the entire commercial marketplace, both buyers and sellers, benefit from a general climate of equity preserved by weights and measures regulation. Unfortunately, with State and local governments unable to meet payrolls or provide critical services at even minimal levels, the need to levy additional "licensing" or "fees" to cover shortfalls may be a reality for some time to come. License and fee-based programs are a form of "targeted taxation"; licenses assess a regulatory and service "tax" on businesses that can be identified with ownership of measurement devices. 
Those State and local jurisdictions that concentrate on device inspection and do less package inspection than perhaps they should, find or say their own laws force this, since many State laws require annual device inspection, but require package inspection only "from time to time." Also, fee-based weights and measures programs find it easier to assess fees per device rather than per package. How can a licensing or fee system support a package inspection or consumer complaint program? Can it be done? One possibility is to license the business rather than the device. We need measures of the consequences if fee systems do not support package inspection programs. After all, an accurate scale can be used to package short weight packages; the operator only needs is set the scale to deduct the wrong (or no) amount of tare.

\section{What are the Minimum Functions of Government in Weights and Measures?}

Weights and Measures includes:

1. provision of traceability from national standards to standards used in and for commerce;

2. regulation of measurement devices used in commerce;

3. regulation of measurement practices in commerce;

4. response to complaints; investigation of measurement practices; consultative services to government, business, and private citizens
What does Weights and Measures Encompass?

\section{Metrology}

Maintain traceability of State standards to national and international standards in mass, length, volume

Verify accuracy of other government and private business standards

Provide consultation on measurement standards and their use

I. Metrology Laboratory (fee for service for the non-regulatory services)

- maintain traceability in length, mass, volume

- verification of standards

a weights and measures inspector

b service agency repair person

c other businesses

b and c take approximately $80 \%$ of many State laboratories resources. Shifting costs by charging fees for laboratory services is feasible and advocated by NIST and the NCWM.

In the laboratory area, States have the option of contracting their laboratory needs for regulatory purposes to

- other states;

- private accredited laboratories.

Potential problems need to be confronted with either approach: (1) neighboring States need to plan substantially in advance to do the amount of tolerance testing most States need to maintain a State's regulatory program. One

What Is Needed to Provide Metrology Services?

NIST Certified Laboratory: including

appropriate environment, equipment,

fully-trained personnel, and

on-going quality control measurement system

participation in proficiency tests State in the Northeast, not accredited by NIST has encouraged private companies and local jurisdictions to go to a neighboring State for laboratory services. The neighboring State is accredited and complains that it cannot keep up with its own workload. No formal scheduling, service requests, or cost-sharing arrangements have been made between the two States. The situation has simply been allowed to happen. (2) Any State contemplating the use of other State or private laboratories will have to pay for such services. Such services are valuable. Additional costs for shipping or other transport may be involved. In fact, States concerned about maintaining adequate laboratory services should contact their "customers," both private repair agencies and local enforcement officials, to find out if they would join in the support for obtaining adequate laboratory services within the 
State. The cost and time delays associated with out-of-State laboratory services can often be sizeable. (NIST OWM is assisting the NIST National Voluntary Laboratory Accreditation Program to institute an accreditation program for private laboratories providing mass and volume calibration services. This may be an alternative resource for States looking to shift responsibility away from the State to other accredited services; however, this service will not be underway before late in 1993, and will not be an inexpensive alternative for absolutely indispensable legal defensibility in any regulatory action the State may take in the weights and measures area.) Incidentally, Darrell Guensler mentioned in passing that they are planning to acquire enough weights that the State can provide a "bank" of weights that can be issued to public agencies when they come to the State laboratory for tolerance testing. The weights brought in will be exchanged for weights already tested. This will eliminate the problem of turn-around time and provide a more even work load for the laboratory personnel.

Several States have private testing laboratories instead of government laboratories for motor fuel testing. Turnaround time is critical, as well as accuracy. Laboratory accreditation in the area of motor fuel quality is not available. Participation in round-robin tests must be required as a minimum.

\section{Weighing and Measuring Devices}

- prototype evaluation program adopt a regulation requiring an NTEP CC

- initial verification adopt Handbook 44; use modules to train new inspectors

- training at the plant (load cells)

- standards at installation (heavy capacity scales)

- documentation administrative database: where is device; what is device
What is Needed to Administer this part of weights and measures function? (Continued)

Law (UWML) that adopts current version of NIST Handbook 130 "Uniform Regulation for the Registration of Service Person and Service Agencies";

\section{State should also adopt NIST Handbook 130 "Uniform Weighmaster Law";}

Device Accuracy and Suitability for Commercial Use is ensured by:

Evaluation of prototypes of devices to determine whether they can meet codes;

Initial verification of particular device upon installation of its accuracy and suitability;

\section{Subsequent verification of device performance during use; \\ Verification that entire transaction was fair}

When a jurisdiction must investigate sources of revenue other than taxes, such as fee or license system, the traditional system is based on licensing devices or setting fees for testing devices, rather than licensing businesses. There are advantages and disadvantages to both systems, whether device or businessbased. A device license is preferable to a fee for testing. (1) Licensing can be constructed that there is not promise that a test will accompany payment of the license. A fee for testing requires testing in order to get paid. This can be a serious disincentive to instituting any kind of sampling of devices that routinely comply (another cost saving approach). The advantage to a device license is that it can often be "sold" to the business community by their identifying a service they will most likely receive for the price they pay. The disadvantage of a business license is businesses are used to a large number of licenses they must purchase with no services in return for the money. The advantage of a business license, as compared with a device license, is that package checking and other investigative services can be justified and paid for from a general weights and measures business license. One State has been challenged because it uses device fees to underwrite part of its package checking program. Whatever the type of license or fee program a jurisdiction finds necessary to institute, it should thoroughly review how much money must be raised. Many programs have been told to raise only $50 \%$ of their operating funds from fees, only to learn later that they must depend entirely upon fees during lean times. For this latter reason, make sure that the type of fee or licensing program instituted is (1) deposited into an account which is targeted to support the weights and measures regulatory program; (2) broadly constructed so that it does not narrowly depend on testing devices to collect the revenue; and (3) worded generally enough to permit package testing and other legitimate weights and measures operations to be conducted using these revenues. 
When first instituting a licensing or device fee program, it is important to obtain adequate information in order to register every device. The most valuable resource, is of course, the local inspector's own log books, but it will probably also be necessary to cross reference with (1) the Department of Revenue; (2) the local fire marshals; and (3) local telephone books.

What is Needed to Administer this part of weights and measures function? (Continued)

Equipment and field standards to use to test the accuracy of commercial devices Examples, $40,000 \mathrm{lb}$ of known test weights on truck with gross vehicle weight of $\mathbf{8 0 , 0 0 0}$ lb to test large capacity scales; $1500 \mathrm{gal}$ truck-mounted volumetric prover to test large capacity meters; Liquid Propane Gas Prover; 5th wheel for taximeter testing, etc.

Fully equipped general duty inspector should include field standard test weight kits, volumetric measures, electronic balances; notebook computer, etc.

funds to allow undercover buying and selling

\section{What is Needed to Administer this part of weights and measures function? (Continued)}

Enough personnel to test all devices annually (at least initially in order to obtain baseline data on businesses, devices, repair history)

Personnel should receive training appropriate to their responsibilities. NCWM training modules are intended for beginning inspectors; updated training should be provided at least annually.

\section{Personnel should be NCWM certified in those} areas for which certification is offered.

\section{Annual Device Inspection Vs. Variable Frequency of Inspection Programs}

Of course, any device testing program must maintain adequate frequency of inspection, but what is considered as adequate must be based upon (1) the type of device; (2) the use that any device gets; and (3) the maintenance each specific device gets annually or more frequently. For example, CA has found that LP Gas meters need inspection much more frequently than annually, whereas in their opinion gas pumps can perhaps go on a 5-year cycle without undue damage to marketplace equity; watt-hour meters in CA are tested only on a 10-year frequency. North

Carolina is not prepared to say that gas pumps can go on a 5 year cycle. Their experience is that 2 years stretches the issue if one considers labeling, cash/credit signs, multi-tier pricing, etc. as weights and measures concerns. There is more to weights and measures than testing for accuracy. Deli scales need frequent maintenance, for example. Annual inspection of every commercial device may not make sense if routine maintenance and service is obtained by private service companies throughout the year, or at least annually. The jurisdiction must use its resources wisely and annual inspection must be considered when putting resources to work. Weights and measures government should perhaps shift to a variable frequency of inspection. Unfortunately, many jurisdictions are locked into annual inspection by law or by fees specifically linked to testing; that is, no test, no fee.

Moreover, in order to determine the frequency of testing required in any given jurisdiction, that jurisdiction is going to have to test $100 \%$ of the commercial devices for 3 to 5 years in order to shift resources from where they are less needed to where they are more important. For example, many jurisdictions have discovered that the better they do the inspection, the better the maintenance provided by the private repair companies. One drives the quality of the other. A computer analysis of inspections will then be required. Large monetary resources will be needed to do this job properly.

Only very recently have rugged hand-held and pen-based computers been available for data entry in the field, so that office clerks do not have to re-enter data taken by field inspectors as hand-written forms. Now, the Work Group can encourage jurisdictions to obtain such computers and keep historical data on devices, their age, their frequency of service, what company serviced the device, and actual device readings (rather than just in or out of tolerance). This kind of data is needed in order to determine whether certain classes of devices, brands, service companies, types of businesses, need to be inspected more or less often than annually.

The Work Group also believes that registration of service agencies should be recommended by the National Conference as a mandatory system, rather than voluntary, as the Uniform Regulation for the Registration of Service Persons and Service Agencies now provides. The Work Group would like to recommend this as new work for the Laws and 
Regulations Committee. Mandatory registration is the ideal way to manage the marketplace; otherwise, the weights and measures agency does not know who is providing service and the quality of their service, with respect to the accuracy of the resultant serviced device. Registration of sellers has been considered in some jurisdictions, but the Work Group was not able to come to any conclusion about whether to recommend seller registration; the problem is how to fairly treat businesses in a State and those that sell by mail order from outside a State.

The Work Group determined that device customers need a brochure explaining their rights and responsibilities under weights and measures regulation. This brochure would be an ideal accompaniment to the one being developed for consumers by the National Conference. Sid Colbrook is having one prepared in Illinois.

Government can perform the tests, or can oversee some other group or organization or business performing the tests; however, government must verify the accuracy and fairness of the testing provided by these other groups. The only way government can verify accuracy is by making measurements. This means that government oversight will require capital equipment investment or use similar to that necessary to conduct the testing itself.

One alternative is for government to provide the equipment to test devices; perhaps this would make a private business without conflict of interest problems viable.

Whatever the type of private/public mix of business and government to service and test commercial devices, government must verify that transactions are fair and honest. This goes beyond device testing, but requires audit, and not just of review of records. The audit that the Work Group believes to be necessary is to buy and sell product in the manner of a private company or citizen in order to determine if the commercial measurement is accurate and honest. Tom Geiler enlists the assistance of consumer groups to buy and sell product with weights and measures assistance to check the accuracy of these transactions.

The Work Group is concerned, for example, about the actual effectiveness of transaction verification programs and methods. For example, checking packages rather than scales is a type of transaction verification. However, the recent changes in U.S. Department of Agriculture requirements for meat and poultry plants to have them get their scales inspected at least annually may indicate that transaction verification for this segment of the manufacturing population has not proven effective.

\section{What Can Be Privatized?}

The Work Group hypothesized that many services provided by weights and measures government could be shifted to the private sector. It should not be done to merely shift the costs, and if regulatory functions are shifted, it must be designed with some type of third-party oversight such that an entirely new type of business without any conflicts of interest is created.

Privatization often only shifts costs; if the weights and measures director wishes to avoid it, the director must clarify that there are not two groups performing the same function (usually perceived as "just" testing [and adjusting] scales). One problem the Work Group saw was that most States are following a "good enough" policy and selling the necessity of the program is not perceived as necessary in and of itself.

What functions normally performed by weights and measures government agents might be privatized?

- device testing

- contract out package inspection 
motor fuel sampling

Any State contemplating privatizing weights and measures must determine how much government regulation can be contracted out. For example, the Federal government does not consider law enforcement as appropriate under any circumstances to privatize. The California representative was not aware if private companies were permitted or could be authorized any police powers; Illinois can authorize police powers, that is removing the rights of private citizens for public purposes (such as condemning a device), to private companies. Another feature to examine is whether government immunity can be provided a private company, to avoid liability for any company that might reject a device and subsequently be sued for it.

For example, in many States, private companies test autos for pollution emissions. These private companies ordinarily only declare a car as having passed or failed; they can't prevent the driver from driving the car. The latter enforcement or withholding of a license is the responsibility of government.

The members of the Work Group will investigate in their individual jurisdictions whether the government can delegate to private agencies the power to confiscate devices, to arrest, or to remove a device from service.

\section{Non-Devices (Methods of Sale / Packages)}

- Net contents determine - package inspection

- quantity

- deceptive packaging / slack fill

- labeling - full disclosure

Minimal Program includes

- database

- sampling everything

- at-source as much as possible

- use retail to focus on in-plant

The jurisdiction should have adopted Handbook 130: Packaging and Labeling; Method of Sale; Open Dating; Unit Pricing; Handbook 133.

Although many States believe that all they need is the Uniform Packaging and Labeling Regulation (and that from the 1970 's and rarely updated since that time), a method of sale of commodities regulation is needed to control not only prepackaged products but the sale of commodities from bulk. Both regulations should be kept up-to-date with respect to the revisions and additions recommended by the National Conference, because this is the only national standard available to packagers and bulk marketers. States may be accused of restriction of interstate commerce if they actually enforced local standards rather than national standards of practice. States need to recognize that the Uniform Unit Pricing and Open Dating Regulations should at least be adopted as voluntary standards, to be followed if retailers decide voluntarily to provide open dating or unit pricing.

The Work Group also believes that all States should have a weighmaster standard and a motor fuel standard voluntary or mandatory in nature. The standardization function of government is essential, even if the standard only applies if business voluntarily chooses to provide the service.

\section{Other}

Complaints

Investigations

- does a pattern exist (whether or not a complaint has been lodged)?

Consulting

- Answering questions

- businesses

- other government agencies

- the public

Public education 
- businesses

- citizens

\section{Further Work}

A report has been completed by Canada concerning privatization; this will be circulated to the Work Group.

Agencies and companies that favor privatization of weights and measures should be called in to meet with the Work Group. The Work Group needs more input from this perspective. The Work Group might, for example, hold its next meeting in Kansas or Washington.

Public sector members will consult with their attorneys to determine whether private firms can take enforcement action. This may require consultation with the State's Attorney General.

Device manufacturer representatives on the Work Group (Tonini, Tucker, Stabler) will contact service companies in KS and $\mathrm{NH}$ to determine their guidelines, written authorization, etc., concerning authority to certify or test equipment; what service or sales companies in these State understand the law and weights and measures regulations are; and what instructions and other guidance they have been provided in documentation or in training. Work Group members who represent the device users (Hutton, Colman) will contact the retail grocers associations in KS and NH to determine the user understanding of their responsibilities for devices, and packages; and for what they pay service agencies. What are their costs for registration, service; and what is the quality of the service they receive as compared with the former system? The Work Group will also talk with Bob Gunja, K.C., KS concerning his experience and perceptions.

The Work Group will contact railroad weighing bureaus and utilities to determine how they avoid conflict of interest and maintain other equity issues.

\section{Questions That Are Repeatedly Asked}

The reason for weights and measures government involvement is to maintain equity in the marketplace. How is this accomplished? With skilled, trained inspectors applying uniform standards. As to what kind of administrative system is ideal for weights and measures, the Work Group believes that any system can succeed and any type can fail depending on the dedication and leadership of the management. In any given jurisdiction, the administrative system is often a given by historical circumstances. Some weights and measures jurisdictions that are consolidated in administration and responsibility are not successful; on the other hand, many that are combinations of State and local enforcement systems, that would seem to have difficulties of supervision and communications, are quite successful. Questions as to how frequently devices need to be

\begin{tabular}{c}
\hline Some aspects of \\
Weights and Measures \\
may be provided by public or private agencies \\
However, \\
Government must oversee and audit all aspects in \\
order \\
to govern and to manage the marketplace \\
\end{tabular}
inspected can only be answered by measuring different rates of inspection against the resulting levels of compliance in a given jurisdiction, not cross comparing jurisdictions of different geographical size, number of businesses, number of inspectors, their training, differences in the training and administrative oversight given to private repair and service companies. Correspondingly, jurisdictions must measure before and after instituting a registration program for service agencies whether this increases the efficiency of the weights and measures system. What is the cost for the corresponding benefit? This is the only way to determine how many inspectors a jurisdiction needs, versus how much error a region can tolerate. What is the percentage error for the total sales in a given area? For example, grocery profit margin for last year was $0.77 \%$ of total sales, on the average. This means that not taking tare in the meat and poultry packaging area of a grocery may wipe out the profitability of all that grocery's competitors. It is a common misconception that, if there is no enforcement of weights and measures laws, or poor training in the legal use of commercial measuring devices, the marketplace will weed out these offenders. Unfortunately, measurement this is not so, even though consumers take the accuracy of measuring devices for granted; businesses must still compete with those who are dishonest or careless. The consumer does not carry his own measuring device; however, transaction errors affect competing businesses more than individual consumers. 
In an oral survey with one grocery chain's store managers, their greatest concern is that they want their competitors under the same rules as they are. Is my competitor being made to comply? Is my competitor ignoring the rules? Poor training and inadequate equipment leads to nonuniformity in application of the rules. The benefits of local inspectors, that they get to know the local businesses, that they provide consulting services, have better rapport, less prosecutions, higher compliance, can also be used as evidence that local weights and measures is not needed, if one examines only the number of court cases or level of noncompliance as an indication of the value or need for weights and measures. However, with highly distributed local inspectorates, it is more difficult to obtain uniformity in enforcement, and maintain minimum professional levels of knowledge and skills. In certain urban or ethnic settings, there can sometimes be a mind-set that all businesses are crooked.

An important reason for weights and measures oversight is that the State government is also an important customer to protect. The State needs verification that its motor fuel taxes are being paid, that its institutions such as schools, prisons, and hospitals are receiving what they pay for, and that its suppliers are providing what they have been contracted to supply, such as road materials, fuel, heating supplies, office supplies, etc.

In order to determine the appropriate level of staffing, one must have a sound database indicating the number of devices, number of retail sales, population, geography, number of retail and wholesale businesses, etc. Whatever a jurisdiction has resources to do, prioritize the most important tasks, and do those tasks right. In the opinion of the Work Group, the highest priority for a State should be to maintain its measurement accuracy in its metrology program. The second priority should be to set appropriate standards for fair commerce. This is the task of the weights and measures administrator to communicate with the State legislature. Then, the next priority is to provide adequate training and equipment to a staff to at least audit (sample) those transactions that affect the largest number of people. In most States, these transactions are (1) retail groceries (2) retail motor fuel sales. Every State will differ after these two categories are covered. lt may be apple growers in Washington, livestock or grain exchange in other States, etc. There must be some mechanism for handling complaints. If States were more responsive to complaints, some of them might not be in their predicaments. However, complaint resolution takes many more hours than ordinary inspection, and so many jurisdictions avoid giving high priority to complaints because they know how much time and resources complaints use. However, when a department of weights and measures gains a reputation for service to the community, it becomes institutionalized and much harder to dissolve.

When more responsibility for device and transaction accuracy is shifted to the private sector, more enforcement power must be in the hands of the government agency overseeing the marketplace. This is because there is not the reminder of need to comply provided by more frequent "cop-on-the-beat" inspections. Because the jurisdiction has probably privatized in order to reduce the amount of resources government is spending on weights and measures, the effort to obtain compliance when noncompliance is discovered, must be fairly efficient. Therefore, all jurisdictions privatizing must be given civil penalty authority in their law (in order to reduce the backlog on the courts too), and also be permitted to avoid criminal penalties, because businesses will probably claim that no government authority explained their legal responsibilities.

Privatization will require some type of sampling expertise, at least initially, in order to set up an efficient way to target what will be inspected under what criteria. In addition, the jurisdiction must obtain expertise or capability to investigate complaints by anonymous or undercover methods. This will be increasingly difficult in local jurisdictions. However, the registered service agency is vital in this respect, to the State, to the device owners, and to other service agencies. They must to have minimum training and minimum equipment; they are the "other" weights and measures inspectors, even in those jurisdictions that cannot transfer police powers to private agencies. The Uniform Registration Regulation is, in fact, a form of privatization, since registered agencies can place equipment into service without the presence of a weights and measures government representative. A level playing field is needed, however, for these service agencies. They must be required to provide minimum training, and minimum equipment, or else the least capable and equipped will be able to offer inadequate services at reduced rates. 


\section{Washington Case Study:}

This State's weights and measures resources has been allowed to erode so badly that there are some devices in rural areas that have not been tested in several years. The major population centers around Seattle and Spokane have city weights and measures agencies that cover their relatively small geographic areas. These agencies feel threatened by the State Legislature's linking a new fee for service program to what fees the cities can charge (most inadequate in urban areas) and when they can charge (only when a device passes inspection). The Washington Legislature also established a Task Force to study the current weights and measures situation and advise on implementing an appropriate system. The Work Group determined that the Washington Task Force should be encouraged to authorize testing every device for at least two years in order to obtain a history of compliance before varying the testing schedule. Rumor is that testing in Washington State has not been provided in 5 to 7 years in some rural areas. The Washington Task Force has asked other States what their error rates are with respect to certain classes of devices. The Work Group was emphatic that such error rates could not be disassociated from the level of government testing presently provided. A jurisdiction reporting a $90 \%$ compliance rate with testing every 6 months; may not be comparable to the compliance that another jurisdiction finds with testing on a 3-year cycle. It is reported that certain members of the Washington Task Force believe that the government weights and measures inspectors are performing the same functions as the private service agencies. It will be necessary to explain to the WA Task Force what weights and measures regulation by government is.

Jan Gee, WA Retail Grocers Association, is a vocal proponent of turning all aspects of weights and measures over to private service companies. The Work Group will contact farmer and grower representatives to determine if they, too, favor privatization. Unfortunately, it appears that Washington State has tested infrequently and cannot attest to the effects of the program up to this point in time; in addition, it appears that Washington State has focussed on device inspection to the detriment of the rest of the program, such as package inspection. They have probably assumed that the program up to this point in time was adequate, and an audit has probably never been done. All the scales may be weighing accurately, but all the packages may be short weight because tare is never subtracted.

The Work Group decided that a few States would be able to offer an inspector and small package checking equipment to the WA Task Force to do a narrow survey costing no more than the inspector's travel and per diem expenses. It would not be a broad-based survey, but would indicate the present condition of the marketplace in one narrow area. If the State Department of Agriculture concentrated on the accuracy of the scales, this would verify package transactions. The WA Task Force could be offered several inspectors, their scales, weights, using H133 and dry tare, to determine the quality of the retail package marketplace. The NCWM would offer this as a fact finding study, looking at city and rural areas, accompanied by WA inspectors to determine where to go and providing access to the places of business. The Work Group estimates that 3 inspectors, travel, per diem would cost less than $\$ 10,000$ to do a 1-week study.

Kristie Anderson enlisted the local chapter of the International Society of Weighing and Measurement (ISWM) to host its "Scales on Saturday" as a forum for the Washington Task Force to hear from concerned private sector representatives about the need for weights and measures regulation. All members of the Work Group contacted Washington Task Force members to discuss the issue with them in advance. A subgroup composed of Tom Geiler and Darrell Guensler traveled to Washington to carry out the plan. They presented orally and in overhead transparencies an exposition of the necessity for weights and measures. They argued for Washington to audit some part of the marketplace in order to determine whatever the direction they take in weights and measures enforcement, they can measure its effectiveness from the present condition of the marketplace. California State Weights and Measures always makes an audit when a new county weights and measures director assumes office. This is the only way to determine if your program is working as well as, better than, or worse than the former management.

No definitive results from the discussions with the Washington Task Force can yet be reported; the legislative session ended without Washington taking action. 


\section{Appendix $\mathbf{H}$ \\ ISO 9000 Task Force Report to the Executive Committee \\ Interim Meeting, January 12, 1993}

\section{Why is ISO 9000 an Issue?}

For weights and measures enforcement and regulatory activities, ISO 9000 is generally not an issue. An initial assessment of the impact of ISO 9000 on the weights and measures industry led people to believe that there was no impact at all. However, when a laboratory receives a call from customers stating that they need assurance that the laboratory meets ISO 9000 , it becomes an issue. Since many State laboratories rely on non-weights and measures customers for a significant portion of their operating budget, it is essential to meet the needs of this market.

In fact, more and more service companies, that operate in the legal-for-trade arena also provide services for non-legal applications. They are being required to comply with ISO-9000 criteria. This provides an opportunity for States to meet the need for their registered service agents, but we have focused on the need of the laboratory customer.

\section{What do Laboratory Customers Want?}

Simply put, laboratory customers want assurance that the measurement services they receive meet their needs and that the laboratory from which they obtain calibration services meets ISO criteria. According to ISO guidelines, customers must either obtain services from an ISO-9000 registered (or ISO Guide 25 accredited) organization, or they are obligated to audit the organization from which they are obtaining services. Since most people are generally not qualified to assess quality systems and companies usually do not have resources allotted for these audit activities, it is easier and more costeffective to rely on third-party registration (or accreditation,) for assurance.

\section{What is the Common Ground Among OWM, NVLAP and ISO?}

The Office of Weights and Measures (OWM) has managed an accreditation program for State laboratories for more than 25 years. This program has evolved continuously to meet the needs of the laboratories and their customers. The New States Standards Program, as established by Congress in 1965 provided the basis for the laboratory program but it has changed and evolved over the years. State laboratories originally provided services only to support legal metrology, but have increasingly been providing support to industry, government, and scientific institutions.

The NIST National Voluntary Laboratory Accreditation Program (NVLAP) has been given the responsibility to develop an accreditation program for private laboratories consistent with international guidelines. At the same time, NVLAP recognizes that the OWM program has been in place for quite some time with a successful track record. It is a logical progression of NVLAP's

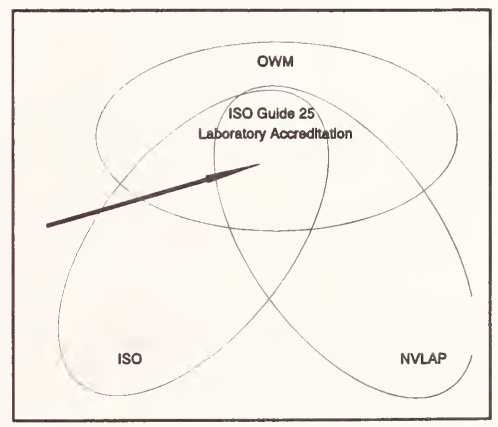

Figure 1 development and OWM's need to upgrade the program that we have chosen to work together toward common goals.

The International Organization for Standardization (ISO) publishes the ISO-9000 standards and ISO Guide 25, which is designed around ISO Standard 9002, but specifically tailored for calibration and testing laboratories. NVLAP and OWM have chosen to formally adopt ISO Guide 25 criteria to facilitate international recognition of U.S. accreditation programs. Figure 1 shows one example of the intersection of activities between these three organizations and ISO Guide 25 .

\section{What is ISO Guide 25?}

Components of Guide 25 are listed in Figures 2 through 5. Many of these components are already part of the OWM State 
laboratory program, so very little will need to be done in most areas to meet the criteria. Documentation of the quality system and procedures is the number one failure of ISO 9000 audits, and will likely be the number one failure in laboratory accreditation audits as well. This is one reason why we have chosen to work on quality manuals at all of the regional metrology meetings during 1993.

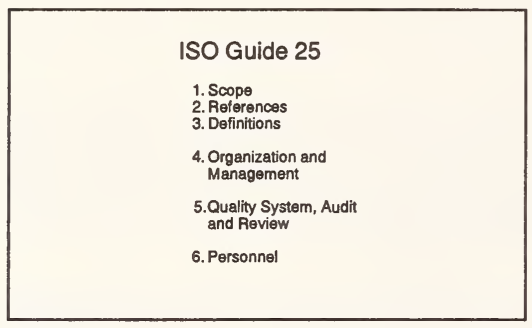

Figure 2

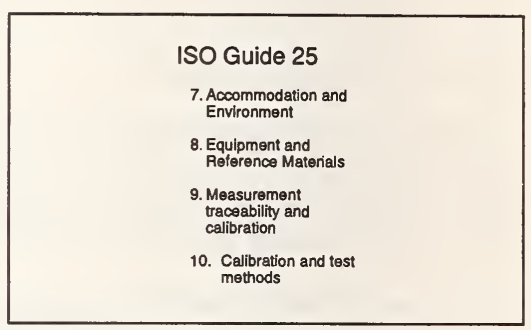

Figure 3

Two additional examples of the implementation of ISO Guide 25 are item numbers 14 and 15 . State laboratories generally do not obtain outside calibration support other than direct NIST calibration. However, many laboratories are seeking to obtain calibration of environmental monitoring equipment through other sources; in this case they must assess the service they get from another laboratory. If the other laboratory is accredited, an audit of their calibration services is not required.

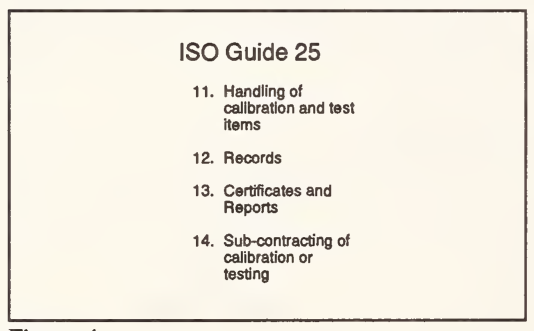

Figure 4

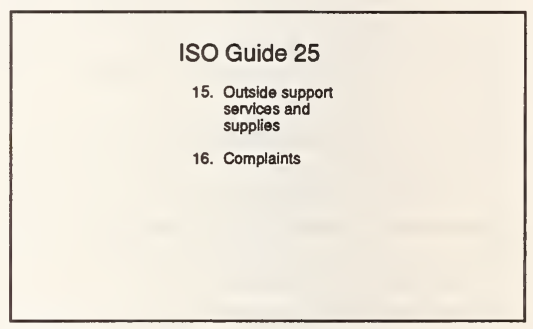

Figure 5

\section{What has Task Force Done? What Will They Do?}

The Task Force activity is summarized in Figure 6; participants have primarily looked for deficiencies in the current program when compared against ISO Guide 25 criteria. This allows us to focus on deficient areas for improvement first. Not only have task force members looked for deficiencies, but they have responded with positive suggestions for improvement. We will not continuously improve with a "get by" mentality; we must have suggestions to exceed our current limits.

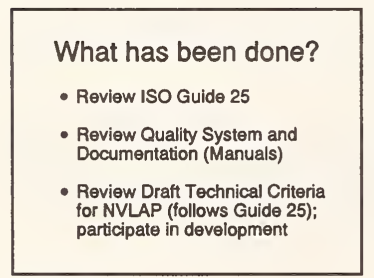

Figure 6
Continued activity of the task force includes review of draft technical criteria for "volume calibration laboratories" and a self-assessment using the completed new criteria and checklist. We also plan to have on-site assessments, using a team approach, for those laboratories who believe that they fully meet the criteria. The major deficiency identified at this time is the lack of a quality manual that contains all required components. 


\section{What are the Benefits of NCWM Coordination?}

The benefits listed in Figure 7 are related to the coordination of activities to assess the current OWM accreditation program, to develop a plan to upgrade the program, and to duplicate the program for NVLAP. We would not be able to get as much done, as quickly, without working together.

Several metrologists on the ISO 9000 Task Force have pointed out that we can look at the benefits of coordinating these upgrading activities, or we can look at the cost of failure. The cost of failure most often noted is the amount of time personnel actually spend preparing for audits and in being audited. A primary goal of coordinated activity among OWM, NCWM, and NVLAP is to ensure that the State laboratories accredited by OWM meet the same criteria as private laboratories and are recognized as such. We hope the recognition to be national and international in scope to eliminate the need for multiple audits.

Another benefit of the recent activity to upgrade the criteria consistent with ISO Guide 25 is that several State metrologists have participated in the process and will be able to augment OWM assessment activities in the State laboratories; this will

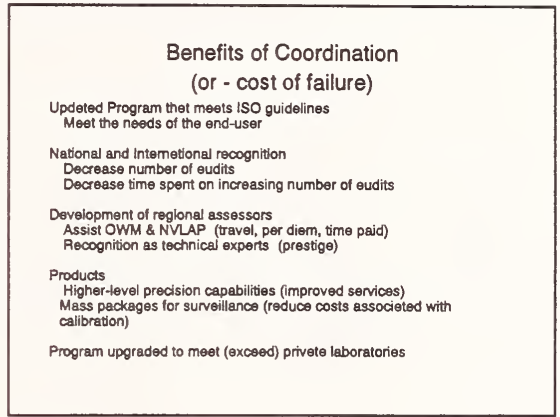

Figure 7 reduce the time between on-site visits. It is expected that reducing the time between on-site visits will allow more timely feedback and opportunity for improvement.

\section{What is OWM Doing to Meet State Needs?}

Training - 1993
At all regional metrology meetings:
1. Writing and Assessing a Laboratory Quality Manual
2. Internal Auditing
3. Technical Management of a Weights and Measures
Laboratory
Advanced Mass Measurements Seminar
1. Provide training in advanced weighing designs to
improve surveillance procedures with computer
assistance in data reduction; and
2.Upgrade potential service to end users.

Figure 8

In addition to regular training provided to metrologists, the OWM accreditation program continues to provide a more comprehensive program than will be available to private industry. These services may at some time be available to private industry, but the NVLAP program is fee-funded and requires cost reimbursement for all support activities. If OWM develops these activities to respond to requests from industry, it will also be fee-funded. Several outstanding components of the OWM program are listed in Figure 9. One such feature of the development and management of the OWM program is that it continues to evolve and meet the needs of the laboratory's and their customers through teamwork and the joint efforts of State metrologists and OWM. As was mentioned before, we can effectively meet the challenges, if we continue to work together as a team.
A memorandum dated December 30, 1992, to State Weights and Measures Directors and Metrologists identified a number Committee. The training OWM will provide at each of the regional metrology meetings during 1993 is summarized in Figure 8 , but the memorandum details training information that will be provided in response to upgrading the program to meet ISO Guide 25 general criteria. Directors, supervisors, and laboratory managers are welcome to participate in the regional training to allow States to adapt these recommendations for the entire weights and measures program.

OWM and State Metrologists
Continuing to Meet the Challenge
Training
Evaluation of Data
Technical Advice
Assistance with Measurement Needs
Proficiency Testing
Cooperative Relationship
Better Services
Professional Staff Development

Figure 9 of issues that were presented in this report to the Executive 


\begin{tabular}{|c|c|c|c|c|c|c|c|c|c|c|c|c|c|c|c|}
\hline & \multirow{3}{*}{ 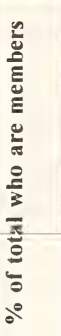 } & 2 & iे & $\underset{\sim}{\stackrel{D}{\infty}}$ & $\begin{array}{l}\vec{\partial} \\
\text { Dे }\end{array}$ & & in & $\underset{I}{\dot{I}}$ & & $\dot{\bar{N}}$ & $\stackrel{\vec{\infty}}{\underline{\infty}}$ & $\underset{\text { i }}{\infty}$ & & & 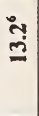 \\
\hline & & $\tilde{\sigma}$ & $\underset{⿱ 亠 凶}{\sigma}$ & 苛 & $\stackrel{3}{5}$ & & in & $\overrightarrow{0}$ & & $\stackrel{\infty}{\bar{N}}$ & $\overline{\mathbb{N}}$ & $\overline{\text { n }}$ & & & $\stackrel{\circ}{\stackrel{\leftrightarrow}{\circ}}$ \\
\hline & & $\bar{a}$ & $\stackrel{\sim}{\sigma}$ & :̊. & 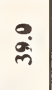 & & $\stackrel{\bullet}{\vec{j}}$ & $\begin{array}{l}\infty \\
\underline{\operatorname{m}}\end{array}$ & & 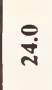 & $\hat{\vec{j}}$ & & & & 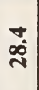 \\
\hline \multirow{3}{*}{ 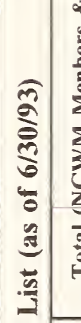 } & \multirow{3}{*}{ 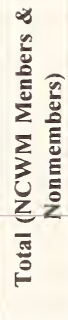 } & 2 & $\underline{n}$ & $\bar{n}$ & f & $\stackrel{n}{n}$ & $\begin{array}{l}\text { ळ. } \\
\stackrel{2}{2}\end{array}$ & $\stackrel{\text { సે }}{\circ}$ & $\begin{array}{l}\text { Z } \\
\stackrel{\mathrm{o}}{\circ}\end{array}$ & $\vec{\sim}$ & 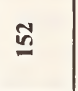 & $\hat{6}$ & $\widetilde{\Xi}$ & $\overline{\widetilde{m}}$ & 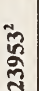 \\
\hline & & $\tilde{\alpha}$ & $\begin{array}{l}\stackrel{0}{\infty} \\
\stackrel{n}{n}\end{array}$ & $\hat{\mathscr{\alpha}}$ & $\bar{n}$ & $\stackrel{\Leftrightarrow}{m}$ & $\begin{array}{l}\tilde{0} \\
0 \\
0\end{array}$ & $\stackrel{\Xi}{\sim}$ & 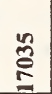 & లె & $\stackrel{\infty}{=}$ & 串 & อั & జ్లె & 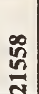 \\
\hline & & $\bar{\sigma}$ & $\stackrel{\tilde{n}}{\underline{n}}$ & $\frac{\mathscr{2}}{2}$ & $\begin{array}{l}\mathscr{0} \\
\ddot{n}\end{array}$ & 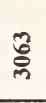 & $\underset{\sim}{\stackrel{n}{N}}$ & 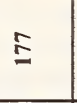 & $\underset{乛}{\approx}$ & 今ે & $\stackrel{\varrho}{\varrho}$ & & $\frac{0}{m}$ & $\tilde{\pi}$ & 芯 \\
\hline \multirow{8}{*}{ 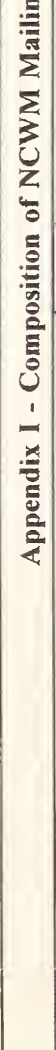 } & \multirow{3}{*}{ z } & 2 & $\underset{R}{\stackrel{2}{2}}$ & $\stackrel{\infty}{\infty}$ & 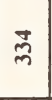 & $\underset{0}{*}$ & 疍 & $\stackrel{\infty}{\cong}$ & $\stackrel{5}{\Xi}$ & $\cong$ & $\underset{\Xi}{ \pm}$ & క్ & ठूे & $\bar{m}$ & 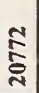 \\
\hline & & $\alpha$ & $\stackrel{\infty}{\infty}$ & 怘 & 号 & $\stackrel{8}{=}$ & $\bar{\Xi}$ & $\bar{n}$ & $\tilde{\sigma}$ & $\stackrel{\circ}{\infty}$ & $\alpha$ & ले & స్ర & ల్లె & ڤ్జ \\
\hline & & $\bar{a}$ & $\stackrel{\infty}{\stackrel{\infty}{*}}$ & in & 点 & $\Xi$ & 离 & $\stackrel{\hat{z}}{ }$ & 㻤 & 点 & $\vec{\infty}$ & & $\bar{J}$ & $\tilde{\mathrm{s}}$ & $\underset{\infty}{\mathbb{\infty}}$ \\
\hline & \multirow{4}{*}{ 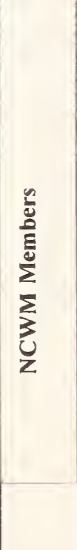 } & 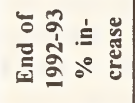 & & & & $\stackrel{0}{i}$ & & & $\overline{\mathbf{i}}$ & \multicolumn{4}{|c|}{ i } & & 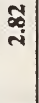 \\
\hline & & 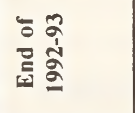 & $\frac{m}{\infty}$ & 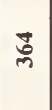 & $\frac{m}{N}$ & స్ & 喜 & ల్ల & $\stackrel{5}{6}$ & F & $\stackrel{\sim}{~}$ & in & $\Xi$ & & $\overline{\overline{0}}$ \\
\hline & & 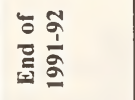 & oे & $\vec{\Phi}$ & 气े & $\stackrel{n}{2}$ & $\frac{\pi}{6}$ & సి & $\stackrel{?}{6}$ & เి & i & $\stackrel{2}{2}$ & $\alpha$ & & స్ల్ \\
\hline & & 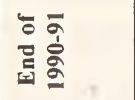 & $\hbar$ & हे & $\underset{\sim}{\mathbb{ే}}$ & 记 & $\stackrel{n}{\underline{x}}$ & $\stackrel{\sim}{\mathbf{N}}$ & $\stackrel{\mathbb{Z}}{=}$ & เి & $\approx$ & & $\approx$ & & 흘 \\
\hline & 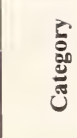 & & 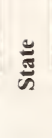 & 远 & $\vec{z}$ & 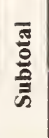 & 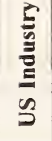 & 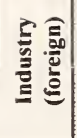 & $\begin{array}{l}\bar{g} \\
\text { है } \\
\text { है } \\
\text { के }\end{array}$ & 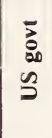 & 童 & 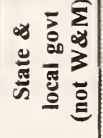 & 嵒 & 离 & 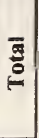 \\
\hline
\end{tabular}

(5)

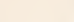




\section{Appendix $\mathbf{J}$ \\ National Conference on Weights and Measures \\ Draft Budget for 1994 (Jan 1 - Dec 31) \\ Compared with 1992 Actual and 1993 Budget}

\section{Chart of NCWM Accounts}

\section{Balance Sheet Accounts}

100 Series Accounts for Assets

200 Series Accounts for Liabilities
Income and Expense Accounts

400 Series Accounts for Income 500 Series Accounts for Expenses

Accrued expenses for consumer brochure and Interim Meeting committee expenses obligated but not yet paid as of December 31, 1992 are shown in estimated form. The accounts are shown in the following tables.

\begin{tabular}{|c|c|c|c|}
\hline \multicolumn{4}{|c|}{ Balance Sheet Accounts } \\
\hline \multicolumn{2}{|l|}{ Assets } & \multicolumn{2}{|c|}{ Liabilities } \\
\hline \multicolumn{4}{|c|}{ Carry-Over as of Jan 1, 1993} \\
\hline 111 Signet Bank & 314.24 & $\begin{array}{l}210 \text { Expenses } \\
\text { accrued from } \\
1992\end{array}$ & \\
\hline $\begin{array}{l}112 \text { European American Bank - NCWM } \\
\text { General }\end{array}$ & $59,583.91$ & Publication 2 printing & $\$ 6,242$ \\
\hline $\begin{array}{l}113 \text { European American Bank - NCWM } \\
\text { Associate }\end{array}$ & $8,878.35$ & Consumer pamphlet & $\$ 20,500$ \\
\hline 110 Liquitd Assets & $68,776.50$ & & \\
\hline $\begin{array}{ll}121 & \text { Certificate of Deposit \#2 } \\
122 & \text { Certificate of Deposit \#1 }\end{array}$ & $\begin{array}{l}12,572.29 \\
27,277.22\end{array}$ & & \\
\hline 125 Equipment & & & \\
\hline $\begin{array}{l}126 \text { Accumulated Depreciation on Equi- } \\
\text { pment }\end{array}$ & 0 & & \\
\hline 120 Other Assets & 39.849 .51 & & \\
\hline 100 Total Assets & $\$ 108,626.01$ & 200 Total Litabilities & 26.742 \\
\hline
\end{tabular}

\section{Income and Expense Accounts}

Income is of two types:

(1) that from general revenues (i.e., membership and registration fees) [410 series] and

(2) that from reimbursables (i.e., sale of publications, special events, etc.) [480 series].

Similarly, expenses are

(1) those paid from general revenues (i.e., meetings) [510 series] and

(2) those incurred for services provided (i.e., cost of printing publications for sale, underwriting training, etc.) [580 series]. 


\section{General Revenues and Expenses}

General Revenue and Expense accounts are shown in the following tables, Income and Expense Accounts. General Revenues are Registration Fees, Membership Fees, and Other Income (interest, etc.). These have been assigned to the 410 series of accounts for income and 510 series for expense.

General Expenses are categorized into eight areas:

(1) Annual Meeting;

Conference Coordinator has shifted optional event costs directly to tour contractors; associate membership outing was decided to be a joint outing, costs incurred by NCWM will be shown here; for example, in 1993, this will be cost of busses to rodeo.

(2) Interim Meeting;

(3) Travel expenses of standing and annual committee members (other than that associated with the Annual and Interim Meetings);

(4) Travel expenses of members of Task Forces and Special Committees;

(5) Expenses of the Chairman and Chairman-Elect;

(6) Administration of the business of the NCWM, including the National Training Program (NTP);

(7) Printing and publication expenses; and

(8) Training delivery including Train-the-Trainer

\section{Reimbursable Accounts}

Reimbursable accounts (income and expense) are categorized into six areas:

(1) Special (optional) events have been shifted entirely to outside contractor in 1993. This will be the aim for all future years.

(2) Publications (NTP modules, NCWM publications, videos);

(3) NTEP Operations for which an NTEP maintenance fee is planned;

This includes underwriting travel and per diem costs of public sector participation on standards-development meetings of the National Type Evaluation Technical Committee Sectors, and other associated work groups; costs for administering the billing and accounts; costs for publishing and maintaining Publication 5, the index of NTEP Certificates; the costs of meetings of the Participating Laboratory personnel to maintain uniformity in interpretation and application; the costs of obtaining mutual recognition of NTEP with Canada; and any special meeting costs for conduct of an NTEP Appeal. Other labor costs are underwritten by the public or private sector organization contributing their staff and delegate time to the work.

(4) National Training Program including reimbursable training delivery;

(5) Promotional materials; and

(6) Grain equipment cooperative agreement with NIST and the U.S. Department of Agriculture Federal Grain Inspection Service (this underwrites NTEP development costs for Grain Moisture and Protein Analyzer Sectors).

\section{Operating Budget for Fiscal Years 1992, 1993, and 1994}

(Jan 1 to Dec 31)

The Operating Budget is shown in four tables. Table 1 shows income in the major accounts; Table 2 shows expenses. For each account, the information provided includes:

the account number and description;

the proposed budget for 1994;

the budget for 1993;

the comparable actual amount for the FY 1992.

Table 3 shows the subaccounts for income and Table 4 shows the subaccounts for expenses. Each of the tables contains notes to provide additional insight into the derivation of the budget entries. 
Table 1. Income

\begin{tabular}{|c|c|c|c|c|}
\hline Number & $\begin{array}{l}\text { Account } \\
\text { Description }\end{array}$ & $\begin{array}{c}\text { FY 94 } \\
\text { Proposed } \\
\text { Budget } \\
\end{array}$ & $\begin{array}{c}\text { FY } 93 \\
\text { Revised } \\
\text { Budget } \\
\end{array}$ & FY 92 Actual \\
\hline \multicolumn{5}{|c|}{ General Funds } \\
\hline 481 & Registration Fees & $\$ 66,000$ & $\$ 38,000$ & $\$ 35,850$ \\
\hline \multicolumn{5}{|c|}{$\begin{array}{l}\text { If registration for Annual Meeting is raised from } \$ 100 \text { to } \$ 150,300 \text { registrants will generate another } \$ 15,000 \text { (from } \\
\$ 30,000 \text { at the } \$ 100 \text { fee to } \$ 45,000 \text { income at the } \$ 150 \text { fee.) } \\
\text { If registration for Interim Meeting is raised from } \$ 50 \text { to } \$ 150 \text { for industry and to } \$ 100 \text { for public sector members: of } \\
184 \text { registrants in } 1993,148 \text { paid the } \$ 50 \text { fee and there were about } 45 \text { active members present. Therefore only about } \\
10 \text { active members paid the } \$ 50 \text { registration fee. Estimating } 140 \text { paid associate member registrants in } 1994 \text {, a } \$ 150 \\
\text { registration will generate } \$ 21,000 \text {. }\end{array}$} \\
\hline 412 & Membership Fees & $\$ 122,500$ & $\$ 122,500$ & $\$ 117,505$ \\
\hline 413 & Interest & $\$ 1,000$ & $\$ 2,000$ & $\$ 3,027.73$ \\
\hline 414 & Associate Membership Account & $-0-$ & -0 & $\$ 22,635.00$ \\
\hline 416 & Other Income & 0 & 0 & 0 \\
\hline 410 & Income, General Fund & $\$ 189,500$ & $\$ 162,500$ & $* 179,017.73$ \\
\hline \multicolumn{5}{|c|}{ Expense \& Income (Reimbursable) } \\
\hline 481 & Special Events & $\$ 2,000$ & $\$ 6,000$ & $\$ 14,321.75$ \\
\hline 482 & Publications & $\$ 20,000$ & $\$ 15,000$ & $\$ 9,988.25$ \\
\hline 484 & NTEP, Operations & $\$ 92,000$ & $-0-$ & $\$ 1,630.00$ \\
\hline 484 & NTP, Seminars & $\$ 6,000$ & $\$ 3,000$ & $\$ 1,630.00$ \\
\hline 485 & Promotional & $\$ 2,000$ & $\$ 200$ & $\$ 110.00$ \\
\hline 486 & $\begin{array}{l}\text { Grain Equipment Cooperative Agre- } \\
\text { ement }\end{array}$ & $\$ 15,000$ & $\$ 15,000$ & $\$ 8,511.36$ \\
\hline 480 & Income, E\&I & $\$ 137,000$ & $\$ 39,200$ & $36,161.36$ \\
\hline \multicolumn{5}{|c|}{ Total Income } \\
\hline 400 & Total Income & $\$ 326,500$ & $\$ 201,700$ & $\$ 215,392.81$ \\
\hline
\end{tabular}

Table 2. Expenses

\begin{tabular}{|c|c|c|c|c|}
\hline \multicolumn{2}{|r|}{ Account } & \multirow{2}{*}{$\begin{array}{c}\text { FY 94 } \\
\text { Proposed } \\
\text { Budget }\end{array}$} & \multirow{2}{*}{$\begin{array}{c}\text { FY 93 } \\
\text { Revised } \\
\text { Budget } \\
\end{array}$} & \multirow[b]{2}{*}{ FY 92 Actual } \\
\hline Number & Description & & & \\
\hline \multicolumn{5}{|c|}{ General Funds } \\
\hline 511 & Annual Meeting & $\$ 44,000$ & 41,900 & $\$ 34,437.99$ \\
\hline 512 & Interim Meeting & $\$ 37,500$ & 46,200 & $\$ 31,924.48$ \\
\hline 513 & Travel-Committees & $\$ 17,000$ & 33,300 & $\$ 17,051.52$ \\
\hline 514 & Travel-Task Forces/Special Committees & $\$ 17,700$ & 25,900 & $\$ 18,778.68$ \\
\hline 515 & Chairman/Chair Elect & $\$ 22,000$ & 20,000 & $\$ 18,695.25$ \\
\hline 514 & Administration & $\$ 36,500$ & 34,000 & $\$ 32,872.19$ \\
\hline 517 & Printing/Publications & $\$ 13,500$ & 21,500 & $\$ 12,275.13$ \\
\hline 518 & Training \& Train-the-Trainer & $-0-$ & 15,000 & $3,327.48$ \\
\hline 510 & Expenses, General Fund & $\$ 188,200$ & $\$ 237,800$ & $69,362,72$ \\
\hline \multicolumn{5}{|c|}{ Expense \& Income (Reimbursable) } \\
\hline 581 & Special Events & $\$ 2,000$ & $\$ 4,000$ & $\$ 18,744.82$ \\
\hline 582 & Publications & $\$ 13,500$ & $\$ 11,500$ & $\$ 5,415.33$ \\
\hline 583 & NTEP, Operations & $\$ 87,500$ & $-0-$ & $\$ 16,179.73$ \\
\hline
\end{tabular}




\begin{tabular}{|c|c|c|c|c|}
\hline Number & $\begin{array}{l}\text { Account } \\
\text { Description }\end{array}$ & $\begin{array}{c}\text { FY 94 } \\
\text { Proposed } \\
\text { Budget } \\
\end{array}$ & $\begin{array}{c}\text { FY } 93 \\
\text { Revised } \\
\text { Budget }\end{array}$ & FY 92 Actual \\
\hline 584 & NTP, Seminars & $\$ 6,000$ & $\$ 6,000$ & $\$ 2,424.50$ \\
\hline 585 & Promotional & $\$ 2,000$ & -0 & -0 \\
\hline 586 & Grain Equipment Cooperative Agreement & $\$ 15,000$ & $\$ 15,000$ & $\$ 14,535.90$ \\
\hline 580 & Expinses, E\&I & $\$ 125,000$ & $\$ 36,500$ & 57,30028 \\
\hline \multicolumn{5}{|c|}{ Total Expenses } \\
\hline 500 & Total Expenses & $\$ 313,200$ & $\$ 274,300$ & $\$ 226,663,00$ \\
\hline
\end{tabular}

Table 3. Subaccounts of Income

\begin{tabular}{|c|c|c|c|c|}
\hline Number & $\begin{array}{l}\text { Account } \\
\text { Description }\end{array}$ & $\begin{array}{l}\text { Proposed } \\
\text { FY } 94 \\
\text { Budget } \\
\end{array}$ & $\begin{array}{l}\text { FY } 93 \\
\text { Budget }\end{array}$ & $\begin{array}{l}\text { FY } 92 \\
\text { Actual }\end{array}$ \\
\hline \multicolumn{5}{|c|}{ Registration Fees } \\
\hline 411.1 & $\begin{array}{l}\text { Registration Fees: } \\
\text { Annual Meeting }\end{array}$ & $\$ 45,000$ & $\$ 30,000$ & $\$ 27,800$ \\
\hline 411.2 & $\begin{array}{l}\text { Registration Fees: } \\
\text { Interim Meeting }\end{array}$ & $\$ 21,000$ & $\$ 8,000$ & $\$ 8,050$ \\
\hline 411 & Regfstration fees; Total & $\$ 66,000$ & $\$ 38,000$ & $\$ 35,850$ \\
\hline 412 & Membership Fees & $\$ 122,500$ & $\$ 122,500$ & $\$ 117,505$ \\
\hline 413 & $\begin{array}{l}\text { Interest on Certificates of Deposit and checking } \\
\text { account }\end{array}$ & $\$ 1,000$ & $\$ 2,000$ & $\$ 3,027.73$ \\
\hline 416 & Associate Membership Account & & 0 & $\$ 22,635.00$ \\
\hline 416 & Other Income & 0 & 0 & 0 \\
\hline 410 & Income, General funds & $\$ 189,500$ & $\$ 162,500$ & $\$ 179,017.3$ \\
\hline \multicolumn{5}{|c|}{ Expense \& Income (Reimbursable) } \\
\hline 481.1 & Annual Meeting & $\$ 1,000$ & $\$ 3,000$ & $9,921.50$ \\
\hline 481.2 & Interim Meeting & $\$ 1,000$ & $\$ 1,000$ & 213.72 \\
\hline 481.3 & Receptions & $-0-$ & $\$ 2,000$ & $4,400.25$ \\
\hline 481 & Spectal Events & 2,000 & 36,000 & 14.321 .75 \\
\hline 482.1 & Pubs: NTP Modules & $\$ 3,000$ & $\$ 2,000$ & $\$ 931.00$ \\
\hline 482.2 & Pubs: NCWM Publications & $\$ 10,000$ & $\$ 7,000$ & $\$ 8,251.00$ \\
\hline 482.3 & Pubs: Videotapes & $\$ 7,000$ & $\$ 6,000$ & 0 \\
\hline 482.1 & Pubs: Handbook 133, 3rd Ed & $-0-$ & $-0-$ & 806.25 \\
\hline 482 & Publications: total & 20,000 & 515,000 & $9,988.25$ \\
\hline 483.1 & NTEP: Logo Sales & $\$ 1,500$ & $-0-$ & $\$ 1,000$ \\
\hline 483.2 & NTEP: Maintenance Fee & $\$ 87,500$ & $-0-$ & - \\
\hline 483.3 & NTEP: Publications Sales & $\$ 3,000$ & $-0-$ & - \\
\hline 483 & NTEP Operations: & $\$ 92,000$ & 0 - & 100000 \\
\hline 484 & NY Seminars & $\$ 6,000$ & 33,000 & 163000 \\
\hline 485 & Promotional & $\$ 2,000$ & $\$ 200$ & $\$ 110.00$ \\
\hline 486 & Grain Ecutprnent Cooperative Agreenent & $\$ 15,000$ & $\$ 15,000$ & 8,51136 \\
\hline 489 & Incone, ER: & $\$ 137,000$ & $\$ 39,000$ & $36.61,36$ \\
\hline 400 & Total fncone & $\$ 326,500$ & $\$ 201,500$ & $\$ 215,392.81$ \\
\hline
\end{tabular}


Table 4. Subaccounts of Expenses

\begin{tabular}{|c|c|c|c|c|c|}
\hline Account Number & $\begin{array}{c}\text { Sub } \\
\text { Account }\end{array}$ & Description & $\begin{array}{l}\text { Proposed } \\
\text { FY } 94 \\
\text { Budget }\end{array}$ & $\begin{array}{l}\text { Budget } \\
\text { FY 93 }\end{array}$ & $\begin{array}{l}\text { Actual } \\
\text { FY } 92\end{array}$ \\
\hline \multicolumn{6}{|l|}{ Annual Meeting: } \\
\hline \multirow[t]{9}{*}{ Annual Meeting } & 511.1. & $\begin{array}{l}\text { Hotel, Food Service, Meeting } \\
\text { services, etc. }\end{array}$ & $\$ 22,000$ & $\$ 20,000$ & $\$ 15,877.39$ \\
\hline & 511.2 & Equipment, AV, Office, Supplies & $\$ 4,500$ & 4,000 & $\$ 3,475.87$ \\
\hline & 511.3 & Personnel, Photographer & $\$ 2,500$ & 2,000 & $\$ 1,419.25$ \\
\hline & 511.4 & Printing/Copying & $\$ 4,500$ & 4,000 & $\$ 3,027.89$ \\
\hline & 511.5 & Awards & $\$ 4,500$ & 2,900 & $\$ 4,819.19$ \\
\hline & 511.6 & Treasurer \& Committee Expenses & $\$ 1,000$ & $\$ 1,000$ & $\$ 187.00$ \\
\hline & 511.7 & Printing of Announcement Book & $\$ 8,000$ & $\$ 8,000$ & $\$ 5,631.40$ \\
\hline & $511 . ?$ & Associate Membership Account & $-0-$ & $-0-$ & $\$ 11,145.15$ \\
\hline & 511.7 & Miscellaneous & $-0-$ & 0 & 0 \\
\hline 511 & & Annual Meeting & $\$ 44,000$ & $\$ 41,900$ & $\$ 34,437.99$ \\
\hline \multicolumn{6}{|l|}{ Interim Meeting } \\
\hline \multirow[t]{9}{*}{ Interim Meeting } & 512.4 & Hotel, Food Service & $\$ 16,500$ & $\$ 15,000$ & $\$ 14,234.75$ \\
\hline & 512.2 & Equipment, Personnel, Printing & $\$ 1,000$ & $\$ 3,000$ & $\$ 224.50$ \\
\hline & 512.9 & Exec Committee & $\$ 4,500$ & 4,000 & $\$ 3,541.20$ \\
\hline & 512.4 & L\&R Committee & $\$ 2,300$ & 2,000 & $\$ 1,468.90$ \\
\hline & 512.5 & S\&T Committee & $\$ 2,300$ & 2,000 & $\$ 2,114.90$ \\
\hline & 512.6 & Education Committee & $\$ 2,300$ & 2,000 & $\$ 1,652.70$ \\
\hline & 512.7 & Liaison Committee & $-0-$ & 2,000 & $\$ 643.20$ \\
\hline & 512.8 & $\begin{array}{l}\text { Other Committees \& TF/Nomina- } \\
\text { ting, Budget Review, Auditing }\end{array}$ & $\$ 4,000$ & 5,000 & $\$ 2,381.70$ \\
\hline & 512.9 & Printing of Agenda & $\$ 1,000$ & 7,000 & $\$ 5,662.63$ \\
\hline 512 & & Interim Mecting & $\$ 37.500$ & 46,200 & $\$ 31,924.48$ \\
\hline \multicolumn{6}{|c|}{ Committee Travel - Other } \\
\hline \multirow[t]{7}{*}{ Cmte Travel -Other } & 513.1 & Executive Committee & $\$ 4,500$ & $\$ 7,000$ & $\$ 1,531.18$ \\
\hline & 513.2 & $\begin{array}{l}\text { Laws \& Regulations Committee } \\
\text { (H133 Work Group) }\end{array}$ & $\$ 5,000$ & $\$ 3,500$ & 0 \\
\hline & 513.3 & $\begin{array}{l}\text { Specifications \& Tolerances } \\
\text { Committee (Solid Volume } \\
\text { Devices Work Group) }\end{array}$ & $\$ 5,000$ & 3,500 & $\$ 3,539.64$ \\
\hline & 513.4 & Education Committee & $-0-$ & 3,500 & 0 \\
\hline & 513.5 & Liaison Committee & $-0-$ & 0 & 0 \\
\hline & 513.6 & $\begin{array}{l}\text { NTE Technical Committees: } \\
2 \text { weighing sector; } 1 \text { meas sector; } \\
1 \text { belt conveyor }\end{array}$ & $-0-$ & $\$ 14,000$ & $\$ 11,980.70$ \\
\hline & 513.7 & Annual Committees & $\$ 2,500$ & 1,800 & 0 \\
\hline 513 & & Travel - Committees & $\$ 17,000$ & 33,300 & $\$ 17.051 .52$ \\
\hline \multicolumn{6}{|c|}{ Travel - Task Forces, Work Groups, special committees } \\
\hline \multirow[t]{2}{*}{$\begin{array}{l}\text { Travel - TF, WG, } \\
\text { special committees }\end{array}$} & 514.1 & $\begin{array}{l}\text { Privatization Work Group and TF } \\
21 \text { st Century }\end{array}$ & $\$ 5,200$ & 3,500 & $\begin{array}{l}\$ 4293.90 \\
\$ 2246.91\end{array}$ \\
\hline & 514.2 & Checkweigher Work Group & $-0-$ & $\$ 2,900$ & 0 \\
\hline
\end{tabular}


Executive Committee

\begin{tabular}{|c|c|c|c|c|c|}
\hline Account Number & $\begin{array}{c}\text { Sub } \\
\text { Account }\end{array}$ & Description & $\begin{array}{c}\text { Proposed } \\
\text { FY } 94 \\
\text { Budget }\end{array}$ & $\begin{array}{l}\text { Budget } \\
\text { FY } 93\end{array}$ & $\begin{array}{l}\text { Actual } \\
\text { FY } 92\end{array}$ \\
\hline & 514.3 & OIML & $\$ 3,000$ & $\$ 3,000$ & 0 \\
\hline & 514.9 & FPLA - Metric Work Group & -0 & 0 & 0 \\
\hline & 514.5 & $\begin{array}{l}\text { U.S. - Canada Mutual } \\
\text { Recognition Work Group }\end{array}$ & -0 & $\$ 7,000$ & $\$ 3,319.48$ \\
\hline & 514.6 & Petroleum Subcommittee & $\$ 5,000$ & $\$ 5,000$ & $\$ 4,207.49$ \\
\hline & 514.9 & ISO 9000 Task Force & $\$ 3,500$ & 3,500 & $\$ 3,546.80$ \\
\hline & 514.9 & Miscellaneous & $\$ 1,000$ & $\$ 1,000$ & $\$ 1,164.10$ \\
\hline 514 & & $\begin{array}{l}\text { Travel - Task Forces, Spectal } \\
\text { Committees: }\end{array}$ & 17,700 & 25,900 & $818,778.68$ \\
\hline \multicolumn{6}{|l|}{ Chairman/Chair-Elect } \\
\hline \multirow[t]{3}{*}{ Chairman/Chair Elect } & 515.1 & Chairman, Travel, per diem & $\$ 10,250$ & $\$ 10,000$ & $\$ 8,550.75$ \\
\hline & 515.2 & Chairman-Elect, Travel, per diem & $\$ 10,250$ & 10,000 & $\$ 10,000$ \\
\hline & 515.3 & Breakfast Meetings at Regionals & $\$ 1,500$ & 0 & $\$ 144.50$ \\
\hline 515 & & Chairman Chairman Elect & 22,00000 & 20,000 & 818.695 .25 \\
\hline \multicolumn{6}{|l|}{ Administration } \\
\hline \multirow[t]{7}{*}{ Administration } & 516.4 & Equipment & 1,000 & 1,000 & $\$ 1,407.38$ \\
\hline & 516.2 & Contracts, Personnel & $\$ 32,000$ & 30,000 & $29,993.31$ \\
\hline & 516.3 & Mailing \& PO Box & $\$ 500$ & 500 & $\$ 273.52$ \\
\hline & 516.4 & Treasurer's bond & $\$ 500$ & 500 & 0 \\
\hline & 516.9 & Bank Charges & $\$ 500$ & 500 & $\$ 20.00$ \\
\hline & 516.6 & $\begin{array}{l}\text { NTP (CEU registry, copyright, } \\
\text { equipment, supplies) }\end{array}$ & $\$ 1,500$ & 1000 & $\$ 1,024.00$ \\
\hline & 516.9 & Miscellaneous & $\$ 500$ & 500 & $\$ 156.48$ \\
\hline 516 & & Administration & $\$ 36,500$ & 34,000 & $\$ 32,872,19$ \\
\hline \multicolumn{6}{|l|}{ Publications } \\
\hline \multirow[t]{5}{*}{ Publications } & 517.1 & Membership & $\$ 4,500$ & 3,500 & $\$ 2,089.50$ \\
\hline & 517.2 & NCWM Publications for members & $\$ 3,500$ & $\$ 7,000$ & $\$ 769.30$ \\
\hline & 517.3 & Consumer Pamphlet & $-0-$ & $\$ 5,000$ & $\$ 4,500$ \\
\hline & 517.4 & Video updates of $\mathrm{H}-44 / \mathrm{H} 130$ & $\$ 5,000$ & $\$ 5,000$ & $\$ 4,916.33$ \\
\hline & 517.9 & Miscellaneous & $\$ 500$ & 1,000 & 0 \\
\hline 517 & & Printing and Plibfications & 13,500 & 81,500 & 612.275 .13 \\
\hline \multicolumn{6}{|l|}{ Training } \\
\hline \multirow[t]{2}{*}{ Training } & 516.4 & Train-the-Trainer & $-0-$ & 0 & $\$ 3,327.48$ \\
\hline & 518.2 & Training & $-0-$ & $\$ 15,000$ & 0 \\
\hline 518 & & Trarning & 0 . & $\$ 15,000$ & $\$ 3.327 .48$ \\
\hline \multicolumn{6}{|c|}{ Reimbursables } \\
\hline \multicolumn{6}{|c|}{ Reimbursable Special Events } \\
\hline \multirow[t]{3}{*}{ Special Events } & 581.1 & Annual Meeting & 1,000 & 4,000 & $\$ 7,599.67$ \\
\hline & 581.4 & Joint Outing & $-0-$ & $-0-$ & $\$ 11,145.15$ \\
\hline & 581.2 & Interim Meeting & 1,000 & -0 & 0 \\
\hline 581 & & Spectal Events - Reimbursable & $\$ 2,000$ & $\$ 4,000$ & $\$ 18,744.82$ \\
\hline
\end{tabular}




\begin{tabular}{|c|c|c|c|c|c|}
\hline Account Number & $\begin{array}{c}\text { Sub } \\
\text { Account }\end{array}$ & Description & $\begin{array}{c}\text { Proposed } \\
\text { FY 94 } \\
\text { Budget }\end{array}$ & $\begin{array}{l}\text { Budget } \\
\text { FY 93 }\end{array}$ & $\begin{array}{l}\text { Actual } \\
\text { FY } 92\end{array}$ \\
\hline \multirow[t]{4}{*}{ Publications } & 582.1 & NTP, Modules & $\$ 5,000$ & 5,000 & $\$ 2,388.03$ \\
\hline & 582.2 & $\begin{array}{l}\text { NCWM, Publications (not } \\
\text { Agenda or Announcement Book) }\end{array}$ & $\$ 7,500$ & $\$ 6,500$ & $\$ 2,670.14$ \\
\hline & 582.3 & Videotapes & $\$ 1,000$ & 500 & $\$ 357.16$ \\
\hline & 582.4 & H-133, 3rd Edition & $-0-$ & 0 & 0 \\
\hline 582 & & Prubfications - Reimbursable & $13,500,00$ & 12,000 & $\$ 5.415 .33$ \\
\hline \multicolumn{6}{|c|}{ Reimbursable NTEP Operations } \\
\hline \multirow[t]{9}{*}{ NTEP Operations } & 583.1 & $\begin{array}{l}\text { Executive Committee - Board of } \\
\text { Governors }\end{array}$ & $\$ 7, \$ 00$ & 7,000 & $\$ 1,531.18$ \\
\hline & 583.2 & NTETC: Weighing Sector & $\$ 12,000$ & 8,000 & $\$ 4525.39$ \\
\hline & 583.3 & NTETC: Measuring Sector & $\$ 5,000$ & $\$ 3000$ & $\$ 3344.57$ \\
\hline & 583.4 & NTETC: Belt Conveyor Scale & $\$ 3,500$ & $\$ 3000$ & $\$ 2414.97$ \\
\hline & 583.5 & Checkweigher Work Group & $\$ 6,000$ & $\$ 2,900$ & 0 \\
\hline & 583.6 & $\begin{array}{l}\text { U.S. - Canada Mutual } \\
\text { Recognition Work Group }\end{array}$ & $\$ 10,000$ & $\$ 7,000$ & $\$ 3,319.48$ \\
\hline & 583.7 & $\begin{array}{l}\text { Participating Lab Conference- } \\
\text { Training }\end{array}$ & $\$ 10,000$ & & \\
\hline & 583.8 & NTEP Personnel/cashier/clerk & $\$ 22,000$ & & \\
\hline & 583.9 & NTEP Publications Pub 14/5 & $\$ 12,000$ & & \\
\hline 583 & & NTEP Operations & $\$ 87,500$ & -0 & $\$ 16,179,73$ \\
\hline 584 & & NTP Serninars & $\$ 6,000$ & $\$ 3,000$ & $\$ 2,424,50$ \\
\hline 585 & & Promotions & $\$ 1,000$ & 0. & 0 \\
\hline 586 & & Grain Cooperative Agreement & $\$ 15,000$ & $\$ 15,000$ & $\$ 14,535.90$ \\
\hline 580 & & Total Reimbursable & $\$ 125,000$ & $\$ 36,500$ & $\$ 57,300: 28$ \\
\hline
\end{tabular}

Carryover assets from Jan 1, 1993:

Actual carry over Jan 1, 1993: $\quad 108,626.01-8,878.35$ moved to Associate Membership bank account $=\$ 99,747.36$

Estimated Income 93

Estimated Expenses 93
$201,700.00$

$274,300.00$

Estimated carry over Jan 1, 1994: 27,147.36 


\section{Appendix K \\ ASTM Report \\ N. David Smith}

Sid Colbrook asked me to serve as the liaison between ASTM Committee D-2 on Petroleum products and lubricants and the NCWM. This is a brief report on the Committee's last meeting which was held December 6-11, 1992, in San Jose, California.

\section{Subcommittee A on Gasoline}

Subcommittee A is chaired by Bob Furey of General Motors Research Laboratories. This is the subcommittee responsible for standards such as D 4814, "Standard Specification for Automotive Spark-Ignition Engine Fuel," and P 232, "Proposed Specification for Fuel Methanol (M85) for Automotive Spark-Ignition Engines." Work continued on the constant updating of D 4814 with a total of 13 ballot items. Many of the changes involved the subcommittee's effort to keep pace with changing EPA requirements. Four items are of particular interest to NCWM members.

- Amoco Oil Company proposed to reduce minimum T50 for gasoline classes D and E in D4814. Amoco argued that the current ASTM minimum 50 percent distillation temperature (T50) specification of $170^{\circ} \mathrm{F}$ for classes D and E gasolines is restrictive and costly. The addition of oxygenates to gasoline significantly reduces the T50 of the final blend and causes it to decrease below the minimum limit of $170^{\circ} \mathrm{F}$ specified in ASTM D 4814. Expensive refining and blending changes are required to meet the current specification. A recent CRC Volatility Group study did not identify a loss in hot-start driveability performance when lower T50 gasolines are used. As you might expect, the proposal generated much debate. Amoco proposed lowering the T50 to $158{ }^{\circ} \mathrm{F}$ and other groups wanted it lowered to around $145^{\circ} \mathrm{F}$. Some did not want any change. A compromise was struck which will lead to a ballot proposing a T50 of 154 for D and E classes of gasoline.

- Wendy Clark of Automotive Testing Laboratories, Inc. is chairing a task group on reformulated gasoline. The task group is developing specifications and test methods for reformulated gasoline.

- A new Standard Test Method for Vehicle Evaluation of Unleaded Automotive Spark-Ignition Engine Fuel for Intake Valve Deposit Formation is currently out for ballot.

- Syd Andrews proposed that Subcommittee A change its name since the subcommittee has taken responsibility for the development of so many standards for fuels which are not strictly gasoline. Syd suggested a change to "Subcommittee A on Automotive Spark-Ignition Engine Fuels." A group was appointed to study the issue.

\section{Subcommittee $J$ on Aviation Fuels}

Subcommittee $\mathrm{J}$ has a new chairman, Steve Casper of United Airlines. As the name implies, this subcommittee is responsible for aviation fuel standards. The subcommittee has two issues which should be of interest to NCWM members.

- Congress is studying the possibility of dyeing grades of motor gasoline to prevent misrepresentation of octane. In particular, it has been suggested that blue dye be added to regular unleaded motor gasoline. Subcommittee $J$ is strongly opposed to the proposal as grade $100 \mathrm{LL}$ aviation gasoline is dyed blue. Grade $100 \mathrm{LL}$ is the predominately used aviation gasoline for small aircraft in the United States. If the wrong gasoline is used, the aircraft could experience rapid catastrophic engine deterioration and failure. In general, Subcommittee $J$ is opposed to the use of blue dye in any fuel which could be mistaken for grade 100LL aviation gasoline. The chairman of D-2, Dr. Ed White, has written a letter detailing the problems with the use of blue dye in motor gasoline. A copy of his letter has been sent to weights and measures officials.

- Subcommittee $\mathrm{J}$ is proposing the development of a new aviation gasoline, grade 82 unleaded. Work is just beginning on this proposal, and it may be some time before it is final. This gasoline would be dyed purple. This new aviation gasoline standard is being proposed since there is much concern about the use of motor gasoline in aircraft.

The other D-2 subcommittees were quite busy with important work. A common theme throughout all the subcommittees was that companies have reduced staff and fewer people are being asked to do more work. There is less time to devote to outside activities such as handling ASTM matters. (A personal observation is that ASTM is losing many knowledgeable people and their expertise may never be replaced.) During the meeting of the D-2A Advisory Section, I reported on the formation of the NCWM Petroleum Subcommittee and the subcommittee's first meeting. There were no comments or questions. Please contact me if you desire additional information. 


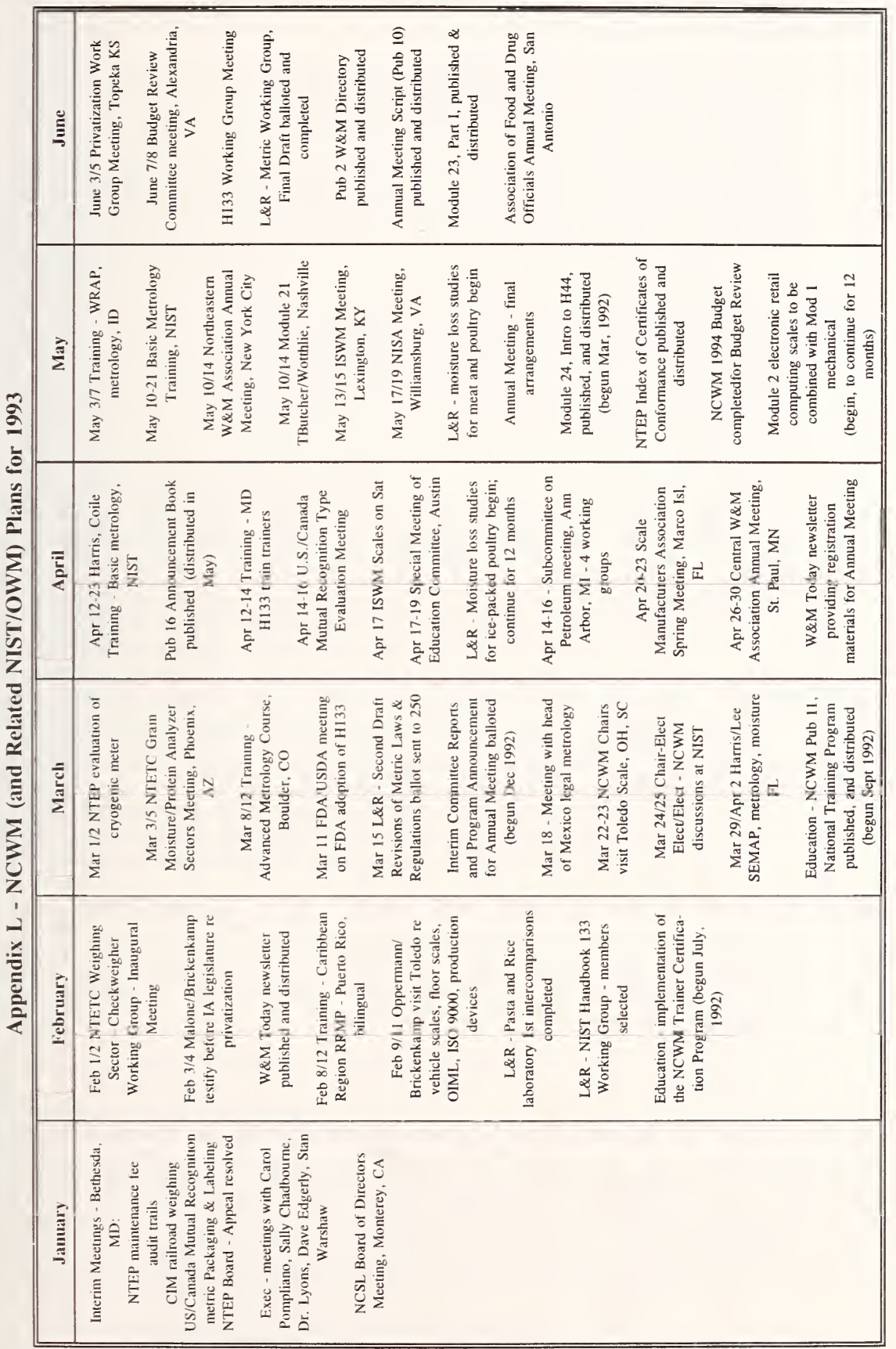




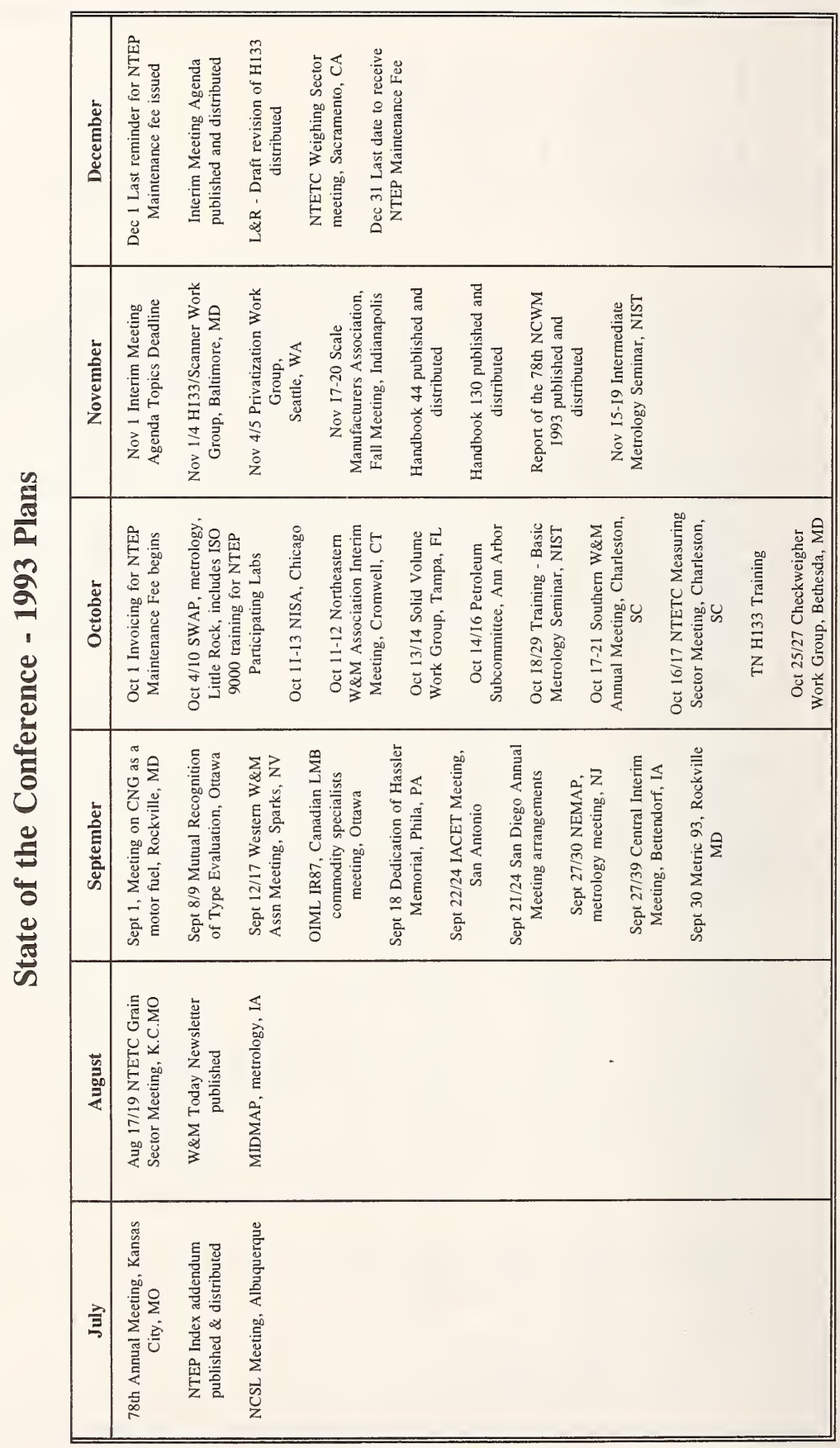




\section{Appendix M - Report on OIML}

Samuel E. Chappell, Chief

Standards Management Program, NIST

\section{International Committee of Legal Metrology (CIML)}

The CIML establishes the policy and approves the technical plans and work of the various OIML Secretariats. Its 27 th meeting was in Athens, Greece from November 2-6, 1992 in conjunction with the 9th International Conference of Legal Metrology. Representatives for 41 of the 49 member nations attended both meetings. The following significant reports and decisions were made at the meeting:

- The 4th draft "Directives for the Technical Work. Part 1: Structures and Procedures for the Development of OIML International Recommendations and Documents" was approved. The ad hoc task group (Chappell,U.S.A.; Brinkmann, Germany; and Referowski, Poland) was requested to meet and review the comments provided on the forth draft and prepare the final Directives.

- A new structure for the technical activities was approved with the following Technical Committees (TCs) established, assigned, and participating member states identified as of the meeting date:

TC1 Terminology (Poland and 14 participants)

TC2 Units of Measurement (Austria with 15 participants)

TC3 Metrological Control (U.S.A. with 22 participants)

TC4 Calibration and Verification Devices (Czechoslovakia with 14 participants)

TC5 Electronic Instruments (Netherlands with 17 participants)

TC6 Prepackaged Products (U.S.A. with 15 participants)

TC7 Measuring Instruments for Length and Associated Quantities (unassigned with 15 participants)

TC8 Instruments for Measuring Quantities of Fluids (Switzerland with 20 participants)

TC9 Instruments for Measuring Mass and Density (U.S.A. with 21 participants)

TC10 Instruments for Measuring Pressure, Force, and Related Quantities (tentatively U.S.A. with 14 participants)

TC11 Instruments for Measuring Temperature and Associated Quantities (Germany with 14 participants)

TC12 Instruments for Measuring Electrical Quantities (unassigned with 15 participants)

TC13 Instruments for Measuring Acoustics and Vibration (Germany with 15 participants)

TC14 Measuring Instruments Used in Optics (unassigned with 9 participants)

TC15 Measuring Instruments for Ionizing Radiations (unassigned with 13 participants)

TC16 Instruments for Measuring Pollutants (U.S.A. with 13 participants)

TC17 Instruments for Physico-chemical Measurements (Russia with 14 participants)

TC18 Medical Measuring Instruments (Germany with 12 participants)

- A list of initial projects to be included in the new technical committees was approved including the additional suggested project by the United States on "Liquid-in- Glass Thermometers."

- A proposal to use the comma as the decimal sign in all OIML publication was strongly opposed by the United States. With support from Canada, the proposal was withdrawn and referred to TC1 on Terminology.

- Knut Birkeland was reelected to serve as President of CIML for an extraordinary 2 year period until December 31, 1994.

The next meeting of CIML is scheduled for October 4-6, 1993 in Berlin, Germany.

\section{International Conference of Legal Metrology}

The International Conference of Legal Metrology is held once every 4 years with diplomatic representation from OIML member nations. It establishes overall policy for OIML, sanctions (ratifies) the OIML Recommendations approved by CIML during the previous 4 years, and establishes a budget for the International Bureau of Legal Metrology (BIML) for the next 4 years. Dr. Gordon of NIST was head of the U.S. Delegation to the 9th Conference with Mr. Burkette of the Department of State and myself as official members. Observing members of the U.S. Delegation were Dr. Brickenkamp of NIST and Executive Secretary of NCWM, Mr. Alan Nelson, Chairman of NCWM, Mr. Otto Warnlof of NIST, and Dr. Walter Kupper of Mettler Instrument Corp. All OIML member nations that were represented at the 27th CIML meeting were also represented at the Conference.

Reports were provided on the following matters and other organizations:

- The OIML Certification System

- The new work structures (discussed under the CIML meeting) 
- The Council for Developing Countries

- Liaison with other organizations

- $\quad$ ISO (cooperation mainly in TAG4 "Metrology" in revision of the "International Vocabulary of Metrology" and in the development of the "Guide to the Expression of Uncertainty in Measurement")

- IUPAC (International Union of Pure and Applied Chemistry - expressed a need for OIML to revise Recommendations on "Conductivity" and the "PH-scale")

CEN (European Committee for Norms - current relevant activities)

- $\quad$ CENELEC (European Committee for Electrotechnical Norms - current activities)

- WELMEC (Western European Legal Metrology Cooperation - current activities)

- CECEP (European Scale Manufacturers Committee - participation in OIML Secretariat on "Weighing Instruments")

The following significant decisions were made:

- All 18 Recommendations were sanctioned (ratified) and the United States voted yes on all except the following:

- $\quad$ "Measuring Instrumentation for Human Response to Vibration" Vote - abstained. (Reason: Format does not allow unambiguous interpretation of all performance requirements.)

"Pure-tone Audiometers" Vote - no. (Reason: The international standard on which it is based was unpublished and, hence, unavailable to U.S. experts. The tests referenced for determining electromagnetic compatibility has not been agreed upon.)

- "Refractometers for the Measurement of the Fruit Content of Fruit Juices" Vote - no. (Reason: The instrument requirements are incompatible with equity in trade of this product according to the State of Florida and a U.S. trade association of fruit juice producers and detailed U.S. comments on the draft Recommendation were not adequately responded to.)

It should be noted that the United States was directly responsible for four Recommendations (Load Cells, Atomic Absorption Spectrometers for Measuring Metal Pollutants, Electronic Weighing Instruments, and Direct Mass Flow Measuring Systems for Liquids) and was strongly influential in the development of four other Recommendations (Instruments for Measuring Vehicle Exhaust Emissions, Nonautomatic Weighing Instruments, Automatic Railweighbridges, and Discontinuous Totalizing Automatic Weighing Instruments.)

o The budget proposed by BIML for 1993-96 was approved unanimously.

o The long term policy of the organization and the future of legal metrology were discussed. In particular, new trends appear to diminish the differences between legal and industrial, or ordinary practical, metrology. The Conference requested CIML to consider the remarks presented by the delegates and to develop a policy and plan of action on the subject. This subject will be discussed at the next meeting of the Presidential Council in February 1993.

- It was proposed by Cuba that the next Conference be held in Havana in 1996. A decision was not made by the Conference that referred the matter to CIML and requested a decision be made by 1994 . The U.S. Delegation opposed Cuba's proposal.

\section{CIML Presidential Council}

The Presidential Council of CIML is its executive steering committee. Its next meeting is scheduled from February 15-16, 1993 in Paris, France. The principal items on the agenda will be as follows:

- A review of the current technical work of the Secretariats.

- A review of the draft of the new "procedures" for the technical work of OIML prepared by the ad hoc editing group. This new draft was approved at the 27th CIML meeting.

- A review of a proposed new organizational structures. Technical Committees were approved at the 27th CIML meeting, and new Subcommittees will have to be established and their Secretariats allocated to member nations. The new work structures are expected to improve the efficiency and timeliness of the technical work of OIML. The United States will be requesting responsibility for several of the Subcommittees.

\section{Activities of OIML Secretariats}

This part of the report provides: (1) an identification of work, either Recommendations (Rs) or Documents (Ds), being developed in Pilot Secretariats (PSs) and Reporting Secretariats (RSs) of specific interest to the NCWM and (2) a schedule of meetings of the International Working Groups (IWGs) of those Secretariats that have been recently held or planned for the near future. More details of these activities were reported by Otto Warnlof to the Specifications and Tolerances Committee. 
- PS5D "Dynamic Measurement of Liquids" (Germany)

PS5D/RS1 "Meters with Measuring Chambers or Turbines" (Germany and France) The United States participated in an IWG meeting held from December 7-11, 1992 in Germany at which a first draft OIML R "Measuring Systems for Liquids Other than Water" was developed. This draft combines R5, R27, R57, R67, and R77 (Volume Meters, Ancillary Equipment, General Provisions, Particular Assemblies, and Metrological Controls, respectively). It will be distributed for vote along with other issues not decided at the meeting in March 1993.

- PS5D/RS5 "Data for the Calculation of Quantities of Liquids" (U.S.A.) The draft revision of R63 "Petroleum Measurement Tables" will be sent to CIML for review and vote in March 1993. It includes a reference to ISO 91-2 "Petroleum Measurement Tables - Part 2: Tables based on a Reference of $20^{\circ} \mathrm{C}(11 / 15 / 91)$.

- PS5D/RS7 "Methods and Devices for the Verification of Measuring Instruments for Liquids" (Japan) The Secretariat distributed the following 1st draft OIML Recommendations for comment and vote: "Pipe Provers for Testing Measuring Systems for Liquids," "Testing Procedures and Pattern Examination of Fuel Dispensers for Motor Vehicles," and "Characteristics of Standard Capacity Measures and Test Methods for Measuring Systems." These drafts were received in November 1992 and were distributed to the NWG for comment by January 15, 1993.

- PS5D/RS9 "Vortex Meters" (Japan) The Secretariat distributed a first draft OIML Recommendation on "Vortex Meters used in Measuring Systems for Liquids" for comment and vote. The draft was received in November 1992 and was distributed to the NWG for comment by January 15, 1993.

- PS5D/RS10 "Direct Mass Flow Meters" (U.S.A.) A draft Recommendation on "Direct Mass Flow Measuring Assemblies for Quantities of Liquids" has been sanctioned by the 9th Conference. Type evaluation report forms are being developed and will be distributed to the IWG for review and vote in February. A meeting of the NWG was held during the interim meeting.

- PS5S "Static Measurement of Quantities of Liquids" (Portugal)

- PS5S/RS12 "Static Direct Mass Measurement of Quantities of Liquids" (Australia) The Secretariat prepared a forth preliminary draft Recommendation that was discussed at an IWG meeting held in Germany in December 1992. A first draft is expected this year.

- PS7 "Measurement of Mass" (U.S.A.)

PS7/RS2 "General Problems - Electronic Devices" (U.S.A.) A draft revision of R74 on "General Requirements for Electronic Measuring Instruments" was sanctioned by the 9th Conference. A meeting of the NWG was held during the interim meeting to discuss future work.

PS7/RS4 "Nonautomatic Weighing Instruments" (Germany and France) A draft revision of R76 Part 1 on "Nonautomatic Weighing Instruments" was sanctioned by the 9th Conference. Part 2 on format of test reports was received in January 1993 for review by the United States, Secretariat of PS 7.

PS7/RS5 "Automatic Weighing Instruments" (United Kingdom) The U.S. attended a IWG meeting in the United Kingdom December 1992 at which the following drafts were discussed : (a) a revision of R50 on "Continuous Totalizing Automatic Weighing Instruments (Belt Weighers)" (adopted by the PS and will be sent to CIML for vote) (b) a revision of R51 on "Checkweighing and Weight Grading Machines," (to be distributed to the IWG for comment and vote by the Secretariat in March 1993), and (c) a revision of R61 on "Automatic Gravimetric Filling Machines (Hoppers)" (likewise will be distributed in March 1993). The following Recommendations were sanctioned by the 9th Conference: "Automatic Rail Weighbridges" and "Discontinuous Totalizing Automatic Instruments (Totalizing Hopper Weighers)." A meeting of the IWG has been tentatively scheduled for June 1993 in the United Kingdom.

PS7/RS8 "Load Cells" (U.S.A.) The revised R60 on "Load Cells" was sanctioned by the 9th Conference. The draft "format of the test report" for R60 has been accepted by the IWG. It will be edited and sent out for approval by CIML in January 1993.

PS8 "Weights" (U.S.A.)

PS8/RS5 "Weights Used in Trade and Industry" (Belgium and U.K.) A draft Recommendation on "Weights of Classes E1, E2, F1, F2, M1, M2, and M3" has been prepared mainly through consolidating the requirements of R1, R2, R20, and R25 as well as the Monographs I, II, III, and IV related to weights. This draft has been distributed for comment and vote to the IWG. The draft was sent to the NWG for comment by December 31 , 1992. If approved, it will be distributed to CIML for comment and vote. 


\author{
Appendix N \\ National Conference on Weights and Measures \\ Technical Committee on National Type Evaluation \\ Weighing Sector \\ June 16-17, 1992 \\ Alexandria, Virginia
}

Agenda Items -- Overview

$\underline{\text { Load Cell Issues }}$

1. Information Item on August 1, 1992 Deadline

2. Update on National Type Evaluation (NTEP) Test Capability

3. NTEP Testing When Facilities are Limited

4. Load Cell Mechanical Configuration Information

$\underline{\text { Scale Issues }}$

5. Audit Trails

6. Identifying the Main Elements of a Scale on Certificates of Conformance

7. Railroad Issues

8. Decreasing-Load Tests for Class III L Devices

9. Testing Class III L Devices

10. Suitability of Equipment Tables

11. Customer Indications on Shipping Scales

12. NTEP Testing of Remanufactured Devices

13. Parameters for Modular Vehicle Scales

14. Maintenance Fee for NTEP Certificates of Conformance

15. Parameters of Vehicle Scales Included on Certificates of Conformance

16. Testing of Vehicle Scales with Capacities Above 200,000 lb

17. Identifying the Version of Software Used in a Weighing System

18. Require Descriptors for Keyboard Weight Entries to be Printed on Weight Tickets and Require the Type of Tare to be Identified on the Receipt

19. Covering Concrete vs. Steel on NTEP Certificates of Conformance

20. Type Evaluation of Modified Weighbridges, Weighing Elements and/or Load Receiving Elements

21. Clarification of "One-of-a-Kind" Devices

22. Performance of Shift Test on Floor Scales; and

Performance and Permanence Tests for Floor Scales (Including Computing Scales)

23. Performance and Permanence Tests for Railway Track Scales Used to Weigh Statically

24. Devices an Option for Intrinsic Safety Barriers

25. NTEP Testing of Vehicle Scale "Extension Kits"

26. Indication of Zero After "Sleep Mode"

27. Minimum Use Criteria for Type Evaluation of Large-Capacity Scales

\title{
Meeting Summary
}

\section{Information Item on August 1, 1992 Deadline}

Committee members were reminded that, per August 22, 1991 memorandum from Henry Oppermann (National Institute of Standards and Technology [NIST]), all existing provisional load cell Certificates of Conformance (CCs) must be upgraded to full CCs by August 1, 1992. Manufacturers may continue to receive provisional load cell CCs based upon data from the manufacturer until January 1, 1993; however, the manufacturer must make arrangements within 90 days of the date that the Provisional CC is issued (but not later than January 1, 1993) to upgrade the CC to a full CC. 
testing. She noted that those manufacturers who plan to schedule testing or plan to have tests observed should make these arrangements as soon as possible since the NIST Force Group may not be able to accommodate requests made at the last minute.

\section{Update on National Type Evaluation (NTEP) Test Capability}

An April 24, 1992 memorandum (see attached copy) from Mr. Henry Oppermann announced that the NIST Force Group has expanded its test capability to include testing load cells in tension in the 25,000-lbf dead weight machine. Mr. Ken Yee (NIST) and Dr. Simone Yaniv provided the Committee with an update on NTEP test capability for load cells.

Dr. Yaniv indicated that NIST will soon announce the capability to test load cells from $200 \mathrm{lbf}-500 \mathrm{lbf}$ in tension and compression with a minimum dead load of $10 \mathrm{lb}$. However, NIST will rely heavily on the manufacturer to provide necessary flexures, yokes, or other mounting hardware. Mr. Tom Bartel (301) 975-6461 is the NIST contact for machine dimensions and interface information.

NIST is also in the process of working with California Division of Measurement Standards to establish test capability for testing load cells in tension below the $200 \mathrm{lbf}$ range using hand weights. No firm date has been set for establishing this capability; however, it is projected that this capability can be arranged by sometime in August 1992.

A memorandum will be distributed to announce these updates in test capabilities for load cells.

\section{NTEP Testing When Facilities are Limited}

Background/Discussion: The Board of Governors indicated that it desires to have NTEP testing of load cells performed at NIST or an NTEP laboratory. In order for NTEP to test at NTEP/NIST facilities rather than witnessing testing, it may be necessary to deviate from midrange (nominally a 4:1 ratio) or even to test at the extremes of the load cell family to cover ranges of capacities (gaps) where NTEP does not have test capability.

Conclusions: The Committee agreed to establish the following policy:

Load cells should be tested at NTEP/NIST facilities whenever possible. Deviation from the mid-range (nominally a 4:1 ratio) and/or testing at the extremes of a load cell family is permitted in order io accommodate testing at NTEP/NIST facilities rather than witnessing testing.

\section{Load Cell Mechanical Configuration Information}

Background/Discussion: Comments were received that it is not possible for other than NIST personnel to determine the actual mechanical configuration of a load cell for which a CC has been issued. Due to possible proprietary nature, this information has not been distributed with the CC. It was suggested that dimensional outline drawings or similar documents detailing the mechanical configuration of the load cell be provided by the manufacturer for each CC.

No objections were raised to making the drawings and dimensional information available with the Certificate. Although marked "proprietary," many manufacturers do not consider this type of information truly "proprietary"; the marking is more routine than from need. Legal responsibilities for handling the information must be satisfied; however, it was noted that NIST would not consider the basic "type" proprietary information. Committee members indicated that the mechanical characteristics of the load cell (e.g., mounting, support, installation, etc.) are just as significant as the metrological characteristics when selecting an "equivalent" cell, and providing this information could also help to ensure that the design of load cells being manufactured and installed are consistent with the Certificate.

In spite of the evident benefit of this information in ensuring that a scale is installed with a correct and appropriate load cell(s), some Committee members questioned the value of the information to weights and measures officials, noting that the official does not typically examine the load cell in a device to such an extent that a dimensional outline drawing would be useful (or even used), and the official may not have ready access to this type of information. The logistics of providing the information and the increase to the bulk of the $\mathrm{CC}$ may outweigh the benefit.

The Committee considered a suggestion to provide a "generic" example (outline sketch) of the type (e.g., S-beam type) of load cell along with a master set of drawings. However, concern was expressed about the number of drawings that 
would be needed for each basic type to adequately describe the design variations and different methods of mounting.

Conclusions: The Committee agreed that, although the type of load cell is currently identified on the Certificate, efforts must be made to improve the standardization of terms used to describe load cell types than has been done in the past. (This will be accomplished by inserting generic word definitions along with typical configuration sketches in Publication 14.) However, there appeared to be no clear consensus on the additional information that should be provided (if any) on the CC.

The Committee concluded by vote that the current format of the Certificate of Conformance provides sufficient information, and that the format should be maintained.

\section{Scale Issues}

\section{Audit Trails}

Background/Discussion: Audit trails were discussed at the last meeting and at the Annual and Interim Meetings of the NCWM. As a result of these discussions, an updated audit trail paper was included in NCWM Publication 16, Program and Committee Reports for the NCWM, 77th Annual Meeting, July 19-23, 1992 (see the Specifications \& Tolerances (S\&T) Committee Report in NCWM Publication 16 for the audit trail information.) The audit trail paper outlines the minimum requirements for forms of audit trails used in place of physical seals. This item appeared on the agenda of the Weighing Sector to provide an opportunity for additional input from industry and weights and measures officials on the proposed requirements for audit trails.

It was noted that both the Central and the Northeast Regional Weights and Measures Associations had voted to change the audit trail item from the status of a "Voting" item to an "Information" item, and it seemed likely that this would also be the recommendation of the S\&T Committee. Some members of the Weighing Sector expressed concern about how NTEP would address devices submitted with the audit trail feature if no requirements were recognized by the NCWM for yet another year.

The Scale Manufacturer's Association (SMA) requested that the Committee review the need for two event counters, which was discussed by the S\&T Committee. It was noted that the S\&T Committee wanted weights and measures officials to have an opportunity to distinguish between adjustments to setup parameters and to those parameters affecting device accuracy. It is expected that adjustment parameters would be changed routinely, but configuration parameters would not. It was also noted that the ease of access provided to the operator to make these changes (i.e., it is not necessary to break a physical security seal) provides less opportunity for detection by weights and measures; consequently, the S\&T Committee believes that two event counters are warranted.

The Committee discussed the fact that audit trails will not prevent fraud from occurring, but will deter it from occurring, in addition to detecting changes that might affect the metrological integrity of the device or its operation. It was noted that this objective is analogous to the purpose of the physical security seal and that G-S.8. does not require the audit trail if adequate security can be provided with the physical seal. This latter point remains an issue of discussion.

Although the audit trail paper describes scenarios of how a manufacturer might provide the required information through an audit trail, there appeared to be concern about how the weights and measures official would access the information, how the information would be analyzed, how difficult it would be to obtain the information, and how the field official would reference the requirements contained in the audit trail paper if no change was made to Handbook 44 . Concern was also expressed based on input from the last two regional meetings that many weights and measures officiais may not fully understand the requirements for an audit trail, and that there are also a significant number of questions from industry. It was noted that, despite the questions, there is support for the concept of audit trails, but a vote by the NCWM may be premature.

Conclusions: While the discussion on this issue was quite lengthy, no conclusions were drawn or suggestions developed by the Committee for suggested changes or additions to the audit trail requirements as specified in NCWM Publication 16. 


\section{Identifying the Main Elements of a Scale on Certificates of Conformance}

Background/Discussion: It was proposed that CCs for Class III L scales should be written for complete scales (that is, list all of the main elements and components used during the evaluation) and that the CC should not be issued for just the weighing/load-receiving elements. It was also commented that the main elements and load cells used to comprise the complete system must be certified components.

NTEP issues separate CCs for main elements and load cells in order that the manufacturer, installer, and user will have flexibility in choosing among compatible main elements that have been evaluated by NTEP. It was stated that substitutions can be made only if information about the indicator used in the evaluation of the weighing/load-receiving element is known; this, along with the use of applicable formulas, enable the customer and weights and measures official to judge whether or not a given indicator is compatible for substitution. This information has not been consistently identified on the $\mathrm{CC}$ in the past.

The primary area of concern with this issue appeared to be that of indicators without NTEP CCs being used during NTEP evaluations of large capacity weighing/load-receiving elements. It was commented that the load cell(s) used during an NTEP evaluation is(are) required to have a valid NTEP CC, and that the indicator should also be required to have a valid CC, which NTEP has not always required. If an indicator without an NTEP CC performs worse than an indicator with an NTEP CC, then the performance of the weighing/load-receiving element may not be as good. If the manufacturer is willing to risk the results of the evaluation by using a non-NTEP indicator, the NTEP laboratories feel that the manufacturer should be permitted to make this choice. It is expected that use of the weighing/load-receiving element with an indicator that has an NTEP CC (as would be required by the weights and measures official) should be better than the performance observed with the non-NTEP indicator.

Conclusions: The Committee agreed that CCs should detail the main elements, load cells, and auxiliary devices used during an evaluation, including model designation and other significant parameters, under the "Test Conditions" portion of the CC. The Committee agreed that Certificates should not limit a scale system to the specific combination of load cell, indicator, and weighing/load-receiving element used during the type evaluation; substitutions ("mixing and matching") of metrologically equivalent components should continue to be recognized according to current NTEP policy. Each weights and measures jurisdiction should require that the individual main elements and load cells comprising a weighing system (the indicator, load cell(s), and weighing/load-receiving element) each have a valid NTEP CC and that the components be compatible and suitable for the installation.

The Committee agreed that NTEP will continue to permit non-NTEP evaluated indicators and peripheral equipment to be used in the evaluation of a weighing/load-receiving element under certain conditions; however, the load cell used in electronic or electro-mechanical devices must have a current NTEP CC.

\section{Railroad Issues}

(Note: A related issue for type evaluation testing of railroad scales appears in Item 23)

Background/Discussion: A submission was made to the Committee stating that all the railroad issues need to be reviewed. Also questioned was whether or not anything should be placed in Handbook 44 that cannot be type evaluated or tested by the regulatory agencies in whose jurisdiction they become law.

Concern has been expressed to the Committee that only a few states actively participate in testing of railroad scales, and several more witness testing of railroad scales. Railroad scales in the remaining states may not be examined by weights and measures officials; therefore, the railroads are responsible for testing the devices. It has been questioned whether or not it is appropriate for states to adopt requirements for railroad scales into Handbook 44 that will not be enforced by the weights and measures officials.

It was noted that some states do not routinely test railroad scales; however, they have jurisdiction over these devices, and they reserve the right to participate in or conduct tests. It was also noted that these states are given the opportunity to witness tests performed with rail cars since the states may not possess equipment of their own. In other states, the weights and measures officials do perform the testing of these scales or they may witness testing of these devices on a regular basis. The precedent for this approach to testing railroad scales has been set by the approach taken for other devices addressed by Handbook 44 ; some devices are actively tested, some are not actively tested, and for some the tests are witnessed by the weights and measures official. The level of involvement of the weights and measures official in 
the regulation of a particular device is based on a cost-benefit analysis of the available resources of time and equipment, the degree of use of the device and how it is maintained, the economic impact, and the expertise of the officials.

Conclusions: The Committee believes that this issue is best addressed by the S\&T Committee as it addresses related issues. The Committee noted that its responsibility is to develop type evaluation procedures to test compliance with Handbook 44 requirements. It is not within the purview of this Committee to dictate policies to individual weights and measures jurisdictions on how a particular type of device is regulated within that State's jurisdiction; the individual authority must establish policies appropriate for its individual circumstances.

\section{Decreasing-Load Tests for Class III L Devices, and}

\section{Testing Class III $\mathrm{L}$ Devices}

(Note: Because agenda Items 8 and 9 are closely related, these items were addressed in a single discussion by the Committee.)

Background/Discussion: The Committee was requested to review decreasing-load test procedures for Class III L devices to see if the difference from increasing-load tests are sufficiently significant to preclude backing test trucks onto a scale to place weights on the inside sections and mid-span between sections; it was suggested that the latter facilitates more thorough testing as part of the increasing-load and shift tests. Although this is primarily a field enforcement issue, input from the Committee on the technical points might be useful.

Comments were forwarded to the Committee indicating that new and more efficient ways of testing Class III $\mathrm{L}$ devices in general need to be developed, and that procedures may need to be changed to reflect the growing number of electronic devices. Committee members were reminded that the decreasing-load test as part of the strain load test of vehicle scales was the subject of detailed analysis in November 1988, resulting in changes to the NTEP procedures. (See pages 119-125 of the Report of the 76th NCWM, July 1991.)

It was noted that, with the prospect of Handbook 44 Scales Code Table 4 becoming mandatory in 1994, many jurisdictions need help with test methods, and with the increased amounts of weight that will be required for testing vehicle scales, a different approach to testing might be more efficient. It was suggested that, if a scale is tested to at least 80 percent of the declared concentrated load capacity (CLC) at each section and at mid-span between sections, it is not necessary to proceed with a strain test. Since this is less testing than currently performed, it will be necessary to demonstrate the difference (if any) between the current procedure and the proposed procedure through the evaluation of actual data. All NTEP tests are performed using at least 90 percent of the CLC over the section and mid-sections, and it was suggested that the Committee consider analyzing data collected from NTEP tests supplemented with information on devices that are already in use.

Conclusions: The Committee agreed that a review of the current NTEP test procedures (including the proposal to discontinue the strain load test) for large capacity vehicle scales is appropriate to determine if improvements in testing efficiency can be made. This review would encompass the performance of the decreasing-load test for Class III $\mathbf{L}$ devices (Item 8 ) as well as test procedures in general (Item 9).

The Committee agreed that a task force should be established to study this issue and to develop recommendations concerning the current test procedures. In the course of this review, it is likely that the task force will identify areas in which improvements might also be made for routine tests performed by weights and measures jurisdictions. If so, these comments can be passed on to the NCWM Education Committee to be considered as possible changes to the existing examination procedure outlines in NCWM Publication 12.

Task Force members include:

* Fairbanks Scale Company

David Hawkins (Thurman Scale)

Terry James (Cardinal/Detecto)

* Toledo Scale Company

Otto Warnlof (NIST)

* Weigh-Tronix

(* Representatives of these companies indicated that representatives of their companies will participate in the Task Force.)

Mr. Daryl Tonini was asked to conduct the initial portion of the Task Force meeting to elect a chairman for the Task Force. The Task Force will hold its first meeting at 3:00 p.m. on Tuesday, July 21, 1992, at the Stouffer 
Hotel in Nashville, TN in conjunction with the annual meeting of the NCWM.

\section{Suitability of Equipment Tables}

Background/Discussion: Comments indicated that the suitability of equipment tables put forward by the S\&T Committee need thorough review and extensive revision, and that there are disagreements within the weights and measures industry on values in the tables and on the concept of the tables.

These comments are based on the suitability of equipment table for scales put forward by the S\&T Committee in 1991 . A frequent criticism was that the 1991 table was too specific, and there were disagreements over individual values in the table. At the Interim Meeting.in January 1992, a proposal from the Central Weights and Measures Association (CWMA) to express the suitability of scales requirements as formulae was reviewed by the S\&T Committee. The S\&T Committee has proposed that the formulae suggested by the CWMA be considered as an alternative to the previous table.

It was noted that the Handbook 44 requirements for suitability of equipment identify a number of parameters which must be considered by the user and the weights and measures official in determining the suitability of a scale for a given application. However, the interpretation of these requirements has, historically, been quite varied, and the applications of the requirements can differ depending upon the interpretation made by an individual device owner or weights and measures official.

Conclusions: This is primarily a field enforcement issue; however the Committee agreed to briefly discuss the issue in order to provide feedback to the S\&T Committee. The SMA agrees with the principle, preferring the approach taken by the CWMA; however, it does not agree that Handbook 44 is the appropriate place for the information to appear. The general opinion of the meeting participants appeared to favor the use of the formulae, noting that they are more usable and leave fewer parameters open to interpretation than the current text in Handbook 44. There was also a suggestion that the formula might be further simplified. For example: average net load $\geq 100 \mathrm{~d}$; minimum net load $\geq 20 \mathrm{~d}$.

\section{Customer Indications on Shipping Scales}

Background/Discussion: Paragraph S.1.8.3., Scales Code, Handbook 44 requires that "Computing scales equipped on the operators' side with digital indications, such as the net weight, price per pound, or total price, shall be similarly equipped on the customer's side." Some of the shipping scales that have been evaluated by NTEP have had only one display and are intended for use in installations in which both the customer and the operator can view the indications. Many shipping scales are computing scales and have been required to indicate weight, zone, and total price. The Committee was asked to determine what information (e.g., weight, total price, unit price/zone/rate, carrier, etc.) must be displayed to the customer on a shipping scale that has computing capabilities.

The Committee agreed that shipping scales used in direct sales must be equipped with displays on both sides or equipped with a remote customer display; alternatively, the Certificate must limit the application to installations where the information is visible to both the operator and the customer. Since this information affects the amount that the customer will pay for the service, the customer is entitled to view the information used in the determination. There was some disagreement as to how some information should be displayed to the customer to avoid confusion. However, this appeared to be resolved when the Committee noted that S.1.8.3. refers to the display of digital information.

Conclusions: The Committee agreed that the customer's side must display the same metrologically significant numerical information as is on the operator's side; including as a minimum, the shipping weight, zone code, and total price.

\section{NTEP Testing of Remanufactured Devices}

Background/Discussion: NTEP has primarily evaluated newly manufactured devices submitted by the original equipment manufacturer (OEM) and has received few requests for remanufactured equipment. However, as the number of states requiring all new installations to have NTEP CCs increases, NTEP is beginning to receive more applications for remanufactured equipment. There has been a great deal of discussion on how these devices should be addressed by NTEP and how the criteria currently applicable to prototype devices would apply. 
As with newly manufactured equipment, NTEP is concerned that the design and performance of the "prototype" or sample of remanufactured device submitted for type evaluation be consistent with the devices being remanufactured on a regular basis, that is the "production" devices for the remanufacturing process. NTEP is also concerned that the prototype of the remanufactured device series be consistent with the performance requirements of Handbook 44 . In discussing these issues, the Committee addressed the following points:

- equipment may be remanufactured by the original equipment manufacturer (OEM), an authorized agent of the OEM, or a company independent of the OEM;

- the OEM or the authorized OEM agent may be better able to ensure remanufacturing consistent with that used for the original production device;

- the replacement parts used in the remanufacturing process may be OEM parts or may be other than OEM parts;

- the use of OEM parts may help to ensure consistency of performance for devices with existing NTEP CCs; "equivalent" parts may not carry this same assurance;

- parts in varying stages of wear may be repaired (vs. replacement of worn parts); and

- each device may vary in its degree of disrepair when it is remanufactured.

The Committee acknowledged that remanufacturer is responsible for selecting for type evaluation a device representative of the model series with respect to remanufacture, performance, and permanence. Verifying that the device is representative of that model series must be through feedback from field enforcement as is currently done with newly manufactured devices. Similarly, the current criteria and parameters for devices covered on a CC will be applied.

There was some objection to the term "overhaul" with respect to "remanufactured." It was generally agreed that "repaired" is typically applied to devices already installed in a given location. A separate policy has already been established for the repair and replacement of load cells. The Committee clarified that the term "remanufactured" in the discussion of this issue refers to a device that has had parts overhauled or replaced in order that the device can be installed in a new location.

\section{Conclusions: The Committee established the following guidelines for remanufactured equipment.}

The following criteria apply to remanufactured equipment, that is, to devices to which the overhaul or replacement of parts has been performed in order that the device can be installed in a new location. The guidelines for repair and replacement of scale parts established by the Technical Committee on National Type Evaluation, Weighing Sector, still apply to the repair of devices in existing installations.

(1) If a device with an existing NTEP CC is remanufactured by the OEM or authorized agent of the manufacturer using OEM parts, no additional evaluation is required. The original CC applies, provided that the remanufacturing process does not modify the design of the device.

If a device without an existing NTEP CC is remanufactured by the OEM or authorized agent, the device must be submitted to NTEP for evaluation in order to be recognized on an NTEP CC.

(2) If a device with or without an existing NTEP CC is remanufactured by a company other than the OEM or authorized agent, the device must be marked with the remanufacturer's name, model designation, nonrepetitive serial number, and the term identifying the serial number as required by Handbook 44.

The device must be submitted to NTEP for evaluation, and the device submitted to NTEP for evaluation should be a device considered to be a "typical" example of that remanufacturer's remanufactured devices.

(3) Remanufactured devices will be evaluated in the same manner, using the same test procedures and criteria, as newly manufactured devices. No test results obtained for the original equipment will be accepted in lieu of actual testing.

(4) The guidelines for including parameters of a scale on a CC that apply to newly manufactured equipment shall also apply to remanufactured equipment. 


\section{Parameters for Modular Vehicle Scales}

Background/Discussion: NTEP permits a manufacturer to add models and capacities to a CC according to specified criteria. For such extensions of CCs, the current language does not permit different capacity load cells to be used on the models to be added.

While the language does not permit the larger capacities to be used, a question was raised as to whether or not this was the Committee's intent when it originally adopted the language at the June 1990 meeting. For example, NTEP policy may permit an existing CC for a 100,000-lb vehicle scale to be extended to include a 135,000-lb scale. The manufacturer may wish to use a larger capacity load cell (with an NTEP CC) in the 135,000-lb device than is used in the 100,000-lb device; however, the policy does not permit a different capacity load cell to be used. It was suggested that, if the load cell is the same type, mounted in the same manner, and uses the same hardware, it would be appropriate to allow the larger capacity cell to be used.

It was noted that, when the Committee originally defined the parameters to apply to modular electronic scales, it was understood that individual modules would be combined to created devices with larger capacities. It was understood that the individual modules used the same capacity load cells as well as the same design and mounting. It was also noted that, if the Committee were to change the existing policy to permit larger load cells (than used in the original evaluation) to be used, it would be necessary to revisit the other parameters currently applicable to modular electronic scales.

Conclusions: The Committee agreed that the existing policy for modular electronic scales reflects the original intent of the Committee. The Committee concluded that the existing policy for modular scales will be maintained as currently written and encouraged the Participating NTEP laboratories to enforce the policy. It was noted that, for modular scales, scale capacity can be increased without re-evaluation by adding previously evaluated modules. If higher capacity load cells are to be used, then the module using the higher capacity load cell must be evaluated.

\section{Maintenance Fee for NTEP Certificates of Conformance}

Background/Discussion: The NCWM Board of Governors met during the January 1992 NCWM Interim Meetings and decided to implement a maintenance fee for NTEP CCs to account for increasing administrative costs. Costs include those associated with issuing and maintaining CCs; developing, printing, and distributing publications listing current CC's; performing tests for companies (which do not receive CCs) that fail to pay their bill; and testing of production equipment.

Conclusions: This item was placed on the Committee's agenda to provide an opportunity for the Committee to discuss the issue and forward comments to the Board of Governors. The Committee generally supported the idea of a maintenance fee for Certificates, with some discussion of the areas where the funds will be used. Questions were raised concerning how the fee will be applied, especially for product lines which are not high volume. Also of concern are those product lines which are no longer being manufactured: if a manufacturer elects to let a CC "expire", some record should still be maintained to indicate that the $\mathrm{CC}$ had once been issued. SMA supports the general principle of the fee, but would like additional information on how the funds are intended to be collected and used.

\section{Parameters of Vehicle Scales Included on Certificates of Conformance}

Background/Discussion: Comments have been received concerning how the NTEP policies for including specific configurations of scales on a CC apply to "side-by-side" or "double-wide" scales which typically consist of two independent weighbridges installed side-by-side to provide a weighing surface wide enough to accommodate oversize vehicles. These devices are typically used in quarries, mines, power plants, steel mills, and lumber companies. Current policy permits a CC to be issued for scale widths of 10 to 12 feet based upon testing of a scale with a width of 10 feet; a scale width greater than 12 feet is considered to be significantly different in design from a 10 -ft wide scale and requires a separate type evaluation. Formalized guidelines have not been established for other sizes and is left to the judgement of NTEP.

The Committee considered a proposal to permit platform widths equal to or less than $120 \%$ of the width of the device evaluated to be included on the Certificate of Conformance, provided that the scale is of the same construction and strength as the scale evaluated. Comments received indicated that the only physical possibility for scale errors in an electronic, "side-by-side" or "double-wide" scale, other than load cell error, is longitudinal and lateral bending of the weighbridge and the sensitivity of the load cell to the resulting side loads. Since a narrower platform will inherently 
deflect less laterally, the worst case will be the widest platform.

Committee members noted that the distribution of loads in a "side-by-side" scale differ from an "end-to-end" (singlewidth) scale. The types of vehicles weighed on side-by-side scales (e.g., euclids and other off-road vehicles) are significantly different from those weighed on end-to-end scales, and the load distribution on a side-by-side scale is through the center of the two modules, rather than following the wheel pattern found on an end-to-end scale. It was argued that the side-by-side scales are designed specifically for the purpose of weighing the larger type vehicles. However, a different test procedure must be used on the side-by-side device to reflect the different design and typical loading distribution.

Conclusions: The Committee concluded that the design and loading pattern of a "side-by-side" scale (created by placing two modules side-by-side) are significantly different from an "end-to-end" scale. The side-by-side scale and the end-to-end scale must have separate evaluations, and a separate CC must be issued for each. For example, the test of a 10-foot wide scale can not be extended to cover two 10-foot modules placed side-by-side. The Committee agreed that a test procedure must be developed for these devices.

\section{Testing of Vehicle Scales with Capacities Above 200,000 lb}

Background/Discussion: The NCWM Board of Governors met during the January 1992 NCWM Interim Meetings when a question was posed concerning whether or not NTEP should accept requests to test vehicle scales above a capacity of $200,000 \mathrm{lb}$. The Board determined that such requests should continue to be accepted; however, issues need to be resolved regarding test procedures, amount of test weights required, and scale parameters to be included on a CC.

During the Committee's discussion, it was noted that many scales in the capacity range above $200,000 \mathrm{lb}$ are designed to weigh specific equipment. These scales are, in a sense, custom-made and may not be readily identifiable within a general type. However, they do not fall into the "one-of-a-kind" category because the manufacturer may manufacture several of the same general model of device for use within the same or different states. Industry comments indicated that it is unrealistic for a manufacturer to pursue an NTEP CC on such a limited production device, and it was noted that some companies are being forced into obtaining NTEP evaluations by states that require NTEP CCs on commercial devices. Concern was expressed by some industry members that $\mathrm{CCs}$ for these devices become a marketing tool because they are not truly representative of a family or type of device.

Concern was expressed that, if NTEP refuses an application for such a device, the states may not have the expertise to develop adequate test procedures. The test procedure for this type of device will vary according to the specific design of the scale and the types of vehicles being weighed. A test of such a device is typically designed based on consultation with NTEP, the weights and measures jurisdiction, and the manufacturer. Lack of expertise and availability of standards within a given state is not believed adequate justification to require an NTEP evaluation.

Conclusions: The Committee agreed that devices with capacities in excess of $200,000 \mathrm{lb}$ do fall within the realm of NTEP evaluations; however, due to the limited number of devices typically involved for a given model series, the relative cost to manufacturers for a small number of devices, the limited resources of NTEP, and the tendency for these devices not to be categorized within a general type the Committee encourages states to perform their own evaluations of these devices. NTEP will handle applications for these devices on a case-by-case basis. The Committee indicated that states should not generally expect CCs to exist for these devices.

NTEP will be available for consultation on the development of test procedures appropriate for given devices and installations and, in some cases, may be available to witness testing. The states are encouraged to take advantage of the experience available within the NTEP system.

\section{Identifying the Version of Software Used in a Weighing System}

Background/Discussion: A meeting was held in conjunction with the LMB, Canada in April 1992 to discuss userprogrammable software and how it and its modifications should be handled during type evaluation. A review of some of the objectives and main points of the meeting was presented to the Committee. A copy of the meeting summary is being prepared and will be distributed to Committee members upon completion. As a result of the meeting, weights and measures officials should be better prepared to make more informed decisions.

NTEP does not require a manufacturer to submit software separately from the complete device; however, a number of 
manufacturers have requested separate evaluations and have obtained separate CCs for software. (This is especially prevalent for companies that develop software but do not manufacture hardware.) NTEP has been applying checklist criteria and issuing CCs to software operating on suitable hardware. This began with point-of-sale systems and has expanded to include other applications, such as weigh-in/weigh-out systems and livestock auction systems. Software is often revised and updated in response to user needs. When metrological revisions are made, NTEP requires that the software be resubmitted for evaluation. Software revisions occur quite often, and revisions sometimes occur several times just during the type evaluation process. Therefore, identification of the version number of the software may be difficult to track or enforce.

Conclusions: No conclusions were made by the Committee on this issue. The Committee will monitor the progress of this issue. (A copy of the April 1992 software meeting summary is attached to this meeting summary.)

\section{Require Descriptors for Keyboard Weight Entries to be Printed on Weight Tickets and Require the Type of Tare to be Identified on the Receipt}

Background/Discussion: Several instances have been brought to the attention of OWM concerning the keyboard tare feature on a vehicle scale and how that feature is used to manipulate weight information for a transaction. At least one scale operator was printing keyboard tare entries as the gross weight on a pre-printed ticket (e.g., in the gross weight space) when a full truck drives onto the scale. Later, the empty truck is weighed and the actual tare weight value is printed as the tare value in the tare space on the pre-printed ticket. The net weight is manually calculated to generate a fraudulent net weight.

The Committee generally agreed that General Code paragraph G-S.2., Facilitation of Fraud, can be applied to scenarios such as these to prevent the use of tare in a fraudulent manner. The Committee discussed the possibility of requiring that the descriptors for gross, tare, and net be printed on the receipt by the device. The Committee also discussed requiring that the type of tare taken (e.g., keyboard, stored) be identified on the receipt. It was noted that a requirement for identifying manual weight entries is currently included in the checklist.

Conclusions: The Committee concluded that this item is best addressed by the S\&T Committee since a change to Handbook 44 would be needed to require a device to print the descriptors. That this item is closely related to the S\&T Item 320-3, Manual Gross Weight Entries and might be best addressed in conjunction with that item. The Committee recommends that the S\&T Committee consider permitting the use of an asterisk (*) to designate each manual weight entry on receipts with multiple manual weight entries provided a corresponding asterisk $(*)$ with the definition "manual weight entry" appears at the bottom of the receipt.

\section{Covering Concrete vs. Steel on NTEP Certificates of Conformance}

Background/Discussion: Concern was expressed over whether or not a CC for a scale tested with a concrete deck can be extended to include a scale with a steel deck and vice versa. Also questioned was what criteria should be used and what information should be supplied to determine if additional testing is needed and how much testing should be done.

A recommendation was received from industry suggesting that NTEP should require testing on both concrete and steel decks in order to include both options on a CC: the performance of the two is significantly different, hence they should be considered as completely different devices in terms of design and performance. It was also noted that this issue is different from the modification of a weighbridge; a concrete-deck scale and a steel-deck scale must be addressed as completely different devices, not modified versions of the same device. Concrete-deck and steel-deck scales should be marked with unique model designations to indicate the difference.

Concern was expressed by some Committee members that not all concrete deck and steel deck versions of a given series differ significantly in terms of performance. The Committee generally agreed that the only way for NTEP to determine with any degree of certainty whether there is a difference between the two types of decks is to test both types.

Conclusions: The Committee agreed that different decks can affect the performance of a scale. The Committee agreed that concrete and steel decks must be tested separately; full NTEP tests are required on both options unless NTEP decides otherwise. A composite scale consisting of a minimum of two decks (i.e., two spans), one span deck of steel construction and the other of concrete, may be submitted and tested to include both types of decks. Concrete-deck and steel-deck scales should be marked with unique model designations to indicate the difference. 


\section{Type Evaluation of Modified Weighbridges, Weighing Elements and/or Load Receiving Elements}

Background/Discussion: NTEP is having difficulty in assessing the technical information provided on modified weighbridges to judge whether or not they are equivalent. There is also concern that theory always carries through into device performance.

Manufacturers are responsible for notifying NTEP of modifications to designs of devices, and NTEP needs to emphasize the importance of reporting these modifications so that a determination can be made as to whether or not the modified device can be included on the $\mathrm{CC}$ without additional testing. While many manufacturers are conscientious about notifying NTEP of modifications, concern has been expressed that most of the modifications that should be reported to NTEP are not actually being reported. The field official may sometimes have difficulty identifying modifications; some are not obvious and the field official may not always have access to the CC. Consequently, modifications to production devices may not be reported to NTEP.

NTEP currently receives notifications of modifications which include detailed engineering data and/or test data, while some notifications may provide only a brief description of the modification. Some modifications have been described by detailed analysis of stresses and mechanical engineering; however, NTEP labs do not have the expertise to make the required analysis.

NTEP often receives requests to waive the requirement for type evaluation of modified weighbridges. The most frequent inquiries received concern whether or not additional testing is needed when load-receiving elements are flipped upside down, load-receiving element material is altered (concrete, wood, mild steel, etc.), load-receiving element widths are extended, load cell type is changed, load cell mounting is slightly altered, etc. Even when a manufacturer provides detailed information about a modification, it may be difficult to determine whether or not the change will affect the performance of the device, and it may be difficult to make these determinations consistently for the various modifications suggested by different companies. It was also noted that there has been a significant increase in requests in this area.

Conclusions: The Committee recognized that NTEP may have difficulty assessing some of the technical information provided with notifications of modifications to previously evaluated weighbridges; however, it agreed that NTEP should continue to use the same judgement that it has in the past. The Committee agreed that if NTEP feels uneasy about fairly assessing information submitted, additional testing can be required.

To emphasize the importance of notifying NTEP of modifications to devices, the Committee suggested that a reminder to this effect be included with the original CCs issued to a manufacturer.

\section{Clarification of "One-of-a-Kind" Devices}

Background \Discussion: Concern was expressed that there is not a clear definition for "one-of-a-kind" devices. For example, a company may install one scale in each of several states and claim that each scale is "one-of-a-kind"; it is unlikely that the individual state jurisdictions will be any wiser. However, the scale company has, in effect, violated the intent of the definition.

The Committee considered other examples including the following scenarios: (1) a company itself installs load cells into existing hoppers for use within the company; (2) a scale company installs load cells in hoppers in existing installations at different establishments; and (3) a scale company builds and installs a one-of-a-kind, then decides to build and install a second device of the same type.

Concern has been expressed by some scale companies that their competitors are using the one-of-a-kind provision inappropriately. The competitors are apparently installing the same "one-of-a-kind" device in several states. This practice might not come to the attention of the individual states involved and the devices may be accepted as "one-of-a-kind" without being required to have an NTEP evaluation.

It was noted that the primary area of concern with respect to this issue is that of hopper scales which are created by converting existing hoppers into scales, or hopper scales which have the old hopper replaced with a new one. Many of these situations involve a limited number of devices of a given type, and NTEP's resources must be considered. The Committee agreed that further clarification is needed for "one-of-a-kind" scales in general, and generalized language 
should be developed to include all (weighing) equipment.

Conclusions: The Committee recommends that the Board of Governors consider the following policy for "one-of-akind" devices for inclusion in NCWM Publication 14.

- If a scale company converts an existing structure such as a hopper into a weighing device in an existing installation or retrofits an existing scale, the device can be considered to fall into the "one-of-a-kind" category under NTEP policy. In this case, an NTEP CC is not required and the device should be evaluated for compliance with Handbook 44 by the individual weights and measures jurisdiction. This does not apply to equipment purchased by the scale company for conversion and installation into a new location.

- If a device manufactured for sale by a company has been categorized and tested as a "one-of-a-kind" device and the manufacturer then decides to manufacture an additional device or devices, the device would no longer be considered "one-of-a-kind." This would also apply to a device that has been determined to be a "one-of-a-kind" device by a weights and measures jurisdiction in one state and the manufacturer then decides to manufacture and install the device in another state. In this case, the manufacturer of the device must request an NTEP evaluation on the device through the normal application process, unless NTEP has already deemed that such evaluation will not be conducted.

Note that, for "one-of-a-kind" installations, the weights and measures jurisdiction should require the device to use an indicator and load cells with an NTEP CC.

\section{Performance of Shift Test on Floor Scales; and Performance and Permanence Tests for Floor Scales (Including Computing Scales)}

Background/Discussion: In the course of developing test procedures for floor scales, comments were received concerning the capacity at which the shift test should or can be performed. NTEP laboratories reported that some devices will perform within applicable requirements when the shift test is performed at $1 / 2$-capacity; however, if the test is performed at loads less than $1 / 2$-capacity, the device may exceed the applicable tolerances due to the fact that smaller tolerances may apply.

The shift test is performed to identify the performance characteristics of the scale, especially when off-center loading is used during the normal operation of the scale. Paragraph N.1.3., Scales Code, Handbook 44 is being interpreted as being very specific concerning the amount of weight to be used during the shift test. Since H44 states that the shift test shall be performed using weights equal to half the capacity of the scale, the interpretation has been made that weights other than half-capacity cannot be used. However, this should not prevent additional testing using smaller loads.

The objective of asking the Committee to review this issue is not to change paragraph N.1.3.7., but to clarify the intent of the paragraph and to give additional flexibility to the NTEP laboratories in performing testing. The Committee agreed that a scale must perform within tolerance at test loads less than half-capacity test loads; however, there was no clear consensus on the distribution of the load at less than half-capacity.

Some members of industry expressed concern that the step tolerance reduces the tolerance permitted for the shift test and this additional tolerance is needed. Other Committee members believe that the same tolerance applies just below the breakpoint and anywhere between the tolerance bands. The participating NTEP laboratories generally agree that shift tests should be permitted to be performed at any test load below half-capacity, particularly if performance problems are suspected for off-center loading.

Conclusions: Since the Committee was unable to reach a consensus on this issue, the Committee recommends that the issue be presented to the S\&T Committee for review and further clarification and, if warranted, a change to Handbook 44.

The Committee reviewed and suggested several changes to the Performance and Permanence Tests for Floor Scales (Including Computing Scales) that has been used by the NTEP laboratories. The Committee recommends that the revised document be incorporated into the next edition of Publication 14. (A copy of the procedures are attached to this summary.) 


\section{Performance and Permanence Tests for Railway Track Scales Used to Weigh Statically}

Background/Discussion: A detailed proposal suggesting numerous changes to the permanence test procedures currently specified in NCWM Publication 14 for railway track scales. The Committee positions regarding a number of the suggested changes are listed below.

The reference in the proposal to documenting compliance with AAR rules and specifications will be deleted since Handbook 44 does not refer to these requirements. Committee members noted that it is not always necessary to meet AAR requirements; the approval of the carrier railroad usually dictates whether or not the AAR requirements must be met.

The use of the term "FGIS car" was questioned as possibly being too restrictive. The Committee agreed that it is not the intent of NTEP to preclude the use of another car; therefore the term "FGIS-type or equivalent" will be used. It was also noted that it is often difficult to have two test cars available for the test. The Committee preferred the use of the term "railroad test weight cars" to "composite cars."

The Committee agreed that loads of at least $30,000,40,000$, and $50,000 \mathrm{lb}$ should be observed; readings may be taken at $10,000 \mathrm{lb}$ and $20,000 \mathrm{lb}$. The Committee also made modifications to the positioning of the test weights at the 50,000lb test load and for repeat tests.

The Committee agreed to delete the reference to the difference between sections since, if the device meets the required acceptance tolerance, the device will automatically meet the agreement between sections requirement.

A question was also raised concerning the reference to footnote \#2 which discusses the application of maintenance tolerance if the subsequent performance test cannot be completed within 30 days. Although this conflicts with paragraph G-T.1. in Handbook 44, the Committee agreed in 1988 that the evaluating laboratory must use judgement in determining which tolerance applies. Different circumstances exist for each test, and only a small number of evaluations are not repeated within the 30 -day time frame.

Conclusions: The Committee recommends the following changes to the current language in Publication 14 for testing of static railway track scales. Changes to the current language are denoted by underlining (for added text) or striking out (for deleted text).

\section{Performance and Permanence Tests for Railway Track Scales Used to Weigh Statically}

Performance tests are conducted to determine compliance with the tolerances and, in the case of nonautomatic indicating scales, the sensitivity requirements specified in NBS NIST Handbook 44. The tests described here apply primarily to the weighing element. It is assumed that the indicating element used during the test has already been examined and found to comply with applicable requirements. If the design and performance of the indicating element is to be determined during the same test, the applicable requirements for weighbeams, poses, dials, electronic digital indications, etc., must also be referenced.

\section{Influence Factors}

If tests are necessary to determine compliance with influence factors, individual main element and component tests must be conducted according to NTEP Policy.

\section{Test Standards}

The FGIS-type or equivalent test car shall be used for the initial test using A a minimum of 100,000 pounds of known test weights shall be used, generally in increments of 10,000 pounds. Railroad test weight cars shall not be used exclusively for the initial test. 


\section{Sensitivity and Discrimination Tests}

\section{Weighbeams}

The sensitivity test is conducted at zero load and at maximum load. The sensitivity test is conducted by determining the actual test weight value necessary to bring the beam from a rest point at the center of the trig loop to rest points at the top and bottom of the trig loop. The maximum load at which the sensitivity test is conducted need not be comprised of known test weight.

\section{Digital Indications}

Width-of-zero, zone of uncertainty, and automatic-zero-setting mechanism (if so equipped) tests shall be conducted as specified in other sections of this Handbook.

\section{Increasing Load and Section Tests}

1. With the test car of one end of the scale, remove weights from car and place on the end (closest section) of the scale. A minimum of three Qobservations shall be made at test loads of at least 30,000-, 40,000 - and $50,000-1 \mathrm{~b}$ test loads ${ }^{1}$. Readings may be taken at $10,000 \mathrm{lb}$ and $20,000 \mathrm{lb}$. Additional observations

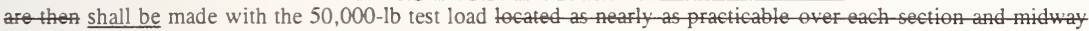
oncentrated to the right and left over the section with one pair of wheels over the section midway between sections of the scale. Remove test load from farthest section, record any zero balance change, zero the scale if necessary, and repeat this test moving the weights in the opposite direction. When the weights have been returned to the near section, apply additional loads, making observations in increments equal to the value of each test weight ( 10,000 pounds) up to 100,000 pounds at each end if practical. Repeat tests with the load concentrated to the right and left over each section and midway between sections in both directions.

The results shall be within acceptance tolerance.

\section{Strain Load Tests}

Place thest a strain load (as a minimum, use the FGIS-type test car without weights) on the scale so that the test load can be placed on one end section and observe the weight to the smallest increment practical. Add test load to end section. If practical, repeat this test on other end section. Remove test load, observing any balance change, then remove the strain load.

Place strain load and the empty FGIS-type test car on the platform so that the weights can be incrementally loaded from the weight cart which remains off the platform. Observe weight to the smallest increment practicable. Load test car with the test weights. $\Theta$ Observe weight indications in increments equal to each added test weight $(10,000 \mathrm{lb})$. At this maximum load, sensitivity and discrimination tests should be conducted.

The results of all observations shall be within acceptance tolerance.

\section{Permanence Test}

The permanence test shall be conducted from 20 to 30 days after successful completion of the initial performance test. It is recommended that the performance tests described above be repeated. However, it the original test car is not available, the test may be conducted to the extent possible with at least two railroad test weight cars.

The results of this test must be within acceptance tolerance. ${ }^{2}$ If the device does not meet these tolerance limits, the entire test must be repeated.

\section{Devices With an Option for Intrinsic Safety Barriers}

Background/Discussion: OWM agreed with the NTEP laboratories upon a policy that any device with intrinsic safety barriers would have to be submitted for type evaluation; however, the use of the intrinsic barrier is considered the "worst

'Do not exceed sectional capacity.

${ }^{2}$ If the subsequent performance test cannot be completed within 30 days because of the unavailability of test cars, maintenance erance will be applied. 
case" situation in terms of using the lowest excitation voltage or power supply for the system. NTEP has been advised that intrinsic safety barriers are temperature sensitive. NTEP has required that testing be performed on devices and components that are temperature sensitive to ensure that the compliance of the device with Handbook 44 is not affected by temperature. Committee members agreed that barriers can be temperature sensitive, and that barriers should not be covered under a CC unless they have undergone testing with the device. Concern was expressed that barriers may be external to the device, and barriers may be changed in the field installation. However, if another company installs an intrinsic safety barrier on a manufacturer's device, the device has been modified. The Committee generally agreed that testing the "worst case" situation will address the problem.

Questions were also raised concerning other temperature sensitive components such as load cell cabling; however, Committee members indicated that credible companies will take measures to make these components non-metrologically significant.

Conclusions: The Committee recommends that the following policy be recognized consistent with the policy currently applied by NTEP:

A device that offers an intrinsic safety barrier as an option, if submitted for type evaluation must be tested for compliance with influence factors requirements. If influence factors testing is performed on a unit with an intrinsically safe barrier, the device would also be covered on the resulting $\mathrm{CC}$ for direct-wire connections.

\section{NTEP Testing of Vehicle Scale "Extension Kits"}

Background/Discussion: "Extension kits" are being used to extend the platform area of previously (NTEP) evaluated scales in existing installations. Some of the extensions include widening a portion of the load-receiving element to 12 feet when the rest of the scale is 10 feet wide. Several requests were received concerning whether or not NTEP evaluations are required on these "extension kits." At the 1992 NCWM Interim Meetings, the Board of Governors determined that extensions are subject to type evaluation if they are "kits"; that is if there is more than a single unit of the extension manufactured. An extension that is a custom one-of-a-kind installation is not subject to type evaluation.

The Committee was asked to determine whether any changes are needed in NTEP test procedures and to clarify the guidelines for testing these devices and for addressing the various types of "extension kits" available as they apply to an existing CC. If an independent electronic weighing element is added to an existing electronic scale, the example easily falls under existing parameters for modular electronic scales. However, this does not address the case in which a lever system "extension kit" is ties into an existing lever system. The issue depends on whether the extension of the scale is actually a unique modification of an existing device or if a new weighing/load-receiving element is added to the existing scale to create a multiple-weighing element system.

Varying opinions were expressed. Some comments indicated that the installation of extension kits must be handled on a case-by-case basis, and the original manufacturer's expertise and approval should be obtained before making the addition. Others indicated that, if a manufacturer adds an extension kit to his own equipment (with an existing CC) and the resulting combination is within the parameters for devices covered under a $\mathrm{CC}$, no additional testing is needed; however, if the extension kit is added to another manufacturer's device, another evaluation is necessary. Some members stated that kits used with other than the original manufacturer's device need tests in addition to routine field tests to track continued performance of the device. Extending a lever system scale is different from extending an electronic scale; lever scale "extension kits" should not be considered in the same category electronic scale "extension kits."

The Committee discussed whether extension kits should be tested separately, or in conjunction with the scales the kit will be used with, or both. The Committee generally agreed that any required testing would entail using the same procedures as are currently used for vehicle scales.

Conclusions: The Committee was clearly divided on this issue, and no consensus could be reached. Some members believed that testing must be performed on each device/kit combination. Others believe that the use of these kits with devices currently covered by NTEP CCs has been a normal practice and consider the field test at initial evaluation as sufficient to determine compliance. The Committee agreed that the Board should be informed of the diverging views and ask that the Board review the issue again. 


\section{Indication of Zero After "Sleep Mode"}

Background/Discussion: A memorandum was distributed to the NTEP laboratories in September 1990 concerning the indication of zero after the "sleep (battery conservation) mode" for battery-powered scales. The memo reviewed the requirements of paragraph S.1. of the Scales Code and noted the exemption for certain point-of-sale systems. The NTEP laboratories have been applying the policy outlined in this memorandum for all battery-powered scales with a "sieep mode" feature based on the NCWM decisions made in 1986 and 1987.

Handbook 44 (and NTEP) requires that a device, other than a point-of-sale system, indicate a zero balance condition prior to a weighing operation; this means that a device in the sleep mode must provide a zero indication (usually by pressing a "zero" button) prior to beginning a weighing transaction. Some battery-powered devices inhibit operation when out of zero balance. Other devices' automatically monitor the zero-balance condition while in the sleep mode and display weight values when out of zero balance. This eliminates the need for the operator to zero the device each time it exits the sleep mode in order to start a weighing operation. Provided that a device clearly indicates or records an out-ofbalance condition (e.g., by the use of a marked indicator light or printed indication), the device would appear to satisfy the intent of Paragraph S.1.1. However, S.1.1. still requires a continuous digital zero indication for other than point-ofsale systems.

Point-of-sale systems are permitted to have other than a continuous digital zero indication if an effective automatic means is provided to inhibit a weighing operation when the scale is in an out-of-balance condition. The Board of Governors determined by a narrow margin that indications other than a digital zero indication are permitted under certain conditions on other scales. Participating NTEP laboratories generally believe that S.1. must be changed to recognize other systems.

The Committee was asked to discuss from a technical standpoint a proposal that the exemption provided for point-of-sale systems might be extended to battery-operated systems; this would permit battery-powered devices to indicate a zero balance condition by other than a continuous digital zero indication. It was noted that the NCWM was initially reluctant to permit a deviation from a digital zero. The original intent of the NCWM was to limit this technology specifically to point-of-sale systems and require new technology to be reviewed by weights and measures officials.

Conclusions: Those commenting on this issue indicated that it is appropriate to allow the use of other than a continuous indication of zero provided that the device inhibits use or otherwise clearly indicates an out-of-balance condition if present. The Committee generally agreed this issue is most appropriately addressed by the NCWM.

\section{Minimum Use Criteria for Type Evaluation of Large-Capacity Scales}

Background/Discussion: The S\&T Committee requested that the Weighing Sector review the language proposed by the SMA for Item 320-19 of the July 1992 S\&T Committee Report and provide the S\&T Committee with comments. The S\&T Committee specifically requested clarification of the intent of the proposed changes and how they would be applied.

Item 320-19 addresses the minimum use criteria for the type evaluation of large-capacity scales and details information to be included in Publication 14 for scales with capacities greater than $2000 \mathrm{lb}$. The intent of the original language developed for these criteria was to require the scale to be loaded repetitively to get an adequate permanence test. In doing this, it was necessary to define the number of loads and to determine what is a "qualifying" load.

Two concerns with the SMA proposal pertained to (1) basing the loads to be applied on a percentage of the axle loads rather than the entire load and (2) how this criteria could reasonably be met with normal highway loads. Comments indicated that one objective of SMA's proposal was to try to get the loads specified relative to the CLC since this is the basis for the manufacturer's design. The insertion of the term "axle" into the proposal was not intentional.

Committee members expressed concern that basing the upper limit solely on a percentage of the CLC may not provide an adequate test of some scales (e.g., some scales are submitted with CLCs as low as 40,000 lb or 50,000 lb, which puts the qualifying load below normal highway loads). As a compromise, the Committee agreed to set the qualifying load as a weight value or as a percentage of the CLC, whichever is greater.

Recommendation: The Committee reviewed the current test procedures and comments received from regional weights and measures associations and the SMA. The Committee recommended that the S\&T Committee consider presenting the following language for adoption: 
III. Count only those loads applied using a method representative of the intended use and in the following ranges:

A. For vehicle scales with capacities over 75,000 lb:

(1) 50 percent of the loads must be above $50,000 \mathrm{lb}$ or 80 percent of the CLC, whichever is greater; and

(2) 100 percent of the loads must be above $20,000 \mathrm{lb}$ or 50 percent of the CLC, whichever is greater. *

B. For all other scales:

(1) 50 percent of the loads must be above $\mathbf{5 0}$ percent of scale capacity; and

(2) 100 percent of the loads must be above 20 percent of scale capacity.

* The scale may be used to weigh other loads, but only these loads identified above are counted as part of the permanence test.

(Editor's Note: This language was adopted by the NCWM in July 1992.)

NTEP Technical Committee Weighing Sector

June 16-17, 1992

Alexandria, Virginia

Meeting Participants

Name

Michael Adams

Ross Andersen

Robert Anslow

Robert Badenhop

Carroll Brickenkamp

Tina G. Butcher

Carl Conrad

Constantine Cotsoradis

Steve Cook

John Elengo

Sy Feinland

Tom Geiler

Bill Goodpaster

David Hawkins

Terry James

Ted Johnson

Gary Lameris

Tom Leahy

Tom Luna

Nigel C. Mills

Allan M. Nelson

Henry Oppermann

Paul L. Peterson

David Quinn

John W. Reimer

Bob Reinfried

Tom Stabler

Daryl Tonini

Otto K. Warnlof

Dick Whipple

Simone Yaniv

Ken Yee

\section{Organization}

Fairbanks Scales

New York Weights and Measures

Revere Transducers, Inc.

Ohio Weights and Measures

National Institute of Standards and Technology

National Institute of Standards and Technology

New Jersey Office of Weights and Measures

Maryland Weights and Measures

California Division of Measurement Standards

Revere Transducers, Inc.

Pitney Bowes

Town of Barnstable, Massachusetts, Consumer Affairs

Cardinal/Detecto

Thurman Scale Company

Cardinal/Detecto

Sensortronics

PMI/Hobart Corporation

Rice Lake Weighing Systems

Scales Unlimited, Inc.

Toledo Scale

State of Connecticut Weights and Measures

National Institute of Standards and Technology

USDA, Packers and Stockyards Administration

Fairbanks Scales

Weigh-Tronix

Scale Manufacturers' Association

Toledo Scale

Scale Manufacturers' Association

National Institute of Standards and Technology

National Institute of Standards and Technology

National Institute of Standards and Technology

National Institute of Standards and Technology 


\section{Technical Committee on National Type Evaluation \\ Weighing Sector \\ Meeting, December 8, 1992 \\ Holiday Inn Crowne Plaza, Rockville, Maryland}

\section{Overview of Agenda Items}

\section{$\underline{\text { Load Cell Issues }}$}

1. Update on National Type Evaluation Program (NTEP) Test Capability

\section{$\underline{\text { Scale Issues }}$}

1. Complete Scales Too Large to Fit Into an Environmental Chamber

2. Abbreviations for Weight Indications (Printed and Displayed)

3. Symbols Used to Represent Over/Under Indications

4. Indicated and Recorded Units of Weight

5. Marking of Non-Functional Keys

Additional Item - NTEP Operation

\section{Meeting Summary}

The Technical Committee on National Type Evaluation (TCNTE) Weighing Sector met in Rockville, MD; a summary of the issues discussed appears below. The next meeting will be called by the Chairman at an appropriate time and place as discussed later in these minutes. The tentative timing is in or about June 1993.

\section{Load Cell Issues}

\section{Update on NTEP Load Cell Test Capability}

The Force Group provided a summary of the current National Institute of Standards and Technology (NIST) test capability for load cells as shown below:

NIST Force Group Load Cell Test Capability

\begin{tabular}{|c|c|c|c||}
\hline Direction of Loading & $\begin{array}{c}\text { Test Range } \\
(\mathrm{lbf})\end{array}$ & $\begin{array}{c}\text { Minimum Dead Load } \\
(\mathrm{lbf})\end{array}$ & Test Machine \\
\hline \hline Tension \& Compression & $200-500$ & 10 & 500 \\
\hline Tension \& Compression & $4,000-28,000$ & 400 & 25,000 \\
\hline Compression & $28,000-120,000$ & 3,000 & 112,000 \\
\hline
\end{tabular}

California's NTEP Participating Laboratory announced that it expects to be ready in early 1993 to perform NTEP evaluations on load cells up to approximately 250 -pound capacity using new equipment. That equipment consists of a loading frame with environmental chamber, instrument, and weights. The weight increments are 0 to $10 \mathrm{~kg}$ by $5-\mathrm{kg}$ increments continuing on to $110 \mathrm{~kg}$ total in $10-\mathrm{kg}$ increments. The dead load is $5 \mathrm{~kg}$. It is anticipated that in-line load cells would be placed in a suspension string. Beam-type load cells would be mounted on a plate with a through-hole to attach the suspension string. Once on-line, NIST will formally announce its availability along with the allowable range of load cell capacities. 


\section{Scale Issues}

\section{Complete Scales Too Large to Fit Into an Environmental Chamber}

Background: NTEP periodically receives applications for complete scales that use load cells that have not had a separate NTEP evaluation. Testing of complete scales for compliance with influence factors requirements is limited to devices which can fit into the environmental chambers available at NTEP Participating Laboratories. In general, load cells are tested separately for scales that are too large for the environmental chamber. However, there are instances where this is not possible due to physical and other constraints. In these cases, the NTEP Laboratory is unable to perform environmental tests to determine compliance with associated influence factor requirements.

NTEP has been applying a policy to these devices that is consistent with the policy applied to load cells; however, this policy has not been documented for complete scales. Some concern was expressed that this approach does not appear to be consistent with the policy applied to small capacity scales. It was noted that this approach is somewhat of a compromise compared to that used for small capacity scales; however, the policy applies only when load cells used in a scale cannot be easily tested as a separate component (e.g., in some crane scales, the load cells are an integral part of the device).

(It was noted that the permanence test for devices is performed separately from testing for compliance with influence factors requirements, and the permanence test may be conducted in the laboratory or in a field installation, depending on the individual device. For example, some devices may be easily tested in a laboratory environmental chamber for compliance with influence factors requirements, but the range of capacities or the scale application do not lend themselves to performing the permanence test in the laboratory.)

Conclusions: The Committee voted and established the following technical policy for devices which are not equipped with NTEP approved load cells and which do not lend themselves to being tested in NTEP environmental chambers (e.g., some wheel load weighers and crane scales).

For a given family of devices, to determine the capability of the series to comply with the influence factors requirements, NTEP will require testing as follows:

- A single device in the middle of the range between smallest and largest capacity may be tested in an environmental chamber to include the entire series provided:

- the device tested will not generally exceed a 4:1 ratio from either extreme of capacities; and

- the range of capacities from lowest to highest shall not exceed a 10:1 ratio unless more than one device is tested.

- Several devices in the series may be tested as described above to cover a wider range of capacities.

- For series of devices that can not be generally covered under the ratios described above and that will not fit into environmental chambers available to Participating NTEP Laboratories or that do not lend themselves to testing in an NTEP Laboratory (e.g., some wheel load weighers and crane scales), the manufacturer must either:

1) have the device testing performed in a private environmental laboratory under the direction of a Participating NTEP Laboratory representative, OR

2) have the load cell used in the device tested separately.

In addition to demonstrating compliance with influence factors requirements, additional capacities within the series may be selected for conducting other required NTEP tests.

(Note: The results of the vote were: 12 "Yes"; 1 "No"; and 1 "Abstain," in favor of continuing to apply this policy to these devices.)

\section{Abbreviations (Printed and Displayed) for Weight Indications and Other Scale Features}

Background: NTEP periodically receives requests for a listing of acceptable abbreviations/symbols for weight indications and other functions. Such abbreviations/symbols are currently recognized in NCWM Publication 14 but appear dispersed throughout and not in a convenient list.

The Committee reviewed an editorially produced list of acceptable abbreviations/symbols which currently appear in 
Publication 14. It is not intended that this list be limiting; the Committee agreed to expand the list to include those abbreviations/symbols which NTEP currently does not permit.

As a result of this review, the Committee added acceptable abbreviations/symbols for load cell verification interval, gross/tare/net, off(power), on(power), print, zero device, and verify tare.

The Committee noted that OIML apparently has not finalized work toward standardization of abbreviations/symbols. The Committee has made no attempt to adopt draft international recommendations but believes that the availability of this list will also facilitate any future harmonization activity.

Conclusions: The Committee agreed that a separate listing of abbreviations/symbols should be included in NCWM Publication 14. This list does not standardize the symbols that must be used, rather it identifies the symbols that are routinely acceptable. This list is not limiting or all-inclusive; other symbols may be acceptable. When additional abbreviations/symbols are encountered by the participating NTEP laboratories the Committee recommends that the list be expanded to include these abbreviations/symbols as appropriate. A copy of the list developed by the Committee follows this summary.

\section{Symbols Used to Represent Over/Under Indications}

Background: In a recent NTEP evaluation of a scale, a manufacturer used a " + " and "-" sign in the weight display to represent a "high" and "low" fill condition for checkweighing on scales that could be used in direct sale. Because " + " and "-" symbols are also associated with positive or negative weight values NTEP did not consider the use of these symbols to be acceptable without additional definition.

Conclusions: The Committee established the following technical policy:

Any indication of function or condition shall not be represented in a manner which interferes with the interpretation of weight. For example, a "+" and "-" sign used as an over/under indication may not be placed adjacent to a weight value.

The Committee recognizes that the judgement of the NTEP laboratories is required to administer this policy.

\section{Indicated and Recorded Units of Weight}

Background: NTEP has performed evaluations of software designed specifically for vehicle weigh-in/weigh-out systems in landfill applications. In at least one occasion, it was noted that the scale display indicated in one unit of weight (pounds) and the printed ticket used for billing in a different unit of weight (tons).

In this example, the weight indication was in 20-pound divisions and the printed representation of weight was in terms of decimal tons (programmed to indicate to 4 or 5 decimal places). The software processed the indication in pounds by converting it to equivalent tons. As billing was based on price per ton, the software calculated the cost by applying a price per ton rate to the converted weight value (tons).

The Committee generally agreed that NTEP was correct in its decision in the example given above and noted that a certain amount of judgement is required on the part of the evaluating laboratory depending on the individual scenario and the specific conversions being made. It was noted that the primary weight indications and the first recorded representation of weight must agree exactly as specified in NIST Handbook 44. The Committee agreed that derived indications may be in other units of weight provided that correct conversion factors are used in the conversion process. The accuracy of the conversion is best preserved if rounding is not performed until the final mathematical operation.

There was considerable discussion of (1) whether or not more decimal places should be permitted in later weight representations as a load is subdivided, and (2) whether or not the subdivided weight representations are a concern of weights and measures officials.

Conclusions: Lacking a clear consensus, the Committee was balloted on the issue of deriving the converted weight representation. By a vote of 7 to 5 , the Committee decided to require that the derived unit of weight be rounded to a resolution equal to the primary indication and that rounding should not occur until the last operation as opposed to no restriction on rounding or resolution. 
The Committee adopted the following technical policy.

The primary weight indication and the printed value must agree exactly as specified in NIST Handbook 44 and must be in the same unit of weight. Derived indications and recorded representations may be in other units of weight provided:

(1) they are mathematically correct, that is, they are based upon the values specified in the General Tables of Weights and Measure found in H44;

(2) they are of equal resolution to the primary weight indication; and

(3) rounding is not performed until the last mathematical operation.

\section{Marking of Non-Functional Keys}

Background: NTEP policy currently requires that non-functional keys cannot be marked. This has been an annoyance for manufacturers (and NTEP laboratories). In some cases, these keys can be set up to be functional or non-functional ("on" or "off") depending upon the end application. Further, the requirement that "non-functional keys cannot be marked" is not uniformly enforced in the field by weights and measures officials. NTEP policy also requires that programmable keys (that is, keys whose functions can be programmed differently for each application) must be marked to reflect their metrological or operational function.

The Committee considered two alternatives: (1) permit non-functional keys to be marked OR (2) permit non-functional keys to be marked, but require a visual or audible error message if the key is pressed.

Conclusions: Following discussion, the Committee decided to change its policy by allowing markings to appear on non-functional keys. The second alternative is permitted, but the Committee concluded it could not be required since it exceeds the requirements of Handbook 44.

\section{General Discussion Relating to Meetings of the Committee}

Background: The Committee currently meets twice a year, generally independent of other weights and measures meetings. This precedent was established at a time that NTEP was growing from infancy. Now that NTEP has somewhat matured, issues have moved from formative to tracking and sustaining in nature.

Over the past two years, the quantity and substance of agenda items has varied significantly. For example, the October 1992 meeting was canceled for lack of sufficient items and the work of this meeting was completed in the first of two scheduled days. On the other hand, 27 agenda items were placed before the Committee at its June 1992 meeting. Approximately $25 \%$ of those items were not in line with the direct charter of the Committee, but were placed before the Committee so that it might provide the service of being a "sounding board" in recognition that the members are knowledgeable and often participants in other matters pending within the NCWM.

In addition, the NCWM subsidizes attendance of selected Public Members, primarily those directly involved with NTEP operations. Funding methods for NTEP operations are currently under discussion within the NCWM. If meetings were held less frequently or in conjunction with other weights and measure meetings, then the cost might be reduced.

A recommendation was made to hold only one meeting a year. If too many items are on the agenda, they might be prioritized, with low priority items carried over to the next. The Committee felt that such a policy would not be responsive to the needs of NTEP and that more than one meeting is required. The Committee did not wish to meet just for the sake of meeting and believed that a meeting should take place only when sufficient items of substance and/or quantity dictate.

The Chairman expressed concern over abutting meetings with the NCWM Conference; much time can be expended educating one-time attendees about the NTEP process. TCNTE meetings are public and the individuals who currently choose to attend are those generally concerned with NTEP operations; as a result, a certain efficiency and continuity of operation has been attained.

Conclusions: A recommendation was made that the meeting not take place concurrent with the annual meeting 
of the NCWM for the reasons noted above, but that consideration be given to alternating between an independent meeting and a meeting held in association with a regional conference. This might achieve reduced costs without significant loss of efficiency and provide more national exposure to NTEP operations. A further recommendation was made that it would be useful to hold a meeting at the location of a Participating Laboratory to provide Committee members with the opportunity to view the facilities of the Participating Laboratory.

On the matter of agenda items which go beyond the scope of the TCNTE, the Committee believes it is appropriate to include such other weights and measures matters when the Committee is asked to act in an advisory role. The agenda is currently segmented between "Load Cell Issues" and "Scale Issues." A third segment headed "Advisory Issues" will be added as required.

The Committee Chairman will inform members quarterly of the nature of pending agenda items and, working with the Technical Advisor, will establish future meetings using the guidelines above.

\section{Additional Item - NTEP Operations}

The group was addressed by representatives from the Office of Weights and Measures (OWM)/NIST in their role as coordinators of the NTEP program. The purpose was to notify members of changes made by OWM/NIST to improve service to NTEP users and to obtain customer feedback.

OWM has assigned Mr. Richard Whipple to nearly full-time support of NTEP. NTEP administration systems have been improved. A control number is assigned to each application and its progressed is tracked. Assignments to Participating Laboratories are being monitored and expedited. A "how to" pamphlet is planned to increase information readily available to users; it is hoped that this will reduce the number of direct verbal questions which must currently be responded to by OWM staff.

NTEP processed approximately 400 certificates (revisions, modifications, and new) in 1992. OWM suggested that its work could be simplified if users would provide draft certificates for new families which are similar to models which are already certified. For example, the similar certificate could be marked up by the user with the updated information and forwarded to NTEP for final review.

The Committee noted that both past meeting minutes and a new issue of NCWM Publication 14 are overdue. OWM/NIST stated that it does not have sufficient resources to enable timely preparation and that current resources can only maintain higher priority issues. OWM/NIST suggested that it might be possible to employ outside services but it is unclear how such services would be funded.

The Committee Chairman has regularly provided NIST with a summary report of decisions reached at meetings in the form of a report made by him at periodic and regular Scale Manufacturer Association meetings. It was suggested that this report could be used by NIST or reformatted into summary minutes.

Summary prepared by:

John J. Elengo

Chairman, TCNTE Weighing Sector

Tina G. Butcher

Technical Advisor 
Michael Adams

Ross Andersen

Joseph Antkowiak

*Carroll Brickenkamp

Tina Butcher

Steven Cook

Constantine Cotsoradis

John Elengo

Bill Goodpaster

Terry James

Ted Johnson

John Lacy

Gary Lameris

Allan M. Nelson

Henry Oppermann

Dick Pforr

Joseph Rusignuolo

Tom Stabler

Daryl Tonini

Jim Truex

John W. Reimer

Dick Whipple

Stanley Wulf

(* Attended $1 / 2$ day)
Attendance at December 8, 1992 Weighing Sector Meeting

\section{Fairbanks Scales}

NY Weights and Measures

HBM, Inc.

National Institute of Standards and Technology National Institute of Standards and Technology

CA Division of Measurement Standards

MD Weights and Measures

Revere Transducers

Cardinal/Detecto

Cardinal/Detecto

Sensortronics

Packers and Stockyards Administration

PMI/Hobart Corporation

CT Weights and Measures

National Institute of Standards and Technology USDA/FGIS

Chronos Richardson

Mettler Toledo

Scale Manufacturer's Association

$\mathrm{OH}$ Weights and Measures

Weigh-Tronix

National Institute of Standards and Technology NMB Technologies, Inc. 


\section{List of Acceptable Abbreviations/Symbols}

This list does not standardize the abbreviations/symbols that must be used, rather it identifies abbreviations/symbols that are routinely acceptable. This list is not limiting or all-inclusive; other abbreviations/symbols may be acceptable.

\begin{tabular}{|c|c|c|c|}
\hline Device/Application & Term & Acceptable & Not Acceptable \\
\hline \multirow[t]{8}{*}{ General: } & $\begin{array}{l}\text { value of scale division } \\
\text { (displayed) }\end{array}$ & d & \\
\hline & $\begin{array}{l}\text { value of verification } \\
\text { scale division }\end{array}$ & $\mathrm{e}$ & 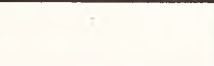 \\
\hline & $\begin{array}{l}\text { number of scale } \\
\text { divisions }\end{array}$ & $\bar{n}$ & \\
\hline & gross & gross, $\mathrm{G}$ & \\
\hline & tare & tare, $\mathrm{T}, \mathrm{TA}$ & \\
\hline & net & net, $\mathrm{N}$ & \\
\hline & pieces & pieces or pcs & \\
\hline & count & $\begin{array}{l}\text { count or ct or symbol } \\
\text { for pieces }\end{array}$ & \\
\hline \multirow[t]{3}{*}{ Values Defined: } & SI Units & $\begin{array}{l}\text { Table } 1 \text { of the General } \\
\text { Code }\end{array}$ & \\
\hline & \multicolumn{3}{|c|}{$\begin{array}{l}\text { Notes on SI Units: } \\
\text { - lower case "kg" on display panels \& keys } \\
\text { - lower case "kg" should be used for printing when possible; upper case "KG" } \\
\text { is acceptable only if lower case "kg" cannot be printed }\end{array}$} \\
\hline & Other symbols & $\begin{array}{c}\text { General Tables of } \\
\text { Weights and Measures, } \\
\text { HB } 44^{*}\end{array}$ & \\
\hline \multirow{5}{*}{$\begin{array}{l}\text { Exceptions to Gen'I } \\
\text { Tables of W\&M, HB 44: }\end{array}$} & carat & $\mathrm{ct}, \mathrm{c}$ & \\
\hline & U.S. short ton & ton or $\mathrm{TN}$ & \\
\hline & \multicolumn{3}{|c|}{$\begin{array}{l}\text { (Note: For belt conveyor scales, the abbreviation " } \mathrm{T} \text { " is acceptable to denote the } \\
\text { U.S. short ton.) }\end{array}$} \\
\hline & U.S. long ton & LT & \\
\hline & grain & grain, GRN, grn, or GN & gr \\
\hline \multirow[t]{5}{*}{$\begin{array}{l}\text { Operational Controls, } \\
\text { Indications, Features: }\end{array}$} & $\begin{array}{l}\text { zero key or center of } \\
\text { zero indicator }\end{array}$ & 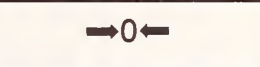 & \\
\hline & Off (Power) & & \\
\hline & On (Power) & & \\
\hline & zero device & $\Rightarrow 0-$ & \\
\hline & print & & \\
\hline
\end{tabular}


List of Acceptable Abbreviations/Symbols (continued)

\begin{tabular}{|c|c|c|c|}
\hline Device/Application & Term & Acceptable & Not Acceptable \\
\hline \multirow[t]{3}{*}{ Operational Controls (cont.): } & tare enter key & $\Rightarrow \mathrm{T}$ & \\
\hline & tare clear key & $T-$ & \\
\hline & verify tare & $T-$ & \\
\hline \multirow[t]{3}{*}{ Weighing Elements: } & accuracy class & I, II, III, III L, IIII & \\
\hline & $\begin{array}{l}\text { maximum number of } \\
\text { scale divisions }\end{array}$ & $\mathrm{n}_{\max }$ & \\
\hline & $\begin{array}{l}\text { minimum verification } \\
\text { scale division }\end{array}$ & $\mathrm{e}_{\min }$ & \\
\hline \multirow[t]{2}{*}{ Indicating Elements: } & accuracy class & I, II, III, III L, IIII & \\
\hline & $\begin{array}{l}\text { maximum number of } \\
\text { scale divisions }\end{array}$ & $\mathrm{n}_{\max }$ & \\
\hline \multirow[t]{3}{*}{ Load Cells: } & $\begin{array}{l}\text { maximum number of } \\
\text { scale divisions }\end{array}$ & $\mathrm{n}_{\max }$ & \\
\hline & $\begin{array}{l}\text { single or multiple cell } \\
\text { applications }\end{array}$ & $\begin{array}{c}\mathrm{S}=\text { Single; } \\
\mathrm{M}=\text { Multiple }\end{array}$ & \\
\hline & $\begin{array}{l}\text { load cell verification } \\
\text { interval }\end{array}$ & $\mathrm{v}_{\min }$ & \\
\hline \multirow[t]{2}{*}{$\begin{array}{l}\text { ECRs, Indicating \& Recording } \\
\text { Elements: }\end{array}$} & manual weight entry & $\begin{array}{l}\text { manual weight, } \\
\text { MAN WT, MANUAL } \\
\text { WT, MAN WEIGHT, or } \\
\text { similar statement }\end{array}$ & "M" or "MW" \\
\hline & symbols for kilogram & $\begin{array}{l}\text { same as noted for } \\
\text { "Values Defined" }\end{array}$ & $\begin{array}{l}\text { mixed upper and } \\
\text { lower case letters } \\
\text { are not permitted }\end{array}$ \\
\hline $\begin{array}{l}\text { ECRs, Recorded Representa- } \\
\text { tions: }\end{array}$ & $\begin{array}{l}\text { net weight indication in } \\
\text { pounds }\end{array}$ & $\begin{array}{c}\text { "pound", "lb", or the } \\
\text { symbol "\#" }\end{array}$ & \\
\hline \multirow[t]{3}{*}{ Livestock \& Animal Scales: } & Head (sale by) & $\mathrm{HD}$ or $\mathrm{H}$ & \\
\hline & Weight (sale by) & WT or W & \\
\hline & \multicolumn{3}{|c|}{ Other symbols recognized by the Packers \& Stockyards Administration } \\
\hline Belt-Conveyor Scales: & $\begin{array}{l}\text { U.S. short ton } \\
\text { (note: different from } \\
\text { "General" application) }\end{array}$ & $\mathrm{T}$ & \\
\hline
\end{tabular}




\section{National Conference on Weights and Measures Technical Committee on National Type Evaluation Measuring Sector \\ October 21-22, 1992 Meeting Annapolis, Maryland Meeting Summary}

\section{Overview of Agenda Items}

1) Use of a Compact Prover for Type Evaluation Testing

2) Identifying the Version of Software Used in a Measuring System

3) Requiring Receipts on Card Readers

4) Audit Trails

5) Classification of Liquids for PD Meters

6) Distinguishing Between "Agri-chemicals" and "Chemicals" for Tolerance Application

7) Compressed Natural Gas Metering

8) NTEP Testing of Remanufactured Devices

9) Manual Volume Entries for Electronic Cash Registers

10) Criteria for Water Meters

11) Criteria for Cash Acceptor Option

12) G-UR.3.4. Responsibility Money-Operated Devices

13) Update Checklists for Changes Made to H44 at the 1992 NCWM

14) Suitability of Equipment Criteria Under Study By S\&T

15) Permanence Tests for the Type Evaluation of Liquid-Measuring Devices

16) Meter Sizes to be Included on a Certificate Based on Testing

\section{Meeting Summary}

\section{1) Use of a Compact Prover for Type Evaluation Testing}

Background \& Discussion: The Committee received a request from Brooks Instruments to consider permitting the use of a compact or small volume prover (SVP) for the field permanence portion of an NTEP test of a liquid-measuring device.

Committee member, Tim Scott, Brooks Instruments, gave a short presentation on the design and operation of Brooks' SVP to provide the Committee with background information on this issue. Mr. Scott reviewed the history of the SVP and identified some of the principal companies that have been involved in the development of SVPs. He reviewed the typical components of an SVP and how these components operate. He reported that (1) there is no change in repeatability or linearity over the flow rate range of the SVP (which can be 1000:1) and (2) agreement with neck-type provers is on the order of 0.02 percent to 0.05 percent. He indicated that there is a strong history of industry acceptance of these devices, 
and he identified a number of major companies that currently use SVPs in their operations. Mr. Scott also reviewed a number of comparisons between the SVP and the volumetric neck-type test measure typically used by weights and measures officials; comparisons included operator safety, environmental safety, ease of use, wholesale meter (load rack) applications, maintenance, and system uncertainty. Mr. Scott concluded by summarizing four main benefits of using an SVP for meter testing: (1) improvement of operator safety; (2) improves environmental safety; (3) broad industry acceptance; and (4) improves efficiency testing. (Hard copies of Mr. Scott's presentation are available upon request from Tina Butcher, NIST, Tel: (301) 975-2196.)

The Committee then heard a presentation from Dr. George Mattingly, Fluid Mechanics Group, NIST. Dr. Mattingly began by giving an overview of some of the facilities and programs at NIST related to fluid measurement. Dr. Mattingly recently published a paper entitled "The Characterization of a Piston Displacement-Type Flowmeter Calibration Facility and Calibration and Use of Pulsed Output Type Flowmeters" in the Journal of Research of the National Institute of Standards and Technology (September-October 1992). (Copies of Dr. Mattingly's paper are available upon request from Tina Butcher, NIST (Tel: (301) 975-2196). Dr. Mattingly indicated that the paper describes methods for calibrating the prover, calibrating a flowmeter with the prover, and using this flowmeter to prove other flowmeters.

In summarizing the main points of the paper, Dr. Mattingly described the benefits of a measurement assurance program over the classic calibration and standards transfer used by NIST in the past. Dr. Mattingly indicated that the benefits of a measurement assurance program which involves round robin testing include reduced overall uncertainty, "calibration" of entire laboratories (as opposed to simply calibration of artifacts) outside NIST, and continual data feedback. Dr. Mattingly reviewed the methods used to plot and analyze data from the round robin testing that NIST has been conducting for some time, and he described how the data plots can be used to determine the tendency for the process to be random or to be systematic. He also described how the data presented in this manner has been used to identify strengths as well as possible areas for improvement in the procedures, test methods, and precision of individual laboratories participating in the round robins. With respect to the use and design of the SVP, Dr. Mattingly noted that temperature and pressure effects are critical to the measurement process and indicated that work had been done based on the round robin test results to improve these measurements. Suggestions have also been made to companies concerning design changes necessary to improve the measurement of these two parameters. In reviewing the relative benefits of the SVP as found in the round robin testing, Dr. Mattingly indicated that compact provers can be very reliable and noted that many companies have taken advantage of their benefits.

The Committee noted that this issue can be examined from two viewpoints: (1) the use of compact provers for NTEP testing, and (2) the use of compact provers for routine weights and measures testing. The purview of this Committee is to evaluate the inspection and testing of devices under NTEP, therefore, the majority of the discussion was limited to the use of these devices in NTEP testing.

One objective of NTEP testing is to determine compliance of the device with Handbook 44 through testing the device as it is normally used. NTEP has required that field testing be performed using a volumetric, neck-type prover or gravimetrically since these methods duplicate the manner in which the device under test will be used in normal operation, and these are the methods most commonly used by weights and measures officials in routine enforcement. Consequently, issues related to the use of these devices in routine field testing were also part of the discussion.

The following points were raised during the discussion of this issue:

- The uncertainty associated with any standard used to test a device shall not exceed one third of the tolerance applicable to the device. Manufacturers of compact provers have indicated that this ratio can be met using the compact prover.

- It was claimed that compact provers may be as or more accurate than volumetric neck-type provers; however, they may not be typical of actual use. Volumetric neck-type provers duplicate the "start and stop" effects on the accuracy of a delivery. Since compact provers operate "on-the-fly," the question of whether or not these provers provide an accurate reflection of the accuracy of a typical delivery was raised. It was commented that the "start/stop" effects found in loading-rack type installations should not be a significant enough impact on the typical size delivery to invalidate the results.

Volumetric neck-type provers may also duplicate more closely the effects of vaporization, which is not true for compact provers. The basis for a transaction must be the quantity of liquid in the tanks after the tanks have been filled, not simply the liquid that has passed through the meters. 
- Participation in round robin testing such as that coordinated by the Fluid Mechanics Group at NIST helps to: ensure traceability to NIST (as is required for any standard used in an NTEP test); ensure that a company will be able to take advantage of suggested design changes to improve temperature and pressure measurement; and to assure NTEP that the prover is capable of providing the level of accuracy which has been required for NTEP testing in the past.

- The use of compact provers is most attractive in situations where alternative equipment does not exist or is difficult to obtain or use, in cases where return of the product used in testing the meter can be difficult (e.g., where oxygenates are added as the product is loaded), or when alternative methods of testing are not feasible.

- The NCWM and NTEP has required that new technology (or technology not previously addressed by the NCWM) be as good as or better than the existing technology. Compact provers have been used by industry for many years; however, NTEP and weights and measures officials have not recognized these devices due to a lack of information on how closely these devices can approximate actual delivery, and the performance (accuracy) of the SVP is over a range of temperatures. NTEP is sensitive to the possible reluctance on the part of the weights and measures official to accept the use of compact provers since this can impact the acceptance of the NTEP Certificate of Conformance for a device.

- NTEP currently permits other than volumetric neck-type provers (e.g., ball-type, loop provers, etc.) to be used in the laboratory portion of type evaluation. The laboratory portion of the evaluation is conducted primarily to examine the linearity and repeatability of the meter, and it is followed by a field test using a volumetric neck-type prover (or gravimetric methods) to verify the performance of the device as it is actually used. NTEP has also permitted the use of other types of test equipment in special cases where other types of testing are not feasible.

- The use of the SVP as a legal standard must still be justified. A structured study to collect data is needed to permit compact provers to be recognized as legal field standards. Such a plan should outline the type and extent of tests needed to provide adequate comparisons between the SVP and the volumetric neck-type prover and to demonstrate that the SVP provides results that reflect actual device performance.

- Based on the technical information presented, the Committee saw no need to restrict the use of these devices only to tests where alternative methods are not available or impractical. The Committee agreed that the weights and measures jurisdiction having authority at an NTEP test site can still reserve the right to conduct a test using proving methods officially recognized in their jurisdiction.

Conclusions: The Committee recommends that NTEP permit compact provers (and other provers such as ball-type provers) to be used during the laboratory and field portions of type evaluation tests. If the policy of the weights and measures jurisdiction with authority over a device undergoing type evaluation does not recognize the use of compact provers for official tests, it is recommended that the weights and measures jurisdiction perform an official test following the completion of the NTEP permanence test. Data must be provided or developed before a decision is made regarding whether or not NIST will recognize that compact provers be used as acceptable substitute legal standards in place of the neck-type prover or gravimetric testing.

The Committee recommends that NTEP maintain its policy that standards used for NTEP testing must be traceable to NIST. Brooks Instruments has agreed to develop a plan to perform comparison testing with current proving methods used by NTEP. This plan will be designed to demonstrate that these devices provide a reliable means of testing which is equivalent to current test procedures used by NTEP for demonstrating that a device complies with the applicable requirements of NIST Handbook 44. It is anticipated that this plan will be presented to NIST Office of Weights and Measures (OWM) in January 1993.

\section{2) Identifying the Version of Software Used in a Measuring System}

Background \& Discussion: A meeting was held in conjunction with the LMB, Canada in April 1992 to discuss userprogrammable software and how software and modifications to software should be handled during type evaluation. (A copy of the meeting summary was provided to Committee members with the agenda for this meeting.) A review of some of the objectives and main points of the meeting was presented to the Committee. It was noted that, as a result of the meeting, weights and measures officials should be better prepared to make more learned decisions concerning this issue.

In the course of discussing this issue, it became apparent that two varieties of user-changeable software exists. One variety is software designed to be reprogrammed by the user if desired; the Committee agreed to refer to this as "userprogrammed" software. A second variety is software with a variety of "menu" options which can be selected by the user 
when the software is installed and set up on the system; the Committee agreed to refer to this type of software as "userconfigurable."

The Committee agreed that the selection of menu options in user-configurable software is not pertinent to this discussion; its discussions on this issue are limited to changes to the software itself. The Committee agreed that NTEP can evaluate the menu options submitted with user-configurable software, and the user can select from any of the options evaluated. The field official must ensure that the menu options selected by the user are suitable for the end installation; no additional evaluation is needed from NTEP provided options are selected from the menu originally evaluated.

When "user-programmed" software is currently submitted to NTEP, NTEP evaluates the basic package and issues a certificate for that version of the software. If the end user (or the manufacturer) changes the software using the userprogrammed attribute, then the manufacturer or user must resubmit the software for evaluation of the altered version; otherwise, the altered version is not recognized by the original CC. For other types of software, it is expected that a manufacturer may periodically make changes to the software, however, it is not expected that a user will make changes. As with changes to user-programmed software, NTEP must be notified of any changes and the software re-evaluated.

It was agreed that no software is "foolproof"; there is usually a way to circumvent the safeguards built into the system, and computer hackers may be able to make unauthorized changes. Of most concern to NTEP is: how NTEP can protect against unauthorized changes from being readily made to the weights and measures portion of the software; how the field official can determine if unauthorized changes have been made; and how NTEP can ensure that NTEP is notified of changes.

One company indicated that the version number is currently included with the software for the company's own needs, and that experience indicates that other countries may already require this of device/software manufacturers. Other companies indicated that changes are continually made to the non-weights and measures portions of the software; they are concerned that it would be difficult to keep up with the most current version number on the $\mathrm{CC}$ which may result in rejection of the system.

Conclusions: The Committee concluded that NTEP should continue to handle user-programmed and userconfigurable software as currently done, and that current policies should be documented. The current policies used by NTEP are shown below (along with a definition of each type) and will appear in the liquid-measuring devices portion of NCWM Publication 14.

\section{User-Programmed Software:}

If the manufacturer wishes to have the basic software package covered by an NTEP CC, the package must be submitted to NTEP for evaluation. Successful evaluation will result in an NTEP CC which covers the basic software package only (no programming changes by the user).

If the manufacturer has elected not to submit the basic software package to NTEP, the user may choose to submit either the basic software package (if no changes are made) or the version of software with changes made by the user. In either case, the resulting $\mathrm{CC}$ will be issued in the name of the user, will apply only to sites belonging to that user, and will apply to only the version of software evaluated by NTEP.

If a change is made (e.g., by the user or by the manufacturer at the request of the user) to user-programmed software with an existing $\mathrm{CC}$, the original Certificate of Conformance no longer applies to that software and the re-programmed version of the software must be submitted by either the user or the manufacturer for a reevaluation. Successful re-evaluation will result in an update to the existing $\mathrm{CC}$ to include the re-programmed version or the issuance of a new $\mathrm{CC}$ to reflect the re-programmed version of software, as appropriate.

\section{User-Configurable Software:}

User-configurable software is software with a fixed set of "menu" options that can be selected by the end-user in the final installation of the software, and the options from which the user can select can be evaluated and verified during an NTEP evaluation.

User-Configurable software can be submitted for NTEP evaluation by the manufacturer (in which case the 
resulting $\mathrm{CC}$ will bear the manufacturer name and apply to any installation) or by the user (in which case the resulting $\mathrm{CC}$ will bear the user name and will apply only to installations authorized by the user).

The menu options of user-configurable software will be evaluated and their operation verified by NTEP during the initial evaluation. The resulting $\mathrm{CC}$ will include all menu options evaluated. The $\mathrm{CC}$ will cover installations with any combination of the evaluated menu options. This will enable the user to select from any of the menu options in the final installation and, assuming the selected options are appropriate for the individual installation, resulting setup of software will be covered by the existing NTEP CC.

The Committee agreed that manufacturers should be encouraged to isolate the "weights and measures" portion of user-programmed software from the other "non-weights and measures" functions; however, no specific policies were established to require this.

\section{3) Requiring Receipts on Card Readers}

Background \& Discussion: The checklist for card readers and for liquid-measuring devices currently requires receipts to be issued for debit cards, cash-value cards, and for invoice billing systems. NTEP laboratories believe that a receipt should be made available to the customer at the time of the transaction for all card-activated devices, and the NTEP laboratories have been requiring this for some time. Indirect reference is currently made to printed receipts in the "CardActivated Retail Motor-Fuel Dispenser" portion of the Liquid Measuring Devices Checklist in Publication 14; however, no clear requirement is stated.

Recommendation: The Committee recommends the following changes be made to the Liquid-Measuring Devices Checklist under Code Reference G-S.5.1., Indicating and Recording Elements/General to clarify the requirements for credit card- and debit card-activated retail motor-fuel dispensers.

\section{Credit Card- or Debit Card-Activated Retail Motor-Fuel Dispenser}

On efedit card-activated retail motor fuel dispensers, the customer authorizes the dispenser by inserting the card or swiping the card through a slot. On credit card transactions, the customer is typically billed through the same methods as have been used for credit transactions handled through a station attendant. On debit card transactions, payment is made directly from the purchaser's account by electronic funds transfer.

1. A receipt must be available to the customer at the completion of the transaction. The issuance of the receipt may be initiated at the option of the customer.

\section{COMPLIES? - Y Y NO • N/A}

2. The customer receipt must contain the following information.

the identity (codes may be used) of the seller, purchaser, product purchased (eodes-matbet); the date of the transaction, the quantity purchased, the unit price, and the total price.

\section{COMPLIES? - Y YES - NO $\quad$ N/A}

\section{4) Audit Trails}

Background \& Discussion: An updated paper on audit trails appeared in NCWM Publication 16, Program and Committee Reports for the NCWM, July 1992. This issue was placed on the agenda to provide the Committee an opportunity to discuss any comments on this issue as it pertains to liquid-measuring devices and to enable comments to be forwarded to the S\&T Committee prior to the Interim Meetings.

The S\&T Committee of the Southern Weights and Measures Association (SWMA) developed proposed language specifying the minimum requirements for the audit trail of a liquid measuring device or associated equipment, and the SWMA voted to forward this proposal to the NCWM S\&T Committee. A suggestion was made to support the SWMA recommendation as the position of the Measuring Sector on this issue.

Mr. Ron Murdock (Chairman, SWMA S\&T Committee) reviewed the details of the proposal. The primary differences 
between the SWMA proposal and the original proposal of the NCWM S\&T Committee were noted:

- octane blend settings can not be performed remotely (e.g., from a console) from the individual retail motor-fuel dispenser (It was noted that this removes the convenience of establishing all of the octane settings at once, however, manufacturers have found that the need to change octane settings should not occur that frequently.)

- only 2 counters are required

- the values of blend settings are not required to be maintained

Several Committee members expressed concern that the proposed requirement was still too severe. lt was noted from an industry standpoint that the proposal would provide a starting point for the requirements of an audit trail and a proposal can be made at a later date to delete features that are deemed unnecessary or overly restrictive.

Conclusions: A vote was taken to determine whether or not the SWMA proposal should be supported by the Committee. The results of the vote were 11 "Yes"; 2 "No"; and 3 "Abstain."

A unanimous vote was not obtained; however, the consensus of the Committee is to support the SWMA proposal and recommend that the NCWM S\&T Committee consider adopting the language.

\section{5) Classification of Liquids for PD Meters}

Background \& Discussion: At its November 1991 meeting, the Committee discussed a proposal from Mel Hankel (Liquid Controls) for using a "family of liquids" approach for the type evaluation of positive displacement (PD) meters. Since the performance of a positive displacement meter is usually predictable within a given viscosity range, the Committee agreed to begin trying this concept with NTEP evaluations with the understanding that the families presented could be modified based on input from manufacturers and weights and measures officials. There was also some indication at the 1991 meeting that revisions may be needed to the table to account for variations in meter material types and the class designations used by different manufacturers.

Under the family of liquids approach agreed upon by the Committee, a PD meter could be tested using products with viscosities at each end of a family (e.g., one at the low viscosity end of the family and one at the high viscosity end of the family) and cover the entire family. Additional testing may be required based on the results of a type evaluation test. This would eliminate testing with every product in the family as was previously required for PD meters. In some cases, the manufacturer may not want an entire family to be covered for a particular device, therefore NTEP will limit the CC application to the range of viscosities tested within the product family.

Mr. Hankel indicated that the Meter Manufacturer's Association (MMA) has been working since the November 1991 meeting to further develop this issue and has been attempting to incorporate comments from other meter manufacturers. Mr. Hankel presented to the Committee a revised version of the table which breaks down the Petroleum Products family into four sub-groups and the Agricultural Liquids Family into three subgroups, with individual subgroups within two of these. Other suggested changes to the family of liquids concept were also made, including a suggestion to list an "accuracy class" for the meter on the Certificate.

In discussing this issue, the Committee agreed upon the following points:

- If a manufacturer finds a new product application for a device with an existing $\mathrm{CC}$ and the new product falls within the family currently listed on the $\mathrm{CC}$, no additional testing is needed to cover the product under the existing $\mathrm{CC}$; if the product does not fall within the family currently listed, additional testing must be performed.

- Fluids (such as stoddard solvent) typically found in testing laboratories may still to be used as the test fluid in NTEP evaluations. However, the application section of the resulting CC is limited to products with similar viscosity and physical characteristics. If a manufacturer wants to cover additional products, additional testing must be performed using other products.

- When a meter must be interfaced with equipment having particular features, such as multiple calibration factor capability, the NTEP CC should reflect this in the "Application" section of the CC. 
- If a field site has products at both ends of a product family, testing can be done at a single location to cover the entire family. Otherwise, two sites are needed to cover the family.

- Additional information is needed to address the question of where oxygenates fall within the established product families.

Conclusions: The Committee acknowledged that the liquid family concept has been used a number of times since the November 1991 meeting and has worked quite well. It agreed that the concept should continue to be used utilizing the revised table.

Additional information is still needed for some areas in the table. Some of the terminology, such as "lubricity number," must be defined to be meaningful to the field official; tolerances must be added to reflect the current Handbook 44 tolerances (current table only includes OIML tolerances); and the concept of the accuracy class designation must be further developed. It was recommended that a small working group be established to refine the table, incorporate suggestions from other meter manufacturers, and develop a revised table for consideration by the Committee. The MMA, led by Mr. Hankel, agreed to function as this working group.

Mr. Rall indicated that he would request experts in this field at API to provide a critique of the table developed by the Committee and to provide input on the issue of oxygenates. He agreed to assist the working group in refining the table based on API's comments.

NTEP CCs for metering devices will include a statement in the "Application" section of the CC indicating the capability of the meter to measure several products with a single calibration factor. For example, "Recalibration may be necessary for meters dispensing more than one type of product" or "Meter is capable of measuring more than one product using a single calibration factor" or "Meter is to be used only with indicating and controlling elements having multiple calibration factor capability."

\section{6) Distinguishing Between "Agri-chemicals" and "Chemicals" for Tolerance Application}

Background \& Discussion: There seems to be confusion about when a chemical is considered an "Agri-chemical." For example, during NTEP evaluation, a device is tested with a given product that may be designated as an "agri-chemical"; however, the same chemical may be used in a primarily non-agricultural application. When a type evaluation is conducted it is difficult for the manufacturer to anticipate how a particular chemical might be used. The Committee reviewed the use of the term "Agri-Chemical" as it concerns the application of tolerances during type evaluation.

Handbook 44 currently specifies the following tolerances for wholesale meters:

T.2.3.1. Measurement of Agri-Chemical Liquids. - Maintenance tolerances and acceptance tolerances shall be:

\begin{tabular}{|l|c|c|}
\hline & Acceptance & Maintenance \\
\hline Normal test & $0.5 \%$ & $1.0 \%$ \\
\hline Special test & $1.0 \%$ & $1.0 \%$ \\
\hline
\end{tabular}

T.2.3.2. Measurement of Other Liquids. Maintenance tolerances and acceptance tolerances shall be:

The tolerances for agri-chemicals were added to Handbook 44 in 1986 to recognize the corrosive, non-lubricating nature of these products and were based on conclusions from the Meter Manufacturer's Technical Committee. At the time the issue was studied, agri-chemicals were identified as including: fertilizer, feed, herbicides, pesticides, insecticides, fungicides, defoliants, and similar liquids normally used in the agriculture and chemical industries.

The Committee discussed the application of tolerances during type evaluation and how this will affect applications covered under the Certificate. If a meter is submitted for the less stringent tolerance (i.e., agri-chemicals), but has test results 
within more stringent tolerances (i.e., other liquids) it was questioned whether or not the CC could include the more stringent "Other Liquids" application. The Committee agreed that the manufacturer designs a device to meet a specific application; therefore, the manufacturer should specify what tolerances to apply at the time the device was submitted for testing. NTEP can not be certain whether or not production devices would be capable of meeting the more stringent tolerances since the manufacturer did not design the device to meet the stringent tolerances; therefore, the tolerances requested by the manufacturer at the time of submittal must dictate the application on the CC.

Conclusions: The Committee agreed that this issue should be reviewed again after additional work has been completed on the product family issue (see Agenda/Summary Item 5). Additional information developed on the product family issue should clarify the application of tolerances to particular products and product families.

The Committee recommends that the following (current) NTEP policy be maintained for the application of tolerances to wholesale meters for NTEP testing.

If a meter is tested to the (tighter) tolerances for "Other Liquids" for a given product family, it can be used with that same product family in applications which would fall under "Other Liquids" OR "Agri-chemicals" since the tolerance for agri-chemical applications is larger. If, however, the meter is tested using the "Agri-chemicals" tolerance, the meter is restricted to use in agri-chemical applications until additional testing is performed.

The tolerance applied during type evaluation will be listed on the Certificate of Conformance along with the product family or families covered under the Certificate for all metering devices.

The Committee agreed that a manufacturer must specify the application (and consequently, the tolerance to be applied) at the time a device is submitted for evaluation. NTEP will not shift the device applications based on the results of the type evaluation, since the number of devices tested are not enough to assess the performance for tighter tolerances.

\section{7) Compressed Natural Gas Metering}

Background \& Discussion: At least one request has been received by NTEP for a compressed natural gas (CNG) retail motor-fuel device, which was evaluated under existing criteria and test procedures (gravimetric testing) for mass flow meters. The Committee was asked to consider whether or not additional criteria are needed for NTEP tests of CNG.

The NCWM S\&T and L\&R Committees are currently reviewing industry requests for the use of various methods of sale and units of measurement for CNG. The Measuring Sector has been asked for input which might assist these committees in their deliberations.

The Committee reviewed a list of notes for use in testing CNG meters for possible inclusion in NCWM Publication 14 and noted the variety of device types used to measure CNG. All of these devices will be tested gravimetrically. Difficulties in testing are reflected in the testing notes, and several other areas were mentioned by the Committee. (For example, some companies are uncertain about determining the value for the Minimum Measured Quantity (MMQ).)

Concern was expressed that it may not be reasonable to expect the evaluating NTEP laboratory to be able to address all of the points specified in the notes, particularly those, such as temperature variation which cannot be easily controlled. The Committee agreed that the identified areas are important, but it may not be possible to perform all of the tests in every situation. The notes should be considered as minimum tests, and the participating laboratory should try to follow the recommendations.

The Committee also recognizes that items may have to be added as more devices are tested. For example, the second note refers to the fact that these devices are often used to "top off" tanks; therefore testing should duplicate conditions where the receiving tank is partially full and almost completely full. Other tests should employ a completely empty tank.

Conclusions: The Committee recommends that the following notes be added to the permanence tests for mass flow meters in NCWM Publication 14.

- Ideally, the device should be tested over a temperature range. Since this is not possible to easily regulate in the field, some testing should be performed early in the day and some later in the day to observe the effects of temperature changes. Note: The evaluating laboratory should attempt to test over as wide a temperature range 
as possible; however, this may not always be possible and, in some cases, little or no variation in temperature will be experienced.

- The magnitude of the draft (and, therefore, the time required for delivery) may affect test results. For very small drafts, the start and stop effects can become significant and may result in large variability. Since CNG stations are presently few and far between in some areas, it is anticipated that these devices will be heavily used to "top off" tanks. Consequently, the minimum measured quantity declared for the device can be significant. It is desirable to have at least some tests run at or near the minimum measured quantity.

- In setting up the arrangements for testing, the resolution of the scale relative to the test draft must be considered and "rounding error" of the scale must be kept to an acceptably small level. As a general guideline, the value of the scale division should not exceed one-tenth of the tolerance applied to the device. Either a high-resolution scale is needed, error weights should be used, or a larger test draft selected. A combination of these approaches may be used. The total error of the transfer standard must be limited to less than one-third of the tolerance. Therefore, the scale must be thoroughly tested, the repeatability of the scale verified, and corrections made to the results of the meter test to correct for any errors determined during the scale test.

- The repeatability of the test results must be within 0.6 percent of the measured quantity (see $1992 \mathrm{~S} \& \mathrm{~T}$ Report, Item 337-5).

- Repeat tests should be run over a range of flows or, since the device may operate at only one flow in the field installation, over a range of quantities.

- The typical size of the tank being filled by the device will be 16-20 lb. A very large tank size may be $40 \mathrm{lb}$ if a vehicle is equipped with two tanks. The average amount dispensed will probably be around $8 \mathrm{lb}$.

- Since the zero changes with temperature, the zero must be sealable as noted in the tentative code in $\mathrm{H} 44$ for mass-flow meters (see 1992 S\&T Report Item 337-2).

The Committee agreed that CNG meters should indicate on the basis of mass, and the computation of total sale must be based on mass units. The Committee noted that supplemental units may be used in addition to the mass units; however, these must be clearly identified as supplementary units. It was also suggested that conversion charts be provided to explain to the consumer how the conversion factor for the supplemental units is derived.

\section{8) NTEP Testing of Remanufactured Devices}

Background \& Discussion: Requests have been received for the type evaluation of remanufactured devices. The Committee was asked to consider how this equipment should be addressed by NTEP with respect to the checklist criteria, permanence testing, and whether or not the evaluated device is representative of the series.

At least one manufacturer expressed concern over how the repair and replacement of significant components of liquidmeasuring devices (LMD's) affect an existing NTEP Certificate of Conformance. It was suggested that a policy established by the TCNTE Weighing Sector for remanufactured complete scales in new locations might be useful as a basis for developing criteria for liquid-measuring devices.

There appeared to be some difference of understanding of the term "remanufactured" and how it is used. To some, it means a complete overhaul and rebuilding of a device using new and repaired components; to others, it may mean that a significant component has been rebuilt or replaced. A third interpretation is based on the custody or ownership of the device. The Committee agreed that the term "remanufactured" means that at least some significant changes have been made to the original device.

"Remanufacturers" who rebuild complete devices may or may not use original equipment manufacturer parts; consequently, it is difficult to determine how a rebuilt piece of equipment might differ in performance from the original. It is difficult or impossible to determine from visual examination whether or not a component, such as a metering chamber, has been rebuilt or repaired by the replacement of internal components; again, the internal components used in the repair may or may not be purchased from the original manufacturer. In either case, the NTEP CC issued to the original device would certainly be invalidated if the work was done by other than the original manufacturer or authorized representative. 
A question was raised concerning the responsibilities of the original equipment manufacturer who "authorizes" a service company to repair or rebuild devices. The basic requirement is to ensure that the authorized service company is capable of performing the work and agrees to use only OEM or equivalent parts. This might help to ensure that the performance of the repaired or remanufactured device would be consistent with the original device.

The Committee agreed that NTEP policies must be established for two areas of remanufacturing:

(1) complete devices installed in new installations, and

(2) repair and remanufacture of device components for devices in existing locations.

Such policies also provide a useful enforcement tool for weights and measures in determining whether or not a CC has been invalidated.

Conclusions: The Committee recommends that the following policy be established for remanufactured liquidmeasuring devices and associated equipment in new installations:

(1) If a device with an existing NTEP CC is remanufactured by the OEM or authorized agent using OEM parts, no additional evaluation is required; the original $\mathrm{CC}$ applies, provided that the remanufacturing process does not modify the design of the device.

If a device without an existing NTEP CC is remanufactured by the OEM or authorized agent, the device must be submitted to NTEP for evaluation in order to be recognized on an NTEP CC.

(2) If a device with or without an existing NTEP CC is remanufactured by a company other than the OEM or authorized agent, the device must be marked with the remanufacturer's name, model designation, nonrepetitive serial number, and the qualifier for the serial number as required by G-S.1., General Code of Handbook 44.

The device must be submitted to NTEP for evaluation and should be considered by the remanufacturer to be a "typical" example of the devices remanufactured by that remanufacturer.

(3) Remanufactured devices will be evaluated in the same manner, using the same test procedures and criteria, as newly manufactured devices. No test results obtained for the original equipment will be accepted in lieu of actual testing.

(4) The same guidelines for including parameters of a device on a CC that apply to newly manufactured equipment shall apply to remanufactured equipment.

The Committee agreed that further work is needed to develop a policy for repair of components used in existing installations. Mr. Gordon Johnson, Gilbarco, agreed to draft language for such a policy for the Committee's review. (A copy of a proposal prepared by Mr. Johnson is enclosed with this summary; comments on the proposal are requested by March 5, 1993.)

\section{9) Manual Volume Entries for Electronic Cash Registers}

Background: An inquiry has been received concerning manual volume entries by an electronic cash register (ECR) interfaced with a retail motor-fuel dispenser. They are not currently permitted by NTEP, as specified in the ECR checklist of Publication 14. It has been suggested that they be permitted when the ECR is "off-line" from the dispensers.

Conclusions: Due to the large number of items on the Committee agenda, the Committee was not able to address this issue. Specific inquiries need to be resolved, hence a separate letter ballot and the background information originally presented in the meeting agenda are included with this summary for Committee members.

\section{0) Criteria for Water Meters}

Background: NTEP periodically receives requests to test residential water meters. These requests have been denied in the absence of check list criteria for NTEP testing of these devices. 
The Water Meters Code in Handbook 44 does not apply to vehicle-mounted meters. Although NTEP does not test residential water meter it might test, a meter used to dispense water in a vehicle-mounted application using the criteria established for vehicle-tank meters.

The Committee was asked to consider whether or not (a) the demand for performing NTEP tests of such meters is sufficient to warrant the development of criteria using the Water Meters Code, and (b) additional criteria are needed in the existing areas of the checklist for vehicle-tank meters to address meters dispensing water.

Conclusions: Due to the large number of items on the Committee agenda, the Committee was not able to address this issue. If Committee members feel this issue must be addressed immediately, please contact Tina Butcher at (301) 975-2196. Otherwise, this issue will be held for review by the Committee at its next regular meeting.

\section{1) Criteria for Cash Acceptor Option}

Background \& Discussion: NTEP evaluations have been performed on several retail motor fuel dispensers with cash acceptor options using existing criteria and applying appropriate paragraphs of Handbook 44; however, more definitive guidelines are needed. Based on the evaluations performed, proposed criteria for the cash acceptor option on a device were developed and presented to the Committee for review.

The Committee reviewed the proposed checklist along with some related questions. The Committee agreed upon the following points:

- It is not necessary that all devices be able to recall the running total display for a set period of time (e.g., 15 minutes). Recalling the running total display is provided as one option for a manufacturer to use to satisfy the power loss requirement. If the manufacturer uses another method to recover the information (e.g., a printed receipt), recalling the running total display should not also be required.

- The running total display should be required as the customer inserts money to avoid confusion and to help the customer keep track of the total amount entered. However, the information should not be required to be displayed once the customer has started to deliver product.

- A printed receipt must be made available to the customer for cash acceptor transactions, and this receipt must be obtained from the device (rather than at some other location, such as the service station console).

- NTEP should assume that all cash acceptors currently under development (for use with retail motor-fuel dispensers) have some form of low paper sensor. (Most cash acceptors are manufactured by the same company.) If NTEP encounters a device without a low paper sensor, NTEP must prove that the device does not satisfy the section of the checklist which requires that the cash acceptor must not initiate a transaction if insufficient paper is available.

- All cash acceptors should automatically issue a receipt if the amount dispensed is less than the total money inserted, including devices that offer the receipt as a customer option.

- The change due must be printed on the receipt, and this is sufficient to alert the customer to the amount of change due. The device is not required to display the amount of change due.

- At present, no devices which issue change are being marketed. The Committee agreed to address such devices as the need arises.

- Unlike a card-activated dispenser, a "time out" period is not needed for cash sales after the device has been authorized, but a "time out" period is not prohibited. If a time out feature is provided, there is no limit on the maximum time. The purpose of the time out period for card-activated devices is to ensure that a customer's account does not remain authorized indefinitely. With a cash payment, there is no open account. The customer who decides to terminate the transaction, can cancel it manually. If a power loss occurs, other provisions must ensure that the customer will receive a refund of the tendered amount.

- Instructions must be provided to the customer on how to operate the cash acceptor; however, standardized messages and instructions are not needed. The NTEP laboratories must evaluate the clarity of the instructions on a case by case basis, using judgement as to adequacy. 
- A device may accept cash while a transaction is in progress, provided that the device correctly accounts for all cash inserted.

Among the questions discussed by the Committee is whether or not the cash acceptor can be used in an unattended location, particularly how the customer will obtain a refund for product not obtained. If a power failure occurs or if the customer is unable to retrieve a bill from the device, the customer will not be able to easily verify the amount that was inserted unless a printed receipt is available. Unlike a vending machine where the dollar amounts are usually small, the cash acceptor may have accepted large dollar amounts (e.g., \$10, \$20, or more): it was suggested that additional precautions are needed prior to including this option on devices in unattended locations.

Conclusions: A number of changes to the proposed checklist for the cash acceptor option were identified by the Committee. The Committee agreed that it is appropriate for specific test methods to be developed for some areas of the checklist to describe how the participating laboratories should verify compliance of a device. The Committee agreed that the technical advisor will change the checklist as recommended by the Committee and will add appropriate test procedures. The resulting document will be distributed to the Committee along with a letter ballot for Committee members to indicate whether the revised checklist is acceptable for inclusion in Publication 14 or if additional work is needed.

The Committee anticipates that there will be increased demand for the use of the cash acceptor in unattended locations. The Committee will limit the use of the cash acceptor option to attended stations at the present time, but further consideration must be given to this use. The Committee concluded that language must be added to the checklist (or a separate checklist developed) to address these installations, and the Committee should develop this language. Mr. Gordon Johnson (Gilbarco), Ms. Debbie Joines (Wayne Division Dresser Industries), Mr. Larry Murray (Wayne Division Dresser Industries), and Mr. Rich Tucker (Tokheim) agreed to work together to develop suggested language for the use of the cash acceptor option in unattended locations.

\section{G-UR.3.4. Responsibility, Money-Operated Devices}

Background \& Discussion: In the course of conducting a recent type evaluation of a cash acceptor option on a retail motor-fuel dispenser, it was noted that paragraph G-UR.3.4. applies since the cash acceptor would make the device a money-operated device. This user requirement was not applied during type evaluation. It was pointed out to the manufacturer so that customers could be informed of the requirement and to provide an opportunity for the manufacturer to allow space for the information to be marked on the device.

Committee members agreed that it is reasonable that the user should not be required to post the information required by G-UR.3.4. in situations where the employees on the premises are responsible for the money-operated equipment and a customer can resolve any problems with the employee(s) prior to leaving the business. Since this would require a change to the current wording of the paragraph, it was suggested that a recommendation be forwarded to the S\&T Committee for consideration. The Committee agreed that the exemption for cash acceptor options proposed for G-UR.3.4. should not apply to unattended locations since station personnel will not be present to help resolve problems that might occur.

Conclusions: The Committee recommends that the S\&T Committee consider the following change to General Code paragraph G-UR.3.4.

G-UR.3.4. Responsibility, Money-Operated Devices. - A device of the money-operated type, except parking meters, shall have clearly and conspicuously displayed thereon, or immediately adjacent thereto, adequate information detailing the method for the return of monies paid when the product or service cannot be obtained. This information shall include the name, address, and phone number of the local servicing agency for the device. This requirement does not apply to cash acceptor options on retail motor-fuel dispensers at attended locations where station employees are responsible for resolving any monetary discrepancies for the customer. (Amended 1977)

\section{3) Update Checklists for Changes Made to H44 at the 1992 NCWM}

Background \& Discussion: The Committee reviewed specific language to be added to NCWM Publication 14 to reflect changes to Handbook 44 as adopted by the NCWM in July 1992. A note was also added to the Code Reference in item (B) to clarify that reversion to a base unit price may result in a (permitted) mathematical disagreement. 
Conclusions: The Committee agreed upon the following additions to Publication 14. (Page numbers reflect the 1989 (current) version of Publication 14.)

\section{(A) Retail Motor-Fuel Dispensers, Code Reference S.1.6.5.4., Page 217:}

Change this code reference to read:

Except for dispensers used exclusively for truck refueling (e.g., truck stop dispensers used only to refuel trucks), when a product or grade is offered for sale at more than one unit price through a computing device, the selection of the unit price shall be made:

(a) prior to delivery using controls on the device or

(b) other user-activated controls.

COMPLIES ? • YES $\quad$ NO $\quad$ N N NA

A system shall not permit a change to the unit price during delivery of product.

COMPLIES ? $\quad$ YES $\quad$ NO $\quad$ N NA

(B) Retail Motor-Fuel Dispensers, Add new code reference S.1.6.5.5., Page 217 following S.1.6.5.4.

\section{Code Reference. S.1.6.5.5. Display of Quantity and Total Price}

When a delivery is completed, the total price and quantity for that transaction shall be displayed on the face of the dispenser for at least 5 minutes or until the next transaction is initiated by using controls on the device or other useractivated controls.

[Nonretroactive as of January 1, 1994.]

Note: The displayed unit price may revert to a base unit price immediately after the completion of a transaction, defined as the time the delivery has been terminated and payment has been settled. Any display of quantity, unit price, and total price that is not in mathematical agreement occurs between transactions and is permitted (in response to demands of device users) because the displayed values between "transactions" are not "significant" relative to the actual delivery process (transaction).

COMPLIES ? - Y Y NO $\quad$ NO NIA

\section{(C) Common Specific Code Criteria, Mass Flow Meters}

- Add to the end of Liquid-Measuring Devices, Common Specific Code Criteria, Page 204:

\section{Mass Flow Meters}

Code Reference: S.3.5. Provision for Sealing

Adequate provision must be made for an approved means of security (e.g., data change audit trail) or physically applying security seals in such a manner that an adjustment on any device that affects the measurement result cannot be made without breaking the security seal. Provision shall be made for the zero adjustment mechanism to meet this requirement.

$\begin{array}{lllll}\text { COMPLIES ? } & \text { YES } & \text { NO } & \bullet & \text { N }\end{array}$

Code Reference: UR.2., Low-Flow Cut-Off Valve

NOTE: If a metering system is equipped with a programmable or adjustable "low-flow cut-off" feature, the application section of the Certificate of Conformance should indicate that the device is to be used in installations with the following setup parameters:

(a) the low-flow cut-off value shall not be set at flow rates lower than the minimum operating flow rate specified 
by the manufacturer on the meter; and

(b) the system shall be equipped with flow control valves which prevent the flow of product and stop the indicator from registering product flow whenever the product flow rate is less than the low-flow cut-off value.

(D) $\underline{\text { LPG \& NH}}_{3}$ Liquid Meters, Printed Ticket

- Add a note following S.1.1.6., Printed Ticket, Page 254 to reference UR.2.6.:

NOTE: Vehicle-mounted metering systems must be equipped with a ticket printer. If the device submitted for type evaluation is equipped with a ticket printer, this should be listed as a standard feature. If the device submitted is not equipped with a ticket printer, the application section of the Certificate of Conformance must indicate that a the device is suitable for installation only in applications where an appropriate and compatible ticket printer is provided. (Code Reference UR.2.6., Ticket Printer)

Nonretroactive as of January 1, 1993. To become retroactive as of January 1, 1994.

\section{(E) Permanence Tests for Retail Motor-Fuel Dispensers}

Add new number 4 to "Initial Examination":

4. Repeatability. - When consecutive multiple tests are conducted at approximately the same flow rate, the range of the test results for the flow rate shall not exceed 40 percent of the absolute value of the maintenance tolerance.

\section{(F) Permanence tests for Vehicle-Tank and Wholesale Meters}

- Add the following note in reference to the definition of "normal tests."

NOTE: The "normal" test of a measuring system shall be made at the maximum discharge rate that may be anticipated under the conditions of the installation. Any additional tests conducted at flow rates down to and including one-half of the sum of the maximum discharge flow rate and the rated minimum discharge flow rate shall be considered normal tests. (Code Reference N.4.1.)

- Add the following reference to the requirements for automatic temperature-compensating systems.

The difference between the meter error for results determined with and without the automatic temperature compensating system activated shall not exceed:

(a) 0.2 percent of the test draft for mechanical automatic temperature compensating systems; and

(b) 0.1 percent of the test draft for electronic automatic temperature compensating systems.

The results of each test shall be within the applicable acceptance or maintenance tolerance.

- Add the following references to repeatability requirements:

Repeatability on Wholesale Meters (Code Reference T.2.3.3.): When multiple tests are conducted at approximately the same flow rate, the range of the test results for the flow rate shall not exceed 40 percent of the applicable tolerance. This tolerance does not apply to the test of the automatic temperature compensating system.

Repeatability on Vehicle-Tank Meters (Code Reference T.4.): When multiple tests are conducted at approximately the same flow rate, the range of the test results for the flow rate shall not exceed 40 percent of the applicable tolerance.

(G) Permanence Tests for LPG \& Cryogenic Meters 
- Add the following reference to repeatability requirements:

Repeatability on LPG \& $\mathrm{NH}_{3}$ Meters (Code Reference T.3.): When multiple tests are conducted at approximately the same flow rate, the range of the test results for the flow rate shall not exceed 40 percent of the applicable tolerance. This tolerance does not apply to the test of the automatic temperature compensating system.

- Add the following reference to temperature-compensating systems:

The difference between the meter error for results determined with and without the automatic temperature-compensating system activated shall not exceed:

(a) 0.5 percent of the test draft for mechanical automatic temperature compensating systems; and

(b) 0.25 percent of the test draft for electronic automatic temperature compensating systems.

The results of each test shall be within the applicable acceptance or maintenance tolerance.

\section{(H) Permanence Tests for Mass Flow Meters, Page 267}

- Add reference to permanence tests for mass flow meters:

\section{Permanence Tests for Mass Flow Meters}

Repeatability. - When multiple tests are conducted at approximately the same flow rate, the range of the test results for the flow rate shall not exceed:

(a) 0.2 percent of the measured quantity for liquid measurement; and

(b) 0.6 percent of the measured quantity for vapor measurement.

(Code Reference: T.4.)

\section{4) Suitability of Equipment Criteria Under Study By S\&T}

Background: The Committee was asked to review criteria currently proposed by the NCWM S\&T Committee for suitability of equipment for liquid-measuring devices. (See ltem 330-6 from the July 1992 final report of the S\&T Committee.) The Committee was asked for input on whether changes/additions are needed or if a different approach should be used.

Conclusions: Due to the large number of items on the Committee agenda, the Committee was not able to address this issue. Committee members were encouraged to submit individual comments to the S\&T Committee before the Interim Meeting to assist the S\&T Committee in the development of this issue.

\section{5) Permanence Tests for the Type Evaluation of Liquid-Measuring Devices}

Background \& Discussion: The S\&T Committee proposed guidelines (see Item 330-11 in the July 1992 final report of the S\&T Committee) for conducting type evaluation of liquid-measuring devices and asked for input from the Measuring Sector. The proposed guidelines outline the choice of location for the testing and specify the number of hours of operation for a test run in a government laboratory.

Questions were raised about how the term "appropriate facilities" should be defined/qualified. Although the S\&T Committee had intended the term to mean only a facility with good measurement traceability, quality management guidelines might be an appropriate basis for establishing minimum criteria to define an appropriate facility.

The Committee agreed that the "family of liquids" criteria will apply regardless of where the meter is tested. For example, if a device is tested in a laboratory with a product such as varsol, the meter will be limited to applications measuring products of similar viscosity and other physical characteristics. Before use with products with different characteristics, additional testing must be performed. This makes laboratory testing of only limited applicability since field tests will 
almost always be required.

A number of Committee members feel that a laboratory test alone is not a sufficient basis for an NTEP CC, particularly for vehicle-mounted applications or where the installation can influence the performance of the device. Field testing subjects devices to wear and tear, environmental elements, vibration, and customer and user abuse that would normally be experienced with the device. The field test is judged to be more severe than the laboratory test and a better indication of how the device will perform in actual use.

The 100 hours minimum time limit suggested for tests conducted in a laboratory facility may have been derived from a draft OIML document, but OIML, has not yet issued a final document. Although there was no objection to a suggested time limit, there was concern that a limit be established before agreed upon by OIML.

The Committee agreed that additional language will need to be added to Publication 14 to reflect the decision of the S\&T Committee and, by the NCWM when it endorses it.

Conclusions: The Committee agreed that NTEP should not require that a manufacturer should submit a device to a government laboratory for testing. The manufacturer should be allowed to choose one of the following:

(a) a government laboratory;

(b) a field test;

(c) a manufacturer's laboratory

Committee members question whether a laboratory test alone is an adequate basis for a CC.

The Committee recommends that the comments generated in this discussion (as reflected above) be forwarded to the S\&T Committee.

\section{6) Meter Sizes to be Included on a Certificate Based on Testing}

Background \& Discussion: In the past, NTEP has permitted meters "one size larger" and "one size smaller" to be included on a Certificate based upon the testing of a given meter with the understanding that the "adjacent" sizes are closely related in flow rate and diameter. In some cases, the next higher size may be quite a bit larger than the meter evaluated. For example, a 2" meter is tested and the next higher size offered by the manufacturer is 8 ". This does not meet the intent of the "one size higher" concept.

In discussing proposed language for Publication 14, it was noted that a typical progression of meter sizes might be 11/2", $2 ", 3 ", 6 "$. The Committee agreed that an upper limit of $200 \%$ is reasonable since flow rates depend upon the inside area of the pipe $\left(A=\pi r^{2}\right)$; it would closely follow the normal progression of sizes used by the typical manufacturer; and it is consistent with the current approach used by NTEP. In this example, if the maximum flow rate of the 2 -inch meter were $100 \mathrm{gpm}$ and the 3 " meter were $200 \mathrm{gpm}$, the 3 -inch would be covered based on successful testing of the 2 " meter.

Conclusions: The Committee established the following policy for inclusion in Publication 14.

The parameters of meters which can be covered on a Certificate of Conformance based on NTEP testing are as follows:

If there are more than three meter sizes in a family, to cover a family of meters on a Certificate of Conformance, the largest and smallest meters in the family shall be submitted for evaluation. It is suggested that these meters represent the meter with the lowest minimum rated flow and the meter with the highest rated flow rate. Depending upon the range between the largest and smallest meters, additional meters may be required to be submitted for testing.

Based upon the test of a meter (or meters) of only one size the Certificate may cover meters one size larger and one size smaller than that is tested under the following criteria:

a. meter sizes with rated maximum flow rates of $50 \%$ to $200 \%$ of the rated maximum flow rate of the meter tested; and 
b. meter sizes with rated minimum flow rates of $50 \%$ to $200 \%$ of the rated minimum flow rate of the meter tested.

\section{Additional Item:}

A discussion concerning improvements to the current NTEP process was held in conjunction with the regular meeting of the Committee. Results of this discussion are available upon request from OWM.

\section{NTEP Technical Committee Measuring Sector \\ October 21-22, 1992 Meeting \\ Southern Weights and Measures Association \\ Annapolis, Maryland}

\section{Attendance List}

Name

Richard Tucker

Doug Smith

Steve Cook

Bob Rall

Gordon Johnson

Steve Malone

Dick Whipple

Ross Andersen

Jim Truex

Otto Warnlof

Michael Keilty

Larry Murray

Debbie Joines

Michael Belue

Tim Scott

Bob Traettino

Mel Hankel

Chris Wright

Jack Jeffries

Frances Holland

Ronald Murdock

\section{Company Affiliation}

Tokheim Corporation

Gasboy International

State of California Division of Measurement Standards

Texaco/American Petroleum Institute

Gilbarco, Inc.

Nebraska Weights and Measures

NIST

New York Weights and Measures.

Ohio Weights and Measures

NIST/OIML

Micromotion

Wayne Division Dresser Industries

Wayne Division Dresser Industries

Belue Associates/American Petroleum Institute

Brooks Instruments

Liquid Controls Corporation

Liquid Controls Corporation

Badger Meter, Inc.

Florida Department of Agriculture

Schlumberger Technologies

North Carolina Department of Agriculture 


\section{Meeting Summary \\ National Type Evaluation Technical Committee \\ Belt-Conveyor Sector}

June 18, 1992

A one-day meeting was held to discuss a lengthy agenda. Decisions included significant changes to the NTEP Checklist, Data Sheet, and Laboratory Test Procedures. Which will be implemented in all type evaluations of belt-conveyor scales from June 18, 1992. For references to the "Belt-Conveyor Scale Data Sheet and Laboratory Test Procedure," e.g., "data sheet," see pages I8-2I of the checklist showing the changes resulting from the meetings.

\section{Technical Agenda for the Meeting}

I. Is the allowable temperature-effect-on-zero for static scale tests (AZES) correct relative to the dynamic test tolerance as stated in the Test Procedures formula AZES $=0.0007\left(\mathrm{SSC}_{\min }\right)$ ?

II. Can the length of time now required to run dynamic tests be shortened without affecting the validity of the test?

III. Was the philosophy that established the return-to-zero tolerance for static tests as equivalent to the static tolerance for a 3000-division scale valid?

IV. Is it possible to consider utilizing a scale digital indicator in some fashion for observing raw counts from the A/D converter when performing simulated static tests?

V. Develop guidelines for the formatting of information printed on tickets.

VI. Review the evaluation of changes in zero for totalizers that don't totalize negative weight.

VII. Should consideration be given to running a dynamic zero test every time a static zero test is performed after a temperature change?

VIII. How many idlers should be permitted in a family based upon the type evaluation performed?

IX. Should component testing of any kind be permitted if complete systems cannot be assembled in temperature chambers?

X. Should the proposed changes to the "Belt-Conveyor Scale Data Sheet and Laboratory Test Procedures" be incorporated?

XI. Review available data and determine what constitutes agreement (or lack of) when comparing static and dynamic results.

XII. Discuss and agree on methods for predicting likely temperature effects from the published specs of major system components such as load cells and instrumentation.

XIII. Discuss establishing a uniform method for predicting the theoretical performance of a belt scale as part of the approval process.

XIV. Discuss what, if any, influence tare load effects should have on lab testing procedures.

XV. Discuss and suggest wording to clarify the following statement: "Based upon the test of a single scale, a Certificate of Conformance will usually cover parameters over a range of $10: 1$ with the limits for any one parameter not to exceed 4:I from the characteristics of the scale that was tested. 


\section{Item Discussions}

\section{Is the allowable temperature-effect-on-zero for static scale tests (AZES) correct relative to the dynamic test tolerance as stated in the Test Procedures formula AZES $=0.0007\left(\mathrm{SSC}_{\min }\right)$ ?}

\section{Meeting Results}

The allowable temperature-effect-on-zero formulae $\mathrm{AZES}=0.0007\left(\mathrm{SSC}_{\min }\right)$ for static scale testing, and $\mathrm{AZE}=\left(0.0007\left(\mathrm{SC}_{\min }\right)(\right.$ time $) / 60$ for dynamic scale testing, are correct as stated. Since static testing has been eliminated from the type evaluation test procedures, as discussed and decided in item VII, this information is moot. It is preserved in this meeting summary report, however, for historical purposes.

\section{$\underline{\text { Discussion }}$}

This item was included on the agenda because the validity of the formulae had been questioned. The following rationale was presented for discussion.

For a specific size weighbridge, the same load cells and weighbridge are used for the entire range of capacities $\left(\mathrm{BL}_{\max }\right.$ and $\mathrm{BL}_{\min }, \mathrm{SSC}_{\max }$ and $\mathrm{SSC}_{\min }$ ). The "worst case" capacity for temperature effect on zero is the lowest capacity rating (dynamic and static). The smallest tolerance for AZE and AZES (device parameters 5. and 6. on the data sheet) are at the lowest capacity rating (dynamic and static).

Dynamic capacity is a function of time (speed) and the static capacity of the scale.

- Selection of the load cell is based on the static capacity of the scale. While the load cell was probably evaluated to 0.7 of scale tolerance, the static test on the belt-conveyor scale in the laboratory is for a complete weighing system but does not include the belt; therefore T.N.8.1.3. applies which is a ld tolerance.

When the weighbridge is tested in the laboratory, it is tested without the belt. Therefore, the temperature-effect-onzero is due almost entirely to the static weighing characteristics of the weighbridge. Consequently the relationship of the temperature effect on zero for the load cell is directly dependent on the static capacity of the scale.

Per Handbook 44 for Belt-Conveyor Scales T.3.1.1., the temperature effect on zero for $10^{\circ} \mathrm{C}$ is equal to or less than 0.07 percent of the lowest rated capacity of the scale. This equates to a temperature effect on zero of 0.035 percent of the lowest rated capacity of the scale per $5^{\circ} \mathrm{C}$ change in temperature. For Class III static weighing scales with 3000 divisions, the tolerance for the temperature effect on zero is $1 \mathrm{~d}\left(\mathrm{~T} . \mathrm{N} .8 .1 .3\right.$.) per $5{ }^{\circ} \mathrm{C}$ change in temperature. This is a tolerance of 1 part in 3000 or approximately 0.033 percent per $5{ }^{\circ} \mathrm{C}$ change in temperature. This corresponds closely to the 0.035 percent tolerance for the dynamic operation of belt-conveyor scales; therefore, the appropriate static scale tolerance for temperature-effect-on-zero for belt-conveyor scales is equivalent to a Class III, 3000 division load cell.

As a whole, the Committee considered the rationale presented above as reasonable and the tolerances acceptable. It was concluded that comparing the tolerance with that applicable to $3000 \mathrm{~d}$ load cells is reasonable.

\section{Can the length of time now required to run dynamic tests be shortened without affecting the validity of the test?}

\section{Meeting Results}

In the "Initial Tests" section of the checklist, remove item \#4,page 11, "Apply a load of 150 percent of static weighing capacity to the scale to verify that the accuracy is not affected by overloading (S.2.3.)" and replace it with "Exercise the scale three times by loading the scale to 98 percent of scale capacity. Do not run the exercise tests before the other temperature tests."

Insert "Apply a load of 150 percent of static weighing capacity to the scale to verify that the accuracy is not affected by overloading (S.2.3.)" after the second $20^{\circ} \mathrm{C}$ dynamic test, and add another step for a dynamic test at $0.98 \mathrm{SSC}_{\max }$ at $20^{\circ} \mathrm{C}$ to verify performance after the $150 \%$ load.

Run zero dynamic load tests for 20 minutes, or the longest time of $0.35 \mathrm{SSC}_{\min }$, whichever is greater.

Ask the S\&T Committee to determine what scale indications should be required when loads above 100 percent capacity are weighed, and how should they apply to scale performance. 
Note: It was not discussed during the meeting; however, placing the $150 \%$ load test after the last temperature test creates a zero shift that requires a recovery period and reestablishment of a zero reference before the voltage tests can be run. Actually, the voltage tests should probably be run before the temperature tests. If the scale should fail a voltage test, then the failure can be resolved before time is spent running temperature tests. For this reason the voltage tests will be placed before the temperature tests. This change will become an item for discussion at the next meeting of the Committee.

\section{$\underline{\text { Discussion }}$}

The following tables were presented as examples to illustrate test times based on the original checklist requirements and based on new proposed test times. Consider the following device:

$$
\begin{aligned}
& \mathrm{BL}_{\max }=95.25 \mathrm{lb} / \mathrm{ft} \quad \mathrm{SC}_{\max }=1500 \text { ton } / \mathrm{hr} \\
& \mathrm{BL}_{\min }=40.0 \mathrm{lb} / \mathrm{ft} \quad \mathrm{SC}_{\min }=630 \text { ton } / \mathrm{hr} \\
& \mathrm{SP}_{\max }=525 \mathrm{ft} / \mathrm{min} \quad \mathrm{SSC}_{\max }=1000 \mathrm{lb} \\
& \mathrm{SP}_{\min }=525 \mathrm{ft} / \mathrm{min} \quad \mathrm{SSC}_{\min }=420 \mathrm{lb} \\
& \text { Weighbridge length }=10.5 \mathrm{ft} \\
& \text { MTL }_{\max }=(1500 \mathrm{ton} / \mathrm{hr})(10 \mathrm{~min})(1 \mathrm{hr} / 60 \mathrm{~min})=\mathbf{2 5 0} \text { ton } \quad(10 \mathrm{~min}) \\
& \text { MTL }_{\min }=(630 \mathrm{ton} / \mathrm{hr})(10 \mathrm{~min})(1 \mathrm{hr} / 60 \mathrm{~min})=105 \mathrm{ton} \quad(10 \mathrm{~min})
\end{aligned}
$$

The following table illustrates the static loads, and the dynamic loads for the time shown that would be used when testing using existing checklist guidelines. The total dynamic time would be 230 minutes. Note that for this scale $1000 \mathrm{~d}$ is 100 tons.

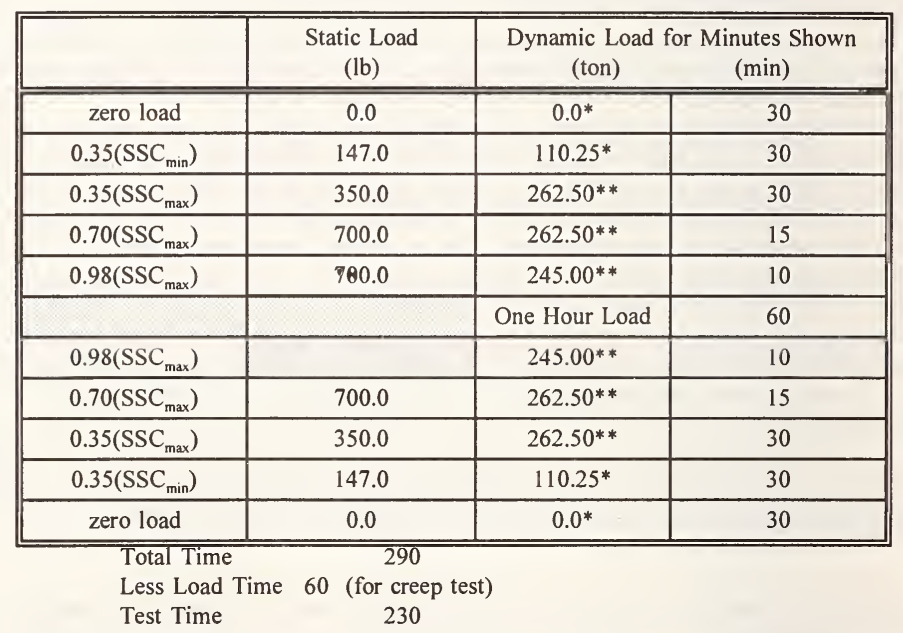

* This time is reduced because entry 8 in the Data Sheet was split to recognize an MTL based on the minimum dynamic capacity rating. This MTL is based upon the time to deliver at least $1000 \mathrm{~d}$ using the lowest dynamic capacity rating for the belt-conveyor scale, e.g., $630 \mathrm{ton} / \mathrm{hr}$. If the test time had been based upon the MTL for the maximum dynamic scale capacity, the test time would have been 68 minutes. $(250)(2000) /(.35)(40)(525)=68 \mathrm{~min}$

** These times are based upon the maximum dynamic capacity rating for the scale, e.g., 1500 ton $/ \mathrm{hr}$.

A question was raised as to the time required for the zero test. Ten minutes was proposed, but was not believed to be sufficient. Enough time is needed to assure the integration of the fluctuating signals during operation, and sufficient weight must be accumulated to be able to be detected by the master weight totalizer based on its resolution. The checklist presently indicates that the scale shall have sufficient resolution to permit the test to be completed in 20 minutes. A consensus was reached for running the zero test for "20 minutes or the longest time of the $0.35 \mathrm{SSC}_{\min }$ test, whichever is greater." 
OIML runs three 5-minute zero tests to be able to assess repeatability, which is possible because of higher OlML master weight totalizer resolution requirements than in the United States. There is some value in repeatability testing, except that the same value won't be obtained on consecutive tests; however, Handbook 44 doesn't include a repeatability tolerance on zero. Furthermore, the master weight totalizer may not provide sufficient resolution to measure small changes in zero over such short time periods. Consideration was given to running a thirty-minute zero test, reading every 10 minutes. This would give more information of the quality of the test. Further discussion on this suggestion was put off until the next meeting.

Discussion led further into how to best establish the zero load value since the scale could ultimately fail if this first reading is off due to the scale possibly not being properly "seated" after installation, or the scale may still be recovering from the application of a load equal to 150 percent of the static weighing capacity. It may be better to exercise the static weighbridge in some other fashion before starting the dynamic testing. In the "Initial Tests" section of the checklist, the last action before beginning the "Temperature Tests," (page 11, item 4.) states, "Apply a load of 150 percent of static weighing capacity to the scale to verify that the accuracy is not affected by overloading (S.2.3.)," but this is suspected as a source of drift/creep which can cause the zero load value to be inaccurate. A consensus was reached to move this step after the second $20^{\circ} \mathrm{C}$ test, followed by a dynamic test at $0.98 \mathrm{SSC}_{\max }$ to verify performance after the 150 percent load.

Due to the 150 percent overloading, however, the scale may not be accurate. This accuracy question led into other comments dealing with mechanical stops being used at 110 percent of load even though the scale must be able to withstand a 150 percent load. Statements such as the following were reviewed:

There should be a live load indication above 98 percent because material is moving across the scale and would be lost. This committee can recommend a change to $\mathrm{H} 44$

If there are no mechanical stops, can a live load of 150 percent be applied but not have to be accurate?

lsn't the intent to require active indication to 150 percent?

Whatever number used is specifying scale capacity

The scale should not be required to weigh accurately above 100 percent.

The rate of flow alarm is intended for mechanical scales to provide indication before the overload stops are reached.

OlML doesn't require a shut-off. The 150 percent load is a dead load and is not required to register.

It was concluded that the S\&T Committee should be asked to resolve what indications should apply and how they are used above 100 percent of capacity.

To ensure that everyone was in agreement as to the establishment of the zero reference points, the following summary was offered and accepted:

The initial zero reference point is established at the start of the first $20{ }^{\circ} \mathrm{C}$ temperature test immediately after statically exercising the scale 3 times at 0.98 percent capacity.

- The zero test, after completion of the dynamic tests at the previous temperature is used as the reference point for type evaluation on zero for the next temperature.

- The first zero reference point at the new temperature is used for type evaluation on zero for the temperature change and for reference zero for the dynamic performance tests.

The length of test time for the $0.35 \mathrm{SSC}_{\max }, 0.70 \mathrm{SSC}_{\max }$, and $0.98 \mathrm{SSC}_{\max }$ dynamic tests was next reviewed to determine if there was justification to shorten them. Since no belt is used "under lab conditions," agreement was reached that running the dynamic "Maximum Static Capacity Units of Weight" for a time sufficient to accumulate 1000d of weight is sufficient. Agreement was also reached to run the zero test for "20 minutes, or for a time equivalent to the test time required for the test run at 35 percent of the minimum static capacity, whichever is greater."

The following table illustrates the static loads, and the dynamic loads for the time shown that would be used when running the dynamic zero test for 20 minutes or the longest time of $0.35 \mathrm{SSC}_{\min }$, whichever is greater, and running $0.35 \mathrm{SSC}_{\max }$, $0.70 \mathrm{SSC}_{\max }$, and $0.98 \mathrm{SSC}_{\max }$ for $1000 \mathrm{~d}$. The total dynamic time would be 136 minutes which is 94 minutes less than current checklist guidelines. 


\begin{tabular}{|c|c|c|c|}
\hline & $\begin{array}{l}\text { Static Load } \\
\text { (lb) }\end{array}$ & \multicolumn{2}{|c|}{$\begin{array}{l}\text { Dynamic Load for Minutes Shown } \\
\text { (ton) }\end{array}$} \\
\hline zero load & 0.0 & 0.0 & 28 \\
\hline $0.35\left(\mathrm{SSC}_{\min }\right)$ & 147.0 & 103 & 28 \\
\hline $0.35\left(\mathrm{SSC}_{\max }\right)$ & 350.0 & 105 & 12 \\
\hline $0.70\left(\mathrm{SSC}_{\max }\right)$ & 700.0 & 105 & 6 \\
\hline \multirow[t]{2}{*}{$0.98\left(\mathrm{SSC}_{\max }\right)$} & 980.0 & 100 & 4 \\
\hline & & One Hour Load & 60 \\
\hline $0.98\left(\mathrm{SSC}_{\max }\right)$ & & 100 & 4 \\
\hline $0.70\left(\mathrm{SSC}_{\max }\right)$ & 700.0 & 105 & 6 \\
\hline $0.35\left(\mathrm{SSC}_{\max }\right)$ & 350.0 & 105 & 12 \\
\hline $0.35\left(\mathrm{SSC}_{\min }\right)$ & 147.0 & 103 & 28 \\
\hline zero load & 0.0 & 0.0 & 28 \\
\hline
\end{tabular}

\section{Was the philosophy that established the return-to-zero tolerance for static tests as equivalent to the static tolerance for a 3000 -division scale valid?}

\section{Meeting Results}

It as concluded that the rationale presented is correct; however, there is no specification in Handbook 44 for a return-tozero tolerance for static tests. Further discussion was then deferred until after discussion of items IV and VII. Since decisions made while considering item V11 led to the elimination of static testing from type evaluation test procedures, this item is no longer applicable.

\section{Discussion}

It was considered desirable to review the philosophy that established this tolerance. The following rationale was presented for discussion:

- As stated in Step 12 of the Test Procedures, the static scale tolerance for zero load is $0.45(\mathrm{SSC}) / 3000$.

- For lab testing, the tolerance is reduced using a multiplier of 0.45 since the belt is not present.

- Since the "worst case" for a return to zero is from the maximum load condition, the tolerance is computed using the highest capacity rating for the belt-conveyor scale. This corresponds to the maximum static scale capacity $\left(\mathrm{SSC}_{\max }\right)$.

- OIML Recommendation 60 applies a tolerance of $0.5 \mathrm{v}_{\min }$ for the return to zero test. For this test a load is applied for 30 minutes and removed quickly. Additionally, Handbook 44 specifies the tolerance of $0.5 \mathrm{~d}$ for the return to zero for the decreasing load test. Assuming $\mathrm{n}=3000$, this is $0.5 \mathrm{v} / 3000 \mathrm{v}$ or 0.0167 percent.

- The return to zero tolerance for the static test of a belt-conveyor scale is $0.45 / 3000$ or 0.015 percent.

- Because these values are consistent, the tolerance on the return to zero appears to be reasonable. Since a $3000 \mathrm{~d}$, Class III load cell is needed to satisfy the temperature effect on zero for belt-conveyor scales, the same return to zero requirement should be applied.

It was concluded that the rationale is acceptable; however, there is no specification in $\mathrm{H} 44$ for a return-to-zero tolerance for static tests. How are dynamic and static scale tolerances related? It was decided to defer this discussion until after item 7 was decided. Based on the item 7 decision, this item is no longer applicable. 


\section{Is it possible to consider utilizing a scale digital indicator in some fashion for observing raw counts from the $A / D$ converter when performing simulated static tests?}

\section{Meeting Results}

It was decided to defer this discussion until after item 7 was decided. Based on the item 7 decision, this item is no longer applicable.

\section{Should consideration be given to running a dynamic zero test every time a static zero test is performed after a temperature change?}

\section{Meeting Results}

A consensus was reached to eliminate static testing from type evaluation test procedures. Further;

- The tolerance for the dynamic zero test is $1 \mathrm{~d}$ which is one part in 10,000 .

- When performing the dynamic zero test time, start the test when the least significant digit of the totalizer just

"clicks" over.

\section{Discussion}

After type evaluation testing had been performed on one device, the data obtained, suggested that the loading for the static tests affected the results of the temperature effect on zero for the dynamic load tests. The appropriate order of conducting static and dynamic zero reference tests be addressed.

The opening discussion on this item immediately raised the question of whether or not static testing should be allowed. Previously, conducting static scale tests had been agreed to as a possible means to reduce test time by conducting static tests and not conducting dynamic tests. Following are several statements made by committee members.

Devices are dynamic devices and should be tested dynamically.

The lack of acceptable resolution of readings from the A/D converter and varying indications prevent obtaining acceptable readings.

- From the theoretical standpoint, testing statically seems to be an acceptable approach to minimizing test time, but it has been proven otherwise.

H44 contains no requirements for a static weight indicator in a belt-conveyor scale.

A consensus was easily reached to drop static testing. Discussion then immediately reverted to the subject of what is the dynamic return-to-zero tolerance? Is the tolerance, for the entire time of the zero test, $0.45 \mathrm{~d}$ ? A resolution problem exists because the totalizer's division size is 1d. Further, it is not clear whether or not totalizers are designed to round off their indications and exactly where the test time is started. OIML starts the zero test time when the least significant digit of the totalizer just "clicks" over to the next digit. A consensus was reached that the dynamic return-to-zero tolerance has to be $1 \mathrm{~d}$, because the totalizer division size is $1 \mathrm{~d}$. Also, the zero test time of $0.35 \mathrm{BL}_{\min }$ should be started when the least significant digit of the totalizer just "clicks" over.

\section{Develop guidelines for the formatting of information printed on tickets.}

\section{Meeting Results}

No requirement exists in Handbook 44 for a recording element ticket "format." However, the following information must appear on the ticket: date, time, initial reading on MWT, final reading on MWT, and the total quantity weighed. The following conclusions were reached.

The descriptive statement "MO/DAY/YR", or any other date description, need not appear on the ticket as long as the date provided is of the MO/DAY/YR format such as 06/29/92. If the format is otherwise, such as DAY/MO/YR, the date description must be included.

The TIME description need not appear on the ticket. The time may be stated based on a 24-hour clock or a 12 -hour clock; however, a 24-hour time requires a "0", such as in 0700 , and a 12-hour time requires AM or PM. 
- As stated in item 9, page 3 of the checklist, the ticket need only provide initial and final weight values, with no descriptions.

Further discussion confirmed that:

- A hard copy of a ticket is required

- A printer must be submitted with the scale for type evaluation but the printer model need not be specifically identified for use.

- A subtotal is not required.

- S.1.4. of the Belt-Conveyor Code must be addressed by the S\&T Committee to require the listing of the initial and final weight values.

- Other information (audit trail data) can be printed on the ticket as desired.

\section{Discussion}

The following "Possible Ticket Format" was offered for discussion and, since there is no requirement for a ticket format in Handbook 44, it was suggested to change the name of the figure to "Information required on the ticket."

Possible Ticket Format

Information required on the ticket

\begin{tabular}{|lr|}
\hline & 050692 \\
& $15: 30$ \\
MASTER START TOTAL & $44113.5 \mathrm{~T}$ \\
MASTER STOP TOTAL & $44300.5 \mathrm{~T}$ \\
\hline
\end{tabular}

The only other requirements for recording elements were identified as follows:

- The value of the scale division for the recording element shall be the same as for the MWT.

- The recording element must print the weight unit with the quantity, the date, and the time.

- Valid abbreviations for the unit weight are;

$\begin{array}{ll}\text { pounds } & \mathrm{lb} \text { or LB } \\ \text { U.S. short ton } & \text { ton or T } \\ \text { U.S. long ton } & \mathrm{LT} \\ \text { Metric ton } & \mathrm{t} \\ \text { kilograms } & \mathrm{kg}\end{array}$

- All weight values shall be recorded as digital values.

- The recorded weight value must be expressed without the use of a multiplier.

\section{Review the evaluation of changes in zero for totalizers that don't totalize negative weight.}

\section{Meeting Results}

"No flow lockout" must be disabled during lab tests and the MWT must provide plus and minus indication.

\section{Discussion}

It was questioned whether or not, during any zero load test, the equipment manufacturer should be penalized if the MWT can't totalize both plus and minus, and whether it is allowed to switch into a special mode for this purpose? No problem was noted. Discussion centered mostly on "no flow lockout," which does not allow any accumulation below 3\%. Plus or minus accumulation around zero does add or subtract material but the value will always be above zero for material tests. The conclusion was reached that "no flow lockout" must be disabled during lab tests and the MWT must provide plus and minus accumulation. 


\section{How many idlers should be permitted in a family based upon the type evaluation performed?}

\section{Meeting Results}

Three or more idlers at 3 to 5 foot spacing can define a family. For 1 or 2 idlers, test in the field at different flow rates. A field test is desired with the minimum number of idlers at whatever spacing can be achieved but preferably the minimum. A lab test is desired with the maximum number of idlers that fit in the test chamber.

\section{$\underline{\text { Discussion }}$}

Initial discussions led to agreement that field tests should set the minimum number of idlers. Could fewer idlers be used if additional tests (low, medium, and high flow rates would reveal possible problems on a fewer number of idlers such as 1 or 2) were required? The Chairman concluded that "Devices can have more idlers than the device that was tested but no fewer."

Other comments made include:

- The number of idlers and idler spacing are the key factors in evaluating device performance more so than weigh span and speed.

The use of more idlers improves performance.

Increased tare weight for more idlers complicates things but that is a design choice of the manufacturer.

Tare is not addressed in any documentation but the tare weight of the device being tested should reflect representative tare weight of the family.

Tare will obviously be a factor during zero condition testing.

Various proposals of number of idlers and idler spacing were discussed and a consensus was finally reached that 3 or more idlers at 3 to 5 foot spacing would define a family, but what about 1 or 2 idlers, and what about the fact that $\mathrm{H} 44$ does not specify the number of idlers required? There is logic to use the minimum number of idlers for field testing and the maximum number of idlers for lab testing except for physical limitations in a test chamber. The statement, "For 1 or 2 idlers, test in the field at different flow rates" was added to the consensus. Since the effects of belt misalignment and belt tension are significantly greater for 1 or 2 idlers, testing at a second flow rate will test performance of the scale with a second level of belt tension and a different tare. Idler spacing was also discussed as a factor. A final consensus was reached that "The field test is desired with the minimum number idlers at whatever spacing can be achieved but preferably the minimum." New ideas should be submitted for the next meeting.

\section{Should component testing of any kind be permitted if complete systems cannot be assembled in temperature chambers?}

\section{Meeting Results}

Component testing is not permitted. Use a refrigerated trailer, with external heat, for witness testing at the manufacturer's site as the method for testing long weighbridges that do not fit in the NTEP test chambers.

\section{$\underline{\text { Discussion }}$}

A consensus was easily reached that no component testing of any kind should be permitted. Component testing means testing the MWT and the load cells separately for the influence factors. Discussion continued concerning temperature chambers. At the previous meeting the use of trailers was rejected because it was believed that uniform temperatures could not be reached, and the floor of trailers may not be sufficiently strong to prevent deflection in the scale. The suggestion was raised again that the use of a refrigerated truck, with an external heat source, should be reconsidered for test use because that is probably the way the manufacturer originally made tests, and no other alternative appears available for longer weighbridges. Following are other comments heard:

Can the testing be done at the manufacturer's site? Yes, as witness testing.

Testing of scaled down versions should not be allowed.

Another problem is scales being installed out of level. 
- High costs of time and money (a major consideration) should not compromise tests since they are performed only one time for type evaluation.

- Is there a benefit using common heating, cooling, and fan for circulation?

- Temperature variations and safety are concerns.

- Temperature variations must be held to $\pm 2{ }^{\circ} \mathrm{C}$ and safety must be satisfied.

- The trailer must be blocked for support and substantial plating must be used on the floor of the trailer.

- At least week would be needed for testing.

A consensus was reached that using a refrigerated trailer, with external heat, for witness testing at the manufacturer's site, is the best solution for testing long weighbridges.

\section{Should the proposed changes to the "Belt-Conveyor Scale Data Sheet and Laboratory Test Procedures" be incorporated?}

\section{Meeting Results}

The proposed changes were acceptable and are to be incorporated into the document as well as all other changes made necessary by the results of this meeting.

XI. Review available data and determine what constitutes agreement (or lack of) when comparing static and dynamic results.

\section{Meeting Results}

This item was not discussed because it is no longer applicable based on the previous decision made to eliminate static testing. (see item 7)

XII. Discuss and agree on methods for predicting likely temperature effects from the published specs of major system components such as load cells and instrumentation.

XIII. Discuss establishing a uniform method for predicting the theoretical performance of a belt scale as part of the approval process.

XIV. Discuss what, if any, influence tare load effects should have on lab testing procedures.

\section{Meeting Results}

Existing type evaluation practices are acceptable, and no consideration of tare, and no additional forms of testing are desired by the Committee. Practical limits of testing preclude a greater analysis of these parameters. The Cummittee reaffirmed testing to the parameters previously agreed upon.

\section{$\underline{\text { Discussion }}$}

A presentation was made by Thayer Scale relating to the above three issues including such statements as;

- $\quad$ "There are no references to tare loading in the type evaluation procedures"

- "A theoretical approach should be used when type evaluating scale designs"

- "Certificates of Conformance may cover ranges of parameters that are not technically feasible."

After many questions and statements, primarily supporting present type evaluation practices, the Chairman concluded that "existing practices, no consideration of tare, and no additional testing were desired by the Committee. 
XV. Discuss and suggest wording to clarify the following statement: "Based upon the test of a single scale, a Certificate of Conformance will usually cover parameters over a range of $10: 1$ with the limits for any one parameter not to exceed $4: 1$ from the characteristics of the scale that was tested.

\section{Meeting Results}

The definition was retained pending receipt of alternative recommendations.

\section{Discussion}

Thayer Scale expressed a feeling that the range was too large, but no alternate definition was proposed. The members of the committee were requested to review this definition and submit recommendations, if appropriate. 



\title{
Final Report of the Laws and Regulations Committee
}

\author{
Fred Clem, Chairman \\ Weights and Measures Inspector \\ City of Columbus, Ohio
}

Reference

Key Number

\section{Introduction}

This is the Final Report of the Laws and Regulations Committee for the 78th National Conference on Weights and Measures. This report is based on the Interim Report offered in the Conference "Program and Committee Reports" (NCWM Publication 16), the Addendum Sheets issued at the Annual Meeting, and actions taken by the membership at the Voting Session of the Annual Meeting.

Table A identifies the items in the Report by Reference Key Number, Item Title, and Page Number. The item numbers are those assigned in the Interim Meeting Agenda. Voting items are indicated with a "V" after the item number. Consent calendar items are marked with a "VC." Items marked with an "I" after the reference key number are information items. The items marked with a "W" were withdrawn by the Committee. Items marked with a "W" generally will be referred back to the regional weights and measures associations because they either need additional development, analysis, and input, or did not have sufficient support of the Committee to bring them before the NCWM.

The attached Report contains many recommendations to revise or amend National Institute of Standards and Technology (NIST) Handbook 130, 1993 Edition, "Uniform Laws and Regulations," and NIST Handbook 133, "Checking the Net Contents of Packaged Goods." Proposed revisions to the handbooks are shown in bold face print by what is to be deleted, and underlining what is to be added. Entirely new paragraphs or sections proposed for addition to the handbook are designated as such and shown in bold face print.

Note: NIST editorial policy is to use SI units of measurement in all of its publications; however, in this publication, recommendations received by the NCWM technical committees have been printed as they were submitted and, therefore, may contain references to inch-pound units.

\section{Subject Series}

Handbook 130 - General

210 Series

Uniform Laws

220 Series

Weights and Measures Law (WML)

221 Series

Weighmaster Law (WL)

222 Series

Motor Fuel Inspection Law (MFIL)

223 Series

Uniform Regulations

230 Series

Packaging and Labeling Regulation (PLR)

231 Series

Method of Sale of Commodities Regulation (MSCR)

232 Series

Unit Pricing Regulation (UPR)

233 Series

Voluntary Registration of Servicepersons and Service Agencies

for Commercial Weighing and Measuring Devices (VRSR)

234 Series

Open Dating Regulation (ODR)

235 Series

National Type Evaluation Regulation (NTER)

236 Series

Motor Fuel Regulation (MFR)

Interpretations and Guidelines

237 Series

238 Series

NIST Handbook 133 - General

240 Series

250 Series

Petroleum Subcommittee

260 Series 
Table A

Index to Reference Key Items

Reference

Key No.

Title of Item

Page

210-1 VC SI Amendments to NIST Handbook $130-$ General $\ldots \ldots \ldots \ldots \ldots \ldots \ldots \ldots \ldots \ldots 212$

221-1 VC SI Amendments to the Uniform Weights and Measures Law . . . . . . . . . . . 213

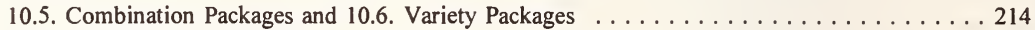

Mechanical Pump Dispensers . . . . . . . . . . . . . . . . . . . . . . . 216

Meat, Poultry, and Seafood - Packaged with Other Packages of Food . . . . . . . . . . . 221

1.6. Fluid Milk Products - Permit 3-Quart Package Size . . . . . . . . . . . . . . . . . . . . . 222

1.12. Ready-to-Eat Food . . . . . . . . . . . . . . . . . . . . . . . . . . . . . 222

Hardwood Lumber - Measurements in Retail Sales . . . . . . . . . . . . . . . . . . . . . . 223

SI and Other Revisions - Retail Sales of Softwood Lumber . . . . . . . . . . . . . . . 226

Baler Twine . . . . . . . . . . . . . . . . . . . . . . . . . . . . . . . . . . . . . . . . . . . . . . 229

232-8 VC

Compressed Natural Gas (CNG) When Sold as a Vehicle Fuel . . . . . . . . . . . . . . . . . . 229

SI Revisions to the Uniform Method of Sale of Commodities Regulation . . . . . . . . . . 230

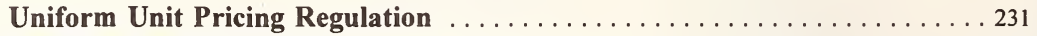

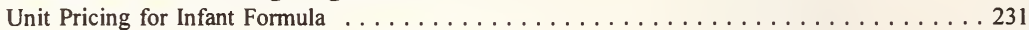

Fuel Specification For Compressed Natural Gas . . . . . . . . . . . . . . . . . . . 232

Retail Sale of Compressed Natural Gas as a Vehicle Fuel . . . . . . . . . . . . . . 233

238-2 I 2.6.8. Commodities Excluded From FTC Jurisdiction $\ldots \ldots \ldots \ldots$

238-3 I SI and Other Revisions to the Interpretations and Guidelines Section 
Table A (Continued)

Index to Reference Key Items

\section{Reference}

Key No.

Title of ltem

Page

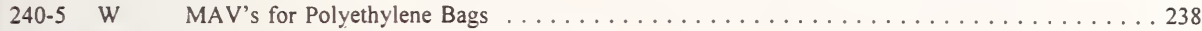

240-6 I Foam Aerosol Products - Test Allowance . . . . . . . . . . . . . . . . . . . . 238

240-7 I Gray Areas for Meat and Poultry Products . . . . . . . . . . . . . . . . . . . . . . . 239

240-8 I Section 3.18. Meat and Poultry from Federally lnspected Plants . . . . . . . . . . . . . . . 239

240-9 I Joint State Petition to FDA for Exemption Under NLEA . . . . . . . . . . . . . . . . . . 239

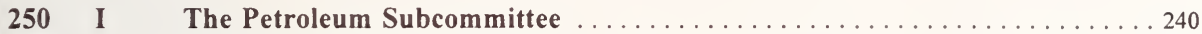

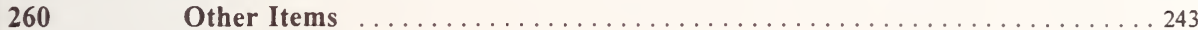

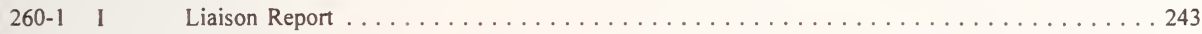

\section{Table B}

Appendices

\begin{tabular}{llrl} 
Appendix & Title & Reference Key No. & Page \\
\hline A & SI Revisions to the Uniform Packaging and Labeling Regulation & $231-3$ & 244 \\
B & 2.6.8. Commodities Under FTC Jurisdiction Under FPLA and Exclusions & $238-2$ & 279
\end{tabular}

\begin{tabular}{c|c|c|c|c|c}
\hline \multicolumn{5}{c}{$\begin{array}{c}\text { Table C } \\
\text { Voting Results }\end{array}$} \\
\hline \multirow{2}{*}{$\begin{array}{c}\text { Reference Key No. } \\
\text { House of State } \\
\text { Representatives }\end{array}$} & \multicolumn{2}{c}{ House of Delegates } & \multirow{2}{*}{ Results } \\
\cline { 2 - 5 } & Yes & No & Yes & No & \multirow{2}{*}{ Passed } \\
\hline $\begin{array}{c}\text { 233-1 Motion to remove from consent } \\
\text { calendar }\end{array}$ & 41 & 0 & 55 & 0 & \multirow{2}{*}{ Passed } \\
$233-1$ & 41 & 2 & 55 & 2 & Passed \\
$232-3$ & 37 & 7 & 47 & 6 & Passed \\
200 (in entirety) & 43 & 0 & 58 & 0 & \\
\hline
\end{tabular}




\title{
Details of All Items
}

(In order by Reference Key Number)

\section{0-1 VC SI Amendments to NIST Handbook 130 - General}

\author{
(This item was adopted as part of the consent calendar.)
}

Background: At the 77th NCWM Interim Meeting, the Committee began a study to determine how to revise NIST Handbook 130 to bring it into greater conformance with NIST Metric Transition Policy, issued in accordance with Executive Order 12770 of July 25, 1991. (See NIST Special Publication 814.) NIST policy requires that SI units be used as the primary unit of measure in all NIST publications. The policy permits the optional use of inch-pound units in following parentheses if the field of application requires use of non-SI units. Changes were also needed to recognize the 1992 amendments to the Federal Fair Packaging and Labeling Act, which require use of the International System of Units (SI) on packages of consumer commodities. (See Item 210-1 in the Report of the 77th NCWM, 1992, page 133, for more information.)

An SI Working Group was organized at the NCWM 77th Annual Meeting to draft revisions to the Uniform Weights and Measures Law and to the Uniform Regulations on Packaging and Labeling, Method of Sale of Commodities, and Unit Pricing. The working group, comprised of more than 300 members, reviewed draft revisions for the Laws and Regulations Committee prior to and during the 1993 Interim Meeting. Proposed revisions to NIST Handbook 130 and the Uniform Law and Regulations were reviewed and discussed at the Interim Meetings. Items 210-1, 221-1, 231-3, 232-8, 233-2, and 238-3 resulted from these discussions.

The 1992 SI amendments to the Fair Packaging and Labeling Act (FPLA) include references to the term "mass" and permit its use on packages in combination with quantity statements. For example, packages can be labeled using the terms "net mass" or "net weight." The first drafts of the uniform law and regulations provided an explanation of the terms "mass" and "weight" in the introduction to each section, and "mass" or "masses" was included throughout the text in parentheses wherever "weight" was used. The Committee received several comments supporting the inclusion of the term "mass," and the introductory text relating to "mass" and "weight," in NIST Handbook 130, but several people complained about the redundant explanation of the terms in each section, and that the use of "weight (mass)" throughout the text was confusing and unnecessary. The Committee believes that this redundancy can be eliminated by the following:

\section{Committee Recommendations:}

1. Change all references to "metric" to "SI" or "SI units" as appropriate. Include SI values in all examples, with the inchpound equivalent following in parentheses. Add a new paragraph $\mathrm{H}$. The International System of Units to Section I. Introduction in NIST Handbook 130 (page 2):

\section{H. The International System of Units. - The "International System of Units," "SI," or "SI Units" means the modernized metric system as established in 1960 by the General Conference on Weights and Measures. In 1988 Congress amended the Metric Conversion Act of 1975 (see $\$ 5164$ of Public Law 100- 418) to declare that it is the policy of the United States to designate the metric system of measurement as the preferred measurement system for U.S. trade and commerce, and it further defined "the metric system of measurement" to be the International System as established by the General Conference and as interpreted or modified for the United States by the Secretary of Commerce. I(See Metric Conversion Act of 1975 (Public Law 94-168, § 3(1) and § 4(4)); NIST Special Publication 330 - The International System of Units (SI); NIST Special Publication 814 -Metric System of Measurement; and Interpretation of the International System of Units for the United States in Federal Register of December 20, 1990, (FR 90- 21913) or subsequent revisions.)] In 1992, Congress amended the Federal Fair Packaging and Labeling}


Act to require the most appropriate units of the SI and the customary inch-pound systems of measurement on certain consumer commodities.

2. Add a new paragraph I. to Section I., Introduction, of NIST Handbook 130 to explain the terms "mass" and "weight":

I. "Mass" and "Weight."- Mass is the amount of matter in an object. In trade and commerce and everyday use, the term "weight" nearly always means "mass." The "net weight" declared on a label indicates that the package contains a specific amount of commodity exclusive of wrapping materials. When used in this handbook, the term "weight" means "mass."

3. Add a new paragraph J. to Section I., Introduction, of NIST Handbook I30 to explain how the terms "mass" and "weight" will be used in the handbook. The style explained in this new section will be used, not the repetition of the terms "weight (mass)" throughout the text. The term "weight" will be used when inch-pound units are addressed, or when both inch-pound and SI units are included in a requirement. The term "mass" or "masses" will be used when only SI units are cited in a requirement.

J. Use of the Terms "Mass" and "Weight." - When appearing in this handbook, the term "weight" shall mean "mass." The term "weight" appears when inch-pound units are cited due to commercial practice, or when both inch-pound and SI units are included in a requirement. The term "mass" or "masses" is used when SI units are the only units cited in a requirement. The following note appears where the term "weight" is first used in a law or regulation.

NOTE 1: When used in this law (or regulation), the term "weight" means "mass." (See paragraph $\mathbf{H}$. in Section I., Introduction, of NIST Handbook 130 for an explanation of these terms.)

For example, in the Uniform Weights and Measures Law:

1.2. Weight. -- The term "weight"-1 as used in connection with any commodity or service means net weight. When a commodity is sold by drained weight the term means net drained weight.

NOTE 1: When used in this law, the term "weight" means "mass." (See paragraphs H, I, and J, in Section I. Introduction to NIST Handbook I30 for an explanation of these terms.)

\section{VC SI Amendments to the Uniform Weights and Measures Law}

(This item was adopted as part of the consent calendar.)

Background: See Item 210-I for background on this issue. The Committee believes that only minor technical and editorial changes are needed to bring the Uniform Weights and Measures Law into agreement with the SI requirements mentioned above. The Committee recommends adoption of the following changes.

Committee Recommendations:

1. In § 1.10. Net Weight - Add a reference to "net mass":

1.10. Net "Mass" or Net "Weight." -- The term "net mass" or "net weight" means the weight_ of a commodity excluding any materials, substances, or items not considered to be part of the commodity......(Retain the remainder of current $\S 1.10$. without change.) 
NOTE 1: When used in this law, the term "weight" means "mass." (See paragraph H in Section I. Introduction, of NIST Handbook 130 for an explanation of these terms.)

2. In $\S 1.12$. Standard Package - Add SI equivalents to the examples:

1.12. Standard Package. -- A package that is one of a lot, shipment, or delivery of packages of the same commodity with identical net contents declarations; for example, l-liter bottles or 12-fl oz cans of carbonated soda; 500 -g or 5 -lb bags of sugar; 100 -m or 300-ft packages of rope.

3. In $\S 2$. Systems of Weights and Measures - Add a reference to the International System of Units (SI) and a note that provides background on SI:

\section{Section 2. Systems of Weights and Measures}

The International System of Units (SI), ${ }^{1}$ the modernized metric system of weights and measures, and the system of weights and measures in customary use in the United States are jointly recognized, and either one or both of these systems shall be used for all commercial purposes in the State......

NOTE 1: The "International System of Units" means the modernized metric system as established in 1960 by the General Conference on Weights and Measures and interpreted or modified for the United States by the Secretary of Commerce. See Metric Conversion Act of 1975 لPublic Law 94$168, \S 3(1)$ and $\$ 4(4)$ l, and NIST Special Publication 814 - Metric System of Measurement; Interpretation of the International System of Units for the United States or Federal Register of December 20, 1990 (FR 90-21913). (Retain the remainder of current $\S 2$. without change.)

4. Amend Note 2 in $\S 20$. Declaration of Unit Price on Random Weight Packages to reflect changes to the Fair Packaging and Labeling Act that require SI units on packages:

NOTE 2: Packages subject to the Federal Fair Packaging and Labeling Act (except for camera film) must be labeled in SI and inch-pound units of measure. "Either SI or inch-pound units appear first."

5. In $\S 21$. Advertising Packages for Sale - Delete the reference to dual quantity declarations because the FPLA no longer requires them on packages between 1 and 4 pounds:

Section 21. Advertising Packages for Sale. - Whenever a packaged commodity is advertised in any manner with the retail price stated, there shall be closely and conspicuously associated with the retail price a declaration of quantity as is required by law or regulation to appear on the package. Where-dualdeclaration-is-required, only the-declaration-that sets-forth-thequantity in-terms of the-smaller unit-of weight-or-measure-need-appear in the-advertisements

(This item was adopted as part of the consent calendar.)

Background: This was Item 231-12 in the Report of the 75th NCWM, 1990, page 89; Item 231-5 in the Report of the 76th NCWM, 1991, pages 199-200; and Item 231-2 in the Report of the 77th NCWM, 1992, page 135. In 1990, the Committee proposed to adopt the requirements promulgated by the Federal Trade Commission (FTC) concerning variety and combination packages because: (1) they are more specific than existing requirements in the PLR, and (2) the FTC requirements are essentially the same for combination and variety packages. Such a change would consequently eliminate 
the need for specific definitions for these types of packages, and the need to make judgments concerning packages composed of "dissimilar" (combination) or "similar" (variety) commodities. The Food and Drug Administration (FDA) has no definitions or requirements for combination or for variety packages; thus, consumers see packages of "variety" meats or cereals labeled only with a total net weight. Under the FTC regulations for variety packages, the net weight of each style or type of product in a variety package has to be labeled. The Committee believes that because of the extensive changes in labeling for food products (SI and nutrition labeling regulations will go into effect in 1994), it would be impractical to pursue FDA adoption of additional labeling requirements for food products at this time. Since FDA does not have identical requirements, State or local regulations patterned after FTC's requirements would be preempted unless food products were exempted.

Because the Committee continues to receive comments supporting the proposal to adopt the FTC requirements, the Committee recommends adoption of the FTC requirements for variety and combination packages of nonfood products. The Committee prefers this alternative to dropping this item because it recognizes the need in the marketplace for labeling requirements for other types of commodities sold in variety or combination packages. The Committee will reconsider this issue in the future to determine if the NCWM should consider petitioning FDA to amend its regulations to include similar requirements. The Committee believes that a petition to FDA will not be successful if it is based solely on a request to harmonize regulations between FDA and the States. A petition should include marketplace surveys showing that current labeling of variety food products in combination packages misleads consumers or frustrates value comparisons, and documented cases of consumer complaints that confirm consumers have been misled as to the actual contents in packages.

Committee Recommendation: The Committee recommends adoption of labeling requirements for nonfood products identical to those of the FTC. Delete the definitions for combination and variety packages in $\S 2.9$. Combination Packages and $\S 2.10$. Variety Packages. Replace the current requirements in $\S 10.5$. and $\S 10.6$. for combination and variety packages with the following:

10.5. Combination Packages. -- A combination package is a package, intended for retail sale, containing two or more individual packages or units of dissimilar commodities. The declaration of net quantity for a combination package shall contain an expression of weight, volume, measure, or count or a combination thereof, as appropriate, for each individual package or unit, provided that the quantity statements for identical packages or units shall be combined. This section does not apply to food or other commodities subject to the Federal Food, Drug, and Cosmetic Act (21 USC).

Examples:

(1) Lighter Fluid and Flints: 2 cans - lighter fluid - each $236 \mathrm{~mL}(8 \mathrm{noz})$

1 package -8 flints

(2) Sponges \& Cleaner:

2 sponges - each $10 \mathrm{~cm} \times 15 \mathrm{~cm} \times 2.5 \mathrm{~cm}(4$ in $\times 6$ in $\times 1$ in)

1 box cleaner - $170 \mathrm{~g}(6 \mathrm{oz})$

(3) Picnic Pack:

20 spoons, 10 knives, and 10 forks

10 2-ply napkins $25 \mathrm{~cm} \times 25 \mathrm{~cm}$ (10 in x 10 in)

10 cups $-177 \mathrm{~mL}(6 \mathrm{f} \mathrm{oz})$

10.6 Variety Packages. -- A variety package is a package, intended for retail sale, containing two or more individual packages or units of similar, but not identical, commodities. Commodities that are generically the same but that differ in weight, measure, volume, appearance, or quality are considered similar but not identical. This section does not apply to food or other commodities subject to the Federal Food, Drug, and Cosmetic Act (21 USC). The declaration of net quantity for a variety package will be expressed as follows:

(1) The number of units for each identical commodity followed by the weight, volume, or measure of that commodity; 
(2) The total quantity by weight, volume, measure, and count, as appropriate, of the variety package. The statement of total quantity shall appear as the last item in the declaration of net quantity and shall not be of greater prominence than other terms used.

\title{
Examples:
}

$$
\begin{aligned}
& 11 \text { Sponges } 11 \mathrm{~cm} \times 20.3 \mathrm{~cm} \times 1.9 \mathrm{~cm}(4 \mathrm{in} \times 8 \mathrm{in} \times 3 / 4 \mathrm{in}) \\
& 14 \text { Sponges } 5.7 \mathrm{~cm} \times 10 \mathrm{~cm} \times 1.2 \mathrm{~cm}(21 / 4 \mathrm{in} \times 4 \mathrm{in} \times 1 / 2 \mathrm{in})
\end{aligned}
$$

Total 25 Sponges

$$
\begin{array}{ll}
2 \text { Soap Bars } & 85 \mathrm{~g}(3 \mathrm{oz}) \text { ea } \\
1 \text { Soap Bar } & 142 \mathrm{~g} \mathrm{(5} \mathrm{oz)}
\end{array}
$$

\section{Total 3 Soap Bars $312 \mathrm{~g}(11 \mathrm{oz})$}

\author{
Liquid Shoe Polish \\ 1 Brown $89 \mathrm{~mL}(3 \mathrm{floz})$ \\ 1 Black $89 \mathrm{~mL}(3 \mathrm{fl} \mathrm{oz})$ \\ 1 White $148 \mathrm{~mL}(5 \mathrm{fl} \mathrm{oz})$ \\ Total $326 \mathrm{~mL}(11 \mathrm{fl} \mathrm{oz})$
}

\author{
Picnic Ware \\ 34 spoons \\ 33 forks \\ 33 knives \\ Total 100 pieces
}

\section{1-2 W Mechanical Pump Dispensers}

(This item was withdrawn.)

Background: This was Item 231-13 in the Report of the 75th NCWM, 1990, pages 89-90, Item 231-6 in the Report of the 76th NCWM, 1991, page 200; and Item 231-3 in the Report of the 77th NCWM, 1992, page 135. See these reports for a full discussion of the issue. The Committee considered submitting a petition to the Food and Drug Administration (FDA) and the Federal Trade Commission (FTC) to request changes in Federal regulations to require mechanical pump package systems to dispense the labeled weight. Prior to the 77th NCWM Annual Meeting, the Committee received comments from industry and weights and measures officials expressing concern over the possible impact of a "to deliver" requirement on other types of packaging, including toothpaste tubes and hand-pump dispensers (such as those used for hand lotions) that are currently only required to contain the labeled quantity. Several people questioned how far the requirement would reach and whether the economic impact would benefit consumers or lessen the competitive position of manufacturers who use this type of packaging. The Committee did not hear any comments on this item at the Interim Meeting that indicated a significant problem with this type of packaging or that there is national support for further action on the issue. The Committee sought industry participation in further studies due to its concern about product retained by the package delivery system of mechanical pump dispensers, but only one firm expressed concern about the issue. Therefore, the Committee is withdrawing this item from its agenda. The Committee would welcome information on this item in the future. Such information could include the results of investigations into consumer complaints or results of actual product testing or recent net content studies on a wide variety of consumer products that use this type of container. 
(This item was adopted as part of the consent calendar.)

Committee Recommendation: Adopt the Uniform Packaging and Labeling Regulation as presented in Appendix A.

Discussion and Background: See Item 210-1 for additional information on this item. The Committee recommendations for revisions of the UPLR are provided in Appendix A. The Committee would like to thank the members of the SI Working Group, who reviewed the drafts and made recommendations, for their hard work and interest. The recommendations for revisions to the UPLR were based on written comments received on the draft revisions that were published in 1992 and comments received at the Interim Meeting and Annual Meetings. The Committee concentrated its efforts on addressing changes considered to be essential to bring the UPLR into agreement with the 1992 amendments to the Fair Packaging and Labeling Act (FPLA). These recommendations do not include any additional changes that may be needed to bring the UPLR into complete agreement with forthcoming regulations of the Food and Drug Administration and the Federal Trade Commission because proposals from those agencies have not been published in the Federal Register. The Committee will work closely with FDA and FTC to ensure that NCWM recommendations and requirements are identical to those adopted by these agencies. Details of the proposed changes to the UPLR are highlighted in Section I Summary of Proposed Revisions of Appendix A. The Committee urges the NCWM membership to review the proposed changes and give special consideration to the following issues:

\section{Significant Issues for Comments}

The Committee would like to point out some significant issues that it believes deserve special consideration by the NCWM.

1. Converting and Rounding Quantity Declarations - The Committee recommends addition of a new Appendix B: Converting Inch-Pound Units to SI Units for Quantity Declarations on Packages to the UPLR. Appendix B provides guidelines on converting and rounding so that SI equivalents can be uniformly determined from inch-pound units. The following amended rounding rule is also proposed to clarify that the packer is responsible for accurate conversion, proper use of significant digits, and rounding (either up or down):

\subsubsection{Rounding. -- In all conversions for the purpose of showing an equivalent SI or inch-pound quantity to a rounded inch-pound or SI quantity, or in calculated values to be declared in the net quantity statement, the number of significant digits retained must be such that accuracy is neither sacrificed nor exaggerated. Conversions, the proper use of significant digits, and rounding must be based on the packer's knowledge of the accuracy of the original measurement that is being converted. In no case shall rounded net contents declarations overstate a quantity; the packer may round converted values down to avoid overstating the net contents.}

The Committee believes that the proposed amendment will establish uniformity in displaying SI or inch-pound equivalents on package labels without requiring packers to overstate net contents declarations. Under the rounding rule proposed in the first draft of the revisions to the UPLR, packers were required to round up certain values according to a strict rounding rule. Under this proposal, packers may convert a value and round the resulting value down to avoid having to increase package fill levels to meet a higher value. For example, a net content declaration on a $16 \mathrm{oz}(1 \mathrm{lb})$ package is converted to grams by multiplying $16 \mathrm{oz} \times 28.3495 \mathrm{~g}=453.592 \mathrm{~g}$. If the rounding rule proposed in the first draft (that was taken from FDA guidelines) were to be required, the value would have to be rounded up $0.4 \mathrm{~g}$ to $454 \mathrm{~g}$ (since 0.592 is greater than $0.5 \mathrm{~g})$. If a packer targets the package fill at the labeled weight of $16 \mathrm{oz},(453.592 \mathrm{~g})$ packages, could be underfilled by $0.4 \mathrm{~g}$ if the inspector tests the product to the $454 \mathrm{~g}$ labeled contents. The Committee received overwhelming support for this proposal from industry representatives and weights and measures officials who attended the Interim Meeting. Under the Committee's proposal, inspectors would simply verify that packages actually contain the amount of product stated in the largest net content declaration, either the SI or inch-pound unit and, unless the package is underfilled, or the primary or secondary (normally the converted unit) values is found to be confusing, the inspector would not have to verify that the manufacturer rounded according to specific rules. 
2. Quantity Declarations for Packages with Quantities. Congress amended Section 4(3) of the Fair Packaging and Labeling Act to eliminate the requirement for "dual quantity declarations" [for example, "Net Wt $48 \mathrm{oz}(3 \mathrm{lb})$."] The amended Section 4(3) now reads:

\section{Excerpt from the Fair Packaging and Labeling Act}

\section{Section 4, Requirements and Prohibitions}

(a) No person subject to the prohibition contained in Section 3 shall distribute or cause to be distributed in commerce any packaged consumer commodity unless in conformity with regulations which shall be established by the promulgating authority pursuant to Section 6 of this Act which shall provide that:

(1) The commodity shall bear a label specifying the identity of the commodity and the name and place of business of the manufacturer, packer, or distributor;

(2) The net quantity of contents (in terms of weight or mass, measure, or numerical count) shall be separately and accurately stated in a uniform location upon the principal display panel of that label, using the most appropriate units of both the customary inch/pound system of measure, as provided in paragraph (3) of this subsection, and except as provided in paragraph (3)(A)(ii) or paragraph (6) of this subsection, the SI metric system.

(3) The separate label statement of net quantity of contents appearing upon or affixed to any package:

(A) (i) if on a package, labeled in terms of weight, shall be expressed in pounds, with any remainder in terms of ounces or common or decimal fractions of the pound; or in the case of liquid measure, in the largest whole unit (quarts, quarts and pints, or pints, as appropriate) with any remainder in terms of fluid ounces or common or decimal fractions of the pint or quart;

(ii) if on a random package, may be expressed in terms of pounds and decimal fractions of the pound carried out to not more than three decimal places and is not required to, but may include a statement in terms of the SI metric system, carried out to not more than three decimal places;

(iii) if on a package labeled in terms of linear measure, shall be expressed in terms of the largest whole unit (yards, yards and feet, or feet, as appropriate) with any remainder in terms of inches or common or decimal fractions of the foot or yard;

(iv) if on a package labeled in terms of measure of area, be expressed in terms of the largest whole square unit (square yards, square yards and square feet, or square feet, as appropriate) with any remainder in terms of square inches or common or decimal fractions of the square foot or square yard;

In the Legislative History for the amendments, Congress is on record that it did not intend that weight quantities could be declared only by the pound; or that quantities of liquid measure could be declared only by the pint, quart, or gallon. In the July 21, 1992, Congressional Record for the Senate (page S10030), a letter from Congressman George E. Brown Jr., stated: "In amending [§ 4(3)] the new bill uses familiar terms such as "pounds," "inches," and "square inches." I want to make it clear that in using these standard terms, we intend that related terms may also be used when expressing measurements in English terminology. For example, when the bill says "pounds" it means that weight may be expressed in ... pounds or ounces and that weight may be expressed in the largest whole unit, either pounds or ounces." It appears that Congress did not intend to require 2-oz, 4-oz, 8-oz, and 12-oz, packages sold by net weight to be labeled $0.125 \mathrm{lb}$, $0.25 \mathrm{lb}, 0.5 \mathrm{lb}$, or $0.75 \mathrm{lb}$ respectively, or $2 \mathrm{lb}$ packages to be labeled $32 \mathrm{oz}$.

To address the elimination of the requirement for dual quantity declarations, the Committee recommends that packers be required to declare the largest whole unit on packages containing more than 1 pound or 1 pint. Similar requirements are clearly mandated by the revised FPLA, and are required on packages labeled by area and linear measure; we recommend the same for dry volume. Requiring the largest whole unit in quantity declarations is consistent with the FPLA and, in 
most cases, provides the most practical units for consumers to use in value comparisons. The fact that many stores provide unit pricing information in advertisements and on shelf labels simplifies this issue.

The Committee proposes that packers be allowed to voluntarily include dual quantity declarations on packages for consumer convenience. The reasons are (1) that the requirements must allow manufacturers flexibility to present quantity information that they have identified as being useful to consumers, and (2) consumers are familiar with both units, which have been required on packages between 1 and 4 pounds since 1967.

The Committee recommends adoption of a comprehensive revision of Section ( $\$$ ) 6.8. of the UPLR as shown below. If the proposal is adopted, the current Sections 6.8.2., 6.8.3., 6.8.4., 6.8.5. and 6.8.6., will no longer be needed, since the proposed $\S 6.8 .2$. would cover all "equal to or greater than" situations and the current $\S 6.8 .1$. (see below) would address labeling conventions for "less than" situations under current inch-pound forms of measure. No changes are recommended for $\S 6.8 .1$. It is presented for information purposes only:

\subsection{Prescribed Units, Inch-Pound System.}

6.8.1. Less than 1 Foot, 1 Square Foot, 1 Pound, or 1 Pint. -- The declaration of quantity shall be expressed in terms of:

(a) in the case of length measure of less than 1 foot, inches and fractions of inches;

(b) in the case of area measure of less than 1 square foot, square inches and fractions of square inches;

(c) in the case of weight of less than 1 pound, ounces and fractions of ounces;

(d) in the case of liquid measure of less than 1 pint, fluid ounces and fractions of fluid ounces,

provided, the quantity declaration appearing on a random package may be expressed in terms of decimal fractions of the largest appropriate unit, the fraction being carried out to not more than three decimal places.

6.8.2. 1 Foot, 1 Square Foot, 1 Pound, 1 Pint, 1 Dry Pint, 1 Gallon or More. -- The declaration of quantity shall be expressed: (see $\S 6.2$. Largest Whole Unit and $\S$ 6.10. Fractions):

(a) Linear Measure. - If 1 foot or more, in terms of the largest whole unit with the remainder expressed in inches, or fractions of the inch, foot, or yard.

(b) Area Measure. -

(i) If 1 square foot or more, but less than 4 square feet, in square feet with the remainder expressed in square inches and fractions of a square inch or square foot;

(ii) If 4 square feet or more, in terms of the largest whole unit, with the remainder expressed in square inches and fractions of a square inch or square foot;

(c) Weight. - If 1 pound or more, in terms of the largest whole unit with the remainder expressed in ounces and fractions of an ounce or pound.

(d) Liquid Volume. --

(i) If 1 pint or more, but less than 1 gallon, in the largest whole unit (quarts, quarts and pints, or pints, as appropriate) with the remainder expressed in ounces, or fractions of the pint or quart, (except that 2 quarts may be declared as one-half gallon); or, 
(ii) If 1 gallon or more, in terms of the largest whole unit (gallons followed by fractions of a gallon, or by the next smaller whole unit or units, for example, quarts and pints) with any remainder expressed in ounces, or fractions of the pint or quart.

(e) Dry Measure. -- If 1 dry pint or more, in terms of the largest whole unit with the remainder expressed in fractions of dry pints, dry quarts, pecks, or bushels,

provided, that quantity declarations may include dual quantity declarations, and the quantity declaration appearing on a random package may be in decimal fractions of the largest appropriate unit, the fraction being carried out to not more than three decimal places.

Examples of Commodities Labeled by Weight or Volume According to Sections 6.8.1. and 6.8.2.

\section{Weight}

Net Wt $16 \mathrm{oz}$ : Should be $1 \mathrm{lb}$; not $16 \mathrm{oz}$ [although dual quantity declarations such as "16 oz (1 lb)" would be permitted]

Net Wt 17 oz: Should be $1 \mathrm{lb} 1 \mathrm{oz}$ or $1.06 \mathrm{lb}$; not $17 \mathrm{oz}$

Net Wt $20 \mathrm{oz}$ : Should be $1 \mathrm{lb} 4 \mathrm{oz}$, or $1.25 \mathrm{lb}$; not $20 \mathrm{oz}$

Net Wt 24 oz: Should be $1 \mathrm{lb} 8 \mathrm{oz}$, or $1.5 \mathrm{lb}$ or 1 1/2 lb; not $24 \mathrm{oz}$

Net Wt 32 oz: Should be $2 \mathrm{lb}$; not $32 \mathrm{oz}$

Net Wt 48 oz: Should be $3 \mathrm{lb}$; not $48 \mathrm{oz}$

Net Wt 56 oz: Should be $3 \mathrm{lb} 8 \mathrm{oz}$, or $3.5 \mathrm{lb}$ or 3 1/2 lb; not $56 \mathrm{oz}$

\section{Volume}

16 fl oz: Should be $1 \mathrm{pt}$; not $16 \mathrm{fl} \mathrm{oz}$

17 fl oz: Should be $1 \mathrm{pt} 1 \mathrm{fl}$ oz or $1.06 \mathrm{pt}$; not $17 \mathrm{fl} \mathrm{oz}$

$24 \mathrm{fl}$ oz: Should be $1 \mathrm{pt} 8 \mathrm{fl}$ oz, or $1.5 \mathrm{pt}$, or $11 / 2 \mathrm{pt}$; not $24 \mathrm{fl} \mathrm{oz}$

32 fl oz: Should be $1 \mathrm{qt}$; not $32 \mathrm{fl} \mathrm{oz}$

$48 \mathrm{fl}$ oz: Should be 1 qt $1 \mathrm{pt}$, or $1.5 \mathrm{qt}$, or $11 / 2 \mathrm{qt}$; not $48 \mathrm{fl} \mathrm{oz}$

$56 \mathrm{fl}$ oz: Should be 1 qt 1 pt $8 \mathrm{fl}$ oz, or 1 qt 1.5 pt, or 1 qt $11 / 2$ pt; not $56 \mathrm{fl}$ oz, or 3 pt $8 \mathrm{fl}$ oz, or 3.5 pint.

64 fi oz: Should be 2 qt or $1 / 2$ gal, not 64 fl oz.

67.6 f oz: $2 \mathrm{~L}$, Should be 2 qt $3.6 \mathrm{fn} \mathrm{oz}$ or 2 qt $35 / 8$ fi oz or 2.11 qt

96 fl oz: Should be 3 qt; not 96 f oz, or 0.75 gallon

3. Use of "Net Weight" and "Net Mass" -- At the Interim Meeting, the Committee received comments on a proposal to the allow the optional use of either "Net Mass" or "Net Weight" in connection with quantity declarations. It was suggested at the Interim Meeting that $\S 6.3 .1$. of the UPLR be amended to make the use of the terms "net weight" and "net mass" optional, that is, permit the quantity statement to stand alone. 
6.3.1. Use of "Net Mass" or "Net Weight." -- A quantity declaration may stand alone [e.g. "200 g $(7 \mathrm{oz})$ " or "1 lb $(453 \mathrm{~g})$ "] or may include the term "net mass" or "net weight" either preceding or following the declaration. However, the quantity of contents shall always declare the net quantity of contents, even when such terms are not used.

This would (1) simplify quantity declarations and reduce label clutter, especially on small packages and food products that will also have to include nutritional information on the labels, (2) be consistent with the current labeling requirements for packages sold by liquid volume, (3) follow the requirements contained in Recommendation Number 87 - Information on Package Labels of the International Organization of Legal Metrology (OIML), and the legal requirements of other countries, including Canada, and (4) eliminate possible confusion that may occur if some firms use the term "net mass" while others use "net weight."

4. Rule of 1,000 for SI units. - The Committee proposes adding a new paragraph (f) "Rule of 1,000" for SI quantities to $\S 6.5$.

(f) Rule of 1,000 . -- The selected multiple or submultiple prefixes for SI units shall result in numerical values between 1 and 1,000. (This rule allows centimeters or millimeters to be used where a length declaration is less than 100 centimeters.) For example: $500 \mathrm{~g}$, not $0.5 \mathrm{~kg} ; 1.96 \mathrm{~kg}$, not $1960 \mathrm{~g}$; or $750 \mathrm{~mL}$, not $0.75 \mathrm{~L}$, or, $750 \mathrm{~mm}$ or $75 \mathrm{~cm}$, not 0.75 meters;

This proposal would require package quantities of less than 1,000 to be declared as numerical values between 1 and 1,000 , not as decimal fractions. This is equivalent to requiring the largest whole unit for inch-pound declarations. For example, 950 grams, not $0.95 \mathrm{~kg} ; 235 \mathrm{~mL}$, not $0.23 \mathrm{~L}$. For quantities of 1,000 or more, declare as kilogram, meters or liters. For example, 1960 grams would be $1.96 \mathrm{~kg}$, and $3780 \mathrm{~mL}$ would be $3.78 \mathrm{~L}$. This paragraph will ensure uniform SI quantity declarations. For linear measurement, declarations of 100 centimeters could be in millimeters or centimeters because consumers may find centimeters more useful than millimeters. For example, $95 \mathrm{~mm}$ or $9.5 \mathrm{~cm}$, but not $0.095 \mathrm{~m}$, or $91.4 \mathrm{~m}$ not $9144 \mathrm{~cm}$.

\section{Other Information}

The Committee has sent a copy of the draft revisions to the more than 300 members of the SI Working Group for review and comment. To determine if there is a consensus of support for the proposed revisions, the Committee developed a ballot so that participants can express their support or opposition for the Committee's recommendations. The Committee also sent its recommendations to FDA and FTC to assist them in their rulemaking. A summary of the balloting indicated overwhelming support for this issue.

At the Annual Meeting, the NCWM voted to grant editorial privileges to the Executive Secretary to ensure that the Uniform Packaging and Labeling Regulation published in the 1994 Edition of NIST Handbook 130 is identical to the final labeling regulations published by the Food and Drug Administration and the Federal Trade Commission.

\section{Method of Sale of Commodities Regulation}

Background: This was Item 232-3 in the Report of the 75th NCWM, 1990, page 94, and Item 232-3 in the Report of the 77th NCWM, 1992, page 137. Please see those reports for background information. The Food and Drug Administration and the U.S. Department of Agriculture (USDA) recently published new rules for nutrition labeling that will result in improvements in the labeling requirements for meat and poultry. The Committee recommends that weights and measures officials continue to monitor this type of packaging and, where questionable combination packages of meat or poultry are encountered, work with the appropriate USDA Regional Office to determine if the commodity is misbranded. The Committee is withdrawing this item so that it can concentrate its efforts on other issues. 


\section{VC 1.6. Fluid Milk Products - Permit 3-Quart Package Size}

(This item was adopted as part of the consent calendar.)

Background: A nationwide processor of fluid milk and milk products requested addition of a 3-quart container to the list of inch-pound volumes permitted for the packaging of fluid milk products in $\S 1.6(\mathrm{~b})$. This request emanated from the changing demographics of the marketplace. The processor believes that this size would be convenient for smaller families and single households, occupy less space in the refrigerator than the 1-gallon container, and more easily handled by small children and the elderly or infirm. Other beverages, such as orange juice, are sold in this container size and have achieved acceptance by consumers. According to the firm, eight States currently permit the sale of 3-quart (2.84 L) containers for milk without any indication that the additional size causes confusion or makes value comparisons by consumers more difficult. Members of the U.S. Metric Association opposed the addition of the 3-quart package size and urged the milk industry to convert to a 3-liter container, already permitted under $\S 1.6$ (a). The Committee examined a sample of the proposed 3-quart paper container and found that its display panels were sized differently from those of a 1/2-gallon container to eliminate the possibility that consumers might confuse the two packages if placed side-by-side on store shelves. The Committee supports the adoption of the 3-quart size as an additional container size representing a 50 percent increase (over a 1/2-gallon container) or 25 percent decrease (compared to a 1-gallon container) and not likely to confuse consumers or frustrate value comparison. The Committee received comments in support of this proposal from weights and measures officials at the Interim and Annual Meetings.

Committee Recommendation: Amend Section 1.6. to include a 3-quart size for milk.

1.6. Fluid Milk Products. -- All fluid milk products including, but not limited to milk, lowfat milk, skim milk, cultured milks, and cream, shall be packaged for retail sale only in volumes per $\S 1.6$.(a), or $\S$ 1.6.(b), provided SI sizes less than 100 milliliters and inch-pound sizes less than 1 gill shall be permitted.

(a) SI Volumes - 125 milliliters, 250 milliliters, 350 milliliters, 500 milliliters, 1 liter, or multiples of 1 liter.

(b) Inch-Pound Volumes - 1 gill, $1 / 2$ liquid pint, 10 fluid ounces, 12 fluid ounces, 1 liquid pint, 1 liquid quart, 1/2 gallon, 3 liquid quarts, 1 gallon, 1-1/2 gallons, 2 gallons, 2-1/2 gallons, or multiples of 1 gallon.

\section{2-3 1.12. Ready-to-Eat Food}

(This item was adopted.)

Background: This was Item 238-1 in the Report of the 76th NCWM, 1991, pages 212-213, and Item 232-4 in the Report of the 77th NCWM, 1992, pages 137-138. Please see those reports for earlier discussions of this issue. The Committee recommends that $\S 1.12$. Ready-to-Eat Food be amended to permit sales of ready-to-eat food items by weight, measure, or count (count includes serving sizes such as small, medium, or large) if the food is sold from bulk or in single serving packages packed on the premises and ready for consumption. The Committee recommends adoption of the proposal although recognizing that this recommendation may not address all of the concerns raised by weights and measures officials and members of industry who are seeking guidance on this difficult issue.

Committee Recommendation: Replace Section 1.12. with the following:

\subsection{Ready-to-Eat Food}

1.12.1. Definition: -- "Ready-to-Eat Food" is restaurant-style food offered or exposed for sale, whether in restaurants, supermarkets, or similar food service establishments, that is ready for consumption, though not necessarily on the premises where sold. Ready-to-Eat Food does not include sliced luncheon products, such as meat, poultry or cheese when sold separately. 
1.12.2. Methods of Sale -- Ready-to-Eat Food sold from bulk, or in single servings packed on the premises, may be sold by weight, measure, or count (count includes servings.)

The key to applying the proposal is the focus on how a product is advertised. For example, if a product is advertised in the same way as a food item on a restaurant menu, it may be sold by weight, measure, or count.

Weights and measures officials are aware that consumer buying habits and food marketing practices are constantly changing. Today, more than ever before, food stores compete with restaurants in the marketing of prepared, ready-to-eat foods. The traditional methods of sale required in retail food stores for ready-to-eat food items may put grocers at a competitive disadvantage compared to restaurants that sell the same or similar items. For example, several weights and measures officials and industry representatives commented that consumers want to purchase these foods in supermarkets, but find it difficult to relate the cost per pound of a ready-to-eat item in the food store to the common method of sale used in a restaurant (for example,"by each"). Allowing supermarkets to offer ready-to-eat food for sale by the piece may actually enhance value comparison for some consumers. For example, when purchasing ready-to-eat items in the supermarket, many consumers do not compare the price per pound of a ready-to-eat food item to the price of unprepared ingredients or products, but rather consider the total cost of the meal, and consider the convenience when making a purchasing decision. Several weights and measures officials indicated that limiting the exemption to food items sold from bulk or packaged in single-serving sizes would narrow the list of exempted products and still allow food stores to sell products using the same methods of sale as used by restaurants.

The following list illustrates some of the items that would be defined as ready-to-eat foods. The list is not intended to be all-inclusive:

- Single-serving packages of pastas, salads, vegetables, or rice

- Cooked, whole chickens or turkeys

- Cooked ribs by the slab or piece

- Cooked, stuffed peppers, tomatoes, or cabbage

- Single slices of cake, pie, or quiche

- Sandwiches, tacos, enchiladas, or tostadas

- Buckets of cooked chicken or fish

- Cooked pizzas, whole or sliced, and servings of cooked chili or soup

\section{$232-4$}

\section{VC Hardwood Lumber - Measurements in Retail Sales}

(This item was adopted as part of the consent calendar.)

Background: This was Item 238-4 in the Report of the 76th NCWM, 1991, page 213, and Item 232-9 in the Report of the 77th NCWM, 1992, page 142. Please see those reports for additional background on this issue. In 1990, a weights and measures official contacted NIST concerning a complaint about a purchase of hardwood lumber. The price of the lumber was quoted per board foot; however, the actual dimensions of the hardwood lumber were considerably less than the labeled amount when converted to board feet ( 1 board foot $=12 \times 12 \times 1$ in $=144 \mathrm{cu}$ in). For example, a 6 -foot by 7-1/4-inch by 3/4-inch board was labeled 4 board feet, the labeled amount corresponding to dimensions of 6 feet by 8 inches by 1 inch. When contacted about the complaint, an official of the National Hardwood Lumber Association (NHLA) indicated that it is industry practice to declare the number of board feet in a piece of lumber as the dimensions before the piece was surfaced. This complaint prompted a complete review of the current $\S 2.12$. on hardwood by the NHLA and the Committee. Based on the review, it was decided that a complete revision of $\S 2.12$. was needed. The goal was to clarify and broaden the section to include any subsequent processing of the lumber, rather than just kiln drying.

Committee Recommendation: Amend $\S 2.12$. by replacing the current requirement with the following:

2.12. Hardwood Lumber - Retail Sales. - The requirements of this section apply to retail sales of hardwood lumber, but not to hardwood flooring, molding, or other pre-formed products.

2.12.1. Definitions. - 
2.12.1.1. Board Foot. -- The inch-pound unit of volume measurement for hardwood lumber. A board foot is the volume of a board 1-foot long, 1-foot wide, and 1-inch thick or its equivalent (144 cubic inches of wood).

2.12.1.2. Surfaced Lumber. -- Lumber that has been surfaced for the purpose of attaining smoothness of surface and uniformity of size.

2.12.1.3. Kiln Drying. -- A specialized process used to minimize dimensional changes in service. Hardwood lumber used for most products must have moisture removed by placing it in a drying kiln with controlled humidity and heat for a period of time determined by the initial and the final moisture content, the species, and the thickness.

2.12.1.4. Surface Measure. -- A rounded area measurement for hardwood lumber. The surface measure shall be determined by multiplying the full width of the piece in inches and fractions by the standard length (see $\S$ 2.12.1.7. Standard Length) in feet, dividing by 12 , and rounding up or down to the nearest whole square foot. (Fractions less than or equal to one-half square foot are rounded down and those greater than one-half square foot are rounded up.)

2.12.1.5. Species. -- The commercial name assigned to a species of trees.

2.12.1.6. Species Group. -- The commercial name assigned to two or more individual species having similar characteristics.

2.12.1.7. Standard Lengths. -- 4, 5, 6, 7, 8, 9, 10, 11, 12, 13, 14, 15, or 16 feet. Fractional lengths are rounded down to the next lower standard length (for example, if a board is $6 \mathrm{ft} 8 \mathrm{in}$ long, its length is rounded down to $6 \mathrm{ft}$ ).

2.12.1.8. Stock Widths. -- Special items manufactured to predetermined widths, normally for retail sale.

2.12.2. Identity. -- Representations shall include a declaration of identity that specifies the species or species group.

2.12.3. Surfaced (S4S) Lumber Manufactured to Stock Widths. --

2.12.3.1. Quantity. -- Representations shall be in terms of one of the following:

by linear measure, when surfaced width and thickness are stated, or

by count, when length and surfaced width and thickness are stated, or

by surface measure (square feet) when a thickness is stated.

2.12.3.2. Representations. -- The use of nominal dimensions shall be allowed if the table of Minimum Surfaced Sizes for Kiln Dried Hardwood Lumber or the actual dimensions are prominently displayed to the customer, and the term "nominal" or "nom" is used in conjunction with any representation of nominal dimensions.

2.12.3.3. Minimum Surfaced Sizes of Kiln Dried Lumber (width and thickness). -- Table 1 shows the minimum sizes for the stock widths listed. This table includes dimensions for thicknesses of 1-inch and 2-inch thick stock lumber. Hardwood lumber is also manufactured in thicknesses of 1-1/4 inch (1-inch surfaced) and 1-1/2-inch (1-3/16 inch. For other thicknesses, use the nominal and minimum widths from the table. For example: a board with the nominal dimensions of 1-1/4 inches $x 4$ inches would have minimum thickness of 1 -inch and minimum width of 3-1/2 inches.

\subsubsection{Random Width Lumber.}


2.12.4.1. - Sales of random width hardwood lumber measured after kiln drying shall be quoted, invoiced, and delivered on the basis of net board footage, with no addition of footage for kiln drying shrinkage or surfacing. Sales of hardwood lumber measured and sold prior to kiln drying or surfacing shall be quoted, invoiced, and delivered on the basis of net board footage before kiln drying or surfacing. If the lumber is to be kiln dried or surfaced at the request of the purchaser, the kiln drying or surfacing charge shall be clearly shown and identified on the quotation and invoice.

\begin{tabular}{|c|c|c|}
\hline SI Units for Thickness and Width & Thich & n Inches \\
\hline Minimum Sizes in millimeters & Nominal Sizes & Minimum Sizes \\
\hline $38 \times 89$ & $2 \times 4$ & $1-1 / 2 \times 3-1 / 2$ \\
\hline $38 \times 140$ & $2 \times 6$ & $1-1 / 2 \times 5-1 / 2$ \\
\hline $38 \times 184$ & $2 \times 8$ & $1-1 / 2 \times 7-1 / 4$ \\
\hline $38 \times 235$ & $2 \times 10$ & $1-1 / 2 \times 9-1 / 4$ \\
\hline $38 \times 286$ & $2 \times 12$ & $1-1 / 2 \times 11-1 / 4$ \\
\hline $19 \times 19$ & $1 \times 1$ & $3 / 4 \times 3 / 4$ \\
\hline $19 \times 38$ & $1 \times 2$ & $3 / 4 \times 1-1 / 2$ \\
\hline $19 \times 63$ & $1 \times 3$ & $3 / 4 \times 2-1 / 2$ \\
\hline $19 \times 89$ & $1 \times 4$ & $3 / 4 \times 3-1 / 2$ \\
\hline $19 \times 140$ & $1 \times 6$ & $3 / 4 \times 5-1 / 2$ \\
\hline $19 \times 184$ & $1 \times 8$ & $3 / 4 \times 7-1 / 4$ \\
\hline $19 \times 235$ & $1 \times 10$ & $3 / 4 \times 9-1 / 4$ \\
\hline $19 \times 286$ & $1 \times 12$ & $3 / 4 \times 11-1 / 4$ \\
\hline \multicolumn{3}{|c|}{$\begin{array}{l}\text { The dry thickness of nominal } 1-1 / 2 \text {-inch lumber is } 1-3 / 16 \text { inch. The dry thickness of nominal } 1-1 / 4 \text { inch } \\
\text { lumber is } 1 \text { inch. Sizes are shown in inches and millimeters. Minimum sizes in millimeters are } \\
\text { calculated by multiplying the size in inches by } 25.4 \text { and rounding to the nearest millimeter. The rule for } \\
\text { rounding is: round up for numbers greater than } 0.50 \mathrm{~mm} \text { and round down for numbers less than or } \\
\text { equal to } 0.50 \mathrm{~mm} \text {. In case of a dispute on size measurements, the inch measurement takes precedence. } \\
\text { Nominal and minimum widths for these thicknesses are shown above. The SI equivalents for } 1 \text {-inch and } \\
\text { 1-3/16-inch lumber are } 25.4 \mathrm{~mm} \text { and } 30.1 \mathrm{~mm} \text {, respectively. }\end{array}$} \\
\hline
\end{tabular}

In some retail sales, hardwood is kiln dried, surfaced on four sides, and manufactured to stock sizes as is done for softwood lumber. The recommendation provides a clearer format for this section and includes a table that specifies minimum sizes for hardwood lumber after it has been kiln dried and surfaced. The table specifies nominal and minimum inch-pound dimensions, and SI equivalents for the minimum dimensions. The Committee recommends adoption because the proposal: (1) recognizes current manufacturing and sales practices; (2) requires sizes similar to those for softwoods so that consumers will be able to compare equivalent sizes (see $\S 2.10$. Softwood Lumber, pages 88-90, Handbook 130, 1993 edition); (3) will enable consumers who mix woods in the same project to avoid matching problems because the different woods will be manufactured to similar standards; and (4) ensures access to information on the actual dimensions of lumber to consumers who are unfamiliar with the use of nominal sizes in retail sales of lumber. If the NCWM adopts this proposal, the NHLA intends to publish the table in its Rules for the Measurement and Inspection of Hardwood Lumber. The proposal also allows retailers the alternative of posting the actual dimensions on shelf labels adjacent to the nominal dimensions in lieu of posting the table. This alternative is included to allow self-service lumber yards to post 
both dimensions on shelf labels near the product so that consumers who select their own lumber have access to the information. This option will address concerns raised by some retailers who say that requiring the posting of the table is unrealistic in some retail locations. This concern was raised due to the increasing number of huge self-service lumber yards where consumers select lumber from the stacks and go through checkout counters rather than a service counter in the lumber department (where the tables for actual dimensions for hardwood and softwood lumber would typically be posted).

\section{2-5}

\section{VC SI and Other Revisions - Retail Sales of Softwood Lumber}

(This item was adopted as part of the consent calendar.)

Background: The American Lumber Standards Committee (ALSC) was appointed by the Secretary of Commerce and operates as an independent body to establish and maintain Department of Commerce Voluntary Product Standard (VPS) 20-70, American Softwood Lumber Standard. The ALSC submitted recommended amendments to Section 2.10. Softwood Lumber to include Sl units in Table 1 (as required by NIST metric policy), and to update several definitions and requirements to bring them into agreement with VPS 20-70. This Voluntary Product Standard has been amended several times since the method of sale for softwood lumber was first adopted in 1970, hence the updates are necessary for consistency. SI equivalents are included only with actual dimensions, since nominal sizes will not be used after the softwood lumber industry converts to SI units. The proposal allows retailers the alternative of posting actual dimensions on shelf labels adjacent to the nominal dimensions in lieu of posting the table. This will allow self-service lumber yards to post both dimensions on shelf labels near the product so that consumers who select their own lumber have access to the information. This option addresses the concerns of retailers who say that requiring the posting of the table is impractical in some locations. This concern was raised due to the increasing number of huge self-service lumber yards where consumers select lumber from the stacks and go through checkout counters rather than a service counter in the lumber department (where the tables for actual dimensions for hardwood and softwood lumber would typically be posted). The VPS, to be published by the Department of Commerce as VPS 20-94, is currently undergoing amendment. The Committee recommends adoption of the following amendments to $\S 2.10$. Softwood Lumber.

Committee Recommendation: Adopt the following amendments to harmonize definitions with VPS 20-94 and incorporate S1 units for actual dimensions. Add a provision for alternative posting of actual dimensions and delete Note 6 since SI units are being included in the amendments.

2.10. Softwood Lumber. -- Applies to softwood boards, timbers, and dimension lumber that have been surfaced on-four sides, but shall not apply to rough lumber; to lumber that has been matched, patterned, or shiplapped; or to lumber remanufactured or joined so as to have changed the form or identity, such as individually assembled or packaged millwork items. "Nominal sizes" for inch-pound dimensions are size designations used for convenience in describing approximate, rather than actual, sizes of lumber. "Nominal sizes" were originally derived from the dimensions of rough lumber before surfacing and are always greater than the actual dimensions; thus a dry " $2 \times 4$ " is surfaced to actual dimensions of 1-1/2 inches $\times 3-1 / 2$ inches (38 millimeters x 89 millimeters). The requirements in this section refer to actual sizes of lumber; for nominal sizes see Table 1. The nominal sizes used in this section follow Department of Commerce Voluntary Product Standard 20-94, American Softwood Lumber Standard, or latest edition. SI equivalents are included for actual measurements only.

AOTE 6:-Vatues in metric units for softwod twmber will not be added unth a new standard is developed to cover metric softwood lumber.

\subsubsection{Definitions. --}

2.10.1.1. Surfaced Lumber. -- Lumber that has been surfaced by a machine for-the-purpese-of (to attaining smoothness of surface and uniformity of size): on one side (S1S), on two sides (S2S), one edge (S1E), two edges (S2E), or a combination of sides and edges (S1S1E, S1S2E, S2S1E, S4S). 
2.10.1.2. Boards. - Lumber $1-144 \underline{38 \mathrm{~mm}(1-1 / 2}$ inches) or less in actual thickness and $38 \mathrm{~mm}(1-1 / 2)$ inches or more in actual width. Lumber less than $1-1 / 2139 \mathrm{~mm}(5-1 / 2$ inches) in actual width may be classified as strips.

2.10.1.3. Timbers. - Lumber $1-1 / 2114 \mathrm{~mm}$ (4-1/2 inches) or more in smallest dimension. Timbers may be etsified designated as beams, stringers, posts, caps, sills, girders, or purlins.

2.10.1.4. Dimension lumber. -- Lumber from $\underline{38 \mathrm{~mm}}$ (1-1/2 inches) to, but not exing including, 114 $\mathrm{mm}$ (4-1/2 inches) in actual thickness, and $38 \mathrm{~mm}$ (1-1/2 inches) or more in actual width. Dimension lumber may be elassified designated as framing, joists, planks, rafters, studs, or small timbers.

2.10.1.5. Rough lumber. -- Lumber that has not been surfaced, but that has been sawed, edged, and trimmed at least to the extent of showing saw marks, or other primary manufacturing marks in the wood on the four longitudinal surfaces of each piece for its overall length.

2.10.1.6. Matched lumber. - Lumber that has been worked with a tongue on one edge of each piece and a groove on the opposite edge to provide a close tongue-and-groove joint by fitting two pieces together; when end-matched, the tongue and groove are worked in the ends also.

2.10.1.7. Patterned lumber. - Lumber that is shaped to a pattern or a molded form, in addition to being dressed, matched, or shiplapped, or any combination of these workings.

2.10.1.8. Shiplapped lumber. - Lumber that has been worked or rabbeted on both edges of each piece to provide a closelapped joint by fitting two pieces together.

2.10.1.9. Grade. - The commercial designation assigned to lumber meeting specifications established by a nationally recognized grade rule writing organization.

2.10.1.10. Species. - The commercial name assigned to a species of trees.

2.10.1.11. Species group. -- The commercial name assigned to two or more individual species having similar characteristics.

2.10.1.12. Representation. -- A "representation" shall be construed to mean any advertisement, offering, invoice, or the like that pertains to the sale of lumber.

2.10.1.13. Minimum dressed sizes (width and thickness). - The standardized width and thickness at which lumber is dressed when manufactured in accordance with the U.S. Department of Commerce Voluntary Product Standard 20-94, "American Softwood Lumber Standard," or latest edition, and regional grading rules conforming to VPS 20-94 or latest edition. (See Table 1 Softwood Lumber Sizes.)

2.10.2. Identity. - Representations shall include a declaration of identity that specifies the grade or grades, species or species group, and whether the lumber is unseasoned (green) or dry.

2.10.3. Quantity. - Representations shall be in terms of:

(a) the number of pieces,

(b) the minimum surfaced width and thickness, and either

(c) the length of individual pieces or the lineal footage; 
except that the use of nominal dimensions shall be allowed as long as a table of minimum surfaced sizes is displayed prominently or the actual dimensions are prominently displayed to the customer and the term "nominal" or "nom" is also used in conjunction with any representation of dimensions.

\section{Table 1. Softwood Lumber Sizes}

Minimum standard surfaced sizes at the time of manufacture for both unseasoned (green) and dry lumber as published by the U.S. Department of Commerce in Voluntary Product Standard (VPS) 20-94 or latest edition. Sizes are given in inches and millimeters. Actual (minimum surfaced sizes) in millimeters are calculated by multiplying the size in inches by 25.4 and rounding to the nearest millimeter. The rounding rule is to round up to the next greater millimeter for numbers greater than $0.5 \mathrm{~mm}$ and to round down to the next lower millimeter for numbers less than or equal to $0.5 \mathrm{~mm}$. In case of a dispute on size measurements, the inch measurement shall take precedence.

\begin{tabular}{|c|c|c|c|c|}
\hline \multirow{2}{*}{$\begin{array}{c}\text { Product Classification } \\
\text { Nominal Size) }\end{array}$} & \multicolumn{5}{|c|}{ Minimum Dressed Sizes $* *$} \\
\cline { 2 - 5 } & \multicolumn{5}{|c|}{ Unseasoned } & \multicolumn{2}{c|}{ Dry } \\
\cline { 2 - 5 } & \multicolumn{5}{|c|}{ Inches } & \multicolumn{4}{|c|}{ millimeters } & Inches & millimeters \\
\hline \multirow{2}{*}{$2 \times 4$} & $1-9 / 16 \times 3-9 / 16$ & $40 \times 90$ & $1-1 / 2 \times 3-1 / 2$ & $38 \times 89$ \\
\hline $2 \times 6$ & $1-9 / 16 \times 5-5 / 8$ & $40 \times 143$ & $1-1 / 2 \times 5-1 / 2$ & $38 \times 140$ \\
\hline $2 \times 8$ & $1-9 / 16 \times 7-1 / 2$ & $40 \times 190$ & $1-1 / 2 \times 7-1 / 4$ & $38 \times 184$ \\
\hline $2 \times 10$ & $1-9 / 16 \times 9-1 / 2$ & $40 \times 241$ & $1-1 / 2 \times 9-1 / 4$ & $38 \times 235$ \\
\hline $2 \times 12$ & $1-9 / 16 \times 11-1 / 2$ & $40 \times 292$ & $1-1 / 2 \times 11-1 / 4$ & $38 \times 286$ \\
\hline \multicolumn{5}{|c|}{ Board Lumber } \\
\hline $1 \times 4$ & $25 / 32 \times 3-9 / 16$ & $20 \times 90$ & $3 / 4 \times 3-1 / 2$ & $19 \times 89$ \\
\hline $1 \times 6$ & $25 / 32 \times 5-5 / 8$ & $20 \times 143$ & $3 / 4 \times 5-1 / 2$ & $19 \times 140$ \\
\hline $1 \times 8$ & $25 / 32 \times 7-1 / 2$ & $20 \times 190$ & $3 / 4 \times 7-1 / 4$ & $19 \times 184$ \\
\hline $1 \times 10$ & $25 / 32 \times 9-1 / 2$ & $20 \times 241$ & $3 / 4 \times 9-1 / 4$ & $19 \times 235$ \\
\hline $1 \times 12$ & $25 / 32 \times 11-1 / 2$ & $20 \times 292$ & $3 / 4 \times 11-1 / 4$ & $19 \times 286$ \\
\hline
\end{tabular}

*The dry thicknesses of nominal 3-in and 4-in lumber are 2-1/2 in $(63 \mathrm{~mm})$ and 3-1/2 in $(89$ $\mathrm{mm})$; unseasoned thicknesses are 2-9/16 in $(65 \mathrm{~mm})$ and 3-9/16 $(90 \mathrm{~mm})$. Widths for these thicknesses are the same as shown above.

**VPS 20-94 defines dry lumber as being 19 percent or less in moisture content and unseasoned lumber as being over 19 percent moisture content. The size of lumber changes approximately 1 percent for each $\mathbf{4}$ percent change in moisture content. Lumber stabilizes at approximately 15 percent moisture content under normal use conditions. (Added 1971) 
(This item was withdrawn.)

Background: This was Item 232-7 in the Report on the 77th NCWM, 1992, page 141. Please review that report for further background on this issue. At the 77th Annual Meeting the NCWM adopted a method of sale to require that baler twine be sold by length and weight. The new section was adopted to ensure equitable marketing practices. After the NCWM action, the Cordage Institute requested that the NCWM amend the method of sale to require length and knot strength on bales of baler twine instead of length and net weight. At the Interim Meeting the Cordage lnstitute requested that the Committee withdraw the proposal.

\section{2-7 \\ I Compressed Natural Gas (CNG) When Sold as a Vehicle Fuel}

Background: Numerous requests were received from weights and measures officials and industry for a method of sale regulation for compressed natural gas (CNG) when sold for use as a vehicle fuel. (See Item 237-2 under the Uniform Motor Fuel Regulation in this agenda for related information.) The Committee has identified at least five methods of sale that are currently in use in the United States to sell CNG for use as a motor fuel:

- "Equivalent Gallon," Energy - Several retail outlets sell CNG using the equivalent BTU' content in a gallon of gasoline to convert from BTU of CNG to "gallons equivalent" (to gasoline). This is often an arbitrary figure which varies a great deal. It is known that the energy content of a gallon of diesel fuel is much greater than that of a gallon of gasoline, and that the energy content of both fuels varies as much as \pm 10 percent.

- Mass - A majority of firms make retail sales on the basis of mass in terms of kilograms or pounds.

- Energy Units - The extent of use of this method in retail sales is not known, but some firms sell CNG by therms (1 therm equals 100,000 BTUs).

- Others include: sales by standard cubic feet and sales by pressure (the extent of use of these methods in retail sales is not known).

Industry, consumers, and weights and measures officials acknowledge that the use of several methods of sale in the marketplace frustrates value comparisons by consumers and hampers the acceptance of CNG as an alternative motor fuel. At the same time, everyone recognizes that commercial transactions must be based on a legal unit of measure, such as, kilograms or pounds. Several people commented that the use of "equivalent gallon" may be confusing, or subject to misuse; however, they recognize that it may be needed for marketing because it will be very difficult for potential customers to recognize the benefits of using natural gas if not somehow related to the price of gasoline and other fuels. (The S\&T Committee has recommended that auxiliary indications be allowed on CNG dispensers to provide this type of information. See the S\&T Committee Report for further information.) Several industries originally supported a method of sale by energy content (for example, in the SI unit "joules" and "megajoules"), but those proposals were withdrawn due to anticipated difficulties in trying to educate the public to compare the price of fuels on the basis of energy content, which is known to vary widely among fuels. The Natural Gas Vehicle Coalition's (NGVC) Measurement and Metering Task Group proposed that mass be the method of sale for CNG when sold as an engine fuel at retail. The NGVC believed that if a commercial device is used in retail sales to dispense compressed natural gas, its primary indication must be a legal unit of measure, for example, either kilograms or pounds; if it is a computing device, the unit price must be indicated as dollars per kilogram or pound, with the total price based upon these values. The NGVC membership includes most of the firms that produce and distribute natural gas in the United States. The definition is needed because natural gas occurs in a wide variety of composites, and not all natural gas may be suitable for: (1) compression and storage on-board a vehicle and (2) combustion in an automotive (spark or combustion ignition) engine. The Central and Southern Weights and Measures Associations are on record as supporting this method of sale.

British thermal unit. The amount of heat energy required to raise the temperture of 1 pound of water 1 degree Fahrenheit. $1 \mathrm{BTU}=1055.056$ joules (approximately). 
Note: References to the Society of Automotive Engineers recommended practice for CNG fuel composition were deleted pending consideration of this issue by the Petroleum Subcommittee.

Committee Recommendation: Add the following section on Compressed Natural Gas.

\subsection{Retail Sales of Natural Gas When Sold as a Vehicle Fuel}

2.27.1. Natural Gas. -- Natural gas means a gaseous fuel composed primarily of methane that is suitable for compression and dispensing into a fuel storage container(s) for use as an engine fuel.

2.27.2. Method of Sale and Display. -- All natural gas kept, offered, or exposed for sale and sold at retail as a vehicle fuel shall be in terms of mass in terms of kilograms or pounds.

At the Annual Meeting the S\&T and L\&R Committees were formally notified by the Natural Gas Vehicle Coalition that, due to concerns over the possible negative impact of the proposed method of sale, the Coalition was withdrawing its support for mass as the method of sale for CNG. The coalition requested that the NCWM study this item for consideration at the 79th NCWM. In a joint decision of the S\&T and L\&R Committees, it was decided to change this item from a "Voting" to an "Informational" item. The Committees agreed that many questions have to be answered before the Committees can make final recommendations on a method of sale for CNG to the NCWM. The Committees agreed to establish a joint working group with the Natural Gas Vehicle Coalition to (1) study proposals for the appropriate method of sale for CNG, (2) develop procedures for determining conversion factors and audit trails, (3) develop technical requirements for devices, and (4) establish Examination Procedure Outlines for use in field tests.

\section{2-8 VC SI Revisions to the Uniform Method of Sale of Commodities Regulation}

(This item was adopted as part of the consent calendar.)

Background: See Item 210-1 for additional background on this issue. The Committee reviewed the draft SI revisions to the Uniform Method of Sale of Commodities Regulation prepared by the SI Working Group and, except as noted below, decided that most of the SI revisions were adequately addressed under the proposals detailed in Item 210-1 SI Revisions to NIST Handbook 130 - General. One exception is the Committee's recommendation to include SI units and to make other editorial changes to $\S 2.10$. Softwood Lumber in Item 232-5 of this report. Please see that item for details.

In its review of the MSCR, the SI Working Group identified the need to include SI units for thickness declarations on polyethylene and recommended adoption of the SI unit "micrometer." Prior to the Interim Meeting, the Committee received comments recommending that either the obsolete term "micron" be permitted or that no SI unit be included at this time because of the potential for confusion on the part of consumers. The Committee considered these comments and believes that it would be counterproductive not to recommend a uniform SI unit in connection with the current changes in labeling that are underway in the United States in response to the changes to the FPLA. The "micron" is an obsolete term and its use is to be avoided. The Committee is also concerned that unless a specific SI unit is recommended, some manufacturers may use the obsolete term "micron" instead of the correct SI term "micrometer." The Committee is concerned that, without specific guidance, some manufacturers might declare the SI equivalent for 1 mil as "0.025 millimeter" or " 0.0025 centimeter" to declare thickness. This would result in nonuniformity and might cause confusion for consumers. The Committee recommends the following revisions to ensure that the SI unit "micrometer" be required in addition to inch-pound thickness declarations on polyethylene products. For example, Thickness: "25.4 $\mu \mathrm{m}$ (1 mil)" or "1 mil (25.4 micrometers)".

Amend the following sections as indicated:

1. In $\S 2.13$. Polyethylene Products - under $\S 2.13 .1 .1$. Sheeting and film (c), and $\S 2.13 .2 .2$. Lawn and trash bags, add a requirement for "micrometers" as the SI unit for thickness. [ 1 mil $=0.001$ inch $=25.4$ micrometers $(\mu \mathrm{m})$ or $0.00254 \mathrm{~cm}$. 1 micrometer $=0.000039$ inch.] Amend Note 7 to include micrometer. 


\subsubsection{Sheeting and film. -.}

(c) thickness in micrometers and mils. [NOTE 7, see page $\_$]

\subsubsection{Lawn and trash bags. --}

(c) thickness in micrometers and mils.

NOTE 7: $1 \mathrm{mil}=0.001$ inch $=25.4$ micrometers $(\mu \mathrm{m}) .1$ micrometer $=0.000039$ inch .

2. In $\S 2.13 .4$. Declaration of Weight, add the following formula for calculating the net mass of polyethylene in SI units:

\section{For SI dimensions:}

$M=T \times A \times D / 1000$, where:

$M=$ net mass in kilograms

$T=$ nominal thickness in centimeters

$\mathbf{A}=$ nominal length in centimeters times nominal width in centimeters

D = density in grams per cubic centimeter as determined by ASTM Standard D1505-68, "Standard Method of Test for Density of Plastics by the Density Gradient Technique" (or latest issue)

For the purpose of this regulation, the minimum density shall be $0.92 \mathrm{~g} / \mathrm{cm}^{3}$ (when $\mathrm{D}$ is not known).

\section{Uniform Unit Pricing Regulation}

233-1 V Unit Pricing for Infant Formula

(This item was adopted.)

Background: A manufacturer of infant formula requested that the Uniform Unit Pricing Regulation be amended to permit the advertising of unit prices for infant formulas on the basis of the price per reconstituted fluid ounce. This proposal would include liquid concentrates and powdered formulas that must be reconstituted with water. This method of unit pricing would enable consumers to make a realistic value comparison between ready-to-use liquid formulas and condensed or powdered formulas. Retailers would be permitted to display the unit price of the powdered or condensed infant formulas (currently sold on the basis of price-per-pound) and liquid ready-to-use products (currently unit priced by liquid pint or quart) on the basis of price per fluid ounce. The fluid ounce unit price for a concentrate or powdered product would be based on the amount of formula that the customer obtains when the product is mixed or reconstituted according to the manufacturer's instructions. Under existing practices, a consumer buying either powder or concentrate cannot readily compare the cost difference between products. If adopted, this proposal would provide a simpler way for consumers to compare the cost of each formulation per feeding, which may be 4 or 8 fluid ounces. Unit price labels for infant formula could include the following information:

- For ready-to-use infant formulas: price per fluid ounce.

- For powdered and concentrated infant formulas:

- A statement of unit price per fluid ounce based on a reconstituted fluid ounce.

- A statement of the liquid volume that the product will provide if reconstituted according to the manufacturer's instructions. For example, "Reconstitutes to $26 \mathrm{fl} \mathrm{oz.,"} \mathrm{or} \mathrm{"Makes} 87.2 \mathrm{fl} \mathrm{oz,"} \mathrm{or} \mathrm{"Makes} 116 \mathrm{fl} \mathrm{oz."}$ 
Implementing unit pricing to reflect a price per reconstituted volume will reduce confusion by making the comparative cost savings or increases of different products evident to consumers so that they can decide which formulation is in their best interest, whether economic or convenience-related.

The amendment will make unit price labels easier to understand at point of purchase since infants do not consume a pound of powder or a quart of concentrate, which is currently how the costs are presented. According to the firm that submitted this proposal, all infant formula manufacturers have products available for retail sale in concentrate, powder, and ready-touse liquid forms; therefore, this proposal would not favor any one manufacturer or provide an unfair advantage for any type of infant formula or brand. The definition of "infant formula" is from the Federal Food, Drug, and Cosmetic Act. Support for this proposal has been expressed by the Food Marketing Institute, the Grocery Manufacturers of America, and the Central and Southern Weights and Measures Associations.

Committee Recommendation: Add the following note to Section 1 of the Uniform Unit Pricing Regulation:

Note: For "infant formula," unit price information may be expressed based on the reconstituted volume. "Infant formula" means a food that is represented for special dietary use solely as a food for infants by reason of its simulation of human milk or suitability as a complete or partial substitute for human milk.

\section{3-2 I SI Revisions to the Uniform Unit Pricing Regulation}

Background: The Committee reviewed the proposed SI revisions to the UPR that were prepared by the SI Working Group and considered the numerous comments received from interested parties requesting that several new product categories be added to the UPR. Several people suggested that the requirements be updated to reflect other units of measure for products sold by length or count. The Committee realized that an effort of this scope could not be accomplished this year and will take up these issues at the next Interim Meeting.

Background: The Committee received a request from the Natural Gas Vehicle Coalition to add a requirement for a quality standard for compressed natural gas (CNG) sold as a motor fuel in $\S 2$. Fuel Specifications in the Uniform Motor Fuel Regulation. The Committee has learned that work is underway in the Society of Automotive Engineers (SAE) to develop quality standards and specifications for CNG when it is used as a vehicle fuel. The Committee will ask the Petroleum Subcommittee to include this item on its agenda and report on its progress on this issue at the Interim Meeting in January 1994.

Compressed Natural Gas Vehicle Coalition Recommendation:

\subsection{Compressed Natural Gas shall be suitable for its intended use as specified under 1.4., (see Item 237-2 below) and in accordance with applicable national, state and local regulations.}

Rationale: Natural gas must meet minimum requirements in order to be used as an automotive fuel. Certain chemical and physical properties of natural gas are important considerations in engine operations and exhaust emissions. Natural gas composition can vary. The properties of natural gas are influenced by the processing of natural gas by the transmission companies and regional gas supply, storage, and demand balancing done by distribution companies to maintain uninterrupted service throughout the year.

Laboratory results cannot fully define all pertinent fuel properties that affect engine operation and exhaust emissions. Currently, there is insufficient field data on natural gas vehicles to specify limits on all properties. Some properties are specified in the National Fire Protection Association's (NFPA) Standard for Compressed Natural Gas (CNG) Vehicular Fuel Systems, NFPA 52-1992. An SAE Recommended Practice for Compressed Natural Gas Fuel Composition, SAE 
J1616, summarizes some of the more important physical and chemical characteristics of compressed natural gas fuel for vehicles. Work to define quality standards is needed.

\section{7-2 I $\quad$ Retail Sale of Compressed Natural Gas as a Vehicle Fuel}

Background: See Item 232-7 under the Method of Sale of Commodities Regulation in this agenda. This regulation is needed because natural gas occurs in a wide variety of composites, and not all natural gas may be suitable for (l) compression and storage on-board a vehicle, and (2) combustion in an automotive (spark or combustion ignition) engine. The Committee recommends that if the method of sale for CNG is adopted as presented in Item 232-7, then it should also be included in the Uniform Motor Fuel Regulation.

At the Annual Meeting, the Specifications and Tolerances Committee and the L\&R Committee deferred actions on this issue at the request of the Natural Gas Vehicle Coalition (NGVC). The NGVC has requested that the NCWM consider adopting the "Gasoline Gallon Equivalent" as the retail method of sale for CNG when it is sold as a motor fuel. Work on this item will be carried over to next year.

Committee Recommendation: Add the following definition and method of sale to the UMFR.

\section{Section 1. Definitions}

1.4. Natural Gas. -- Natural gas means a gaseous fuel composed primarily of methane that is suitable for compression and dispensing into a fuel storage container(s) for use as an engine fuel.

Section 4. Retail Sale of Natural Gas When Sold as a Vehicle Fuel

4.1. Method of Retail Sale. -- All natural gas kept, offered, or exposed for sale and sold at retail as a vehicle fuel shall be in terms of mass in terms of kilograms or pounds.

\section{Interpretations and Guidelines}

238-1

\section{VC Motor Fuel Sample Collection - Product Flush}

(This item was adopted as part of the consent calendar.)

Background: This was 1tem 237-1 in the Report of the 74th NCWM, 1989, pages 111-113. In 1989 the NCWM adopted a policy that recommended a flushing procedure for inspectors to use when collecting motor-fuel samples from blender and single-hose motor-fuel dispensers. The purpose of the procedure was to ensure that the petroleum sample collected accurately represented the product contained in the storage tank or as blended by the dispenser and not contaminated by product from the previous sale remaining in the hose. A note was added to EPO No. 21 for single product retail motorfuel dispensers and multiproduct dispensers that share a single delivery hose for guidance in taking octane samples. (A similar note was added to EPO No. 22 for blended-product dispensers.)

A manufacturer of motor-fuel dispensers requested that the NCWM extend the 0.3 gallon ( 1 liter) flush to all dispensers equipped with a V1 Vapor Nozzle, including multiproduct dispensers with more than one delivery hose. The V1 Vapor System is vacuum-vapor assisted, using a single 2-section pump to collect vapors in accordance with environmental regulations. The product enters one side of the pumping unit, which draws a vacuum at the nozzle. The vapors are removed from the vehicle's gas tank and returned to the storage tank. The manufacturer added a valving network which directs the product through the pump to the proper hose outlet. Using a single pump creates a situation where 0.1 gallon ( 0.3 liter) of fuel is retained in the pump and small manifold in the raceway of the dispenser. When taking octane samples and switching from the low grade to the high grade, a small amount of product will be mixed with the straight grade product. In the absence of flushing, the high grade may test below the posted octane. In a 1-gallon (3.78 liter) sample, a laboratory might see a 0.4 percent reduction in the octane rating of the sample. The manufacturer requested that the NCWM amend the note to apply the 0.3 gallon (1 liter) flush to all dispensers equipped with the V1 Vapor Nozzle. 
At the Interim Meeting, the Committee considered this request and received comments that supported applying the 0.3 gallon (1 liter) flush to all dispensers that deliver multiproducts, not just those that share a single hose. The Southern and Central Weights and Measures Associations are on record as supporting this position. The Central Association submitted the following proposed change to the note in EPO 21 in NCWM Publication 12, Examination Procedure Outlines for Weighing and Measuring Devices:

NOTE: If you are testing a multiproduct dispenser and to draw a sample to check octane during the quantity test, take the sample at the completion of the normal test for each product. If you draw a sample prior to conducting a quantity test, flush a minimum of 0.3 gallon (1 liter) of motor fuel from the dispenser before taking the octane sample. Return the flushed product to the storage tank containing the lowest octane. (See Item 237-1, L\&R Report of the 74th NCWM, 1989, and Item 238-1, L\&R Committee Report of the 78th NCWM, page xx.)

(The corresponding note in EPO 22 covers all blended product dispensers; therefore, it does not need to be changed.)

The Committee agrees that the product flush should be applied to all multiproduct dispensers; therefore, it recommends the following change to the policy adopted in 1989 and requests the NCWM Committee on Education, Administration, and Consumer Affairs to reflect the change of policy, if adopted, in the EPO's and Training Module 8, Retail Motor Fuel Dispensers and Consoles.

Committee Recommendation: Amend the NCWM policy on procedures for taking samples for octane verification as follows:

A minimum of 1 liter ( 0.3 gallon) of motor fuel shall be flushed from the dispensers before taking a sample for octane verification. The flush shall be returned to the storage tank containing the lowest octane.

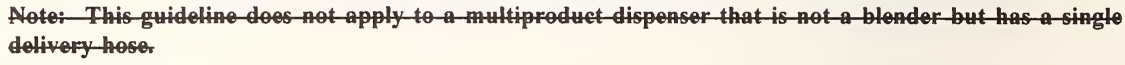

\section{8-2 I 2.6.8. Commodities Excluded From FTC Jurisdiction}

Background: The Committee believes that the information contained in Appendix B relating to commodities under Federal Trade Commission (FTC) jurisdiction under the Federal Fair Packaging and Labeling Act should be added to the Interpretations and Guidelines Section of NIST Handbook 130. This information was originally published in National Bureau of Standards Handbook 108, Weights and Measures Labeling Handbook (1971), which is now out of print and not widely available. The information can help weights and measures officials and manufacturers identify commodities subject to FTC jurisdiction and those that are only subject to State regulation.

Committee Recommendation: Add Appendix B to the Interpretations and Guidelines Section of NIST Handbook 130.

Note: This proposal was changed to an information item at the Annual Meeting because Appendix B was inadvertently omitted from the Program and Committee Report for the 78th NCWM Annual Meeting. This item will be carried over for consideration at the 79th NCWM.

\section{8-3}

\section{SI and Other Revisions to the Interpretations and Guidelines Section}

This year the L\&R Committee has been unable to revise the Interpretations and Guidelines Section to include SI units because of limited resources. The Committee's highest priority in 1993 is updating the UPLR and MSCR to reflect the SI amendments to the FPLA. The Committee intends to place this item on its agenda for 1994. Each item in the interpretations and guidelines section will be reviewed to determine if it is up to date or if it should be revised or deleted. 
NIST Handbook 133 - General

240-1 I Working Group on NIST Handbook 133

Background: The Laws and Regulations Committee, with the approval of the Executive Committee, has established a working group on NIST Handbook 133. The main objective of this working group is to develop a draft revision of NIST Handbook 133 to be considered at the 79th NCWM in July 1994. The draft will include many changes that are editorial in nature (see below) and others that are more substantive, including consideration of the adoption of the new sampling plans proposed in Item 240-2. Another objective is to address several needs recognized over the past few years, including uniform and effective protocols for establishing gray areas used to define reasonable moisture loss. Other objectives include promoting the adoption of NIST Handbook 133 by Federal agencies and establishing an ongoing mechanism to update the Maximum Allowable Variations on a permanent basis. After NIST Handbook 133 is revised, the working group will be asked to prepare draft revisions to the Package Checking Field Manual and to cooperate with the Education Committee in preparing revisions to the National Training Program's Module 10, Checking the Net Contents of Packaged Goods.

\section{Working Group on NIST Handbook 133}

Chairman Allan M. Nelson appointed Barbara J. Bloch, Assistant Chief, California Division of Measurement Standards, to serve as Chairman of the working group. Four public members have been appointed, one from each of the Regional Associations:

- Barbara J. DeSalvo, Ohio Department of Agriculture, Central Weights and Measures Association

- Ross J. Anderson, New York State Bureau of Weights and Measures, Northeastern Weights and Measures Association

- Gary T. Coleman, Maryland Department of Agriculture, Southern Weights and Measures Association

- Patrick E. Nichols, Director, Alameda County Weights and Measures, California, Western Weights and Measures Association

Participation in the working group activities is open to weights and measures officials, industry and trade representatives, Federal agencies and the public.

The tentative work plan for the working group is as follows:

\section{Editorial Revisions}

- Revise NIST Handbook 133 to include SI units as the primary unit of measure throughout the text and in all tables and examples.

- Incorporate the revisions contained in Supplements 1,2, and 3 and change the format to two columns throughout.

- Update the table of contents, index, and information contained in the appendices.

- Review and update graphics as needed and incorporate into the publication electronically. Replace drawings of testing equipment with photographs of up-to-date electronic balances as appropriate.

- Rewrite all sections to eliminate references to mechanical devices wherever appropriate. 


\section{Technical Revisions}

- Solicit comments and suggestions for technical revisions to the handbook from State and local weights and measures officials and industry.

- Solicit comments and suggestions for technical revisions to the handbook from the Food and Drug Administration; Federal Trade Commission; the U.S. Department of Agriculture; Environmental Protection Agency; Bureau of Alcohol, Tobacco and Firearms; and other Federal agencies.

- Consider the need for harmonization with other countries using OIML Recommendations. For example, Canada uses a modification of OIML Recommendation 87, Net Contents in Packages.

- Consider the proposal to combine Sampling Plans A \& B as presented in Item 240. This proposal will require the assistance of statisticians to generate the operating characteristic curves for the sampling plans suggested in this item and in OIML 87 as compared to the plans currently presented in NIST Handbook 133.

- Develop a standardized method, including test protocols and field study methods, for establishing "gray areas" for agencies using "wet tare" for products that lose moisture to the atmosphere. See the Interpretations and Guidelines section in NIST Handbook 130, page 163, 2.5.6. Guidelines for NCWM Resolution of Requests for Recognition of Moisture Loss in Packaged Products.

- Develop a standardized method, including test protocols and field study methods, for establishing "gray areas" for agencies using "wet tare" for products that lose moisture into the packaging material. See the Interpretations and Guidelines Section in NIST Handbook 130, page 163, 2.5.6. Guidelines for NCWM Resolution of Requests for Recognition of Moisture Loss in Packaged Products.

\section{Other Goals}

- Develop a plan to seek adoption or recognition of NIST Handbook 133 by those Federal agencies that regulate packaged commodities with the goal of establishing NIST 133 as the single, national standard for net content inspection procedures for the United States.

- Prepare briefing presentations on the proposed revisions to build consensus positions among the NCWM membership, industry, and other users of the handbook.

- After Handbook 133 is revised, prepare draft revisions to the Package Checking Field Manual and, in cooperation with the Education Committee, prepare revisions to the National Training Program's Module 10, Checking the Net Contents of Packaged Goods.

- Participate as part of the U.S. National Working Group assisting in developing draft revisions to International Organization of Legal Metrology (OIML) Recommendation 87, Net Contents in Packages, and Recommendation 79, Information on Package Labels. The United States assumed responsibility for the OIML Technical Committee for these Recommendations in 1992, and NCWM participation in the revision process will contribute to international harmonization of net content test procedures and package labeling requirements.

Dr. Carroll S. Brickenkamp, Chief of the Office of Weights and Measures, and Ken Butcher, Office of Weights and Measures, will serve as Technical Advisors to the NIST Handbook 133 Working Group. State Directors will automatically receive all information, draft revisions and recommendations from the working group.

\section{0-2 I Combine Sampling Plans A \& B}

Background: This was Item 240-1 in the Report of the 77th NCWM, 1992, page 149. See that Report for additional background information on this issue. The Western and Southern Weights and Measures Associations recommend adoption of the proposal to combine the two sampling plans in NIST Handbook 133 into one. The Committee received several comments supporting the proposals from weights and measures officials and industry. Several people suggested 
that the Committee harmonize NIST Handbook 133 with International Organization of Legal Metrology (OIML) Recommendation 87, Net Contents in Packages. The Committee will include consideration of the OIML Recommendation in its review of this item. Copies of this OIML Recommendation are available from the Office of Weights and Measures. The current Handbook 133 sampling plan Categories A and B were adopted by the NCWM in 1985. Category A plans utilize larger sample sizes and offer a higher degree of confidence that the lot is indeed short for samples that average less than the label declaration. Category B sampling plans utilize smaller sample sizes and offer a lesser degree of confidence. The Category B plans are predominantly used by weights and measure inspectors because they are faster and more efficient. Category B plans also force packagers to target higher than the labeled declaration on the average.

The proposal merges Category A and B sampling plans into a single table. The proposal specifies the Category B approach for smaller "retail size" lots (less than 250 packages) and switches to a Category A approach for lots with more than 250 packages. Larger sample sizes and sample correction factors are provided for situations where a higher degree of confidence is considered necessary for taking larger lots off-sale. The proposal will automatically lead the official directly into taking larger sample sizes for larger lot sizes. The merger of the two plans should result in simpler, easier to apply procedures that include the best attributes from the two plans. The proposal would add a sample size of 10 for lots with 250 packages or less. It would also add a sample size of 315 packages for lots over 50,000. For lots with more than 250 packages, the sampling plan utilizes a correction factor to ensure at least a 95 percent confidence level in the results. The correction factor must be used for large lots with a greater economic value, for which it is desirable to achieve a high degree of confidence in how well the average sample error may represent the average lot error before action is taken. According to the proposal, use of a correction factor is not recommended for sample sizes of 10 packages; however, a correction factor of 0.2719 could be included for use with the smaller sample size to provide a 95 percent confidence level. The Committee presented the proposal for review and comment by weights and measures officials, industry, and other interested parties. The Office of Weights and Measures is developing operating characteristic curves on the proposed sampling plan and the OIML Recommendation for review by the NIST 133 Working Group.

Proposed Sampling Plan for NIST Handbook 133

\begin{tabular}{|c|c|c|c|c|}
\hline 1 & 2 & 3 & 4 & 5 \\
\hline Lot Size $(N)$ & $\begin{array}{c}\text { Sample Size } \\
(n)\end{array}$ & $\begin{array}{c}\text { Minimum Tare } \\
\text { Sample Size }\end{array}$ & $\begin{array}{c}\text { Allowable } \\
\text { Number of MAV's }\end{array}$ & $\begin{array}{c}\text { Correction } \\
\text { Factor }\end{array}$ \\
\hline$\leq 10$ & $100 \%$ & 2 & $N / A$ & N/A \\
\hline $11-250$ & 10 & 2 & $N / A$ & N/A \\
\hline $251-800$ & 30 & 2 & 1 & 0.1570 \\
\hline $801-2,000$ & 50 & 5 & 2 & 0.1216 \\
\hline $2,001-5,000$ & 80 & 5 & 3 & 0.09613 \\
\hline $5,001-15,000$ & 125 & 5 & 5 & 0.07691 \\
\hline $15,001-50,000$ & 200 & 10 & 10 & 0.06080 \\
\hline$\geq 50,001$ & 315 & 10 & 0.04844 \\
\hline
\end{tabular}

\section{0-3 I Moisture Loss for Pasta}

Background: See Item 240-5 in the Report of the 75th NCWM, 1990, page 107; Item 240-4 in the Report of the 76th NCWM, 1991, page 219; and Item 240-4 in the Report of the 77th NCWM, 1992, page 154, for background. At the Interim Meeting, the National Pasta Association (NPA) submitted a proposal for NCWM adoption of a 5 percent gray area for pasta in paperboard boxes, and a 3.2 percent gray area for flexible packaging. These recommendations are based on studies conducted over a 15 -month period on several lots of pasta at retail and wholesale locations in Minnesota and New 
Jersey. The Committee reviewed the studies and requested that the NPA expand them to include several different geographic regions of the country. This will represent a nationwide sampling and will include various pasta products in different packaging materials. The Committee will use the results of the expanded study to develop a proposed gray area for these products. The Committee intends to work closely on this project with the NPA and cooperating State weights and measures programs. The Committee is coordinating a laboratory intercomparison to determine if the moisture determinations made at the point-of-pack by the pasta industry will be consistent with those made by State moisture laboratories. The initial results of laboratory intercomparison study conducted prior to the 77th NCWM Annual Meeting indicated that it is possible to reach the required level of agreement between the laboratories. Revisions made to a detailed oven-test procedure should improve the agreement of test results. The modified test methods are being evaluated in a second interlaboratory comparison be completed (but not reported) before the 78th Annual Meeting.

\section{0-4 I Moisture Loss for Rice}

Background: This was ltem 240-7 in the Report of the 76th NCWM, 1991, pages 221-222, and Item 240-5 in the Report of the 77th NCWM, 1992, page 154. The Rice Millers Association (RMA) has requested the Conference to address the moisture loss of packaged rice in a manner similar to flour, that is, to establish a gray area for packaged rice. An interlaboratory comparison on several varieties of milled rice is underway to determine if moisture contents reported by RMA members at the time of pack are equivalent to moisture contents as determined by weights and measures laboratories and the Federal Grain Inspection Service (FGIS). This equivalence is key to utilizing the NCWM gray area approach for recognizing moisture loss in foods. The Committee will work with the RMA to conduct field studies on several varieties of rice packaged in different types of packaging at wholesale and retail locations around the country. Data collected in these studies will be used in establishing recommendations for gray areas. Gray areas must be established for rice so that weights and measures officials can allow for reasonable moisture loss as required under Federal laws and regulations when testing at locations other than the point of pack.

\section{0-5 W MAV's for Polyethylene Bags}

(This item was withdrawn.)

Background: This was Item 240-5A in the Report of the 76th NCWM, 1991, page 219, and ltem 240-6 in the Report of the 77th NCWM, 1992, page 155. At the Interim Meeting for the 77th NCWM, the Committee reviewed the results of a study by the Flexible Packaging Association (FPA). The study was initiated by FPA after it notified the Committee prior to the 76th Annual Meeting that it was collecting further information on bags less than $25.4 \mu \mathrm{m}$ (1 mil) thick. The purpose of this study was to determine if existing measurement equipment is suitable for thicknesses under 1 mil ( 0.001 in) and if the MAV's specified in NIST Handbook 133 are appropriate. At the lnterim Meeting for the 78th NCWM, several manufacturers made presentations to the Committee requesting that it consider: (1) recommending an increase in MAV's for polyethylene bag thickness to 7 percent from the present 4 percent, adopted in 1989, and (2) amending the test procedures in NIST Handbook 133 to require thickness measurements to be taken diagonally across a bag instead of along the edges of a bag's length and width to recognize the changes in bag thickness that occur during the extrusion process. The Committee decided not to recommend changes at this time because: (1) there have been no comments on this item from weights and measures officials indicating that products are unable to meet the current MAV's, and (2) the Committee is still concerned about the uncertainty associated with thickness measurements below 1 mil with the micrometers generally available.

\section{0-6 I Foam Aerosol Products - Test Allowance}

Background: See Item 240-6 in the Report of the 76th NCWM, 1991, pages 220-222, and Item 240-8 in the Report of the 77th NCWM, 1992, page 155 for previous discussions on this item. At the Interim Meeting, the Committee received comments from representatives of the Gillette Company and the Chemical Specialty Manufacturers Association indicating that they would support additional testing on foam aerosol products to determine if the test allowances (Table 3-2) in NIST Handbook 133 should be retained. The Committee encourages interested industries and weights and measures jurisdictions to participate in this work by contacting the Committee's Technical Advisor on 301-975-3991. 
Background: The U.S. Department of Agriculture (USDA) requested that the NCWM develop six new gray areas for certain poultry, beef, and pork products. At the Interim Meeting, the Committee reviewed a plan to proceed in this effort in cooperation with USDA, industry, and State and local jurisdictions that would be asked to participate. The Committee has reviewed the proposed test procedures submitted by the National Broiler Council and the American Meat Institute and is drafting formal procedures to be used in the testing. The Committee plans to have final protocols developed so that field studies can begin in 1993.

The Committee determined it necessary to prioritize the studies due to limited resources. Some of the expressed concerns were: (1) the many categories of products to be tested, (2) the extensive time to test (several years for each category), and (3) the total number of packages that would have to be tested for each category. The Committee agreed to start with studies of gray areas for products which lose moisture even when tested using dry tare. This includes two of the six commodity groups being considered for gray areas. The Committee will concentrate its efforts on (1) ice-packed bulk poultry and (2) dry salami and other meat or poultry products that lose moisture to the atmosphere. This decision is based on the fact that specific gray areas are needed for these groups in all 50 States so that testing can continue on these products. Since gray areas for the remaining groups are needed only when these products are tested using wet tare, the Committee felt it necessary to concentrate its resources in the areas that will affect the most jurisdictions. The Committee urges jurisdictions normally using wet tare to test the USDA products listed in the other commodity groups (see below) using dry tare so that they can continue to test those products until resources are available to the NCWM to conduct additional studies. Jurisdictions identified as using "wet tare" (Arizona, California, Michigan, New Jersey, Oregon, Washington, and Chicago) will be asked to participate in studies related to gray areas for both "dry" and "wet" tare studies. All States will be asked to participate in the studies for the other gray areas. Jurisdictions and industry representatives interested in participating in these studies should contact the Committee's Technical Advisor.

The Committee had established the following priorities for conducting gray area studies:

\section{Priority Commodity Group}

1. Ice-packed bulk poultry
2. Meat or poultry products that lose moisture to the atmosphere
3. Cured pork products (hams, shoulders, and loins)
4. $\quad$ Cured beef products (corned beef, corned beef brisket, and tongues)
5. Raw meat products (chopped beef, ground beef, hamburger, and beef patties)
6. Ham patties, chopped ham, pressed ham, and similar products

\section{0-8 I Section 3.18. Meat and Poultry from Federally Inspected Plants}

Background: This issue relates to adoption of NIST Handbook 133 by the U.S. Department of Agriculture, Food Safety and Inspection Service (FSIS). To ensure the successful implementation of NIST Handbook 133, FSIS requests that State and local jurisdictions contact their regional offices for information relating to Federally inspected meat and poultry products and to arrange to conduct package inspections at meat and poultry plants. This would serve three purposes: (1) allow regional offices to establish working relationships with State and local weights and measures officials, (2) allow for regional office coordination of in-plant inspections with FSIS personnel responsible for the plant, and (3) provide for greater cooperation between FSIS and the jurisdiction in resolving any problems that may be identified with package weights. The Committee believes that the effectiveness of State and local inspections will be enhanced through close interagency cooperation. The Working Group on NIST Handbook 133 will review Section 3.18 to ensure that it facilitates clear communication between weights and measures and USDA officials.

\section{0-9}

\section{Joint State Petition to FDA for Exemption Under NLEA}

Background: On November 9, 1992, 47 States, the District of Columbia, the Virgin Islands, and Puerto Rico joined in filing a petition with the Food and Drug Administration (FDA) requesting that FDA grant an exemption from Federal preemption to permit the States to continue the use of NIST Handbook 133 in net content inspection programs. An 
exemption from preemption would permit State and local jurisdictions to use NIST Handbook 133 in enforcement action related to net quantity violations on foods, drugs, and cosmetics without facing the possibility that their actions would be preempted under Federal requirements. Adoption of NIST Handbook 133 as the "national standard" for quantity declarations was supported in a joint letter from the Grocery Manufacturers of America, the Food Marketing Institute, National Pasta Association, and National Food Processors Association. A response to the petition has not been received from FDA.

\section{The Petroleum Subcommittee}

Background: See Items 232 and 237 in the Report of the 77th NCWM, page 147, for background on this issue. At the 1992 Interim Meeting, the NCWM Executive Committee established the Subcommittee on Petroleum reporting to the Laws and Regulations Committee. The Subcommittee held its first meeting in November 1992 in Raleigh, North Carolina. At the 1993 Interim Meeting, Celeste Bennett, Chairperson, Motor Fuel Quality/Weights and Measures Investigation Unit Coordinator, Michigan Department of Agriculture, provided a report on the first meeting and presented the Subcommittee's work plan for 1993. A brief summary of the report is presented below.

\section{Meeting Summary}

The Subcommittee has 24 members ( 8 Public Sector, 16 Private Sector). Its members include public sector representatives from States that have fuel inspection programs, the Federal Trade Commission (FTC), and the Environmental Protection Agency (EPA). Private sector representatives include the American Society for Testing and Materials (ASTM), American Petroleum Institute (API), and others active within the petroleum industry. A representative from the consumer group Public Citizen has recently been appointed.

The first meeting allowed members to share information concerning State motor fuel laboratory and field testing capabilities, ASTM standards, the correlation between test values and fuel quality, and the changes in fuel composition expected in order to meet the latest Clean Air Act Amendments. The Subcommittee discussed existing legal requirements and laboratory tests and identified several areas where changes are needed. Presentations by several members provided background on technical subjects and organizational information. The presentations included an overview on ASTM, testing methodologies, the model motor fuel laboratory of the future, fuel quality issues from an automobile manufacturer's standpoint, and the roles of ASTM and NCWM in standards development. Another presentation was made on the implementation of the motor fuel provisions of the Federal Clean Air Act Amendments. The Subcommittee toured North Carolina's central petroleum laboratory and observed one of the State's mobile laboratories.

\section{Working Groups and Action Items}

Several working groups were established with objectives and priorities developed for each. Two working groups were formed to update (1) the uniform law and (2) the uniform regulation. Two other working groups will (3) develop laboratory recommendations and (4) develop procedures to increase safety and uniformity in field inspection activities.

Law Working Group - This working group will update and expand the Uniform Motor Fuel Inspection Law to recognize the needs of State programs in regulating and testing alternative motor fuels and petroleum products. The members of the working group are:

N. David Smith, North Carolina, Chairman

Bill Butterbaugh, National Propane Gas Association
Eric Hamilton, Florida

Jim Williams, American Petroleum Institute

Regulation Working Group - This working group will update and expand the Uniform Motor Fuel Regulation to reflect current test procedures and standards for motor fuel and petroleum products. The members of the working group are:

Ron Hayes, Missouri, Chairman

Wyn Gardner, Mobil Oil Corporation
Randy Jennings, Tennessee

Marilyn Herman, Renewable Fuels Association 
Laboratory Working Group - This working group will update the NCWM recommendations for a Basic Motor Fuel Testing Laboratory. Members of the Laboratory Working Group are:

Eric Hamilton, Florida, Chairman

Wayne Becker, Inspectorate America Corporation
Mike Steffey, New Mexico

William Scheller, Scheller \& Associates, Incorporated

The group will consider model layouts for laboratories and recommend operational program designs based on the needs of regulatory programs. The group will make recommendations relating to the efficient collection, shipping, and handling of samples and will also provide enforcement guidelines to enhance laboratory functions. Also considered for development will be guidelines on selecting test equipment that can use small sample sizes to aid in reducing collecting and shipping costs, storage space, and waste removal. The use of statistical sampling as an alternative to short cut screening methods will also be considered as a means to improve efficiency. Other topics identified for future consideration by the Laboratory Working Group included safety and chemical hygiene programs, training, and the use of private laboratories for testing. The possible certification of laboratories under programs sanctioned by, or based on, those of the International Organization for Standardization (ISO), NIST's National Voluntary Laboratory Accreditation Program (NVLAP), or other programs on the certification of quality was also identified as an area for exploration. Other topics will include the National Exchange Program (sponsored by ASTM), the need for other interlaboratory exchanges, disposal of toxic and hazardous wastes, certification of equipment, laboratory information systems and automation, preserving the chain of custody, and sample storage and retention.

Field Working Group - The Field Working Group will develop NCWM recommendations for field sampling and collection procedures, safety, enforcement, and other administrative procedures. It will also recommend guidelines on the field collection process and other issues relating to the collection of petroleum samples in the field and administrative procedures concerning their control. Members of the Field Working Group are:

\section{Barbara Bloch, California, Chairman}

Charles Gardner, Suffolk County, New York

Neil Blickman, Federal Trade Commission

Other issues include providing information on health and safety, and developing training courses, inspection manuals, and other supporting materials for field personnel. The working group was instructed to expand on the scope of its responsibilities and develop a work plan before the next meeting.

\section{Other Information}

The Subcommittee agreed that the 78th National Conference theme "Excellence through Standards" should be reflected in its work by defining the "standards" that a uniform law or regulation should accomplish:

- Protect the marketplace from fraud through realistic requirements.

- Include flexible requirements that can address new products and other issues without further changes.

- Be concise, easy to understand, and have requirements based on the latest technical information.

- Be identical to Federal laws and regulations except when exceptions are needed for special needs.

- Not be overly restrictive or stifle innovation so as to encourage technological improvements.

- Provide enforceable requirements which provide benefits that outweigh the costs.

- Be competitively neutral and recognize the difference between intentional abuse and honest mistakes.

Law and Regulation Items - The Law Working Group will consider questions such as whether the law should be expanded to incorporate gaseous products now used as engine fuels and heating fuels such as compressed natural gases and liquefied petroleum gases. The group will determine whether the law should include requirements for engine oils, other automotive fluids, and heating fuels. To achieve uniformity, the working group will refer to ASTM standards whenever such standards are available. Where ASTM standards are not available, ASTM or other standards bodies will be asked to develop them. 
The Subcommittee prepared the following list of engine fuel specifications needed to encompass new fuels and technology. It was decided not to focus upon fuel additives by themselves, but instead direct efforts on the base or finished product because the latter is what consumers buy.

$\begin{array}{ll}\text { ASTM Designation } & \text { Product Subject to Standard Specification } \\ \text { D396 } & \text { Fuel Oils } \\ \text { D910 } & \text { Aviation Gasoline } \\ \text { D975 } & \text { Diesel Fuel Oils } \\ \text { D1655 } & \text { Aviation Turbine Fuels } \\ \text { D1835 } & \text { Liquefied Petroleum Gases } \\ \text { D3699 } & \text { Kerosene } \\ \text { D4814 } & \text { Automotive Spark-Ignition Engine Fuel } \\ \text { P232 } & \text { (Proposed) M-85 (85\% methanol - 15\% gasoline) }\end{array}$

It was noted that several products for which no ASTM standards exist are now being introduced in the field. The products include E-85 (85\% ethanol-15\% gasoline), M-100 (100\% methanol), bio-diesel (ethanol and animal oils or vegetable oils), and CNG (Compressed Natural Gas). ASTM will be asked to pursue development of specifications for these products. The American Gas Association will also be contacted to determine the possibility of developing standards for CNG. Since the current Subcommittee members include fuel experts, but no lubricant experts, discussion on lubricants was postponed. At future meetings of the Subcommittee, individuals with other areas of expertise, such as lubricants, aviation gasoline, and turbine fuel, will be invited to address regulations for these products.

The Regulation Working Group will consider whether the regulations should limit the amount of water in retail storage tanks. The issue is of some concern because alcohol-blended gasoline will separate in storage with significant levels of water in the tank. This working group will also consider whether the labeling of kerosene, diesel fuel, and fuel oil at the retail dispenser, including their methods of sale, should be addressed.

The Subcommittee also discussed the need to establish a forum for NCWM participation in the development of standards and test methods in cooperation with the ASTM and other organizations. The Subcommittee is considering establishing a nucleus of public and private individuals interested in technical issues relating to engine fuels, petroleum products, and lubricants to develop standards and test methods. This issue will be pursued by generating and maintaining a mailing list to disseminate information to interested parties. The second meeting of the Subcommittee was held April 1993 in Ann Arbor, Michigan, report is available from the Office of Weights and Measures. 


\section{Other Items}

\section{0-1 I Liaison Report}

At the 77th NCWM, the Liaison Committee assigned W.H. Braun of W.H.B. Resources and Lester Barrows of the State of Missouri to work with the Laws and Regulations Committee and to serve in liaison roles for the L\&R Committee. Immediately after the Annual Meeting, Mr. Braun assumed responsibility for seeking industry participation and comments that assisted the Committee in the resolution of Item 231-2 Mechanical Pump Dispensers. Mr. Braun agreed to coordinate industry participation in the NIST Handbook 133 Working Group (See Item 240-1) and to assist in resolving the issues relating to the foam aerosol test allowance described in Item 240-6 and in addressing the moisture loss issues described in Subject Series 240 - NIST Handbook 133, in Items 240-7 Meat and Poultry Products, 240-3 Pasta, and 240-4 Rice.

F. Clem, Columbus, Ohio, Chairman

B. Bloch, California, Chairperson, NIST 133 Working Group

S. Millay, Maine

S. Rhoades, Arizona

L. Straub, Maryland

W. Braun, WHB Resources, Liaison Representative

L. Barrows, Missouri, Liaison Representative

C. Bennett, Michigan, Chairperson, Petroleum Subcommittee

E. Heffron, Michigan, Chairman, SI Working Group

G. Vinet, Legal Metrology Branch, Canada, Technical Advisor

J. Jorowski, Consumer Products Branch, Canada, Technical Advisor

K. Butcher, NIST, Technical Advisor

Committee on Laws and Regulations 


\section{Appendix A \\ Uniform Packaging and Labeling Regulation (UPLR)}

(This appendix was adopted as part of the consent calendar.)

The membership of the NCWM at the 78th Annual Meeting adopted the following revisions to the Uniform Packaging and Labeling Regulation (UPLR) in NIST Handbook 130. These recommendations do not include any additional changes that may be needed to bring the requirements into conformance with proposed regulations from the Food and Drug Administration and the Federal Trade Commission because final regulations from those agencies have not yet been published. These changes include requirements for the mandatory labeling of S1 units on consumer commodities to bring the UPLR into compliance with:

1. The 1992 amendments to the Fair Packaging and Labeling Act (FPLA), (Public Law 102-329), signed into law by President Bush on August 3, 1992; the effective date of the amendments is February 14, 1994.

The FPLA amendments require both SI and inch-pound units in net content statements [either unit may be primary, for example, Net Wt $16 \mathrm{oz}(453 \mathrm{~g})$ or Net Mass $453 \mathrm{~g}$ (16 oz)]; permit optional use of either "net mass" or "net weight" in quantity declarations; allow decimal fractions on random packages to be carried out to three places; and eliminate requirements for dual quantity declarations. SI requirements do not apply to: labels printed before February 14, 1994, foods packaged at the retail store level, random weight packages, unit pricing, advertising, recipe programs, package sizes, nutrition labeling, and general pricing information. In addition, under $\S 5(\mathrm{~b})$ of FPLA, FDA and FTC have authority to grant exemptions when compliance is impractical or not necessary for adequate protection of consumers. Agencies may also provide exemptions under $\S 1454(\mathrm{~b})$ of Chapter 39 of the United States Code, Exemption of Commodities from Regulations.

2. Anticipated changes in regulations by the Food and Drug Administration and the Federal Trade Commission under FPLA; and,

3. NIST Metric Transition Policy, issued in accordance with Executive Order 12770 of July 25, 1991, (See NIST Publication 814). NIST policy requires that SI units be used as the primary unit of measure in all its publications. The policy permits the optional use of inch-pound units in parentheses where the field of application requires use of non-S1 units.

Changes or additions are underlined or clearly marked. Deletions are presented as strike-throughs (strikethrougs). The Committee did not suggest SI units for all requirements. The NCWM must delay making recommendations on S1 units for some products until affected industries can be contacted and suggestions solicited for appropriate S1 units. The delays are justified because of the possible economic impact of the changes; lead time needed by industry to comply; the need to involve consumers, industry, and other regulatory agencies in the selection of appropriate S1 units to be required; and the need to address compliance deadlines. 


\section{Summary of Revisions - Listed by Section \\ Uniform Packaging and Labeling Regulation}

Section

Page

1. Background

Amended to include reference to the International System of Units (SI) and amendments to the Federal Fair Packaging and Labeling Act.

2. Status of Promulgation

No change

Preamble

No change

Section 1. Application

No change

Section 2. Definitions

No revisions to the current definitions are proposed. Include SI units in the examples given in Section 2. Added a footnote to explain how the terms "weight" and "mass" are presented in the regulation. Added a definition for "SI" (see 2.15.).

2.2. Consumer Package: Package of Consumer Commodity

2.3. Nonconsumer Package: Package of Nonconsumer Commodity

2.4. Random Package.

2.5. Label

2.6. Person

2.7. Principal Display Panel or Panels

2.8. Multi-Unit Package

2.9. Combination Package

2.10. Variety Package

2.11. Petroleum Products

2.12. Spot Label

2.13. Header Strip

2.14. Standard Package

Added SI examples

2.15. SI or SI Units

Added new definition and references

Section 3. Declaration of Identity: Consumer Package

No change

Section 4. Declaration of Identity: Nonconsumer Package

No change

Section 5. Declaration of Responsibility: Consumer and Nonconsumer Packages

No change

Section 6. Declaration of Quantity: Consumer Packages

6.1. General

Added a specific requirement for SI Units on Consumer Packages.

6.2. Largest Whole Unit

No change

6.3. Net Quantity

No change

6.3.1. Use of "Net Weight" 
Amended to permit optional use of "net weight" or "net mass"

6.3.2. Lines of Print or Type

No change

6.4. Terms: Weight, Liquid Measure, Dry Measure, or Count

No change

6.4.1. Combination Declaration

No change

6.5. Metric Units: Weight, Measure

Changed "Metric" to "SI." Replaced "weight" with "mass." Added § (f) "Rule of $1000 "$ for SI quantities. This section would require package quantities of less than $\mathbf{1 0 0 0}$ to be declared as numerical values between 1 and 1000, not as decimal fractions. For example, $750 \mathrm{~mm}$ or $75 \mathrm{~cm}$, not 0.75 meters; 950 grams, not $0.95 \mathrm{~kg} ; 235 \mathrm{~mL}$, not $0.23 \mathrm{~L}$. For 1000 or more, declare as kilogram, meters or liters etc. For example, 1960 grams would be declared as $1.960 \mathrm{~kg}$, and $3,785 \mathrm{~mL}$ would be declared as $3.78 \mathrm{~L}$. This paragraph will ensure uniform SI quantity declarations.

6.5.1. Symbols

Added symbols for cubic and square decimeter and micrometer.

6.5.2. Fractions and Prefixes

Added SI units, including prefixes.

6.6. Prescribed Units, Metric System

6.6.1. Less than 1 Meter, 1 Square Meter, 1 Kilogram, or 1 Liter

Changed "metric" to "SI." Replaced "weight" with "mass." Deleted Note 3

because FPLA amendments will permit labels to include quantity declarations to three decimal places. Added square decimeter to (b) for area measure. Renumbered from 6.7.1.

6.6.2. One Meter, 1 Square Meter, 1 Kilogram, 1 Liter, or More

Changed "metric" to "SI." Replaced "weight" with "mass." Deleted last sentence and reference to Note 3 because FPLA amendments will permit labels to include quantity declarations to three decimal places. Renumbered from 6.7.2. 6.6.3. Bidimensional Commodities

Renumbered from 6.7.3.

6.7. Inch-Pound Units: Weight, Measure 257

Renumbered from 6.6.

6.7.1. Symbols and Abbreviations

Added symbols to be consistent with FDA and FTC guidelines. Renumbered from 6.6.1. 6.7.2. Units of Two or More Meanings

Renumbered from 6.6.2.

6.8. Prescribed Units, Inch-Pound System

6.8.1. Less than 1 Foot, 1 Square Foot, 1 Pound, or 1 Pint

No change

6.8.2. Weight, Dual Quantity Declaration

Amended to require largest whole unit.

6.8.3. Liquid Measure: Dual Quantity Declaration

Deleted

6.8.4. Length Measure: Dual Quantity Declaration

Deleted

6.8.5. Area Measure: Dual Quantity Declaration

Deleted

6.8.6. Four Feet, 4 Square Feet, 4 Pounds, 1 Gallon, or More

Deleted

6.8.7. Bidimensional Commodities

No change except for renumbering

6.9. Count: Ply

No change

6.10. Fractions

Amended paragraph (d) to permit decimal fractions to three places. Added SI units, including prefixes. 
6.11. Supplementary Declarations

6.11.1. Supplementary Quantity Declarations 260

No change

6.11.2. Combined Metric and Inch-Pound Declarations

Deleted to conform with FPLA amendments which make SI units mandatory.

6.11.3. Rounding

The Committee recommendation clarifies that responsibility for rounding converted values on the packer who will be held accountable for the declared values. Reference added to include.

6.12. Qualification of Declaration Prohibited

No change

6.13. Character of Declaration: Average

No change

Section 7. Declaration of Quantity: Nonconsumer Packages 260

7.1. General 260

7.2. Location 260

No change

7.3. Terms: Weight, Liquid Measure, Dry Measure, or Count 260

No change

7.4. Metric Units: Weight, Measure

Replaced "metric" with "SI" and "weight" with "mass."

7.4.1. Symbols

No change

7.5. Inch-Pound Units: Weight, Measure 261

No change

7.5.1. Symbols and Abbreviations

No change

7.6. Character of Declaration: Average

No change

Section 8. Prominence and Placement: Consumer Packages 261

8.1. General

No change

8.1.1. Location

No change

$\begin{array}{ll}\text { 8.1.2. Style of Type or Lettering } & 261\end{array}$

No change

$\begin{array}{lr}\text { 8.1.3. Color Contrast } & 261\end{array}$

No change

8.1.4. Free Area

No change

8.1.5. Parallel Quantity Declaration 262

No change

8.2. Calculation of Area of Principal Display Panel for Purposes of Type Size 262

Added SI equivalents in examples.

8.2.1. Minimum Height of Numbers and Letters

Added SI equivalents to Table 1 as primary units.

8.2.2. Numbers and Letters: Proportion

No change

Section 9. Prominence and Placement: Nonconsumer Packages 263

9.1. General

No change

Section 10. Requirements: Specific Consumer Commodities, Nonconsumer Commodities, Packages, Containers

Added SI equivalents to examples 
10.1. Display Card Package

10.2. Eggs

No change

10.3. Aerosols and Similar Pressurized Containers

10.4. Multi-Unit Packages

10.5. Combination Packages

No change

10.6. Variety Packages

This section completly revised to be consistent with the Federal Trade Commission

10.7. Cylindrical Containers

This section completly revised to be consistent with the Federal Trade Commission

10.8. Measurement of Container-Type Commodities, How Expressed

10.8.1. General

No change

10.8.2. Capacity

No change

10.8.3. Terms

No change

10.9. Textile Products, Threads, and Yarns

10.9.1. Wearing Apparel

Changed to "centimeters and inches"

10.9.2. Textiles

No change

10.9.3. Textiles: Variations from Declared Dimensions

No change

10.9.4. Sewing Threads, Handicraft Threads, and Yarns

10.10. Packaged Seed

Added SI units and terms and edit for clarity.

10.11. Mulch: Variations from Declared Volume

No change

10.12. Polyethylene Products: Variations from Declared Thickness

Added SI units. The SI equivalent $(25.4$ micrometers $(25.4 \mu \mathrm{m})$ is included for 1 mil (0.001 inch);

\section{Example of Label: $20 \mathrm{ft}$ X $100 \mathrm{ft}(6.09 \mathrm{~m} \times 30.4 \mathrm{~m})$ $1 \mathrm{mil}(25.4 \mu \mathrm{m})$ \\ Net Mass $38.6 \mathrm{lb}(17.5 \mathrm{~kg})$}

10.13. Polyethylene Products: Variations from Declared Weight

11. Exemptions No change

Renumber Sections as indicated in draft document if changes adopted.

11.1. General

Deleted to conform to FPLA amendments

11.2. Random Packages

Add exemption for SI units. Delete reference to dual quantity declarations.

11.3. Small Confections

No change

11.4. Small Packages of Meat or Meat Products

No change

11.5. Individual Servings

No change

11.6. Cuts, Plugs, and Twists of Tobacco and Cigars

No change 
11.7. Reusable (Returnable) Glass Containers

No change

$\begin{array}{ll}\text { 11.8. Cigarettes and Small Cigars } & 268\end{array}$

No change

11.9. Packaged Commodities with Labeling Requirements Specified in Federal Law

Deleted reference to dual quantity declarations. At the suggestion of the

Environmental Protection Agency "pesticides" has been inserted to replace

"insecticides, fungicides, and rodenticides".

11.10. Fluid Dairy Products, Ice Cream, and Similar Frozen Desserts

Deleted exemption for dual quantity declarations in paragraph (b).

11.11. Single Strength and Less than Single Strength Fruit Juice Beverages, Imitations Thereof, and

Drinking Water

Deleted exemption for dual quantity declarations in paragraph (b).

11.12. Soft-Drink Bottles

No change

11.13. Multi-Unit Soft-Drink Packages

No change

11.14. Butter

Deleted exemption for dual quantity declarations.

11.15. Eggs

No change

11.16. Flour

Deleted exemption for dual quantity declarations.

11.17. Small Packages

Add SI units for area of principal display panel.

11.18. Decorative Containers

Add SI equivalents.

11.19. Combination and Variety Packages

No change

11.20. Margarine

Deleted exemption for dual quantity declarations.

11.21. Corn Flour and Corn Meal

No change

11.22. Prescription and Insulin-Containing Drugs

No change

11.23. Camera Film

No change

11.24. Paints and Kindred Products

Deleted exemption for dual quantity declarations and changed title to Tint Based Paints.

11.25. Automotive Cooling System Antifreeze

Deleted section because it only relates to dual quantity declarations.

11.26. Motor Oils

Amend to clarify that this exemption applies to cans and eliminate references to sizes and dual quantity declarations.

11.27. Pillows, Cushions, Comforters, Mattress Pads, Sleeping Bags, and Similar Products

No change

11.28. Commodities' Variable Weights and Sizes

No change

11.29. Packaged Commodities Sold by Count

No change

11.30. Fishing Lines and Reels

Deleted section because it relates to dual quantity declarations.

11.31. Textile Packages

No change

11.32. Spot Label

No change 
11.33. Header Strip

No change

11.34. Decorative Wallcovering Border

Deleted references to dual quantity declarations.

11.32. SI Units, Exemptions, Consumer Commodities

Added new section on exemptions to requirements for SI Units.

Section 12. Variations to Be Allowed

No changes in Section 12

Section 13. Retail Sale Price Representations

No changes in Section 13

UPLR Appendix A: SI/Inch-Pound Conversions

Added conversion factors for micrometer, grain, rod, dry pint, dry quart and peck.

UPLR Appendix B: Converting Inch-Pound Units to SI Units for Quantity Declarations on Packages 276 Added this appendix to provide guidance on converting and rounding values for quantity declarations. 


\section{Uniform Packaging and Labeling Regulation}

\section{Background}

The Uniform Packaging and Labeling Regulation was first adopted during the 37 th National Conference on Weights and Measures in 1952. Reporting to the Conference, the Committee on Legislation stated:

The National Conference should adopt a model package regulation for the guidance of those States authorized to adopt such a regulation under provisions of their weights and measures laws. Since so much of the work of weights and measures officials in the package field concerns food products, the importance of uniformity between the Federal Food and Drug Administration's regulations and any model regulations to be adopted by this Conference cannot be overemphasized.

Since its inception, the Uniform Packaging and Labeling Regulation has been continually revised to meet the complexities of an enormous expansion in the packaging industry--an expansion that, in late 1966, brought about the passage of the Fair Packaging and Labeling Act (FPLA). Recognizing the need for compatibility with the Federal Act, the Committee on Laws and Regulations of the 53rd National Conference in 1968 amended the "Model Packaging and Labeling Regulation" (renamed in 1983) to parallel regulations adopted by Federal agencies under FPLA. The process of amending and revising this Regulation is a continuing one, in order to keep it current with practices in the packaging field and make it compatible with appropriate Federal regulations. Amendments and additions since 1971 are noted at the end of each section.

The revision of 1978 provided for the use of the metric International System of Units (SI), the modernized metric system, labels for those commodities not covered by Federal laws or regulations. "SI" means the International System of Units as established in 1960 by the General Conference on Weights and Measures and interpreted or modified for the United States by the Secretary of Commerce. SSee Metric Conversion Act of 1975 (Public Law 94-168, \& 3(1) and $\S 4(4)$, and NIST Special Publication 814 - Metric System of Measurement; Interpretation of the International System of Units for the United States or Federal Register of December 20, 1990, (FR 90-21913) or subsequent revisions.] In 1988, Congress amended the
Metric Conversion Act of 1975 (see $\$ 5146$ of Public Law $\underline{100-418)}$ to declare that it is the policy of the United States to designate the International System of Units (S1) of measurement as the preferred system of weights and measures for U.S. trade and commerce. In 1992, Congress amended the Federal Fair Packaging and Labeling Act (FPLA) to require the most appropriate units of the SI metric and the customary inch-pound systems of measurement on certain consumer commodities. The 1993 amendments to N1ST Handbook 130 require SI and inchpound units on certain consumer commodities in accordance with Federal laws or regulations. Requirements for labeling in both units of measure are effective February 14, 1994, under FPLA and as specified in $\$ 15$; except as specified in $\S 11.32$. SI UNITS, EXEMPTIONS for CONSUMER COMMODITIES. SIonly labeling is not permitted on consumer commodities unless specifically required in this regulation or by Federal law or regulation.

Nothing contained in this regulation should be construed to supersede any labeling requirement specified in Federal law or to require the use of metrie SI units on nonconsumer packages.

\section{Status of Promulgation}

The table beginning on page shows the status of adoption of the Uniform Packaging and Labeling Regulation.

*The National Conference on Weights and Measures is sponsored by the National Institute of Standards and Technology in partial implementation of its statutory responsibility for "cooperation with the States in securing uniformity in weights and measures laws and methods of inspection." 


\section{Committee Recommendation Uniform Packaging and Labeling Regulation}

\section{Preamble}

The purpose of this regulation is to provide accurate and adequate information on packages as to the identity and quantity of contents so that purchasers can make price and quantity comparisons.

(Added 1989)

\section{Section 1. Application}

This regulation shall apply to packages, but shall not apply to:

(a) inner wrappings not intended to be individually sold to the customer,

(b) shipping containers or wrapping used solely for the transportation of any commodities in bulk or in quantity to manufacturers, packers, or processors, or to wholesale or retail distributors, but in no event shall this exclusion apply to packages of consumer or nonconsumer commodities, as defined herein,

(Added 1971)

(c) auxiliary containers or outer wrappings used to deliver packages of such commodities to retail customers if such containers or wrappings bear no printed matter pertaining to any particular commodity,

(d) containers used for retail tray pack displays when the container itself is not intended to be sold (e.g., the tray that is used to display individual envelopes of seasonings, gravies, etc., and the tray itself is not intended to be sold), or

(e) open carriers and transparent wrappers or carriers for containers when the wrappers or carriers do not bear any written, printed, or graphic matter obscuring the label information required by this regulation.

\section{Section 2. Definitions}

2.1. Package. -- Except as modified by $\S 1$. APPLICATION, the term "package," whether standard package or random package, means any commodity:

(a) enclosed in a container or wrapped in any manner in advance of wholesale or retail sale, or

(b) whose weight (Note I see pase 252) or measure has been determined in advance of wholesale or retail sale.
An individual item or lot of any commodity on which there is marked a selling price based on an established price per unit of weight or of measure shall be considered a package or packages.

(Amended 1988, 1991)

NOTE 1: When used in this regulation, the term "weight" means "mass." (See paragraph H. in Section I. Introduction to NIST Handbook I 30 for an explanation of these terms.)

\subsection{Consumer Package: Package of} Consumer Commodity. -- A package that is customarily produced or distributed for sale through retail sales agencies or instrumentalities for consumption or use by individuals for the purposes of personal care or in the performance of services ordinarily rendered in or about the household or in connection with personal possessions.

(Amended 1988, 1991)

2.3. Nonconsumer Package: Package of Nonconsumer Commodity. -- Any package other than a consumer package, and particularly a package intended solely for industrial or institutional use or for wholesale distribution.

(Amended 1988, 1991)

2.4. Random Package. -- A package that is one of a lot, shipment, or delivery of packages of the same consumer commodity with no fixed pattern of net contents.

(Amended 1988, 1990)

2.5. Label. -- Any written, printed, or graphic matter affixed to, applied to, attached to, blown into, formed, molded into, embossed on, or appearing upon or adjacent to a consumer commodity or a package containing any consumer commodity, for purposes of branding, identifying, or giving any information with respect to the commodity or to the contents of the package, except that an inspector's tag or other nonpromotional matter affixed to or appearing upon a consumer commodity shall not be considered a label requiring the repetition of label information required by this regulation.

(Amended 1988)

2.6. Person. -- The term "person" means either singular or plural, and shall include any individual, partnership, company, corporation, association, and society.

(Amended 1988) 
2.7. Principal Display Panel or Panels. -- That part, or those parts, of a label that is, or are, so designed as to most likely be displayed, presented, shown, or examined under normal and customary conditions of display and purchase. Wherever a principal display panel appears more than once on a package, all requirements pertaining to the "principal display panel" shall pertain to all such "principal display panels."

(Amended 1988)

2.8. Multi-Unit Package. -- A package containing two or more individual packages of the same commodity, in the same quantity, intended to be sold as a multi-unit package, but where the component packages are labeled individually in full compliance with all requirements of this regulation.

(Amended 1988)

2.9. Combination Package. -- A package intended for retail sale, containing two or more individual packages or units of dissimilar commodities. (Examples: an antiquing or housecleaning kit; sponge and cleaner; lighter fluid and flints.)

(Added 1989)

2.10. Variety Package. -- A package intended for retail sale, containing two or more individual packages or units of similar, but not identical, commodities. Commodities that are generically the same, but that differ in weight, measure, volume, appearance, or quality, are considered similar but not identical. (Examples: 2 sponges of different sizes; plastic tableware, consisting of 4 spoons, 4 knives, and 4 forks.)

(Added 1989)

2.11. Petroleum Products. - Gasoline, diesel fuel, kerosene, or any product (whether or not such a product is actually derived from naturally occurring hydrocarbon mixtures known as "petroleum") commonly used in powering, lubricating, or idling engines or other devices, or is labeled as fuel to power camping stoves or lights. Therefore, sewing machine lubricant, camping fuels, and synthetic motor oil are "petroleum products" for the purposes of this regulation. Brake fluid, copier machine dispersant, antifreeze, cleaning solvents, and alcohol are not "petroleum products."

(Added 1987; Amended 1988)

2.12. Spot Label. -- A spot label is a label, clearly defined by means of a border, indentation, or other means, that covers only a small portion of the surface of a principal display panel of a package; the entire portion of the principal display panel outside the area of the label contains no printed or graphic matter of any kind. A spot label may contain all required labeling information (identity, responsibility, and net contents), but it must at least indicate the identity and net contents. See $\$ 11.29$ 32. for net contents placement exemption for a spot label. Also see figure 1, page 253.

(Added 1990; Amended 1991)

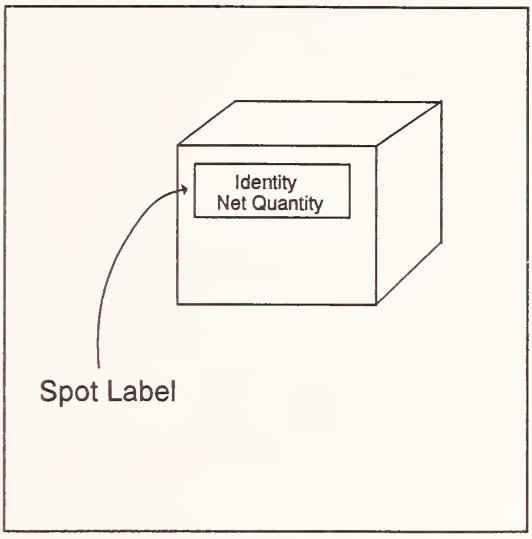

Figure 1.

2.13. Header Strip. -- A header label or header strip is a label that is attached across the top of a transparent or opaque bag or other container that bears no other printed or graphic material. See $\S 11.30$ 33. for net contents placement exemptions. Also see figure 2, page 254 .

(Added 1990)

2.14. Standard Package. -- A package that is one of a lot, shipment, or delivery of packages of the same commodity with identical net contents declarations; for example, I-liter bottles or $12 \mathrm{fl} \mathrm{oz}$ cans of carbonated soda, $500 \mathrm{~g}$ or $5 \mathrm{lb}$ bags of sugar or $100 \mathrm{~m}$ or $300 \mathrm{ft}$ packages of rope.

(Added 1991)

2.15. SI or SI Units. -- "SI" or "SI Units" means the International System of Units as established in 1960 by the General Conference on Weights and Measures and interpreted or modified for the United States by the Secretary of Commerce. [See Metric Conversion Act of 1975 (Public Law 94-168, \& 3(1) and \& 4(4), and NIST Special Publication 814 - Metric System of Measurement; Interpretation of the International System of Units for the United States or Federal Register of December 20, 1990 (FR 90-21913)]. (Added 1993) 


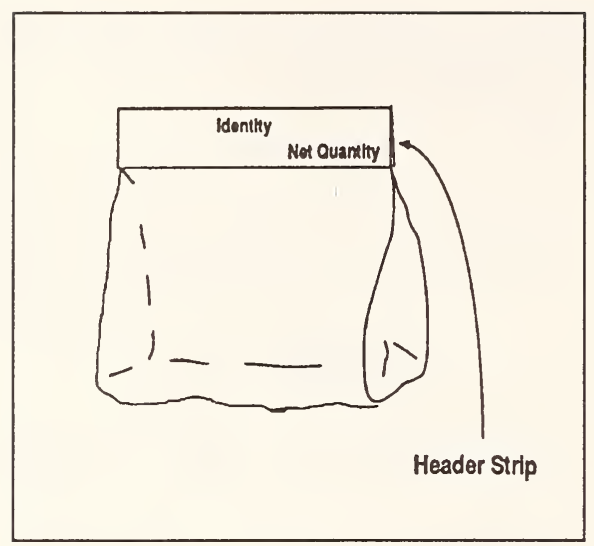

Figure 2.

\section{Section 3. Declaration of Identity: Consumer Package}

\subsection{Declaration of Identity: Consumer} Package. -- A separate declaration of identity ${ }^{\text {[NOTE 2, see }}$ page ${ }^{254]}$ on a consumer package shall appear on the principal display panel and shall not be misleading or deceptive. The identity shall be in terms of:

(a) the name specified in or required by any applicable Federal or State law or regulation or, in the absence of this,

(b) the common or usual name or, in the absence of this,

(c) the generic name or other appropriate description, including a statement of function (such as "cleaning powder").

(Amended 1990; Footnote added 1986)

NOTE 2: Section 19.(a) of the Uniform Weights and Measures Law (and 2I CFR 101.100 (b) (3) for non-meat and non-poultry foods) specifically exempts packages from identity statements if the identity of the commodity "can easily be identified through the wrapper or container." (Added 1986)

\subsubsection{Parallel Identity Declaration:}

Consumer Package. -- A declaration of the identity on a consumer package shall appear generally parallel to the base on which the package rests as it is designed to be displayed.

\section{Section 4. Declaration of Identity: Nonconsumer Package}

A declaration of identity ${ }^{\text {NOTE } 2 \text {, see page 254] }}$ on a nonconsumer package shall appear on the outside of a package and shall not be misleading or deceptive. The identity shall be in terms of:

(a) the name specified in or required by any applicable Federal or State law or regulation or, in the absence of this,

(b) the common or usual name or, in the absence of this,

(c) the generic name or other appropriate description, including a statement of function (such as "cleaning powder").

(Amended 1990, Note added 1986)

\section{Section 5. Declaration of Responsibility: Consumer and Nonconsumer Packages}

Any package kept, offered, or exposed for sale, or sold, at any place other than on the premises where packed shall specify conspicuously on the label of the package the name and address of the manufacturer, packer, or distributor. The name shall be the actual corporate name, or, when not incorporated, the name under which the business is conducted. The address shall include street address, city, State, and ZIP Code; however, the street address may be omitted if this is shown in a current city directory or telephone directory.

If a person manufactures, packs, or distributes a commodity at a place other than his principal place of business, the label may state the principal place of business in lieu of the actual place where the commodity was manufactured or packed or is to be distributed, unless such statement would be misleading. Where the commodity is not manufactured by the person whose name appears on the label, the name shall be qualified by a phrase that reveals the connection such person has with such commodity, such as "Manufactured for and packed by ___ "Distributed by ___ or any other wording of similar import that expresses the facts.

\section{Section 6. Declaration of Quantity: Consumer Packages}

6.1. General. [NOTE 3, See page 255] -. The International System of Units (SI), known as the modernized metric system and the inch-pound systems of weights and measures are recognized as proper systems to be used in the declaration of quantity. Effective February 14, 1994, the most appropriate units of both systems shall be presented in a declaration of quantity except as specified 
in $\$ 11.32$. SI UNITS, EXEMPTIONS for CONSUMER COMMODITIES.

(Amended 1985, 1990, 1993)

NOTE 3: Packages subject to this Section and /or the Federal Fair Packaging and Labeling Act shall be labeled in units of the International System of Units (SI) and the inch-pound system of measure effective February 14, 1994, (except for camera film and seed, and as specified in \$ 11.32. SI UNITS, EXEMPTIONS for CONSUMER COMMODITIES). SI units may

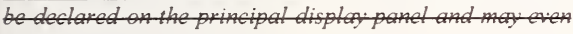
appear first.

(Added 1982; Amended 1990, 1993)

6.2. Largest Whole Unit. -- Where this regulation requires that the quantity declaration be in terms of the largest whole unit, the declaration shall, with respect to a particular package, be in terms of the largest whole unit of weight or measure, with any remainder expressed (following the requirements of $\$ 6.5 .2$. and $\$ 6.10$. Fractions):

(a) SI Hetrie Units, in decimal fractions of such largest whole unit.

\section{(b) Inch-Pound Units}

(1) in common or decimal fractions of such largest whole unit, or in

(2) the next smaller whole unit, or units, with any further remainder in terms of common or decimal fractions of the smallest unit present in the quantity declaration.

6.3. Net Quantity. -- A declaration of net quantity of the commodity in the package, exclusive of wrappers and any other material packed with such commodity (except as noted in $\S 10.3$.), shall appear on the principal display panel of a consumer package and, unless otherwise specified in this regulation (see $\S 6.6$. through 6.8.3.3.), shall be in terms of the largest whole unit.

6.3.1. Use of "Net Mass" or "Net Weight." -A quantity declaration may stand alone [e.g. "200 g $(7 \mathrm{oz})$ " or "1 $\mathrm{lb}(453 \mathrm{~g})$ "] or may include the term "net mass" or "net weight" either preceding or following the declaration. However, the quantity of contents shall always declare the net quantity of contents, even when such terms are not used.

(Amended 1993)

6.3.2. Lines of Print or Type. -- A declaration of quantity may appear on one or more lines of print or type. (Amended 1982)

\subsection{Terms: Weight, Liquid Measure, Dry}

Measure, or Count. -- The declaration of the quantity of a particular commodity shall be expressed in terms of:

- weight if the commodity is solid, semisolid, viscous, or a mixture of solid and liquid, or

- liquid measure if the commodity is liquid, or

- dry measure if the commodity is dry, or

- numerical count.

However, if there exists a firmly established general consumer usage and trade custom with respect to the terms used in expressing a declaration of quantity of a particular commodity, such a declaration of quantity may be expressed in its traditional terms, provided such traditional declaration gives accurate and adequate information as to the quantity of the commodity. Any net contents statement that does not permit price and quantity comparisons is forbidden.

(Amended 1989)

\subsubsection{Combination Declaration. --}

(a) A declaration of quantity in terms of weight shall be combined with appropriate declarations of the measure, count, and size of the individual units unless a declaration of weight alone is fully informative.

(b) A declaration of quantity in terms of measure shall be combined with appropriate declarations of the weight, count, and size of the individual units unless a declaration of measure alone is fully informative.

(c) A declaration of quantity in terms of count shall be combined with appropriate declarations of the weight, measure, and size of the individual units unless a declaration of count alone is fully informative.

(Added 1971)

6.5. SI Metrie Units: Mass, Weight, Measure $^{[\mathrm{NOTE}}$ 3, see page 255] -- A declaration of quantity:

(a) in units of mass shall be in terms of the kilogram, gram, or milligram;

(b) in units of liquid measure shall be in terms of the liter or milliliter, and shall express the volume at $20^{\circ} \mathrm{C}$, except in the case of petroleum products or distilled spirits, for which the declaration shall express the volume at $15{ }^{\circ} \mathrm{C}$, and except also in the case of a commodity that is normally sold and consumed while frozen, for which the declaration shall express the volume at the frozen tempera- 
ture, and except also in the case of malt beverages or a commodity that must be maintained in the refrigerated state, for which the declaration shall express the volume at $4{ }^{\circ} \mathrm{C}$;

(Amended 1985, 1990)

(c) in units of linear measure shall be in terms of the meter, centimeter, or millimeter;

(d) in units of area measure, shall be in terms of the square meter, square centimeter, or square millimeter;

(e) in units of volume other than liquid measure, shall be in terms of the liter and milliliter, except that the terms cubic meter and cubic centimeter will be used only when specifically designated as a method of sale.

(f) Rule of 1000. -- The selected multiple or submultiple prefixes for SI units shall result in numerical values between 1 and 1000 . This rule allows centimeters or millimeters to be used where a length declaration is less than 100 centimeters. For example: $500 \mathrm{~g}$ not $0.5 \mathrm{~kg} ; 1.96$ $\mathrm{kg}$ not $1960 \mathrm{~g}$; or $750 \mathrm{~mL}$, not $0.75 \mathrm{~L}$, or, $750 \mathrm{~mm}$ or 75 $\mathrm{cm}$, not 0.75 meters;

(Added 1993)

6.5.1. Symbols. -- Any of the following symbols for SI metric units, and none other, may be employed in the quantity statement on a package of commodity:

$\begin{array}{lllr}\text { centimeter } & \mathrm{cm} & \text { cubic meter } & \mathrm{m}^{3} \\ \text { cubic centimeter } & \mathrm{cm}^{3} & \text { kilogram } & \mathrm{kg} \\ \text { meter } & \mathrm{m} & \text { gram } & \mathrm{g} \\ \text { milligram } & \mathrm{mg} & \text { millimeter } & \mathrm{mm} \\ \text { liter } & \mathrm{L} \text { or l } & \text { square meter } & \mathrm{m}^{2} \\ \text { milliliter } & \mathrm{mL} \mathrm{or} \mathrm{ml} & \underline{\text { cubic decimeter }} & \underline{\mathrm{dm}^{3}} \\ \begin{array}{l}\text { square centimeter } \\ \text { micrometer }\end{array} & \underline{\mathrm{cm}^{2}} & \underline{\text { square decimeter }} & \underline{\mathrm{dm}^{2}} \\ & & & \end{array}$

(a) Symbols, except for liter, are not capitalized unless the unit is derived from a proper name. Periods should not be used after the symbol. Symbols are always written in the singular form--do not add "s" to express the plural when the symbol is used.

(b) The "L" symbol and the " $\mathrm{mL}$ " symbol are preferred; however, the "l" symbol for liter and "ml" symbol for milliliter are permitted.

(Amended 1980, 1993)

\subsubsection{Fractions and Prefixes ..}

(a) Fractions Metrie: An metric SI statement in a declaration of net quantity of contents of any consumer commodity may contain only decimal fractions. (b) Prefixes: the following chart indicates SI prefixes that may be used on a broad range of consumer commodity labels to form multiples and submultiples of SI units:

\begin{tabular}{|c|c|c|}
\hline$\underline{\text { Prefix }}$ & Symbol & Multiplying Factor* \\
\hline kilo- & k & $\times 10^{3}$ \\
\hline$\overline{\text { deci- }}$ & $\overline{\mathrm{d}}$ & $\times 10^{-1}$ \\
\hline centi- & $\underline{\mathrm{c}}$ & $\times 10^{-2}$ \\
\hline milli- & $\underline{\mathrm{m}}$ & $\times 10^{-3}$ \\
\hline micro- & $\underline{\mu}$ & $\times 10^{-6}$ \\
\hline
\end{tabular}

Thus, $2 \mathrm{~kg}=2 \times 1000 \mathrm{~g}=2000 \mathrm{~g}$ and $3 \mathrm{~cm}=3 \times 0.01 \mathrm{~m}$ $=0.03 \mathrm{~m}$

(Amended 1993)

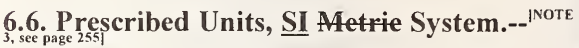

\subsubsection{Less than 1 Meter, 1 Square Meter, 1}

Kilogram, or 1 Liter. - The declaration of quantity shall be expressed in terms of:

(a) in the case of length measure of less than 1 meter, centimeters or millimeters;

(Amended 1979)

(b) in the case of area measure of less than I square meter, square decimeters and decimal fractions of a square decimeter, square centimeters and decimal fractions of a square centimeter;

(c) in the case of weight mass of less than 1 kilogram, grams and decimal fractions of a gram, but if less than 1 gram, then in milligrams;

(d) in the case of liquid or dry measure of less than 1 liter, milliliters;

provided, the quantity declaration appearing on a random weight mass package may be expressed in terms of decimal fractions of the largest appropriate unit, the fraction being carried out to not more than three $\mathrm{NOIE} 4$ seepaye 256 decimal places.

(Amended 1980, 1993)

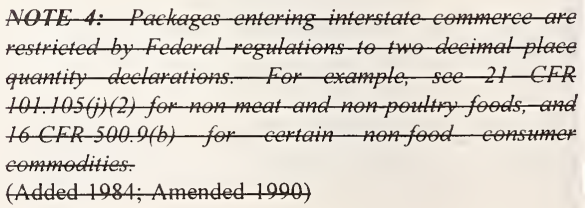

NOTE 4: Packages entering interste comere are restried by Federal regutans to two decinal place quantily dectations. For exple, see 21 CFR

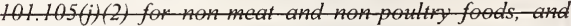
16 CFR 500.9 (b) for certain non fool consume* (Added 1984; Amended 1990) 
6.6.2. One Meter, 1 Square Meter, 1 Kilogram, 1 Liter, or More. --In the case of:

(a) length measure of 1 meter or more; in meters and decimal fractions to not more than three places;

(b) area measure of 1 square meter or more; in square meters and decimal fractions to not more than three two places;

(c) mass of 1 kilogram or more; in kilograms and decimal fractions to not more than three places;

(d) liquid or dry measure of 1 liter or more; in liters and decimal fractions to not more than three places:proded the quantity declafation appearing on a randem weight-package may be expressed in tems of kilograms and-decimal fractions carried out to not more than three (Note-4- see page 256) decimal places.

(Added 1986, Amended 1993)

6.6.3. Bidimensional Commodities. -- For bidimensional commodities (including roll-type commodities) the quantity declaration shall be expressed:

(a) if less than 1 square meter in terms of length and width;

(b) if 1 square meter or more, in terms of square measure followed in parentheses by a declaration of length and width, provided:

(1) quantity declarations on bidimensional commodities with a width of 100 millimeters or less may be expressed in terms of width and length, only;

(2) commodities consisting of usable individual units (except roll-type commodities with individual usable units created by perforations, for which see $\S 6.9$. Count: Ply.) require a declaration of unit area but not a declaration of total area of all such units;

(3) no declaration in square units is required for commodities for which the length and width measurements are critical in terms of end use (such as tablecloths or bedsheets) if such commodities clearly present the length and width measurements on the label.

\subsection{Inch-Pound Units: Weight, Measure. -- A declaration of quantity:}

(a) in units of weight, shall be in terms of the avoirdupois pound or ounce; (b) in units of liquid measure, shall be in terms of the United States gallon of 231 cubic inches or liquid-quart, liquid-pint, or fluid-ounce subdivisions of the gallon, and shall express the volume at $68^{\circ} \mathrm{F}$ except in the case of petroleum products and distilled spirits, for which the declaration shall express the volume at $60^{\circ} \mathrm{F}$, and except also in the case of a commodity that is normally sold and consumed while frozen, for which the declaration shall express the volume at the frozen temperature, and except also in the case of a commodity that must be maintained in the refrigerated state, for which the declaration shall express the volume at $40^{\circ} \mathrm{F}$, and except also in the case of malt beverages, for which the declaration shall express the volume at $39.1^{\circ} \mathrm{F}$;

(Amended 1985, 1990)

(c) in units of linear measure, shall be in terms of the yard, foot, or inch;

(d) in units of area measure, shall be in terms of the square yard, square foot, or square inch;

(e) in units of volume measure, shall be in terms of the cubic yard, cubic foot, or cubic inch;

(f) in units of dry measure, shall be in terms of the United States bushel of 2,150.42 cubic inches, or peck, dry-quart, and dry-pint subdivisions of the bushel.

6.7.1. Symbols and Abbreviations. -- Any of the following symbols and abbreviations, and none other, shall be employed in the quantity statement on a package of commodity:

$\begin{array}{llll}\text { avoirdupois } & \text { avdp } & \text { ounce } & \text { oz } \\ \text { piece } & \mathrm{pc} & \text { count } & \mathrm{ct} \\ \text { pint } & \mathrm{pt} & \text { cubic } & \mathrm{cu} \\ \text { pound } & \mathrm{lb} & \text { each } & \text { ea } \\ \text { feet or foot } & \mathrm{ft} & \text { quart } & \mathrm{qt} \\ \text { fluid } & \mathrm{fl} & \text { square } & \mathrm{sq} \\ \text { gallon } & \text { gal } & \text { weight } & \text { wt } \\ \text { inch } & \text { in } & \text { yard } & \text { yd } \\ \text { liquid } & \text { liq } & \text { drained } & \underline{\mathrm{dr}} \\ \text { diameter } & \text { dia } & & \end{array}$

(There normally are no periods following, nor plural forms of, symbols. For example, "oz" is the symbol for both "ounce" and "ounces." Both upper and lower case letters are acceptable.)

(Added 1974; Amended 1980, 1990)

6.7.2. Units of Two or More Meanings. -- When the term "ounce" is employed in a declaration of liquid quantity, the declaration shall identify the particular meaning of the term by the use of the term "fluid"; however, such distinction may be omitted when, by as- 
sociation of terms (for example, as in "1 pint 4 ounces"), the proper meaning is obvious. Whenever the declaration of quantity is in terms of the dry pint or dry quart, the declaration shall include the word "dry."

(Amended 1982)

\subsection{Prescribed Units, Inch-Pound System.}

\subsubsection{Less than 1 Foot, 1 Square Foot, 1} Pound, or 1 Pint. -- The declaration of quantity shall be expressed in terms of:

(a) in the case of length measure of less than 1 foot, in inches and fractions of inches;

(b) in the case of area measure of less than 1 square foot, in square inches and fractions of square inches;

(c) in the case of weight of less than 1 pound, in ounces and fractions of ounces;

(d) in the case of liquid measure of less than 1 pint, in fluid ounces and fractions of fluid ounces,

provided, the quantity declaration appearing on a random package may be expressed in terms of decimal fractions of the largest appropriate unit, the fraction being carried out to not more than three [NOTE 4, see page 256] decimal places.

(Amended 1984)

\subsubsection{Foot, 1 Square Foot, 1 Pound, 1 Pint,} 1 Gallon or More. - - The declaration of quantity shall be expressed: (see 6.2. Largest Whole Unit and 6.10. Fractions)

(a) Linear Measure. -- If 1 foot or more, expressed in terms of the largest whole unit with the remainder expressed in inches, or fractions of the inch, foot or yard.

\section{(b) Area Measure. --}

(i) If 1 square foot or more, but less than 4 square feet, expressed in square feet with the remainder expressed in square inches and fractions of a square inch or square $\underline{\text { foot; }}$

(ii) If 4 square feet or more, expressed in terms of the largest whole unit, with the remainder expressed in square inches and fractions of a square inch or square foot;

(c) Weight. -- If 1 pound or more, expressed in terms of the largest whole unit with the remainder expressed in ounces and fractions of an ounce or pound.

(d) Liquid Volume. -- (i) If 1 pint or more, but less than 1 gallon, expressed in the largest whole unit (quarts, quarts and pints, or pints, as appropriate) with the remainder expressed in ounces, or fractions of the pint or quart, (except that 2 quarts may be declared as one-half gallon); or,

(ii) If 1 gallon or more, expressed in terms of the largest whole unit (gallons followed by fractions of a gallon, or by the next smaller whole unit or units, for example, quarts and pints) with any remainder expressed in ounces, or fractions of the pint or quart.

(e) Dry Measure. - If 1 dry pint or more, expressed in terms of the largest whole unit with the remainder expressed in fractions of dry pints, dry quarts, pecks, or bushels,

provided, that quantity declarations may include dual quantity declarations, and the quantity declaration appearing on a random package may be expressed in decimal fractions of the largest appropriate unit, the fraction being carried out to not more than three decimal places. (Amended 1993)

\subsubsection{Weight:-Dual-Quantity-Deelaration.} On packages-containing 1 pound-or more but-less than 4 pounds, the declaration shall beexpressed in ounces and, in addition, shall be followed by a-declaration in parentheses, expressed in terms of the largest whole unit, prod the quantity declaration appearing on a random package may beexpressed in terms of pounds and docimat fractions of the pound carried-out to not more than three [NOTE 4, see page 256]-decimat places.

(Amended 1984)

\subsection{3.-Liquid Measure: Dual-Quantity Dee-} laration.-On packages containing 1 pint or more, but less-than-1-gallen, the-dectaration-shall be expressed in fluid ounces and, in addition, shall be followed by a dectaration in parentheses, expressed in terms of the largest whole unit.

\subsection{4--Length-Measure:-Dual-Quantity-Dee- laration.-On packages containing 1 foot or more, but tes than 4 feet, the declafation shall be expressed in inches and, in addition, shall be followed by a declaration in parentheses, expressed in terms of the lafgest whole unit.}

\footnotetext{
6.8.5.-Area-Aeastre:-DuatQuantity-Decharation.-On packages containing 1-square foot or more but tess than 4 square-foet, the declafation shall be-expressed in-square inches and, in addition, shall be followed by a declaration in parentheses, expressed in terms of the targest whole unit.
} 


\subsection{6.-Four Feet, 4-Square-Feet,4-Pounds,-1 Gallom,or-Hore. - In the}

(a) length-mestre-of 4 feet or more, thedaration-of quantity shall bo expressed in toms of feot, followed-in paresthes by a-doclaration of yads-and-common-of docimal fractions of the yard, of in tems of feet followed in parentheses by a-declaration-of yards with - any remainder in tems of foet and inches. In the-case-of:

\section{(b) -area-mesure-of 4 -square feet-or more;}

(e) woight-of 4 pounds-or-more;

(d) liquid mofure of 1 gallen-ormore

the-dectaration of quantity shall bo expressed-in-tems-of the-largest whelounit.

6.8.3.7. Bidimensional Commodities. -- For bidimensional commodities (including roll-type commodities) the quantity declaration shall be expressed,

(a) if less than 1 square foot, in terms of length and width in linear inches and fractions of linear inches;

(b) if at least 1 square foot but less than 4 square feet), in terms of square inches followed in parentheses by a declaration of both the length and width, each being in terms of the largest whole unit, provided:

(1) no square inch declaration is required for a bidimensional commodity of 4 inches width or less,

(2) a dimension of less than 2 feet may be stated in inches within the parenthetical declaration, and

(3) commodities consisting of usable individual units (except roll-type commodities with individual usable units created by perforations, for which see $\S 6.9$. Count: Ply.) require a declaration of unit area but not a declaration of total area of all such units;

(c) if 4 square feet or more, in terms of square feet followed in parentheses by a declaration of the length and width in terms of the largest whole unit, provided:

(1) no declaration in square feet is required for a bidimensional commodity with a width of 4 inches or less,

(2) bidimensional commodities, with a width of 4 inches or less, shall have the width first followed by the length expressed in inches followed by a statement in parentheses of the length in the largest whole unit. [Example: 2 in $\times 360$ in (10 yd)], (Added 1972)

(3) a dimension of less than 2 feet may be stated in inches within the parenthetical declaration, and

(d) no declaration in square units is required for commodities for which the length and width measurements are critical in terms of end use (such as tablecloths or bedsheets) if such commodities clearly present the length and width measurements on the label.

6.9. Count: Ply. -- If the commodity is in individually usable units of one or more components or plies, the quantity declaration shall, in addition to complying with other applicable quantity declaration requirements of this regulation, include the number of plies and total number of usable units. Roll-type commodities, when perforated so as to identify individual usable units, shall not be deemed to be made up of usable units; however, such roll-type commodities shall be labeled in terms of:

(a) total area measurement,

(b) number of plies,

(c) count of usable units, and

(d) dimensions of a single usable unit. (Amended 1988)

\subsection{Fractions}

(a) Inch-Pound: An inch-pound statement of net quantity of contents of any consumer commodity may contain common or decimal fractions. A common fraction shall be in terms of halves, quarters, eighths, sixteenths, or thirty-seconds, except that:

(1) if there exists a firmly established general consumer usage and trade custom of employing different common fractions in the net quantity declaration of a particular commodity, they may be employed, and

(2) if linear measurements are required in terms of yards or feet, common fractions may be in terms of thirds.

(b) (e) Common fractions: A common fraction shall be reduced to its lowest term (Example: 2/4 becomes $1 / 2$ ).

(c) (d) Decimal fractions: A decimal fraction shall not be carried out to more than three places.-exept 
that the quantity declaration appearing on a-random package may be carried out to not more than three pare 4 see page 256]-decimal places.

(Amended 1986, Amended 1993)

\subsection{Supplementary Declarations. --}

\subsubsection{Supplementary Quantity Declarations.}

-- The required quantity declaration may be supplemented by one or more declarations of weight, measure, or count, such declaration appearing other than on a principal display panel. Such supplemental statement of quantity of contents shall not include any term qualifying a unit of weight, measure, or count that tends to exaggerate the amount of commodity contained in the package (e.g., "giant" quart, "larger" liter, "full" gallon, "when packed," "minimum," or words of similar import).

\subsubsection{Combined Metrie and Ineh-Pound}

Beetarations-... An-equivatent statement-of the-net quantity of contents in terms of either the metric or inch pound system is not regarded as a supplemental statement and such-statement may atso appear on the principat display panel, prod it-conforms to both- \& 6.5. and $\$ 6.6$.

6.11.3. Rounding._. In all conversions for the pupose-of showing-an-equivatent metric-or inch-pound quantity to a rounded inch-pound or metric-quantity,-or in calculated values to be declared-in the net-quantity statement, the number of significant-digits retained must be such that accuracy is neither sacrificed nor-exagerated. (Amended 1991)

6.11.2. Rounding. -- In all conversions for the purpose of showing an equivalent Sl or inch-pound quantity to a rounded inch-pound or SI quantity, or in calculated values to be declared in the net quantity statement, the number of significant digits retained must be such that accuracy is neither sacrificed nor exaggerated. Conversions, the proper use of significant digits, and rounding must be based on the packer's knowledge of the accuracy of the original measurement that is being converted. In no case shall rounded net contents declarations overstate a quantity; the packer may round converted values down to avoid overstating the net contents. (Amended 1993)

\subsection{Qualification of Declaration Prohibited.}

-- In no case shall any declaration of quantity be qualified by the addition of the words "when packed," "minimum," or "not less than," or any words of similar import, nor shall any unit of weight, measure, or count be qualified by any term (such as "jumbo," "giant," "full," or the like) that tends to exaggerate the amount of commodity.
6.13. Character of Declaration: Average. -The average quantity of contents in the packages of a particular lot, shipment, or delivery shall at least equal the declared quantity, and no unreasonable shortage in any package shall be permitted, even though overages in other packages in the same shipment, delivery, or lot compensate for such shortage. (Added 1981)

\section{Section 7. Declaration of Quantity: Nonconsumer Packages}

7.1. General. -- The SI and inch-pound systems of weights and measures are recognized as proper systems to be used in the declaration of quantity. Units of both systems may be combined in a dual declaration of quantity. [NOTE 5, see page 260]

NOTE 5: Although nonconsumer packages under this Regulation may bear SI declarations only, this Regulation should not be construed to supersede any labeling requirement specified in Federal law.

7.2. Location. -- A nonconsumer package shall bear on the outside a declaration of the net quantity of contents. Such declaration shall be in terms of the largest whole unit (see § 6.2. Largest Whole Unit).

\subsection{Terms: Weight, Liquid Measure, Dry} Measure, or Count. -- The declaration of the quantity of a particular commodity shall be expressed in terms of liquid measure if the commodity is liquid, or in terms of dry measure if the commodity is dry, or in terms of weight if the commodity is solid, semisolid, viscous, or a mixture of solid and liquid, or in terms of numerical count. However, if there exists a firmly established general consumer usage and trade custom with respect to the terms used in expressing a declaration of quantity of a particular commodity, such declaration of quantity may be expressed in its traditional terms, if such traditional declaration gives accurate and adequate information as to the quantity of the commodity.

\subsection{SI Metrie Units: Mass Weight, Measure. -- A declaration of quantity:}

(a) in units of mass shall be in terms of the kilogram, gram, or milligram;

(b) in units of liquid measure, shall be in terms of the liter or milliliter, and shall express the volume at $20^{\circ} \mathrm{C}$, except in the case of petroleum products or distilled spirits, for which the declaration shall express the volume at $15{ }^{\circ} \mathrm{C}$, and except also in the case of a commodity that is normally sold and consumed while frozen, for which the declaration shall express the volume at the frozen 
temperature, and except also in the case of malt beverages pr a commodity that is normally sold in the refrigerated state, for which the declaration shall express the volume at $4{ }^{\circ} \mathrm{C}$;

(Amended 1985)

(c) in units of linear measure, shall be in terms of the meter, centimeter, or millimeter;

(d) in units of area measure, shall be in terms of the square meter or square centimeter;

(e) in units of volume other than liquid measure, shall be in terms of the liter and milliliter, except that the terms cubic meter and cubic centimeter will be used only when specifically designated as a method of sale.

7.4.1. Symbols. -- Only those symbols as detailed in § 6.5.1. Symbols, and none other, may be employed in the quantity statement on a package of commodity

\subsection{Inch-Pound Units: Weight, Measure.-- A} declaration of quantity:

(a) in units of weight, shall be in terms of the avoirdupois pound or ounce;

(b) in units of liquid measure, shall be in terms of the United States gallon of 231 cubic inches or liquid-quart, liquid-pint, or fluid-ounce subdivisions of the gallon, and shall express the volume at $68^{\circ} \mathrm{F}$ except in the case of petroleum products or distilled spirits, for which the declaration shall express the volume at $60^{\circ} \mathrm{F}$, and except also in the case of a commodity that is normally sold and consumed while frozen, for which the declaration shall express the volume at the frozen temperature, and except also in the case of a commodity that is normally sold in the refrigerated state, for which the declaration shall express the volume at $40^{\circ} \mathrm{F}$, and except also in the case of malt beverages, for which the declaration shall express the volume at $39.1^{\circ} \mathrm{F}$;

(Amended 1985)

(c) in units of linear measure, shall be in terms of the yard, foot, or inch;

(d) in units of area measure, shall be in terms of the square yard, square foot, or square inch;

(e) in units of volume measure, shall be in terms of the cubic yard, cubic foot, or cubic inch;

(f) in units of dry measure, shall be in terms of the United States bushel of 2,150.42 cubic inches, or peck, dry-quart, and dry-pint subdivisions of the bushel.
7.5.1. Symbols and Abbreviations. -- Any generally accepted symbol and abbreviation of a unit name may be employed in the quantity statement on a package of commodity. (For commonly accepted symbols and abbreviations, see $\S 6.7 .1$. Symbols and Abbreviations.)

7.6. Character of Declaration: Average. -- The average quantity of contents in the packages of a particular lot, shipment, or delivery shall at least equal the declared quantity, and no unreasonable shortage in any package shall be permitted, even though overages in other packages in the same shipment, delivery, or lot compensate for such shortage.

\section{Section 8. Prominence and Placement: Consumer Packages}

8.1. General. -- All information required to appear on a consumer package shall appear thereon in the English language and shall be prominent, definite, and plain, and shall be conspicuous as to size and style of letters and numbers and as to color of letters and numbers in contrast to color of background. Any required information that is either in hand lettering or hand script shall be entirely clear and equal to printing in legibility.

8.1.1. Location. -- The declaration or declarations of quantity of the contents of a package shall appear in the bottom 30 percent of the principal display panel or panels. For cylindrical containers, see also $\S 10.7$. for additional requirements.

(Amended 1975)

8.1.2. Style of Type or Lettering. -- The declaration or declarations of quantity shall be in such a style of type or lettering as to be boldly, clearly, and conspicuously presented with respect to other type, lettering, or graphic material on the package, except that a declaration of net quantity blown, formed, or molded on a glass or plastic surface is permissible when all label information is blown, formed, or molded on the surface.

\subsubsection{Color Contrast. -- The declaration or} declarations of quantity shall be in a color that contrasts conspicuously with its background, except that a declaration of net quantity blown, formed, or molded on a glass or plastic surface shall not be required to be presented in a contrasting color if no required label information is on the surface in a contrasting color.

8.1.4. Free Area. -- The area surrounding the quantity declaration shall be free of printed information: 
(a) above and below, by a space equal to at least the height of the lettering in the declaration, and

(b) to the left and right, by a space equal to twice the width of the letter " $\mathrm{N}$ " of the style and size of type used in the declaration.

8.1.5. Parallel Quantity Declaration. -- The quantity declaration shall be presented in such a manner as to be generally parallel to the declaration of identity and to the base on which the package rests as it is designed to be displayed.

\subsection{Calculation of Area of Principal Display} Panel for Purposes of Type Size. -- The area of the principal display panel shall be:

(a) in the case of a rectangular container, one entire side that properly can be considered to be the principal display panel, the product of the height times the width of that side;

For figure 3, page 262 the area of the principal display panel is:

$20 \mathrm{~cm}(8$ in $) \times 15 \mathrm{~cm}(6$ in $)=300 \mathrm{~cm}^{2}\left(48 \mathrm{in}^{2}\right)$

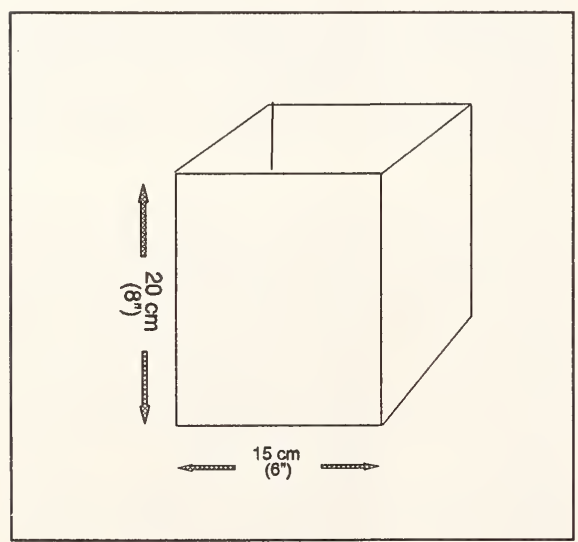

Figure 3.

(b) in the case of cylindrical or nearly cylindrical container, 40 percent of the product of the height of the container times the circumference;

For figure 4, page 262 the area if the principal display panel is: $25 \mathrm{~cm}(10 \mathrm{in}) \times 5 \mathrm{~cm}(2 \mathrm{in})=125 \mathrm{~cm}\left(20 \mathrm{in}^{2}\right)$ x $0.40=50 \mathrm{~cm}^{2}\left(8 \mathrm{in}^{2}\right)$
See also $§ 10.7$.

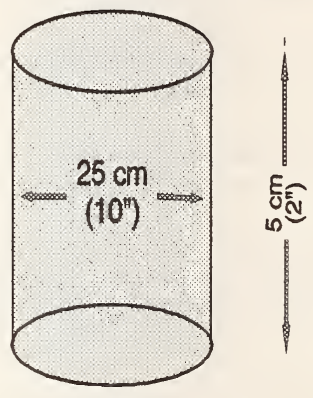

Figure 4.

For Figure 5, page 262:

The area of the principal display panel is the same in both examples. The declaration of net quantity of contents must be of the same height in both cases. It is not the size of the label that is used to determine the minimum type size of the quantity statement, but the size of the surface of the package exposed to view to the customer. The package on the right side of the figure has a spot label; see § 2.12. and 11.29 32 .
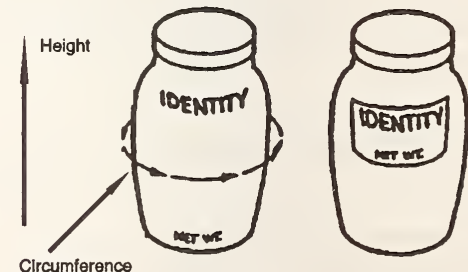

Figure 5. 
(c) in the case of any other shaped container, 40 percent of the total surface of the container, unless such container presents an obvious principal display panel (e.g., the top of a triangular or circular package of cheese, or the top of a can of shoe polish), in which event the area shall consist of the entire such surface.

Determination of the principal display panel shall exclude tops, bottoms, flanges at tops and bottoms of cans, and shoulders and necks of bottles or jars.

\subsubsection{Minimum Height of Numbers and}

Letters. -- The height of any letter or number in the required quantity declaration shall be not less than that shown in Table 1 with respect to the area of the panel, and the height of each number of a common fraction shall meet one-half the minimum height standards. In the of the symbol for milliliter, the " $m$ "- shall meet the minimum heights when upper and lower case, or all lowercase letters are used in metric symbols, it is the uppercase "L," lowercase "d," or their equivalent in the print or type that shall meet the minimum height requirement. Other letters and exponents must be presented in the same type style and in proportion to the type size used. (Amended 1993)

8.2.2. Numbers and Letters: Proportion. -- No number or letter shall be more than three times as high as it is wide.

\section{Section 9. Prominence and Placement: Nonconsumer Packages}

9.1. General. -- All information required to appear on a nonconsumer package shall be definitely and clearly stated thereon in the English language. Any required information that is either in hand lettering or hand script shall be entirely clear and equal to printing in legibility.

\section{Section 10. Requirements: Specific Con- sumer Commodities, Nonconsumer Commodities, Packages, Containers}

(Title amended 1979)

10.1. Display Card Package. -- For an individual package affixed to a display card, or for a commodity and display card together comprising a package, the type size of the quantity declaration is governed by the dimensions of the display card.

10.2. Eggs. -- When cartons containing 12 eggs have been designed so as to permit division in half by the retail purchaser, the required quantity declaration shall be so positioned as to have its context destroyed when the carton is divided.

\subsection{Aerosols and Similar Pressurized}

Containers. -- The declaration of quantity on an aerosol package, and on a similar pressurized package, shall disclose the net quantity of the commodity (including propellant), in terms of weight, that will be expelled when the instructions for use as shown on the container are followed.

Table 1. Minimum Height of Numbers and Letters

\begin{tabular}{|c|c|c|}
\hline Area of principal display panel & $\begin{array}{l}\text { Minimum height of } \\
\text { numbers and letters }\end{array}$ & $\begin{array}{l}\text { Minimum height: label } \\
\text { information blown, formed, or } \\
\text { molded on surface on } \\
\text { container }\end{array}$ \\
\hline$\leq 32 \mathrm{~cm}^{2}\left(5 \mathrm{in}^{2}\right)$ & $1.6 \mathrm{~mm}(1 / 16 \mathrm{in})$ & $3.2 \mathrm{~mm}(1 / 8 \mathrm{in})$ \\
\hline$>32 \mathrm{~cm}^{2}\left(5 \mathrm{in}^{2}\right) \leq 161 \mathrm{~cm}^{2}\left(25 \mathrm{in}^{2}\right)$ & $3.2 \mathrm{~mm}(1 / 8 \mathrm{in})$ & $4.8 \mathrm{~mm}(3 / 16 \mathrm{in})$ \\
\hline$>161 \mathrm{~cm}^{2}\left(25 \mathrm{in}^{2}\right) \leq 645 \mathrm{~cm}^{2}\left(100 \mathrm{in}^{2}\right)$ & $4.8 \mathrm{~mm}(3 / 16 \mathrm{in})$ & $6.4 \mathrm{~mm}(1 / 4 \mathrm{in})$ \\
\hline$>645 \mathrm{~cm}^{2}\left(100 \mathrm{in}^{2}\right) \leq 2581 \mathrm{~cm}^{2}\left(400 \mathrm{in}^{2}\right)$ & $6.4 \mathrm{~mm}(1 / 4 \mathrm{in})$ & $7.9 \mathrm{~mm}(5 / 16 \mathrm{in})$ \\
\hline$>2581 \mathrm{~cm}^{2}\left(400 \mathrm{in}^{2}\right)$ & $12.7 \mathrm{~mm}(1 / 2 \mathrm{in})$ & $14.3 \mathrm{~mm}(9 / 16 \mathrm{in})$ \\
\hline
\end{tabular}


10.4. Multi-Unit Packages. ${ }^{[N O T E}$ 6, see page 264] -- Any package containing more than one individual "commodity in package form" (see § 2.1.) of the same commodity shall bear on the outside of the package a declaration of:

(a) the number of individual units,

(b) the quantity of each individual unit, and

(c) the total quantity of the contents of the multi-unit package., d any such declaration of total quantity shall not be required to include the parenthetical quantity statemt-of a-dual quantity representation. [Example: Soap bars, "6 Bars, Net Wt $100 \mathrm{~g}$ (3.53 oz) each; Total Net Wt $600 \mathrm{~g}(1.323 \mathrm{lb})]$

NOTE 6: Open multi-unit retail food packages under the authority of the Food and Drug Administration or the U.S. Department of Agriculture that do not obscure the number of units or prevent examination of the labeling on each of the individual units are not required to declare the number of individual units or the total quantity of contents of the multi-unit package, if the labeling of each individual unit complies with requirements so that it is capable of being sold individually. (See also § 11.12. and 11.13.) (Added 1984)

10.5. Combination Packages. -- A combination package is a package intended for retail sale, containing two or more individual packages or units of dissimilar commodities. The declaration of net quantity for a combination package shall contain an expression of weight, volume, measure, or count or a combination thereof, as appropriate, for each individual package or unit, provided that the quantity statements for identical packages or units shall be combined. This section does not apply to food or other commodities subject to the Federal Food, Drug, and Cosmetic Act (21 USC).

Examples:

(1) Lighter Fluid and Flints:

2 cans - lighter fluid each $236 \mathrm{~mL}(8 \mathrm{fl} \mathrm{oz})$

1 package -8 flints

(2) Sponges \& Cleaner:

2 sponges - each $10 \mathrm{~cm} \mathrm{x}$

$15 \mathrm{~cm} \times 2.5 \mathrm{~cm}$

(4 in $\times 6$ in $\times 1$ in)

1 box cleaner -

Net Mass $170 \mathrm{~g}(6 \mathrm{oz})$

(3) Picnic Pack:
20 spoons, 10 knives, and

10 forks

10 2-ply napkins

$25 \mathrm{~cm} \times 25 \mathrm{~cm}$

(10 in $\times 10$ in)

10 cups $-177 \mathrm{~mL}(6 \mathrm{fl} \mathrm{oz})$

(Amended 1993)

10.6. Variety Packages. -- A variety package is a package intended for retail sale, containing two or more individual packages or units of similar but not identical commodities. Commodities that are generically the same but that differ in weight, measure, volume, appearance, or quality are considered similar but not identical. This section does not apply to foods or other commodities subject to the Federal Food, Drug, and Cosmetic Act (21 USC). The declaration of net quantity for a variety package will be expressed as follows:

(1) The number of units for each identical commodity followed by the weight, volume, or measure of that commodity;

(2) The total quantity by weight, volume, measure, and count, as appropriate, of the variety package. The statement of total quantity shall appear as the last item in the declaration of net quantity and shall not be of greater prominence than other terms used.

Examples:

(1) 11 Sponges $11 \mathrm{~cm} \times 20.3 \mathrm{~cm} \times 1.9 \mathrm{~cm}$

$(4$ in $\times 8$ in $\times 3 / 4$ in)

14 Sponges $5.7 \mathrm{~cm} \times 10 \mathrm{~cm} \times 1.2 \mathrm{~cm}$

(2 $1 / 4$ in $\times 4$ in $\times 1 / 2$ in)

Total: 25 Sponges

$$
\frac{2 \text { Soap Bars }}{\underline{1 \text { Soap Bar }}} \frac{85 \mathrm{~g}(3 \mathrm{oz}) \text { ea }}{142 \mathrm{~g}(5 \mathrm{oz})}
$$

Total: 3 Soap Bars $312 \mathrm{~g}(11 \mathrm{oz})$

(3) Liquid Shoe Polish

1 Brown $89 \mathrm{~mL}(3 \mathrm{fl} \mathrm{oz})$

1 Black $89 \mathrm{~mL}(3 \mathrm{fl} \mathrm{oz})$

1 White $148 \mathrm{~mL}(5 \mathrm{fl} \mathrm{oz})$

$\underline{\text { Total: }} \underline{326 \mathrm{~mL}(11 \mathrm{fl} \mathrm{oz})}$

(4) Picnic Ware

34 spoons

33 forks

33 knives

Total: 100 pieces

(Aniended 1993) 
10.7. Cylindrical Containers. -- In the case of cylindrical or nearly cylindrical containers, information required to appear on the principal display panel shall appear within that 40 percent of the circumference which is most likely to be displayed, presented, shown, or examined under customary conditions of display for retail sale.

\subsection{Measurement of Container-Type Commodities, How Expressed. --}

10.8.1. General. -- Commodities designated and sold at retail to be used as containers for other materials or objects, such as bags, cups, boxes, and pans, shall be labeled with the declaration of net quantity as follows:

(a) For bag-type commodities, in terms of count followed by linear dimensions of the bag (whether packaged in a perforated roll or otherwise).

When the unit bag is characterized by two dimensions because of the absence of a gusset, the width and length will be expressed:

(1) SI Hetrie units - in millimeters or centimeters except a dimension of one meter or more will be expressed in meters with the remainder in terms of decimal fractions of the meter (Examples: "25 Bags, $50 \mathrm{~cm} \times$ $60 \mathrm{~cm}$ " or "50 Bags, $75 \mathrm{~cm} \times 1.2 \mathrm{m"}$ )

(2) Inch-pound units - in inches, except that a dimension of 2 feet or more will be expressed in feet with any remainder in terms of inches or common or decimal fractions of the foot. (Example: "25 Bags, 17 in x 20 in" or "100 Bags, 20 in $x 2 \mathrm{ft} 6$ in" or "50 Bags, 20 in $x$ $2-1 / 2 \mathrm{ft}$ )

When the unit bag is gusseted, the dimensions will be expressed as width, depth, and length.

(3) SI Hetrie units - in millimeters or centimeters except a dimension of 1 meter or more will be expressed in meters with the remainder in terms of decimal fractions of the meter. (Examples: "25 Bags, $43 \mathrm{~cm} \times 100 \mathrm{~cm} \times$ $50 \mathrm{~cm}$ " or "50 Bags, $50 \mathrm{~cm} \times 30 \mathrm{~cm} \times 1.2 \mathrm{~m} ")$

(4) Inch-pound units - in inches, except that a dimension of 2 feet or more will be expressed in feet with any remainder in terms of inches or the common or decimal fractions of the foot. (Examples: "25 Bags, 17 in x 4 in $\times 20$ in" or "100 Bags, 20 in x 12 in x 2-1/2 ft")

(b) For other square, oblong, rectangular, or similarly shaped containers, in terms of count followed by length, width, and depth, except depth need not be listed when less than 50 millimeters or 2 inches [Example: "2 Pans, $20 \mathrm{~cm}$ x $20 \mathrm{~cm}$ ( 8 in x 8 in)"]

\section{(c) For circular or other generally round-} -shaped containers, except cups, and the like, in terms of count followed by diameter and depth, except depth need not be listed when less than 50 millimeters or 2 inches. [Example: "4 Pans, $20 \mathrm{~cm}$ (8 in) diameter $x$ $10 \mathrm{~cm}(4 \mathrm{in}) "]$

(d) Cups - Notwithstanding the above requirements, the net quantity statement for containers such as cups will be listed in terms of count and liquid capacity per unit. (Examples: "24 Cups, $177 \mathrm{~mL}(6 \mathrm{fl} \mathrm{oz})$ capacity")

10.8.2. Capacity. -- When the functional use of the container is related by label references in standard terms of measure to the capability of holding a specific quantity of substance or class of substances such references shall be a part of the net quantity statement and shall specify capacity as follows:

(a) SI Hetrie units: Volume measure for all containers and liners. (Examples: "4 Boxes, 1 L capacity, $15 \mathrm{~cm} \times 12 \mathrm{~cm} \times 9 \mathrm{~cm}$ "; "8 Bags, 200 L capacity, $8.5 \mathrm{~cm}$ x $1.5 \mathrm{~m}$ " or "10 Liners, $75 \mathrm{~cm} \times 1 \mathrm{~m}$, FITS UP TO $120 \mathrm{~L}$ Cans")

\section{(b) Inch-Pound Units:}

(1) Liquid measure for containers that are intended to be used for liquids, semisolids, viscous materials, or mixtures of solids and liquids. The expressed capacity will be stated in terms of the largest whole unit (gallon, quart, pint, ounce, with any remainder in terms of the common or decimal fraction of that unit). (Examples: Freezer Box - "4 Boxes, $946 \mathrm{~mL}$ (1 qt) capacity, $12.7 \mathrm{~cm} \times 10 \mathrm{~cm} \times 7.6 \mathrm{~cm}(5$ in $\times 4$ in $\times 3$ in")

(2) Dry measure for containers that are intended to be used for solids. The expressed capacity will be stated in terms of the largest whole unit (bushel, peck), with a remainder in terms of the common or decimal fraction of that unit. [Example: Leaf Bags - "8 Bags, $211 \mathrm{~L}$ (6-bushel) capacity, $91 \mathrm{~cm} \times 1.52 \mathrm{~m} \mathrm{(3 \textrm {ft } \times 5 \mathrm { ft } " ) ]}$

(3) Where containers are used as liners for other more permanent containers, in the same terms as are normally used to express the capacity of the more permanent containers. (Example: Garbage Can Liners - "10 Liners, $76 \mathrm{~cm} \times 114 \mathrm{~cm}(2 \mathrm{ft} 6$ in $\times 3 \mathrm{ft} 9$ in). FITS UP TO $113 \mathrm{~L}$ (30 gal) Cans").

10.8.3. Terms. -- For purposes of this section, the use of the terms "CAPACITY," "DIAMETER," and "FLUID" is optional. 


\subsection{Textile Products, Threads, and Yarns.}

10.9.1. Wearing Apparel. -- Wearing apparel (including nontextile apparel and accessories such as leather goods and footwear) sold as single-unit items, or if normally sold in pairs (such as hosiery, gloves, and shoes) sold as single-unit pairs, shall be exempt from the requirements for a net quantity statement by count, as required by $\S 6.4$. of this regulation.

10.9.2. Textiles. -- Bedsheets, blankets, pillowcases, comforters, quilts, bedspreads, mattress covers and pads, afghans, throws, dresser and other furniture scarfs, tablecloths and napkins, flags, curtains, drapes, dishtowels, dish cloths, towels, face cloths, utility cloths, bath mats, carpets and rugs, pot holders, fixture and appliance covers, non-rectangular diapers, slip covers, etc., shall be exempt from the requirements of $\S 6.7 .3$. and $\S 6.8 .37$ of this regulation, provided:

(a) The quantity statement for fitted sheets and mattress covers shall state, in centimeters and inches, the length and width of the mattress for which the item is designed, and the size designation of the mattress, if the item is intended to fit a mattress identified as "twin," "double," "queen," "king," "California king," etc. (Example: "Double sheet for $137 \mathrm{~cm} \times 190 \mathrm{~cm}$ (54 in x $75 \mathrm{in})$ mattress") (Amended 1987)

(b) The quantity statement for flat sheets shall state, in centimeters and inches, the length and width of the mattress for which the sheet is designed, followed in parentheses by a statement, in centimeters and inches, of the length and width of the finished sheet. The quantity statement shall also state the size designation of the mattress for which the sheet is designed, such as "twin," "double," "queen," "king," "California king," if the item is intended to fit such a mattress. (Example: "Twin Flat Sheet for $99 \mathrm{~cm} \times 190 \mathrm{~cm}$ (39 in x 75 in) mattress $167 \mathrm{~cm}$ x $244 \mathrm{~cm}$ (66 in x 96 in) finished size")

(Amended 1987)

(c) The quantity statement for pillowcases shall state, in centimeters and inches, the length and width of the pillow for which the pillowcase is designed, followed in parentheses by a statement, in centimeters and inches of the length and width of the finished pillowcase. The quantity statement for pillowcases shall also state the size designation of the pillow for which the pillowcase is designed, e.g., "youth," "standard," "queen," etc., if the item is intended to fit such pillows. (Example: "Standard Pillowcase for $51 \mathrm{~cm} \times 66 \mathrm{~cm}(20$ in $\times 26$ in) pillow, $51 \mathrm{~cm} \times x$ $76 \mathrm{~cm}$ (20 in x $30 \mathrm{in})$ in finished size")

(Amended 1977, 1987) (d) The quantity statement for blankets, comforters, quilts, bedspreads, mattress pads, afghans, and throws shall state, in centimeters and inches, the length and width of the finished item. The quantity statement shall also state the length of any ornamentation and the size designation of the mattress for which the item is designed, if it is intended to fit, for example, a "twin," "double," "queen," "king," or "California King," etc., mattress. (Amended 1988)

(e) The quantity statement for tablecloths and napkins shall state, in centimeters and inches, the length and width of the finished item. The quantity statement also may state parenthetically, in centimeters and inches, the length and width of the item before hemming and properly identified as such.

(f) The quantity statement for curtains, drapes, flags, furniture scarfs, etc., shall state, in centimeters and inches, the length and width of the finished item. The quantity statement also may state parenthetically, in centimeters and inches, the length of any ornamentation.

(g) The quantity statement for carpets and rugs shall state, in meters and feet, with any remainder in decimal

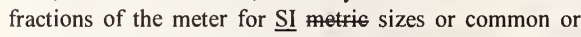
decimal fractions of the foot or in inches for inch-pound sizes, the length and width of the item. The quantity statement also may state parenthetically, in centimeters and inches, the length of any ornamentation.

(h) The quantity statement for woven dish towels, dish cloths, towels, face cloths, utility cloths, bath mats, etc., shall state, in centimeters and inches, the length and width of the item. The quantity statement for such items, when knitted, need not state the dimensions.

(i) The quantity statement for textile products such as pot holders, fixture and appliance covers, slip covers, non-rectangular diapers, etc., shall be stated in terms of count and may include size designations and dimensions.

(j) The quantity statement for other than rectangular textile products identified in $\S($ a) through (h) shall state the geometric shape of the product and the dimensions that are customarily used in describing such geometric shape. (Examples: "Round scarf: $190 \mathrm{~cm}$ (74 in) in diameter; "Oval Tablecloth $177 \mathrm{~cm} \times 254 \mathrm{~cm}$ (70 in x 100 in)" representing the maximum length and width in this case)

(k) The quantity statement for packages of remnants of textile products of assorted sizes, when sold by count, shall be accompanied by the term "irregular dimensions" and the minimum size of such remnants. (Added 1971) 


\subsubsection{Textiles: Variations from Declared Dimensions. --}

(a) For an item with any declared dimension equal to or greater than 60 centimeters or 24 inches, a minus variation greater than 3 percent of the declared dimension and a plus variation greater than 6 percent of the declared dimension should be considered unreasonable.

(b) For an item with any declared dimension less than 60 centimeters or 24 inches, a minus variation greater than 6 percent of that declared dimension and a plus variation greater than 12 percent of that declared dimension should be considered unreasonable. (Added 1971)

\subsubsection{Sewing Threads, Handicraft Threads,}

and Yarns. -- Sewing and handicraft threads shall be exempt from the requirements of $\S 6.7 .2$. 6.8 .6 . of this regulation, provided:

(a) The net quantity statement for sewing and handicraft threads shall be expressed in terms of meters and yards.

(b) The net quantity statement for yarns shall be expressed in terms of weight.

(c) Thread products may, in lieu of name and address, bear a trademark, symbol, brand, or other mark that positively identifies the manufacturer, packer, or distributor, provided such marks, employed to identify the vendor, shall be filed with the director.

(d) Each unit of industrial thread shall be marked to show its net length in terms of meters or yards or its net weight in terms of kilograms or grams or avoirdupois pounds or ounces, except that ready-wound bobbins that are not sold separately shall not be required to be individually marked to show the number of bobbins contained therein and the net meters or yards of thread on each bobbin.

10.10. Packaged Seed. -- Packages of seeds intended for planting, weighing less than 225 grams or 8 ounces, shall be labeled in full accord with this regulation except as follows:

(a) The quantity statement shall appear in the upper 30 percent of the principal display panel.

(b) The quantity statement shall be in terms of:

(i) the largest whole SI unit of thetricsystem for all packages with weights up to 7 grams, and, (ii) in grams or in ounces for all other packages with weights less than 225 grams or 8 ounces;

(c) The quantity statement for coated seed, encapsulated seed, pelletized seed, preplanters, seed tapes, etc., shall be in terms of count

(Added 1972; Amended 1975, 1993)

\subsection{Mulch: Variations from Declared} Volume. [NOTE 7, see page 267] - An individual package minus variation greater than 5 percent of the declared volume shall be considered unreasonable. (Added 1983)

NOTE 7: In addition, the average net contents of lots, shipments, or deliveries must equal or exceed the labeled net contents. See $\S 12.1$.

\subsection{Polyethylene Products: Variations from Declared Thickness ${ }^{\text {[NOTE }}$ 7, see page 267]}

\section{(a) Any single measurement of thickness:}

(1) When the labeled thickness is less than 25.4 micrometers [ $1 \mathrm{mil}(0.001 \mathrm{in})]$, any individual thickness measurement of a polyethylene product may be as much as 35 percent below the labeled thickness (i.e., at least 65 percent of the labeled thickness). [NOTE 8 . see page 267]

(2) When the labeled thickness is 25.4 micrometers [ 1 mil $(0.001$ in)] or larger, any individual thickness measurement of a polyethylene product may be as much as 20 percent below the labeled thickness (i.e., at least 80 percent of the labeled thickness). NOTE 9, see page 267

(b) Average thickness for a single package:

The average thickness of a single package of polyethylene sheeting, film, or bags may be as much as 4 percent below the labeled thickness (i.e., at least 96 percent of the labeled thickness).

(Added 1985; Amended 1988, 1989, 1993)

NOTE 8: ASTM Standard D2103-86, "Standard Specification of Polyethylene Film and Sheeting," 1986.

NOTE 9: ASTM Standard D-4397-91, "Specification for Polyethylene Sheeting for Construction, Industrial and Agricultural Applications", 1991.

\subsection{Polyethylene Products: Variations}

from Declared Weight ${ }^{[\text {NOTE } 7 \text {, see page 267] }}$-- An individual package minus variation greater than 4 percent of the declared weight shall be considered unreasonable. (Added 1989) 


\section{Section 11. Exemptions $\mathbf{s}^{\text {(Note } 10 \text { see page 268) }}$}

11.1. General. Wheneveranysumerommodity of package of consumer commodity is exempted from the requirements for dual quantity declaration, the netquantity required to appear-on the package shall be in terms of the targest whole unit (except see- $\$ 10.4 .(6)$ ).

NOTE 10: Section 11. Exemptions includes several requirements that refer only to the historic use of inchpound units or are direct restatements of exemptions contained in Federal Laws or regulations which do not include SI units. SI equivalents are omitted in most of these requirements because the SI units would not be meaningful or useful.

(Added 1993)

11.1 z. Random Packages. -- A random package bearing a label conspicuously declaring:

(a) the net weight,

(b) the price per kilogram or pound, and

(c) the total price

shall be exempt from the SI units, type size, duat docation, and free area requirements of this regulation. In the case of a random package packed at one place for subsequent sale at another, neither the price per unit of weight nor the total selling price need appear on the package, provided the package label includes both such prices at the time it is offered or exposed for sale at retail.

This exemption shall also apply to uniform weight packages of cheese and cheese products labeled in the same manner and by the same type of equipment as random packages exempted by this section.

This exemption shall also apply to packages of fresh fruit or vegetables labeled by count in the same manner and by the same type of equipment as random packages exempted by this section.

(Amended 1989)

11.2 3 Small Confections. -- Individually wrapped pieces of "penny candy" and other confectionery of less than 15 grams or $1 / 2$ ounce net weight per individual piece shall be exempt from the labeling requirements of this regulation when the container in which such confectionery is shipped is in conformance with the labeling requirements of this regulation. Similarly, when such confectionery items are sold in bags or boxes, such items shall be exempt from the labeling requirements of this regulation, including the required declaration of net quantity of contents, when the declaration of the bag or box meets the requirements of this regulation.

\subsection{Small Packages of Meat or Meat}

Products. -- Individually wrapped and labeled packages of meat or meat products of less than 15 grams or $1 / 2$ ounce net weight, which are in a shipping container, need not bear a statement of the net quantity of contents when the statement of the net quantity of contents on the shipping container is in conformance with the labeling requirements of this regulation.

(Added 1987)

\section{$11.45 . \quad$ Individual Servings. --} Individual-serving-size packages of foods containing less than 15 grams or $1 / 2$ ounce or less than 15 milliliters or $1 / 2$ fluid ounce for use in restaurants, institutions, and passenger carriers, and not intended for sale at retail, shall be exempt from the required declaration of net quantity of contents specified in this regulation.

\subsection{Cuts, Plugs, and Twists of Tobacco} and Cigars. -- When individual cuts, plugs, and twists of tobacco and individual cigars are shipped or delivered in containers that conform to the labeling requirements of this regulation, such individual cuts, plugs, and twists of tobacco and cigars shall be exempt from such labeling requirements.

\subsection{Reusable (Returnable) Glass} Containers. -- Nothing in this Regulation shall be deemed to preclude the continued use of reusable (returnable) glass containers, provided such glass containers ordered after the effective date of this regulation shall conform to all requirements of this regulation.

\subsection{Cigarettes and Small Cigars. -- Cartons} of cigarettes and small cigars, containing ten individual packages of twenty, labeled in accordance with the requirements of this regulation, shall be exempt from the requirements set forth in $\S 8.1 .1$. Location, $\S 8.2 .1$. Minimum Height of Numbers and Letters, and $\S 10.4$. Multi-Unit Packages, provided such cartons bear a declaration of the net quantity of commodity in the package.

\subsection{Packaged Commodities with Labeling Requirements Specified in Federal Law. --} Packages of meat and meat products, poultry products, tobacco and tobacco products, pesticides, insticides, fungicides, renters and alcoholic beverages shall be exempt from those portions of these regulations dual dectarions in -ustomary units and specifying location and minimum type size of the net quantity declaration, provided quantity labeling requirements for such products are specified in Federal Law, so as to 
follow reasonably sound principles of providing consumer information. (See also 11.32)

\subsection{Fluid Dairy Products, Ice Cream, and Similar Frozen Desserts. --}

(a) When packaged in 1/2-liquid-pint and 1/2-gallon containers, are exempt from the requirements for stating net contents of 8 fluid ounces and 64 fluid ounces, which may be expressed as $1 / 2$ pint and $1 / 2$ gallon, respectively.

(b) When packaged in - 1 liquid-pint, 1-liquid-quart, and $1 / 2$ gatton containers, are-exempt from the dual net contents declaration requirements of 56.8 .3 .

(b e) When measured by and packaged in measure containers as defined in "Measure Container Code of National Institute of Standards and Technology Handbook 44 ," are exempt from the requirements of $\S 8.1$.1. that the declaration of net contents be located within the bottom 30 percent of the principal display panel.

(c d) Milk and milk products when measured by and packaged in glass or plastic containers of 1/2-pint, 1-pint, 1-quart, 1/2-gallon, and 1-gallon capacities are exempt from the placement requirement of $\S 8.1 .1$. that the declaration of net contents be located within the bottom 30 percent of the principal display panel, provided other required label information is conspicuously displayed on the cap or outside closure, and the required net quantity of contents declaration is conspicuously blown, formed, or molded on, or permanently applied to that part of the glass or plastic container that is at or above the shoulder of the container. (Amended 1993)

\subsection{Single Strength and Less than} Single Strength Fruit Juice Beverages, Imitations Thereof, and Drinking Water. --

(a) When packaged in glass, plastic, or fluid milk type paper containers of 8- and 64-fluid-ounce capacity, are exempt from the requirements of $\S 6.2$., to the extent that net contents of 8 fluid ounces and 64 fluid ounces (or 2 quarts) may be expressed as $1 / 2$ pint (or half pint) and $1 / 2$ gallon (or half gallon), respectively.

(b) When packaged in glass, plastic, or fluid milk type paper containers of 1 pint, 1 quat, and $1 / 2$ gallon Eapacities, are-exempt from the dual netcontents declara tion requirements of $\{6.8 .3$.

(b e) When packaged in glass or plastic containers of 1/2-pint, 1-pint, 1-quart, 1/2-gallon, and 1-gallon capacities, are exempt from the placement requirements of $\S 8.1 .1$. that the declaration of net contents be located within the bottom 30 percent of the principal display panel, provided other label information is conspicuously displayed on the cap or outside closure and the required net quantity of contents declaration is conspicuously blown, formed, or molded into or permanently applied to that part of the glass or plastic container that is at or above the shoulder of the container.

(Amended 1993)

11.11 12. Soft-Drink Bottles. -- Bottles of soft drinks shall be exempt from the placement requirements for the declaration of:

(a) identity, when such declaration appears on the bottle closure, and

(b) quantity, when such declaration is blown, formed, or molded on or above the shoulder of the container and when all other information required by this regulation appears only on the bottle closure.

11.12 13. Multi-Unit Soft-Drink Packages. -Multi-unit packages of soft drinks are exempt from the requirement for a declaration of:

(a) responsibility, when such declaration appears on the individual units and is not obscured by the multi-unit packaging, or when the outside container bears a statement to the effect that such declaration will be found on the individual units inside, and

(b) identity, when such declaration appears on the individual units and is not obscured by the multi-unit packaging.

11.13 14. Butter. -- When packaged in 4-ounce, 8-ounce, and 1-pound packages with continuous label copy wrapping, butter is exempt from the requirements that the statement of identity $(\S 3.1 .1$ ) and the net quantity declaration ( $\S 8.1 .5$.) be generally parallel to the base of the package. When packaged in 8-ounce and 1-pound units, butter is exempt from the requirement for location (§ 8.1.1.) of net quantity declaration. and, when packaged in 1 pound units, is exempt from the requirement for duat quantity declaration $(\$-6.8 .2$.).

(Amended 1980, 1993)

11.14 15. Eggs. -- Cartons containing 12 eggs shall be exempt from the requirement for location ( $\$ 8.1 .1$.) of net quantity declaration. When such cartons are designed to permit division in half, each half shall be exempt from the labeling requirements of this regulation if the undivided carton conforms to all such requirements.

11.15 16. Flour. -- Packages of wheat flour in conventional 2-, 5-, 10-, 25-, 50-, and 100-pound packages shall be exempt from the requirement in this regulation for 
location ( $\S 8.1 .1$.) of the net quantity declaration. and, when packaged in units of 2 pounds, shall be exempt-alse from the requirement for 2 - duat-quantity declaration $(\S-6.8 .2)$.

(Amended 1980, 1993)

11.16 17. Small Packages. -- On a principal display panel of 32 square centimeters (5 square inches) or less, the declaration of quantity need not appear in the bottom 30 percent of the principal display panel if that declaration satisfies the other requirements of this regulation.

(Amended 1980)

11.17 18. Decorative Containers. -- The principal display panel of a cosmetic marketed in a "boudoir-type" container including decorative cosmetic containers of the "cartridge," "pill box," "compact," or "pencil" variety, and those with a capacity of 7 grams (1/4 ounce) or less, may be a tear-away tag or tape affixed to the decorative container and bearing the mandatory label information as required by this regulation.

(Amended 1980)

11.18 19. Combination and Variety Packages. -- Combination and variety packages are exempt from the requirements in this regulation for:

(a) Location (see § 8.1.1.),

(b) Free area (see § 8.1.4.), and

(c) Minimum height of numbers and letters (see $\S 8.2 .1$.). (Amended 1989)

11.19 20. Margarine. -- Margarine in 1-pound rectangular packages, except for packages containing whipped or soft margarine or packages containing more than four sticks, shall be exempt from the requirement in this regulation for location (see $\S 8.1 .1$.) of the net quantity declaration, and shall be-exempt-from the requirement-for a dual quantity dectaration - (see \& 6.8.2.). (Amended 1980, 1993)

11.20 z1. Corn Flour and Corn Meal. -- Corn flour and corn meal packaged in conventional 5-, 10-, 25-, 50 , and 100-pound bags shall be exempt from the requirement in this regulation for location (see $\S$ 8.1.1.) of the net quantity declaration. (Amended 1978, 1980)

\subsection{Prescription and Insulin-Containing}

Drugs. -- Prescription and insulin-containing drugs subject to the provisions of $\S 503$ (b) (1) or 506 of the Federal Food, Drug, and Cosmetic Act shall be exempt from the provisions of this regulation.

\subsection{Camera Film, Video Recording} Tape, Audio Recording Tape and Other Image and Audio Recording Media Intended for Retail Sale and Consumer Use. -- Image and audio media packaged and labeled for retail sale are exempt from the net quantity statement requirements of this regulation that specify how measurement of commodities should be expressed, provided:

(a) Unexposed or Unrecorded Media. -- The net quantity of contents of unexposed or unrecorded image and audio media is expressed:

\section{(1) For still film, tape, or other still image} media, in terms of the usable or guaranteed number of available still image exposures. The length and width measurements of the individual exposures, expressed in millimeters or inches, are authorized as an optional statement. (Example, "36 exposures, $36 \mathrm{~mm}$ x $24 \mathrm{~mm}$ " or "12 exposures, $2-1 / 4$ in $\times 2-1 / 4$ in)."

(2) For bulk or movie film, in terms of length (in meters or feet) of film available for exposure.

\section{(3) For all other image and/or audio} media, in terms of length of time of electronic media available for recording, together with recording and/or playing speed or other machine settings as necessary. Supplemental information concerning the length of the media [NOTE 11, see page 270] may be provided.

Supplemental information may be provided on other than the principal display panel.

NOTE 11: Size, length of media, and format details to ensure interchangeability and other characteristics of audio and imaging media are available in the applicable American National Standards.

(b) Exposed, Recorded, or Processed Media. - The net quantity of contents of exposed or processed film or prerecorded electronic media shall be expressed in terms of the length of time that is of entertainment value.

"Entertainment value" is defined as that portion of a film, tape, or other media, that commences with the first frame of sound or picture, whichever comes first after the countdown sequence (if any), and ends with either:

(a) the last frame of credits; or (b) the last frame of the phrase "The End," or (c) the end of sound, whichever is last. (Amended 1990) 


\subsection{Tint Based Paints Produets. ..}

(a) Paints, vashes, laceuers, thinners, removers, oits, resins, and solvents, when packed in 1-liquid-pint-and H liquid-quat units shall beexempt from the duatquantity declaration requirements of $\$-6.8 .3$.

Tint based paint may be labeled on the principal display panel, in terms of a liter, quart or a gallon including the addition of colorant selected by the purchaser, provided the system employed ensures that the purchaser always obtains a liter, quart or a gallon; and further, provided in conjunction with the required quantity statement on the principal display panel, a statement indicating that the tint base paint is not to be sold without the addition of colorant is presented; and further provided the contents of the container, before the addition of colorant, is stated in fluid ounces elsewhere on the label.

Wherever the above conditions cannot be met, containers of tint base paint must be labeled with a statement of the actual net contents prior to the addition of colorant in full accord with all the requirements of this regulation. (Added 1972; Amended 1980, 1993)

\subsection{Automotive Cooling System} Antifreeze,-Antifreeze, when packed in 1 liquid-quat $t$ mits, in metal or plastic containers, shall be exempt from the-dual quantity dectaration requirements of $\$ 6.8 .3$.

11.24 26. Motor Oils In Cans. -- Motor oils, when

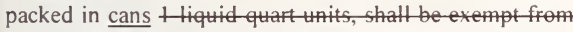
the duat quantity dectaration requirements of $\$ 6.8 .3 . \mathrm{Ad}$ ditionally, oil in 1 liquid quatt, 1 gallen, $11 / 4$ galton, 2 alton, and 2-1/2 gallon units, bearing the principal display panel on the body of the container, is are exempt from the requirements of SECTION 3. DECLARATION OF IDENTITY: CONSUMER PACKAGE, to the extent that the Society of Automotive Engineers (SAE) viscosity number is required to appear on the principal display panel, provided the SAE viscosity number appears on the can lid and is expressed in letters and numerals in type size of at least $6 \mathrm{~mm}$ or $1 / 4 \mathrm{in}$. (Amended 1974, 1980, 1993)

\subsection{Pillows, Cushions, Comforters,} Mattress Pads, Sleeping Bags, and Similar Products. -- Those products, including pillows, cushions, comforters, mattress pads, and sleeping bags, that bear a permanent label as designated by the Association of Bedding and Furniture Law Officials or by the California Bureau of Home Furnishings shall be exempt from the requirements for location ( $\$ 8.1 .1$.$) , size of$ letters or numbers $(\S 8.2 .1$, and 8.2.2.), free area (§ 8.1.4.), and the declarations of identity and respon- sibility ( $\$ 3.1$. and 5.), provided declarations of identity, quantity, and responsibility are presented on a permanently attached label and satisfy the other requirements of this Regulation, and further, provided the information on such permanently attached label be fully observable to the purchaser.

(Added 1973)

\subsection{Commodities' Variable Weights}

and Sizes. -- Individual packaged commodities put up in variable weights and sizes for sale intact, and intended to be weighed and marked with the correct quantity statement prior to or at the point of retail sale, are exempt from the requirements of SECTION 6. DECLARATION OF QUANTITY: CONSUMER PACKAGES, while moving in commerce and while held for sale prior to weighing and marking, provided the outside container bears a label declaration of the total net weight.

(Added 1973)

\subsection{Packaged Commodities Sold by} Count. ${ }^{[N O T E}$ 12, see page 27]] - - When a packaged consumer commodity is properly measured in terms of count only, or in terms of count and some other appropriate unit, and the individual units are fully visible to the purchaser, such packages shall be labeled in full accord with this Regulation except that those containing six or less items need not include a statement of count.

(Added 1973)

NOTE 12: When the net contents declaration of a package that may enter interstate commerce includes count, Federal regulations under the Federal Fair Packaging and Labeling Act provide no exemption from declaring the count unless the count is one (1). (Added 1990)

\subsection{0. - Fishing Lines-and-Reels_-_ Packaged} fishing lines and reels are exempt from the dual quantity declaration requirements of $\$$ - 6.8.6.(a), provided tength-of tine-or capacity of reet as appropriate is presented in terms of meters or yards in full-aceord-with all other re etuifements of this Regulation.

(Added 1973)

11.28 31. Textile Packages. -- Packages of textiles that are required by $\S 6.4 .1$. to provide a combination declaration stating the quantity of each individual unit and the count shall be exempt from the requirements in this regulation for:

(a) Location (see § 8.1.1.),

(b) Free area (see $\S 8.1 .4$.), and 
(c) Minimum height of numbers and letters (see $\S 8.2 .1$.). (Added 1971; Amended 1989)

11.29 32. Spot Label. -- The declaration of quantity of the contents of a package is exempt from $\S$ 8.1.1. Location, requiring the quantity declaration to appear in the bottom 30 percent of the principal display panel, as long as the declaration of quantity appears in the lower 30 percent of the spot label. In no case may the size of the spot label be used to determine the minimum type size; see $\S 8.2$. for this determination.

(Added 1990)

11.30 33. Header Strip. -- The declaration of quantity of the contents of a package is exempt from $\S 8.1 .1$. Location, requiring the quantity declaration to appear in the bottom 30 percent of the principal display panel, as long as the declaration of quantity appears in the lower 30 percent of the header strip or header label. In no case may the size of the header strip be used to determine the minimum type size; see $\S 8.2$. for this determination. (Added 1990)

\subsection{Decorative Wallcovering Borders. --} Decorative wallcovering borders, when packaged and labeled for retail sale, shall be exempt from the duat quantity requirements of $\S 6.7 .2 ., 6.7 .3 ., 6.8 .6$. and 6.8.2 7., provided that the length and width of the border are presented in terms of the largest whole unit in full accord with the other requirements of the regulation. (Added 1992, 1993)

\subsection{SI Units, Exemptions - Consumer}

Commodities. -- The requirements for statements of quantity in SI units (except for those in $\$ 10.10$. Packaged Seed and \$ 11.23. Camera Film) in \$ 6. DECLARATION OF QUANTITY: CONSUMER PACKAGES shall not apply to:

a. Foods packaged at the retail store level,

b. Random weight packages (see $\S 2.4$ and $\S 11.1$ )

c. Package labels printed before February 14, 1994.

d. Meat and poultry products subject to the Federal Meat or Poultry Products Inspection Acts,

e. Tobacco or tobacco products,

f. Any beverage subject to the Federal Alcohol Administration Act.

g. Any product subject to the Federal Insecticide, Fungicide, and Rodenticide Act, h. Drugs and cosmetics subject to the Federal Food, Drug and Cosmetic Act.

\section{(Added 1993)}

Editor's note: Because there may be substantial economic impact on small business, FDA and FTC may exempt certain firms from the requirements or extend the effective dates for complying with the SI provisions of FPLA. If these extensions are published in final regulations in the Code of Federal Regulations, they will be added to this section.

\section{Section 12. Variations to Be Allowed}

\subsection{Packaging Variations. --}

\subsubsection{Variations from Declared Net Quan-}

tity. -- Variations from the declared net weight, measure, or count shall be permitted when caused by unavoidable deviations in weighing, measuring, or counting the contents of individual packages that occur in good packaging practice, but such variations shall not be permitted to such extent that the average of the quantities in the packages of a particular commodity, or a lot of the commodity that is kept, offered, or exposed for sale, or sold, is below the quantity stated, and no unreasonable shortage in any package shall be permitted, even though overages in other packages in the same shipment, delivery, or lot compensate for such shortage. Variations above the declared quantity shall not be unreasonably large.

\subsubsection{Variations Resulting from Exposure.}

-- Variations from the declared weight or measure shall be permitted when caused by ordinary and customary exposure to conditions that normally occur in good distribution practice and that unavoidably result in change of weight or measure, but only after the commodity is introduced into intrastate commerce, provided the phrase "introduced into intrastate commerce" as used in this paragraph shall be construed to define the time and the place at which the first sale and delivery of a package is made within the State, the delivery being either

(a) directly to the purchaser or to his agent, or

(b) to a common carrier for shipment to the purchaser, and this paragraph shall be construed as requiring that, so long as a shipment, delivery, or lot of packages of a particular commodity remains in the possession or under the control of the packager or the person who introduces the package into intrastate commerce, exposure variations shall not be permitted. 
12.2. Magnitude of Permitted Variations. -The magnitude of variations permitted under $\S 12$., 12.1., 12.1.1., and 12.1.2. of this regulation shall be those expressly set forth in this regulation and variations such as those contained in the procedures and tables of National Institute of Standards and Technology Handbook 133, "Checking the Net Contents of Packaged Goods." (Amended 1976, 1980, 1984, 1988)

\section{Section 13. Retail Sale Price Representations}

\section{1. "Cents-off" Representations. --}

(a) The term "cents-off representation" means any printed matter consisting of the words "cents-off" or words of similar import (bonus offer, 2 for 1 sale, I c sale, etc.), placed upon any consumer package or placed upon any label affixed or adjacent to such package, stating or representing by implication that it is being offered for sale at a price lower than the ordinary and customary retail sale price.

(Amended 1982)

(b) Except as set forth in $\S 13.2$, the packager or labeler of a consumer commodity shall not have imprinted thereon a "cents-off" representation unless:

(1) The commodity has been sold at an ordinary and customary price in the most recent and regular course of business where the "cents-off" promotion is made.

(2) The commodity so labeled is sold at a reduction from the ordinary and customary price, which reduction is at least equal to the amount of the "cents-off" representation imprinted on the commodity package or label.

(3) Each "cents-off" representation imprinted on the package or label is limited to a phrase that reflects that the price marked by the retailer represents the savings in the amount of the "cents-off" the retailer's regular price; e.g., "Price Marked is __ Cents Off the Regular Price," "Price Marked is _ $\varepsilon$ off the Regular Price of This Package", provided the package or label may in addition bear in the usual pricing spot a form reflecting a space for the regular price, the represented "cents-off," and a space for the price to be paid by the consumer.

(4) The commodity at retail presents the regular price, designated as the "regular price," clearly and conspicuously on the package or label of the commodity or on a sign, placard, or shelf-marker placed in a position contiguous to the retail display of the "cents-off" marked commodity. (5)(i) Not more than three "cents-off" promotions of any single size commodity may be initiated in the same trade area within a 12-month period;

(5)(ii) At least 30 days must lapse between "cents-off" promotions of any particular size packaged or labeled commodity in a specific trade area; and

(5)(iii) Any single size commodity so labeled may not be sold in a trade area for a duration in excess of 6 months within any 12-month period.

(6) Sales of any single size commodity so labeled in a trade area do not exceed in volume 50 percent of the total volume of sales of such size commodity in the same trade area during any 12-month period. The 12-month period may be the calendar, fiscal, or market year provided the identical period is applied in this subparagraph and subparagraph (5) of this paragraph. Volume limits may be calculated on the basis of projections for the current year but shall not exceed 50 percent of the sales for the preceding year in the event actual sales are less than the projection for the current year.

(c) No "cents-off" promotion shall be made available in any circumstances where it is known or there is reason to know that it will be used as an instrumentality for deception or for frustration of value comparison; e.g., where the retailer charges a price that does not fully pass on to the consumers the represented price reduction or where the retailer fails to display the regular price in the display area of the "cents-off" marked product.

(d) The sponsor of a "cents-off" promotion shall prepare and maintain invoices or other records showing compliance with this section. The invoices or other records required by this section shall be open to inspection and shall be retained for a period of one year subsequent to the end of the year (calendar, fiscal, or market) in which the "cents-off" promotion occurs.

(Added 1972)

\subsection{Introductory Offers. --}

(a) The term "introductory offer" means any printed matter consisting of the words "introductory offer" or words of similar import, placed upon a package containing any new commodity or upon any label affixed or adjacent to such new commodity, stating or representing by implication that such new commodity is offered for retail sale at a price lower than the anticipated ordinary and customary retail sale price. 
(b) The packager or labeler of a consumer commodity may not have imprinted thereon an introductory offer unless:

(1) The product contained in the package is new, has been changed in a functionally significant and substantial respect, or is being introduced into a trade area for the first time.

(2) Each offer on a package or label is clearly and conspicuously qualified.

(3) No commodity so labeled is sold in a trade area for duration in excess of 6 months.

(4) At the time of making the introductory offer promotion, the offerer intends in good faith to offer the commodity, alone, at the anticipated ordinary and customary price for a reasonably substantial period of time following the duration of the introductory offer promotion.

(c) The packager or labeler of a consumer commodity shall not have imprinted thereon an introductory offer in the form of a "cents-off" representation unless, in addition to the requirements in paragraph (b) of this section:

(1) The package or label clearly and conspicuously and in immediate conjunction with the phrase "Introductory Offer" bears the phrase "_ cents-off the after-introductory offer price."

(2) The commodity so labeled is sold at a reduction from the anticipated ordinary customary price, which reduction is at least equal to the amount of the reduction from the after-introductory offer price representation on the commodity package or label.

(d) No introductory offer with a "cents-off" representation shall be made available in any circumstance where it is known or there is reason to know that it will be used as an instrumentality for deception or for frustration of value comparison; e.g., where the retailer charges a price that does not fully pass on to consumers the represented price reduction.

(e) The sponsor of an introductory offer shall prepare and maintain invoices or other records showing compliance with this section. The invoices or other records required by this section shall be open to inspection and shall be retained for a period of 1 year subsequent to the period of the introductory offer.

(Added 1972)

\subsection{Economy Size. --}

(a) The term "economy size" means any printed matter consisting of the words "economy size," "economy pack," "budget pack," "bargain size," "value size," or words of similar import placed upon any package containing any consumer commodity or placed upon any label affixed or adjacent to such commodity, stating or representing directly or by implication that a retail sale price advantage is accorded the purchaser thereof by reason of the size of that package or the quantity of its contents.

(b) The packager or labeler of a consumer commodity may not have imprinted thereon an "economy" size representation unless:

(1) At the same time the same brand of the commodity is offered in at least one other packaged size or labeled form.

(2) Only one packaged or labeled form of that brand of commodity labeled with an "economy size" representation is offered.

(3) The commodity labeled with an "economy size" representation is sold at a price per unit of weight, volume, measure, or count that is substantially reduced (i.e., at least 5 percent) from the actual price of all other packaged or labeled units of the same brand of that commodity offered simultaneously.

(c) No "economy size" package shall be made available in any circumstances where it is known that it will be used as an instrumentality for deception; e.g., where the retailer charges a price that does not pass on to the consumer the substantial reduction in cost per unit initially granted.

(d) The sponsor of an "economy size" package shall prepare and maintain invoices or other records showing compliance with paragraph (b) of this section. The invoices or other records required by this section shall be open to inspection and shall be retained for one year. (Added 1972)

\section{Section 14. Revocation of Conflicting Regulations}

All provisions of all orders and regulations heretofore issued on this same subject that are contrary to or inconsistent with the provisions of this regulation, and specifically are hereby revoked.

\section{Section 15. Effective Date}

This regulation shall become effective on 
Given under my hand and the seal of my office in the

City of , on this day of

\section{SIGNED}

\section{UPLR Appendix A: SI/Inch-Pound Conversion Factors}

\begin{tabular}{|c|c|c|c|c|c|}
\hline \multicolumn{6}{|c|}{ Length } \\
\hline $1 \mathrm{mil}(0.001 \mathrm{in})$ & $=$ & $25.4 \mu \mathrm{m}$ & 1 micrometer & $=$ & 0.00003937 in \\
\hline 1 inch & $=$ & $2.54 \mathrm{~cm}^{*}$ & 1 millimeter & $=$ & $0.0393701 \mathrm{in}$ \\
\hline 1 foot & $=$ & $30.48 \mathrm{~cm}^{*}$ & 1 centimeter & $=$ & 0.393701 in \\
\hline 1 yard & $=$ & $0.9144 \mathrm{~m}^{*}$ & 1 meter & $=$ & $3.28084 \mathrm{ft}$ \\
\hline $1 \mathrm{rod}$ & $=$ & $5.0292 \mathrm{~m}$ & & & \\
\hline \multicolumn{6}{|c|}{ Area } \\
\hline 1 square inch & $=$ & $6.4516 \mathrm{~cm}^{2} *$ & 1 square centimeter & $=$ & $0.155000 \mathrm{in}^{2}$ \\
\hline I square foot & $=$ & $929.030 \mathrm{~cm}^{2}$ & 1 square decimeter & $=$ & $0.107639 \mathrm{ft}^{2}$ \\
\hline 1 square yard & $=$ & $0.836127 \mathrm{~m}^{2}$ & 1 square meter & $=$ & $10.7639 \mathrm{ft}^{2}$ \\
\hline \multicolumn{6}{|c|}{ Volume or Capacity } \\
\hline 1 cubic inch & $=$ & $16.3871 \mathrm{~cm}^{3}$ & 1 cubic centimeter & $=$ & $0.6102374 \mathrm{in}^{3}$ \\
\hline 1 cubic foot & $=$ & $0.0283168 \mathrm{~m}^{3}$ & 1 cubic decimeter & $=$ & $0.0353147 \mathrm{ft}^{3}$ \\
\hline \multirow[t]{2}{*}{1 cubic yard } & \multirow[t]{2}{*}{$=$} & \multirow{2}{*}{$0.764555 \mathrm{~m}^{3}$} & \multirow[t]{2}{*}{1 cubic meter } & $=$ & $35.3147 \mathrm{ft}^{3}$ \\
\hline & & & & $=$ & $1.30795 \mathrm{yd}^{3}$ \\
\hline 1 fluid ounce & $=$ & $29.5735 \mathrm{~mL}$ & 1 milliliter & $=$ & $0.0338140 \mathrm{fl} \mathrm{oz}$ \\
\hline \multirow[t]{2}{*}{1 liquid pint } & \multirow{2}{*}{$\begin{array}{l}= \\
=\end{array}$} & \multirow{2}{*}{$\begin{array}{r}473.177 \mathrm{~mL} \\
0.473177 \mathrm{~L} \\
\end{array}$} & 1 liter & $=$ & 1.05669 liq qt \\
\hline & & & 1 liter & $=$ & $0.264172 \mathrm{gal}$ \\
\hline \multirow[t]{2}{*}{1 liquid quart } & \multirow{2}{*}{$\begin{array}{l}= \\
=\end{array}$} & \multirow{2}{*}{$\begin{array}{l}946.353 \mathrm{~mL} \\
0.946353 \mathrm{~L} \\
\end{array}$} & 1 dry pint & $=$ & $550.6105 \mathrm{~mL}$ \\
\hline & & & 1 dry quart & $=$ & $1.101221 \mathrm{~L}$ \\
\hline 1 gallon & $=$ & $3.78541 \mathrm{~L}$ & 1 peck & $=$ & $8.809768 \mathrm{~L}$ \\
\hline 1 bushel & $=$ & $35.2391 \mathrm{~L}$ & 1 gill & $=$ & 118.2941 \\
\hline \multicolumn{6}{|c|}{ Mass (Weight) } \\
\hline 1 ounce & $=$ & $28.3495 \mathrm{~g}$ & 1 milligram & $=$ & $0.0000352740 \mathrm{oz}$ \\
\hline \multirow[t]{3}{*}{1 pound } & $=$ & $453.59237 \mathrm{~g}^{*}$ & & $=$ & 0.0154324 grain \\
\hline & $=$ & $0.453592 \mathrm{~kg}$ & 1 gram & $=$ & $0.0352740 \mathrm{oz}$ \\
\hline & & & 1 kilogram & $=$ & $2.20462 \mathrm{lb}$ \\
\hline \multicolumn{6}{|c|}{ Temperature } \\
\hline
\end{tabular}

$$
t_{{ }^{\circ} \mathrm{C}}=\frac{5}{9}\left(t_{{ }^{\circ} F}-32\right)^{\circ} \quad t_{{ }^{\circ} F}=1.8 t_{{ }^{\circ} \mathrm{C}}+32^{*}
$$

NOTE 13: These conversion factors are given to six or more significant digits in the event such accuracy is necessary. To convert to inch-pound units divide by the factor rather than multiplying. 


\section{UPLR APPENDIX B: Converting Inch-Pound Units to SI Units for Quantity Declarations on Packages}

Conversion - To convert an inch-pound quantity to an SI quantity, multiply the appropriate conversion factor in Table 1 in Appendix A by the inch-pound unit and round according to the following rules.

Rounding and Significant Digits - It is the packager's responsibility to round converted values appropriately and select the appropriate number of significant digits to use in quantity declaration. [These rounding rules are for converting quantity determinations on packages and do not apply to digital scales that automatically round indications to the nearest indicated value.] Conversions, the proper use of significant digits, and rounding must be based on the packer's knowledge of the accuracy of the original measurement that is being converted. For example; if a package is labeled $453.59 \mathrm{~g}(1 \mathrm{lb})$, the packer is implying that the package declaration is accurate within $\pm 0.005 \mathrm{~g}$ (or $\pm 5 \mathrm{mg}$ ). For liquid volume measure, a label declaration of $473 \mathrm{~mL}(16 \mathrm{fl} \mathrm{oz})$ implies that the package declaration is accurate to within $\pm 0.5 \mathrm{~mL}(0.01 \mathrm{fl} \mathrm{oz})$. The requirements of 6.11.2. Rounding apply to all quantity declarations that are derived from converted values:

6.11.2. Rounding. -- In all conversions for the purpose of showing an equivalent SI or inch-pound quantity to a rounded inch-pound or SI quantity, or in calculated values to be declared in the net quantity statement, the number of significant digits retained must be such that accuracy is neither sacrificed nor exaggerated. Conversions, the proper use of significant digits, and rounding must be based on the packer's knowledge of the accuracy of the original measurement that is being converted. In no case shall rounded net contents declarations overstate a quantity; the packer may round converted values down to avoid overstating the net contents.

To Round - Do not round conversion factors or any other quantity used or determined in the calculation; only round the final quantity to the number of significant digits needed to maintain the accuracy of the original quantity. Use the rounding rules presented below in Table 1 as guidance to round the final result. In general, quantity declarations on consumer commodities should only be shown to two or three significant digits (for example, $453 \mathrm{~g} \mathrm{or} 85 \mathrm{~g}$ ). Any final zeros to the right of the decimal point need not be expressed. The inch-pound and SI declarations of quantity must be accurate and equivalent to each other. For example, a package bearing a net weight declaration of $2 \mathrm{lb}(32 \mathrm{oz})$ must also include an SI declaration of $907 \mathrm{~g}$.

Table 1. Rounding Rules

\begin{tabular}{|c|c|c|}
\hline When The First Digit Dropped is: & The Last Digit Retained is: & Examples \\
\hline$<5$ & Unchanged & 2.44 to 2.4 \\
& & 2.429 to 2.4 \\
$>5$, or 5 followed by at least 1 & Increased by 1 & 2.46 to 2.5 \\
digit other than 0 & & 2.451 to 2.5 \\
5 followed by zeros & Unchanged if Even, or Increased by & 2.450 to 2.4 \\
& 1 if Odd & 2.550 to 2.6 \\
\hline
\end{tabular}

(a) When the first digit discarded is less than five, the last digit retained should not be changed. For example, if the quantity 984.3 is to be declared to three significant digits, the figure 3 to the right of the decimal point must be discarded since it is less than 5 and the last digit to be retained (the figure "4") will remain unchanged. The rounded number will read 984 . The same rationale applies to numbers declared to two significant digits (for example 68.4 and 7.34); again the final digit is dropped and the last digit retained remains unchanged so that the "rounded-off" numbers become 68 and 7.3 respectively.

(b) When the first digit to be discarded is greater than five, or it is a five followed by at least one digit other than zero, the last digit to be retained should be increased by one unit. 


\begin{tabular}{|c|c|c|c|}
\hline \multirow[t]{4}{*}{ Examples: } & 984.7 & becomes & 985 \\
\hline & 984.51 & becomes & 98 \\
\hline & 6.86 & becomes & \\
\hline & 6.88 & becomes & \\
\hline
\end{tabular}

(c) When the first digit to be discarded is exactly five, followed only by zeros, the final digit to be retained should be rounded up if it is an odd number $(1,3,5,7$, or 9$)$, but no adjustment should be made if it is an even number $(2,4,6$, or 8$)$.

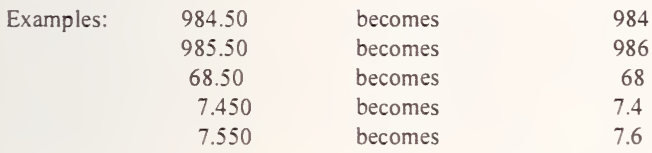

\section{Examples}

Weight: to convert ounces to grams - multiply ounces x 28.3495 grams to convert pounds to kilograms - multiply pounds x .453 59237 kilogram

$\begin{array}{lll}\begin{array}{l}\text { Inch-pound } \\ \text { Quantity }\end{array} & \begin{array}{l}\text { Calculated SI } \\ \text { Quantity }\end{array} & \begin{array}{l}\text { Rounded SI } \\ \text { Quantity }\end{array} \\ 1.0 \mathrm{oz} & 28.3495 \mathrm{~g} & 28 \mathrm{~g} \\ 5.0 \mathrm{oz} & 141.7476 \mathrm{~g} & 142 \mathrm{~g}^{*} \\ 10 \mathrm{1} / 4 \mathrm{oz} & 290.58238 \mathrm{~g} & 291 \mathrm{~g}^{*} \\ 16.0 \mathrm{oz} & 453.5924 \mathrm{~g} & 454 \mathrm{~g}^{*} \\ 32.0 \mathrm{oz} & 907.184 \mathrm{~g} & 907 \mathrm{~g} \\ 48.0 \mathrm{oz} & 1360.776 \mathrm{~g} & 1.36 \mathrm{~kg} \\ & & \\ 5 \mathrm{lb} & 2.26796185 \mathrm{~kg} & 2.27 \mathrm{~kg}^{*} \\ 10 \mathrm{lb} & 4.5359237 \mathrm{~kg} & 4.54 \mathrm{~kg}^{*} \\ 25 \mathrm{lb} & 11.33980925 \mathrm{~kg} & 11.3 \mathrm{~kg}^{2}\end{array}$

Liquid Volume: $\quad$ to convert fluid ounces to milliliters multiply fluid ounces $\times 29.5735$ milliliters to convert quarts to liters - multiply quarts $\mathrm{x} 0.947353$ milliliters to convert gallons to liters - multiply gallons $\times 3.78541$ liter

$\begin{array}{llc}\begin{array}{l}\text { Inch-pound } \\ \text { Quantity }\end{array} & \begin{array}{l}\text { Calculated Sl } \\ \text { Quantity }\end{array} & \begin{array}{l}\text { Rounded S } \\ \text { Quantity }\end{array} \\ 1.0 \mathrm{fl} \mathrm{oz} & 29.5735 \mathrm{~mL} & 30 \mathrm{~mL}^{*} \\ 8.0 \mathrm{fl} \mathrm{oz} & 236.588 \mathrm{~mL} & 237 \mathrm{~mL}^{*} \\ 16.0 \mathrm{fl} \mathrm{oz} & 473.176 \mathrm{~mL} & 473 \mathrm{~mL} \\ 32.0 \mathrm{fl} \mathrm{oz} & 947.353 \mathrm{~mL} & 947 \mathrm{~mL} \\ & & \\ 1 \mathrm{gal} & 3.78541 \mathrm{~L} & 3.79 \mathrm{~L}^{*} \\ 2 \mathrm{~g} / 2 \mathrm{gal} & 9.463525 \mathrm{~L} & 9.46 \mathrm{~L} \\ 5 \mathrm{gal} & 18.92705 \mathrm{~L} & 18.9 \mathrm{~L}\end{array}$

* See $\mathrm{E}$ in Section 3 
Dry Measure:

to convert dry pints to milliliters - multiply dry pints x 550.610 5 milliliters to convert dry quarts to liters - multiply dry quarts x 1.101221 liters

$\begin{array}{lll}\begin{array}{l}\text { Inch-pound } \\ \text { Quantity }\end{array} & \begin{array}{l}\text { Calculated SI } \\ \text { Quantity }\end{array} & \begin{array}{l}\text { Rounded SI } \\ \text { Quantity }\end{array} \\ 1 \text { dry pt } & 550.6105 \mathrm{~mL} & 551 \mathrm{~mL}^{*} \\ 1 \text { dry qt } & 1.101221 \mathrm{~L} & 1.1 \mathrm{~L}\end{array}$

Length: to convert inches to millimeters - multiply inches $\times 25.4$ millimeters to convert feet to centimeters - multiply feet $\mathrm{x} 30.48$ centimeters to convert feet to meters - multiply feet $x 0.3048006$ meters

$\begin{array}{lll}\begin{array}{l}\text { Inch-pound } \\ \text { Quantity }\end{array} & \begin{array}{l}\text { Calculated SI } \\ \text { Quantity }\end{array} & \begin{array}{l}\text { Rounded SI } \\ \text { Quantity }\end{array} \\ 1 \mathrm{in} & 25.4 \mathrm{~mm} & 25 \mathrm{~mm} \\ 10.5 \mathrm{in} & 266.7 \mathrm{~mm} & 267 \mathrm{~mm}^{*} \text { or } 26.7 \mathrm{~cm}^{*} \\ 1 \mathrm{ft} & 30.48 \mathrm{~cm} & 305 \mathrm{~mm}^{*} \text { or } 30.5 \mathrm{~cm}^{*} \\ 5 \mathrm{ft} & 152.4 \mathrm{~cm} & 152 \mathrm{~cm} \text { or } 1.5 \mathrm{~m} \\ & & 15.2 \mathrm{~m} \\ 50 \mathrm{ft} & 15.24003 \mathrm{~m} & 30.5 \mathrm{~m}^{*}\end{array}$

* See E in Section 3

\section{Additional Advice on Rounding and Significant Digits}

A. These rules require the packer to use good judgement in making decisions on how to round and the number of significant digits to use in quantity declarations. Rounding should always be done in one step; for example, if $16.94647 \mathrm{~g}$ has to be rounded to 3 significant digits, it should be rounded to $16.9 \mathrm{~g}$, not 16.9465 , then to 16.946 , then to 16.95 which would then round to $17.0 \mathrm{~g}$ (See rounding rules above).

B. Do not use rounded SI values to calculate quantities. For example, using $1 \mathrm{inch}=25.4 \mathrm{~mm}$, rounded to $25 \mathrm{~mm}$, should not be multiplied by 2 to determine the SI equivalent for 2 inches. The SI equivalent for 2 in is determined by multiplying 2 in $x 25.4 \mathrm{~mm}=50.8 \mathrm{~mm}$, then rounding to $51 \mathrm{~mm}$.

C. If a dimension given as 8 feet is valid to the nearest $1 / 10$ inch, consider it to mean 96.0 inches and treat it as having 3 significant digits. The rounded dimension would then be $2.44 \mathrm{~m}$ instead of $2.4 \mathrm{~m}$.

D. Conversions using a multiple digit conversion factor usually give a product with more digits than the original quantity. The final product should contain no more significant digits than are contained in the number with the fewest significant digits used in the conversion. For example, the area of a sheet of paper is determined on a calculator by multiplying $1.25 \mathrm{~cm}$ (length) $\mathrm{x} 1.5 \mathrm{~cm}($ width $)=1.875 \mathrm{~cm}^{2}$. The product given to 4 significant digits on the calculator cannot be any more accurate than 2 significant digits (the number of significant digits in $1.5 \mathrm{~cm}$ ), so the area should be declared as $1.9 \mathrm{~cm}^{2}$.

E. Packagers of consumer commodities should be aware that when a converted value is rounded up, there may be a need to (1) increase the package contents and/or, (2) select a converted value that does not exaggerate the precision of the quantity or overstate the net contents. For example, under the rules above, a net weight declaration of $16 \mathrm{oz}(453.592437 \mathrm{~g}$ ) would be rounded up $0.4 \mathrm{~g}$ to $454 \mathrm{~g}$ for 3 significant digits. Inspections by weights and measures officials are typically conducted using devices with a resolution of $0.5 \mathrm{~g}$ or less. If the packer does not address this possibility, some lots of commodities may pass when the inch-pound declaration is tested, but fail when the SI declaration is verified. 


\section{Appendix B \\ 2.6.8. Commodities Under Federal Trade Commission Jurisdiction Under the Fair Packaging and Labeling Act and Exclusions.}

\subsubsection{Commodities Under Federal Trade Commission Jurisdiction Under the Fair Packaging and Labeling Act and Exclusions.}

This list indicates the commodities and commodity groups that are not within the scope of the Fair Packaging and Labeling Act administered by the Federal Trade Commission (FTC). The following codes appear with each commodity and designate the reason that the particular commodity has been excluded.

BATF - designates commodities subject to laws administered by the Bureau of Alcohol Tobacco and Firearms.

CI (Commission Interpretation) - designates those categories that have been excluded by the Commission in the light of legislative history of the definition of "consumer commodity". By applying this definition to individual commodities, the Commission has more narrowly applied the latter term and set forth a list of items that do not meet the criteria of consumer commodities. On occasion the Commission is requested in both a formal and informal manner to consider individual products and to determine their status relative to the definition of "consumer commodity" as it is used in the Act

EPA - designates commodities subject to the Federal Environmental Pest Control Act of 1972 administered by the Environmental Protection Agency.

FDA - designates those commodities which are subject to regulation by the Food and Drug Administration either under the portion of the FPLA administered by that agency or the Federal Food, Drug and Cosmetic Act. (Section IO(a) (3) and Section 7 of the FPLA). Following the code FDA will be a letter further designating the commodity as either a food (f), drug (d), cosmetic (c), or device (dv).

USDA - designates those commodities excluded from jurisdiction by Section 10(a) of the FPLA and represents a commodity within one of the following categories: Meat or meat products, poultry or poultry products, or tobacco or tobacco products.

It may be of some help in ascertaining whether a particular product is or is not included within the
FPLA definition of "consumer commodity" and thus subject to FTC jurisdiction under that Act, to refer to the following definition:

". . . Any article, product, or commodity of any kind or class which is customarily produced or distributed for sale through retail sales agencies or instrumentalities for consumption by individuals, or use by individuals for purposes of personal care or in the performance of services ordinarily rendered within the household, and which is usually consumed or expended in the course of such use."

By applying these criteria to the particular product in question and then reviewing the list of excluded commodities, the observer will be able, in most instances, to determine the status of the item. In the event, however, that the observer is unable to ascertain whether a particular commodity is covered or excluded from FTC jurisdiction, contact FTC for an opinion.

\section{Commodities Excluded From FTC Jurisdiction}

\author{
ADHESIVE TAPE (FDA-D) \\ ALCOHOLIC BEVERAGES (BATF) \\ ALUMINUM CLOTHESLINE (plastic clothesline \\ with a steel core) $(\mathrm{CI})$ \\ ANTIFREEZE (CI) \\ ARTIFICIAL FLOWERS AND PARTS (CI) \\ AUTOMOTIVE ACCESSORIES (floor mats, seat \\ covers, spare parts, etc.) (CI) \\ AUTOMOTIVE CHEMICAL PRODUCTS (auto \\ polish, wax, and finish conditioner, rubbing \\ compound, tire paint, chrome polish, gasoline \\ additives, etc.) (CI)
}

\section{BATH OIL AND BUBBLE BATH (FDA-C) BICYCLE TIRES AND TUBES (CI) \\ BOOKS (CI) \\ BOTTLED GAS (cooking or heating) (Cl)}

BRUSHES (bristle, nylon, etc., including hairbrushes, toothbrushes, hand and nail brushes, paint brushes, etc.) (CI)

BROOMS AND MOPS (glass, floor and dish mops, etc.) $(\mathrm{Cl})$

"BUG PROOF" SHELF PAPER (EPA)

CANDLE HOLDERS (without candles) (Cl)

CAMERAS $(\mathrm{CI})$

CHINAWARE (Cl)

CHRISTMAS LIGHT SETS (replacement or other 
bulbs sold separately are not excluded) (CI)

CIGARETTE LIGHTERS (CI)

CLOTHESPINS (CI)

CLOTHING AND WEARING APPAREL (socks, gloves, shoelaces, underwear, etc.) $(\mathrm{Cl})$

COMPACTS AND MIRRORS (CI)

COSMETICS (Defined by Section 20I(i) of the Food, Drug, and Cosmetic Act as "(l) articles intended to be rubbed, poured, sprinkled, or sprayed on, introduced into, or otherwise applied to the human body or any part thereof for cleansing, beautifying, promoting 9 attractiveness, or altering the appearance, and (2) articles intended for use as a component of any such articles; except that such term shall not include soap.") (FDA-C)

COTTON PUFFS (Sterilized) (FDA-D)

CRYSTALWARE (CI)

DETERGENT BAR WITH ANY DRUG OR COSMETIC CLAIM (If the observer experiences difficulty in ascertaining whether or not a given product is a soap or a detergent contact the manufacturer or FDA)

DECORATIVE MAGNETS $(\mathrm{Cl})$

DEVICES (Defined by Section 20I(h) of the Food, Drug, and Cosmetic Act as "instruments, apparatus, and contrivances, including their components, parts, and accessories, intended (I) for use in the diagnosis, cure, mitigation, treatment, or prevention of disease in man or other animals; or (2) to affect the structure or any function of the body of man or other animals." This category includes trusses, syringes, arch supports, etc.) (FDA-DV)

DIARIES AND CALENDARS (CI)

DISINFECTANTS (EPA)

DRUGS (Defined by Section 20l(g) (I) of the Food, Drug, and Cosmetic Act as "(a) articles recognized in the official United States Pharmacopeia, official Homeopathic Pharmacopeia, or official National Formulary, or any supplement to any of them; and (b) articles intended for use in the diagnosis, cure, mitigation, treatment, or prevention of disease in man or other animals; and (c) articles (other than food) intended to affect the structure or any function of the body of man or other animals; and (d) articles intended for use as a component of any articles specified in clause (a), (b) or (c); but does not include devices or their components, parts, or accessories.") (FDA-D)

DURABLE ARTICLES OR COMMODITIES (CI)

EPA COVERED PRODUCTS (Products subject to regulation under the Federal Environmental Pesticide Control Act that is administered by the Environmental Protection Agency (EPA)

FINGERNAIL FILES (CI)

FLOWERS, FLOWER SEEDS, FERTILIZER, AND

FERTILIZER MATERIALS, PLANTS OR SHRUBS,
GARDEN AND LAWN SUPPLIES (CI)

FOOD (Defined by Section 20I(f) of the Food, Drug, and Cosmetic Act as "(I) articles used for food and drink for man or other animals, (2) chewing gum, and (3) articles used for components of any such article.") (FDA-F)

FOUNTAIN PENS, MECHANICAL PENCILS, AND KINDRED PRODUCTS (ball point pens, lead pencils, and lead refills, etc.) (CI)

GARDEN TOOLS (hose, trowels, grass clippers, etc.) (Cl)

GERMKILLING OR GERMPROOFING PRODUCTS (EPA)

GIFT TAPE AND TIES (ribbon, tape, etc.) (CI)

GIFT WRAPPING MATERIAL (decorative wrapping foil, paper, cellophane, etc.) (CI)

GLASSES AND GLASSWARE (disposable plastic glasses are not excluded) (CI)

GLOVES (of any type) (CI)

GREETING CARDS (CI)

HAIR COMBS, NETS, and PINS (FDA-DV)

HAND TOOLS $(\mathrm{Cl})$

HANDICRAFT AND SEWING THREAD (yarn, etc.) (CI)

HARDWARE (extension cords, thumb-tacks, hose clamps, nails, screws, picture hangers, etc.) (CI)

HOUSEHOLD APPLIANCES, EQUIPMENT, OR FURNISHINGS, INCLUDING FEATHER AND DOWN-FILLED PRODUCTS, SYNTHETICFILLED BED PILLOWS, MATTRESS PADS AND PATCHWORK QUILTS, COMFORTERS, AND DECORATIVE CURTAINS (CI)

INK (CI)

INSECTICIDES (insect repellents in any form, mothballs, etc.) (EPA)

IRONING BOARD COVERS (CI)

JEWELRY (CI)

LAMBS WOOL DUSTERS (CI)

LUGGAGE (CI)

MAGNETIC RECORDING TAPE (reels, cassettes, and cartridges.) (CI)

MEAT AND MEAT PRODUCTS (USDA)

METAL PAILS (CI)

MOTOR OIL (including additives. Household multipurpose oil is not excluded) $(\mathrm{CI})$

MOUSE AND RAT TRAPS (CI)

MOUTHWASH (FDA-D)

MUSICAL INSTRUMENTS $(\mathrm{Cl})$

PAINTS AND KINDRED PRODUCTS (wallpaper, turpentine, putty, paint removers, caulking and glazing compounds, wood fillers, etc. Note, however, that 
bathroom caulking materials are not excluded as are patching plaster, spackling compound, and plastic wood. In the event of uncertainty, contact FTC.) (CI) PAINTINGS AND WALL PLAQUES (CI)

PET CARE SUPPLIES (CI)

PEWTERWARE (CI)

PHOTO ALBUMS (CI)

PICTURES (CI)

PLASTIC BUCKETS AND GARBAGE CANS (CI) PLASTIC TABLECLOTHS, PLASTIC PLACE MATS (CI)

PLASTIC SHELF LINING (CI)

PRE-MOISTENED TOWELETTES (FDA-C)

POLISHING CLOTHS (polishing cloths that are impregnated with polish or chemicals (silicone, etc.) are not excluded) (CI)

POULTRY AND POULTRY PRODUCTS (USDA)

RUBBER GLOVES (CI)

RUBBING ALCOHOL (FDA-D)

SAFETY FLARES (CI)

SAFETY PINS (CI)

SANITARY NAPKINS (FDA-D or C)

SCHOOL SUPPLIES (rulers, crayons, paper, pencils, etc.) (CI)

SELF STICK PROTECTIVE FELT TABS (CI)

SEEDS OF ALL KINDS (USDA)

SEWING ACCESSORIES (needles of any type, thimbles, kindred articles, etc.) (CI)

SHAMPOO (FDA-C or D)

SHOELACES $(\mathrm{CI})$

SMALL ARMS AMMUNITION (CI)

SILVERWARE, STAINLESS STEELWARE, AND PEWTERWARE (CI)

SMOKING PIPES (CI)

SOAP BARS WITH A DRUG CLAIM (Including any claim for removing facial blemishes, etc. Refer to Detergent Bars for further discussion in this area.) (FDA-D)

SOAP DISHES (CI)

SOUVENIRS $(\mathrm{CI})$

SPORTING GOODS (CI)

STATIONERY AND WRITING SUPPLIES (looseleaf binders, paper tablets, etc.) (CI)

TEXTILES AND ITEMS OF WEARING APPAREL (cloth laundry bags, towels, cheese cloth, shoe shine cloths, etc.) (CI)

TOBACCO AND TOBACCO PRODUCTS (pipes, cigarettes, etc.) (BATF - USDA)

TOOTHPASTE (FDA-D)

TOYS (CI)

TYPEWRITER RIBBON (CI)

WIRE OF ANY TYPE (CI)

WOODENWARE (CI) 


\section{Commodities Included Under FTC Jurisdiction}

1. Soaps and Detergents
a. Powder, flakes, chips, etc.
b. Liquid
c. Paste, cake, or tablet

8. Household Supplies

2. Cleaning Compounds
a. Liquid
b. Powder
c. Paste or cake

3. Laundry Supplies
a. Conditioners and softeners, ironing aids, distilled water.
b. Sizings and starches
c. Bluings and bleaches
d. Pre-soaks, enzymes, etc.

4. Cleaning Devices
a. Sponges
b. Steel wool, scouring, and soap pads
c. Chamois

5. Food Wraps
a. Plastic and cellophane
b. Wax paper and paper
c. Foil

6. Paper Products
a. Toweling
b. Napkins, table cloths, and place mats
c. Facial tissues
d. Bathroom tissues
e. Disposable diapers
f. Crepe paper
g. Other, e.g., shelf paper, wrapping paper, eye glass tissues, etc.

7. Waxes and Polishes
a. Powder
b. Liquid
c. Paste and cake
d. Other, e.g., polish impregnated cloths, scratch removers, etc.
a. Matches
b. Candles and holders
c. Toothpicks
d. Cordage (string, twine, rope, clothes line, etc.)
e. Drinking straws
f. Lighter and propane torch fuel, flints, pipe cleaners, etc.
g. Household lubricants
h. Picnic supplies
i. Sand paper and emory paper
j. Charcoal briquets, chips, logs, etc.
k. Dyes and tints
l. Camera film and photo supplies
m. Protective fabric sprays

9. Containers
a. Paper (plain, waxed, or plastic coated)
b. Foil
c. Plastic or styrofoam

10. Air Fresheners and Deodorizers

a. Potpourri 


\title{
Report of the Specifications and Tolerances Committee
}

\author{
Charles H. Carroll, Chairman \\ Director, Department of Weights and Measures \\ Massachusetts
}

\section{Introduction}

This is the Final Report of the Specifications and Tolerances Committee for the 78th National Conference on Weights and Measures. This report is based on the Interim Report offered in the Conference "Program and Committee Reports" (NCWM Publication 16), the Addendum Sheets issued at the Annual Meeting, and actions taken by the membership at the Voting Session of the Annual Meeting.

Table A identifies the items in the Report by Reference Key Number, Item Title, and Page Number. The item numbers are those assigned in the Interim Meeting Agenda. Voting items are indicated with a "V" after the item number. Consent calendar items are marked with a "VC." Items marked with an "l" after the reference key number are information items. The items marked with a "W" were withdrawn by the Committee. Items marked with a "W" generally will be referred back to the regional weights and measures associations because they either need additional development, analysis, and input, or did not have sufficient support of the Committee to bring them before the NCWM.

The attached Report contains many recommendations to revise or amend National Institute of Standards and Technology (NIST) Handbook 44, 1993 Edition, "Specifications, Tolerances, and other Technical Requirements for Weighing and Measuring Devices." Proposed revisions to the handbook are shown in bold face print by ersing what is to be deleted, and underlining what is to be added. Requirements that are proposed to be nonretroactive are printed in italics. Entirely new paragraphs or sections proposed for addition to the handbook are designated as such and shown in bold face print.

Note: The policy of the National Institute of Standards and Technology is to use metric units of measurement in all of its publications; however, recommendations received by the NCWM technical committees have been printed in this publication, as they were submitted and, may therefore contain references to inch-pound units.

Table A

Index to Reference Key Items

Reference

Key No.

Title of Item

Page

\section{General Code}

310-1 V Provision for Sealing Electronic Adjustable Components; Audit Trails. . . . . . . . . . . . 287

310-2 V G-S.8. Provision for Sealing Electronic Adjustable Components and Scales Code S.1.11.

Provision for Sealing . . . . . . . . . . . . . . . . . . . . . . . 291

310-3 VC G-UR.3.4. Responsibility, Money-Operated Devices . . . . . . . . . . . . . . . . . 292

310-4 I User-Programmable Software; Manufacturer-Modified Software . . . . . . . . . . . . . . 293

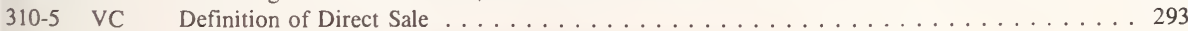


Reference

Key No.

\section{Scales Code}

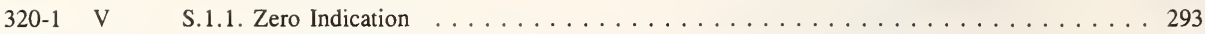

320-2 VC S.1.13. Vehicle On-Board Weighing Systems: Operation When in Motion . . . . . . . . . 294

320-3 V S.4. Design of Weighing Elements and S.5. Accuracy Class . . . . . . . . . . . . . 295

320-4 V N.X. Uncoupled-in-Motion Railroad Weighing Systems; Test Procedure . . . . . . . . . . . 298

320-5A V Coupled-in-Motion Railroad Weighing Systems for the Sale of Liquids in Individual Tank Cars and Commodities in Individual Cars in Mixed Merchandise Trains . . . . . . . . . . . . . . 299

320-5B V N.4.3.1.1. Initial Verification; Coupled-in-Motion Railroad Weighing Systems . . . . . . . 302

320-6 W T.N.3.6. Coupled-in-Motion Railroad Weighing Systems; Custody Transfer of Liquids in Individual $\mathrm{Cars} \ldots \ldots \ldots \ldots \ldots \ldots 303$

320-7 I UR.1.5. Selection Requirements; Suitability of Equipment . . . . . . . . . . . . . . 303

320-8 W UR.1. Selection Requirements; Use of Stored Vehicle Tare Weights . . . . . . . . . . . 304

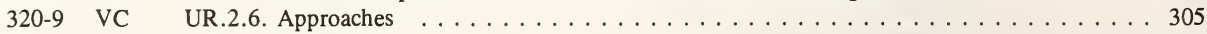

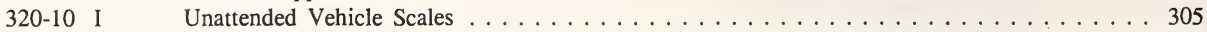

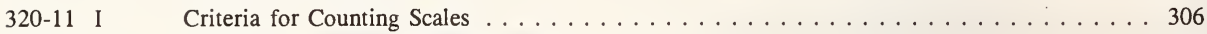

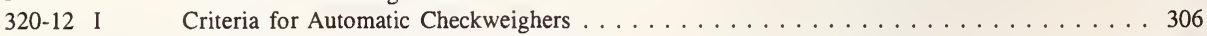

320-13 I $\quad$ Definition of Concentrated Load Capacity . . . . . . . . . . . . . . . . . . . 307

320-14 I NCWM Position on OIML Influence Factors and Disturbance Tests . . . . . . . . . . . . 307

320-15 I Additional Agenda Item: Minimum Amount of Test Weight Required in N.4 . . . . . . . 308

\section{Belt-Conveyor Scale Systems Code}

321-1 VC S.1.4. Recording Elements and Recorded Representations. . . . . . . . . . . . . . . . . . . . . . . . . . . . .

321-2 VC N.3.2.1. Accuracy of Material and T.1. Tolerance Values .................. . . . . . . .

\section{Automatic Bulk Weighing Systems Code}

322-1 VC S.3. Interlocks and Gate Control

\section{Liquid-Measuring Devices}

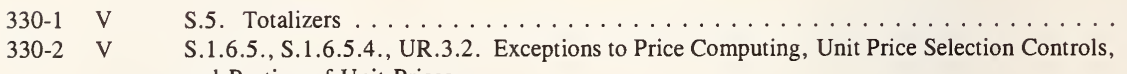

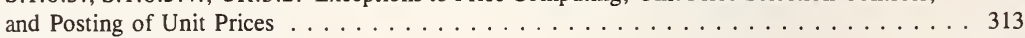

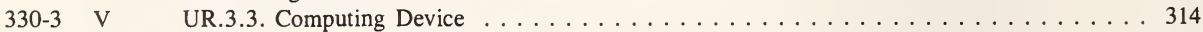

330-4 VC Definition of Contract or Club Sale . . . . . . . . . . . . . . . . . . . . . . 315

330-5 I T.2.3.4. Automatic Temperature Compensating Systems; Accuracy of the Temperature

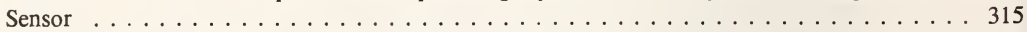

330-6 W T.2.4. Tolerances for Meters Measuring Automotive Fluids . . . . . . . . . . . . . . 316

330-7 W Blending at the Loading Rack for Wholesale Transactions; Adjustments for Changes in Product

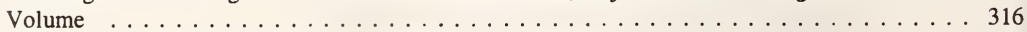

330-8 I UR.1.X. Selection Requirements; Suitability of Equipment $\ldots \ldots \ldots \ldots$

\section{Vehicle-Tank Meters Code}


Table A (Continued)

Reference

Key No.

Title of Item

Page

\section{Liquefied Petroleum Gas and Anhydrous Ammonia Liquid-Measuring Devices Code}

$332-1 \quad I$

T.3. Automatic Temperature-Compensating Systems; Accuracy of the Temperature Sensor . . 320

\section{Cryogenic Liquid-Measuring Devices Code}

334-1 I S.2.4. Automatic Temperature or Density Compensation .............. . . 321

\section{Tentative Code - Mass Flow Meters}

337-1 VC

$337-2 \quad I$

337-3 V

$337-4$ VC

337-5 I

354-1
S.1.2.2. Mass Measurement

S.1.2.6. Units of Measure for Natural Gas Sold as an Engine Fuel

T.2. Tolerances for Liquid-Measuring Devices; T.5. Type Evaluation Examinations . . . . 327

Requirements for Retail Computing Devices and Interlocks . . . . . . . . . . . . . . 327

Tentative Status of the Code . . . . . . . . . . . . . . . . . . 328

\section{Taximeters Code}

\section{Grain Moisture Meters Code}

356-1 V NTEP Sectors for Grain Measurement Equipment 330

\section{Other Items}

360-1 I Volume Measuring Machines for Shipping Charges . . . . . . . . . . . . . 336

360-2 W Proposed Code for Hot Water Meters . . . . . . . . . . . . . . . . . . . . . 337

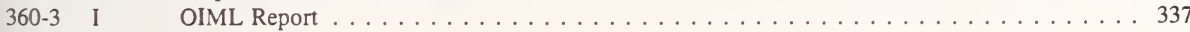

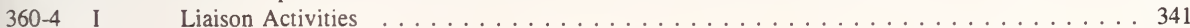


Specifications and Tolerances Committee

\begin{tabular}{|c|c|c|c|c|c|}
\hline \multicolumn{6}{|c|}{ Table B } \\
\hline \multicolumn{6}{|c|}{ Voting Results } \\
\hline & \multicolumn{2}{|c|}{$\begin{array}{l}\text { House of State } \\
\text { Representatives }\end{array}$} & \multicolumn{2}{|c|}{ House of Delegates } & \multirow[t]{2}{*}{ Results } \\
\hline Reference Key No. & Yes & No & Yes & No & \\
\hline 300 (Revised Consent Calendar) & 45 & 0 & 71 & 0 & Passed \\
\hline $\begin{array}{c}310-2,320-1,320-4,320-5 \mathrm{~B}, 330-1,330-2, \\
\text { and } 330-3 \text { (Removed from the Consent } \\
\text { Calendar and voted on in a single block) }\end{array}$ & 42 & 1 & 64 & 2 & Passed \\
\hline $310-1$ & 44 & 1 & 64 & 3 & Passed \\
\hline $320-3$ & 45 & 0 & 67 & 0 & Passed \\
\hline $320-5 \mathrm{~A}$ & 19 & 22 & 30 & 35 & Split Vote \\
\hline $331-2$ & 39 & 4 & 65 & $\bullet$ & Passed \\
\hline $337-3$ & 30 & 11 & 44 & 11 & Passed \\
\hline $\begin{array}{l}\text { 356-1 (Motion to hear amendment to make } \\
\text { informational item) }\end{array}$ & 27 & 5 & 52 & 11 & Passed \\
\hline $\begin{array}{l}\text { 356-1 (Motion to amend to make } \\
\text { informational item) }\end{array}$ & 12 & 27 & 29 & 34 & Failed \\
\hline 356-1 (Original item) & 31 & 6 & 51 & 11 & Passed \\
\hline 300 (in entirety) & 43 & 0 & 64 & 0 & Passed \\
\hline
\end{tabular}




\section{Details of All Items}

\section{General Code}

\section{0-1 V Provision for Sealing Electronic Adjustable Components; Audit Trails.}

(This item was adopted.)

\section{Source: Carryover Item 310-1}

Recommendation: The issue of the minimum forms of audit trails has in recent years been discussed in terms of General Code paragraph G.S.8. Provision for Sealing Electronic Components. The Committee recommends that the following requirements for audit trails be added to the Scales and Liquid-Measuring Devices Codes to specify the acceptable forms of audit trail for three different categories of devices. The Committee believes that these changes to two different codes must be voted on as a single item to ensure consistency in the requirements.

Add the following definitions.

audit trail. An electronic count and/or information record of the changes to the values of the calibration or configuration parameters of a device.

calibration parameter. Any adjustable parameter that can affect measurement or performance accuracy and, due to its nature, needs to be updated on an ongoing basis to maintain device accuracy, e.g., span adjustments, linearization factors, and coarse zero adjustments.

configuration parameter. Any adjustable or selectable parameter for a device feature that can affect the accuracy of a transaction or can significantly increase the potential for fraudulent use of the device and, due to its nature, needs to be updated only during device installation or upon replacement of a component, e.g., division value (increment), sensor range, and units of measurement.

event counter. A nonresettable counter that increments once each time the mode that permits changes to sealable parameters is entered and one or more changes are made to sealable calibration or configuration parameters of a device.

event logger. A form of audit trail containing a series of records where each record contains the number from the event counter corresponding to the change to a sealable parameter, the identification of the parameter that was changed, the time and date when the parameter was changed, and the new value of the parameter.

remote configuration capability. The ability to adjust a weighing or measuring device or change its sealable parameters from or through some other device that is not itself necessary to the operation of the weighing or measuring device or is not a permanent part of that device.

Amend the Scales Code paragraph S.1.11. by adding a new nonretroactive part (c) and the following table.

\section{S.1.11. Provision for Sealing.}

(a) Except on Class I scales, provision shall be made for applying a security seal in a manner that requires the security seal to be broken before an adjustment can be made to any component affecting the performance of an electronic device.

[Nonretroactive as of January 1, 1979.] 
Specifications and Tolerances Committee

(b) Except on Class I scales, a device shall be designed with provision(s) for applying a security seal that must be broken, or for using other approved means of providing security (e.g., data change audit trail available at the time of inspection), before any change that affects the metrological integrity of the device can be made to any electronic mechanism.

[Nonretroactive as of January 1, 1990.]

(c) Except on class I scales, audit trails shall use the format set forth in Table S.1.11.

\begin{tabular}{|c|c|}
\hline \multicolumn{2}{|c|}{ Table S.1.11. Categories of Device and Methods of Sealing } \\
\hline Categories of Device & Method of Sealing \\
\hline $\begin{array}{l}\text { Category 1: No remote configuration } \\
\text { capability }\end{array}$ & $\begin{array}{l}\text { Seal by physical seal or two event counters: one for } \\
\text { calibration parameters and one for configuration parameters. }\end{array}$ \\
\hline $\begin{array}{l}\text { Category 2: Remote configuration capability, } \\
\text { but access is controlled by physical hardware } \\
\text { Device shall clearly indicate that it is in the } \\
\text { remote configuration mode and record such } \\
\text { message if capable of printing in this mode. }\end{array}$ & $\begin{array}{l}\text { The hardware enabling access for remote communication } \\
\text { must be at the device and sealed using a physical seal or two } \\
\text { event counters: one for calibration parameters and one for } \\
\text { configuration parameters. }\end{array}$ \\
\hline $\begin{array}{l}\text { Category 3: Remote configuration capability } \\
\text { access may be unlimited or controlled } \\
\text { through a software switch (e.g., password) }\end{array}$ & $\begin{array}{l}\text { An event logger is required in the device; it must include an } \\
\text { event counter (000 to 999), the parameter ID, the date and } \\
\text { time of the change, and the new value of the parameter. A } \\
\text { printed copy of the information must be available through the } \\
\text { device or through another on-site device. The event logger } \\
\text { shall have a capacity to retain records equal to ten times the } \\
\text { number of sealable parameters in the device, but not more } \\
\text { than } 1000 \text { records are required. (Note: Does not require } \\
1000 \text { changes to be stored for each parameter.) }\end{array}$ \\
\hline
\end{tabular}

EEffective and nonretroactive as of January 1, 1995.]

The Committee recommends that paragraph S.2.2. of the Liquid-Measuring Devices Code be amended by adding subparagraphs (c) and (d) along with the table shown below.

S.2.2. Provision for Sealing. - Adequate provision shall be made for an approved means of security (e.g., data change audit trail) or physically applying security seals in such a manner that no adjustment may be made of:

(a) any measurement element, or

(b) any adjustable element for controlling delivery rate when such rate tends to affect the accuracy of deliveries.

When applicable, the adjusting mechanism shall be readily accessible for purposes of affixing a security seal.

(c) Except for retail motor-fuel dispensers, audit trails shall use the format set forth in Table S.2.2. 


\begin{tabular}{|c|c|}
\hline \multicolumn{2}{|c|}{ Table S.2.2. Categories of Device and Methods of Sealing } \\
\hline Categories of Device & Method of Sealing \\
\hline $\begin{array}{l}\text { Category 1: No remote configuration } \\
\text { capability }\end{array}$ & $\begin{array}{l}\text { Seal by physical seal or two event counters: one for } \\
\text { calibration parameters and one for configuration parameters. }\end{array}$ \\
\hline $\begin{array}{l}\text { Category 2: Remote configuration capability, } \\
\text { but access is controlled by physical hardware } \\
\text { Device shall clearly indicate that it is in the } \\
\text { remote configuration mode and record such } \\
\text { message if capable of printing in this mode. }\end{array}$ & $\begin{array}{l}\text { The hardware enabling access for remote communication } \\
\text { must be at the device and sealed using a physical seal or two } \\
\text { event counters: one for calibration parameters and one for } \\
\text { configuration parameters. }\end{array}$ \\
\hline $\begin{array}{l}\text { Category 3: Remote configuration capability } \\
\begin{array}{l}\text { access may be unlimited or controlled } \\
\text { through a software switch (e.g., password) }\end{array}\end{array}$ & $\begin{array}{l}\text { An event logger is required in the device; it must include an } \\
\text { event counter }(000 \text { to } 999) \text {, the parameter } I D \text {, the date and } \\
\text { time of the change, and the new value of the parameter. A } \\
\text { printed copy of the information must be available through the } \\
\text { device or through another on-site device. The event logger } \\
\text { shall have a capacity to retain records equal to ten times the } \\
\text { number of sealable parameters in the device, but not more } \\
\text { than } 1000 \text { records are required. (Note: Does not require } \\
1000 \text { changes to be stored for each parameter.) }\end{array}$ \\
\hline
\end{tabular}

[Nonretroactive and enforceable as of January 1, 1995.]

(d) Retail motor-fuel dispensers shall not have remote configuration capabilities and shall be sealed according to category 1 devices in the above table. [Nonretroactive and enforceable as of January 1, 1995.]

Discussion: Readers are referred to the 1992 report of the S\&T Committee for the definition of terminology applicable to this item, for the list of sealable parameters for scales and liquid-measuring devices, and to obtain a general understanding of the details of this issue.

\section{Changes from the 1992 Recommendation}

The Specifications and Tolerances (S\&T) Committee has extensively modified its recommendation based upon comments from industry and the regional weights and measures associations. The recommendation put forward by the Committee would have provided considerable electronic documentation of the changes to metrological features of devices. However, many comments from industry were that the detailed information is not needed, would not be used by weights and measures officials, and would be unjustifiably expensive to implement for the extent to which industry anticipated the audit trail would be used. The Committee received comments from weights and measures officials indicating that many officials would not use the information in the manner envisioned by the S\&T Committee to reap the benefits of having the detailed information that would have been available. Specifically, many weights and measures officials stated that they did not believe they could go to court on the basis of an electronic record of apparently improper adjustments to device accuracy or to other sealable parameters of the device. Consequently, the Committee is recommending the minimum forms of audit trails submitted by the Southern Weights and Measures Association (Southern). The Committee believes that these forms represent the minimum forms of audit trails that are necessary to monitor adjustments or changes to features required to be sealed.

A major change from the 1992 S\&T recommendation is that remote configuration (changes to accuracy adjustments, blend settings, and changes to other sealable parameters) would be prohibited on retail motor-fuel dispensers. This restriction would eliminate many problems in equipment design that would have otherwise developed to incorporate the event logger. (Under the 1992 recommendations, an event logger would have been required if dispenser parameters, blend settings, or accuracy adjustments were to be accessible from the service station control console.) 
As presented last year, three minimum levels of security are required for each of three different categories of devices. They are physical security seals, electronic audit trails, or a choice of a physical seal or electronic audit trail with a clear indication that the remote configuration mode is active. The overriding concern on the part of the Committee is the ability to change sealable calibration or configuration parameters from a remote location. The extent of audit trail required for each category of device is based upon the ease with which changes can be made to sealable parameters. The ease of accessing a device from a remote location greatly facilitates the potential for fraudulent use of such a device through changes to sealable parameters. The recommended forms of audit trail are based upon the ease with which the device can be accessed from a remote location. Access to the sealable parameters from any location or device other than from the specific weighing or measuring device under inspection is considered remote access.

\section{Rationale for Two Event Counters}

Two event counters are recommended for devices in categories 1 and 2. One event counter is to monitor only adjustments for accuracy (calibration parameters). The second event counter is to count the number of times that changes have been made either to the configuration parameters of the device. Two event counters are specified to aid the weights and measures official in detecting whether changes have been made either to calibration parameters or configuration parameters. After a device has been installed, changes to configuration parameters should rarely be required. Consequently, the event counter for configuration parameters should rarely change, which means that the inspector is effectively assured that the operational characteristics of the device have not changed since the last inspection. The inspector can then readily determine the number of adjustments made to the device by comparing the current number in the event counter with that recorded during the last inspection. If only one event counter were used, the inspector could not determine if a change represented an accuracy adjustment or a change to a configuration parameter. Without this information, an inspector would have to conduct a much more extensive inspection of the device to verify that the operation of the device had not changed.

\section{Categories of Levels of Security}

Category 1 devices are those where all adjustments or changes to sealable parameters must be made through the device itself. Category 1 devices may be sealed with a physical security seal or have security provided in the form of two event counters as specified in the table for category 1 devices.

Category 2 devices are those for which adjustments for accuracy (calibration parameters) or sealable configuration parameters may be changed from a remote device. The remote device may be either on the same site as the weighing or measuring device or at a distant location. To qualify as a category 2 device, the remote access to the weighing or measuring device must either be capable of being physically enabled or disabled through some type of hardware (most commonly a switch) that can be şealed with a physical security seal, or two event counters must be used to indicate the number and types of changes that have been made to sealable parameters.

Category 3 devices are those for which remote access to the sealable parameters is virtually unlimited or controlled through a software switch (e.g., a password). An event logger is required for such devices. The event logger must have an event counter to record the number of changes made to sealable parameters, and must also record the time and date of the adjustment, identify the parameters that are changed, and record the new values for the parameters. The event logger must have the memory capacity to retain up to ten times the number of sealable parameters in the device, but the memory capacity need not exceed 1000 events. It is not necessary to retain ten values for each parameter; the memory can be filled in the order in which sealable parameters are changed until the available memory is filled. It is expected that category 3 devices will usually be rather sophisticated devices with considerable computer memory storage capability. Hence, this requirement is not expected to present an undue hardship in the design or memory requirements for the weighing or measuring system. A printed copy of the information in the event logger must be available through either the device itself or another device that is on the same site as the weighing or measuring device.

\section{Access to the Audit Trail Information}

Device manufacturers are encouraged to standardize the methods for accessing and displaying the contents of the event counters for category 1 and 2 devices. If the method of access cannot be standardized for a specific type of device, each manufacturer is encouraged to standardize to the extent possible the method of access for his particular devices. The method of accessing the audit trail for a particular device will be reported in Certificates of Conformance issued by the National Type Evaluation Program (NTEP). 


\section{G-S.8. Provision for Sealing Electronic Adjustable Components and Scales Code S.1.11. Provision for Sealing}

(This item was adopted.)

Source: Mettler Instrument Corporation

Recommendation: Add the following definition.

metrological integrity (of a device). The design, features, operation, installation, or use of a device that facilitates (1) the accuracy and validity of a measurement or transaction, (2) compliance of the device with weights and measures requirements, or (3) the suitability of the device for a given application.

Amend General Code paragraph G-S.8. Provision for Sealing Electronic Adjustable Components to read:

G-S.8. Provision for Sealing Electronic Adjustable Components. - A device shall be designed with provision(s) for applying a security seal that must be broken, or for using other approved means of providing security (e.g., data change audit trail available at the time of inspection), before any change that detrimentally affects the metrological integrity of the device can be made to any electronic mechanism.

A device may be fitted with an automatic or a semi-automatic calibration mechanism. This mechanism shall be incorporated inside the device. After sealing, neither the mechanism nor the calibration process shall facilitate fraud.

Amend Scales Code paragraph S.1.11. Provision for Sealing to read:

\section{S.1.11. Provision for Sealing.}

(a) Except on Class I scales, provision shall be made for applying a security seal in a manner that requires the security seal to be broken before an adjustment can be made to any component affecting the performance of an electronic device.

[Nonretroactive as of January 1, 1979.]

(b) Except on Class I scales, a device shall be designed with provision(s) for applying a security seal that must be broken, or for using other approved means of providing security (e.g., data change audit trail available at the time of inspection), before any change that detrimentally affects the metrological integrity of the device can be made to any electronic mechanism.

[Nonretroactive as of January 1, 1990.]

A device may be fitted with an automatic or a semi-automatic calibration mechanism. This mechanism shall be incorporated inside the device. After sealing, neither the mechanism nor the calibration process shall facilitate fraud.

Discussion: A scale may be equipped with a semi-automatic adjustment for the accuracy of the device. The adjustment mechanism may also be designed to be fully automatic in operation. When properly designed and used, this feature promotes measurement accuracy without facilitating fraudulent adjustment of the device. The Committee reviewed the design of one scale with this mechanism and believes that automatic or semi-automatic adjustment of a device should be explicitly recognized as acceptable for devices. However, the Committee emphasizes that this change recognizes selfcalibration mechanisms built into a device; it does not at this time recognize external standards that may be brought to a device for automatic or semi-automatic calibration. The Committee needs additional information on this subject before it can make a decision that might have a broader impact.

Automatic and semi-automatic span adjustment devices perform the calibration of a scale either automatically (e.g., when the scale is turned on; at certain time intervals; when the temperature has changed by a certain amount; etc.) or semiautomatically (i.e., when the operator presses a key on the scale). The scale has a built-in mechanism which performs 
the same procedure as one would otherwise perform manually in an electronic scale: (a) set the scale to an exact zero; (b) place the built-in calibrated weight on the scale and take the weight reading; and (c) adjust the span (if needed), so that the scale will give the correct reading for the built-in weight. The semi-automatic calibration sequence may be initiated at the device or from a remote device. This feature is particularly useful in scales with a large number of scale divisions where variations in the local force of gravity become noticeable if the scale is moved to a different location.

One significant aspect of this proposal is that external influence on the self-calibration process must be virtually impossible. Adequate safeguards must be built into the device to prevent interference that would affect the accuracy of the self-calibration. During type evaluations, the NTEP laboratories must assess whether or not the reference standard is accessible from outside the device and, therefore, subject to tampering. Adequate safeguards must be incorporated into the device to assure a valid zero reference and system calibration using the reference standard. The system design and software must protect against manipulation that could result in a fraudulent calibration.

The Committee believes that automatic or semi-automatic calibration mechanisms promote accurate measurement for scales and other devices; they should be permitted whenever they do not facilitate fraud. Hence, the Committee has included a clarification to G-S.8. to permit any similar mechanism that does not detrimentally affect the metrological integrity of the device.

\section{0-3 VC G-UR.3.4. Responsibility, Money-Operated Devices}

(This item was adopted as part of the consent calendar.)

Source: Measuring Sector, National Type Evaluation Technical Committee

Recommendation: Amend General Code paragraph G-UR.3.4. to read:

G-UR.3.4. Responsibility, Money-Operated Devices. - Money-operated devices other than parking meters shall have clearly and conspicuously displayed thereon, or immediately adjacent thereto, adequate information detailing the method for the return of monies paid when the product or service cannot be obtained. This information shall include the name, address, and phone number of the local servicing agency responsible party for the device. This requirement does not apply to devices at locations where employees are present and responsible for resolving any monetary discrepancies for the customer.

Discussion: The Measuring Sector of the National Type Evaluation Technical Committee addressed the trend of adding cash acceptors to retail motor-fuel dispensers to automatically activate the dispensers for delivery. When a cash acceptor is added to a retail motor-fuel dispenser, paragraph G-UR.3.4. applies since the cash acceptor makes the dispenser a money-operated device. Since G-UR.3.4. is a user requirement, it is not applied during type evaluation; it is the user's responsibility to mark the device to comply with this requirement.

Paragraph G-UR.3.4. was originally intended to apply to equipment installed in either unattended sites or those where the identity of the party responsible to correct any problems is not readily apparent. When devices are installed in locations where the identity of the responsible party is readily apparent and available, the Committee believes that a statement of responsibility is not needed. Note that this exemption extends beyond retail-motor fuel dispensers: it applies to all devices where the identity of the responsible party is available to resolve monetary discrepancies for the customer.

The Committee agrees with the position of the Measuring Sector that the proposed exemption should not apply to unattended locations. 


\section{0-4 I User-Programmable Software; Manufacturer-Modified Software}

Source: Carryover Item 310-4

This item is concerned with the security of the metrological aspects of software that is changed after type evaluation, whether independent software packages or software modified by the manufacturer after a device has undergone type evaluation. Some software, referred to as user-programmable software, is designed to be changed by the user of the device. Moreover, manufacturers routinely upgrade software after type evaluation to correct problems or to incorporate additional features. This issue does not apply to "user-configurable" software where the device parameters or optional features are selected from a set-up routine or a menu that has been programmed into the device, but the software itself is not modified.

Approaches to enhance the security of software have been explored, but a clear direction has not been developed. The Scale Manufacturers Association is studying the issue. Since an effective means of maintaining the security of software is not yet apparent, the S\&T Committee requests input from industry and weights and measures officials regarding the best ways to assure that the metrological portions of the software packages remain valid when other portions of the software are modified.

\section{0-5 VC Definition of Direct Sale}

(This item was adopted as part of the consent calendar.)

Recommendation: Amend the definition of direct sale to read:

direct sale. A sale in which both parties in the transaction are present when the quantity is determined. An unattended automated or customer-operated weighing or measuring system is considered to represent the device/business owner in transactions involving an unattended device. [1.10]

Discussion: The number of customer-operated or automated weighing and measuring devices used in the sale of commodities is increasing. These devices are designed to buy or sell a commodity or dispense a service based upon quantity in the absence of the device owner or the owner's representative. In these cases, the automated device represents the interests of the device owner. The Committee believes that the definition of direct sale must be expanded to include such transactions as direct sales. The Committee included a revised definition in Item 320-24 of its 1992 report for consideration. The definition recommended above is the result of the review process.

This subject was included as part of Item 320-10 of the S\&T Committee agenda, but has been moved to the General Code portion of its report to promote review by parties outside the scale industry. This issue has been discussed at the meetings of the regional weights and measures associations since July 1992.

\section{Scales Code}

320-1 V S.1.1. Zero Indication

(This item was adopted.)

Source: Carryover Item 320-29

Recommendation: Amend paragraph S.1.1. to read: 


\section{S.1.1. Zero Indication.}

(a) On a scale equipped with indicating or recording elements, provision shall be made to either indicate or record a zero-balance condition.

(b) On an automatic-indicating scale or balance indicator, provision shall be made to indicate or record an out-of-balance condition on both sides of zero.

(c) On point-of-sale-systems, A zero-balance condition may be indicated by other than a continuous digital zero indication, provided that an effective automatic means is provided to inhibit a weighing operation or to return to a continuous digital indication when the scale is in an out-of-balance condition.

Discussion: Scale manufacturers are designing scales with indications for zero other than a digital representation. Alternative indications may be a zero annunciator, a series of sequencing dashes moving across the display, or a scrolling message moving across the customer display. These latter indications must be clearly defined on the device as the zero indication as required by General Code paragraph G-S.6. Marking Operational Controls, Indications, and Features.

When a shared weight display was incorporated into a point-of-sale scanner/scale in 1986 and 1987, many Conference members had serious reservations about the absence of a digital zero indication. Since that time, weights and measures officials appear to have become much more comfortable with devices having zero indications other than the digital zero. Comments submitted to the Committee indicate that weights and measures officials are willing to accept alternative forms for indicating the zero balance condition if clearly defined.

Consequently, the Committee recommends that all scales be permitted to indicate the zero balance condition by means other than a digital zero indication; however, scales using other than a digital zero indication for the zero-balance condition must either inhibit the weighing operation or return to a continuous digital weight indication when the scale is no longer at zero. This alternative is also extended to point-of-sale systems, as indicated by deleting the qualifying phrase at the beginning of S.1.1.(c) which previously restricted part (c) to point-of-sale systems.

\section{S.1.13. Vehicle On-Board Weighing Systems: Operation When in Motion}

(This item was adopted as part of the consent calendar.)

Source: National Type Evaluation Program; Carryover Item 320-26

Recommendation: Add a new paragraph S.1.13. to read:

S.1.13. Vehicle On-Board Weighing Systems: Vehicle in Motion. - When the vehicle is in motion, a vehicle on-board weighing system shall either:

(a) be accurate; or

(b) inhibit the weighing operation.

Amend the definition of vehicle on-board weighing system to read:

vehicle on-board weighing system. A weighing system designed as an integral part of or attached to the frame, chassis, lifting mechanism, or bed of a vehicle, or trailer, industrial truck, industrial tractor, or forklift truck.

Discussion: When a weighing system is installed on a vehicle, the movement of the vehicle is likely to have a detrimental effect on the accuracy of the weighing systems. Because acceleration and deceleration are likely to cause weight indications to be inaccurate, particularly for fork-lift truck scales, the Committee recommends that either the weight indications be accurate whenever the vehicle is in motion or that the weighing operation be inhibited when the vehicle is in motion. Since the Conference has repeatedly taken the position that these systems shall be class III scales, 
it is unlikely that vehicle on-board weighing systems will be able to perform within tolerance when the vehicle is in motion. It is therefore expected that virtually all systems will have to inhibit operation when the vehicle is in motion.

The Committee wants to make clear that the proposed S.1.13. addresses the motion of the vehicle on which the weighing system is installed. The weighing system itself may be in motion since some systems are designed to weigh during the lifting operation of the loaded weighing system, such as the lifting arms on a waste collection truck. To clearly state the types of vehicles that are included in the scope of vehicle on-board weighing systems, the Committee recommends that the definition of vehicle on-board weighing systems be amended as indicated above.

To clarify a potential misinterpretation, the Committee emphasizes that floor scale weighing/load-receiving elements are class III devices. Since forklift trucks are considered to be vehicles, questions have been raised whether that means floor scales are vehicle scales. The answer is "no." The Handbook 44 definition of vehicle scale explains that a vehicle scale is one "adapted to weighing highway, farm, or other large industrial vehicles (except railroad freight cars), loaded or unloaded." Hence, while forklift trucks are vehicles as related to vehicle on-board weighing systems, the scales on which they and their loads are weighed do not qualify as vehicle scales.

\section{0-3 V S.4. Design of Weighing Elements and S.5. Accuracy Class}

$$
\text { (This item was adopted.) }
$$

Source: Southern Weights and Measures Association

Recommendation: To specify the relationship of the $\mathrm{v}_{\min }$ of a load cell to the division value of the scale, add a new paragraph S.5.4. to read as follows.

\section{S.5.4. Relationship of Load Cell Verification Interval Value to the Scale Division. - The relationship of the value for the load cell verification scale interval, $v_{\min }$, to the scale division, $d$, for a specific scale installation shall be:}

(a) $\quad v_{\min } \leq \frac{d}{\sqrt{N}}$ where $N$ is the number of load cells in the scale for scales without lever systems; and

(b) $\quad v_{\min } \leq \frac{d}{\sqrt{N} \times(\text { scale multiple })}$ for scales with lever systems.

[Nonretroactive as of January 1, 1994.]

[Note: When the value of the scale division, $d$, is different than the verification scale division, $e$, for the scale, the value of e must be used in the formulae above.]

Discussion: The Committee considered a series of changes to specify the relationship of the $\mathrm{v}_{\min }$ of a load cell, the dead load of a scale, and the concentrated load capacity (CLC) of a scale to determine the suitability of the load cell(s) used in a scale. Due to the complexity of the relationships and the difficulty in enforcement of the concepts, the Committee decided to include only the relationship for $\mathrm{v}_{\min }$ to the scale division so it is readily available to enforcement officials.

The Committee believes that the principles of the design relationships considered by the Committee are valid and should oe incorporated into the design of scales. Consequently, the Committee reports below the additions it considered making to the Scales Code along with the explanation of the principles and the logic that led to the proposed changes.

The Committee considered adding the following new paragraphs in addition to the one recommended above as a new paragraph S.5.4. 
S.4.4. Dead Load for Weighing Elements Using Load Cells. - The minimum dead load for a load-receiving element shall be equal to or greater than the sum of the dead load ratings for the load cells used in the weighing element. In the case of a lever scale, the minimum dead load for a load-receiving element shall be equal to or greater than the sum of the dead load ratings for the load cells used in the weighing element multiplied by the scale multiple.

[Nonretroactive as of January 1, 1994.]

S.4.5. Portion of Total Load Applied to Any Individual Load Cell.- The portion of a weighing element's total load applied to any individual load cell under any normal scale load distribution for example, based upon the shift test or concentrated load capacity), shall not exceed the load cell's maximum capacity. The total load consists of the weighing element's dead load and the largest load applied, up to and including the rated capacity of the scale analyzed according to the applicable ratings for the scale.

[Nonretroactive as of January 1, 1994.]

S.5.5. Scale Capacity Limits. - The rated capacity of a scale shall be within the limits specified in Table S.5.5.

Table S.5.5. Scale Capacity Limits

\begin{tabular}{||l|l|l||}
\hline \hline For scales: & Capacity shall be at least: & Capacity shall not exceed: \\
\hline Without lever systems & $n \times v_{\min } \times \sqrt{N}$ & $(N \times$ load cell capacity $)-($ scale dead load $)$ \\
\hline With lever systems & $n \times v_{\min } \times \sqrt{N} \times($ scale multiple $)$ & $(N \times$ load cell capacity $\times$ scale multiple $)$ \\
$-($ scale dead load $)$
\end{tabular}

In the formulae, $n$ is the number of scale divisions for the installation, $v_{\min }$ is the load cell verification scale interval, and $N$ is the number of load cells in the scale. If a lever scale uses more than one load cell in the system, then apply the last line of Table S.5.5. to the part of the lever system to which each load cell applies. [Nonretroactive as of January 1, 1994.]

The figure that follows illustrates the load cell parameters that must be considered.

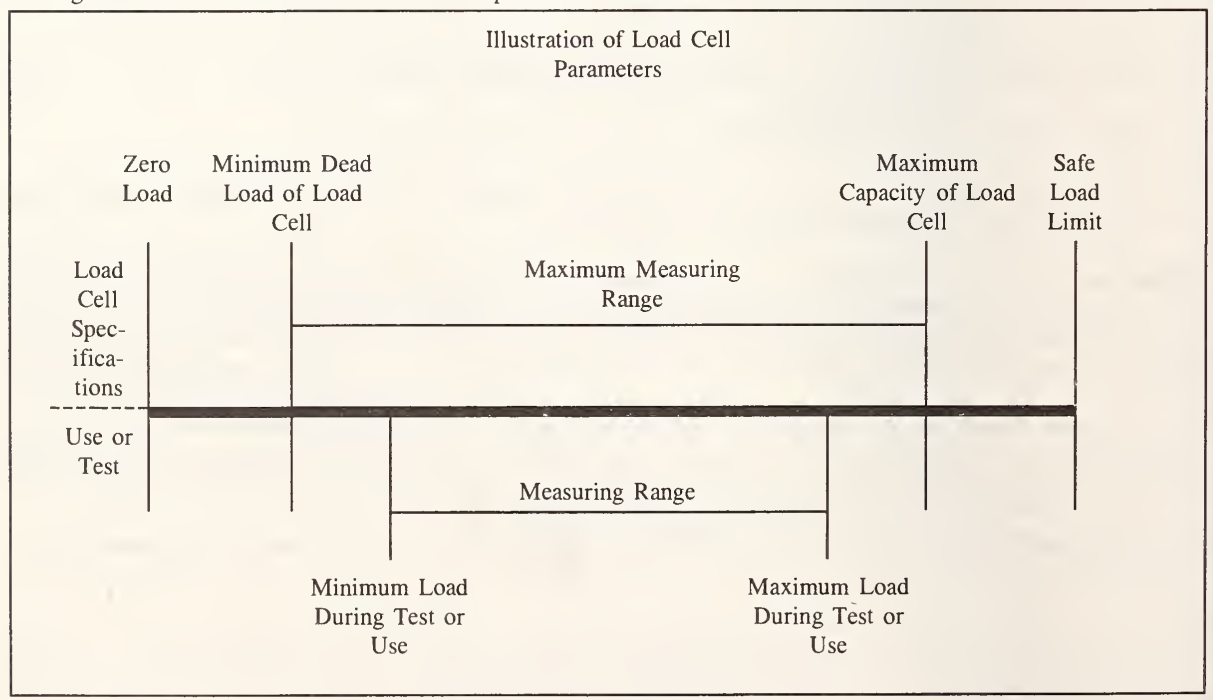


Load cell manufacturers are encouraged to review the values that they declare for the load cell verification division, $v_{\min }$. Load cell manufacturers may find that the concept expressed in the suggested paragraph S.5.5. may limit the number of divisions for which a scale may be installed, although the load cell has an NTEP Certificate of Conformance for a specified value of $\mathrm{n}_{\max }$. For example, suppose that a class III L load cell with $\mathrm{n}_{\max }$ equal to 10,000 is to be installed in the steelyard rod of a mechanical scale. Assume that the load cell manufacturer declares the value for $\mathrm{v}_{\mathrm{min}}$ to be equal to the capacity of the load cell divided by 10,000 (the value for $n_{\max }$ ). Since part of the maximum measuring range of the load cell is used by the dead load of the scale, the available measuring range of the load cell for the scale will be less than 10,000 divisions since 10,000 times $\mathrm{v}_{\min }$ plus the dead load will exceed the capacity of the load cell. Hence, when $\mathrm{v}_{\min }$ is declared as equal to load cell capacity divided by $\mathrm{n}_{\max }$, the load cell cannot be used in a scale installation where the maximum number of divisions equals $\mathrm{n}_{\max }$.

The S\&T Committee expresses its appreciation to Mr. John Elengo, Chairman, Weighing Sector, Technical Committee on National Type Evaluation, for providing the following analysis of the issue. The check included for the capacity of vehicle, axle-load, and livestock scales includes a check of the formula in S.6.1. When scales with lever systems are checked, use the appropriate formulae from S.5.4. and S.5.5. in the four checks provided below.

The mathematical checks shown below are based on the following premises:

a. The load applied to any load cell at the time of measurement does not exceed the load cell capacity.

b. The load applied to any load cell under no-load scale conditions is not less than the load cell's minimum deal load requirement.

c. The range of loads applied to any load cell is limited to loads within the load cell's limits as specified on the NTEP Certificate of Conformance.

The analysis is for scales with a scale multiple of 1 (no levers) and with the scale division, d, equal to the verification interval, e.

1. Check of Scale Dead Load

Scale Dead Load $\geq N \times($ Load Cell Minimum Dead Load Requirement $)$

where $N=$ number of load cells.

2. Check of Size of Scale Division

$$
v_{\min } \leq \frac{\text { Scale Division }}{\sqrt{N}} \text { or Scale Division } \geq v_{\min } \times \sqrt{N}
$$

where $\mathrm{N}=$ number of load cells.

3. Check of Scale Capacity for Other than Vehicle, Axle-load, and Livestock Scales

Both of the following must be satisfied.

(a) Scale Capacity $\leq(N \times$ Load Cell Capacity $)-($ Scale Dead Load $)$

(b) Scale Capacity $\geq n \times v_{\min } \times \sqrt{N}$

where $\mathrm{n}$ is the number of divisions in the scale and $\mathrm{N}=$ number of load cells.

4. Check of Scale Capacity for Vehicle, Axle-load, and Livestock Scales

All of the following must be satisfied.

(a) Scale Capacity $\leq(N \times$ Load Cell Capacity $)-($ Scale Dead Load $)$, and

(b) Scale Capacity $\leq C L C \times\left(\frac{N}{2}-0.5\right)$ where $N=$ number of load cells, or

Scale Capacity $\leq C L C \times\left(N_{1}-0.5\right)$ where $N_{1}=$ number of sections, and

(c) Scale Capacity $\geq n \times v_{\min } \times \sqrt{N}$

where $\mathrm{n}$ is the number of divisions in the scale and $\mathrm{N}$ is the number of load cells. 
The formulae were developed in the following manner. The technical policy of the National Type Evaluation Program (NTEP) specifies that the relationship of the minimum verification division for the load cell, $\mathrm{v}_{\min }$, to the scale verification division, e, of the scale shall be:

$$
v_{\min } \leq \frac{e}{\sqrt{N}}
$$

where $\mathrm{N}$ is the number of load cells in the scale. The number of scale divisions, $\mathrm{n}$, in a scale must not exceed the maximum number of divisions, $\mathrm{n}_{\max }$, for the load cell based upon the NTEP Certificate of Conformance. Hence, the verification division, $\mathrm{v}$, for the load cell can vary from:

$$
v_{\min } \quad \text { to } \quad \frac{\text { cell capacity }}{n}
$$

This means that e can vary from

$$
e_{\min }=v_{\min } \times \sqrt{N} \quad \text { to } \quad e_{\max }=N \times \frac{(\text { cell capacity })}{n}
$$

The capacity of a scale can be expressed as $n \times e$. Therefore, the capacity of a scale can vary from:

which is

$$
n \times\left(v_{\min }\right) \times \sqrt{N}
$$

$$
n \times\left(N \times \frac{(\text { cell capacity })}{n}\right)
$$

$n \times\left(v_{\min }\right) \times \sqrt{N}$

to

$N \times($ cell capacity)

Taking the dead load of the scale into consideration, the maximum allowable scale capacity is:

$$
(N \times \text { cell capacity })-(\text { scale dead load }) .
$$

\section{0-4 V N.X. Uncoupled-in-Motion Railroad Weighing Systems; Test Procedure}

(This item was adopted.)

Source: Carryover Item 320-10

Recommendation: Renumber the current paragraph N.5. as N.6., add the following definition for uncoupled-in-motion railroad weighing system, and add the test procedure as a new paragraph N.5.

uncoupled-in-motion railroad weighing system. A device and related installation characteristics consisting of (1) the associated approach trackage, (2) the scale (i.e., the weighing element, the loadreceiving element, and the indicating element with its software), and (3) the exit trackage which permit the weighing of railroad cars uncoupled in motion.

N.5. Uncoupled-in-Motion Railroad Weighing System. - An uncoupled-in-motion scale shall be tested statically before being tested in motion by passing railroad reference weight cars over the scale. When an uncoupled-in-motion railroad weighing system is tested, the car speed and the direction of travel shall be the same as when the scale is in normal use. The minimum in-motion test shall be three reference weight cars passed over the scale three times. The cars shall be selected to cover the range of weights that are normally weighed on the system and to reflect the types of cars normally weighed.

Discussion: Last July, the point of contention on this issue was whether or not an uncoupled-in-motion (UCIM) scale should be tested statically each time before the UCIM system is tested dynamically. In many cases, the UCIM scale is used to determine the static weight of the reference cars that are used to dynamically test the UCIM weighing system. The accuracy across sections in the scale can affect the accuracy of weights obtained from the UCIM system, hence periodic testing of the static scale is essential to obtaining accurate weights. However, at least one railroad has several monitor cars that are tested on a regular basis by weighing the cars on a railroad master scale. This railroad contends that since the weights of their monitor cars are maintained within a narrow range, it is not necessary to statically test the 
UCIM scale each time the system is tested for accuracy. - They report that the accuracy of the scale does not change quickly enough to justify a static scale test each time the system is tested.

The Committee considered the manner in which this railroad operates, but concluded that a thorough static test of the uncoupled-in-motion scale is needed to ensure that the scale is in good working order. In this way, the agreement of sections over the entire scale can be verified without making any assumptions that the scale is accurate over all sections. Consequently, the Committee recommends that the static test of an uncoupled-in-motion scale be conducted as indicated by using the word "shall" in N.5. as shown above.

\section{0-5A V Coupled-in-Motion Railroad Weighing Systems for the Sale of Liquids in Individual Tank Cars and Commodities in Individual Cars in Mixed Merchandise Trains}

(This item received a split vote and was not adopted.)

Source: Carryover Item 320-11

Recommendation: The Committee recommends that language be added to the Scales Code to specifically recognize the use of coupled-in-motion (CIM) weighing systems to weigh individual cars for the sale of commodities (liquids and stable commodities, but excluding individual cars of grain). (Stable commodities may be solids, steel, paper, powders, granules, etc.) The Committee also recommends adding requirements to promote the proper testing and use of CIM weighing systems used for these purposes. Note that weighing for the sale of individual cars of grain is prohibited in UR.5. in this recommendation. Based upon comments received at the Annual Meeting, the Committee decided to expand the scope of the exemption of UR.5.(b) to include "bulk or liquid grain products for which origin weights, destination weights, or per car rates apply. " It also expanded the types of coupled-in-motion weighing systems identified in UR.5.(c) for which notification of weighing on a coupled-in-motion system is required to include coupled-in-motion systems used to weigh "bulk or liquid grain products weighed in individual cars." Additionally, at the Annual Meeting the Committee decided to amend UR.5.(c) to require that the speed at which the train was weighed be reported along with the weight values. The following changes are recommended.

Add a new specification S.1.13. to read:

S.1.13. Speed Detection Mechanism for Coupled-in-Motion Railroad Weighing Systems. - A coupled-inmotion railroad weighing system used to weigh individual cars for the sale of commodities shall be equipped with a speed detection mechanism for which a maximum acceptable speed can be set. The weighing system shall automatically inhibit the indication and registration of a weight value if the speed of an individual car exceeds the maximum acceptable speed for which the speed detection mechanism has been set. The maximum acceptable speed shall be limited to the speed for which the system has been tested and complies with the applicable tolerances. (See UR.5.)

Under the heading of N.4. Coupled-in-Motion Railroad Weighing Systems, add a new paragraph N.4.4. to read:

N.4.4. Systems Used to Weigh Individual Tank Cars and Individual Cars in Mixed Merchandise Trains for the Sale of Commodities. - Coupled-in-motion railroad weighing systems used to weigh individual tank cars and individual cars in mixed merchandise trains for the sale of commodities shall be tested as used at least annually. The weighing system shall be tested in a manner that represents the normal method of operation and length(s) of trains normally weighed; the use of shorter test trains as described in N.4.3.1.1. does not apply to systems used to weigh individual tank cars and individual cars in mixed merchandise trains for the sale of commodities. The weighing systems may be tested using either:

(1) a consecutive-car test train of a length typical of train(s) normally weighed (see N.4.3.1.4.); or

(2) a distributed-car test train of a length typical of train(s) normally weighed (see N.4.3.1.3.). 
Amend T.N.3.6.2, to read:

T.N.3.6.2. - If a weighing system is used to weigh trains of five or more cars, and if the individual car weights are used (including for the sale of commodities in individual cars) any single weight value within the group must meet the following criteria:

(a) no single error may exceed three times the static maintenance tolerance;

(b) not more than 5 percent of the errors may exceed two times the static maintenance tolerance; and

(c) not more than 35 percent of the errors may exceed the static maintenance tolerance.

Amend UR.5. to read:

UR.5. Coupled-in-Motion Railroad Weighing Systems.

(a) A coupled-in-motion weighing system placed in service on or after January 1, 1991, should be tested in the manner in which it is operated, with the locomotive either pushing or pulling the cars at the designed speed and in the proper direction. The cars used in the test train should represent the range of gross weights that will be used during the normal operation of the weighing system. Except as provided in N.4.2. and N.4.3.(a), normal operating procedures should be simulated as nearly as practical. Approach conditions for a train length in each direction of the scale site are more critical for a weighing system used for individual car weights than for a unit-train-weightsonly facility, and should be considered prior to installation.

(b) A coupled-in-motion railroad weighing system may be used to weigh individual tank cars and individual cars in mixed merchandise trains for the sale of commodities, but excluding grain and bulk or liquid grain products for which origin weights, destination weights, or per car rates apply, provided that the system is tested as specified for these systems and that the applicable requirements are met.

(c) Weight values from a coupled-in-motion railroad weighing system used for the sale of commodities in individual tank cars and cars in mixed merchandise trains, or from a coupled-in-motion system used to weigh grain and bulk or liquid grain products in individual cars, must be accompanied with a written or electronic notification that the car was weighed on a coupled-in-motion railroad weighing system and the speed at which the train or car was weighed.

Discussion: This item is of great national significance and may well be one of the most important issues of the Specifications and Tolerances Committee to be addressed by the Conference in a long time. Members need to review the Conference reports since 1988 to make an informed assessment of this item. Weights and measures officials are encouraged to study and educate themselves in the issue to be able to cast an informed vote in July.

\section{Products and Testing}

Examples of the types of commodities that may be weighed for sale in individual cars over CIM weighing systems include a wide range of chemical liquids, powders, and pelletized material, aggregates, ballast, coal, some wood products (e.g., wood chips), some building products (e.g., cement), clay and water slurries for magazine printing, scrap metals, various steel products, mining ores, phosphates, and solid waste material. Many products transported by the railroads are covered by weight agreements. Weight agreements are contracts between the shipper and the railroads that specify, among other things, that the weights will be used as the basis for establishing freight charges.

The "as used" test procedures are the basis for determining whether or not a CIM railroad weighing system can meet the applicable requirements and can be used to weigh individual cars for the sale of commodities. The "as used" testing of CIM systems is expensive and requires major commitments from all parties involved. If there is a wide range of speeds at which trains are weighed, it may be necessary to test a scale over the full range of speeds. Many jurisdictions have had very little involvement with railroad track scales, either static or coupled-in-motion systems. This has resulted 
n the scale owners and railroads undertaking a self-policing approach to the testing and maintenance of railroad weighing ystems.

\section{Droposal Excludes the Sale of Individual Cars of Grain}

This recommendation excludes individual cars of grain from being weighed on CIM scales for the purposes of the sale of the grain. This is done because (1) the grain industry has expressed concern about the proposal and is still developing ts position; (2) the USDA Federal Grain Inspection Service (FGIS) does not accept weights from CIM scales for FGISupervised grain transactions; (3) Handbook 44 has previously required devices used to weigh grain (e.g., grain hopper cales and automatic bulk-weighing systems) to meet a tighter tolerance than other devices; and (4) the railroads have ot been weighing individual cars of grain on CIM systems for the sale of the grain (and have not expressed any interest n doing so) because Handbook 44 has required a tighter tolerance for the weighing of grain than is specified for railroad cales (either static or dynamic weighing). This recommendation does not require any change to current weighing oractices for shippers and users who do not use CIM weighing.

\section{Zoncerns Regarding the Tolerance Distribution}

jome weights and measures officials have expressed concerns about the tolerance distribution allowed in T.N.3.6.2. for he errors permitted in the weight of individual cars. Using a simplified explanation of the tolerance application, up to 5 percent of the individual cars may have errors between 0.4 and 0.6 percent; up to 30 percent of the cars could have orrors between 0.2 and 0.4 percent. The remaining 65 percent of the individual cars may not have errors that exceed J.2 percent. Note that the proposed change to T.N.3.2. requires all CIM weighing systems, whether marked or unmarked and used to determine for sale the weight of commodities in individual cars, to meet the tolerance distribution bf T.N.3.2. This is to clarify that the multiplier of 4 specified in Table T.1.1. does not apply to unmarked scales used o determine the weight of individual cars for the sale of commodities.

Another concern expressed is that CIM weighing must use the stenciled tare weight to arrive at the net weight. An error n the stenciled tare weight might increase the error in the net weight: this is not unique to CIM weighing, but also applies to uncoupled-in-motion weighing and to many static weighing operations.

\section{Predominant Comments Received from Industry}

Industry representatives supporting coupled-in-motion weighing of commodities in individual cars for custody transfer point out that the economic aspect is of paramount concern. They state that a restriction on CIM weighing would have a severe adverse impact on the operations of the railroads, would decrease competitiveness, would disrupt the movement of rail cars, and would unjustifiably increase costs to users. Since 1989, the preponderance of comments from industry have supported the continued use of coupled-in-motion railroad weighing systems to weigh commodities in individual cars for custody transfer.

\section{Tests Witnessed by the S\&T Committee}

This item has been on the agenda since 1988. It has undergone significant change from the original proposal. In 1989 the Committee was asked to address the specific issue of CIM weighing for the sale of commodities in mixed merchandise trains and in liquid tank cars. Since 1991, members of the S\&T Committee have participated in a number of tests of CIM systems. A variety of CIM systems were tested by the railroads and CIM system users to provide the S\&T Committee with a cross section of systems in use, not just the best scale installations. The scales were also selected to provide information on a variety of installations. The Committee has received additional input from a number of other sources. The input received from the Railroad Advisory Committee (made up of representatives from six different railroads involved in CIM weighing) and other users of CIM systems has been very supportive of the use of CIM weighing for the sale of commodities in individual cars. The data collected from the tests witnessed by members of the S\&T Committee indicate that some systems, when installed to strict site specifications and operated properly, can produce individual car weights in compliance with T.N.3.6.2. Graphs of the test results and a synopsis of the graphs are available upon request from the Office of Weights and Measures

\section{Regional Weights and Measures Associations}

The following is provided as background concerning the input received by the Committee from the four regional weights and measures associations prior to the Interim Meeting. Based on information available to the Western Weights and Measures Association (Western) S\&T Committee at the time of their meeting in August, the Western opposed the CIM weighing of individual cars for custody transfer in mixed manifest trains. The Southern defeated a recommendation, 
consisting of two points, stating (1) that it is more appropriate to weigh liquid tank cars on CIM scales rather than on static-weighing scales and (2) support for CIM weighing of mixed manifest trains for custody transfer when the scales are tested as used. Representatives at the Northeastern Weights and Measures Association (Northeastern) Interim Meeting supported recognition of CIM weighing for custody transfer of individual cars.

The Central submitted the following amendments and proposed adding a new paragraph T.N.3.6.X.

T.N.3.6.1. - For any group of weight values (unit train) to be used for the sale of a commodity, the difference in the sum of the individual in-motion car weights of the group as compared to the sum of the individual static weights shall not exceed 0.2 percent.

T.N.3.6.X. - For any individual car weights (not part of a unit train) to be used for the sale of a commodity, the difference in the individual in-motion car weight as compared to the individual static weight shall not exceed 0.2 percent.

T.N.3.6.2. - If a scale is used to weigh trains of five or more cars, and if the individual car weights are used only for tariff or identifying overloads, any single weight value within the group must meet the following criteria:

(a) no single error may exceed three times the static maintenance tolerance;

(b) not more than 5 percent of the errors may exceed two times the static maintenance tolerance; and

(c) not more than 35 percent of the errors may exceed the static maintenance tolerance.

Many weights and measures officials believe that T.N.3.6.2. applies only to the use of individual car weights for determining tariffs or identifying overloaded cars. However, this tolerance distribution has been applied within the railroad industry and by the owners of CIM weighing systems used to determine the weight of individual cars for the sale of commodities. The proposed change from the Central would have a major impact on the users of CIM scales for the sale of commodities and has been opposed by the railroad industry.

320-5B V N.4.3.1.1. Initial Verification; Coupled-in-Motion Railroad Weighing Systems

(This item was adopted.)

Source: Carryover Item 320-11

Recommendations: Amend paragraph N.4.3.1.1. to read:

N.4.3.1.1. Initial Verification. - Initial verification tests should be performed on any new weighing system and whenever either the track structure or the operating procedure changes. If a consecutive-car test train of length shorter than trains normally weighed is to be used for subsequent verification, the shorter consecutive-car test train results shall be compared either to a distributed-car or to a consecutivecar test train of length(s) typical of train(s) normally weighed.

The difference between the total train weight of the train(s) representing the normal method of operation and the weight of the shorter consecutive-car test train shall not exceed $\mathbf{0 . 1 5}$ percent. If the difference in test results exceeds $\mathbf{0 . 1 5}$ percent, the length of the shorter consecutive-car test train shall be increased until agreement within 0.15 percent is achieved. Any adjustments to the weighing system based upon the use of a shorter consecutive-car test train shall be offset to correct the bias that was observed between the full-length train test and the shorter consecutive-car test train. 
Discussion: As the Committee reviewed the proposal for the use of CIM railroad weighing systems to weigh commodities in individual cars for custody transfer, it concluded that the clarification shown above for N.4.3.1.1. is needed to promote the proper adjustment of a CIM system when a shorter consecutive-car test train is used. This change is to ensure that an adjustment made to a CIM weighing system, based upon a shorter consecutive-car test train, will promote the greatest accuracy for the full-length trains normally weighed on the scale.

The Committee is also concerned that accuracy requirements are correctly applied when multiple unit trains are combined in a single train. The Committee points out that the errors in each unit train may not exceed 0.2 percent (T.N.3.6.1. and T.N.3.6.3). Consequently, when a system is tested, the errors in the cars in the test train corresponding to unit trains shall not have an error in excess of 0.2 percent. Note that if a train consists of only one unit train, then the last part of N.4.3.1.1. does not apply since only the average of the entire unit train is relevant.

\section{0-6 W T.N.3.6. Coupled-in-Motion Railroad Weighing Systems; Custody Transfer of Liquids in Individual Cars}

(This item was withdrawn.)

Source: Carryover Item 320-12

See Item 320-5. Because of the similarity in the issues related to this item, the recommendation and discussion have been combined in Item 320-5A.

\section{0-7 I UR.1.5. Selection Requirements; Suitability of Equipment}

Source: Carryover Item 320-14

Discussion: The Committee explored various approaches to assist the enforcement official and device users to assess the suitability of devices used in different applications. Its latest proposal suggested the following criteria in a new paragraph UR.1.5.

UR.1.5. Suitability of Division Value for Loads Weighed. - To be suitable for its application, a scale shall have a division value such that the requirements of Table UR.1.5. are satisfied for the minimum and average loads weighed on the scale.

[Nonretroactive as of January 1, 1994.]

Table UR.1.5. Suitability of Division Value for Loads Weighed

\begin{tabular}{||l|c|c|}
\hline \multicolumn{1}{|c|}{ Range of Scale Capacities } & Average Net Load & Minimum Net Load \\
\hline \hline $\begin{array}{l}\text { Capacities from } 2 \mathrm{~kg}(5 \mathrm{lb}) \text { to } 1000 \mathrm{~kg} \\
(2500 \mathrm{lb}) \text {, inclusive }\end{array}$ & average net load $\geq 100 \mathrm{~d}$ & Table 8 applies \\
\hline $\begin{array}{l}\text { Capacities less than } 2 \mathrm{~kg}(5 \mathrm{lb}) \text { and } \\
\text { greater than } 1000 \mathrm{~kg}(2500 \mathrm{lb})\end{array}$ & average net load $\geq 500 \mathrm{~d}$ & \\
\hline
\end{tabular}

[Nonretroactive as of January 1, 1994.]

Several conflicts with currently accepted device applications were reported. Consequently, the Committee decided to study this issue for another year. The Committee requests that this issue be studied by the trade and regional groups over the next year. Any other conflicts should be reported so modifications to this proposal may be considered.

Over the past 2 years, the S\&T Committee has made proposals to aid in determining the suitability of scales for certain applications. The specific tables based upon commodities and applications suggested by the Committee were rejected in favor of a table specifying the relationship to the minimum and average net loads to be weighed on a scale. 
Comments to the Committee have stressed that the suitability of equipment should not be specified by commodity or by the cost of commodities. Although this recommendation is not based upon the price of a commodity, it is in many cases indirectly related to price since customers tend to purchase smaller quantities when price increases. In the past there has been opposition to including additional suitability of equipment criteria in Handbook 44. However, weights and measures officials report difficulty in enforcing suitability of equipment requirements if specific criteria are not included in Handbook 44. Consequently, the Committee believes that criteria must be in the Handbook to be enforceable.

The Commitiee believes determining the average net load for a scale is not a difficult process; however, it does require some investigation on the part of the weights and measures official. For an existing installation, it is a matter of reviewing sales receipts, scale tickets or register tapes, talking with employees of the business, or merely observing the weighing operation for a period of time. The length of time or the number of transactions to be considered is left to the discretion of the official or may be a policy of the jurisdiction. When a business owner requests advice about an appropriate scale division for an application, the business is responsible for providing the value to be used for the average net weight. The business owner generally has a good idea of the range of loads and net weights to be weighed. If the inspector and the business owner disagree in their assessments of the average net load, the scale owner has the responsibility to provide documentation to support the average net weight claimed.

Item 320-14 in the 1992 report of the S\&T Committee provided examples of how this table should be applied. The reader is referred to the 1992 report for details.

\section{0-8 W UR.1. Selection Requirements; Use of Stored Vehicle Tare Weights}

(This item was withdrawn.)

\section{Source: Carryover Item 320-15}

Discussion: Several States permit vehicle tare weights to be stored in scale memory to eliminate the weighing of empty trucks and thus speed up the weighing operation. Depending upon the company, these tare weights may be updated daily, weekly, monthly, or on an irregular basis. Two States, Maryland and North Carolina, compared the stored weights for vehicles with the actual weight of the vehicles at 20 and 14 companies, respectively. The errors ranged from $-1820 \mathrm{~kg}$ $(-4020 \mathrm{lb})$ to $+2050 \mathrm{~kg}(+4520 \mathrm{lb})$ in Maryland and $-910 \mathrm{~kg}(-2000 \mathrm{lb})$ to $+1540 \mathrm{~kg}(+3400 \mathrm{lb})$ in North Carolina. (See the 1992 report of the S\&T Committee for details.) The regional weights and measures associations were requested to study this issue to assist the S\&T Committee in the development of a recommendation of the proper way to deal with this practice.

There is extensive support for the continued use of stored tare weights in some applications, despite the fact that this may introduce significant errors in the net weight of the commodity. There have been several suggestions that the appropriateness of using stored tare weights in certain applications be left to the discretion of each State. Some States already have policies in place to address the use and verification of stored tare weights. The Committee considered setting guidelines on the frequency with which the tare weights must be updated, but was unable to find a guideline that would be universally accepted. Since there did not appear to be a single recommendation that would be supported by the Conference, the Committee has withdrawn this item.

The Committee wishes to emphasize that weights and measures laws require accurate net weight for the sale of commodities. States are encouraged to establish a program to check the validity of stored tare weights to ensure that they are maintained within acceptable limits. Unless further comments are received through the regional weights and measures associations, the Committee leaves the determination of the acceptability of using stored vehicle tare weights to the policy of individual States. 


\section{0-9 VC UR.2.6. Approaches}

(This item was adopted as part of the consent calendar.)

Source: Southern Weights and Measures Association

Recommendation: Amend the beginning of UR.2.6.1. to read:

UR.2.6.1. Vehicle Scales. - On the approach-end-or ends entrance and exit ends of a vehicle scale installed in any one location for a period of six months or more, there shall be a straight approach as follows: ...

Discussion: This recommendation has the effect of requiring that both ends of the vehicle scale meet the installation requirements for approaches, even if the vehicular traffic enters only from one end, and exits at the other. On scales with inadequate exit areas, improper exiting from the scale may cause excessive wear and tear on the scale. The objective of the proposed amendment is to reduce wear and tear due to inappropriate exiting of the scale by requiring a good exit path. This requirement will have significant impact on potential installations where space for the scale installation is limited.

The Committee is convinced that scales without adequate exit avenues experience unnecessary wear, leading to inaccuracy and increased maintenance requirements. The Committee believes that adequate avenues for access and exit should apply to both ends of vehicle scales.

This requirement does not affect installations where one end of the scale is used for both entrance and exit, that is, vehicles drive on from one end and exit by backing off at the same end. This type of installation is still permitted. Since the approach requirement applies to the single end of the scale used as both the entrance and exit, this type of installation should already meet this modified requirement.

\section{0-10 I Unattended Vehicle Scales}

\section{Source: Carryover Item 320-24}

Discussion: The issue of requirements for unattended vehicle scales has been on the agenda of the S\&T Committee since 1991. The Committee has modified and expanded the proposal from the Scale Manufacturers Association. The Committee concluded that specific requirements for unattended vehicle scales must be incorporated into Handbook 44 . Because these systems are customer operated without the owner of the scale being represented, the Committee believes that the recommended requirements provide the minimum safeguards to facilitate and document the transactions.

If the recommendation in Item 320-1 is accepted, then a digital zero indication will not be required for unattended vehicle scales. Manufacturers of unattended vehicle scales have reported that many of these unattended scales already use red and green lights to indicate whether or not the scale is at zero and ready to weigh the next vehicle. As indicated in Item 320-1, these zero indications must be defined as required by General Code paragraph G-S.6.

The Committee has changed this item to an information item to permit additional study of its recommendations, which are reported below.

To incorporate specific requirements for unattended vehicle scales, add a definition for an unattended vehicle scale to read:

unattended vehicle scale. An axle, full-length, or multi-platform vehicle scale which is available for use without the presence of the scale owner or a representative of the business operating the scale. [3.20]

Add the following new specification S.1.14. (a new paragraph S.1.13. is recommended in Item 320-2): 
S.1.14. Unattended Vehicle Scales. - The weighing operation shall be automatically inhibited if the scale is not in its zero-balance condition before the vehicle moves onto the load-receiving element or if the load being weighed is not fully supported on the load-receiving element.

An unattended vehicle scale shall be equipped with a printer to generate a printed weight ticket for the driver of the vehicle being weighed. The ticket must include the scale location, time and date of weighing, and the cost of the weighing service if a fee is charged (e.g., through a card- or money-operated system). The scale operation shall be inhibited if a printed ticket cannot be generated, e.g., if there is no paper in the printer.

Add the following new user requirement.

UR.3.10. Unattended Vehicle Scale. - An unattended vehicle scale shall not be used unless it is part of an installation that has:

(a) an automatic means of indicating to the vehicle operator that the scale is in its zero-balance condition and that the vehicle operator may proceed onto the load-receiving element; and

(b) a printer that automatically issues a weight ticket for each weighing.

\section{0-11 I Criteria for Counting Scales}

\section{Source: Carryover Item 320-25}

Discussion: This issue has been on and off the S\&T agenda for several years. See the 1992 report of the S\&T Committee for a discussion. Both the Western and the Southern support development of criteria for counting scales.

The S\&T Committee supports the development of criteria for counting scales, but the Office of Weights and Measures has not been able to dedicate resources to this task. The Scale Manufacturers Association has been advised of this fact and requested to develop criteria for consideration by the Committee.

Industry representatives have suggested that the position of the International Organization of Legal Metrology (OIML) be followed, that is, to allow counting features on scales provided that they do not interfere with the metrological characteristics of the device. If this suggestion is accepted, then counting features could appear on scales even though the features have not been evaluated by the National Type Evaluation Program (NTEP). One justification for this approach is that the accuracy of count cannot be controlled by device criteria alone because the accuracy depends upon the variability in weight of the items being counted and the sample size used to determine the average weight of an item.

The S\&T Committee is not prepared to accept this suggestion, at least not at this time. It is the position of the Committee that NTEP should not issue a Certificate of Conformance for a feature that may be used commercially (e.g., count), if the feature cannot be evaluated through NTEP for compliance with Handbook 44.

\section{0-12 I Criteria for Automatic Checkweighers}

\section{Source: Carryover Item 320-27}

Discussion: A Working Group has been formed to develop design, performance, type evaluation criteria, and test procedures to evaluate automatic checkweighers. The criteria will apply primarily to checkweighers used in food processing plants falling under the jurisdiction of the Food Safety Inspection Service (FSIS) of the U.S. Department of Agriculture. This Working Group had its initial meeting in on February 1 and 2, 1993. The Working Group has a series of familiarization and comparison issues to resolve. The Group plans a second meeting in October 1993 and will report on its activities as work progresses. 


\section{0-13 I Definition of Concentrated Load Capacity}

Source: Southern Weights and Measures Association

Discussion: The S\&T Committee provides the following background information to aid in the further development of this issue.

Some manufacturers provide an axle-load rating for their vehicle scales in addition to the concentrated load capacity (CLC) rating required in the Scales Code. The axle-load rating is usually lower than the CLC rating. This confuses purchasers of scales and weights and measures officials. Whereas the Handbook 44 definition for CLC states that the CLC is for both test and use (i.e., was intended to be the same value as the axle-load capacity), many scale design engineers view axle loads and CLC as different values due to the manner in which the load is applied to the load receiving element. David Quinn of Fairbanks Scales gave a presentation at the Interim Meetings to explain why the CLC and axle-load ratings are often viewed differently. A brief summary is provided below. Although the presentation explained how the differences in the CLC and axle-load ratings had developed, no solution to the problem was offered, nor was one readily apparent. This issue will continue to be studied.

When a weighbridge (load-receiving element) is being designed for a vehicle scale, the engineer must determine the weight of the load that the weighbridge can support. This value will depend on the "footprint" of the load on the scale. The footprint refers to the area of contact between the load and the load-receiving element. Mr. Quinn used the diagram below to illustrate the differences in load considerations when a truck is on the scale as compared to loading the scale with 1000 -lb weights of the block configuration.

The basic design of a weighbridge must consider (1) deflection, (2) bending stress, and (3) fatigue of the metal. The loading pattern for two truck axles spaced at $100-\mathrm{cm}$ (40-inch) centers results in an area of contact that is approximately $20 \mathrm{~cm}$ ( 8 inches) long for each tire. The $100-\mathrm{cm}$ (40-inch) center for axles plus an area of contact that is $10 \mathrm{~cm}$ ( 4 inches) longer for each tire than the distance between the axle centers result in a distance of $1.2 \mathrm{~m}$ (48 inches) between the ends of the contact areas as illustrated in the figure. This is the basis for testing scales with loads equal to the CLC but distributed over an area that is $1.2 \mathrm{~m}$ (4 feet) long and equal to the width of the scale.

When block weights are placed on the weighbridge, the load is distributed uniformly over this area. This results in

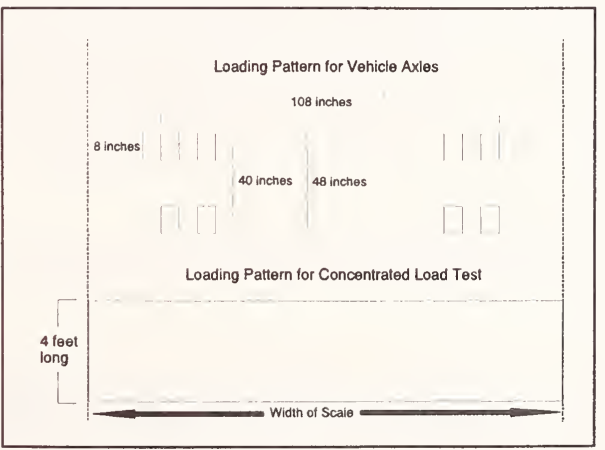
less stress than when a load equal to the CLC, but placed on a set of truck axles, is applied to the same area. When engineers look at the worst case for loading the scale, they look at the largest axle load placed with the axles near one side of the scale. The stress of axle loading under these conditions is significantly more severe than when loading a scale with block weights to the CLC limit.

\section{0-14 I NCWM Position on OIML Influence Factors and Disturbance Tests}

Source: Office of Weights and Measures, NIST

Discussion: The recommendations of the OIML are being referenced with increasing frequency to identify the types of changes that should be considered when developing new codes or changing existing codes. As discussions proceed with Canada and the scale industry to pursue reciprocity in type evaluation and type evaluation procedures, it will be important to determine to what extent the U.S. industry would like to see OIML requirements for electronic devices incorporated into Handbook 44. 
At two meetings in December 1992, the U.S. scale industry expressed its initial assessment of the need and desire to adopt the OIML requirements for influence factors and disturbances. A brief summary of the positions on various points follows.

\section{Temperature Testing}

Testing scales and load cells over a range wider than -10 to $40{ }^{\circ} \mathrm{C}$ was discussed in an effort to cover a wider range of outdoor environments in the northern U.S. and Canada. The industry indicated that the temperature range of -10 to $40{ }^{\circ} \mathrm{C}$ was based upon European weighing practices, but it represents the range of temperatures needed to satisfy most commercial and industrial applications. Lowering the coldest temperature to -20 or $-30^{\circ} \mathrm{C}$ would cause costs to go up significantly. It was stated that it may be impossible (but certainly more expensive if possible) for conventional load cells to perform over the entire temperature range within the tolerances specified in OIML and Handbook 44. Any change to the temperature range should be assessed based on the need to correct measurement problems in relation to the additional costs that would be incurred.

\section{Electromagnetic Interference (EMI)}

The procedure of using hand-held transceivers to test for EMI susceptibility is known to lack repeatability and generates varying EMI field strengths around the scale that is subject to the test. There are many sources of EMI in the environment, and the number increases daily. The field strength of EMI is also increasing. Scales must be able to withstand EMI.

The industry reported that it is difficult to design equipment to meet the OIML standard at a field strength of $3 \mathrm{mV} / \mathrm{V}$. However, the $3 \mathrm{mV} / \mathrm{V}$ field strength reasonably reflects the "real world" environment. Manufacturers realize that equipment must resist EMI, but agree that there is great inconsistency in the test results from one laboratory to another, even if the tests are conducted in an anechoic chamber. The lack of correlation is due to the many variables that can affect the susceptibility of equipment. The lack of correlation in test results among sophisticated laboratories has led to the industry conclusion that the tests are not controllable or repeatable among different laboratories. Consequently, since results will not be conclusive for environments outside the EMI chamber in which the tests are conducted, the industry does not support establishing a sophisticated EMI laboratory. The scale manufacturer must correct problems that occur in the field even if the laboratory test has been passed.

\section{Electrostatic Discharge and Electrical Bursts}

Electrostatic discharge (ESD) usually results in the operational failure of a device. While continuous ESD pulses can affect the accuracy of a device, this is not a "real world" condition and is not a significant enough problem to justify the test.

Electrical bursts simulate lighting strikes in the vicinity of the scale installation. Electrical bursts usually result in a loss of memory in the microprocessors and interrupt scale operation. These failures are typically temporary. This test is important if a country has a poor power supply: it may be justified in Europe, but is not considered necessary for the United States at this time.

\section{0-15 I Additional Agenda Item: Minimum Amount of Test Weight Required in N.4.}

Discussion: The Committee was asked to discuss the impact of Scales Code paragraph N.4. Recommended Minimum Test Weights and Test Loads becoming retroactive on January 1, 1994. The Committee recognizes that many weights and measures jurisdictions and service companies have already purchased or made arrangements to purchase test weights to meet these requirements; revising the effective date at this time would not be fair to these agencies and might damage the credibility of those weights and measures agencies who have required that service companies purchase additional weights. The Committee makes no recommendations for change to the retroactive date or for further study on this issue. If weights and measures jurisdictions or service companies feel that additional consideration should be given to revising this paragraph, the Committee recommends that they approach their regional weights and measures associations to request this issue be considered by the NCWM. 


\section{Belt-Conveyor Scale Systems Code}

\section{1-1 VC S.1.4. Recording Elements and Recorded Representations.}

(This item was adopted as part of the consent calendar.)

\section{Source: Belt-Conveyor Scale Sector. Technical Committee on National Type Evaluation}

Recommendation: Amend S.1. $\div$ to read:

S.1.4. Recording Elements and Recorded Representations. - The value of the scale division of the recording element shall be the same as that of the indicating element. The belt-conveyor scale system shall record the initial indication and the final indications on the master weight totalizer ${ }^{*}$, the quantitv delivered*. the unit of measurement (i.e., kilograms, tonnes, pounds, tons, etc.), the date, and time. This information shall be recorded for each deliver:

[Nonretroactive as of Januany 1. 1986.][‥ Vonretroactive as of January 1. 1994]

Discussion: The Belt-Conveyor Scale Sector has developed a type evaluation checklist detailing specific points to be checked during the NTEP type evaluations. Under paragraphs S.1.1. and S.1.f. of the Belt-Conveyor Scale Systems Code, belt-conveyor scale systems are required to have a primary indicating and recording element, and to record the unit of measurement and the time and date of the measurement. It was intended that the quantity for the delivery be indicated and recorded. although this is not specifically stated in the requirement. The change proposed to S.1.4. will clarify the information that is needed to properly document the quantity of material delivered over a belt-conveyor scale.

321-

\section{VC N.3.2.1. Accuracy of Material and T.1. Tolerance Values}

(This item was adopted as part of the consent calendar.)

Source: Chicago and NorhWestern Transportation Company

Recommendation: Amend N.3.2.1. Accuracy of Material and T.1. Tolerance Values as follows. Add a footnote to paragraph T.1. to explain the relative tolerance with respect to the overall accuracy that can be expected for the material weighed on a belt-conveyor scale.

X.3.2.1. Accuracy of Material. - The quantity of material comprising the material test shall be weighed statically or on an uncoupled-in-motion railway track scale to an accuracy of at least 0.1 percent. The scale used to weigh material shall be tested immediately prior to running the material test. Ferifying this they is the responsibility of the official with-stattor-athority. Typical scales used for this purpose include class II. III, and III L scales. or a scale with the tolerances as described in Table T.1.1. of Handbook $4+$ Section 2.20.

T.1. Tolerance Values ${ }^{1}$. - Maintenance and acceptance tolerances on materials tests, relative to the weight of the material, shall be $=0.5$ pert $(1.200) \pm 0.25$ percent of the test load.

The new footnote will read as follows:

${ }^{1}$ The variables and uncertainties included in the relative tolerance represent only part of the variables that affect the accuracy of the material weighed on belt-conveyor scales. If this tolerance were based on an error analysis beginning with mass standards through all of the test processes and following the principle expressed in Section 3.2. of the Fundamental Consideration in Appendix A, the tolerance would be 0.5 percent. 
Discussion: The railroad industry tolerance for a "certified" belt-conveyor scale system is \pm 0.25 percent for material testing. The recommendation is to make the tolerance in Handbook 44 consistent with the tolerance in the Association of American Railroads (AAR) Scale Handbook so that scales that pass NTEP type evaluations will be acceptable for use by the railroad industry.

The diagram for this issue illustrates potential sources of error in the test process and separately identifies variables in the weighing process that affect the accuracy of transactions after the scale is tested. Handbook 44 specifies limits to some of the variables which are assigned to different parts of the belt-conveyor test process. An example of sources of error when testing a vehicle scale illustrates the number of additional steps when testing a belt-conveyor scale. Some factors that can affect the accuracy of the test of a belt-conveyor scale and the final weighing process are listed under the different segments in the diagram.

This recommendation is carefully worded to state the tolerance for the belt-conveyor scale to be 0.25 percent relative to the weight of the material. This is important because the Fundamental Considerations in Handbook 44 state that the error in the standard used to check the accuracy of a device shall not exceed one-third of the tolerance applicable to the device under test (unless corrections are made for the errors in the standards). By stating the tolerance relative to the material, the change limits the acceptable difference between the belt-conveyor scale and the material that is weighed and used as the transfer standard in the material test. The objective is to limit the error in belt-conveyor scale systems to

Diagram of Variables and Uncertainties for Item 321-2

\section{Fundamental Consideration}

Error in Standards
(and test process)

Vehicle Scale

$\begin{array}{ll}\text { Mass } & \begin{array}{l}\text { Vehicle Scale } \\ \text { Ctandards } \\ \text { Class III L } \mathrm{F} \\ (0.2 \%)\end{array} \\ (\leq 0.01 \%) & \rightarrow \begin{array}{l}\text { Accuracy of Weighing } \\ \text { Process }\end{array}\end{array}$

\section{Belt-Conveyor Scale}

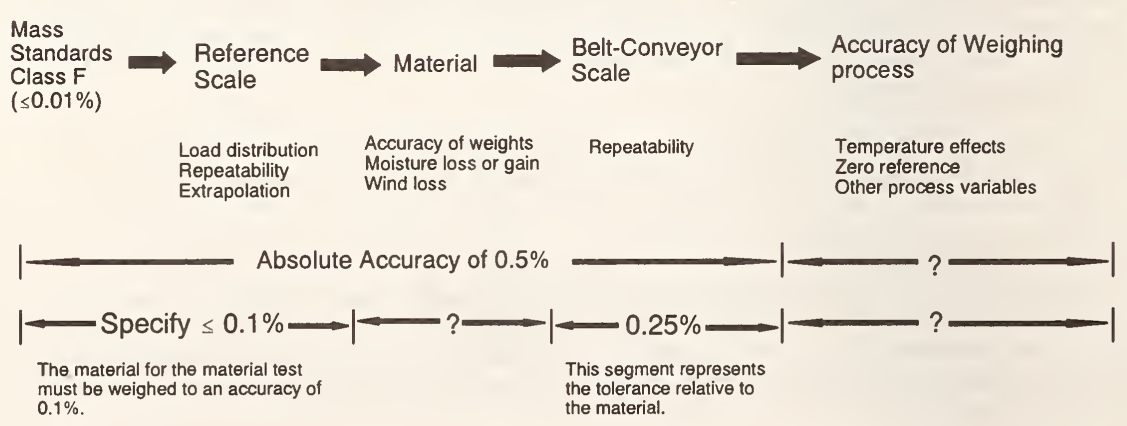


0.25 percent of the reference material, rather than the 0.5 percent normally applied under the current language of Handbook 44.

Since belt-conveyor scales are usually tested against only a single "reference" scale, the systematic error present in the process to test the "reference" scale is a constant bias for all tests of the belt-conveyor scale. In practice, the tolerance of 0.5 percent has been applied entirely to the belt-conveyor scale since the use of a single "reference" scale does not reveal the systematic errors that might be apparent if several different "reference" scales were used and enough tests were performed to permit the systemic errors existing in different reference scales to be detected statistically. By stating the tolerance for the belt-conveyor scale systems relative to the weight of the material, the systematic errors present in the test of the "reference" scale is not a limiting factor in the tolerance applied to the belt-conveyor scale. Consequently, the tolerance for belt-conveyor scales is proposed to be 0.25 percent, which will improve the performance of beltconveyor scales relative to the reference material against which the scale is tested.

The rationale in support of the current tolerance of 0.5 percent is based on the uncertainties present in the standards used to test the "reference" scale, the process of testing the "reference" scale on which the material is weighed, the repeatability of the "reference" scale, the limitations on the ability to thoroughly test the "reference" scale, the stability of the weight of the material between the time the material is weighed and the time when the belt-conveyor scale system is tested, and the repeatability of the belt-conveyor scale system when the material test is conducted. The systematic errors in this process must be less than one-third of the tolerance applied to the belt-conveyor scale. However, this concept is not properly applied in the test of belt-conveyor scales, and must be changed to accommodate the facts that belt-conveyor scales are tested and the resulting values are compared with the static weight of the material used for the materials test.

\section{Automatic Bulk Weighing Systems Code}

\section{VC S.3. Interlocks and Gate Control}

(This item was adopted as part of the consent calendar.)

Source: Central Weights and Measures Association

Recommendation: Add a new requirement under S.3.2. that the system must indicate and record an overfill condition when the overfill alarm is activated, and add a new paragraph S.3. to require a high-level sensor.

S.3.2. Interlocks. - Each automatic bulk weighing system shall have operating interlocks to provide for the following:

(a) Product cannot be cycled and weighed if the weight recording element is disconnected or subjected to a power loss.

(b) The recording element cannot print a weight if either of the gates leading directly to or from the weigh hopper is open.

(c) A "low paper" sensor, when provided, is activated.

(d) The system will operate only in the proper sequence in all modes of operation.

(e) When an overfill alarm is activated, the system shall indicate and record an overfill condition.

S.3.3. Overfill Sensor. - The weigh hopper shall be equipped with an overfill sensor which will cause the feed gate to close, activate an alarm, and inhibit weighing until the overfill condition has been corrected.

Discussion: The USDA Federal Grain Inspection Service and NTEP use the same criteria to evaluate automatic bulk weighing systems. The FGIS has the requirements recommended above as part of their regulations and the Committee believes that they should be required in Handbook 44 as well. The requirements are considered necessary to promote accurate weighing and to alert the scale operator to problems that can affect the accuracy of a transaction. 


\title{
Liquid-Measuring Devices
}

330-1 V S.5. Totalizers

(This item was adopted.)

Source: Southern Weights and Measures Association

Recommendation: Create a new section, S.5. Totalizers, and add two paragraphs under this section to read as follows.

\begin{abstract}
S.5.1. Totalizer for Retail Motor-Fuel Dispensers. - Retail motor-fuel dispensers shall be equipped with a non-resettable totalizer for the quantity delivered through the device. [Nonretroactive as of January 1, 1994. To become retroactive January 1, 1995.J
\end{abstract}

S.5.2. Sealing Totalizers for Retail Motor-Fuel Dispensers. - Adequate provision shall be made for sealing a mechanical totalizer in such a manner that the quantity registration on the totalizer cannot be affected. [Nonretroactive as of January 1, 1994. To become retroactive January 1, 1995.]

Add two user requirements to read:

UR.4.1. Totalizers for Retail Motor-Fuel Dispensers. - Retail motor-fuel dispensers shall be equipped with a non-resettable totalizer for the quantity delivered through the device. [Nonretroactive as of January 1, 1994. To become retroactive January 1, 1995.]

UR.4.2. Sealing Totalizers for Retail Motor-Fuel Dispensers. Adequate provision shall be made for sealing a mechanical totalizer in such a manner that the quantity registration on the totalizer cannot be affected. [Nonretroactive as of January 1, 1994. To become retroactive January 1, 1995.]

The Committee recommends that a paragraph be added to require that motor-fuel dispensers be equipped with a working, sealable, nonresettable totalizer. The Committee agreed that either a mechanical or an electronic totalizer would be acceptable. The electronic totalizer must be nonresettable: it must retain values throughout a power failure. There is no need to apply a security seal since electronic totalizers do not have externally accessible adjustments.

Discussion: Although the present code does not require totalizers, most manufacturers already provide them. It is believed that most retail motor-fuel dispensers currently in use are equipped with totalizers; however, not all may have provisions for sealing. A few States already require that these totalizers be-sealable. Consequently, this change is proposed as a nonretroactive requirement as of January 1, 1994, but to become retroactive January 1, 1995. It is intended that the device owner will be responsible for bringing devices that are currently installed into compliance with this requirement.

It is reported that totalizers on dispensers are needed for the collection of motor-fuel taxes. It was noted that totalizers are also used by weights and measures jurisdictions to track the amount of product dispensed during official testing, detecting diversion of product after it has been metered, detecting discrepancies between blend settings and posted octane values, and detecting if a dispenser has been used after it has been removed from service.

In discussing where such a requirement would be placed in the Liquid-Measuring Devices (LMD) Code, concern was expressed that placing the requirement under S.1. might imply that the totalizer must meet other requirements in the S.1. section, such as the size of the division. Concern was also expressed that the totalizers would be required to meet the agreement requirements for indicators specified in General Code paragraph G-S.5.2.2. The Committee agreed that it is not intended that the other requirements in S.1. applicable to indicating elements be applied to totalizers, and no restriction is placed on the size of the totalizer division. Similarly, the Committee does not intend that the totalizers must meet the requirements of G-S.5.2.2. for agreement. Consequently, the Committee decided to create a new section, S.5. Totalizers to avoid confusion in interpreting the requirements. 


\section{S.1.6.5., S.1.6.5.4., UR.3.2. Exceptions to Price Computing, Unit Price Selection Controls, and Posting of Unit Prices}

(This item was adopted.)

Source: Central Weights and Measures Association

Recommendation: Amend the following three paragraphs of the LMD Code to provide exceptions to price computing, the posting of unit prices, and unit price selection controls for truck stop dispensers used only to refuel trucks.

\section{S.1.6.5. Money-Value Computations.}

(a) A computing device shall compute the total sales price at any single-purchase unit price (i.e., excluding fleet sales, and other price contract sales, and truck stop dispensers used only to refuel trucks) for which the product being measured is offered for sale at any delivery possible within either the measurement range of the device or the range of the computing elements, whichever is less. (Effective and nonretroactive as of January 1, 1991).

S.1.6.5.4. Selection of Unit Price.- Except for dispensers used exclusively for fleet sales, other price contract sales, and truck refueling (e.g., truck stop dispensers used only to refuel trucks), when a product or grade is offered for sale at more than one unit price through a computing device, the selection of the unit price shall be made using controls on the device or other user-activated controls. A system shall not permit a change to the unit price during delivery of product. (Effective and nonretroactive as of January 1, 1991)

\section{UR.3.2. Unit Price and Product Identity.}

(a) The following information shall be conspicuously displayed or posted on the face of a retail dispenser used in direct sale:

(1) Except for dispensers used exclusively for fleet sales, other price contract sales, and truck refueling (e.g., truck stop dispensers used only to refuel trucks), all of the unit prices (excluding flet-sales, and other price entratsates) at which the product is offered for sale; and ...

Discussion: In 1991, the NCWM amended paragraph S.1.6.5.4. to exempt dispensers used exclusively for truck refueling from the requirement for user-activated controls. The rationale given for this decision was that there does not appear to be a strong demand for user-activated controls on dispensers installed at truck stops. It should be noted that part of the S\&T Committee discussions of S.1.6.5. considered that truck stop dispensers had to compute at the unit prices at which the products are offered for sale; however, the unit price selection did not have to be made through controls on the dispenser. The console operator could select the unit price and transmit the information to the dispenser for the purpose of computing the total price for the transaction. This discussion also applies to UR.3.2. which currently requires posting of unit prices.

Not all truck refueling is limited to fleet sales or prearranged price contracts, nor are all fleet sales or contract sales for truck refueling. It is suggested that the same requirements and exemptions should apply to fleet sales, contract sales, and truck stop dispensers used exclusively for refueling trucks, all of which serve similar customers. These customers are typically aware of the pricing structures used and of the prices they will pay at these installations.

The Committee agrees that the clientele served by these types of devices are generally aware of the prices they will pay. Due to this and the added cost that would be required to meet the current requirements, the Committee recommends changes to the LMD Code.

The changes recommended by the Committee will: 
(1) exempt truck stop dispensers from having to compute the total sale price at any single-purchase unit price;

(2) extend to fleet and other price contract sales the exemption currently granted in S.1.6.5.4. to dispensers used exclusively for truck refueling; and

(3) exempt dispensers used exclusively for fleet sales, other price contract sales, and truck refueling from the requirement to post all of the unit prices at which the product is offered for sale. (Note: The requirement to post product identity information would still apply.)

\section{0-3 V UR.3.3. Computing Device}

(This item was adopted.)

Source: Central Weights and Measures Association

Recommendation: Add two new subparagraphs to UR.3.3. to provide an exemption from parts (a) and (b) for dispensers in truck stops if a printed receipt is provided. Additionally, subparagraph (d) will require that the dispenser compute at the highest price (the cash or credit method of payment for different levels of service) for any transaction which may be conducted unless the dispenser complies with S.1.6.4.1. It is noted that this will permit the use of singleprice computing dispensers in multi-tier pricing applied exclusively for refueling trucks at truck stops.

\section{UR.3.3. Computing Device}

(a) Any computing device placed into service after January 1, 1990, in an application where a product or grade is offered for sale at more than one unit price (excluding fleet sales and other price contract sales), shall be used only for sales for which the device computes and displays the sales price for the selected transaction. Individual single unit-price computing devices installed to replace existing devices or to add to station capacity are exempt from this requirement. (Added 1989) (Amended 1992)

(b) A computing device shall be used only for sales for which the device computes and displays the sales price for the transaction.

(Effective and retroactive as of January 1, 1999)

(Added 1990)

(c) A truck stop dispenser used exclusively for refueling trucks is exempt from the requirements in (a) and (b) if all purchases of fuel are accompanied by a printed receipt of the transaction containing the applicable price per gallon, the total gallons delivered, and the total price of the sale.

(d) Unless a truck stop dispenser used exclusively for refueling trucks complies with S.1.6.4.1. (Display of Unit Price), the price posted on the dispenser and the price at which the dispenser is set to compute shall be the highest price for any transaction which may be conducted.

Discussion: This proposal was submitted to the S\&T Committee on the basis that truck stops serve a specific clientele of professional truck drivers and business persons who are informed consumers. It was suggested that, since their livelihood depends in part on the fuel purchases and the price of the fuel, they do not need the same protection afforded the average consumer at the service station.

The systems in use at truck stops are very sophisticated with capabilities that go beyond those in the service station. The number of pricing levels combined with alternative methods of payment go beyond cash, company credit cards, and bank cards. Truck stops usually have a very large number of devices for which the requirements of UR.3.3.(a) and (b) are claimed to pose an excessive and unnecessary expense.

The Committee acknowledged that a variety of pricing structures are used by professional truckers. Because trucking companies are often offered discounts based upon the type of service, method of payment, and the volume of product 
sold, attempting to post and compute at the myriad of prices becomes impractical and costly. Permitting the device owner/user to provide a printed receipt in lieu of computing at every unit price and requiring only the posting of the highest unit price available would provide some relief for those devices that do not comply with paragraph S.1.6.4.1.

\section{0-4 VC Definition of Contract or Club Sale}

(This item was adopted as part of the consent calendar.)

Source: Southern Weights and Measures Association (SWMA), 1992 S\&T Item 330-7

Recommendation: The Committee recommends the following definition for contract sale.

contract sale. A sale where there is a written agreement stating the price as either a fixed price, a price above cost, or an adjustment from the posted price.

Discussion: The Committee reviewed a definition proposed by the SWMA for "contract or club sales." This proposal suggests one approach to clarify the term "price contract sale" and distinguish it from "club" sales where only a credit check is needed to obtain a card, but no price is specified in the contract. In 1992, the S\&T Committee suggested that a "price contract sale" is one where a contract states the price of the product as either a specific price, a nonzero adjustment to the retail posted price, or an adjustment based upon the cost of the product to the service station. Under these conditions, club accounts that offer the product to the general public based solely upon credit checks to become members of a "club" (i.e., there is no contract for product price) are not considered price contract sales and are subject to the requirements of S.1.6.5. and the subparagraphs under S.1.6.5.

In order to clarify that a "club sale" does not automatically fall under the category of a "contract sale," the Committee recommends that the reference to "club sale" be deleted from the definition. If a "club sale" meets the definition of a contract sale, the criteria apply.

\section{0-5 I T.2.3.4. Automatic Temperature Compensating Systems; Accuracy of the Temperature Sensor}

Source: S\&T Item 330-4; Shell Oil

Discussion: The S\&T Committee originally specified the tolerance for automatic temperature compensating systems in terms of the meter test results for compensated and uncompensated runs because the location of the temperature probe in many loading rack systems is often at a considerable distance from the meter. Additionally, many installations do not have a thermometer well adjacent to the temperature probe that can be used to compare the accuracy of the system temperature probe to a reference thermometer. The normal test draft for the application of the tolerance is a neck-type, large volume prover.

The Committee received comments indicating that the tolerance expressed in T.2.3.4. is not practical when small volume provers are used. The Committee understands the term "small volume prover" to refer to a compact prover rather than to a neck-type prover of a smaller capacity. Due to the small size of the test draft when small volume provers are used, the tolerance as a percent of the test draft is too small to be used to check the accuracy of the temperature probe. The Committee was asked to consider expressing the tolerance for a temperature probe in degrees, such as $1^{\circ} \mathrm{C}\left(2^{\circ} \mathrm{F}\right)$, particularly when small volume provers are used to test meters, and to consider specifying all tolerances for automatic temperature compensating systems as a temperature value instead of a deviation in the test results for the compensated and uncompensated test results.

During the discussion of this item, it was pointed out to the Committee that the temperature taken by a small volume prover is not representative of the temperature of the entire delivery; it only represents the temperature of the product at a given period of time during the entire delivery. The performance of the probe only represents part of the overall performance of the measuring system. Consequently, it was stated that the application of the tolerances as currently written is inappropriate and the tolerances should be changed as proposed. 
Some members of industry expressed opposing views to these comments, indicating that evaluating the performance of the temperature probe alone and permitting a tolerance of $2^{\circ} \mathrm{F}$ is excessive. These comments indicated that the proposal would inappropriately relax the tolerances.

The Committee needs additional information before it can develop a position on this issue. The Committee requests advice regarding the following:

(1) What size of provers or test drafts should be considered "small volume"?

(2) How accurately can the temperature of the product used in the test be determined? How is the lag time in the response of the temperature probe addressed?

(3) Should any consideration be given to a potential difference in product temperature if the temperature probe for the metering system is not adjacent to the meter?

The American Petroleum Institute has provided to the S\&T Committee four sections from its Manual of Petroleum Measurement Standards to assist the Committee in its understanding of the design and use of small volume provers. The Committee would appreciate additional input to develop and resolve this issue. The Committee requests additional input from the Measuring Sector of the Technical Committee on National Type Evaluation and from industry.

\section{0-6 W T.2.4. Tolerances for Meters Measuring Automotive Fluids}

(This item was withdrawn.)

Source: Carryover Item 330-2

Discussion: The Committee had recommended tolerances for study in Item 330-7 of its 1991 report. There have been few comments on this issue. Following the 1992 Annual Meeting, the Committee classified this as a low priority item and requested comments on this item to assist the Committee in its disposition of the issue.

These devices are typically tested at volumes such as one quart or one pint to approximate the normal usage of the device. Concern was expressed that the tolerances currently in the liquid-measuring devices code are inappropriately large for small deliveries such as these.

No comments have been received from the regional weights and measures associations or industry to indicate that this issue should be maintained on the Committee's agenda. Consequently, the Committee has withdrawn this item.

\section{0-7 W Blending at the Loading Rack for Wholesale Transactions; Adjustments} for Changes in Product Volume

(This item was withdrawn.)

Source: Carryover Item 330-9

Discussion: The number of sites blending oxygenates and other components into base gasoline stocks at the loading rack continues to increase and more installations exist. This issue addresses whether or not mathematical corrections should be permitted to adjust meter readings for changes in product volume resulting from the blending of different fuel components. Background information on this item is provided in Item 330-9 in the 1992 report of the S\&T Committee.

It is clear from comments made during the discussion of this issue that additional information and review are required before the Committee can adequately evaluate this issue.

The Committee has not received any additional information on this item since the 1992 Annual Meeting and no interest has been expressed by the regional weights and measures associations to develop this issue further. Consequently, the Committee has withdrawn this item from its agenda. The Committee maintains its position that mathematical adjustment for changes in product volume should not be permitted. 


\section{0-8 I UR.1.X. Selection Requirements; Suitability of Equipment}

Source: Carryover Item 330-6

Recommendation: The suitability of equipment table shown below is presented for study and possible addition to the General Code. The Committee notes that, to be considered suitable for a given application, a device must be accurate to at least the accuracy level specified in the table. The specific codes define the performance (accuracy) required for the specific device technology (for example, mass flow meters, retail motor-fuel dispensers, etc.); acceptance and maintenance tolerances still apply to devices as specified in General Code paragraph G-T.1. The Committee suggests that the table be studied with the possibility of incorporating the table as a user requirement in the General Code along with the language shown in G-UR.1.3. below.

G-UR.1.3. Liquid-Measuring Devices. - To be suitable for its application, a liquid-measuring device shall satisfy the criteria in Table G-UR.1.3. for the specific application in which the device is used. (Note: The acceptance and maintenance tolerances stated in the specific codes apply to the devices addressed by the codes.)

Table G-UR.1.3. Suitability of Equipment Criteria for Liquid-Measuring Devices

\begin{tabular}{|c|c|c|c|c|}
\hline \multicolumn{2}{|c|}{ Application or Commodity } & $\begin{array}{l}\text { Minimum } \\
\text { Delivery }\end{array}$ & $\begin{array}{l}\text { Maximum Division } \\
\text { Value }\left(\mathrm{d}_{\max }\right)\end{array}$ & Accuracy Required \\
\hline \multirow{4}{*}{$\begin{array}{l}\text { Motor } \\
\text { Fuel }\end{array}$} & \multirow{2}{*}{ Analog } & $100 d$ & $\begin{array}{c}0.01 \mathrm{~L} \\
0.01 \mathrm{gal}^{*}\end{array}$ & $0.5 \%$ \\
\hline & & $100 d$ & $\begin{array}{l}1.0 \mathrm{~L} \\
0.1 \mathrm{gal}\end{array}$ & $0.3 \%$ \\
\hline & \multirow{2}{*}{ Digital } & \multirow{2}{*}{$100 d$} & $\begin{array}{c}0.01 \mathrm{~L} \\
0.01 \mathrm{gal}\end{array}$ & $0.5 \%$ \\
\hline & & & $\begin{array}{l}0.1 \mathrm{~L} \\
0.1 \mathrm{gal}\end{array}$ & $0.3 \%$ \\
\hline \multirow{2}{*}{$\begin{array}{l}\text { Motor } \\
\text { Fuel }\end{array}$} & \multirow{2}{*}{ LPG } & \multirow[t]{2}{*}{$100 d$} & $\begin{array}{c}0.01 \mathrm{~L} \\
0.01 \mathrm{gal}\end{array}$ & \multirow{2}{*}{$1.0 \%$} \\
\hline & & & $\begin{array}{l}0.1 \mathrm{~L} \\
0.1 \mathrm{gal}\end{array}$ & \\
\hline \multicolumn{2}{|c|}{ Home Heating Oil } & $100 \mathrm{~d}$ & $\begin{array}{r}0.1 \mathrm{~L} \\
0.1 \mathrm{gal}\end{array}$ & $0.3 \%$ \\
\hline \multirow{2}{*}{\multicolumn{2}{|c|}{$\begin{array}{l}\mathrm{NH}_{3} \text { and LPG Other Than Motor } \\
\text { Fuel }\end{array}$}} & \multirow{2}{*}{$100 \mathrm{~d}$} & $\begin{array}{l}0.1 \mathrm{~L} \\
0.1 \mathrm{gal}\end{array}$ & \multirow{2}{*}{$1.0 \%$} \\
\hline & & & $\begin{array}{l}1.0 \mathrm{~L} \\
1.0 \mathrm{gal}\end{array}$ & \\
\hline \multirow{2}{*}{\multicolumn{2}{|c|}{$\begin{array}{l}\text { Milk and other } \\
\text { Food Products }\end{array}$}} & $100 d$ & $\begin{array}{l}0.1 \mathrm{~L} \\
0.1 \mathrm{gal}\end{array}$ & \multirow{2}{*}{$0.3 \%$} \\
\hline & & $100 \mathrm{~d}$ & $\begin{array}{l}1.0 \mathrm{~L} \\
1.0 \mathrm{gal}\end{array}$ & \\
\hline
\end{tabular}




\begin{tabular}{|c|c|c|c|}
\hline Application or Commodity & $\begin{array}{l}\text { Minimum } \\
\text { Delivery }\end{array}$ & $\begin{array}{l}\text { Maximum Division } \\
\text { Value }\left(\mathrm{d}_{\max }\right)\end{array}$ & Accuracy Required \\
\hline \multirow{2}{*}{ Cryogenic Liquids } & \multirow{2}{*}{$100 \mathrm{~d}$} & $\begin{array}{c}1.0 \mathrm{~L} \\
0.1 \mathrm{gal}\end{array}$ & \multirow{2}{*}{$2.5 \%$} \\
\hline & & $\begin{array}{l}10 \mathrm{~L} \\
1 \mathrm{gal}\end{array}$ & \\
\hline \multirow{4}{*}{ All Other Metering Applications } & \multirow{4}{*}{$100 \mathrm{~d}$} & $\begin{array}{l}1.0 \mathrm{~L} \\
1 \mathrm{gal}\end{array}$ & \multirow[b]{2}{*}{$0.3 \%$} \\
\hline & & $\begin{array}{l}0.1 \mathrm{~L} \\
0.1 \mathrm{gal}\end{array}$ & \\
\hline & & $\begin{array}{l}0.01 \mathrm{~L} \\
0.01 \mathrm{gal}\end{array}$ & $0.5 \%$ \\
\hline & & $\begin{array}{l}0.001 \mathrm{~L} \\
0.001 \mathrm{gal}\end{array}$ & $1.0 \%$ \\
\hline \multicolumn{4}{|c|}{$\begin{array}{l}\text { Tolerances apply to tests done at all temperatures, pressures, and flow rates as well as for all liquids } \\
\text { specified by the manufacturer. } \\
* \text { Nonretroactive in terms of new models of devices for measuring motor fuels. }\end{array}$} \\
\hline
\end{tabular}

Discussion: The Committee reviewed the suitability of equipment table developed for liquid-measuring devices. (Background information for this item is included in Item 330-6 in the 1992 S\&T Committee report.)

This issue has been examined by the regional weights and measures associations for several years, with few objections raised to the information contained in the proposed table. However, concerns were expressed about the criteria for the "Minimum Measured Quantity" (MMQ) and the tolerances for agri-chemicals that were included in the 1992 report. Additionally, the reference to marking the accuracy on the meter is not supported by a requirement in the Handbook. The Committee agrees that additional work is needed in these areas before they are incorporated in the table and intends to develop these areas further over the next year.

In order to proceed with this issue, the Committee revised the table to remove the references to the MMQ and agrichemicals and eliminated a reference to marking the accuracy category on the meter. The suitability of equipment table retains a column identifying the accuracy required for a given application. The accuracies are based on the current tolerances specified in Handbook 44 for these applications.

The Committee discussed the possibility of including the revised table in NCWM Publication 3; however, concern was expressed that weights and measures officials may have difficulty enforcing the criteria outlined in the table if it appears only in Publication 3. In addition, there is concern that not all users or weights and measures officials have access to or are familiar with the information provided in Publication 3; providing the table only in Publication 3 would diminish its effectiveness in promoting uniform enforcement of suitability criteria. Consequently, the Committee believes that the table must be included in Handbook 44. Because this table is applicable to many different types of liquid-measuring devices, the Committee agreed that the table is most appropriately placed in the user requirements of the General Code.

The definition currently specified by OIML for MMQ is: "The smallest volume of liquid for which the measurement is metrologically acceptable for that system."

The Committee is considering the possibility of recommending next year that the following definition be included in Appendix D of Handbook 44. The Committee requests that the regional associations and industry study the definition over the next year and provide input to the Committee.

minimum measured quantity. The smallest quantity as specified by the manufacturer for which the device complies with all applicable metrological requirements. [1.10, 3.37] 
Based on the comments received, the Committee recognized that many members have questions about the parameters in the proposed table and about the table's intended application and effective date. The Committee continues to support the concept of establishing definitive criteria for suitability of equipment to assist the field of ficial in assessing suitability of devices; however, the Committee believes that additional study is needed before presenting the table as a voting item. In order to ensure that possible applications of the table have been carefully considered and that members understand how the criteria in the table are intended to be applied, the Committee requests additional input from members over the next year concerning the table proposed in the Committee's Interim Report.

\section{Vehicle-Tank Meters Code}

\section{1-1 VC S.2.1. Vapor Elimination}

(This item was adopted as part of the consent calendar.)

Source: Western Weights and Measures Association

Recommendation: Amend paragraph S.2.1. to read:

S.2.1. Vapor Elimination. - A metering system shall be equipped with an effective vapor or air eliminator or other automatic means to prevent the passage of vapor and air through the meter. Vent lines from the air or vapor eliminator shall be made of metal tubing or some other suitable rigid material.

Discussion: Some companies install manual shutoff valves on air eliminators to close off vent lines into the vapor tank to prevent the vapor tank from filling with product during delivery and overflowing. An effective means to prevent the passage of vapor and air through the meter is in place, but it functions only if the operator opens the manual valve. The air eliminator will not work if the operator closes the valve. Automatic operation of air and vapor eliminators is needed and will be required under this proposal.

The Western suggested developing identical language in both the VTM and LMD Codes to require that the means to prevent the passage of vapor and air through the meter must be automatic in operation. The Committee agreed that changes to paragraph S.2.1. are appropriate to ensure that this feature is automatic. However, the Committee believes that the term "effective" should be maintained in the language for emphasis on the system operation.

\section{$331-2$}

V

UR.2.2. Ticket Printer; Customer Ticket

(This item was adopted.)

Source: 1992 S\&T Item 332-2

Recommendation: Renumber current UR.2.2. and UR.2.3. to UR.2.3. and UR.2.4., respectively and add a new UR.2.2. to read:

\section{UR.2.2. Ticket Printer; Customer Ticket. - Vehicle-mounted metering systems shall be equipped with a ticket printer. The ticket printer shall be used for all sales; a copy of the ticket issued by the device shall be left with the customer at the time of delivery. \\ [Nonretroactive as of January 1, 1995. To become retroactive as of January 1, 1999.]}

Discussion: In July 1992 the NCWM voted to require that vehicle-mounted meters used to deliver liquefied petroleum gas be equipped with a ticket printer. It was suggested that this requirement be extended to the Vehicle-Tank Meters Code. The Committee believes that customers need a delivery ticket at the time of product delivery to document the 
transaction. The delivery ticket is the only assurance that customers receive sufficient information to evaluate accuracy of invoices.

The Committee also discussed whether or not Handbook 44 should also specify the minimum information to be included on the delivery ticket. The Committee concluded that the information that must be provided is adequately specified in NIST Handbook 130 (Section 18, Sale from Bulk, of the Uniform Weights and Measures Law).

Based on comments received the Committee believes that this requirement should become effective January 1 , 1995, to enable companies to budget for purchases of new equipment. It was noted during the discussion of this issue that some jurisdictions have a large number of devices that are not currently equipped with ticket printers or on which the ticket printers are not functional. The Committee believes that making the requirement retroactive as of January 1,1999 would provide device owners a reasonable period of time to repair existing printers or install new printers.

\section{Liquefied Petroleum Gas and Anhydrous Ammonia Liquid-Measuring Devices Code}

\section{2-1 I T.3. Automatic Temperature-Compensating Systems; Accuracy of the Temperature Sensor}

Source: 1992 S\&T Items 332-3 and 330-4; Shell Oil

Discussion: (See Item 330-5 for the liquid-measuring devices issue corresponding to this item.) The S\&T Committee originally specified the tolerance for automatic temperature compensating systems in terms of the meter test results for compensated and uncompensated runs because the location of the temperature probe in many loading rack systems is often considerably distant from the meters. Moreover, many installations do not have a thermometer well adjacent to the temperature probe that can be used to compare the accuracy of the system temperature probe to a reference thermometer.

The Committee received comments indicating that the tolerance expressed in T.2.3.3. is not practical when small volume provers are used. Due to the small size of the test draft when small volume provers are used, the tolerance as a percent of the test draft is too small to be used to check the accuracy of the temperature probe. The Committee was asked to consider (1) expressing the tolerance for a temperature probe in degrees, such as $1{ }^{\circ} \mathrm{C}\left(2^{\circ} \mathrm{F}\right)$, particularly when small volume provers are used to test meters, and (2) specifying all tolerances for automatic temperature compensating systems as a temperature value instead of a deviation in the test results for the compensated and uncompensated test results.

During the discussion of this item, it was pointed out to the Committee that the temperature taken by a small volume prover is not representative of the temperature of the entire delivery; it represents only the temperature of the product at a given period of time during the entire delivery. The performance of the probe represents only part of the overall performance of the measuring system. Consequently, application of the tolerances as currently written is inappropriate and the tolerances should be changed as proposed.

Some members of industry expressed opposing views to these comments indicating that evaluating the performance of the temperature probe alone is unreasonable and permitting a tolerance of $2^{\circ} \mathrm{F}$ is excessive. These comments indicated that the proposal would inappropriately relax the tolerances.

The American Petroleum Institute has provided to the S\&T Committee four sections from its Manual of Petroleum Measurement Standards to assist the Committee in its understanding of the design and use of small volume provers. The Committee would appreciate additional input to develop and resolve this issue. 


\section{Cryogenic Liquid-Measuring Devices Code}

\section{4-1 I S.2.4. Automatic Temperature or Density Compensation}

Source: Compressed Gas Association; Air Products and Chemicals, Inc.

Recommendation: Mr. Lionel Wolpert, representing the Compressed Gas Association (CGA), gave a presentation at the Interim Meeting in support of rescinding the mandatory use of automatic temperature compensating systems on cryogenic metering systems.

It is the position of the CGA that the requirements for automatic temperature or density compensation for the meters is unnecessary, restrictive, and costly from both operational and maintenance perspectives. Other methods are available to ensure consistency in meeting the tolerances. The CGA contends that the tolerances specified in the Code can be and are being met using meters that do not have temperature or density compensation. The Code should be a performance standard, not a design manual.

The Compressed Gas Association reports that a narrow pressure range exists for trailers to pump discharge their lading (the most common delivery mode). This range is mandatory in order to prime and retain the pump prime during transfer, yet not exceed the pressure rating of the trailer as maintained by the pressure relief valve. These operating parameters limit the maximum temperature of the cryogenic product being delivered and metered.

Approximately 25 percent of the 1900 cryogenic meters in commercial use in the United States are not temperature or density compensated. The cost of replacing or modifying present metering systems to incorporate temperature or density compensation ranges from $\$ 600$ to $\$ 3000$ per meter. In addition, maintenance costs increase due to additional instrumentation and hardware. Much of this maintenance cost is due to the rigors of road vibration, particularly for the temperature sensor.

The Committee analyzed the data provided in Mr. Wolpert's presentation along with the report of the meter testing conducted by the State of California. Two points were major considerations to the Committee. The California data indicate a much higher rejection rate for non-temperature compensated meters (34 percent) than for temperature compensated meters ( 9 percent). Since the CGA did not have the California comments prior to the meeting, they were unable to assess and explain why such a large difference in rejection rates existed in the California data. Therefore, the Committee concluded that temperature compensated meters appeared to result in greater accuracy than uncompensated meters.

The second point is based upon the effects of pressure on the accuracy of the measurement, as provided by Mr. Wolpert in his presentation. The variation of pressure from 5 to 25 psig changes the liquid volume correction factor from approximately -1.5 to 2.3 percent. The CGA contends that since this is less than the meter tolerance, then automatic temperature compensation should not be required. The S\&T Committee noted that the acceptance tolerance on cryogenic meters is 1.5 percent; the maintenance tolerance is 2.5 percent. Since the effect of pressure (and therefore temperature) can have an effect greater than the acceptance tolerance, automatic temperature compensation can certainly be justified. The fact that the liquid volume correction varies over almost the entire range of the maintenance tolerance means that there is little provision for meter error. Consequently, the Committee was not persuaded that the requirement for a mandatory temperature or density compensating system should be deleted.

The Committee agreed that CGA will have to provide additional information to justify further consideration of its proposal to rescind the requirement adopted in 1991. The Committee is reluctant to propose changes to the requirements which were adopted in 1991 until information can be provided to indicate that changes are warranted. The S\&T Committee is willing to review this issue again if additional significant justification can be provided by the CGA. See Items $334-1$ and 334-2 in the 1991 the S\&T Committee final report for more information. 


\section{Tentative Code - Mass Flow Meters}

\section{7-1 VC S.1.2.2. Mass Measurement}

(This item was adopted as part of the consent calendar.)

Source: Carryover Item 337-1A

Recommendation: Delete S.1.2.2. and amend S.1.2.1. to read:

S.1.2.1. Units of Measurement. - Deliveries shall be indicated and recorded in grams, kilograms, metric tons, pounds, or tons and decimal subdivisions thereof. The indication of a delivery shall be on the basis of apparent mass versus a density of $8.0 \mathrm{~g} / \mathrm{cm}^{3}$ ).

Delete paragraph N.6. and Table N.6.

Discussion: There are strong advocates for and arguments on each side of the issue as to whether mass flow meters should be required to indicate the quantity as (true) mass or apparent mass versus $8.0 \mathrm{~g} / \mathrm{cm}^{3}$. (See Item $360-1$ in the 1991 S\&T Committee final report and Item 337-1A in the 1992 report for additional information.) This issue is significant because the basis for the quantity indication represents a difference of 0.1 percent for liquids with a density similar to water (such as motor fuels and most liquid chemicals). Quantities indicated as mass correspond to quantities registered by a volume meter, whereas quantities indicated as apparent mass correspond to scale indications. Indications of mass are approximately 0.1 percent greater than the apparent mass value when a water-based solution is exposed to atmosphere. When a commodity is delivered into a closed vessel (e.g., compressed natural gas or anhydrous ammonia metered into a tank), the two quantities are the same since the buoyant effect of air is constant whether the closed vessel is empty or full.

The Committee believes that consumers and businesses do not generally understand the distinction between mass and apparent mass. The Committee had concluded that if mass flow meters indicate in mass units, then the mass units should be identified to distinguish the units from the values routinely obtained from scales. The Committee notes that some people have suggested that a distinction is not needed since the difference is "small" and not likely to be distinguished in commercial transactions.

The Committee has decided to recommend that mass flow meters indicate in apparent mass units. It makes this recommendation to simplify the basis of commercial transactions, to be consistent with apparent mass indications for scales, and to simplify the process of testing a mass flow meter (when the measured commodity is not in a closed vessel). If mass flow meters are required to indicate in apparent mass units, then paragraph N.6. Air Buoyancy Correction, under the "Notes" section is not needed and will be deleted.

\section{7-2 I S.1.2.6. Units of Measure for Natural Gas Sold as an Engine Fuel}

\section{Source: Carryover Item 337-1B}

Recommendation: In a joint decision with the Laws and Regulations Committee, the Committee has changed this item from "voting" to "informational." The Committees agree that many questions concerning this issue continue to be presented, and that additional work is needed prior to making a recommendation to the conference. The Committees agreed to work with a task force which will be established by the National Gas Vehicle Coalition to further examine the questions surrounding this issue, including the method of sale, methods for determining conversion factors, and methods of safely inspecting these devices.

The Committee presents the following changes and additions to that section of the Committee's Interim Report which discusses the establishment of conversion factors and methods of conversion between different units of measure for natural gas. 
Mr. John Lacy, Packers \& Stockyards Administration, USDA, Liaison Advisor to the S\&T Committee, contacted FTC, EPA, DOE, DOT, and state and federal tax revenue offices to advise them of the Committee's recommendations and address any problems that may be identified. The State metrologists developed a draft examination procedure outline (EPO) for CNG dispensers and presented it to the Committee for review. (Copies of the draft EPO are available from the Office of Weights and Measures upon request.)

As a result of the Interim Meeting, the Committee recommended the following changes to Handbook 44 .

Add the following term to Appendix D. Definitions.

Natural Gas. A gaseous fuel, composed primarily of methane, which conforms to SAE J1616 recommendations and is suitable for compression and dispensing into a fuel storage container(s) for use as an engine fuel. [3.37]

Since the Committee has recommended deleting S.1.2.2. (Item 337-1), add a new paragraph S.1.2.2. to read:

\section{S.1.2.2. Units of Measure for Natural Gas When Sold as an Engine Fuel.}

(a) A natural gas dispenser shall display the primary unit of measurement in mass units in terms of kilograms or pounds and shall be capable of displaying a measurement unit for calibration or verification.

(b) The unit of calibration shall be in terms of grams, kilograms, or pounds, and multiples or decimal subdivisions thereof.

(c) Supplemental indications in other appropriate units are permitted. Such units include, but are not limited to, equivalent liters or gallons of gasoline or diesel fuel, standard cubic meters or feet, megajoules or therms (energy), etc. Supplemental indications shall be identified as being for informational purposes only.

(d) Supplemental indications expressed in equivalent liters or gallons of gasoline or diesel fuel shall be derived on an energy equivalent basis based on the fuel's lower heating values. A conversion factor which relates the average annual lower heating value of natural gas supplied to the natural gas refueling facility to the regional average lower heating value of commercial grade gasoline or diesel fuel shall be utilized to convert the unit of sale to the supplemental unit.

(e) The conversion factor relating the unit of calibration to the energy unit shall be displayed on the face of the device.

Discussion: The installation of service station dispensers for natural gas for use as an engine fuel dictates specifying a method of sale for this product. The Committee heard varying proposals: one is to require that compressed natural gas (CNG) be sold on the basis of mass units, another that energy units be used, a third to permit the use of "equivalent gallon of gasoline," and a fourth suggesting that the standard cubic foot of gas at standard temperature and pressure be used as the basis for sale. The Committee was asked to consider the definition, possibly the posting of a conversion factor to some of the units suggested, and permitting supplemental indications in some alternate unit.

While the method of sale of CNG as an engine fuel falls under the scope of the Laws and Regulations Committee, changes to Handbook 44 must be considered either to require or permit certain quantity units to be indicated on the dispensers of CNG. Consequently, the S\&T Committee met with the L\&R Committee in a joint session during the 1993 Interim Meetings to discuss this issue in conjunction with Item 232-6 on the L\&R Committee's agenda.

The Natural Gas Vehicle Coalition (NGVC) presented the Committee with a proposal to require the primary unit of a CNG meter to be expressed in units of mass. The NGVC also recommended permitting the use of properly defined supplemental units to assist the consumer in relating CNG to other forms of motor fuel. 
In conjunction with the recommendation of the Laws and Regulations Committee to specify the sale of CNG used as a retail motor fuel on the basis of mass, the S\&T Committee agreed that devices should be required to register the quantity and compute the sales price on the basis of mass units. The Committee is strongly opposed to permitting any term (such as "equivalent liter" or "equivalent gallon") which is not a defined standard unit of measurement to be used as the primary unit of measurement. (The exact conversion factors used to derive such terms vary with the composition of natural gas and the refined gasoline and diesel fuel; the Committee believes this would cause widespread problems in enforcement of posted requirements and would cause confusion to the consumer in making comparisons among competing stations.) However, the Committee agreed that devices should be permitted to indicate in supplementary units of quantity, such as equivalent gallon of gasoline or diesel fuel, the standard cubic foot, and energy units which must also be estimated from the actual mass flow measurement.

The Committee believes that supplementary units will enable this fledgling industry to provide additional information to the consumer to relate CNG to other forms of motor fuel. The Committee maintains that supplemental units must have a scientific relationship to the mass unit used as a method of sale. The conversion factor must be posted on the dispenser, and the relationships between equivalent gallon, standard cubic foot, and energy units shall be determined using methods such as the one proposed by the NGVC.

The following information establishing the conversion factors and methods of conversion between different units of measure for natural gas was provided by the Institute of Gas Technology and the Natural Gas Vehicle Coalition Technical Subcommittee on NGVMeters; the S\&T Committee expresses thanks to these organizations for providing this information. It is noted that the equivalent of 114,118.8 Btu/gallon (lower heating value) for gasoline is an estimated value; the actual value will depend upon the composition of the individual product. The Committee believes the estimated energy content of $114,118.8 \mathrm{Btu} / \mathrm{gallon}$ (lower heating value) for gasoline should be used along with the conversion factors specified below to define supplementary values used with CNG devices.

\section{Determination of Natural Gas Properties}

These calculation procedures have been created by the Institute of Gas Technology in support of the Natural Gas Vehicle Coalition Technical Subcommittee on NGV Meters. This information is provided as a basis for converting the primary mass-pound unit of measure to a supplemental secondary unit of gallons equivalent of gasoline, 100 SCF (100 standard cubic feet of natural gas), and therms (100,000 Btu). This document discusses the rationale for the composition of natural gas (upon which the calculations are based) and the defined conversion factors.

The intrinsic characteristics of natural gas must be calculated to determine the proper conversion procedures and factors between different units of measure for natural gas. Natural gas is not pure methane or a homogenous mixture, but varies in composition seasonally and by location. Variations occur between the original fields, and composition varies further based on rate of withdrawal from an individual field due to the structure of the supply formation. It is further modified due to processing prior to transmission and the mixing of different gases during pipeline shipment. Natural gas is also affected by the addition of gas from underground storage, liquefied natural gas, propane-air mixtures, and other gas substitutes. These are further influenced by economic factors, city location, and meteorological conditions. As a result, the term "natural gas" does not describe a single type of fuel or a narrow range of characteristics, unlike gasoline or diesel fuel which is manufactured to certain specifications.

The most recent work ${ }^{2}$ on natural gas composition was completed by American Gas Association Laboratories and the Institute of Gas Technology (IGT), under Gas Research Institute funding. The summary data consists of 6,811 natural gas samples listing the following components: methane, ethane, propane, i-butane, n-butane, i-pentane, n-pentane, $\mathrm{C}_{6}$

\footnotetext{
${ }^{1}$ Extracted from "Compressed Natural Gas Measurement Issues" by C.F. Blazek, J.A. Kinast, \& P. Freeman, Institute of Gas Technology, paper presented at the American Gas Association Distribution/Transmission Conference, May 16-19, 1993.

${ }^{2}$ W.E. Liss, W. H. Thrasher, G.F. Steinmetz, P. Chowdiah, and A. Attari. Variability of Natural Gas Composition in Select Major Metropolitan Areas of the United States. Gas Research Institute Report No. GRI92/0123; March 1992.
} 
and higher, nitrogen, carbon dioxide, and oxygen. Information on each sample also includes the higher heating value, specific gravity, Wobbe number, and other factors. Two primary factors most directly describe the general characteristics of natural gas: the concentration of methane and the Wobbe number.

The Wobbe number is a measure of the fuel energy flow rate through a fixed orifice under given inlet conditions. It is calculated as the ratio of the heating value to the square root of the specific gravity. A change in the Wobbe number has a direct correlation to changes in engine performance. Variations in Wobbe number of the gas will produce similar variations in the air-fuel ratio for the orifice-based natural gas metering systems used on vehicles.

The Institute of Gas Technology's analysis was performed on both quantities: methane concentration and Wobbe number. The first step was determining the minimum, maximum, mean average, median, $10 \%$-ile, and $90 \%$-ile values for the methane fraction, as shown in Table 1. Table 2 presents the analysis of the range of Wobbe numbers.

\begin{tabular}{||c|c|}
\hline \multicolumn{2}{|c|}{ Table 1. Methane Fraction Analysis } \\
\hline Minimum & $55.8 \%$ \\
\hline Maximum & $98.1 \%$ \\
\hline Mean (avg) & $93.0 \%$ \\
\hline Std Deviation & $4.5 \%$ \\
\hline Median & $94.9 \%$ \\
\hline $10 \%$-ile & $84.1 \%$ \\
\hline $90 \%$-ile & $96.3 \%$ \\
\hline
\end{tabular}

\begin{tabular}{|c|c|}
\hline \hline \multicolumn{2}{|c|}{ Table 2. Wobbe Number Analysis } \\
\hline Minimum & 1202.6 \\
\hline Maximum & 1418.7 \\
\hline Mean (avg) & 1329.4 \\
\hline Std Deviation & 42.6 \\
\hline Median & 1347.0 \\
\hline $10 \%$-ile & 1233.0 \\
\hline $90 \%$-ile & 1358.5 \\
\hline
\end{tabular}

Having identified the methane fraction and Wobbe number values, the next step was to define a suitable method of calculating the fractions of each of the other components. Because of the inherent variability of an individual natural gas sample, it was unlikely that a representative composition could be formulated from just the few values that fit exactly on the selected methane fraction and Wobbe number values. To select a slightly wider, more representative range of natural gas compositions at a given value, the average of each of the components was calculated considering only those raw data samples within $1 \%$ concentration of the methane fraction. For the $10 \%$-ile, this translated into averaging the natural gas component fractions for all samples within the methane fraction of $83.1 \%$ to $85.1 \%$.

A similar averaging technique was completed using the selected Wobbe numbers, considering only those samples within 2 counts of the identified Wobbe number. These results are shown in Table 3.

Table 3. Composition Based on Wobbe Number

\begin{tabular}{|c|c|c|c|}
\hline \hline & $10 \%$-ile & Mean & $90 \%$-ile \\
\hline \hline methane & 83.96 & 92.87 & 94.80 \\
\hline ethane & 5.72 & 3.34 & 3.03 \\
\hline propane & 1.07 & 0.63 & 0.58 \\
\hline i-butane & 0.09 & 0.07 & 0.10 \\
\hline n-butane & 0.11 & 0.12 & 0.10 \\
\hline i-pentane & 0.03 & 0.04 & 0.05 \\
\hline n-pentane & 0.01 & 0.03 & 0.03 \\
\hline $\mathrm{C}_{6}+$ & 0.03 & 0.05 & 0.07 \\
\hline
\end{tabular}




\begin{tabular}{||c|c|c|c|}
\hline & $10 \%$-ile & Mean & $90 \%$-ile \\
\hline \hline nitrogen & 6.05 & 2.07 & 0.56 \\
\hline $\mathrm{CO}_{2}$ & 1.40 & 0.78 & 0.65 \\
\hline $\mathrm{O}_{2}$ & 1.53 & 0.00 & 0.00 \\
\hline Wobbe & 1232.97 & 1329.15 & 1358.61 \\
\hline
\end{tabular}

In general, the Wobbe number is a good criterion for natural gas because it correlates well with the ability of an internal combustion engine to use a particular gas. It also takes into account many of the gas components because it is a bulk property. Based on this, the mean natural gas composition based on the Wobbe number was selected as representative of natural gas. The composition for the mean, as well as the 10th and 90th percentile Wobbe numbers, is shown in Table 3.

Using the composition based on the mean Wobbe number, the thermodynamic and physical properties of the representative natural gas were determined. This produced the following additional information for the mean natural gas at standard temperature and pressure $\left(60^{\circ} \mathrm{F}\right.$ and $\left.14.73 \mathrm{psia}\right)$ :

$\begin{array}{ll}\text { Molecular weight: } & 17.3084 \\ \text { Compressibility factor: } & 0.997805 \\ \text { Density: } & 0.0458172 \mathrm{lb} / \mathrm{ft}^{3} \\ \text { Higher Heating Value: } & 1024.3 \mathrm{Btu} / \mathrm{scf}^{3} \\ \text { Lower Heating Value: } & 923.7 \mathrm{Btu} / \mathrm{scf}\end{array}$

The lower heating value was used to establish a correlation between natural gas and gasoline, because it reflects more accurately the energy that the engine can utilize. This rationale was used in Colorado (Colorado House Bill 1114), using a "gallon gasoline equivalent" based on a 114,000 Btu/gallon lower heating value. Similar values are used by the US EPA (October 1992 EPA Fuel Economy Estimates, 1993 Gas Mileage Guide) through reliance on Indolene (an Amoco product) as the test fuel to determine MPG data; Indolene has a target lower heating value of $114,132 \mathrm{Btu} / \mathrm{gallon}$.

The properties of gasoline also vary with region and season. To develop a referenced basis, the values used for this analysis were based on the Clean Air Act Amendments of 1990, "Baseline Gasoline Fuel Properties" (pp. 103-4) and "Reference Fuel A" (from Table 10, Blended Fuel Analysis, p. 330, Auto/Oil Air Quality Improvement Research Program, SAE SP-920). Using the values of $18,300 \mathrm{Btu} / \mathrm{lb}$ (net heating value) and a $57.4^{\circ} \mathrm{API}$ gravity $(6.236 \mathrm{lb} / \mathrm{gallon}$ at $60^{\circ} \mathrm{F}$ ) for Reference Fuel A results in an energy content of 114,118.8 Btu/gal (lower heating value).

Using the mean natural gas composition based on the Wobbe number and the lower heating value as well as an estimated energy content of 114,118.8 Btu/gallon (lower heating value) for gasoline, the following conversion factors are proposed for use. (Note: The term " $1 \mathrm{~b}_{\mathrm{m}}$ " indicates "pounds mass.")

$1 \mathrm{SCF}$ (standard cubic foot) of natural gas $=1024.3 \mathrm{Btu}$ higher heating value

$1 \mathrm{SCF}$ (standard cubic foot) of natural gas $=923.7$ Btu lower heating value

$1 \mathrm{lb}_{\mathrm{m}}$ natural gas $=21.826 \mathrm{SCF}$

$1 \mathrm{lb}$ natural gas $=22,356$ Btu (higher heating value)

$1 \mathrm{lb}_{\mathrm{m}}$ natural gas $=0.22356$ THERMS $(100,000 \mathrm{Btu})$ (higher heating value)

1 THERM $=4.473 \mathrm{lb}_{\mathrm{m}}$ natural gas (higher heating value)

$1 \mathrm{lb}_{\mathrm{m}}$ natural gas $=0.21826100$ SCF (100 standard cubic feet)

$100 \mathrm{SCF}=4.582 \mathrm{lb}_{\mathrm{m}}$ natural gas

$1 \mathrm{lb}$ natural gas $=0.17668$ gallons equivalent of gasoline $(@ 114,118.8$ Btu/gallon lower heating value $)$

1 gallon equivalent of gasoline $=5.660 \mathrm{lb}_{\mathrm{m}}$ natural gas

$1 \mathrm{SCF}$ natural gas $=0.00809$ gallons equivalent of gasoline

1 gallon equivalent of gasoline $=123.55 \mathrm{SCF}$ natural gas 


\section{T.2. Tolerances for Liquid-Measuring Devices; T.5. Type Evaluation Examinations}

(This item was adopted.)

Source: Carryover Item 337-4

Recommendation: The Committee recommends the following changes to paragraph T.2. of the Mass Flow Meters Code and recommends the addition of a new section, T.5. as shown below.

T.2. Tolerances for Liquid-Measuring Devices. - The maintenance and acceptance tolerances shall be 0.5 percent of the measured quantity. The eceptance tolenthes shall be 0.3 percent the measured quantity.

T.5. Type Evaluation Examinations for Liquid-Measuring Devices. - For type evaluation examinations, the tolerance values shall be 0.3 percent. This tolerance shall apply under the following conditions:
(a) with any one liquid within the range of liquids,
(b) at any one liquid temperature and pressure within the operating range of the meter, and
(c) at all flow rates within the range of flow rates.

Discussion: Changes are recommended to the tolerances to update Handbook 44 with the latest update of the OIML draft recommendation. The changes would apply a tolerance of $0.5 \%$ for both acceptance and maintenance tolerance and would include a tolerance of $0.3 \%$ for type evaluation tests.

The Committee initially questioned whether or not this change is necessary. In practice, these meters are used at only one flow rate (normally the maximum discharge rate for the installation), and the meter is usually tested at only the one flow rate. It was suggested that a tighter tolerance can be applied when a device is used and tested at only one flow rate instead of over a range of flow rates. Concern was expressed that the same tolerance should apply to a given device application regardless of the type of technology (e.g., a mass flow meter versus a positive displacement meter) used.

The Committee noted that the suitability of equipment table should address concerns over consistently applying tolerances in a given application, regardless of the device technology used. With respect to the suggested tolerance changes, the Committee notes that paragraph T.2. Tolerances for Liquid-Measuring Devices would apply to tests conducted over the entire temperature and pressure range of the meter whereas the tolerance applied during type evaluation would apply to a test conducted at a single liquid temperature and pressure. The Committee concluded that a larger acceptance tolerance is needed for routine testing because the device must perform over a range of temperatures rather than one single temperature.

\section{7-4 VC Requirements for Retail Computing Devices and Interlocks}

(This item was adopted as part of the consent calendar.)

Source: Carryover Item 337-6

Recommendation: The Committee recommends that the following requirements from the Liquid-Measuring Devices Code be added to the Mass Flow Meters Code. Appropriate paragraph numbers will be assigned when the requirements are incorporated into the Mass Flow Meters Code.
S.1.6.2.
Provisions for Power Loss.
S.1.6.3. Return to Zero; part (a) first sentence and part (b).
S.1.6.4.1. Unit Price; part (a).
S.1.6.4.2. Product Identity; part (a).
S.1.6.5. Money-Value Computations; part (a). 


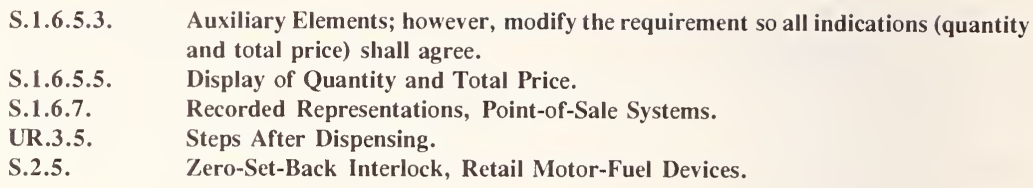

The Committee recommends that the following requirements from the Liquid-Measuring Devices Code be modified as shown and added to the Mass Flow Meters Code.

S.3.3. Pump Discharge Unit for Liquids. A pump-discharge unit for liquids equipped with a flexible discharge hose shall be of the wet-hose type.

UR.3.2. Unit Price and Product Identity for Retail Dispensers. (no changes to rest of paragraph)

UR.3.4. Printed Ticket. - The total price, the total olume quantity of the delivery, and the price per gallonor liter unit shall be shown, either printed or in clear hand-seript on any printed ticket issued by a device of the computing type and containing any one of these values.

The Committee recommends the following new requirement be added to the Mass Flow Meters Code.

S.3.X. Pressurizing the Discharge Hose. - The discharge hose for compressed natural gas shall automatically pressurize prior to the device beginning to register the delivery.

The Committee recommends the following requirements from the Liquefied Petroleum (LP) Gas and Anhydrous Ammonia Liquid-Measuring Devices Code be added to the Mass Flow Meters Code for deliveries of LP gas and other liquids through a mass flow meter:

UR.2.3. Vapor-Return Line.

UR.2.5. Ticket in Printing Device.

Discussion: When the Mass Flow Meters Code is changed from a tentative to a permanent code, references to mass flow meters in the other codes will be deleted. It was suggested that the Code would need all the comparable requirements of the Liquid-Measuring Devices Code for computing devices and interlocks. Several paragraphs of the $\mathrm{LPG}_{\mathrm{P}} \mathrm{NH}_{3}$ code that should also be included in the Mass Flow Meters Code were also identified.

Additionally, the issue of pressurizing the discharge hose was raised at the 1992 Interim Meeting, because CNG dispensers must depressurize the delivery hose to permit connection to the next vehicle. At the completion of each delivery, CNG is released to the atmosphere to depressurize the hose; therefore, to ensure that the next customer is not charged for product that is not received, the hose must be pressurized before the dispenser begins to register product for each delivery.

The Committee noted that the requirements for meters used to dispense milk (as specified in the Vehicle Tank Meters Code and the Milk Meters Code) should also be reviewed to ensure that appropriate references are included in Handbook 44 for mass flow meters used to dispense milk. The Committee plans to review these sections over the next year and requests input on how these devices might be best addressed.

\section{7-5 I Tentative Status of the Code}

\section{Source: Carryover Item 337-6}

Discussion: The Committee discussed whether or not the Mass Flow Meters Code should be made a permanent code. It was noted that the mass flow meter criteria in other codes will be eliminated if this upgrade to a permanent code is adopted. Due to the number of changes being considered to the tentative code in this Item and in Items 337-1 through $337-4$, the Committee agreed that the code should remain tentative. 


\section{Temperature Range}

The Committee considered deleting the marking requirement for the applicable temperature range of the device because the capability to test a mass flow meter at specific temperatures is currently limited in both type evaluations and routine field inspections. Since compliance with the accuracy requirements can only be determined in the field at the temperature at the time of test and since NTEP is unable to test the meters over a temperature range during type evaluation, compliance with the temperature specification cannot be determined at this time.

\section{Markings}

Concern was expressed that deleting the temperature requirement would imply that the device is not required to operate accurately over all temperatures. It was further noted that capability does exist in Canada to verify performance of the device over a temperature range. The Committee reaffirmed its position that mass flow meters must be accurate over the range of environmental conditions over which each meter is used and noted that this is implicit with the accuracy requirements. The Committee agreed that the marking requirement for temperature should be retained since Canada has indicated that type evaluation testing can be done over a temperature range of $-10{ }^{\circ} \mathrm{C}$ to $+30^{\circ} \mathrm{C}$. This would provide a test of at least part of the required range.

Some of the marking requirements proposed in paragraph S.5. are repetitive of those specified in paragraph G-S.1. of the General Code. The Committee received a suggestion to delete the repetitive portions of the paragraph S.5. and reference paragraph G-S.1. in paragraph S.5.

The Committee concluded that the Code should remain a tentative code for at least another year. The Committee presents the following changes to the Tentative Code for consideration by the regions over the next year.

S.5. Markings. - In addition to the required markings specified in General Code paragraph G-S.1. A Aa measuring system shall be legibly and indelibly marked with the following information:

(a) pattern approval mark (i.e., type approval number);

(b) name-and-address of the manufacturer or his trademark and, if required by the-weights and measures atthority, the manufacturer's identification mark in addition to the trademark;

(c) model designation of product name selected by the manufacturer;

(d) nonreptitive serial number;

(eb) maximum and minimum flow rates in kilograms or pounds per unit of time;

(fc) maximum working pressure;

(gd) applicable range of temperature if other than $-10^{\circ} \mathrm{C}$ to $+50{ }^{\circ} \mathrm{C}$;

(he) minimum measured quantity; and

(if) product limitations, if applicable.

\section{Taximeters Code}

\section{4-1 I UR.3.1. Units for Rate Increments}

Source: Western Weights and Measures Association

Discussion: The Taximeter Code requires that rates be stated and conspicuously displayed in the cab, but does not provide for uniformity in units of distance. Modern electronic taximeters are capable of computing at a multitude of rates. Both the amount and distance of registration units can be changed without restriction. This has led to a proliferation of distance rates which are confusing to customers. Some examples of rates currently in use are listed below.

$\$ 2.00$ first $5 / 37$ mile then $\$ .25$ each $5 / 37$ mile

$\$ 2.00$ first $1 / 15$ mile then $\$ .25$ each $1 / 15$ mile

$\$ 2.00$ first $1 / 7$ mile then $\$ .25$ each $1 / 7$ mile

$\$ 2.00$ first $1 / 9$ mile then $\$ .25$ each $1 / 9$ mile 
The above rate schedules inhibit value comparison and are not "readily understandable by the ordinary passenger" as required by UR.3. Additionally, it can create difficulty in testing a meter on a measured-mile course, because there may not be a change in the fare corresponding to tenths of a mile or the 1-mile increment as most measured-mile courses are marked. (See illustration below, which is based upon the first rate structure listed above. The top numbers represent distance in miles; the dollar amounts represent the fare amount corresponding to the distance.) The Southern made this a voting item and recommends that uniform units of distance and time be established within the Taximeter Code.

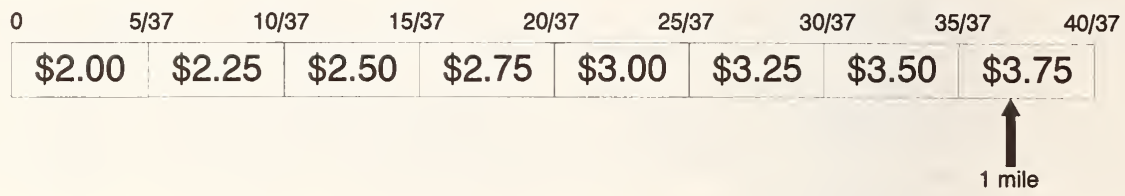

The Western recommended that taximeter rates be based on and programmed to increment in uniform whole cent values, at tenths of kilometers or miles, as stated below:

UR.3.1. Units for Rate Increments. The display of a taximeter shall be programmed to increment in uniform whole cent values, at 0.1 kilometer (or 0.1 mile) intervals for distance, and at uniform whole multiples of the second for time.

The Committee heard conflicting positions on this issue. In opposition to the information presented by the Western, some comments indicated that the proposed change to the units for rate increments will not help the consumer to make value comparisons. It was suggested that consumers do not make value comparisons among taximeter rates, hence, requiring the information to be presented in only these units would not solve the concerns raised. In response to this statement, comments were made indicating that some weights and measures jurisdictions have received complaints from consumers who do make value comparisons and to whom the choice of which taxicab company to use is an economic decision. Comments also indicate that jurisdictions that use a measured-mile course for testing experience difficulty in testing meters programmed with these unusual rates because the distances at which the cost changes does not correspond to a fixed increment.

It was argued that establishing fixed increments for rate changes was not within the domain of weights and measures jurisdictions since weights and measures jurisdictions do not typically establish taxi fares. This argument was raised in 1990 (Item 354-4) when paragraph S.2.1. Initial Time and Distance Intervals was adopted by the NCWM. In response to these comments, it was noted that the proposed requirement does not set the amount of the rate, simply the size of the money value division. It was further noted that precedence exists in other Handbook 44 codes where the maximum/minimum values of the units of measurement and money value have been established. For example, Scales Code Paragraphs S.1.8.1.M. and S.1.8.1., Money-Value Graduations specify the permissible value of the graduated intervals representing money-values on a computing scale.

Due to the differing opinions received on this issue, the Committee requests additional input from the regional weights and measures associations and other interested parties.

\section{Grain Moisture Meters Code}

356-1 V NTEP Sectors for Grain Measurement Equipment

(This item was adopted.)

Source: Grain Moisture Meter Sector, National Type Evaluation Technicål Committee 
Discussion: A number of changes have been proposed to the Grain Moisture Meters Code by the Grain Moisture Meter Sector of the National Type Evaluation Technical Committee (NTETC). In addition to its responsibility to develop type evaluation criteria and test procedures, the Grain Moisture Meter Sector was given the responsibility to develop recommended changes to update Handbook 44 and to develop a system for the calibration of meters to improve the accuracy of commercial grain moisture measurements on a national basis.

This objective forced the Sector to examine the realistic limits for accuracy of meters considering the variation of chemical and electrical properties within each variety of grain to be addressed in a potential calibration program. This resulted in establishment of a variety of performance requirements for type evaluations based upon several different tests. Coupled with the differences in grain characteristics among different varieties within a grain, changes to the tolerances are proposed.

A major decision had to be made regarding the manner in which a meter calibration program could be conducted to promote more comprehensive calibrations on grain moisture meters, while containing costs. Particular consideration had to be given to the total cost of calibration for different grains considering the number of meters of a particular model that are in use. This led to the conclusion that the objective of changes to Handbook 44 will be to phase out meters requiring operator manipulation in favor of instruments that make the grain moisture measurements automatically. This will eliminate many operator-dependent variables. The Sector made the following decisions:

1. NTEP will accept for type evaluation only those devices for which the moisture measurement process and the presentation of the moisture value is automatic (some operator actions are still needed) as soon as the code modifications are adopted.

2. Type evaluation will be based upon nonretroactive requirements that will have an effective date of January 1, 1998 .

3. The requirements directed to the ultimate goal of automating grain moisture measurements (that is, without operator involvement in the measurement process) will have an effective date of January 1,1998 , to give manufacturers time to modify equipment design and calibration, and submit the devices for type evaluation and the calibration program.

4. The nonretroactive requirements will become retroactive on January 1, 2003; code requirements that will become obsolete when the nonretroactive requirements become retroactive will be modified or deleted accordingly. Therefore, devices currently in use, and models currently in production, that do not comply with the requirements with a nonretroactive date of January 1, 1998, will have a useful life in commercial applications not exceeding January 1, 2003. As of January 1, 1998, manufacturers with devices currently in production will have to discontinue production for commercial applications of those devices that do not comply with the nonretroactive requirements taking effect January 1, 1998. Those devices produced in 1997 and earlier could be used in commercial applications until January 1, 2003.

The Committee reviewed the changes recommended by the Grain Moisture Meter Sector in the context of the total scope of the grain moisture meter program. This effort includes proposed changes to Handbook 44; extensive type evaluations on the meters themselves using numerous samples of different varieties within a grain; collection of grain samples reflecting the wide range of physical, chemical, and electrical characteristics on a national basis; and the implementation and maintenance of a continuous moisture calibration program. This effort also requires effective enforcement by weights and measures officials to assure that the efforts made through type evaluation and calibration are ultimately realized in grain moisture measurements made throughout the country. This approach to type evaluation does not preclude a device from having calibrations for grains beyond those that are evaluated through NTEP.

The S\&T Committee expresses its appreciation to the members of the Grain Moisture Meter Sector and the Federal Grain Inspection Service for the extensive technical review of the Grain Moisture Meter Code and the development of criteria and a mechanism to establish a credible type evaluation program for grain moisture meters.

The implementation of nonretroactive requirements and the dates at which they will become effective for the National Type Evaluation Program and State enforcement are summarized below. State enforcement will be based upon the effective dates identified with each requirement when specific dates are shown. 


\begin{tabular}{||l|l|l|}
\hline & \multicolumn{1}{|c|}{ NTEP Evaluations } & \multicolumn{1}{c|}{ State Enforcement } \\
\hline $\begin{array}{l}\text { Nonretroactive } \\
\text { Requirements }\end{array}$ & $\begin{array}{l}\text { Effective immediately. All } \\
\text { devices submitted for type } \\
\text { evaluation must comply with } \\
\text { the nonretroactive } \\
\text { requirements. }\end{array}$ & $\begin{array}{l}\text { Enforced when the effective date occurs, i.e., January 1, } \\
1998 .^{*}\end{array}$ \\
$\begin{array}{l}\text { This will allow manufacturers to sell current models until } \\
\text { January 1, 1998. These devices can be used until January } \\
1,2003, \text { which is the retroactive date for the requirements. }\end{array}$ \\
\hline $\begin{array}{l}\text { Retroactive } \\
\text { Requirements }\end{array}$ & $\begin{array}{l}\text { Same as for nonretroactive } \\
\text { requirements, since the } \\
\text { requirements are the same. }\end{array}$ & $\begin{array}{l}\text { All devices used after January 1, 2003 must comply with } \\
\text { the requirements that become retroactive as of that date. } \\
\text { Essentially, no analog indications will be permitted on } \\
\text { devices used after January 1, 2003. }\end{array}$ \\
\hline
\end{tabular}

*NTEP States should not prohibit the sale of devices without NTEP Certificates of Conformance into commercial applications until the nonretroactive requirements take effect.

Recommendation: The Committee supports the changes proposed by the Grain Moisture Meter Sector and makes the following recommendations.

Renumber the current A.3. to A.4. and add the following as a new A.3.:

A.3. Type Evaluation. - The National Type Evaluation Program will accept for type evaluation only those devices that comply with the nonretroactive requirements scheduled to take effect on January 1, 1998. State enforcement will be based upon the effective dates identified with each requirement when specific dates are shown.

Renumber current paragraphs S.1.2. and S.1.3. to S.1.3. and S.1.4., respectively; renumber paragraphs S.1.4. and S.1.4.1. as S.1.2. and S.1.2.1. Add a new nonretroactive paragraph S.1.2.2 that combines S.1.4. and S.1.5.; this paragraph would require all devices to have digital indications after January 1, 2003. The meters must be equipped with a communications interface to permit connection with recording elements; obtaining a printer is the responsibility of the device owner. A User Requirement specifies that the customer shall receive a printed ticket of the results of the moisture measurement. Paragraphs S.1.1., S.1.4., and S.1.5. would be revised or deleted in 2002 to be consistent with the nonretroactive requirements that become retroactive on January 1, 2003. (Editor's note: The following note has been added to paragraphs S.1.1., S.1.2.1. (previously S.1.4.), and S.1.5. to indicate these paragraphs are to be changed at the specified date: "[To be revised in 2002 to be consistent with the retroactive requirements in S.1.2. effective January 1, 2003.] [Note added 1993]". Also note that paragraph S.1.4. has been renumbered as S.1.2.1. as a result of Conference action.)

\section{S.1.2.2. Digital Indications and Recording Elements.}

(a) Meters shall be equipped with a digital indicating element.

(b) The minimum height for the digits used to display moisture content shall be $10 \mathrm{~mm}$.

(c) Meters shall be equipped with a communication interface that permits interfacing with a recording element.

(d) A digital indicating element shall not display, and a recording element shall not record, any moisture content values before the end of the measurement cycle.

(e) Moisture content results shall be displayed and recorded as percent moisture content, wet basis.

(f) A meter shall not display or record any moisture content values when the moisture content of the grain sample is beyond the operating range of the device, unless the moisture representation includes a clear error indication (and recorded error message with the recorded representation).

[Nonretroactive and effective January 1, 1998. To become retroactive January 1, 2003.] 
Amend UR.3.4. to read:

LR.3.4. Printed Tickets.

(a) Printed tickets, if the shall be free from any previous indication of moisture content or type of grain or seed selected.

(b) The customer shall be given a printed ticket showing the date, grain tvpe, grain moisture results, and calibration version identification. The ticket shall be generated by the grain moisture meter system. Nonretroactive and effective as of January 1, 1998. To become retroactive as of January 1, 2003.]

Amend S.1.6.1. to require grain moisture meters to be capable of indicating the grain types for which it as calibrated and used through a display of up to at least four characters.

S.1.6.1. Grain or Seed Kind and Class Selection and Recording. - Provision shall be made for selecting and recording, if equipped to record, the kind and class (as appropriate) of grain or seed to be measured. The means to select the kind and class of grain or seed shall be readily visible and the kind and class of grain or seed selected shall be clearly and definitely identified in letters (such as Hard Red Spring Wheat or HRSW, etc.). Meters shall be capable of indicating the grain type using a minimum of four characters. Minimum acceptable abbreviations are listed in Table S.1.6.1.*

${ }^{*}$ Nonretroactive and effective as of January 1, 1998. To become retroactive as of January 1, 2003.1 Note: The phrase "if equipped to record" will be deleted in 2003 when recording elements are required on a retroactive basis.l

Add Table S.1.6.1. to identify the grain types that are proposed for the type evaluation and calibration program and to standardize and specify the minimum abbreviations that may be used for these grains. Note that grain types may be added to or deleted from this list as economic importance of the various grains changes.

\begin{tabular}{|c|c|c|c|}
\hline \multicolumn{4}{|c|}{$\begin{array}{l}\text { S.1.6.1. Grain Types Considered for Type Evaluation and Calibration } \\
\text { and Minimum Acceptable Abbreviations }\end{array}$} \\
\hline Grain Type & $\begin{array}{l}\text { Minimum } \\
\text { Acceptable } \\
\text { Abbreviation }\end{array}$ & Grain Type & $\begin{array}{c}\text { Minimum } \\
\text { Acceptable } \\
\text { Abbreviation }\end{array}$ \\
\hline Corn & CORN & Soybeans & SOYB \\
\hline $\begin{array}{l}\text { Durum Wheat } \\
\text { Eastern White Wheat } \\
\text { Western White Wheat } \\
\text { Hard Red Spring Wheat } \\
\text { Hard Red Winter Wheat } \\
\text { Soft Red Winter Wheat } \\
\text { Hard White Wheat }\end{array}$ & $\begin{array}{l}\text { DURW } \\
\text { EWW } \\
\text { WWW } \\
\text { HRSW } \\
\text { HRWW } \\
\text { SRWW } \\
\text { HDWW }\end{array}$ & $\begin{array}{l}\text { Two-rowed Barley } \\
\text { Six-rowed Barley } \\
\text { Oats }\end{array}$ & $\begin{array}{l}\text { TRB } \\
\text { SRB } \\
\text { OATS }\end{array}$ \\
\hline Sunflower seed (Oil) & SUNF & $\begin{array}{l}\text { Long Grain Rough Rice } \\
\text { Medium Grain Rough Rice } \\
\text { Short Grain Rough Rice }\end{array}$ & $\begin{array}{l}\text { LGRR } \\
\text { MGRR } \\
\text { SGRR }\end{array}$ \\
\hline Grain Sorghum & $\begin{array}{l}\text { SORG or } \\
\text { MIILO }\end{array}$ & $\begin{array}{l}\text { Small oil seeds (under } \\
\text { consideration) }\end{array}$ & \\
\hline
\end{tabular}


Renumber the current paragraph S.1.6.3. to S.1.6.4. and insert the following new paragraph as S.1.6.3.

S.1.6.3. Operating Range. - A meter shall automatically and clearly indicate when the operating range of the meter has been exceeded. The operating range shall specify the following.

(a) The temperature range over which the meter may be used and still comply with the applicable requirements shall be specified. The minimum temperature range shall be 10 to $30{ }^{\circ} \mathrm{C}\left(50\right.$ to $\left.86{ }^{\circ} \mathrm{F}\right)$. No moisture value may be displayed when the temperature range is exceeded. An appropriate error message shall be displayed when the temperature of the meter is outside its specified operating range.

(b) The moisture range for each grain or seed for which the meter is to be used shall be specified. A moisture value may be displayed when the moisture range is exceeded if accompanied by a clear indication that the moisture range has been exceeded.

(c) The temperature range for each grain or seed for which the meter is to be used shall be specified. The minimum temperature range for each grain shall be 0 to $40{ }^{\circ} \mathrm{C}\left(32\right.$ to $\left.104{ }^{\circ} \mathrm{F}\right)$. No moisture value may be displayed when the temperature range is exceeded. An appropriate error message shall be displayed when the temperature of the grain sample exceeds the specified temperature range for the grain.

(d) The maximum allowable difference in temperature between the meter and the sample for which an accurate moisture determination can be made shall be specified. The minimum temperature difference shall be $10^{\circ} \mathrm{C}\left(18^{\circ} \mathrm{F}\right)$. No moisture value may be displayed when the maximum allowable temperature difference is exceeded. An appropriate error message shall be displayed when the difference in temperature between the meter and the sample exceeds the specified difference.

[Nonretroactive and effective as of January 1, 1998. To become retroactive as of January 1, 2003.]

To permit adequate testing and calibration of meters submitted for type evaluation, the meters submitted for laboratory tests must provide higher resolution than what is needed for normal field use. Amend the current S.1.6.3., which will be renumbered as $\mathbf{S} \cdot 1 \cdot 6.4$. to read:

S.1.6.3. S.1.6.4. Value of Minimum Indication.

(a) The value of the minimum indicated or recorded moisture indication shall not be greater than 0.1 percent.

(b) For the purposes of type evaluation, the maximum value for the moisture indication shall be 0.01 percent. [Nonretroactive and effective as of January 1, 1998. To become retroactive as of January 1, 2003.]

Add a new paragraph S.1.10. to specify the operating temperatures for a meter to be consistent with the proposed new paragraph S.1.6.3.

\section{S.1.10. Operating Temperature}

(a) A meter shall not display or record any usable values until the operating temperature necessary for accurate determination has been attained, or the meter shall bear a conspicuous statement adjacent to the indication stating that the meter shall be turned on for a time period specified by the manufacturer prior to use.

(b) A meter shall meet the requirements of T.2. Tolerance Values when operated in the temperature range of $10^{\circ} \mathrm{C}$ to $30^{\circ} \mathrm{C}\left(50^{\circ} \mathrm{F}\right.$ to $\left.86^{\circ} \mathrm{F}\right)$ or within the range specified by the meter manufacturer.

(c) If the manufacturer specifies a temperature range, the range shall be at least $20^{\circ} \mathrm{C}\left(68^{\circ} \mathrm{F}\right)$ and shall be marked on the device.

[Nonretroactive and effective as of January 1, 1998. To become retroactive as of January 1, 2003.] 
Add a new paragraph S.2.3. to permit the use of an audit trail as an acceptable form of security for sealing a device. The Sector concluded that each set of calibration values is considered to be a single parameter in terms of the audit trail. Add notes to indicate that paragraphs S.2.1. and S.2.2. will be deleted when S.2.3. becomes retroactive.

S.2.3. Provision for Sealing. - Provision shall be made for applying a security seal in a manner that requires the security seal to be broken, or for using other approved means of providing security (e.g., audit trail available at the time of inspection), before any change that affects the metrological integrity of the device can be made to any mechanism.

[Nonretroactive and effective as of January 1, 1998. To become retroactive as of January 1, 2003.]

[Note: Zero-setting and test point adjustments are considered to affect metrological characteristics and must be sealed.]

Add a new paragraph S.4. to read:

S.4. Minimum Sample Size. - Meters shall be designed to measure the moisture content of representativesize grain samples. The minimum allowable sample size used in analysis shall be $100 \mathrm{~g}$ or $400 \mathrm{kernels}$ or seeds, whichever is smaller.

[Nonretroactive and effective as of January 1, 1998. To become retroactive as of January 1, 2003.]

To obtain the most accurate grain moisture measurements under the type evaluation and calibration program, it is imperative that the latest calibration factors be used. Add two new paragraphs addressing calibration values.

\section{S.5. Calibration Integrity}

S.5.1. Calibration Version. - A meter must be capable of displaying either calibration constants, a unique calibration name, or a unique calibration version number for use in verifying that the latest version of the calibration is being used to make moisture content determinations.

[Nonretroactive and effective as of January 1, 1998. To become retroactive as of January 1, 2003.]

S.5.2. Calibration Corruption. - If calibration constants are digitally stored in an electronically alterable form, the meter shall be designed to make automatic checks to detect corruption of calibration constants. An error message must be displayed if calibration constants have been electronically altered. [Nonretroactive and effective as of January 1, 1998. To become retroactive as of January 1, 2003.]

To recognize the wider range of grain samples to be used for calibrations and the temperature limits under which the grain moisture meters must be accurate, the following changes are proposed to Table 1 . If adopted, the changes in the tolerances are to be effective January 1, 1994. 


\begin{tabular}{|c|c|c|}
\hline \multicolumn{3}{|c|}{ Acceptance Tolerances are equal to the maintenance tolerances. } \\
\hline Type of grain or seed & Tolerance & Minimum Tolerance \\
\hline $\begin{array}{c}\text { Corn, rice, sorghum, sunflower } \\
\text { content }\end{array}$ & 0.04-of the percent-moisture & $\begin{array}{c}\text { 0.6 percent-in-moisture } \\
\text { centent }\end{array}$ \\
\hline $\begin{array}{l}\text { All-other cereal-grains and oil } \\
\text { seeds }\end{array}$ & 0.03 of the percent-moisture-content & $\begin{array}{c}0.6 \text { percent-in-moisture } \\
\text { content }\end{array}$ \\
\hline \multicolumn{3}{|c|}{ Maintenance Tolerances } \\
\hline Type of grain or seed & Tolerance & Minimum Tolerance \\
\hline $\begin{array}{l}\text { Corn, oats, rice, sorghum, } \\
\text { sunflower }\end{array}$ & 0.05 of the percent moisture content & $\begin{array}{c}0.8 \text { percent in moisture } \\
\text { content }\end{array}$ \\
\hline $\begin{array}{l}\text { All other cereal grains and oil } \\
\text { seeds content }\end{array}$ & 0.04 of the percent moisture content & $\begin{array}{c}0.7 \text { percent in moisture } \\
\text { content }\end{array}$ \\
\hline
\end{tabular}

\section{Other Items}

\section{0-1 I Volume Measuring Machines for Shipping Charges}

Source: Carryover Item 360-2

Discussion: Different equipment technologies are used to measure the volume of unpackaged objects and containers for shipping charges. The designs are quickly becoming established for these machines, the use of which is rapidly increasing. These systems often incorporate scales. Two companies, namely Toledo Scale and Weigh-Tronix, have submitted comments regarding specifications and performance tolerances for these machines. Quantronix, Inc., gave a presentation on these devices at the 1992 Interim Meeting. Toledo Scale gave presentations at the meetings of the Western and the Southern.

One company submitted specifications, tolerances, and test procedures that incorporate some of the specifications in the draft developed by the Canadian Legal Metrology Branch. The draft from the Canadian Legal Metrology Branch has been provided to the Committee for its information. Weigh-Tronix provided information on the specific design and operating characteristics of its weighing and dimensioning system.

Although this item may not yet be of great interest to weights and measures officials, the Committee acknowledged that it is of considerable importance to industry. This issue must be addressed if weights and measures officials hope to influence the design and performance of equipment that is currently under development. The Committee emphasizes the importance of involving manufacturers and users, as well as weights and measures officials, in the development of requirements and test procedures for these devices..

The Committee agreed that a work group is needed to address the complexity of the issues involved in addressing these devices and to get affected parties involved in the development of a code, routine field test procedures, type evaluation criteria, and type evaluation test procedures. The Committee met with the Executive Committee to determine the feasibility of establishing a work group to address these issues. The Executive Committee approved the formation of this work group. The work group held its first meeting in June 1993 in Rockville, MD and plans a second meeting in October 1993 in Tampa, FL. Companies and individuals interested in participating in this work group should contact OWM. 
(This item was withdrawn.)

Source: San Diego County, CA

Discussion: San Diego County, CA proposed that a new code for hot water meters be drafted. The proposal is to draft specifications, tolerances, test notes, and user requirements for hot water meters. Additionally, type evaluation standards and test procedures must be developed. The proposal also suggested establishing acceptable billing procedures. No specific recommendations were made by San Diego County regarding the details of these points.

Information provided to the Committee indicates that some jurisdictions are finding that meters designed to measure cold water are used to measure hot water. (In addition, a cold water meter is sometimes placed on the inlet side of the hot water heater.) Jurisdictions which are responsible for regulating the billing practices for these devices encounter difficulties in regulating the amount and type of information disclosed to the consumer on the bill. Concerns arise because the rates charged on the basis of these meters are significantly higher than the prevailing rates for domestic cold water. San Diego County, CA Weights and Measures is particularly interested in determining whether or not other jurisdictions have encountered similar difficulties in regulating these devices.

The Committee received no comments on this item. The Committee noted that the Water Meters Code in NIST Handbook 44 does not make a distinction between meters measuring hot water and meters measuring cold water, and the code applies to either type. The Committee believes that the field test procedures for meters used to measure hot water would be basically the same as meters used to measure cold water. During a State or local type approval process, a hot water meter should also be tested with water at temperatures over the temperature range specified by the manufacturer, and jurisdictions which test water meters on a test bench may also consider testing over the temperature range specified. Since the Committee has received no information to indicate that the requirements currently specified in the Water Meters Code are not appropriate to apply to meters used to measure hot water, the Committee has withdrawn this item from its agenda.

The S\&T Committee encourages other jurisdictions which regulate these devices to share information concerning their experiences with San Diego County.

\section{0-3 I OIML Report}

The following information was provided by Mr. O. K. Warnlof, Standards Management Program, NIST, on OIML activities of significant importance to the NCWM.

The OIML schedule of activities for 1992/1993 included the 9th International Conference that was held November 1 6, 1992, in Athens, Greece. Eighteen International Recommendations were sanctioned by the Conference, and those affecting the work of the S \& T Committee are indicated below.

Also significant was the adoption of a new work plan to go into effect at the end of 1993 . The major Committees now referred to as Pilot Secretariats (of which there were 31) will be called Technical Committees (and reduced to 18). The 145 subcommittees now called Reporting Secretariats will be reduced to 42 Technical Subcommittees, with approximately 150 work projects. The responsibilities of the United States should be about the same.

We appreciate the cooperation and interest of the members of NCWM and urge your continued participation. The following is an outline of the activities of OIML work impacting on the responsibilities of the S \& T Committee since the 77 th NCWM, 1992. The outline highlights the work of each Reporting Secretariat (RS) and the present situation with respect to the documents within its purview.

The following is a list of the acronyms used:

BIML International Bureau of Legal Metrology

CIML International Committee of Legal Metrology 


$\begin{array}{ll}\text { ID } & \text { International Document } \\ \text { IR } & \text { International Recommendation } \\ \text { IWG } & \text { International Working Group } \\ \text { NWG } & \text { National Working Group } \\ \text { OIML } & \text { International Organization of Legal Metrology } \\ \text { PD } & \text { Pre-draft } \\ \text { PR } & \text { Project Recommendation (documents not yet numbered for sanction by the 9th Conference } \\ \text { PS } & \text { Pilot Secretariat } \\ \text { R } & \text { Recommendation } \\ \text { RS } & \text { Reporting Secretariat } \\ \text { SC } & \text { Subcommittee } \\ \text { TC } & \text { Technical Subcommittee }\end{array}$

OIML WORK PROGRAM - 1992/1993

STATUS OF WORK BY REPORTING SECRETARIAT

\author{
PS7/RS2 \\ "GENERAL PROBLEMS, ELECTRONIC WEIGHING INSTRUMENTS"
}

- Revision of R74 "Electronic Weighing Instruments": Adopted by 9th International Conference.

- There was a meeting of NWG at the NCWM Interim Meeting to decide on future work. It was decided to maintain responsibility for this work and to revise $\mathrm{R} 74$ by eliminating all references to "checking facilities" as was done with R 76 "Non-automatic Weighing Instruments."

\title{
PS7/RS4 \\ "NON-AUTOMATIC WEIGHING INSTRUMENTS"
}

- $\quad$ R76 "Non-Automatic Weighing Instruments Part 1": Adopted by the 9th International Conference.

- $\quad$ R76 - Part 2 was received January 8, 1993 and circulated to the NWG.

- $\quad$ R76 - Part 2 "corrected" was received March 29, 1993 and circulated to the NWG.

\section{PS7/RS5 \\ "AUTOMATIC WEIGHING INSTRUMENTS"}

- $\quad$ PR 4 "Automatic Rail Weighbridges": Adopted by 9th Conference.

- $\quad$ PR 5 "Totalizing Hopper Weighers": Adopted by 9th Conference.

- R50 "Belt Weighers": Revision was accepted by PS and circulated to the CIML for vote. Received from BIML on March 9, 1993, circulated to the NWG on March 11, 1993, for vote by July 15, 1993. The U.S. vote was "Yes."

- 4th PD Revision R51 "Catchweighers": Was received from the RS on April 7, 1993, and circulated to the NWG for comment in preparation for a meeting of the IWG to be held in June 1993.

- 6th PD Revision R61 "Gravimetric Filling Instruments": Was received from the RS March 23, 1993, for comment and vote. Circulated to the NWG on April 11, 1993, for comment by June 18, 1993. Comments received and sent to RS. As a result, a 7th PD will be circulated sometime in the late summer of 1993.

- Test Procedures for Belt Weighers, Totalizing Hopper Weighers, and Automatic Rail Weighbridges: Received from the RS on March 12, 1993. The Belt Weigher document circulated to the NWG on March 15, 1993, for response by June 4,1993 . The Hopper Weighers and Rail Weighbridges documents were circulated to the NWG on April 15,1993 for response by June 11, 1993. Comments forwarded to RS.

- A meeting of the IWG was held June 22-24, 1993, NWML, United Kingdom. As a result, the 5th draft Revision of R 51 "Catchweighers" will be circulated to the IWG within 60 days. 


\section{PS7/RS8 \\ "LOAD CELLS"}

- Revision of R60 "Metrological Regulation for Load Cells": Adopted by 9th Conference.

- Type Evaluation Report Forms were accepted by IWG. Edited final version circulated to the IWG and BIML on February 31, 1993, for vote by CIML.

\section{"PICTOGRAMS"}

A new draft developed by CECIP was received from BIML on January 12, 1993, circulated to the NWG on January 15 , 1993 for comment and a vote of endorsement by March 19, 1993. There were 13 responses received with 8-yes, 4-no, and 1 abstention. A "yes" vote was sent to BIML on March 31, 1993 with two pages of comments which, if accepted, should change two of the four "no" votes to "yes."

\section{PS 8 "WEIGHTS"}

A 2nd Draft IR "Weights" was received from BIML on February 9, 1993, indicating that it had been accepted by a vote of 15 -yes and 2-no (Germany \& Sweden). The RS decided that the 2 "no" votes could be eliminated by a few editorial and several technical changes with a request for comment and vote by February 28, 1993 (only 19 days). The NWG could not respond that soon so the RS was notified that more time was needed. On March 18, 1993 a response was faxed with several recommended editorial changes and the United States' refusal to accept the arbitrary technical changes was included in the 2nd Draft. The 3rd Draft IR was received by the United States for CIML vote on March 22, 1993, which included the technical changes not agreed to by the United States. The United States returned the ballot with a "no" vote and included our previous comments.

\section{TC 9 "INSTRUMENTS FOR MEASURING MASSES AND DENSITIES" (PS 7)}

The responsibility for this Technical Committee was assigned to the United States at the last National OIML Conference in Greece in November 1992. The assignment of the work and the SC's will be made by the CIML at their next meeting in October 1993. Germany, with the support of France, has recommended that the work on "Load Cells" be included in the work of the SC "Nonautomatic Weighing Instruments (the responsibility of Germany and France) and the work on "Electronic Weighing Instruments" be assigned to the SC "Automatic Weighing Instruments." Germany and France also recommended that several other Reporting Secretariats held by the United States be assigned elsewhere and to other countries. The United States has responded and it is expected that our responsibilities will be essentially the same.

\section{PS5D \\ "DYNAMIC MEASUREMENT OF LIQUIDS" \\ PS5D/RS1 \\ "METERS WITH MEASURING CHAMBERS OR TURBINES"}

A 1st Draft IR "Measuring Systems for Liquids other than Water" was the result of an IWG meeting held December 7. 11, 1992. It was to be circulated by March 30, 1993, for vote on the document and several separate issues not decided at the meeting.

The 1st Draft IR was received from the RS on June 30,1993, stating that it had been accepted by the IWG at the meeting in December. The document had been accepted in principle, provided that the RS accurately reflected in the IR the results of the meeting (since no minutes were circulated) and provided that several issues in which the vote was not conclusive be submitted for separate vote to the entire IWG. No minutes of the meeting were included nor any separate provisions for vote on the specific issues. A vote has been requested by October 31, 1993, at both the PS and RS level. This document was circulated to the NWG on July 16, 1993, for comment and vote. 


\section{PS5D/RS5 \\ "DATA FOR THE CALCULATION OF QUANTITIES OF LIQUIDS"}

- Revision of R63 "Petroleum Measurement Tables" to include reference to ISO 91-2 "Petroleum Measurement Tables - Part 2: Tables based on a reference of $20^{\circ} \mathrm{C}$, published $11 / 15 / 91$ were accepted by PS \& RS.

- This Revision will be included on the agenda of the CIML for vote at its next meeting in October 1993.

\section{PS5D/RS7 \\ "METHODS \& DEVICES FOR VERIFICATION"}

- 1st Draft IR "Testing Procedures for Pattern Examination of Fuel Dispensers of Motor Vehicles" circulated $11 / 13 / 92$ to NWG for comment by $1 / 15 / 93$.

- $\quad 1$ st Draft IR "Characteristics of Standard Capacity Measures and Test Methods for Measuring Systems" circulated $11 / 13 / 92$ to NWG for comment by $1 / 15 / 93$.

- $\quad$ 1st Draft IR "Pipe Provers for Testing of Measuring Systems for Liquids" circulated 11/13/92 to NWG for comment by $1 / 15 / 93$.

\section{PS5D/RS9 "VORTEX METERS"}

- $\quad$ 1st Draft ID "Vortex Meters Used in Measuring Systems for Fluids" circulated 11/13/92 to NWG for comment by $1 / 15 / 93$.

\section{PS5D/RS10 \\ "DIRECT MASS FLOW METERS"}

- $\quad$ PR 7 "Direct Mass Flow Measuring Systems for Quantities of Liquids" adopted by the 9th Conference. (R105)

- A meeting of the NWG was held at the NCWM Interim Meeting to discuss future work.

- Type Evaluation Test Report Forms were circulated to IWG on February 19, 1993 with a request for response by June 1, 1993. At this time the results are 13-yes, 1-no, with 7 members including comments. The comments were circulated to the NWG for response, with one response to date.

\section{PS5S/RS12 "STATIC MEASUREMENT OF QUANTITIES OF LIQUID"}

An inquiry was received from the RS Australia on March 18, 1993, with a short account of the results of an IWG meeting held in December, 1992 (United States not represented), with a request for a vote by April 30, 1993 on 6 issues not resolved at that meeting, on the 3rd PD "Direst Static Mass Measuring Instruments for Quantities of Liquids." A U.S. response was returned to the RS on April 29, 1993. As a result a 4th PD is due form the RS by December, 1993.

\section{PS6/RS4 "MEASUREMENT OF HYDROCARBON GASSES DISTRIBUTED BY PIPELINE"}

A 4th PD ID "Measurement of Hydrocarbon Gasses Distributed by Pipeline. "General Requirements" was received from the RS (Slovakia) in April 1993. The document was circulated to the NWG for comment and the U.S. comments (in brief, the United States believes the document is not necessary) were forwarded to the RS on June 10, 1993.

\section{TC 8 (PS5D, 5S \& 6) "INSTRUMENTS FOR MEASURING QUANTITIES OF LIQUIDS"}

A meeting of the IWG was held in Bern, Switzerland, June 28-29, 1993. It was decided to recommend to CIML for consideration at its October 1993 meeting that the countries responsible for the Subcommittees of TC 8 be assigned as follows:

SC 1. Static Volume

SC 2. Static Mass

SC 3. Dynamic Volume
France

Australia

Germany 


\author{
SC 4. Dynamic Mass \\ SC 5. Water Meters \\ SC 6. Cryogenics \\ SC 7. Gas Metering \\ SC 8. Gas Meters
}

\author{
United States \\ United Kingdom \\ United States \\ Belgium \\ Netherlands
}

The many work projects under this TC were assigned to the various SC's on a voluntary basis.

\section{0-4 I Liaison Activities}

The following summary was provided by John Lacy, USDA Packers and Stockyards Administration, who is serving as the Liaison Committee representative to the S\&T Committee. The summary highlights the most critical issues requiring liaison with industry or government agencies to facilitate resolution of and consensus on these issues.

Item 337-2: Units of Measure for Natural Gas Sold as an Engine Fuel. State motor fuel revenue offices and those Federal agencies which may have interests in the Specifications and Tolerances Committee's recommendation regarding units of measurement for compressed natural gas sold as an engine fuel were contacted and informed of the recommendation. Notification of those agencies was done sufficiently in advance of the Annual Meeting to provide guidance to the Conference in its consideration for adopting the recommendation. Federal agencies contacted included the Department of Energy, Department of Transportation, Federal Trade Commission, and the Environmental Protection Agency.

Item 320-5A: Coupled-in-Motion Railroad Weighing for the Sale of Commodities in Individual Cars. The Specifications and Tolerances Committee has summarized the arguments on both sides of this issue so that interested parties will be sufficiently aware of the arguments surrounding this issue and the technology before it comes before the Conference for a vote. The States should contact potential users and customers in order to obtain their input for consideration by the Conference before the Annual Meeting in July.

Item 360-1: Dimension and Volume Measuring Machines for Shipping Charges. At the Interim Meeting, comments from several manufacturers and users of this equipment explained the various concerns each had regarding different aspects of the equipment and potential requirements. It became clear that the Committee was not sufficiently knowledgeable regarding the technology and use of the equipment to develop a code, field test procedures, and type evaluation criteria and test procedures; however, this knowledge is available through the manufacturers and users of the equipment. The S\&T Committee requested that the Executive Committee authorize the establishment of a work group, made up primarily of device manufacturers and users, to develop a code and the necessary procedures. The Executive Committee has authorized this working group.

Charles Carroll, Massachusetts, Chairman

J. Jeffries, Florida

R. Kelley, New York City, NY

R. Suiter, Nebraska

G. West, New Mexico

R. Marceau, Canada, Technical Advisor

T. Butcher, NIST, Technical Advisor

H. Oppermann, NIST, Technical Advisor

Committee on Specifications and Tolerances 



\title{
Final Report of the Committee on Education, Administration, and Consumer Affairs
}

\author{
Raymond Kalentkowski, Chairman \\ Supervisor, Weights and Measures Division \\ Connecticut
}

Reference

Key Number

\section{Introduction}

This is the Final Report of the Committee on Education, Administration, and Consumer Affairs for the 78th Annual Meeting of the National Conference on Weights and Measures. The Report consists of the Interim Report offered in the Conference "Program and Committee Reports" as amended by the Addendum Sheets issued during the Annual Meeting.

Table A identifies all of the items contained in the Report by Reference Key Number, Item Title, and Page Number. Item 402-6 was withdrawn (W). All of the other items in the report were informational (I); however, there was a request from the floor that a separate vote be taken on Items 402-7 and 402-9. The voting results are shown in Table $\mathrm{C}$ on the following page.

Table A

Index to Reference Key Items

\section{Reference}

Key No.

Title of Item

Page

Regional Weights and Measures Activities ......... 345

National Training Program (NTP) ............ 345

NTP Status Report $\ldots \ldots \ldots \ldots \ldots \ldots \ldots \ldots \ldots \ldots \ldots \ldots \ldots$

Certification Program Implementation . . . . . . . . . . 346

Registry Summary . . . . . . . . . . . . . . . . . . . . 346

Regional Training Activities $\ldots \ldots \ldots \ldots \ldots \ldots \ldots \ldots \ldots \ldots \ldots \ldots \ldots$

Module Revisions . . . . . . . . . . . . . . . . . . . . . . . . . 348

Withdrawal of NCWM Training Module $6 \ldots \ldots \ldots \ldots \ldots \ldots 348$

Awarding of Additional CEU's for Completion of Revised

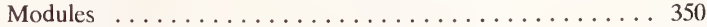

Certification of NTP Instructors $\ldots \ldots \ldots \ldots \ldots \ldots \ldots \ldots$

Weights and Measures Administration Module ........... 351

Field Training vs. Classroom Training . . . . . . . . . . . . 351

Development of a Field Test Manual ................ 351

Participation by Other Countries in the NTP Certification

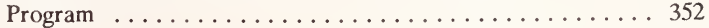


Table A (Continued)

Reference

Key No.

Title of Item

Page

403 I Safety/Above-Ground Storage Tanks

404 I Enforcement Actions

In addition, the Report contains four appendices that are related to specific Reference Key Numbers as follows:

Table B

Appendices

Appendix Title

Reference Key No.

Page

A. NTP Certification Summary

402-2

B. NTP Registry Summary of Activity

C. Enforcement Actions

404

D. Education Committee Response to Input From

the Weights and Measures Community on

Changing Education Needs

401

Table C

Voting Results

\begin{tabular}{|c|c|c|c|c|c|}
\hline \multirow[t]{2}{*}{$\begin{array}{l}\text { Reference } \\
\text { Key No. }\end{array}$} & \multicolumn{2}{|c|}{$\begin{array}{l}\text { House of State } \\
\text { Representatives }\end{array}$} & \multicolumn{2}{|c|}{ House of Delegates } & \multirow[t]{2}{*}{ Results } \\
\hline & Yes & No & Yes & No & \\
\hline $402-7$ & 30 & 12 & 24 & 43 & Split Vote \\
\hline $402-9$ & 35 & 11 & 25 & 38 & Split Vote \\
\hline Rest of Report & 45 & 0 & 69 & 0 & Passed \\
\hline
\end{tabular}




\author{
Details of All Items \\ (in order of Reference Key Number)
}

\title{
I Regional Weights and Measures Activities
}

The Committee reviewed and discussed the following:

1. The final report of the Committee on Education, Administration, and Consumer Affairs to the 35th Annual Technical Conference of the Western Weights and Measures Association (WWMA) (August 1992).

2. The final report of the Committee on Education, Administration, and Consumer Affairs to the 47th Annual Conference of the Southern Weights and Measures Association (October 1992).

3. Comments on carry-over and new Education Committee items from the Central Weights and Measures Association (CWMA Interim Meeting, October 1992).

4. The final report of the Committee on Education, Administration, and Consumer Affairs to the Central Weights and Measures Association (April 1993).

5. The final report of the Committee on Education, Administration, and Consumer Affairs to the 21st Annual Conference of the Northeastern Weights and Measures Association (May 1993).

The positions that the various regional groups have taken on specific items in this report are noted as part of the discussion of the items. The Committee would like to thank all of the regional associations for their input.

At the Annual Meeting, the Committee's Technical Advisor provided a review of some of the comments and suggestions that the Committee has received from the regional weights and measures associations on changing education needs and described some of the actions that have been taken or are being considered for the future in response. (See Appendix D.)

402

$402-1$
National Training Program (NTP)

\section{NTP Status Report}

The status of the National Institute of Standards and Technology (NIST) grants to the NCWM as of June 30, 1993, was as follows:
Grant $1^{*}$
NB83NAHA4003

$\$ 515,189.00$

00.00

$515,189.00$

$515,189.00$

00.00

Total grant funds authorized:

Unobligated balance of funds:

(money available for future module development)

Total funds available for future module development:
Grant 2

70NANB8H0869

$\$ 59,260.22$

$23,000.00$

$82,260.22$

$180,000.00$

$97,739.78$
Grant 1 was closed out in 1992. 
The current status of work accomplished or in progress under grants 1 and 2 is given in Table D on the next page.

\section{2-2 I Certification Program Implementation}

A summary of current participation in the NTP Certification Program is provided in Appendix A.

\section{2-3}

\section{Registry Summary}

The NTP Registry serves as a permanent record of NCWM courses or NIST Office of Weights and Measures (OWM) metrology courses successfully completed and Continuing Education Units (CEU's) earned under the NTP. A summary of information in the Registry is found in Appendix B. The figures in Appendix B on the growth of the NTP Registry indicate a significant decline in the number of new entries processed in 1992 as compared to 1991 (from 528 to 309 , a $41 \%$ decrease). This is the second year in a row that there has been a sharp decline in the number of entries. The economic problems affecting many States over the last few years are probably a major cause of the decline. In these difficult times, the regional weights and measures groups are encouraged to look for ways to help officials in their member States get needed training. One way to do this is to take advantage of the training grants available from the NCWM (see Item 402-4).

\section{2-4 I Regional Training Activities}

The Executive Committee announced in 1992 that it would make a total of $\$ 15,000$ (or $\$ 3,750$ per region) available to the regional weights and measures groups for their use in sponsoring regional training programs. The Executive Committee did not place specific restrictions on the type of training that could be given or how the funds could be used; however, it did say that all proposals to use the funds had to be approved by the Education Committee. As of the Interim Meeting, the Education Committee had received and approved one request from the Northeastern Weights and Measures Association for $\$ 500$ to help support the presentation of two NCWM training module classes.

At the Interim Meeting, a representative of the Western Weights and Measures Association announced that his association was considering using the grant funds to hire a professional facilitator to lead a 3-hour discussion at WWMA's next meeting on how to manage effectively in times of funding cutbacks. It was also reported that both the Southern and the Central Weights and Measures Associations are considering using the funds for a presentation on time management. 
Table D

Grant Accomplishments Status Report

(As of 6/30/93)

\section{Module Subject}

No.

1

2

4

5

6

7

8

10

13

19

20

21

22

23

$23 \mathrm{~A}$

24

27
Mechanical Computing Scales

Electronic Computing Scales

Medium-Capacity Scales

Vehicle and Axle-Load Scales

Meat Beams and Monorail Scales

Livestock and Animal Scales

Retail Motor-Fuel Dispensers

Package Checking

Hopper Scales

Loading-Rack Meters

Vehicle-Tank Meters

LPG Liquid-Measuring Devices

Commodity Regulations

Intro to W \& M Regulation

Weights and Measures Admin. II

Introduction to NIST Handbook 44

Electronic Weighing and

Measuring Systems

\section{Status}

Information from this module is being incorporated into Module 2.

A revision of this module is underway.

Project completed.

Project completed.

Project completed.

Project completed.

Project completed.

Project completed.

The development of this module has been postponed until a review of resources and priorities can be completed.

Project completed.

Project completed.

Project completed.

Project completed.

This module was completed in May and distributed to State weights and measures offices in June.

Three chapters of this module have been written. Further development of the module has been suspended until a review of resources and priorities can be completed.

Project completed.

Project completed. 
The first revision of NCWM Training Module 4, Medium-Capacity Scales, was completed and mailed to the States in October 1992. A revision of Module 24, Introduction to NIST Handbook 44, was completed and mailed to the States in July 1993. Revisions of Module 7, Livestock and Animal Scales; Module 21, Liquefied Petroleum Gas Liquid-Measuring Devices; and Module 27, Introduction to Electronic Weighing and Measuring Systems, are underway. A revision of Module 2, Retail Computing Scales - Electronic, is in progress. Material from Module 1, Retail Computing Scales - Mechanical, will be included in the Module 2 revision. Since Module 1 is considerably out of date and will not be reissued as a separate module, the Committee withdrew it, effective July 1, 1993; consequently, Conitinuing Education Units and NCWM certification will no longer be available for the completion of Module 1 .

In response to feedback from instructors indicating that Module 10, Checking the Net Contents of Packaged Goods, does not allocate enough time to cover all of the material adequately, the Education Committee is considering separating the module into two parts:

Part 1 would be basic training in the core method and would cover introductory package checking information, test procedures by weight, and categories $\mathrm{A}$ and $\mathrm{B}$ sampling plan procedures.

Part 2 would concentrate on miscellaneous test methods by weight, testing by volume, and testing the contents of miscellaneous packages.

Classroom hours and CEU's would be increased from the original 28 hours (2.8 CEU's). Field certification would be offered following completion of Part 2 of the module. The proposed change would be made during the next revision of Module 10. The Education Committee requests comments on this item.

To help ensure the quality of revisions of the modules, the Education Committee plans to begin field testing the major revisions whenever possible. Previously, only new modules were field tested prior to publication.

A summary of the revision status of all published NCWM training modules is shown in Table E on the next page.

402-6

\section{W Withdrawal of NCWM Training Module 6}

(This item was withdrawn.)

See Item 402-5 in the Committee's Report to the 77th NCWM for background information on this item. In response to its published notice of intent to withdraw Module 6, Meat Beams and Monorail Scales, the Committee received only one objection; the Central Weights and Measures Association indicated that its members would like the module to be retained because the need for it may increase as a result of the U.S. Department of Agriculture's (USDA) adoption of Handbook 44. The other regional associations supported the withdrawal of the module.

The Committee has decided to postpone the withdrawal of Module 6 from active status for at least a year. At the 1994 Annual Meeting, the Committee will again review the status of the module to determine if it should be withdrawn. The NCWM will continue to award CEU's or certification for completion of Module 6 as long as the group sponsoring the training updates the module prior to its presentation to a class.

The Committee withdrew this item because it is planning a reevaluation of all of the scales modules. [Note: As a result, the NCWM will continue to award CEU's and certification to individuals who successfully complete this module as long as updated information is provided to them during training.] 


\section{Table E}

Module Revision Status

(As of 6/30/93)

\section{Module}

27

1

10

2

8

20

6

7

21

24

22

19

23
Date of Pub

$1 / 28 / 85$

$11 / 20 / 85$

$11 / 29 / 85$

$2 / 26 / 86$

$9 / 89$

$9 / 90$

$12 / 91$

$12 / 91$

$10 / 31 / 86$

$4 / 3 / 87$

$5 / 27 / 87$

$8 / 5 / 87$

$6 / 22 / 88$

$10 / 92$

$5 / 18 / 89$

6/93

U

$\mathrm{N}$

$\mathrm{N}$

$\mathrm{N}$

$\mathrm{N}$

U

U

N

$\mathrm{N}$

N

$\mathrm{N}$

N

\section{$\underline{\text { Comments }}$}

A revision of this module has been initiated in the NIST Office of Weights and Measures (OWM).

This module is being incorporated into Module 2.

The Committee is planning to split this module into two segments. The NCWM NIST Handbook 133 Working Group will assist in the revision of this module.

Modules 1 and 2 are being revised and combined.

Ohio conducted a field test of the draft revision of this module.

Tina Butcher, Dick Whipple, and Will Wotthlie of OWM have prepared a draft revision of this module.

Joan Mindte of OWM completed a revision of this module.

*Key to module revision status abbreviations: $\mathrm{N}=$ No revision planned in $1993, \mathrm{U}=$ Revision is underway, $\mathrm{R}=$ Revision is planned for $1993, \mathrm{~W}=$ To be withdrawn from active status as of $7 / 1 / 93$. 
(A separate vote was taken on this item and resulted in a split vote.)

The Committee has been asked occasionally if individuals who complete a module class for the second time are eligible to receive additional Continuing Education Units (CEU's) from the NCWM. The Committee's policy has been that individuals could receive CEU's only once for taking a specific module. However, when the latest revision of Training Module 5, Vehicle and Axle-Load Scales, was issued, it became apparent that individuals who had taken the first edition of the module could benefit from taking the revised edition because of the significant changes that had been made. Consequently, the Committee has decided that, in some cases, it will permit individuals to receive additional CEU's for taking revised modules. As soon as the details of this program can be worked out, the Committee will notify each State weights and measures office of the module revisions to which the new policy applies. As each new module revision is issued, the Committee will determine whether additional CEU's can be obtained based on the extent and importance of the changes made. The letter transmitting the revised module to the States will specify if additional CEU's may be received.

Members of the Central Weights and Measures Association (CWMA) did not support this item because they felt that CEU's should be awarded each time a module is given, regardless of whether or not the module has been revised and regardless of the number of times an individual has taken the module. CWMA also felt that Item 402-7 should have been a voting item.

The Education Committee considered making its proposal to award additional CEU's to individuals who retake a module after it has been significantly revised a voting item, but was told by the Executive Committee that it was not necessary. In regard to CWMA's proposal to award CEU's regardless of whether a module has been revised, the Committee consulted with the International Association for Continuing Education and Training (IACET), the organization that establishes the rules for awarding CEU's, and was told that CEU's should only be awarded for new learning experiences. In IACET's opinion, taking the same module again is not a new learning experience; therefore, CEU's should not be awarded in that case. IACET said that it is appropriate to award additional CEU's for the completion of a module that has been substantially revised.

\section{Certification of NTP Instructors}

In July 1992, the 77th NCWM adopted the Education Committee's recommendation to establish a voluntary certification program for individuals who teach NCWM training modules. (See items 402-8A and 402-8B in the Committee's Report to the 77th NCWM.) At the 1993 Interim Meeting, the Committee reviewed and approved drafts of 1) an application form for the certification program, 2) an examination on the National Training Program (NTP) for instructors who apply for certification, 3) a certificate for trainers who meet the NCWM's requirements, and 4) a revision of NCWM Publication 11 on the NTP that includes information on the certification program. As soon as the NCWM is prepared to accept applications, announcements will be sent to all State Directors and to all trainers currently on the NCWM's Trainers List. An announcement will also be published in the Weights \& Measures Today newsletter.

The Central Weights and Measures Association (CWMA) has approached the Education Committee about establishing a reciprocal agreement to simplify the NCWM certification process for instructors who have obtained certification from CWMA. The CWMA trainer certification program, which was initiated in 1992, has certification criteria that are similar to those adopted by the NCWM, except that the CWMA criteria are. stricter in a few cases. CWMA plans to work with trainers in its member States to help them obtain certification. As of the NCWM's Interim Meeting, no trainers had yet completed the CWMA certification process. The Committee will review the progress of CWMA's trainer certification program and will consider whether a reciprocal agreement is appropriate. 
At the Annual Meeting, certificates were presented to the following individuals, who were the first to meet all of the requirements for recognition as NCWM-certified trainers: Richard C. Suiter, NE; José A. Torres, PR; and Don E. Stagg, AL.

\section{Weights and Measures Administration Module}

(A separate vote was taken on this item and resulted in a split vote.)

At the Interim Meeting, the Committee reviewed the second draft of Module 23, Weights and Measures Administration, Part I, a self-study module on the history and organization of regulatory weights and measures activities in the United States. Changes recommended by the Committee were made by the contractor developing the module, and a field test was conducted by the County of Bucks, PA, and the Lancaster County, PA, Bureau of Weights and Measures. The completed module was distributed to the States in June 1993.

The contract for the completion of the second part of Module 23 was canceled at the contractor's request. Part II is intended to be an administrative manual for weights and measures administrators and supervisors that provides detailed information on how to plan, justify, and maintain a regulatory weights and measures program. Drafts of three chapters of the module have been completed. The Committee will continue to look for another contractor with a background in weights and measures regulation to complete Part II. In the meantime, the Committee would appreciate hearing from any volunteers willing to work on portions of the module. Some of the remaining chapters are on program planning, budgeting and funding, records management, and equipment selection and maintenance. A complete list of the remaining chapters is available from the Committee's Technical Advisor.

After the Interim Meeting, the Committee was approached by a freelance writer who offered to assist the Conference in completing Part II. Because of diminishing resources and the need to reevaluate the priorities of the National Training Program, the Committee finds it necessary to postpone action on the further development of this module. If the Conference decides that this is still a high priority item, it will then be necessary to ensure that resources will be available not only to complete development of the module, but also to keep it up to date.

\section{$402-10$}

\section{Field Training vs. Classroom Training}

The Committee reviewed a proposal to substitute a field training program for classroom time in the NCWM training modules. According to the individual who submitted the proposal, the change was suggested because of the substantial time and expense associated with classroom training. The Committee noted that the modules currently have a field training component as well as a classroom training component. It was felt that classroom training is necessary to prepare officials for field work. However, module training does not always have to be given in a traditional classroom setting: it can be a combination of field work and classroom work and can be provided on a oneon-one basis if it costs too much to bring a large number of officials to a central site for training. The modules can also be presented in shorter segments over a longer time period if a jurisdiction cannot afford to keep officials out of the field for 5 days in a row; however, all the requirements of a module must be met before the NCWM will award credits for completion of the course. It is recommended that modules be presented in a classroom to a group of students to help ensure uniformity. The Committee is currently considering various ways to reduce the time needed to present modules, which should help to cut costs associated with module classes. Ideas under consideration include converting some modules to self-study programs and combining two modules into one to reduce duplication.

\section{2-11 I Development of a Field Test Manual}

The Committee discussed a proposal to develop a field test manual that could be used by inspectors to examine, test, and certify commercial weighing and measuring devices. The proposal was supported by the Northeastern Weights and Measures Association. The justification for the proposal was that NIST Handbook 44 is not universally used in the examination of commercial devices because it is not "user friendly"; therefore, national uniformity cannot be achieved. It was suggested that the Education Committee develop field test manuals for specific categories of devices 
that would include among other things:

- An Examination Procedure Outline (or outlines) for the types of devices covered

- Tolerance tables and application guidelines

- Types of tests that are required to be conducted

- A sample test form for recording results

- Pictures of various types of devices that indicate where security seals must be attached and how to properly seal the devices.

The Committee sees a need for field test manuals that would assist both weights and measures officials and device servicepersons in applying Handbook 44. The problem is that it would take a considerable amount of time to develop and maintain the manuals and, unfortunately, the Committee's resources are very limited. With these limited resources, the Committee currently has difficulty developing new training modules, maintaining the 14 published modules, and updating the Examination Procedure Outlines (EPO's) that are contained in the modules and published separately in NCWM Publication 12; taking on any major new projects, such as the proposed field manuals, means that the Committee would have to stop other activities.

It would be helpful if the Committee could get a better idea of the importance of the proposed field test manuals to the NCWM membership. The Committee would like to know, for example, how State and industry representatives would respond to questions such as the following: Are the manuals more important than the training modules? Do the EPO's in Publication 12 serve a useful purpose? Could the existing EPO's be modified in some way to make them more useful as field guides? If it is important to develop a field manual, should all of the items listed above be included in the manual? What items are essential and what items would simply be nice to have? Should other types of information (besides those listed above) be included in a field manual? State and industry representatives are encouraged to provide their views on the development of a field test manual to the Education Committee.

Both the Central and the Northeastern Weights and Measures Associations support the development of field test manuals.

At the Annual Meeting, the Institute for Weights and Measures expressed an interest in assisting the Conference in the development of field test manuals and agreed to provide a draft manual for consideration at the 1994 Interim Meeting.

\section{2-12 I Participation by Other Countries in the NTP Certification Program}

The Education Committee discussed an inquiry it had received about whether individuals in a foreign country who had taken an NCWM training module class were eligible to receive Continuing Education Units (CEU's) and apply for NCWM certification. The class was sponsored by the country's weights and measures office and was presented by an instructor on the NCWM's Trainers List. According to the NCWM's current policies, individuals from other countries are eligible to receive CEU's if they participate in a training module class that is sponsored by a State or Federal agency that has signed a Letter of Agreement with the NCWM to participate in the NTP Certification Program. At present, participation in the NTP Certification Program is limited to U.S. State and Federal agencies that have weights and measures responsibilities; therefore, in foreign countries that conduct their own training module classes, individuals are not eligible to receive CEU's or to be certified by the NCWM.

The Committee is considering whether foreign countries should be permitted to participate in the NTP Certification Program. Comments on this issue would be appreciated.

The Central Weights and Measures Association has indicated that its members support awarding CEU's and NCWM Certification to participants from other countries as long as they meet the requirements of the National Training Program. 
See Item 403 in the Committee's Report to the 77th NCWM for background on the above-ground storage tank (AST) issue. At the 1993 Interim Meeting, Charles Gardner, the NCWM's Safety Liaison, reported that he had received comments from 15 jurisdictions (12 States and 3 counties) on how they addressed the problems associated with returning fuels drawn for test purposes to above-ground storage tanks. All of the respondents expressed concerns for the safety of their officials, yet no one had what they felt was an ideal solution. Some groups have incorporated specific requirements into their regulations; others have sent out informal requests or notices stating what they would like to see at a site where there is an AST.

The various strategies used by jurisdictions to deal with the AST problem fall into three major categories:

1. Require the use of alternate containers or tanks for the return of petroleum products - Some jurisdictions require the facility owner to have alternate containers or tanks available to temporarily retain the product. One jurisdiction requests owners to provide enough containers (preferably 55-gallon drums) to keep various product types separated. A few jurisdictions mentioned returning product to tank trucks. While the use of separate containers saves the weights and measures inspector from having to deal with access to the AST, it raises questions about fire or explosion risks associated with such containers. There could also be problems with possible contamination of product kept even temporarily in easily accessible containers.

2. Require the facility owner to provide assistance in returning product to the AST - Some jurisdictions said they used paragraph G-UR.4.4. Assistance in Testing Operations in the General Code of NIST Handbook 44 to require that the facility owner provide the weights and measures official with assistance in returning product to an AST. Each of the three jurisdictions that reported using this strategy, said they make prior arrangements for the assistance. To prevent someone at the facility from tampering with the pumps prior to the prearranged inspection, jurisdictions say that when they visit the facility to notify the owner/operator that an examination will be conducted and assistance will be needed, they check the security seals on the pumps; when they return to do the examination, they check the seals again to be sure they have not been altered or removed. Althoughrequiring assistance protects the weights and measures official, it may leave the provider of the assistance at risk.

3. Use a Pump Back System to Return Product - Four jurisdictionssaid they either had, or were planning to purchase, a pump back system to return petroleum products to AST's. One jurisdiction noted that it uses a small explosion-proofpump. A drawback to this approach is that the size or design of an AST could make use of a pump back system impractical or unsafe in some cases.

Mr. Gardner said he felt there is a sense of concern that there "must be a better way," but that many jurisdictionsjust do what they have to do to get the job done as safely as possible under the circumstances. He stressed that these jurisdictions are at least addressing the problem and taking positive steps towards increasing the level of awareness that there is a safety concern, while at the same time attempting to minimize the potential for accidents at AST locations. He noted that too many other jurisdictions do not address the problem at all, but let their inspectors decide how to return product safely to the AST's. He said the problem was difficult to resolve because of the varied AST types and installations. What works well at one site may not be sufficient or practical at another. Additionally, many AST'S are installed in the first place because the facility owner could not afford the cost of installing an in-ground tank that meets all requirements of existing environmental and safety regulations; therefore, any solution that would significantlyadd to the cost of the tanks would not be practical. Help is needed from the industry, and especially such groups as the Petroleum Equipment Institute, the American Petroleum Institute, and the National Fire Protection Association, if we are to come up with a universally accepted remedy. Mr. Gardner will continue to collect input on this issue. 
Mr. Gardner also addressed safety concerns about handling lead-and-wire security seals. He said he had contacted several manufacturers and had read various Material Safety Data Sheets (MSDS) and had concluded that, although the hazards associated with lead are well documented, some simple precautions could minimize the exposure of weights and measures officials to lead in the workplace. For example, not holding the lead parts while carrying seals and proper washing of the hands after handling them are recommended, as well as storing large numbers of seals in places that are well-ventilated and/or are separate from working areas.

\section{I Enforcement Actions}

See Item 405 in the Committee's Report to the 77th NCWM for background information on this item. During the Interim Meeting, the Committee considered the need for changes to the sections on weights and measures enforcement actions in NIST Handbooks 130 and 44 for the purpose of recognizing the diverse practice currently being followed by the States. Specific changes were recommended by a member of the Committee who had experienced problems with a program auditor because of the wording in the handbooks. See Appendix C for the types of changes being considered. The Committee would like to receive input from weights and measures jurisdictions on any problems they have experienced with the sections in the handbooks on enforcement actions and any problems they have with the changes that are outlined in Appendix C. Any proposals resulting from the Education Committee's discussions will be referred to the S\&T and L\&R Committees as appropriate.

The Committee also reviewed a draft of some proposed standard definitions for such commonly used enforcement terms as "rejected" and "condemned." (See Appendix C.) The definitions were developed after a review of the regulations and policy guidelines provided to the Committee by 11 jurisdictions. These materials indicated that weights and measures officials usually take one of the following basic enforcement actions after an official device examination: they either 1) approve the device; 2) inform the owner/operator that the device does not meet all requirements, but that it may be used until the problems are remedied; 3 ) inform the owner/operator that the device does not meet all requirements and may not be used until the problems are remedied; or 4) determine that the device is totally inappropriate for the application or does not meet all requirements and would be impossible or impractical to repair and, therefore, they order it to be removed, confiscated, or destroyed. Unfortunately, different jurisdictions use different terms for the same actions; therefore, a device manufacturer who is told that one of his devices has been "condemned" may not be sure whether that means that the device has been temporarily taken out of service for repairs or that it has been judged to be unsuitable and may not be used in a particular application. To avoid confusion, it would be helpful to have a uniform set of definitions for standard enforcement actions. Of course, such terms would be meaningless unless adopted on a nationalbasis. The results of a recent survey of the States in the Central Weights and Measures Association indicated that uniform definitions would be helpful as long as jurisdictionscould implement the definitions through their own policies and procedures. The Committee would like to know how jurisdictions in other regions feel about the establishment of uniform definitions and whether they would be willing to adopt such definitions.

\section{R. Kalentkowski, Connecticut, Chairman}

B. DeSalvo, Ohio

M. Gray, Florida

J. Harnett, Orange County, California

E. Price, Texas

C. Davis, Maine, Liaison Representative

J. Koenig, NIST, Technical Advisor

Committee on Education, Administration, and Consumer Affairs 
Appendix A - NTP Certification Summary

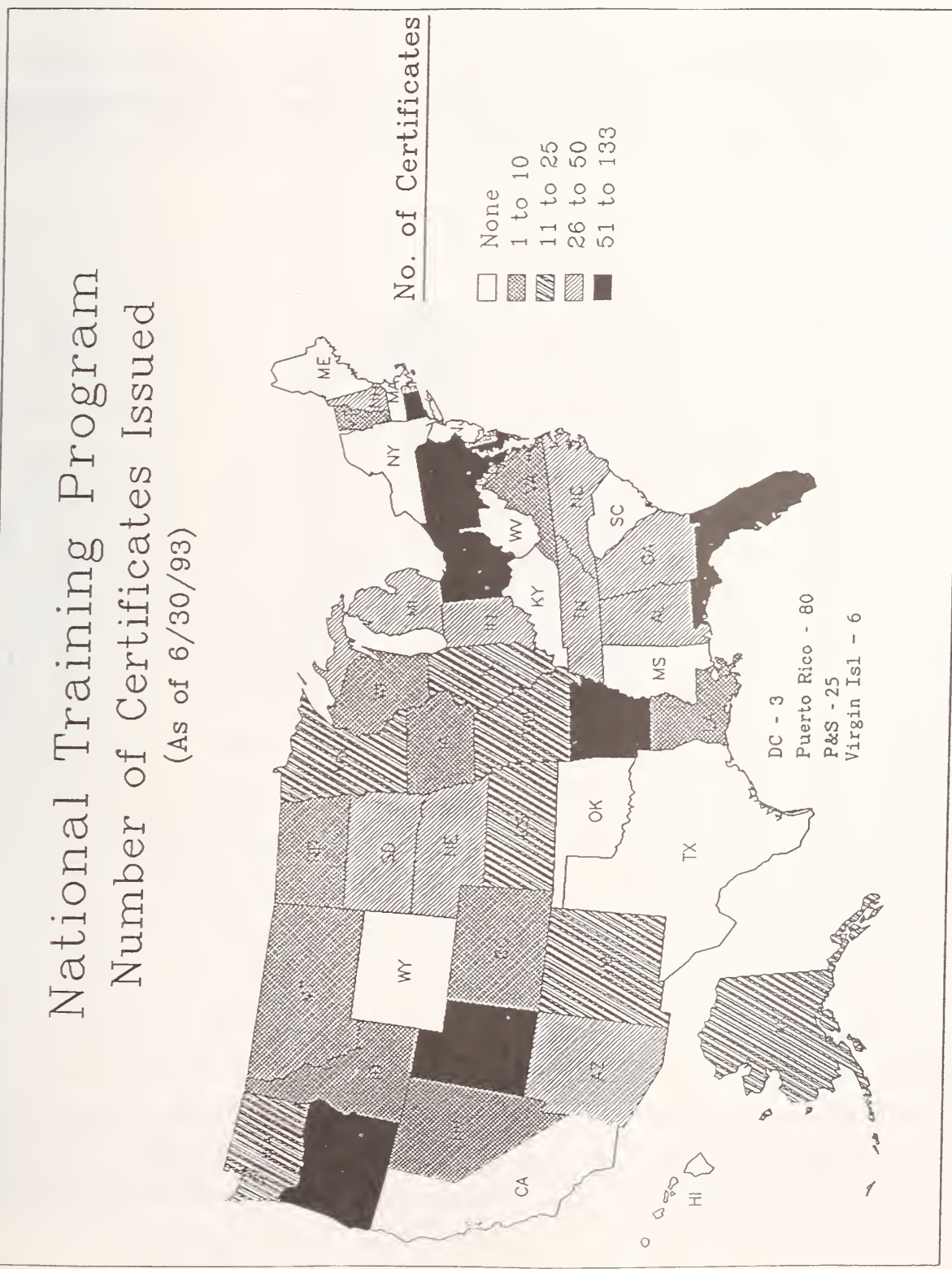


Education Committee

\section{Certification Summary}

(As of June 30, 1993)

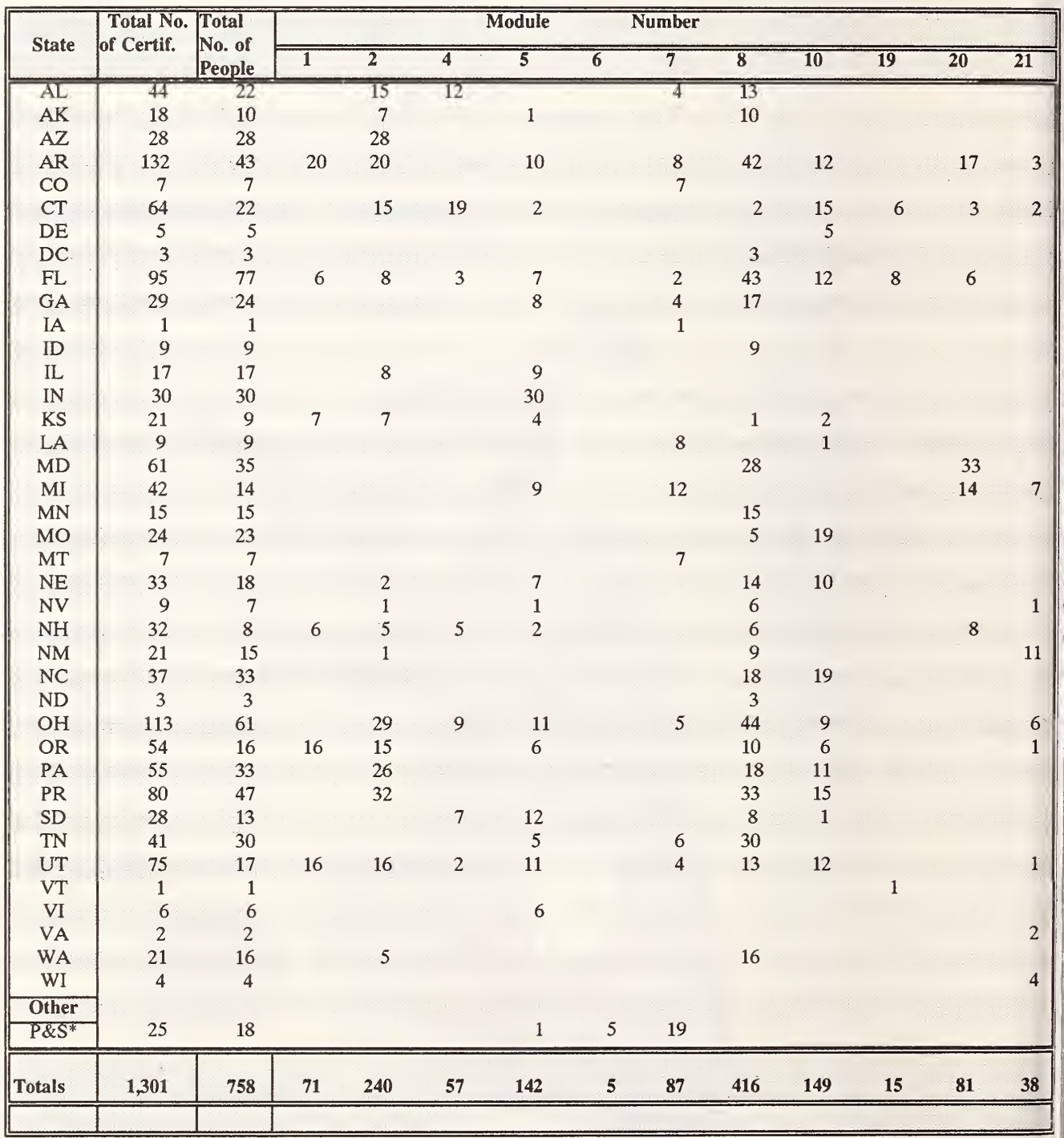

* Packers and Stockyards Administration 


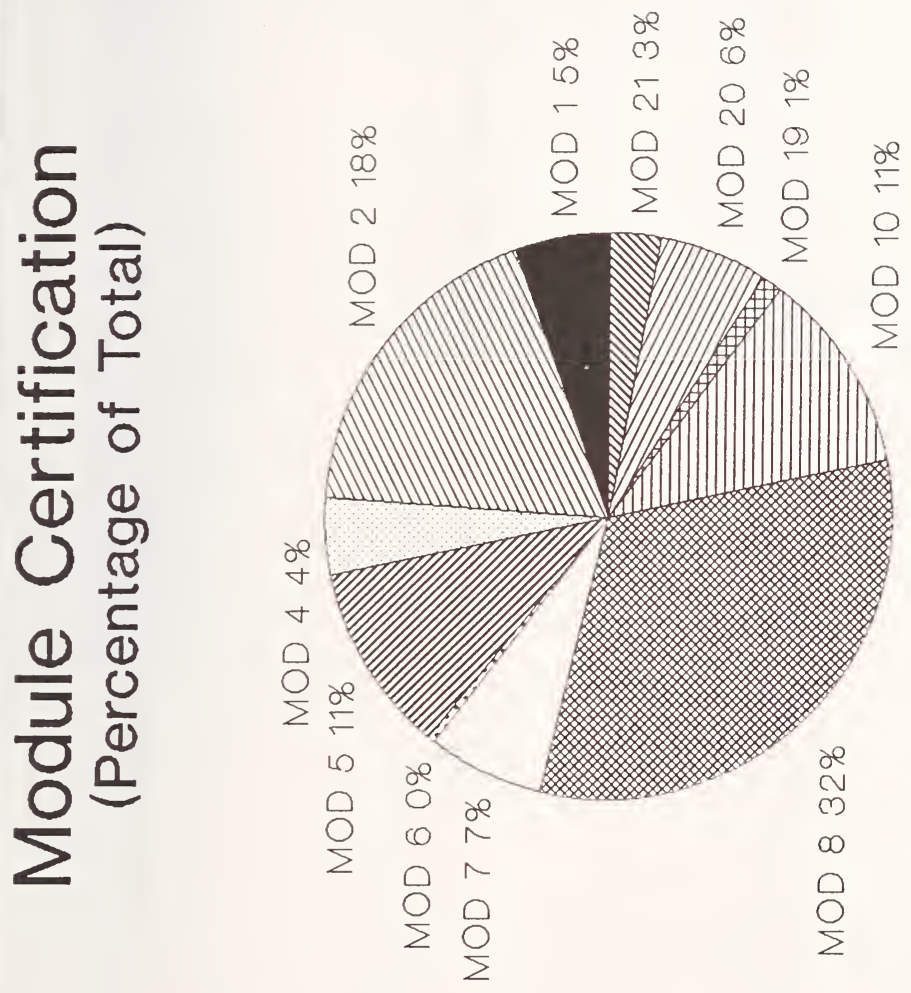

9
0
0
0
0
0
5
0
0
0
0
0
0 
Education Committee

Appendix B

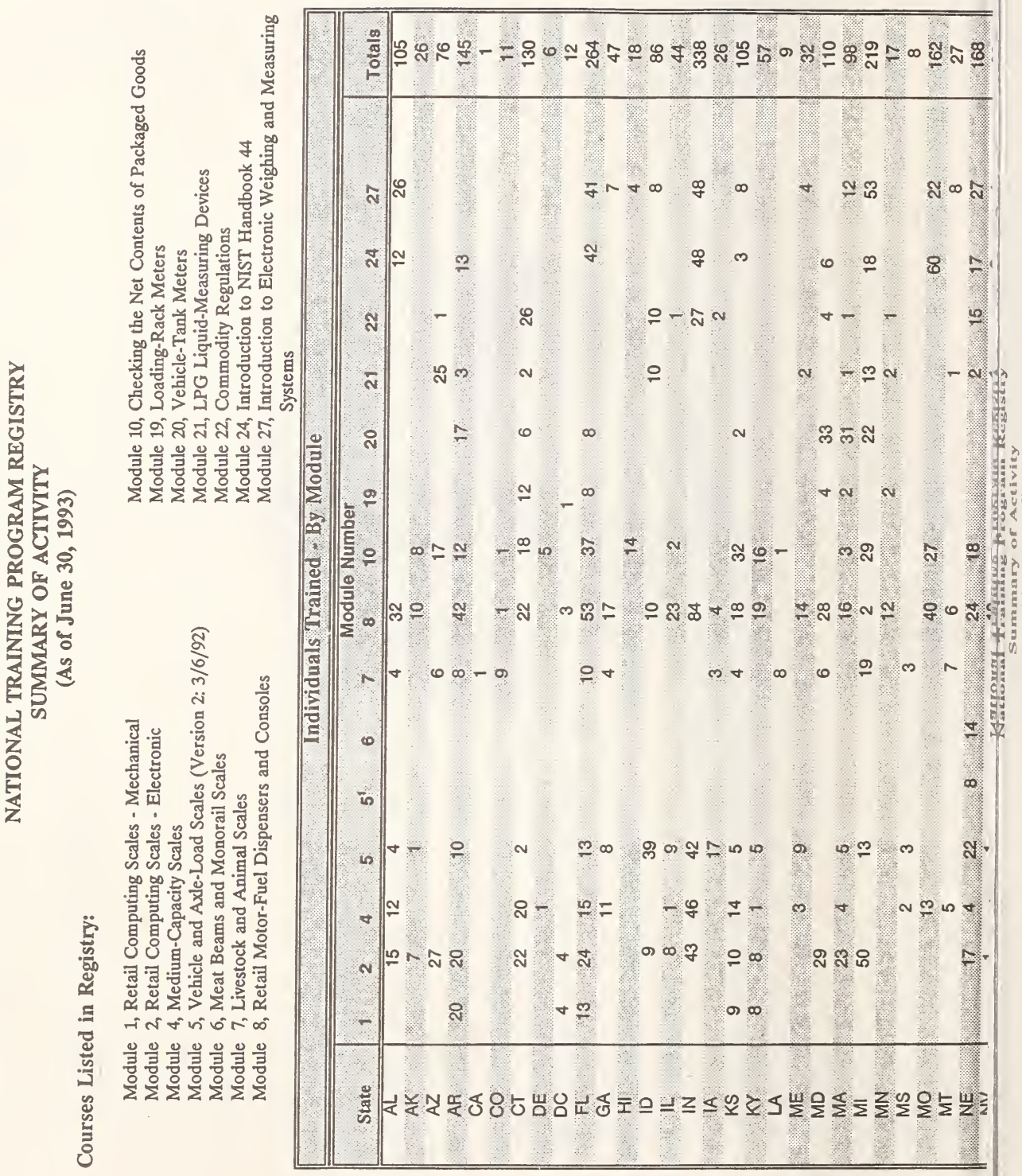


Education Committee

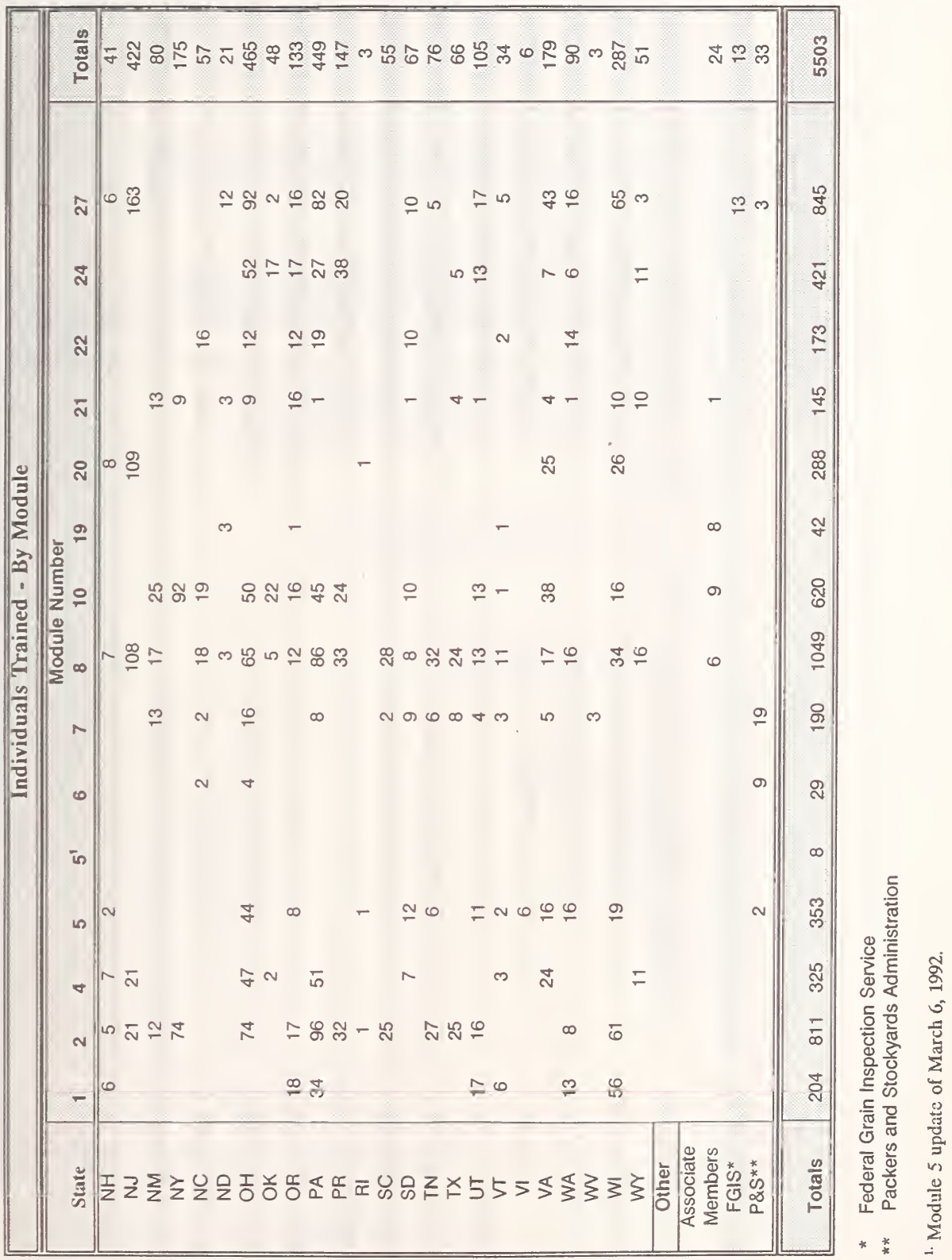


Education Committee

NATIONAL TRAINING PROGRAM REGISTRY

SUMMARY OF METROLOGY SEMINAR ACTIVITY

(As of June 30, 1993)

Courses Listed in the Registry:

No. 201, Basic Metrology I

No. 202, Basic Metrology II

No. 203, Intermediate Metrology

Individuals Trained - By Course

\begin{tabular}{|c|c|c|c|c|}
\hline \multicolumn{5}{|c|}{ Course Number } \\
\hline State & 201 & 202 & 203 & Totals \\
\hline$\overline{\mathrm{AL}}$ & & $\overline{11}$ & & $\overline{1}$ \\
\hline AK & & & 1 & 1 \\
\hline$A Z$ & 2 & 2 & 1 & 5 \\
\hline $\mathrm{CO}$ & 2 & 2 & 1 & 5 \\
\hline CT & & & 1 & 1 \\
\hline DE & 1 & 1 & 1 & 3 \\
\hline $\mathrm{FL}$ & 3 & 3 & & 6 \\
\hline GA & 1 & 1 & & 2 \\
\hline $\mathrm{HI}$ & 1 & 1 & & 2 \\
\hline ID & 1 & 1 & 1 & 3 \\
\hline IL & 3 & 3 & 1 & 7 \\
\hline IN & & & 1 & 1 \\
\hline KS & 1 & 1 & 1 & 3 \\
\hline $\mathrm{KY}$ & 2 & 2 & & 4 \\
\hline $\mathrm{ME}$ & 2 & 2 & & 4 \\
\hline MD & 5 & 6 & 6 & 17 \\
\hline MA & 1 & 1 & & 2 \\
\hline MI & 1 & 1 & 2 & 4 \\
\hline MS & & & 1 & 1 \\
\hline MO & 1 & 1 & 1 & 3 \\
\hline NV & 1 & 1 & & 2 \\
\hline NY & 1 & 1 & & 2 \\
\hline NC & 5 & 5 & 2 & 12 \\
\hline ND & 1 & 1 & & 2 \\
\hline$P A$ & & & 1 & 1 \\
\hline PR & 2 & 3 & 5 & 9 \\
\hline RI & 1 & 3 & & 4 \\
\hline TN & & 1 & & 1 \\
\hline TX & 3 & 3 & 1 & 7 \\
\hline VA & 2 & 2 & 2 & 6 \\
\hline WV & 1 & 1 & & 2 \\
\hline WI & & & 2 & 2 \\
\hline Other & & & 7 & 7 \\
\hline Canada & & & 1 & 1 \\
\hline Totals & $\overline{444}$ & $\overline{49}$ & 40 & 133 \\
\hline
\end{tabular}




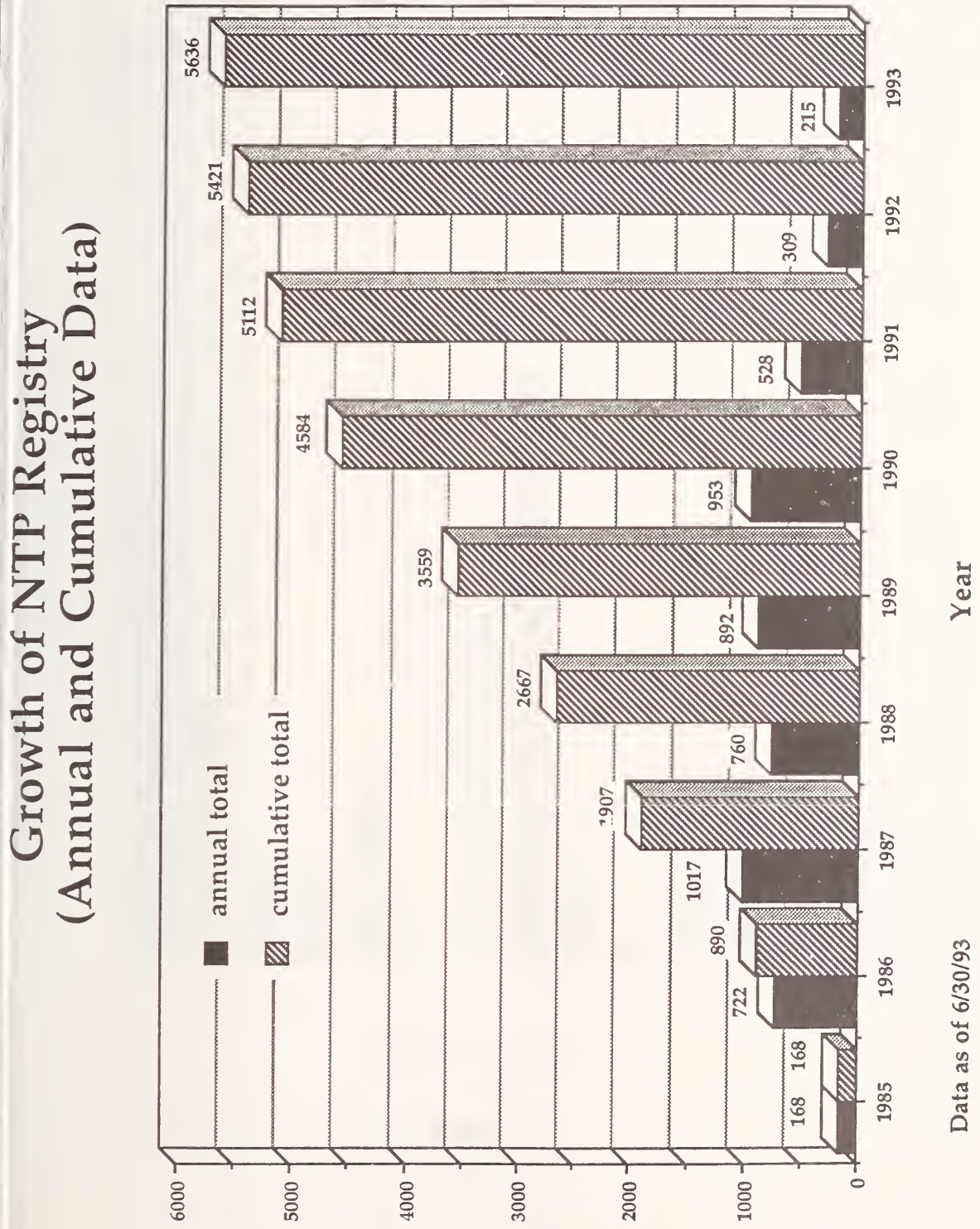

sวเุug Jo səqunN 


\section{Entries in NTP Registry By Module}

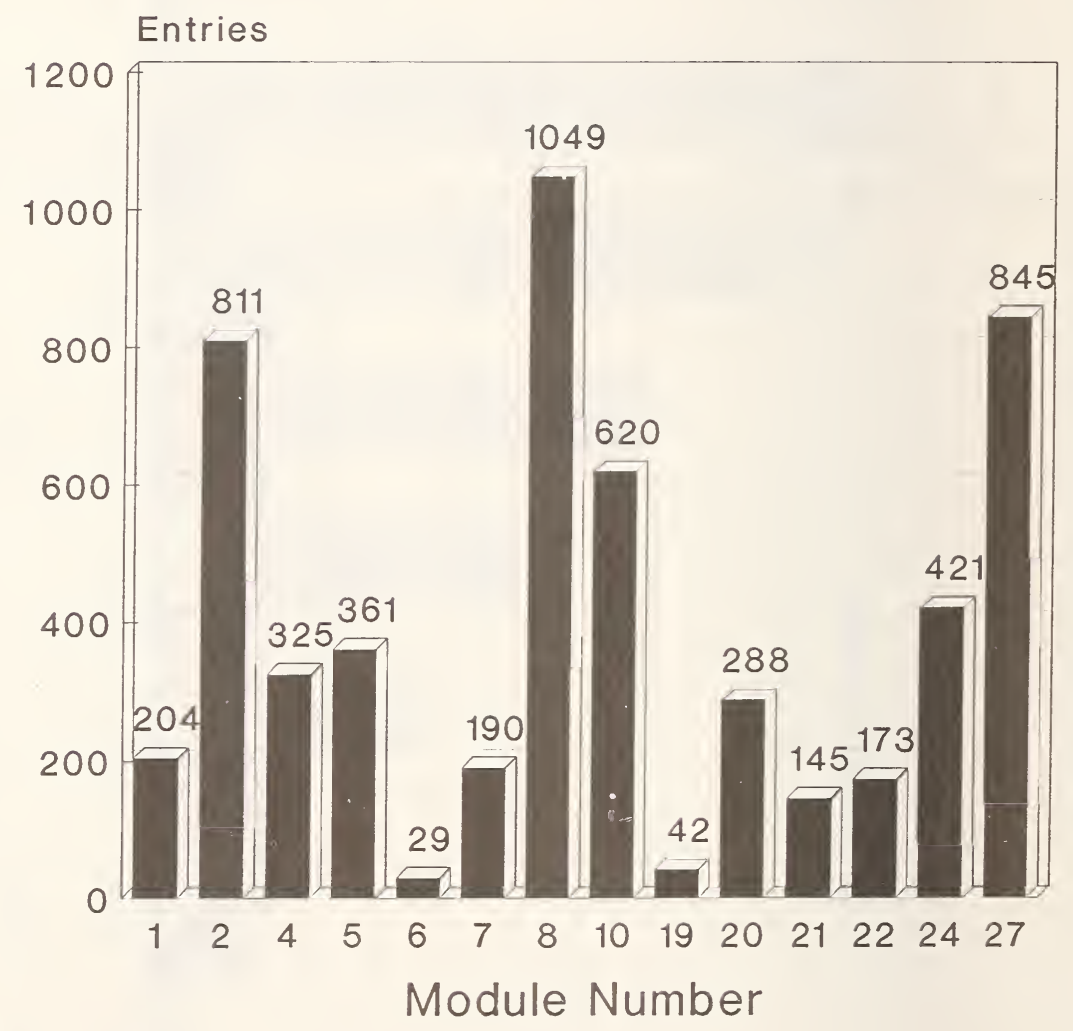

Number of entries 


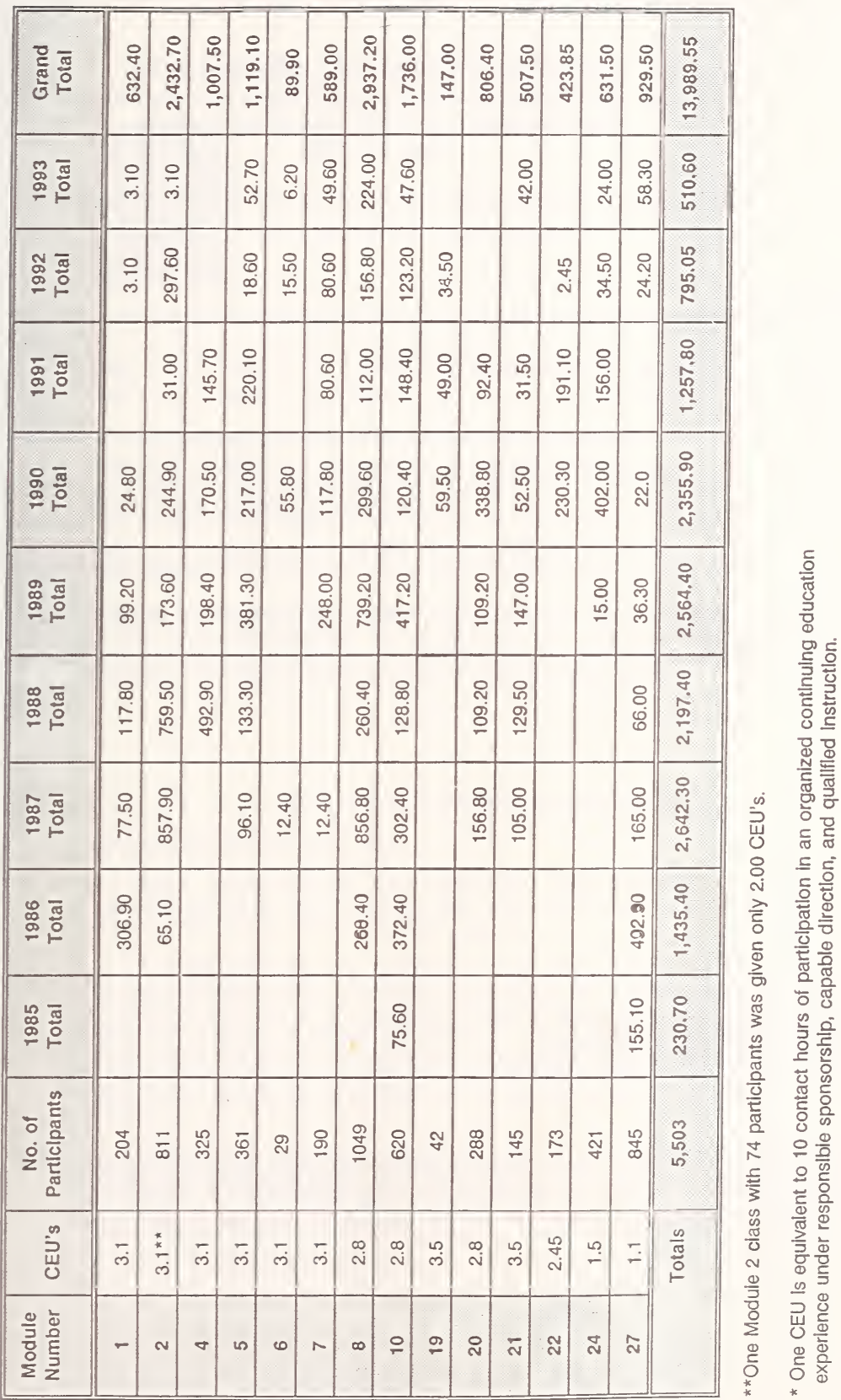


Continuing Faducation linits (C.Y.L'S) Awarded

liy the Vational Conference on Weights and Measures

For Attendance at ()WM Metrology Seminars

Jusu: 31), 19,3

\begin{tabular}{|c|c|c|c|c|c|c|}
\hline $\begin{array}{l}\text { coursor } \\
\text { :iso" }\end{array}$ & 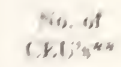 & Participanta & $\begin{array}{l}\text { I'rox) } \\
\text { Total }\end{array}$ & $\begin{array}{l}|x| \mid \\
\text { Jiftal }\end{array}$ & $\begin{array}{l}\text { Joriz } \\
\text { Total }\end{array}$ & $\begin{array}{l}\text { Corand } \\
\text { roteals }\end{array}$ \\
\hline 2131 & 311 & 14 & クカ, & $3 A(1)$ & 728 & IESAN) \\
\hline 2112 & $3 \%$ & S' & $101 \%$ & $57 . \%$ & $17 \%$ & 171.811 \\
\hline 215 & 316 & M) & Sill & (1) $\%$ & 311 & $124(x)$ \\
\hline & fotals & $1: 9$ & $24 \% 31$ & 140,211 & SBy & $453 . \%$ \\
\hline
\end{tabular}

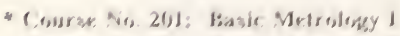

Course Nir. 212: Liasice Metroleney II

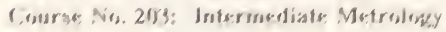

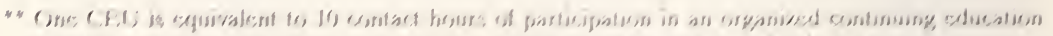

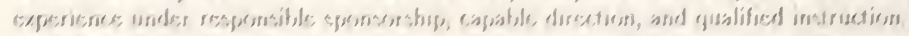




\section{Appendix C - Enforcement Actions}

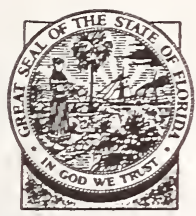

Florida Department of Agriculture \& Consumer Services BOB CRAWFORD, Commissioner

November 12,1992

Ms. Joan Koenig

National Institute of Standards and Technology

Room A617, Administration Building

Gaithersburg, Maryland 20899

Dear Joan:

As you requested, the following are my comments on sections of the Uniform Weights and Measures Law and the Fundamental considerations appendix in Handbook 44 that created the most problems during a performance audit of our program.

\section{Uniform weights and Measures Law}

Section 12, Paragraph (i):

This, according to the auditors, requires the department to inspect and test all weights and measures kept, offered, or exposed for sale (The director shall...).

I explained to the auditors that this would be impossible as well as ineffective. To test a vehicle or livestock scale that is offered for sale at a scale company would require us to construct a pit in which to install it; also, to test even a small scale where it is offered for sale ignores the importance of the installation in its ultimate commercial place of operation, which is critical in it being both accurate and correct.

Since the auditors were interpreting everything literally, I also pointed out that the definition of "weights and measures" (section 1.1) includes all weights and measures of every kind, including carpenters' tapes, measuring cups, bathroom scales, even wristwatches (my point being that this provision obviously was not intended to literally require us to test them all.) 
The way we solved this problem in Florida was by changing paragraph (i) to read "have the authority to inspect and test all -....

Recommendation: Change Section 1.1 to specify that weights and measures addressed in this law are those that used commercially and those used for the receipt and disbursement of supplies in state institutions. Change Section 12, paragraph (i) to give the director authority to inspect weights and measures kept, offered, or exposed for sale.

\section{Section 12, Paragraph (1):}

The problem with this section involves the use of the word "reject" and its meaning in Section 5.2 of the Fundamental Considerations of Handbook 44. This situation is the one that probably started all the discussion about the terms "reject", "condemn" etc.

In Fundamental Considerations Section 5.2, if a device "does not conform to all official requirements, (the W\&M official) is required to reject it and prohibit its use until the device is brought into proper conformance." In the W\&M Law, section 12 (1) requires us to "reject and mark as rejected such weights and measures as are found to be incorrect."

In our state, we will allow someone to continue to use a device that fails to meet some of the more "minor" requirements (i.e.- requirements that have little or no effect on the accuracy or equity in a transaction, such as marking requirements or even slightly out-of-tolerance errors in the customers' favor). We issue a "correction notice" that requires the owner to have the problem corrected within a prescribed time limit. Failure to do so results in the device being removed from service upon reinspection.

As you know, our discussions inaicate that many jurisdictions have similar policies. However, our auditors saw this policy as a blatant violation of our statutory responsibilities, and criticized us for this in their report.

To attempt to solve this, we changed the wording of section 12 (1) in our W\&M Law to read that we shall "order to be corrected such weights and measures that are found to be incorrect", rather than "reject" them.

Recommendation: Change the wording in the W\&M Law Section 12, paragraph (1), to something similar to what we did (above). Rewrite Fundamental Considerations Section 5.2 to recognize that it is acceptable to allow continued use of devices that fail to meet some requirements (especially some specifications) for a reasonable period of time to allow corrections to be made without disrupting the equipment owners' ability to operate. 


\section{Fundamental considerations}

\section{Section 5.2:}

This is the major problem in Fundamental Considerations, as it does not recognize that some requirements do not have a significant effect on a commercial measurement transaction, and that it is appropriate to allow some equipment to remain in service for a reasonable period of time to allow corrections to be made without disrupting the device owners' business or his ability to meet his customers' needs. (See discussion above)

\section{Section 6.1:}

This section would have to be revised to be consistent with any change in Section 12 of the W\&M Law to recognize the procedures being used in many jurisdictions that allow some nontotally correct devices to remain in service until corrections are made.

\section{Section 7.1:}

I think we should consider modifying this section, as well Section 12 (1) of the W\&M Law, to remove wording implying that weights and measures that are not correct must be marked as such. The reason is to prevent unnecessary concern by consumers when a device is not approved due to failure to meet one of the requirements that does effect the transaction. A "rejected" mark placed on such a device can only result in confusion in the marketplace, when the device is actually performing properly and providing equitable measurement.

In summary, it seems that some less restrictive wording is needed in each of these sections that would allow jurisdictions to utilize policies and procedures that are still consistent with our mission of promoting equitable measurement and removing unacceptable devices from commerce. To me, an enforcement policy that recognizes that not all requirements in Handbook 44 are critical to the measurement process and allows time to correct minor deficiencies is justified.

Most programs have these policies now, as policies that result in government placing an unreasonable hardship on citizens and businesses are not very popular with lawmakers. 
Education Committee

Please let me know if you need additional information or wish to discuss my comments further.

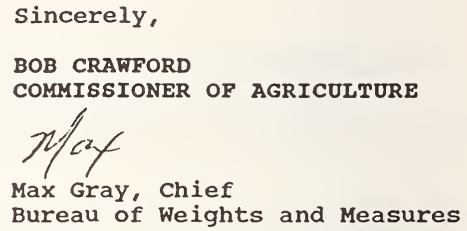

Bureau of Weights and Measures

MG 


\section{Weights and Measures Enforcement Definitions}

\section{Existing Handbook 44 Definitions}

Commercial weighing or measuring equipment - devices commercially used or employed in establishing the size, quantity, extent, area, or measurement of quantities, things, produce, or articles for distribution or consumption, purchased, offered, or submitted for sale, hire, or award, or in computing any basic charge or payment for services rendered on the basis of weight or measure.

accurate - a piece of equipment is accurate when its performance or value--that is, its indications, it deliveries, its recorded representations, or its capacity or actual value, etc., as determined by tests made with suitable standards--conforms to the standard within the applicable tolerances and other performance requirements. Equipment that fails so to conform is inaccurate.

correct - a piece of equipment is correct when, in addition to being accurate, it meets all applicable specification requirements. Equipment that fails to meet any of the requirements for correct equipment is incorrect.

\section{Proposed Enforcement Definitions}

approved - means that the device has been tested by the weights and measures jurisdiction and has been found to be correct. Approved devices may or may not be marked to indicate that they are approved.

unapproved - means that the device has been tested and has been found to be incorrect, and it is the determination of the weights and measures jurisdiction that the device is susceptible of satisfactory repair and may remain in service until it is repaired. Unapproved devices are required to be repaired within the time period specified by the jurisdiction or they may be rejected or condemned. Unapproved devices may or may not be marked to indicate that they are unapproved.

rejected - means that the device has been tested and has been found to be incorrect, and it is the determination of the weights and measures jurisdiction that the device is susceptible of satisfactory repair but may not remain in service until it is repaired. If a rejected device is not repaired within the time period specified by the jurisdiction, it may be condemned. Rejected devices shall be marked to indicate that they have been rejected and may not be used commercially until they are repaired.

condemned - means that the device has been tested and has been found to be incorrect and it is the determination of the weights and measures jurisdiction that the device is unsuitable for use in its current application, or it is not capable of being satisfactorily repaired, or it was previously declared unapproved or rejected and was not satisfactorily repaired within the time prescribed by the jurisdiction. A condemned device may be so marked and shall be removed or replaced or otherwise disposed of by the device owner, or may be sealed out of service or confiscated by the jurisdiction. The jurisdiction has the authority to destroy condemned devices.

not legal for trade - means that the device does not meet the requirements of the jurisdiction for a commercial device and should not be used for buying or selling of commodities. Noncommercial devices that are located in the public areas of commercial establishments should be marked to indicate that they are not legal for trade or are not to be used for commercial purposes. 


\section{Appendix D \\ Education Committee Response to Input From the Weights and Measures Community On Changing Education Needs}

We are at a very critical point in the development of the National Training Program. The Conference has spent over 9 years, one-half million dollars, and countless staff years of effort to develop and maintain the existing 15 training modules (out of the 37 originally identified by the Conference as needed training for new weights and measures officials). We now have less than $\$ 100,000$ left of the grant funds provided by the National Institute of Standards and Technology (NIST) to assist in the development of training modules.

At the same time, because of the difficult economic situations faced by many States, weights and measures jurisdictions and regional weights and measures associations have been asking the Committee to consider ways to help them cut the time and cost associated with providing training to weights and measures officials. We have received lots of great ideas on how we might go about doing just that. We now need your help in putting priorities on those suggestions and ideas and establishing goals and objectives so that we can develop an action plan to direct and find the resources we need to meet your training needs now and in the future.

The following are some examples of the requests and suggestions the Committee has received, followed by examples of the types of actions that the Committee is already taking in response and additional ideas we are considering.

Request: $\quad$ Reduce the time it takes to give the modules.

Background: Originally, the NCWM objective was to include in a module all of the basic information that a new weights and measures official would need to perform a specific function, such as the examination of a device or a package inspection. A draft containing the basic information was prepared, and training specialists were asked how long it would take to present the module. Finally, the module was tested in the field and the time was adjusted according to the recommendations of the jurisdictions doing the testing.

Another objective was that the modules be stand-alone documents so that people would not have to take three or four different courses to learn how to perform a specific function. This meant that there might be some duplication from one module to the next, but at the time, it was believed that the stand-alone approach was the best approach.

That is how we arrived at what we now have, but because of the comments we are getting in these difficult times, we are re-evaluating our approach. The following are some of the things we are doing or are considering.

Response: Combine Modules - One of the Committee's responses to this request has been to combine training Modules 1 and 2 to reduce the time it takes to teach inspectors how to examine retail computing scales. Requirements for both mechanical and electronic scales will be included in one module and one EPO. Recent changes to the tolerances for scales made it practical to take this action. The result will be one course of five or less days rather than two 5-day courses. The new module will also include guidance on how to present the module in shorter increments over a longer period of time; for example, one day a week for 5 or 6 weeks rather than 5 days in a row. This will be an experiment to see if jurisdictions find it easier to use a module if they have more flexibility in how to present it. Actually, this method of presenting the modules is not prohibited under the current program; the information in Module 2 will, however, provide specific guidance on how to use the method effectively. 
Split Modules - Plans are being made to split Training Module 10 on checking the net contents of packaged goods into two parts: one that will cover the basic information needed to check packages and a second part that will cover more advanced testing techniques. The actual purpose of this proposed change is to allow more time to present some of the advanced testing techniques. This means that it will take slightly more time to teach Module 10, but the overall result of the change will be two shorter courses rather than one long course.

Eliminate Duplication - The Committee is also exploring ways to eliminate duplication and cut presentation time. Something we are considering as a short term measure is making it possible for instructors to take duplicative material out of the modules if they are presenting a class to individuals who have previously taken a module class. They could leave out, for example, sections that are common to all modules or to a category of modules, such as the introduction to the National Training Program or the section on what to do upon entering a commercial establishment that is included in the scales modules. In this case, rather than rewriting the module, we would simply establish two sets of Continuing Education Units to be awarded for taking the modules: one number for presentation of the complete module as written and one smaller number for a module class that has eliminated duplicative material that had been presented in other modules. By combining Modules 1 and 2 and eliminating duplication, we could, for example, reduce the time needed to present of all of the Scales Modules $(1,2,4,5,6$, \& 7) from 186 hours or about 31 days to 133 hours or about 22 days. In reality, many jurisdictions will not need to provide training to all of their staff members on all of the scales modules; therefore, if you take the case of training someone on the examination of one small-capacity, one medium-capacity, and one large-capacity scale module, you could complete classroom training in 83 hours (14 days) rather than 124 hours (20 days).

Other suggestions: A longer term solution being considered is the development of introductory courses on Handbook 44 codes that cover a broad category of devices (such as an introduction to the Scales Code) along with the development of a series of short courses on how that code would be applied to individual devices (e.g., computing scales, livestock scales, vehicle scales, etc.).

Request: Find alternatives to classroom training.

Response: The Committee is planning to make more self-study courses available. For example, it has been proposed that we redesign Module 27, An Introduction to Electronic Weighing and Measuring Systems, to make it possible to present it either as a self-study course or in a typical classroom situation. At present, it is designed only for classroom presentation.

Other suggestions: Other things that have been suggested include the development of a video series that would show standard examination procedures for different types of devices, which could be used for selfstudy, short courses, or as part of a training module. Another suggestion is to develop home study tools, such as a kit to help individuals or groups develop specific skills, such as sampling techniques and data analysis related to package checking. It has also been proposed that we consider developing correspondence courses.

Request: Provide shortened courses or learning tools for weighing and measuring device servicepersons, industry representatives, or others who do not need, or are unable to spend the time, to take the comprehensive training provided by the modules.

Response: As a short term measure, the Committee is considering expanding the current Examination Procedure Outlines to make them more useful to individuals who need shorter, less comprehensive training materials. An article describing the EPO's and requesting comments on how to improve them is scheduled to appear in Weighing and Measuring Magazine in August. 
Education Committee

Other suggestions: Other suggestions being considered include the development of field manuals that could serve as the basis for the training and certification of industry servicepersons and the development of short (1 day or less) courses on technical topics such as determination of tolerances or participation in NTEP.

Request: Establish a network to assist States in sharing training resources.

Response: A video library was established within the Office of Weights and Measures to make video training materials developed by the States or industry available to NCWM members. Titles in the library are frequently advertised in the NCWM's W\&M Today Newsletter as well as requests for additional videos.

A Training Calendar, which is published in W\&M Today, was established to make everyone aware of training courses on weights and measures related subjects that are open to NCWM members.

A Trainers List was established to make jurisdictions aware of trainers who are experienced in presenting NCWM training modules who would be willing to provide assistance in putting on training programs.

The fact is that training is a big job, bigger than any one organization can handle. Jurisdictions should consider not only what the Conference can do to help them, but what they can do to help themselves and others in the Conference. If each jurisdiction represented at the Annual Meeting were to identify one training need that was not currently being met and would take some action during the next year to meet that need and then share the results with the Conference, we could make a surprising amount of progress.

These are just a few of the suggestions the Education Committee has received and some of the actions it has taken or is considering for the future. The Conference needs to develop a clear consensus on what its goals and objectives are for the future of the Training Program so that it can put together a plan to meet them. During this week, the Education Committee will be formulating an action plan to get input from NCWM members on what our goals and objectives should be. To aid in defining the training objectives for the future, we are seeking your input through a small survey at this meeting. We plan to follow up with a more detailed survey to further refine training objectives. Our objective will be to find out what your training needs are and how the National Training Program can best help you meet those needs. 


\section{Metrology Working Group Report}

July $18-22,1993$

\section{Regional Group Reports}

\section{NEMAP: prepared by Mike Dynia (CT)}

The NEMAP 1992 annual meeting was hosted by Peter Boykin, Indiana Board of Health, and John Bush, Eli Lilly \& Company Corporate Standards Laboratory and was held in Indianapolis, Indiana from September 14 - 18, 1992.1 There were 18 participants. Steve McGuire (IL), Rick Calkins (Rice Lake), Jerry Everhart, and Dan Szendrey (E G \& G Mound) were visitors. Another meeting was held October $27-28,1992$, at the New Hampshire State laboratory for those New England States that were unable to attend the annual meeting in Indiana. The two-day workshop was a Basic and Intermediate seminar refresher with hands-on work in the lab.

\section{NEMAP Presentations.}

David Baird (DE) - How ISO 9000 Impacts the Delaware Metrology Laboratory

Michael Dynia (CT) - ISO Guide 25 Cross Referenced With the CT Quality Assurance Metrology Manual Frank Ward \& Mark Kline (Troemner) - Video Demonstrating The Interfacing Of Computers and Laboratory Balances for Weight Calibration

Randall Crosser (Ohaus) - Type Approval of Scales in the European Community - '92 Legal Metrology Harold Birgy \& Ron Balaze (MI) - Gravimetric Testing of Meters Used for the Measurement of Bulk Hydraulic and Motor Oils

Peter Boykin (IN) - Form to Track Standards in the Laboratory

David L. Schuette (Consumers Power Company) - Piston Gage Use as a Pressure Standard

Ed Carpenter (PA) - To Stack Or Not To Stack - A Study of Summation Weighing

John Bush (Eli Lilly) - Standards Lab Use Of Spread Sheets

Georgia Harris (NIST) - Statistics, ISO 9000 Laboratory Accreditation, Volume Uncertainties, SOP-5, 3-1 and 4-1 Weighing Designs

Tours. The group toured the Indiana Board Of Health metrology laboratory and toured the Eli Lilly Corporate facilities, including the Corporate Standards Laboratory.

Round Robins. The NEMAP group is currently working on a 5-1 weighing design with mass code data reduction at the $1-\mathrm{kg}^{1}$ level and is 75 percent complete with 13 out of 17 laboratories finished. The round robin coordinators are Randall Crosser (Ohaus), Michael Dynia (CT) and Georgia Harris (NIST). The group finished a round robin with calibration at the $10-\mathrm{g}, 5-\mathrm{g}, 2 \mathrm{-g}, 1 \mathrm{-g}$, and $20-\mathrm{kg}$ levels plus each laboratory tolerance testing a $500-\mathrm{g}$ weight.

Next Meeting. The next NEMAP meeting will be held September 27 to October 1, 1993, to be hosted by Randy Crosser (Ohaus), in Florham Park, New Jersey. All are welcome to attend!

\section{MIDMAP: prepared by Steve McGuire (IL)}

MIDMAP is an association of State and industry laboratories located in the central United States. The principal activity is measurement assurance, with emphasis on pursuing education in measurement science. Its members participate as a team in a broad education and training program. Members of MIDMAP include: IL, IA, MO, MN, NE, ND, SD, WI, NIST, U.S. Department of Agriculture, Federal Grain Inspection Service, Rice Lake Weighing Systems, and the 3M Company.

MIDMAP'S last meeting was held July 27 - 31, 1992, at the Illinois Department of Agriculture's Bureau of Weights and Measures in Springfield, Illinois. All members were represented at the 1992 meeting; special guests included

1 State weights and measures laboratories provide measurement services in both inch-pound and metric units. Round robin measurements are conducted between the laboratories to verify competence using both systems of units. Reference will be made to measurement units as used in each round robin. 
representatives from Mettler-Toledo, Inc.. The 1993 MIDMAP meeting is scheduled for August 2 - 6 at the Iowa Department of Agriculture's Weights and Measures Division in Des Moines, Iowa.

Topics of the 1992 meeting included the round robin analysis of a 500-lb test weight and the review of data generated from testing at the $1-\mathrm{kg}$ level, plus volume uncertainties, diagram and pareto charts, statistics, SOP 2, and Liquified Petroleum Gas (LPG) information. The 1992 meeting concluded with a tour of the Illinois facilities.

Round robin exercises underway and scheduled for review at the 1993 MIDMAP include data generated from testing at the 5-gallon and the 50-lb levels. Other topics to be covered include ISO 9000, a paper on ensuring accuracy and traceability in weighing instruments, internal auditing and assessment, writing and assessing a quality manual and an overview of technical management. The meeting will conclude with a tour of the Iowa facilities and a laboratory evaluation conducted by the group.

MIDMAP provides a test of the measurement system for all participating members. Each member measures an item which has already been measured by NIST, then reviews the difference between its observation and the NIST value. If the member's uncertainty statement does not overlap the NIST value, then investigation and corrective action is started. Both MIDMAP and NIST technical support have enabled its members to strengthen their quality assurance programs and provide improved services.

\section{WRAP: prepared by Kelly Moody (AZ)}

Round Robins. The WRAP round robin measurement that was performed during 1992 - 1993, was tolerance testing on ASTM Class 4 weights. These weights consisted of (2) 5-lb, (2) $200-\mathrm{g}$, (2) $100-\mathrm{g}$, (2) 50-g, (2) 10-g, (2) 5-g, (2) 3-g. Each weight was either polish or satin finish. The procedures used were either SOP 8 modified substitution or direct reading with calibration of internal weights. The objective of this round robin was to assess laboratory capability to provide adequate tolerance testing results.

ISO 9000. The ISO 9000 Task Force report that Ms. Harris presented to the Executive Committee at the Interim Meeting in January 1993 was discussed. The paper, "Ensuring Accuracy and Traceability in Weighing Instruments," was also presented at this meeting and discussed from the perspective of how the State metrologists can help scale service companies in their States comply with ISO 9000 requirements. The draft calibration criteria consistent with ISO Guide 25 was also presented. After the above information was presented to the group a brainstorming session was held. This session provided information to the group to help them answer questions about ISO 9000 and traceability to their customers.

Internal Auditing and Assessment. Two videos were presented to the group on laboratory accreditation. The first described the NVLAP accreditation criteria, and the second the Canadian laboratory accreditation criteria. After viewing the tapes, the group discussed the perspective of accreditation criteria between the two agencies and gave their opinions about which program had the best criteria. This session enabled the participants to gain an understanding of using audit findings to improve (corrective actions) deficiencies found in their laboratories.

Writing and Assessing a Laboratory Quality Manual. The group reviewed the objectives and purpose of the Quality Manual and also spent time in small groups evaluating sections of a draft quality manual.

Tour. The group visited Hewlett-Packard dimensional laboratory and the Idaho weights and measures laboratory.

Technical Management of a Weights and Measures Laboratory. The group reviewed different types of motivation techniques, position descriptions, and discussed managing the laboratory workload.

Next Meeting. The next WRAP Meeting will be hosted in Arizona on the first week of May 1994; an Intermediate seminar will be conducted.

\section{SWAP: prepared by Karl Herken (KS)}

The Annual SWAP meeting was held in Kansas City, Missouri, September 27 - October 2, 1992. Attending: TX, LA, $\mathrm{KS}, \mathrm{CO}$, NM, OK. Absent: AR and newly voted-in associate member Denver Instruments. 
Round robins included the following:

100 -foot tape calibration at $1-\mathrm{ft}, 10-\mathrm{ft}, 50-\mathrm{ft}$, and $100-\mathrm{ft}$ intervals, using either bench or tape to tape method

100-gram set calibration by weighing design A.1.2 and A.1.3 on sets \#3 and \#7

$10-\mathrm{g}, 1-\mathrm{g}, 0.1 \mathrm{-g}, 0.01 \mathrm{~g}, 0.001 \mathrm{~g}$ calibrated by any method in regular use at the participating laboratory

A NIST Intermediate seminar was also conducted during the meeting.

The 1993 annual SWAP meeting will be held in Hot Springs, Arkansas on October 4 - 8, 1993. Hosting this meeting will be Bill W. Sullivant and Charles Kirspel of the Arkansas Bureau of Standards. Discussion will center on 1993 in-progress interlaboratory testing as follows:

Complete calibration of a 5, 3, 2, 1 set from 100 gram to 1 milligram. Methods per regular use in the laboratory

Tolerance testing with values given and accept / reject per weights evaluation. The kit consists of a 31-pound kit starting at 10 pounds.

Calibration of two sets at 1000-g, 500-g, and 200-g using a 4-1 weighing design and masscode data reduction.

At the 1993 meeting, methods will be discussed on the most effective use of round robin data in providing an external evaluation of internal control data and standards surveillance. Further discussion will center on tying round robin data to the annually-submitted NIST report and the value of this type of testing. The value of this analysis will be compared to having an enlarged budget to cover the NIST calibration expense if these services are not available.

Other areas of concern include the lack of density determinations being available at NIST at the 100 gram level. One hundred grams would be the ideal second starting point when using the mass code considering the majority of sets submitted for calibration.

\section{SEMAP: prepared by L. F. Eason (NC)}

SEMAP met March 29 - April 2, 1993, at the Florida Department of Agriculture Laboratory and Office complex in Tallahassee, Florida. All States and one associate member (Duke Power) were represented. We were glad to welcome Kelvin Boone (MS), Jody Gondek (NC), and Paul Gentry (FL), to their first SEMAP meeting. Also, Eric Hamilton, Petroleum Inspection Bureau Chief for the Florida Department of Agriculture, joined us for several of the sessions.

The meeting was called to order by Mike Cook of Florida, the SEMAP Chairman. Welcoming remarks were delivered by Don Farmer, Director of the Division of Standards, and Max Gray, Chief of the Bureau of Weights and Measures. Reports were given from each jurisdiction. Everybody seems to be experiencing increasing workloads, primarily due to 1SO 9000 . With continuing budget woes, most of the SEMAP members have either started charging for their services or have plans to do so in the near future. We were saddened to hear that Mickey Worthington, metrologist from Kentucky, had died in an accident during the past year.

Virtually the entire working session of SEMAP was devoted to laboratory quality assurance issues. On Tuesday, internal auditing was covered with an overview of the ISO 9000 series, 1 SO Guide 25, and the draft mass calibration laboratory certification requirements. The draft mass calibration laboratory criteria will be used by the National Voluntary Laboratory Accreditation Program (NVLAP) for private laboratory certification and will be incorporated into Handbook 143 by the Office of Weights and Measures. Wednesday, Georgia Harris covered the requirements for writing and assessing a laboratory quality manual that will meet the ISO Guide 25 requirements. $1 S O$ requirements were also compared to existing Handbook 143 and Canadian standards. Thursday, technical management of the weights and measures laboratory was discussed. Topics included writing position descriptions, performance evaluation criteria, interview procedures, motivation, communication skills, and time management.

On Friday, Diane Lee/London from Maryland, reviewed the draft criteria for accreditation of grain moisture testing laboratories which she developed while working as an IPA (Intergovernmental Personnel Act contract) with OWM. The 
remainder of Friday was devoted to a business session with the election of officers and selection of the time and place for the next meeting. The next SEMAP meeting will be hosted by Mike Kramer, metrologist from Virginia and current SEMAP chairman, at Richmond, Virginia. The meeting will be held on April 10 - 14, 1994, Sunday through Thursday (in order to take advantage of reduced air fares).

\section{Work Project Status and Development}

\section{Old Projects}

Lis() sorof Task Force. See next section for a summary of activities.

Stability of mg Weights. In 1992, the metrologists decided that additional round robin measurements would be used to continue to evaluate the stability of various designs/materials of $\mathrm{mg}$ weights. Data from past round robins in the range less than I g was made available for review by Georgia Harris (NIST). Laboratory testing was planned by Kelly Moody (A\%) and among the SFMAP States to evaluate wire weights versus leaf weights.

Information regarding the SEMAP round robin with wire weights was presented by L. F. Eason (NC) at the meeting. Data is inconclusive at this time; however, it appears that the standard deviation between laboratories for the leaf weights is smaller. The group emphasized that round robin data will inherently have additional systematic errors and also that the wire weights are extremely difficult to handle. Due to the Arizona laboratory move, data has not been collected.

Lxamination f'rocedure (Julline (LPP()) for CNG. In I992, based on a request from the S\&I Committee, Jim Akey (WI) agreed to develop an LfP() for the testing of CNG devices. Jim completed a first draft and submitted it to NIST prior to the January Interim Meeting.

Metrology Training Modules. Jose forres Ferrer (PR) provided a breakdown of the training sections of the current Basic and Intermediate training to L. F. I:ason (NC) for the development of a proposal to prepare training modules for laboratory metrology. L. F. Eason sent copies of the material to Martin Coile (GA) who has been working with NIS'I as a I3asic seminar trainer to continue work on this project. Georgia Ifarris (NIST) will ask all NIST trainers to participate in the review of training materials and to provide suggestions for modular and video training materials.

Data Sets for Computer f'rograms. No additional work was completed during 1992 - 1993.

Index of Computer P'rograms. In 1992, Jim Akey (WI) volunteered to compile an index of computer programs that are available to share with metrologists. Programs were to be made available on the OWM bulletin board. A memorandum was prepared and circulated by Jim Akey asking for contributions. Responses indicated that people either I) had no computer, or 2) were using programs already on the bulletin board. It was the consensus of the group that people who have developed programs in their laboratories do not have them adequately tested or documented for distribution. No additional work is planned.

Index of Technical Papers and Reports. In 1992, David Dikken (MN) agreed to collect copies of papers along with an abstract ol each one. At some point, this material was to be made available for indexing. The papers were to include any technical material of interest to the metrologists. A memorandum was circulated by David Dikken soliciting papers with very little response. No additional work is planned.

\section{New Projects}

Recommended Calibration Intervals for 105-series Field Standards. Numerous requests have been received by the metrologists and by OWM regarding appropriate calibration intervals for such items as large provers, cast-iron test weights, and precision mass standards. No formal guidelines or recommendations exist to respond to these requests. General guidance is to start with a one-year period and adjust it up or down based on adequate historical data. Randy Wise (KY) volunteered to draft a survey (o) circulate to all metrologists for input in the preparation of a draft Recommendation. Metrologists present at the meeting expressed the concern that care and handling of test equipment plays such a large part in determining appropriate intervals that any type of document should only be considered a recommendation from which to start. Anyone interested in assisting with this project should contact Randy Wise (KY). 
Use of Sensitivity Weights on Electronic Balances. Changing technology, and the instability of milligram weights, has caused numerous metrologists to question the use of the sensitivity weights in the double substitution procedure when using electronic mass comparators and analytical balances. The alternative procedure is often called an "ABBA" or "ABA" procedure and essentially compares the standard and the unknown without using a sensitivity weight to calibrate the electronic range of operation. Concerns which were expressed by OWM include: 1) this procedure is not currently documented; 2) data must be obtained and maintained to ensure appropriate balance sensitivity before this procedure is used; and 3) it is NOT appropriate for mechanical balances. David Dikken (MN), Ken Fraley (OK), and Dick Weber $(3 \mathrm{M})$ will be developing a written procedure and collecting data to evaluate this procedure. Anyone interested in working on this project should contact David Dikken (MN).

EPO for Gravimetric Testing of Motor Oil Meters. David Dikken (MN) brought up the subject of testing oil meters in the field using gravimetric methods. He has been asked to prepare an examination procedure outline for use by Minnesota field staff. Procedures have been developed previously by Ray Cioffi (VT) and Harold Birgy and Ron Balaze (MI) and presented at NEMAP meetings. Anyone wishing to participate or having additional information should contact David Dikken (MN).

Brochure or Information Sheet for End-Users of Analytical and Precision Balance Services. Karl Herken (KS) brought up a concern about the number of scale companies purchasing precision weights and going into the business of servicing and calibrating analytical and precision balances without appropriate knowledge, training, or experience. The group discussed a number of ways this could be approached. Education of the end-user was considered the most feasible. Karl will be contacting the ISWM Analytical and Precision Balance Division to coordinate these activities. A brochure was suggested that weights and measures officials could distribute to the users of this type of service. Anyone wanting to participate in these activities should contact Karl Herken (KS).

Roles and Responsibilities of Metrologists in the NCWM. A formal organizational structure for the metrologists was proposed to the Executive Committee in 1990. No action was taken because formal operation within the NCWM would entail voting on technical issues by every State director which could result in majority opinions in opposition to scientific accuracy. Formalizing the organization as a national metrology group, similar in structure to the current regional groups, is an option that was considered. The 1990 proposed structure could work independently from the NCWM, yet meet at the same time and still work hand-in-hand as appropriate. The 1990 proposal included responsibilities for the chair of the group but not for the regional representatives. L. F. Eason (NC) and Georgia Harris (NIST) will prepare a list of tasks and responsibilities for the group chair and the regional representatives and will distribute it to the metrologists for review.

\section{ISO 9000 Task Force Status Report}

\section{Original Objectives}

\section{ISO 9000 Task Force Objectives}

To develop a guide to assist States (laboratories) to meet ISO 9000 recommendations (and registration to ISO 9000 if they wish). The guide would have enabled laboratories to meet the additional quality system requirements of ISO 9000 . New technical criteria for NVLAP accreditation that were drafted are consistent with ISO Guide 25 and 9000 recommendations; criteria established for private calibration laboratories and State laboratories were to be the same eventually.

The guide was to include:

1) An overview of the registration procedures including a typical time line, contacts, and estimated costs of the complete initial and ongoing process.

2) List of "critical" elements evaluated during a pre-audit and ISO 9000 audit as well as explanations or interpretations of what is needed.

3) Results of a State laboratory pre-audit. Noted deficiencies were to be discussed and remedial recommendations were to be made. The participating State was to provide documentation as to what preparations were required prior to the pre-audit. 


\section{Considerations Regarding Original Objectives}

- The scope of the Task Force changed, based on review of ISO Guide 25, current criteria, draft NVLAP criteria, the program direction, training efforts, and assessment activities of the NIST Office of Weights and Measures.

- Of the original objectives, items 1 and 2 are no longer required to be in the form of a "guide." This type of information is already written and available. The criteria will be incorporated in the OWM program, so formal ISO-9000 registration will not be recommended. Draft technical criteria and guidance are being presented at each of the regional metrology meetings; formalized material used at each of the regional meetings will be updated after all meetings and circulated to the States for further assistance.

- The current training and program direction of the State Laboratory Program (SLP) includes the adoption and updating of the NIST/OWM accreditation program consistent with ISO Guide 25 criteria. Guidance has been presented and will be further developed by the regional metrology groups with the support of OWM. This continues to be a NIST-coordinated activity.

- The expertise of the State metrologists who have participated on the ISO 9000 Task Force may be further developed by their participation in formal NVLAP assessor training. OWM has been working with these metrologists at each of the regional meetings to develop their skills as assessors by participating in an on-site assessment for the SLP. This is a NIST activity.

\section{New and Ongoing Needs and Objectives}

Additional issues or areas of concern to the NCWM are listed below. These items were presented to the Executive Committee to show that ISO 9000 affects numerous aspects of the weights and measures programs and not only laboratory accreditation.

\section{- Continued Integration and Assistance to the SLP -}

- $\quad$ review and report of lab assessments and identification of common deficiencies

- $\quad$ develop brochure for laboratory customers regarding laboratory services and ISO 9000

- $\quad$ update and review of Handbook 143 \& 145

- $\quad$ assist with development of quality manual and round robin guides - to document program

- $\quad$ review and assist with implementation of the SLP Long Range Plan (LRP)

- $\quad$ assist obtaining national and international recognition

- $\quad$ obtain assistance from additional interested participants

- determine alternatives for laboratories that don't meet criteria at the end of a phase-in period; support for commercial-only applications

- $\quad$ NTEP - OIML, ISO Guide 25, ISO Guide 38, and ISO Guide 10012

include NTEP staff in the development and adaptation of needs for NTEP requirements similar to needs of laboratory metrology program

Handbook 130 -

- $\quad$ review and change items identifying "maintenance of traceability" to "maintenance of accredited laboratory"

- $\quad$ model law and voluntary registration programs could include ISO-9000 quality criteria

- possibly change voluntary registration to include ISO-9000 criteria as a government-service benefit

- Accreditation of Weights and Measures Programs -

- $\quad$ investigate the potential for including assessment and accreditation of a State enforcement program in Handbook 130 (model laws and assessment of implementation)

ISO standards are increasingly being adopted by Federal agencies evaluate funding alternatives for weights and measures programs 
"With ISO-9000 registration, larger scale companies may be viewed (with good reason) as having better credentials than the weights and measures programs. It may become a competitive issue in court cases. With the number of scale companies seeking ISO registration, it may happen sooner than we think. How will the courts view a case by a weights and measures field agency with current test reports versus an ISO-registered scale company with full documentation of everything they did?"

\section{National Training Program -}

develop training materials and implement training for weights and measures officials using ISO criteria as impetus

Federal Agencies -

A number of Federal agencies (see attached information sheet) are investigating or adopting ISO-9000 quality criteria as standards of quality operation. Legal requirements probably wouldn't be far behind. Being prepared with the ability to meet such standards is better than catching up or being required to meet criteria through corrective actions after-the-fact.

\section{Proposal of the ISO 9000 Task Force (to the Executive Committee)}

Members of the task force feel that, while the objectives of the group have changed, completed activities have added significantly to the integration of ISO-related criteria into the State Laboratory Program to meet the needs of laboratory customers (including weights and measures programs). However, the job has not been completed.

Metrologists continue to provide substantial and essential support to the NIST Office of Weights and Measures and the State Laboratory Program. Considering the potential effect on laboratory services, we feel that this project requires additional support. Moreover, the potential : npact on NTEP laboratories regarding international agreements, mutual recognition, and compliance to ISO criteria heightens the importance of the activities.

Only so much work can be done by mail and within the laboratory. Unless we get pulled away from the day-to-day tasks, other priorities interfere with these essential and supportive efforts. We propose to continue our work by phone, fax, mail, and within the regional and national group meetings, but feel that periodic off-site meetings are critical. During 1993, we propose a three-day meeting at the end of the SWAP regional meeting (October $9-11,1993$ ) to further assist with the integration/implementation of the ISO standards into the SLP program, associated documentation, and the NTEP program. While we can continue to function in segments at the regional and national meetings, it is important for the entire group to participate on this focused topic periodically. We would anticipate at least one meeting on an annual basis, which could coincide at the beginning or end of another scheduled meeting, in order to be cost efficient.

Ongoing support is requested in the form of changing the organization from a "Task Force" to a "Working Group" with stated functions and purposes, without a fixed life-cycle, and continuing to report and provide recommendations to the Executive Committee.

(The Executive Committee restored funding to enable this group to proceed in the current direction.)

\section{Miscellaneous Items Presented}

The items listed below were presented and discussed at the metrology sessions. These items were also circulated to all metrologists with the annual accreditation memorandum. Review and comments were requested.

Evaluation and Accreditation of State Weights and Measures Laboratories - a paper prepared by Georgia Harris and presented at the 1993 Annual Meeting of the National Conference of Standards Laboratories

Long Range Plan for the NIST/OWM State Laboratory Program - current tasks and long term objectives and projects for the State Laboratory Program was circulated for comment and review

Comparison of Environmental Criteria - a comparison of a number of laboratory environmental standards that will be reviewed for determining criteria for inclusion into Handbooks 145 and 143 
Metrology Working Group

- Draft Guide for Round Robins - a draft for coordinating, planning, implementing, analyzing, and reporting results of interlaboratory tests

- $\quad$ Draft SOP for Railroad Test Cars - presented by Bruce Adams (MN) from work he and Vic Gerber (WY) have been consolidating

Handbook 105-4, 4th Draft - presented by Carl Gile (KS) based on editorial comments and reformatting work he has done

\section{Participants}

Bruce Adams

Jim Akey

Rick Calkins

Randy Crosser

David Dikken

Mike Dynia

L.F. Eason

Herb Eskew

Ken Fraley

Carl Gile

Mike Grenier

Mel Henkel

Karl Herken
$\mathrm{MN}$

WI

RLWS

Ohaus

$\mathrm{MN}$

$\mathrm{CT}$

$\mathrm{NC}$

TX

OK

KS

$\mathrm{NH}$

Liquid Controls

KS
Gary Kliment

Diane Lee/London

Steve McGuire

Kelly Moody

J. W. Noble

Mary Saunders

Billy Sullivant

Bob Traettino

Jerry Wang

Dick Weber

Randy Wise

Bob Wittenberger
NE

MD

IL

AZ

Silas Mason Co

NIST

AR

Liquid Controls

A \& D Engr

$3 \mathrm{M}$

KY

MO 


\title{
Report of the Resolutions Committee
}

\author{
Glen H. Jex, Chairman \\ Chief, Idaho Bureau of Weights and Measures
}

Reference

Key No.

700

\section{GENERAL}

The resolutions committee wishes to express the appreciation of the members of the National Conference on Weights and Measures to those who contributed their time and talents toward the arrangements for the conduct of, and the success of this 78 th Annual Meeting. Special votes of thanks are extended:

(1) to Emanuel Cleaver, Mayor of Kansas City, Missouri, for his address to the Conference and the gracious hospitality extended to Conference members and guests;

(2) to Donald L. Jacka, Jr., Acting Secretary, State of Kansas Department of Agriculture, for his welcoming remarks in support of the work of the Conference, of his own staff, and of weights and measures in general;

(3) to Les Barrows, Director of Weights and Measures, Missouri Department of Agriculture, for his welcoming remarks on behalf of the Missouri Secretary of Agriculture; his staff; and to Sergeants at Arms, John Albert and John Shepard;

(4) to Dr. Arati Prabhakar, Director of the National Institute of Standards and Technology (NIST), for her remarks to the membership, delivered on her behalf by Dr. Edward Heffron, State of Michigan, and for continuing the NIST partnership for the future with NCWM; to Dr. Prabhakar for her vision for the future of weights and measures and her expressions of NIST commitment to strengthen its partnerships with business, Federal, State, and local governments in the area of weights and measures;

(5) to the Kansas Department of Agriculture, Weights and Measures Division, for the extraordinary assistance in preparation for and conduct of the 78th Annual Meeting, particularly the work of DeVern Phillips, Sealer for the State of Kansas, along with his staff;

(6) to Robert Gunja, Standards Administrator, Kansas City, Kansas, Weights and Measures, and his staff for their tireless efforts toward the success of this 78th Annual Meeting;

(7) to our international speakers Graham Harvey, Bernard Athané, Kristine French, and Robert Bruce for their informative and enlightening presentations;

(8) to officers and appointed officials of the National Conference on Weights and Measures for their assistance and service toward progress on national issues;

(9) to committee members for their efforts throughout the past year preparing and presenting their reports; to the subcommittees, task force, and work groups for their discerning and appropriate recommendations;

(10) to regulatory officials of State and local jurisdictions for the advice, interest, and support of weights and measures administration in the United States; 
(11) to representatives of business and industry for their cooperation and assistance in committee and Conference work; to the associate membership organization for the hospitality exhibited in sponsored social functions; particularly Fairbanks Scales for the tour of their outstanding facilities;

(12) to the staff of the Ritz-Carlton Hotel for their assistance and courtesies, all of which contributed to the enjoyment and comfort of the delegates within their fine facilities; and

(13) to the National Institute of Standards and Technology and the Office of Weights and Measures for their outstanding assistance in planning and conducting the work and program of the National Conference on Weights and Measures, especially to Ann Turner, Elizabeth Loveless, and Michele Krebs for their professional and hospitable conduct of the administrative operations of the meeting.

The following Resolution is presented in its entirety for consideration of the members of the Conference.

\section{Nutrition Labeling and Education Act of 1990 (NLEA)}

Whereas, the final rules of the Nutrition Labeling and Education act (NLEA) of 1990 relate to certain procedures established by the Food and Drug Administration (FDA) which grant exemption from the Federal preemption clauses of the NLEA and to the procedures that will permit States to enforce Federal labeling laws; and

Whereas, the Laws and Regulations Committee met with FDA representatives to determine the impact of the NLEA on State and local weights and measures activities; and

Whereas, following thorough review, the following Resolution is recommended by the Laws and Regulations Committee for passage by the Conference; now, therefore, be it

Resolved by the 78th Annual Conference that Weights and Measures Officials allow product manufacturers the period between February 14, 1994, (effective date of the SI amendments to the Uniform Packaging and Labeling Regulations and those published under the Fair Packaging and Labeling Act) and the implementation date of the Nutrition Labeling and Education Act of 1990 (NLEA) regulations for label preparation and updating in order that SI amendments may be implemented in conjunction with the effective date of NLEA regulations. The tentative effective date of the NLEA regulations is May 8, 1994; and it is further

Resolved that enforcement between May 8, 1994, and November 8, 1994 (6 months, or an alternate time period deemed appropriate) be considered in the form of letters stating not only the area of non-compliance, but also the correct way to be in compliance.

G. H. Jex, Idaho, Chairman

R. Kelley, City of New York, New York

C. Fulmer, South Carolina

M. Grenier, New Hampshire

R. Gunja, Kansas City, Kansas

W. Lagemann, Delaware

B. Martell, Vermont

R. Philmon, Illinois

E. Price, Texas

A. Thompson, Alaska

J. Mindte, NIST, Coordinator

\section{Resolutions Committee}




\title{
Report of the Nominating Committee
}

\author{
Sidney A. Colbrook, Chairman \\ Weights and Measures Program Manager \\ Illinois
}

Reference

Key No.

\section{0}

The Nominating Committee met during the Interim Meeting at the Hyatt Regency, Bethesda, Maryland, and nominated the persons listed below to be officers of the 79th Conference. In the selection of nominees from active membership, consideration was given to professional experience, qualifications of individuals, Conference attendance and participation, and other factors considered to be important. Regional representation is no longer taken into account during the selection process.

The following slate of officers was selected by unanimous vote of the Nominating Committee:

CHAIRMAN-ELECT:

VICE-CHAIRMEN:

EXECUTIVE COMMITTEE:

TREASURER:

S. Colbrook, Illinois, Chairman

C. Conrad, Jr., New Jersey

G. Diggs, Virginia

C. Gardner, Jr., Suffolk County, New York

S. Rhoades, Arizona

K. Simila, Oregon

N. David Smith, North Carolina
James C. Truex, Ohio

Clayton F. Davis, Maine

Ken Fraley, Oklahoma

Monty H. Hopper, Kern County, California

Alan Porter, Wisconsin

Aves D. Thompson, Alaska

Carol P. Fulmer, South Carolina

Charles A. Gardner, Jr., Suffolk County, New York

\section{Nominating Committee}




\title{
Report of the Auditing Committee
}

\author{
Edwin M. Hanish \\ Inspector, Laporte County Weights and Measures \\ Indiana
}

Reference

Key No.

\section{0}

The Auditing Committee met on Sunday afternoon, January 14, 1993, during the NCWM Interim Meeting, for the purpose of reviewing the financial reports of the Conference Treasurer, Charles A. Gardner, Jr.; Ann H. Turner, Weights and Measures Coordinator, was also in attendance.

Committee members R. Gunja, Kansas City, Kansas, and J. H. Eskew, Texas, were unable to attend the meeting. G. W. Diggs, Virginia, and C. Conrad, New Jersey, graciously agreed to serve in their absence.

The Auditing Committee finds the financial reports of the Conference Treasurer to be in accordance with Conference procedure and correct.

E. Hanish, Indiana, Chairman

J. H. Eskew, Texas

R. Gunja, Kansas City, Kansas

J. Mindte, NIST, Coordinator

\section{Auditing Committee}




\section{Treasurer's Report}

\begin{tabular}{|c|c|c|}
\hline \multicolumn{3}{|c|}{ Trail Balance as of $12 / 31 / 92$} \\
\hline \multicolumn{3}{|c|}{ Income Accounts } \\
\hline 411.1 & Annual Registration & $\$ 27,800.00$ \\
\hline 411.2 & Interim Registration & $\$ 8,050.00$ \\
\hline 482.1 & Government Member Fees & $\$ 64,690.00$ \\
\hline 412.2 & Associate Member Fees & $\$ 52,815.00$ \\
\hline 413 & Interest & $\$ 3,027.73$ \\
\hline 416 & Associate Member Account & $\$ 13,756.35$ \\
\hline 416 & Other & $\$ 0.00$ \\
\hline $4 \llbracket 1.1$ & Annual Specials & $\$ 9,921.50$ \\
\hline 481.2 & Interim Specials & $\$ 213.72$ \\
\hline 481.3 & Receptions/Meeting Rooms & $\$ 4,400.25$ \\
\hline 482.1 & NTP Modules & $\$ 931.00$ \\
\hline 482.2 & NCWM Modules & $\$ 8,251.00$ \\
\hline 482.1 & Handbook 133 3rd Edition & $\$ 806.25$ \\
\hline 483 & NTEP Operations & $\$ 1,600.00$ \\
\hline 484 & NTP Seminar & $\$ 1,630.00$ \\
\hline 485 & Promotional & $\$ 110.00$ \\
\hline 486 & Grain Coop Agreement & $\$ 8,511.36$ \\
\hline Total & & $\$ 206,514.16$ \\
\hline
\end{tabular}




\begin{tabular}{|c|c|c|}
\hline \multicolumn{3}{|c|}{ Trial Balance as of $12 / 31 / 92$} \\
\hline \multicolumn{3}{|c|}{ Expense Accounts } \\
\hline \multicolumn{3}{|c|}{511 - Annual } \\
\hline 511.1 & Hotel/Food Services & $\$ 15,877.39$ \\
\hline 511.2 & Equipment/AV/Supplies & $\$ 3,475.87$ \\
\hline 511.3 & Personnel/Photo & $\$ 1,419.25$ \\
\hline 511.4 & Print/Copy & $\$ 3,027.89$ \\
\hline 511.5 & Awards & $\$ 4,819.19$ \\
\hline 511.6 & Treasurer Committee Expenses & $\$ 187.00$ \\
\hline 511.7 & Print Announcement & $\$ 5,631.40$ \\
\hline Total 511 & & $\$ 34,437.99$ \\
\hline \multicolumn{3}{|c|}{512 - Interim } \\
\hline 512.1 & Hotel/Food Services & $\$ 14,234.75$ \\
\hline 512.2 & Equipment/Personnell/Printing/Misc. & $\$ 224.50$ \\
\hline 512.3 & Executive Committee & $\$ 3,541.20$ \\
\hline 512.3 & Laws and Regulations Committee & $\$ 1,468.90$ \\
\hline 512.5 & Specificatons and Tolerances Committee & $\$ 2,114.90$ \\
\hline 512.5 & Education Committee & $\$ 1,652.70$ \\
\hline 512.7 & Liaison Committee & $\$ 643.20$ \\
\hline 512.3 & Other \& Task Forces & $\$ 2,381.70$ \\
\hline 512.9 & Print Agenda & $\$ 5,662.63$ \\
\hline \multicolumn{2}{|l|}{ Total 512} & $\$ 31,924.48$ \\
\hline \multicolumn{3}{|c|}{513 - Committee Meetings } \\
\hline 513.1 & Executive Committee/Board of Govoners & $\$ 1,531.18$ \\
\hline 513.2 & Laws and Regulations Committee & $\$ 0.00$ \\
\hline 513.3 & Specifications and Tolerances Committee & $\$ 3,539.64$ \\
\hline 514.6 & Education Committee & $\$ 0.00$ \\
\hline 514.5 & Liaison Committee & $\$ 0.00$ \\
\hline 514.6 & NTETC & $\$ 11,980.70$ \\
\hline 513.7 & Annual & $\$ 0.00$ \\
\hline \multicolumn{2}{|l|}{ Total 513} & $\$ 17,051.52$ \\
\hline \multicolumn{3}{|c|}{514 - Task Forces/Specific Committees } \\
\hline 513.1 & 21 st Century & $\$ 4,293.90$ \\
\hline 514.5 & Privatization Working Group & $\$ 2,246.91$ \\
\hline 514.6 & Petroleum Sub Committee & $\$ 4,207.49$ \\
\hline 513.7 & ISO $9000 \mathrm{TF}$ & $\$ 3,546.80$ \\
\hline 514.5 & USA/Canada Working Group & $\$ 3,319.48$ \\
\hline 514.9 & Miscellaneous & $\$ 1,164.10$ \\
\hline \multicolumn{2}{|l|}{ Total 514} & $\$ 18,778.68$ \\
\hline \multicolumn{3}{|c|}{515 Chairman/Chairman-Elect } \\
\hline 515.1 & Chairman & $\$ 8,550.75$ \\
\hline 515.2 & Chairman-Elect & $\$ 10,000.00$ \\
\hline
\end{tabular}




\begin{tabular}{|c|c|c|c|}
\hline 515.3 & \multicolumn{2}{|l|}{ Chairman Breakfasts } & $\$ 144.50$ \\
\hline \multicolumn{3}{|l|}{ Total 515} & $\$ 18,695.25$ \\
\hline \multicolumn{4}{|c|}{516 - Administration } \\
\hline 516.1 & \multicolumn{2}{|l|}{ Equipment/Supplies/Stat } & $\$ 1,407.38$ \\
\hline 516.2 & \multicolumn{2}{|l|}{ Contracts/Personnel } & $\$ 29,993.31$ \\
\hline 516.3 & \multicolumn{2}{|l|}{ Mail/P.O. Box } & $\$ 273.52$ \\
\hline 516.4 & \multicolumn{2}{|l|}{ Treasury Bond } & $\$ 0.00$ \\
\hline 516.5 & \multicolumn{2}{|l|}{ Bank Charges } & $\$ 17.50$ \\
\hline 516.6 & \multicolumn{2}{|l|}{ National Training Program } & $\$ 1,024.00$ \\
\hline 516.9 & \multicolumn{2}{|l|}{ Miscellaneous } & $\$ 156.48$ \\
\hline \multicolumn{3}{|l|}{ Total 516} & $\$ 32,872.19$ \\
\hline \multicolumn{4}{|c|}{517 - Printing/Publications } \\
\hline 517.1 & \multicolumn{2}{|l|}{ Membership } & $\$ 2,089.50$ \\
\hline 517.2 & \multicolumn{2}{|l|}{ NIST Printing } & $\$ 769.30$ \\
\hline 517.3 & \multicolumn{2}{|l|}{ Consumer Pamphlet } & $\$ 4,500.00$ \\
\hline 517.4 & \multicolumn{2}{|l|}{ Handbook 44 and 130 Video } & $\$ 4,916.33$ \\
\hline 517.9 & \multicolumn{2}{|l|}{ Miscellaneous } & $\$ 0.00$ \\
\hline \multicolumn{3}{|l|}{ Total 517} & $\$ 12,275.13$ \\
\hline \multicolumn{4}{|c|}{518 - Train-the-Trainers } \\
\hline 518.1 & \multicolumn{2}{|l|}{ Train-the Trainers } & $\$ 3,327.48$ \\
\hline 518.2 & \multicolumn{2}{|l|}{ Training } & $\$ 0.00$ \\
\hline \multicolumn{3}{|l|}{ Total 518} & $\$ 3,327.48$ \\
\hline \multicolumn{4}{|c|}{581 - Special Events } \\
\hline 581.1 & \multicolumn{2}{|l|}{ Annual } & $\$ 7,599.67$ \\
\hline 581.4 & \multicolumn{2}{|l|}{ Joint Outing } & $\$ 11,145.15$ \\
\hline \multicolumn{3}{|l|}{ Total 581} & $\$ 18,744.82$ \\
\hline & $582-\mathrm{P}$ & blications & \\
\hline 582.4 & Modules & & $\$ 2,388.03$ \\
\hline 582.2 & NCWM Publications & & $\$ 2,670.14$ \\
\hline 582.3 & Videos & & $\$ 357.16$ \\
\hline 582.4 & Handbook 133 3rd Edition & & $\$ 0.00$ \\
\hline Total 582 & & & $\$ 5,415.33$ \\
\hline 583 & NTEP Operations & & $\$ 16,179.73$ \\
\hline 584 & NTP Seminars & & $\$ 2,424.50$ \\
\hline 585 & Promotions & & $\$ 0.00$ \\
\hline 586 & Grain Equipment Coop Agre & & $\$ 14,535.90$ \\
\hline Total Expenses & & & $\$ 226,663,00$ \\
\hline Associate Account & $\$ 8,878.65$ & & alances \\
\hline & & $\overline{E A B}$ & $\$ 59,583.61$ \\
\hline Start of Year Bal. & $\$ 119,896.20$ & Signet & $\$ 314.24$ \\
\hline Income & $\$ 206,514.16$ & $C D \# 1$ & $\$ 27,277.22$ \\
\hline Expenses & $\$ 226,663.00$ & $\mathrm{CD} \# 2$ & $\$ 12,572.29$ \\
\hline Current Balance & $\$ 99,747,36$ & Current Balance & $\$ 99,747.36$ \\
\hline
\end{tabular}




\section{Treasurer's Report}

Grant Account

1992

\begin{tabular}{|l|l|l|l|}
\hline Beginning Balance & Deposits & Payments & Closing Balance \\
\hline \hline$\$ 2,473.76$ & $\begin{array}{l}\$ 20,819.18 \\
(\text { Interest }=\$ 49.67)\end{array}$ & $\$ 18,725.99$ & $\$ 4,566.95$ \\
\hline & & & \\
\hline
\end{tabular}




\title{
New Chairman's Address
}

\author{
Thomas F. Geiler \\ Director, Consumer Affairs \\ Town of Barnstable, MA
}

I would like Allan Nelson to remain on the podium please, and I request that Jim Truex and Chris Guay join us for the remainder of the session. Jim is Manager of the Weights and Measures Section of the Ohio Department of Agriculture and is your Chairman-Elect for the upcoming year. Chris is Regulatory Affairs Manager for Procter and Gamble Company in Cincinnati, Ohio, and is your Chairman of the Associate Membership Committee.

Allan, Jim, Chris and I, along with Dr. Carroll Brickenkamp and her OWM staff, will form the team that will guide the conference through the next year. Over the last several years, the Conference workload has grown significantly. The several Conference Chairmen over this period have seen the wisdom of involving the Chairman Elect and the Chairman of the Board of Governors, as well as the Chairman of the Associate Membership Committee, in the various issues facing the Conference. Keeping the leadership team informed and utilizing their expertise in addressing issues has proven successful, and I intend to continue down that same road.

The first official act of each incoming chairman is to present a certificate of appreciation to the incoming Chairman of the Board of Governors for his service as Conference Chairman. As Allan has indicated earlier, we have known each other for approximately 20 years. I was just a young boy when I first met Allan. He was then a metrologist and I was a new weights and measures official from a small jurisdiction on Cape Cod. We were both members of the newly formed Northeastern Weights and Measures Association. At the time, I couldn't figure out why a metrologist would be attending a meeting of weights and measures officials. Well, 1 have learned a lot over the last 20 years, including the fact that a metrologist doesn't predict the weather. Allan is now the Director of Weights and Measures for the State of Connecticut and I am still a weights and measures official from a small jurisdiction on Cape Cod.

While many of us have had great difficulty in maintaining funding levels for our programs, Allan has successfully expanded the Connecticut weights and measures programs into new areas. He has successfully incorporated the National Training Program in his State, improving the professional qualifications of his entire staff. He has unselfishly volunteered his energies and skills to the Northeastern Weights and Measures Association and the National Conference on Weights and Measures. For the last year, Allan has served as your chairman and in that capacity has set a standard that will be very difficult for future Conference Chairmen to equal.

Allan, if you would step forward please, it is my pleasure and privilege to present to you this Certificate of Appreciation from the members of the NCWM for your dedicated service and your leadership as Conference Chairman during the 78th Annual National Conference on Weights and Measures. On behalf of the entire membership I thank you for a job well done and I look forward to your continued participation as Chairman of the Board of Governors and member of the Executive Committee.

It is a great privilege and honor for me to stand before you as Chairman of this organization. I take the responsibility seriously and pledge to serve you to the best of my ability. I will work closely with the entire leadership team to continue to make our organization the best that it can be. The National Conference on Weights and Measures is a standards writing organization sponsored by NIST. The standards adopted by the Conference are voluntary standards and have no force of law on their own. However, standards adopted by this organization become the laws and regulations of the various States and some are also adopted by Federal agencies, becoming Federal law. This concept has proven successful over the long history of the Conference.

The defacto legislative activities of the NCWM make the Conference unique in the governmental regulatory scheme. Its value, and even its necessity, is recognized by the States, by industry, by consumer groups and by agencies of the Federal government, and even beyond our borders by foreign governments and international treaty organizations. We have a right to be proud of our organization and its accomplishments and we must put more energy into making the work 
of the Conference known to a wide audience.

I have chosen "Consensus Through Communication" as the theme for the 79th Annual Conference. I believe that the success of this body can be attributed, in part, to our unique process of utilizing consensus as the basis for promulgating laws and regulations. The coming together of regulatory officials, device manufacturers, device users, and consumer representatives for the purpose of developing laws and regulations which will work for all parties concerned, is a proven winner. Our process is one which can and should stand as a model regulatory function. Over the years we have refined our process and improved our success.

The work of the National Type Evaluation Program Technical Committees is an example of our success. The diverse membership of these groups have allowed extremely technical issues to be developed and refined through the consensus process. This process of open communications frequently results in issues reaching the standing committee so well developed that the standing committee is able to dispose of the item through their consent calendar. Our willingness to talk to each other and work together to solve mutual problems at the Conference level should encourage us to do the same in our home jurisdictions. Working with local industry, retailers, and consumer groups can prove just as successful at home as it does here at the national level.

The Conference faces many new challenges that will be addressed by the various committees, task forces, and working groups. The two greatest challenges we face immediately are, funding for weights and measures jurisdictions and funding for the Conference. The reduced revenues of State and local government have caused a need to reduce government spending. It is no longer sufficient justification to fund a program simply because a law exists mandating the program. Budget requests are scrutinized carefully today and most often there is less revenue available than there are requests for funding. Programs with popular support from the public, such as Public Safety, Public Health, and Education, receive the most media attention and are also the subject of heavy outside lobbying activities. Entitlement programs, debt and interest obligations, and capital programs seem to fall into second place on the priority list, while general government expenses receive the lowest priority.

Weights and measures programs generally fall into the third category and must compete for budget dollars along with the rest of the general government function. More and more legislators are demanding that each program justify its benefit to society in general, before allocating scarce budget dollars. Budget justification, and cost of service analysis, has not been easy for many weights and measures programs. For many reasons we have not kept the type of data necessary to clearly substantiate the value of the program. We must commit to changing the way we collect and report data. We all know the value of a weights and measures program. We all know of the need for a level playing field in the marketplace. We all know of the demand for equity in the marketplace and we all know of the potential overcharges that can exist in an unregulated marketplace. However, few of us can produce the data that substantiates the value of a program. This we must begin to do. Many of us will have difficulty in gathering additional data.

I have asked Allan Nelson to assume the Chair of the Privatization Working Group, and I have requested that he steer that group through the process of developing a model format for data collection and reporting. The work that has been done by the State of Washington Office of Budget Management will serve as a good starting point. I believe that it is important that we not only adjust the type of information and records we keep, but that we also do it in some uniform fashion so that different jurisdictions will have comparable data.

I have also asked Chip Kloos to join the Privatization Working Group to assist in this process. Chip's background and experience in statistical analysis should prove very helpful to the group. It is my hope that by this time next year the Conference will be able to provide its members with a model data collection outline that will allow the individual jurisdictions to produce indisputable numbers that will justify the value of the program.

The second funding crisis we face is the escalating cost of the operation of the Conference and how we fund that. You have all heard the discussions on establishing an NTEP CofC maintenance fee, and proposals to increase the Conference registration fee and possibly even increasing Conference dues.

The NTEP maintenance fee should not be considered additional revenue. These moneys are intended to be reimbursement to the Conference for the operational costs of NTEP. It will be a year or two before we see how this fee plays out and what the actual impact will be. These additional fees will be used to pay NTEP expenses only and will 
not be available for other Conference expenses.

A part of the increased cost of operating the Conference is related to reduced support from NIST in the form of a stagnant OWM budget over the last several years. We are told that OWM may receive a funding increase of approximately one million dollars in FY' 94 , beginning in October. We are very grateful for the increase, but we realize that the majority of that money, if in fact it is received, will be earmarked to bolster existing programs.

We must carry our message of concern to NIST and to Congress, if we are to be successful in the future. As we continue to expand our programs in response to the needs of both our public and private sector members, we increase the need for additional technical and clerical support from OWM. The OWM staff has done an outstanding job of meeting the challenge of the increased workload. Without additional staff they will not be able to continue to meet our growing needs.

The need for a computer hot line that will improve and expand on WAMIS and allow OWM and the jurisdictions to share information, is critical. Only NIST can make this a reality. Additional NIST resources are needed for training activities. We have an excellent training program that is becoming stale on the shelf because many States do not have the resources to deliver the training. Efforts to provide train the trainer sessions, and enhance the modules with video additions have helped, but have not solved the problem. I believe we need a NIST supported national weights and measures training facility if we are to achieve uniformity. Federal assistance in delivering structured training to weights and measures officials in a uniform manner should be a long-range goal.

We have established strict criteria for minimum qualifications for personnel involved in metrology functions and instituted the programs to train the officials and to provide ongoing training. The quality of our metrology programs has increased significantly over the last several years as a result of the NIST training program. This program could easily be expanded into a national training facility.

If a good weights and measures program starts with a quality metrology function, can that program succeed without that same quality in the field enforcement program? We must commit our energies to improving the training resources for field inspectors. In order to achieve real uniformity, we must provide the field inspector with the same level of training, the same level of confidence, the same level of professionalism, that we commit to our laboratory function.

In order to accomplish this we must convince NIST and Congress, of the benefit of a strong weights and measures program to the States and our national economy. We have promised our business community, and ourselves, that we would someday reach our goal of uniformity. I will be asking our leadership team and I will be asking all of you to assist in bringing our message to NIST and to Congress.

This Conference has accomplished great things over the years by working together and communicating with each other for a common goal. We can achieve our goals if you will help me to send a strong message to the people that can make it happen. I know I can count on your help. I have asked several of you to accept additional Conference responsibility and you have accepted. Those individuals that have accepted assignments are:

\section{Appointments}

Specifications and Tolerance Committee

Ronald D. Murdock, North Carolina (5)

Laws and Regulations Committee

Robert Gunja, Kansas City, Kansas (5)

Education, Administration and Consumer Affairs

Committee

Bruce Martell, Vermont (5)

\author{
Auditing Committee \\ Raymond Kalentkowski, CT (3) \\ Budget Review Committee \\ Harvey M. Lodge, Cargotec, Inc. (2) \\ N. David Smith, NC (2) \\ Charles A. Gardner, Suffolk County, NY (Treasurer) \\ Dr. Carroll S. Brickenkamp, NIST
}




\section{Chaplain}

William Lagemann, Delaware (1)

\section{Parliamentarian}

Kendrick J. Simila, Oregon (1)

\section{Nominating Committee}

Southern - N. David Smith, North Carolina

Southern - Maxwell H. Gray, Florida

Western - Sharon Rhoades, Arizona

Western - George S. Shefcheck, Oregon

Central - Sidney A. Colbrook, Illinois

Northeast - Charles A. Gardner,

Suffolk County, New York

\author{
Associate Membership Committee \\ Chairman - Chris Guay, Procter \& Gamble \\ Vice Chairman - Terry James, Cardinal Detecto \\ Secretary - Bill Corey, American Frozen Foods \\ Treasurer - Tom Stabler, Mettler-Toledo Inc. \\ Irving Bell, Coca Cola \\ Bill Braun, WRB Associates \\ Rich Davis, James River Corp. \\ Dave Quinn, Fairbanks Scale \\ Chip Kloos, Hunt Wesson \\ Jennifer Colman, Food Marketing Inst.
}

I stated earlier that it is a great privilege and honor for me to be serving as your Conference Chairman. I sincerely mean that. The strength of any organization is in its people and there is no finer group of people than the membership of this Conference. As I travel around the country and get to talk individually with you, I have grown to appreciate the dedication to weights and measures and the Conference, that all of you have. I have made many new friends in this organization and have been impressed with the number of retirees that return to our annual meeting and to the regional meetings to maintain old friendships. I look forward to the work ahead of us, because I know that I can count on the members of this organization to provide the assistance to get the job done.

I look forward to working with Allan, Jim, Chris and Carroll, as well as all of you during the upcoming year. I welcome your comments, your phone calls and urge you to contact me with your concerns or ideas.

The Interim Meeting will be held January 9-14, 1994 at the Hyatt Regency, Bethesda, Maryland. The 79th Annual Meeting will be held July 17-21, 1994 at the Doubletree Inn, San Diego, California.

I now would entertain a motion to adjourn.

I declare the 78th National Conference on Weights and Measures adjourned.

Thank you and travel safely. 


\author{
NCWM Annual Meeting \\ Ritz-Carlton Hotel - Kansas City, Missouri \\ July 18 - 22, 1993

\section{List of Participants}

ce Adams

rologist

Div of Weights \& Measures

7 Hwy 36

eville, MN 55113

phone: $612-639-4010$

$612-639-4014$

thael F. Adams

aager of Technical Support

banks Scales

E St Johnsbury Rd

ohnsbury, VT 05819

phone: 802-748-5111 x326

x: $\quad 802-748-5216$

ues H. Akey

e Metrologist

Dept of Agriculture

Box 78834702 University Ave(05)

Jison, WI 53707-7883

ephone: $608-267-3510$

$x: \quad 608-266-1560$

\section{n Albert}

roleum Inspector

I Dept of Agriculture

Box 101A Rt 1 Water Street

atsville, MO 65259-9772

ephone: $816-277-4417$

Ammons

Inspector II

Weights \& Measures

Box 662

xie, KS $67740-2570$

ephone: $913-267-4641$
Deidre Adams

Staff Product Planner

IBM Corp

2020 Yonkers Rd Dept G68 Bldg 602

Raleigh, NC 27604

Telephone: $919-301-7106$

FAX: $\quad 919-301-7145$

Member \# 11447

Joe Adriano

Standards Inspector

Kansas City KS Wghts \& Meas

701 North 7th Street

Kansas City, KS 66101

Telephone: $913-573-5080$

FAX: $\quad 913-573-5005$

\author{
Member \# 2414 \\ Robert Albers \\ Inspector \\ MO Dept Agriculture \\ Route 2 Box 71 \\ Half Way, MO 65663 \\ Telephone: 417-445-2552
}

Member \# 11502

Norman A. Alston

Manager P D Meter Sales

Daniel Flow Products Inc

9720 Old Katy Rd PO Box 19097

Houston, TX 77224

Telephone: 713-827-3857

FAX: $\quad 713-827-3880$

Member \# 1261

Ross J. Andersen

Assistant Director

NY Bureau of Wghts \& Meas

1 Winners Circle

Albany, NY 12205

Telephone: 518-457-3452

FAX: 518-457-5693
Member \# 13641

Member \# 700

(

Member \# 9823

Member \# 2590

Member \# 2994 
Sydney D. Andrews

Consultant

1133 Myers Park Dr

Tallahassee, FL 32301-4525

Telephone: 904-878-3928

Robert D. Arrington

Program Mgr Wghts \& Meas

WA Dept of Agriculture

PO Box 42560

Olympia, WA 98504-2560

Telephone: 206-902-1856

FAX: 206-902-2086

James K. Aust

Asst Dir Bridge Engineering

Burlington Northern RR

4105 N Lexington

Arden Hills, MN 55126

Telephone: 612-490-6063

FAX: $\quad 612-490-6017$

John A. Baker

Merchandise Admin Manager

Pier 1 Imports

301 Commerce Suite 600

Fort Worth, TX 76161-0020

Telephone: 817-878-8306

FAX: $\quad 817-332-5727$

Jules R. Balogh

Laboratory Manager

ITS/Caleb Brett

333 Dalziel Road

Linden, NJ 07036

Telephone: 908-925-8282

FAX: $\quad 908-862-4288$

Lester H. Barrows

Director Weights \& Measures

MO Dept of Agriculture

1616 Missouri Blvd

Jefferson City, MO 65102-0281

Telephone: $314-751-4316$

FAX: $\quad 314-751-0281$

Member \# 41

Ted M. Andrews

Member \# 1

Quality Assurance Manager

WAWA Inc

260 Baltimore Pike

Wawa, PA 19063

Telephone: $215-358-8180$

FAX: $\quad 215-358-8784$

Member \# 23514

Bernard Athane

Member \# 2

Director

Org Intl de Metrologie Legale

11 Rue Turgot

Paris, 75009050

Member \# 25544

Jose Luis Avilla-Perez

Member \# 2

Legal Metrology Sub Director

Direccion General De Normas

Puente De Tecamachalco

Mexico City DF, 53950

Telephone: 525-540-0451

Member \# 1195

Member \# 25483

Member \# 3926

John J. Bartfai

Director

NY Bureau of Wghts \& Meas

1 Winners Circle

Albany, NY 12205

Telephone: 518-457-3452

FAX: $\quad 518-457-4780$
Member \# 9

Inspector

MO Dept Agriculture

Box 100

Jasper, MO 64755

Telephone: 417-682-2026

Bruce B. Barrow

Technical Advisor

Court House Rd Code DA-T

Telephe: 703-746-7188

FAX: $\quad$ 703-746-6776

Member \# 2

Member \# 23 
ohn W. Beal

Goftware Group Leader

Mettler Toleo Inc

150 Dearborn Drive

Northington, $\mathrm{OH} 43005$

elephone: $614-438-4320$

AX: $\quad 614-438-4355$

Joyle D. Bell

nspector

Delaware Co Weights \& Measures

Room 208 County Building

Muncie, IN 47305

elephone: $317-747-7714$

Michael Belue

resident

selue Associates

'O Box 7012004 Liberty St

3onham, TX 75418

elephone: 903-583-9082

ally A. Bibb

Economist

Jatl Marine Fisheries Service

'O Box 21668

uneau, AK 99802-1668

elephone: $907-586-7229$

AX: $\quad 907-586-7131$

lichael Blacik

oirector

IN Div of Weights \& Measures

277 Highway 36

it Paul, MN 55113-3800

elephone: 612-639-4010

AX: $\quad 612-639-4014$

indel Bolten

hief Inspector

10 Dept of Agriculture

O Box 630

efferson City, MO 65102-0630

elephore: $314-751-5635$
Member \# 25561

Jim Behrendt

Agr Inspector II

Member \# 4667

KS Weights \& Measures

415 Delia

Minneapolis, KS 67467

Telephone: 913-267-4641

Member \# 7211

Irving Bell

Governmental Relations

Member \# 4473

Coca-Cola Co

PO Drawer 1734

Atlanta, GA 30301

Telephone: 404-676-2623

FAX: 404-676-8265

Member \# 691

Celeste Bennett

Member \# 9286

Motor Fuel Coordinator MI Dept of Agriculture P.O. Box 30017

Lansing, MI 48909

Telephone: 517-373-1060

FAX: 517-373-3333

Member \# 25557

Del W. Bissett

Member \# 16251

Vice President

SGS Control Services Inc

20 Lafayette Street

Carteret, NJ 07974

Telephone: 908-541-7200

Member \# 8924

Barbara J. Bloch

Special Assistant

CA Measurement Standard

8500 Fruitridge Rd

Sacramento, CA 95826

Telephone: 916-387-4241

FAX: $\quad 916-387-4260$

Member \# 10156

Peggy Boyer

Member \# 9819 
Harold D. Bradshaw

Inspector

Clark Co Wghts \& Meas

City County Bldg Room 314

Jeffersonville, IN 47130

Telephone: 812-283-6289

William D. Brasher

Senior Quality Control Analyst

Southern Co Services Inc

PO Box 2625 Bin B852

Birmingham, AL 35202

Telephone: 205-877-7653

FAX: 205-877-7795

Cathleen A. Brenner

FGIS

10383 N Executive Hills Blvd

Kansas City, MO 64153

Telephone: 816-891-0436

FAX: $\quad 816-891-8070$

Richard Brewster

Amoco Corp

4545 N Lincoln- Ln Pl Off Ctr \#116

Oklahoma City, OK 73105

Telephone: 405-848-0472

FAX: $\quad 405-557-7589$

Paul Broderick

Petroleum Inspector

MO Dept of Agriculture

932 West 34th Street

Kansas City, MO 64111-3612

Telephone: $816-454-8412$

Robert Bruce

Chief Weights \& Measures

Industry \& Science Canada Off

301 Laurier Ave West, 5th Fl

Ottawa, K1A 0C9 026

Telephone: 613-952-2625

FAX: 613-952-1736
Member \# 2738

Member \# 4417

Member \# 25573

Jeffery Brewer

Inspector

MO Dept of Agriculture

1324 Grandview Drive

Jefferson City, MO 65109-0431

Telephone: $314-751-9487$

Member \# 20538

Carroll S. Brickenkamp

Chief Office of Wts \& Meas

NIST

A617 Admin

Gaithersburg, MD 20899

Telephone: 301-975-4005

FAX: $\quad 301-926-0647$

Member \# 13267

Darryl L. Brown

Weights \& Measures Inspector

IA Dept of Agriculture

Henry A Wallace Building

Des Moines, IA 50319

Telephone: $515-281-5716$

FAX: $\quad 515-281-6800$

Member \# 3932

Norman R. Brucker

Regional Scale Inspector

Burlington Northern Railroad

4105 N Lexington Ave Ste 300

Arden Hills, MN 55126-6181

Telephone: $612-490-6090$

FAX: $\quad 612-490-6017$
Member \# 298 .

Member \# 101

Member \# 239

Member \# 114:

Member \# 9192 
bert $\mathrm{T}$. Brumbaugh

esident

stems Associates Inc

32 Industrial Dr

oertyville, IL 60048

lephone: 708-367-6650

X: $\quad 708-367-6960$

b Budny

erket Regional

od Lion

10 Executive Drive

isbury, NC 28144

lephone: 704-633-8250

nneth S. Butcher

eights \& Measures Coordinator ST

m Bldg 101/A617

ithersburg, MD 20899

lephone: 301-975-3991

301-926-0647

en Butler

ten Instruments

- Box 495

atam, IL 62629-0495

lephone: 217 483-4444

X: $\quad 217483-5130$

hard Calkins

nior Metrologist \& Manager

ze Lake Weighing Systems

1 West Coleman St

ce Lake, WI 54868

lephone: 715-234-9171 x11

715-234-6967

vern W. Carroll

unager Scale Operations

nois Central Railroad

I Gilmore Street

ntralia, IL 62801

lephone: 618-533-3319

$618-533-3329$
Member \# 297

Mark Buccelli

Regional Supervisor

Member \# 8926

MN Div of Weights \& Measures

2277 Highway 36

St Paul, MN 55113

Telephone: $612-639-4010$

FAX: $\quad 612-639-4014$

Member \# 25548

Charles A. Burns, Jr.

Chief Inspector

Member \# 7575

Birmingham Wghts \& Meas

City Hall Rm 207710 N 20th St

Birmingham, AL 35203

Telephone: 205-254-2246

FAX: 205-254-2925

Member \# 2512

Tina G. Butcher

Physical Scientist

NIST

A617 Administration Building

Gaithersburg, MD 20899

Telephone: 301-975-2196

FAX: $\quad 301-926-0647$

Member \# 5189

Sherman Cain

Inspector

MO Dept of Agriculture

2130 Sun Valley Dr

St Louis, MO 63136

Telephone: 314-751-4278

Member \# 9100

Charles H. Carroll

Assistant Director

MA Division of Standards

One Ashburton Place

Boston, MA 02108

Telephone: $617-727-3480$

FAX: 617-227-6094

Member \# 1356

Kim Carson

Asst Dir Standards \& Labeling Internatl Dairy Foods Assn

888 16th St NW 2nd Floor

Washington, DC 20006

Telephone: $202-296-4250$

FAX: $\quad 202-331-7820$

Member \# 8236

Member \# 10627

Member \# 4393

Member \# 25532 
Charles D. Carter

Prog Adm Agr Resources PICS

OK Dept of Agriculture

$2800 \mathrm{~N}$ Lincoln Blvd

Oklahoma City, OK 73105-4298

Telephone: 405-521-3864 x294

FAX: $\quad 405-521-4912$

Samuel E. Chappell

Standards Management

NIST

Bldg 101 Room A625

Gaithersburg, MD 20899

Telephone: 301-975-4024

FAX: $\quad 301-963-2871$

Fred P. Clem

Senior Inspector

Columbus Weights \& Measures

$50 \mathrm{~W}$ Gay St

Columbus, OH 43215-2821

Telephone: 614-645-7397

FAX: 614-645-3994

Sidney A. Colbrook

Wghts \& Meas Program Manager

IL Dept of Agriculture

PO Box 19281801 E Sangamon Ave

Springfield, IL 62794-9281

Telephone: $217-782-3817$

FAX: $\quad 217-524-7801$

\section{Jennifer Colman}

Mgr State Government Relations

Food Marketing Institute

800 Connecticut Ave N W

Washington, DC 20006

Telephone: 202-429-8268

FAX: $202-429-4549$

William J. Corey, Jr.

General Councel

American Frozen Foods

355 Benton Street

Stratford, CT 06497

Telephone: 203-378-7900

FAX: 203-386-8630
Member \# 9838

H. Penny Causgrove

Retired Sealer of Wts \& Meas

Member \# 3 City of New Haven

18 Davis St

New Haven, CT 06515

Telephone: 203-387-4913

Member \# 10610

Buddy Clark

Inspector

Hamilton Co Wghts \& Meas

18901 Eagletown Road

Westfield, IN 46074

Telephone: 317-896-9001

Member \# 169

Martin J. Clements

Owner

SteinLite Corporation

121 North 4th

Atchison, KS 66002

Telephone: 913-367-3945

FAX: $\quad 913-367-4523$

Member \# 47

G. Thomas Coleman

Program Mgr Wghts \& Meas

MD Dept of Agriculture

50 Harry S Truman Parkway

Annapolis, MD 21401

Telephone: $410-841-5790$

FAX: $\quad 410-841-2765$

Member \# 3251

David A. Cook

Quality Control Manager

Kraft General Foods Inc

1 Kraft Court

Glenview, IL 60025

Telephone: 708-646-4406

FAX: $\quad 708-646-6842$

Member \# 16337

Constantine Cotsoradis

Program Mgr Wghts \& Meas

MD Dept of Agriculture

50 Harry S Truman Parkway

Annapolis, MD 21401

Telephone: 410-841-5790

FAX: $\quad 410-841-2765$ 
rry Creason

spector

O Dept of Agriculture

$\mathrm{R}$ \#2 Box $25 \mathrm{AB}$

adison, MO 65263

lephone: 816-291-8619

ndall R. Crosser

etrology Engineer

aaus Corporation

Hanover Rd

rham Park, NJ 07932-0900

lephone: 201-377-9000

201-593-0359

ayton F. Davis

rector

E Div of Regulations

te House Station 28

igusta, ME 04333

lephone: $207-287-3841$

X: $\quad 207-287-7548$

chard L. Davis

gr Product Safety\&Compliance nes River Corp

15 Marathon Ave PO Box 899

enah, WI 54956-0899

lephone: 414-729-8174

$X: \quad 414-729-8089$

rbara J. DeSalvo

วervisor Weights \& Measures

1 Dept of Agriculture

15 East Main St Bldg \#5

ynoldsburg, $\mathrm{OH}$ 43068-3399

lephone: 614-866-6361

X: $\quad 614-866-4174$

nnie G. Dighera

mer/Operator

and D Proves It

7 Pershing

ina, KS 67401

ephone: $913-825-8305$
Member \# 9808

Charles F. Critzer

Inspector

Bartholomew Co Wghts \& Meas

Cnty Off Bl-Rm 305 440-3Rd St

Columbus, IN 47201

Telephone: 812-379-1507

FAX: $\quad 812-379-1765$

Member \# 28526

A.R. Daniels

Director Industry Stds \& Rel

NCR Corp

1700 S Patterson Blvd WHQ-5

Dayton, $\mathrm{OH} 45479$

Telephone: 513-445-1310

FAX: $\quad$ 513-445-1418

Member \# 25

Member \# 3806

Vincent J. Del Giudice

President

Del Giudice \& Associates Inc

6620 N Waukesha Ave

Chicago, IL 60646-2829

Tele phone: $312-763-1183$

Member \# 3842

G.W. (Wes) Diggs

Superv VA Weights \& Measures

VA Weights \& Measures

PO Box 1163 Room 402

Richmond, VA 23209

Telephone: 804-786-2476

FAX: $\quad 804-786-1571$

Member \# 21833

David Dikken

Metrologist

MN Div of Weights \& Measures

2277 Hwy 36

Roseville, MN 55113

Telephone: 612-639-4010

FAX: $\quad 612-639-4014$
Member \# 9034

Member \# 13899

Member \# 163

Member \# 343

Member \# 968

Member \# 352

Member \# 9034

Member \#13899 
Loren Dobyns

Manager Plant \& Electrical

Thunder Basin Coal Co

PO Box 406

Wright, WY 82732

Telephone: $307-939-1300 \times 372$

FAX: $\quad 307-939-1300$

Jeff Dombach

Director of Engineering

Pennsylvania Scale Co

21 Graybill Rd

Leola, PA 17540

Telephone: 717-656-2653

FAX: $\quad$ 717-656-3216

\section{L.F. Eason}

Metrologist Standards Division

NC Dept of Agriculture

PO Box 27647 Dept SD

Raleigh, NC 27611

Telephone: 919-733-4411

FAX: $\quad 919-733-8804$

John J. Elengo

50 Surrey Drive

Cheshire, CT 08410

Telephone: 203-272-3430

FAX: 203-272-3430

Joycelyn M. Encarnacion

Division of Weights \& Measures

VI Dept Licensing \& Con Affs

Golden Rock Shopping Center

Christiansted St Cr, VI 00820

Telephone: 809-773-2226 X18

FAX: $\quad 809-778-8250$

Karen Ervin

Inspector

MO Dept Agriculture

104 Camellia

Cape Girardeau, MO 63701

Telephone: 314-335-5345
Member \# 12941

Donald Doherty

Member \# 25

Executive Director

CAFMA

$600 \mathrm{~S}$ Federal

Chicago, IL 60605

Telephone: 312-922-6222

Member \# 8250

Michael Dynia

Metrologist

CT Weights \& Measures

Rm G-17 State Off Bldg 165 Capitol

Hartford, CT 06106

Telephone: 203-566-5230

FAX: $\quad$ 203-566-7630

Member \# 3886

Steve K. Eckhardt

Product/Market Manager

Micro Motion Inc

196 South Brown Road

Long Lake, MN 55356-9134

Telephone: 612-475-0067

FAX: $\quad 612-475-2779$

Member \# 440

Dean F. Ely

District Supervisor

PA Dept of Agriculture

332 Washington Avenue

Jersey Shore, PA 17740

Telephone: 717-327-3560

FAX: $\quad 717-327-3436$

Member \# 12545

David C. English

President

Measurement Systems Intl

14240 Interurban Avenue South

Seattle, WA 98168-4660

Telephone: 206-433-0199

FAX: $\quad 206-244-8470$

Steve Erxleben MO Dept of Agriculture 2193 Spring Bluff Road

Sullivan, MO 63080

Telephone: $314-468-3575$ 
es H. Eskew

gram Mgr for Metrlolgy Labs

Dept of Agriculture

Cumberland Rd

tin, TX 78704

ephone: 512-462-1441

$512-475-1642$

ert K. Feezor

erintendent Scales

folk Southern Corp

ding Box 14299 Spring Street

unta, GA 30303

ephone: 404-527-2537

র: $\quad 404-527-2589$

nie Fierstein

Inspector Spec II

Div of Wghts \& Meas

94757

:oln, NE 68509

sphone: 402-471-4292

d Fitzgerald

oleum Inspector

Dept of Agriculture

rank Street

गn, MO 63084

phone: $314-583-8019$

ak Forrest

ector

Weights \& Measures

Capitol Avenue Rm G-17

iford, CT 06106

phone: 203-566-4778

tine L. French

Intl de Metrologie Legale

:ue Turgot

s 75009, France 050
Member \# 3435

John Falk

Ad Officer III Div Insp ACAP

KS Dept of Agriculture

2016 SW 37th Street

Topeka, KS 66611-2570

Telephone: 913-267-4641

Member \# 11200

Sy Feinland

SMTS

Pitney Bowes Inc

Parrot Dr

Shelton, CT 06484

Telephone: 203-925-5211

FAX: 203-925-5333

Member \# $10434 \quad$ Russell W. Fish

Inspector

MO Dept of Agriculture

Rt 1 Box 204

Puxico, MO 63960

Telephone: 314-222-3869

Member \# 13422

Robert L. Fonger

Senior Field Representative

Bennett Pump Co

2740 Wood Street

Muskegon, MI 49443

Telephone: 616-733-1302

FAX: $\quad 616-739-8832$

Member \# 7240

Ken L. Fraley

Stds Tech Ultra Prec Insp Dir

OK Bureau of Standards

2800 N Lincoln Blvd

Oklahoma City, OK 73105

Telephone: $405-521-3864 \times 370$

FAX: $\quad 405-521-4912$

Member \# 25553

Charles M. Frieze

Agr Inspector III

KS Weights \& Measures

1420 Coolidge

Wichita, KS 67203

Telephone: 913-267-4641
Member \# 7048

Member \# 3919

Member \# 8177

Member \# 11219

Member \# 10161

Member \# 4148

Member \# 817 
Wayne Fritts

Inspector

MO Dept of Agriculture

Box 205

Laquey, MO 65534

Telephone: 314-765-4866

Carol P. Fulmer

Assistant Commissioner

SC Dept of Agriculture

PO Box 11280

Columbia, SC 29211

Telephone: 803-737-2080

FAX: $\quad 803-737-2068$

Ruth G. Fuqua

Director of Quality Assurance

Flavorich

10140 Linn Station Road

Louisville, KY 40223

Telephone: 502-426-6455

FAX: $\quad 502-423-6790$

Charles A. Gardner

Director

Suffolk Co Wghts \& Meas

County Center N Bldg 340

Hauppauge, NY 11788

Telephone: 516-853-4621

FAX: $\quad 516-853-4578$

\section{Thomas F. Geiler}

Director

Barnstable Consumer Affairs

PO Box 2430230 South Street

Hyannis, MA 02601

Telephone: 508-790-6251

FAX: $\quad 508-778-2412$

Victor L. Gerber

Metrologist

WY Dept of Agriculture

2219 Carey Avenue

Cheyenne, WY 82002-0100

Telephone: 307-777-6586

FAX: $\quad 307-777-6593$
Quality Assurance Specialist

Ralston Purina Company Inc

Checkerboard Square - 4RN

St Louis, MO 63164

Telephone: 314-982-2916

FAX: $\quad 314-982-4072$

Member \# 4463

David B. Funk

Member \# 31

Branch Chief

USDA FGIS QARD QCT Branch

10385 North Exec Hills Blvd

Kansas City, MO 64153

Telephone: 816-891-8070

FAX: $\quad 816-374-6547$

Member \# 7918

Mark G. Galvin

Legal Counsel

NE Div of Weights \& Measures

PO Box 94757

Lincoln, NE 68509

Telephone: 402-471-2341

FAX: $\quad 402-471-2759$

Member \# 3438

Charles H. Gardner

President

Seraphin Test Measure

30 Indel Ave

Rancocas, NJ 08073

Telephone: $609-267-0922$

FAX: $\quad 609-261-2546$

Member \# 219

William G. GeMeiner

Manager-Weights and Measures

Chicago \& North Western RR

165 N Canal Street

Chicago, IL 60606

Telephone: 312-559-6133

FAX: $\quad 312-559-6149$

Carl W. Gile

Member \# 112

Assistant Metrologist

KS Weights \& Measures

2016 SW 37th St

Topeka, KS 66611-2570

Telephone: 913-267-0278
Member \# 25

Member \# 96t

Member \# 562 
rge Goode

ector

Dept of Agriculture

N Taylor

wood, MO 63122

phone: $314-822-2578$

rles H. Gray

ector

Dept of Agr Div W \& M

Box 326

-bon, MO 65441

phone: $314-732-5537$

is ard L. Greaves

onal Sales Manager

ch Industries Inc

Box 68236

inapolis, IN 46268-0236

phone: $317-873-3827$

ıvel Greenwell

oleum Inspector

Dept of Agriculture

tion A \& D

ry City, MO 64763

phone: $314-644-2530$

aael F. Grenier

rrvisor II

Dept of Agriculture

3ox 204210 Ferry St

zord, NH 03301-2042

phone: 603-271-3709

603-271-1109

stopher Guay

latcry Affairs Manager

ter \& Gamble Co

10 Grooms Road

innaii, OH 45242

phorie: 513-626-2222

513-626-1907
Member \# 12883

Member \# 10162

Member \# 13362

Member \# 10163

Member \# 77

Member \# 840

Darrell A. Guensler

Assistant Director

CA Measurement Standards

8500 Fruitridge Rd

Sacramento, CA 95826

Telephone: $916-387-4241$

FAX: $\quad 916-387-4260$

(nspection Service

Maxwell H. Gray 3125 Conner Blvd Lab 2

To4-488-9140

Richard D. Greek

Agr Commissioner Sealer

56 Sierra Way Suite A

( 93401

Telephone: 805-781-5910

Larry Gregory

Design Engineer

22037-0001

Telephone: 703-849-6206

FAX: 703-849-5645

Weights \& Measures

Telephone: 913-267-4641
Member \# 15317

Mm 1600

Chief Bureau of Wghts \& Meas

Member \# 7991

3225 Gallows Road Rm 2M202

Member \# 38 
Robert Gunja

Standards Administrator

Member \# 9956

Kansas City KS Wghts \& Meas

701 North 7th St

Kansas City, KS 66101

Telephone: 913-573-5080

FAX: $\quad 913-573-5005$

Edwin M. Hanish

Inspector

LaPorte Co Wghts \& Meas

119 Tilden Avenue

Michigan City, IN 46360

Telephone: 219-879-9486

James D. Harnett

Agr Commissioner \& Sealer

Orange Co Wghts \& Meas

1010 S Harbor Blvd

Anaheim, CA 92805-5597

Telephone: 714-447-7110

FAX: $\quad 714-774-2741$

Homer A. Harrison

Mettler-Toledo Inc

813 Kingston Court

Liberty, MO 64068

Telephone: 816-781-4476

FAX: $\quad 816-792-4476$

Ronald G. Hayes

Fuel Quality Program Adm

MO Dept of Agriculture

P.O. Box 630

Jefferson City, MO 65102

Telephone: 314-751-2922

FAX: $\quad 314-751-8307$

David K. Heck

Mgr Marketing Legs \& Regs

USA Products Co

575 Market St Room 2236

San Francisco, CA 94105-2856

Telephone: 415-894-0910

FAX: 415-894-5038

Member \# 109

Member \# 7774

Member \# 9061
Paul Hadyka

Industrial Specialist

USDA/FGIS

PO Box 964541400 Independence Ave

Washington, DC 20250-6454

Telephone: 202-720-0262

FAX: 202-720-1015

Melvin C. Hankel

Manager Engineering Support

Liquid Controls Corporation

105 Albrecht Drive

Lake Bluff, IL 60044-9951

Telephone: 708-295-1056

FAX: $\quad 708-295-1089$

Georgia Harris

Metrologist Office Wts \& Meas NIST

A617 Admin Bldg

Gaithersburg, MD 20899

Telephone: 301-975-4014

FAX: $\quad 301-926-0647$

Member \# 14756

Grahame Harvey

Deputy Director

Australian Natl Stds Commision

12 Lyon Park Rd PO Box 282

North Ryde New South, 2113

Telephone: 61-02-888-3922

FAX: $\quad 61-02-888-30$

John U. Hays

Director

AZ Dept of Weights \& Measures

9535 E Doubletree Ranch Rd

Scottsdale, AZ 85258-5539

Telephone: 602-255-5211

FAX: $\quad 602-255-1950$

Member \# 11242

A. James Hedman

Member \# 89

Investigator $2 \mathrm{Wghts} \&$ Meas

MN Dept of Public Service

2277 Highway 36

St Paul, MN 55113

Telephone: 612-639-4010

Member \# 9

Member \# 9:

Member \# 11

Member \# 23 
ward C. Heffron

rector Food Division

Dept of Agriculture

) Box 30017

nsing. MI 48909

lephone: $517-373-1060$

X: $\quad 517-373-3333$

rl Herken

ate Metrologist

Weights \& Measures

16 SW 37h Street

peka, KS 66611-2570

lephone: 913-267-0278

X: $\quad 913-267-2518$

fiuck Hildreth

\& A Scale Service

vy 183 PO Box 270

escent, IA 51526

lephone: 712-545-3461

X: $\quad 712-545-3343$

nneth R. Hoffer

esident

ffer Flow Controls Inc

7 Kitty Hawk Lane PO Box 2145

zabeth City, NC 27906-2145

lephone: 201-787-1997

on Hooker

ogram Supervisor

OD Dept of Agriculture

) Box 630

fferson City, MO 65102-0281

lephone: $314-751-4278$

X: $\quad 314-751-8307$

chael A. Horan

Iministrator

Weights \& Measures

30 W Michigan St

dianapolis, IN 46206

lephone: $317-633-0350$

X: $\quad 317-633-0776$
Member \# 2452

Doyle Heiney

Inspector

MO Dept of Agriculture

Route 2 Box 77

Summersville, MO 65571

Telephone: 417-932-4486

Member \# 2320

Marilyn J. Herman

President

Herman \& Associates

2300 M St NW Suite 800

Washington, DC 20037

Telephone: 202-775-1630

FAX: 202-293-3083

Member \# 22211

James Michae Hile

Assistant Director

AR Bureau of Standards

4608 West 61st St

Little Rock, AR 72209

Telephone: 501-324-9680

FAX: 501-562-7605

Member \# 7192

Frances P. Holland

Authorities \& Stds Adm

Schlumberger Technologies

825 Greenbriar Circle \#M

Chesapeake, VA 23320-2638

Telephone: $804-366-4400 \times 162$

FAX: $\quad 804-424-2746$

Member \# 2441

Monty H. Hopper

Director

Kern Co Weights \& Measures

1116 East California Avenue

Bakersfield, CA 93307

Telephone: 805-861-2418

FAX: $\quad 805-324-0668$

Member \# 8153

Cynthia Hotovy

Agricultural Inspector II

KS Weights \& Measures

1400 N Mill

Beloit, KS 67420

Telephone: 913-267-4641
Member \# 10167

Member \# 9091

Member \# 7153

Member \# 15654

Member \# 11132

Member \# 10618 
Thomas B. Hudson

Senior Vice President

Inspectorate America Corp

PO Box 87689

Houston, TX 77546-7689

Telephone: 713-944-2000

FAX: $\quad 713-947-0300$

Lewis J. Hutfles

PMEP Supervisor

KS Weights \& Measures

2016 SW 37th St

Topeka, KS 66611-2570

Telephone: 913-267-4641

FAX: $\quad 913-267-2518$

Jim Jackson

Inspector

MO Dept of Agriculture

608 Clay

Plattsburg, MO 64477

Telephone: $314-751-4278$

Jack Y. Jeffries

Consumer Protection Adm

FL Division of Standards

3125 Conner Blvd Room 133

Tallahassee, FL 32399-1650

Telephone: 904-487-2634

FAX: $\quad 904-922-8971$

Mark R. Joelson

General Counsel

Gasoline Pump Mfg Assn

1800 M Street N W

Washington, DC 20036

Telephone: 202-467-7240

FAX: 202-467-7176

Jean M. Johnson

Measurement Associate

American Petroleum Institute

1220 L Street NW

Washington, DC 20005-4070

Telephone: 202-682-8227

FAX: 202-682-8036
Member \# 25435

Richard M. Huff

Vice President Electronics

Universal Epsco Inc

1494 Ellsworth Ind Dr Box 93544

Atlanta, GA 30318

Telephone: 404-351-2740

FAX: 404-351-2899

Member \# 12756

Randall L. Hutton

Assoc Dir Community Affairs

Winn-Dixie Stores Inc

5050 Edgewood $\mathrm{Ct}$

Jacksonville, FL 32254-3699

Telephone: 904-783-5408

FAX: $\quad 904-783-5294$

Member \# 10628

W. Terry James

Vice Pres Engineering Services

Cardinal/Detecto

203 E Daugherty PO Box 151

Webb City, MO 64870

Telephone: 417-673-4631

FAX: 417-673-5001

Member \# 2199

Glen H. Jex

Chief

ID Bureau of Wghts \& Meas

2216 Kellogg Lane

Boise, ID 83712

Telephone: 208-334-2345

FAX: 208-334-2170

Member \# 4238

Gordon W. Johnson

Principal Regulatory Engineer

Gilbarco Inc

7300 West Friendly Avenue

Greensboro, NC 27420

Telephone: 919-547-5375

FAX: $\quad 919-547-5516$

Member \# 9935

Roy Johnson

Agricultural Inspector II

KS Weights \& Measures

HCR 66

Garden City, KS 67846-9866

Telephone: 913-267-4641
Member \# 10c

Member \# 111

Member \# 30

Member \# 72

Member \# 33

Member \# 81 
I F. Johnson ector of Marketing usortronics Inc

Arrow Grand Circle vina, CA 91722

ephone: 818-331-0502

X: $\quad 818-332-3418$

va W. Jones

sociate Director

t'l Assn Margarine Mfg

11 th St NW

shington, DC 20005

ephone: 202-785-3232

202-223-9791

ymond Kalentkowski

Jervisor Wghts \& Meas Div

Dept of Consumer Protection

te Office Bldg Consumer Prot

rtford, CT 06106

ephone: 203-566-4778

$X: \quad 203-566-7630$

nald E. Keefer

IEP Inspector

nsas Weights \& Measures

i N Nettleton

nner Springs, KS 66012

lephone: 913-267-4641

bert B. Kelley

puty Director Chief W\&M

C Dept of Consumer Affairs

Broadway 8th Floor

w York, NY 10004

lephone: $212-487-4328$

X: $\quad 212-487-4197$

bert L. Kessler

ec Director - Gen Counsel

estern Coal Trans Assn

) Box 176

nver, CO 80201

lephone: 303-694-6611

$303-220-1891$
Member \# 9899

Member \# 25540

Gerry A. Jorowski

Program Officer Consumer Prod Industry \& Science Canada Off

50 Victoria St Place Du Portage I

Hull Quebec, K1A 0C9

Telephone: 819-953-3645

Sr Design Enginee

Div-Dresser Industries

Telephone: 410-546-6699

FAX: $\quad 410-548-6913$
Member \# 11709

Member \# 9396

Member \# 25566

Distributing Specialist

Sterling Chemicals Inc

201 Bay Street S

Texas City, TX 77590

Telephone: 409-942-3801

FAX: $\quad 409-942-3880$

Telephone: 908-686-2960
Member \# 12834

Michael J. Keilty

Custody Transfer Manager

Micro Motion Inc

7070 Winchester Circle

Boulder, CO 80301

Telephone: 303-530-8231

FAX: $\quad 303-530-8209$

Member \# 228

Thomas W. Kelly

737 Evergreen Parkway

Union, NJ 07083

Member \# 11672

Member \# 28834

Member \# 11693

Brenda K. Kincaid

Program Manager II

Kansas City KS Wghts \& Meas

701 North 7th St

Kansas City, KS 66101

Telephone: 913-573-5080

FAX: 913-573-5005 
Gary Kliment

Metrologist

NE Div of Wghts \& Meas

P O Box 94757

Lincoln, NE 68509

Telephone: 402-479-4171

Rod Kober

V P Transportation

Continental Grain Co

222 S Riverside Plaza Ste 600

Chicago, IL 60606

Telephone: $312-207-5100$

FAX: $\quad 312-207-3840$

David Koets

Regional Supervisor

MN Div of Weights \& Measures

2422 Oakridge Court

Stillwater, MN 55082

Telephone: 612-639-4010

Michele Krebs

NIST

PO Box 4025

Gaithersburg, MD 20855

\section{Dennis Krueger}

Manager Industry Standards

NCR Scanner Development

2651 Satellite Boulevard

Duluth, GA 30136-5810

Telephone: 404-627-7743

FAX: $\quad 404-623-7827$

Walter E. Kupper

Director Tech \& Reg Affairs

Mettler-Toledo

69 Princeton-Htstown Rd POBox71

Hightstown, NJ 08520-0071

Telephone: 800-638-8537 x8861

FAX: $\quad 609-443-5972$
Member \# 4144

Member \# 25063

Joan A. Koenig

Weights \& Measures Coordinator

NIST

Rm A617 Admin Bldg

Gaithersburg, MD 20899

Telephone: 301-975-4007

FAX: $\quad 301-926-0647$

Member \# 8938

Member \# 23997

David James Krejci

Executive Vice President

Grain Elevator \& Processing

PO Box 15026 Commerce Station

Minneapolis, MN 55415-0026

Telephone: $612-339-4625$

FAX: $\quad 612-339-4644$

Member \# 4898

Michael Kumm

Division Director

SD Div of Comm Insp \& Reg

118 West Capitol

Pierre, SD 57501-2080

Telephone: $605-773-3697$

FAX: 605-773-5825

Member \# 3930

Dan Kushnir

Sales Manager

Seraphin Test Measure

30 Indel Ave

Rancocas, NJ 08073

Telephone: 609-267-0922

FAX: $\quad$ 609-261-2546
Member \# 34

Member \# 24!

Member \# 40

Member \# 28?

Member \# 991 
Lliam W. Lackey

iffic Supervisor

tad Coated Board Inc

Box 940

enix City, AL 36868

lephone: 205-855-5224

on Lammers

e President Engineering

igh-Tronix

0 Armstrong Drive

irmont, MN 56031

lephone: $800-533-0456$

X: $\quad 517-238-4195$

\section{bert L. Land}

pector

derson Weights \& Measures

, Box 2100120 E 8th St

derson, IN 46011

lephone: 317-646-9839

$317-646-5668$

\section{Diane Lee}

J Weights \& Measures

Harry S Truman Pkwy

napolis, MD 21401

lephone: $410-841-5790$

\section{B. Letterman}

troleum Inspector

Dept of Agriculture

12 E Linwood

ringfield, MO 65804

lephone: 417-882-0602

yinond J. Lloyd

ecutive Director

ale Manufacturers Assn

2 Hungerford Dr \#36

cliville, MD 20850

lephone: 301-738-2448

X: $\quad 301-738-0076$

Member \# 25588

William Lagemann

Administrator Wghts \& Meas

Member \# 7976

DE Dept of Agriculture

2320 S Dupont Hwy

Dover, DE 19901

Telephone: 302-739-4811 x37

FAX: $\quad 302-697-6287$

Member \# 28830

Phillip J. Lampert

Member \# 25589

Ethanol Work Group

1648 Highway 179

Jefferson City, MO 65109-9020

Telephone: 314-635-8445

FAX: $\quad 314-893-4612$

Member \# 187

Member \# 25591

Member \# 1188

Member \# 7

Harvey M. Lodge

Cargotec Inc

307 Broadway

Swanton, OH 43558

Telephone: 419-825-2331

FAX: $\quad 419-826-8439$

Director of Engineering

715-234-9171

FAX: $\quad 715-234-6967$

ITS/Caleb Brett

PO Box 12973

, TX $7217-2973$

Telephone: 713-624-7000

Dean G. Lies

Engineer

Olathe, KS 66062

Telephone: 913-829-0033

FAX: $\quad 913-829-8791$
Member \# 12891

Rice Lake Weighing Systems

230 West Coleman PO Box 272

Richard S. Lee

Member \# 25603

Member \# 20546

Devices \& Inst In

Member \# 355 
John Lopez

Engineering Manager

DVCO Fuel Systems Inc

600 Diagonal Highway

Longmont, CO 80501

Telephone: 303-651-1895

FAX: $\quad 303-678-1754$

\section{Elizabeth Loveless}

Secretary

NIST

A617 Admin

Gaithersburg, MD 20899

Telephone: 301-975-4004

FAX: $\quad 301-926-0647$

\section{David Lunceford}

Laboratory Manager

SGS Control Services Inc

7305 South State Road 69

Mt Vernon, IN 47620

Telephone: 812-838-9546

Clement Magras

Commissioner

Dept Licensing \& Cons Affairs

8201 Subbase

St Thomas, VI 00802

Telephone: 809-774-3130

FAX: $\quad 809-776-0675$

Claude E. Makepeace

PMEP Inspector

KS Weights \& Measures

Box 50

DeSoto, KS 66018

Telephone: 913-267-4641

Renald Marceau

Program Officer

Canada Legal Metrology Branch

301 Laurier Ave West 5th Fl

Ottawa, K1A 0C9 026

Telephone: 613-952-2629

FAX: 613-952-1736
Member \# 28613

Antonio Lopez-Lopez

Member \# 25

Legal Metrology Director

Dereccion General De Norman

Puente De Tecamachalco 6

Mexico City, 53950

Telephone: 525-540-0451

FAX: $\quad 525-540-5153$

Member \# 11655

Forrest Joe Loyd, Jr.

Member \# 90

Engineer-Scales \& Weighing

CSX Transportation Inc

500 Water St Room 907

Jacksonville, FL 32202

Telephone: 904-359-1024

FAX: $\quad 904-359-7476$

Member \# 94

Christa Luttmann

Dir Consumer \& Public Affairs

Lucas County Auditor's Office

1 Government Center Suite 600

Toledo, $\mathrm{OH}$ 43604-2255

Telephone: 419-245-4394

FAX: $\quad 419-245-4399$

Member \# 19419

James E. Maka

Member \# 80

Administrator

HI Measurement Standards 725 Ilalo St

Honolulu, HI 96813-5524

Telephone: 808-586-0870

FAX: $\quad$ 808-586-0889

Member \# 12835

Steven A. Malone

Member \# 55

Director

NE Div of Wghts \& Meas

Box 94757/301 Centennial Mall South

Lincoln, NE 68509

Telephone: 402-471-4292

FAX: $\quad 402-471-3252$

Member \# 10211

Patrick Marino

Member \# 93t

Technical Service Manager

New Brunswick Internatl Inc

76 Veronica Ave

Somerset, NJ 08873

Telephone: 201-828-3633

FAX: 201-828-4884

Member \# 10 
Marrier

zctor

Div of Weights \& Measures

Highway 36

aul, MN 55113-3800

phone: 612-639-4010

612-639-4014

ey X. Mason

ag Chief

Wghts \& Meas Administration

U Street SE

hington, DC 20020

phone: 202-767-7923

nael A. Mattia

ctor, Risk Management

tute for Scrap Recycling

G Street N W Suite 1000

hington, DC 20038-7718

phone: $202-466-4050$

202-775-9109

\section{elique McCoy}

iector

Imbus Weights \& Measures

$\checkmark$ est Gay Street

imbus, OH 43215

phone: 614-645-7397

614-645-6675

id O. McKay

ghts \& Measures Inspector

Dept of Agriculture

N Redwood Rd

Lake City, UT 84116

phone: 801-538-7156

801-538-7126

ene A. Mechtly

essor

ersity of Illinois

E Mumford Drive

ana, IL 61801

phone: $217-344-4925$

217-333-7427
Member \# 19017

Member \# 10874

Member \# 16338

Member \# 11497

Member \# 8438

Member \# 23530

James Melgaard

Retired Director

Div Commercial Insp \& Reg

114 Hapton Drive

Pierre, SD 57501

Telephone: 605-773-3697

FAX: $\quad 605-773-4117$
Vernon Lee Massey

Sealer

Shelby Co Weights \& Measures

157 Poplar Suite 402

Memphis, TN 38103

Telephone: 901-576-3920

FAX: $\quad$ 901-576-3796

Kristi Maxson-Esqui

Agricultural Inspector II

KS Weights \& Measures

Rt 2 Box 67A

Hope, KS 67451

Telephone: 913-267-4641

Stephen E. McGuire

Metrologist

IL Dept of Agriculture

801 E Sangamon Ave

Springfield, IL 62794-9281

Telephone: 217-782-3817

FAX: $\quad 217-524-5960$

Member \# 10126

Member \# 3634

Member \# 11218

Member \# 4000

Member \# 2286

Marketing Director

Pitt Way

Telephone: 412-826-5052

FAX: $\quad 412-826-5444$

Member \# 39 
Charles W. Michell, Jr.

Staff Loss Control Rep.

Shell Oil Company

PO Box 2463 Rm 2286 One Shell Plaza

Houston, TX 77001

Telephone: 713-241-0455

FAX: 713-241-1139

Joan Mindte

Training Coordinator

NIST

Adm Bldg 101 A617 Div 213

Gaithersburg, MD 20899

Telephone: 301-975-4003

FAX: 301-926-0647

Gene Mittermaier

Representative

PMAA

3401 Kirkwood Drive

Ft Wayne, IN 46805

Telephone: $219-484-8827$

FAX: 219-484-8827

Charles W. Moore

Inspector

Madison Co Wghts \& Meas

Govt Center 16 E 9th St Box 15

Anderson, IN 460161

Telephone: $317-641-9662$

FAX: $\quad 317-641-9486$

Louis G. Moreno

Director

Cumberland Co W \& M Cons Prot

788 East Commerce St

Bridgeton, NJ 08302

Telephone: 609-453-2204

FAX: 609-453-2206

Jeanne M. Mourrain

Chemist

US EPA

410 M Street SW 05-331

Washington, DC 20460

Telephone: $202-260-8722$

FAX: 202-260-1381
Member \# 9082

Stanley K. Millay

Weights \& Measures Supervisor

Member \# 74

ME Dept Agriculture

Div of Regulations Station 28

Augusta, ME 04333

Telephone: 207-287-3841

FAX: 207-287-7548

Member \# 12500

Robert W. Mitchell

Lab Manager R \& D

Hunt-Wesson Foods

1645 W Valencia Drive

Fullerton, CA 92633-3899

Telephone: 714-680-1321

FAX: 714-680-2185

Member \# 25605

Kelleen K. Moody

Lab Equip Technician

AZ Dept of Weights \& Measures

9535 E Doubletree Ranch Rd

Scottsdale, AZ 85258-5539

Telephone: 602-255-5211

FAX: $\quad 602-255-1950$

Member \# 2739

James M. Moreillon

Inspector

Floyd Co Wghts \& Meas

1203 Westwood Lane

New Albany, IN 47150

Telephone: 812-948-5351

Member \# 22182

Thomas L. Morrow

Business Unit Manager

TEC America Inc

19300 S Hamilton Ave Suite 200

Gardena, CA 90248

Telephone: $310-329-9600$

FAX: $\quad 310-329-1490$

Member \# 25569

Slierrill Mullenmaster

Regional Supervisor

Department of Public Service

2277 Highway 36

St. Paul, MN 55113

Telephone: 612-639-4010
Member \# 2423

Member \# 255

Member \# 109

Member \# 3458

Member \# 3380 
ry M. Mullins

Zuel Specialist

orgia Power Company

Box 4545

anta, GA 30302

ephone: 404-526-7738

404-526-6948

ry Murray

ef Engineer

yne Div-Dresser Industries

W College Ave PO Box 1859

sbury, MD 21802-1859

ephone: 410-546-6690

X: $\quad 301-548-6913$

an M. Nelson

ector Weights \& Measures

Dept of Consumer Protection

Capitol Avenue

rtford, CT 06106

ephone: 203-566-4778

X: $\quad 203-566-7630$

rick E. Nichols

ector Weights \& Measures

meda Co Wghts \& Measures

Fifth Street

kland, CA 94607-4189

ephone: 510-268-7343

X: $\quad 510-444-3879$

Noble

partment Engineer

is Mason Co Inc

Box 30020

arillo, TX 79177

ephone: $806-477-4301$

ureen Noll

- Inspector II

Weights \& Measures

1 Box 203 B

awkie, KS 66070

ephone: 913-267-4641
Member \# 25530

Ronald D. Murdock

Member \# 8366

rogram Mgr Meas Sec Stds Div

NC Dept of Agriculture

PO Box 27647 Dept SD

Raleigh, NC 27611

Telephone: 919-733-3313

FAX: $\quad 919-715-0524$

Member \# 5879

Curtis Musil

Owner

Precision Scale

PO Box 183

Brewster, KS 67762

Telephone: 913-694-2230

Member \# 2515

Karl Newell

Office of Weights \& Measures

NIST

Admin $101 \mathrm{Rm}$ A617

Gaithersburg, MD 20899

Telephone: 301-975-4013

FAX: $\quad 301-926-0647$

Member \# 110

Phil G. Nichols

Regional Manager

WWIB Transportation Service

906 Olive St Suite 906

St Louis, MO 63119

Telephone: 314-231-1919

FAX: 314-231-0044

Member \# 13479

Garry N. Nolan

Senior Weights \& Measures Spl

Federal Express Corp

2828 Business Park Drive

Memphis, TN 38118-2811

Telephone: 901-375-6566

FAX: $\quad 901-375-6313$

Thomas O'Connor

Member \# 5271

Member \# 8180

Director Technical Service

National Grain \& Feed Assn

1201 New York Ave NW Suite 830

Washington, DC 20005

Telephone: 202-289-0873

FAX: $\quad 202-289-5388$
Member \# 5660

Member \# 20038

Member \# 9879

Member \# 19716 
John L. O'Neill

$1317 \mathrm{~S}$ Elm

Ottawa, KS 66067

Telephone: 913-242-2374

Henry V. Oppermann

General Physical Scientist

NIST

Admin $101 \mathrm{Rm} \mathrm{A617}$

Gaithersburg, MD 20899

Telephone: 301-975-4008

FAX: $\quad 301-926-0647$

Tammy Packer

Packaging Services Coordinator

Georgia-Pacific Corp

233 Peachtree Street NE Ste 1500

Atlanta, GA 30303

Telephone: 404-527-8913

FAX: $\quad 404-527-0070$

Michael A. Peery

General Manager

Central Marketing

Shelby, NE 68662-0128

Telephone: 402-527-5591

FAX: $\quad 402-527-5160$

Paul L. Peterson

Industrial Specialist

USDA Packers \& Stockyards Adm

14th \& Independence SW Rm 3414 S

Washington, DC 20250

Telephone: 202-720-5841

FAX: $\quad 202-690-2173$

David Phillips

Director of Technology

Natural Gas Vehicle Coalition

1515 Wilson Blvd Ste 1030

Arlington, VA 22209

Telephone: 703-527-3022

FAX: 703-527-3025
Member \# 3389

Member \# 25571

Don Onwiler

Moisture Tester Inspector

NE Public Service Comm

PO Box 94927

Lincoln, NE 68509

FAX: $\quad 402-471-0254$

Member \# 25568

James E. Peeples

Director Legislative Affairs

Information Resources Inc

1925 N. Lynn Street, Suite 1000

Arlington, VA 22209

Telephone: 703-528-2500

FAX: 703-528-1603

Member \# 25607

James S. Pekor

Manager-Energy Services

Equitable Gas Co

Allegheny Center Mall Suite 2000

Pittsburgh, PA 15212-5352

Telephone: $412-442-3106$

FAX: $\quad 412-442-3155$

Member \# 248

Cal Phelps

Food Lion Inc

PO Box 1330

Salisbury, NC 28144-1330

Telephone: 704-633-8250Ext2572
Telephone: 402-471-3101

Member \# 25!

Member \# 28

Member \# 750

Member \# 239

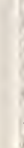

Member \# 130 .

DeVern H. Phillips

Member \# 106
State Sealer

KS Weights \& Measures

2016 SW 37th St

Topeka, KS 66611-2570

Telephone: 913-267-4641

FAX: $\quad 913-267-2518$ 
Phillips

suty Inspector

laware Co Weights \& Measures

unty Bldg 100 West Main Room 20

uncie, IN 47305

lephone: $317-747-7714$

chard L. Philmon

ogram Coordinator

Dept of Agriculture

$1 \mathrm{E}$ Sangamon Ave

ringfield, IL 62794-9281

lephone: $217-782-3817$

X: 217-524-7801

nald Pierce

Ir Inspector II

Weights \& Measures

) Box 66

nith Center, KS 66967

lephone: 913-267-4641

iil Pittman

anch Manager

S Control Services Inc

09 Linbar Drive Suite 600

ishville, TN 37211

lephone: $615-831-1044$

IX: $\quad 615-831-1236$

an Porter

ogram Manager Wghts \& Meas

I Dept of Agriculture

1 W Badger Road Box 8911

adison, WI 53708

:lephone: 608-266-7244

IX: $\quad 608-266-7205$
Member \# 28854

Michelle I. Phillips

Member \# 9076

Assistant Administrator

Indianapolis Wghts \& Meas

200 E Washington St Ste 1760

Indianapolis, IN 46204-3325

Telephone: $317-236-4272$

Member \# 9168

Richard Pierce

Leader Type Approval Group

USDA FGIS

10383 N Executive Hills Blvd

Kansas City, MO 64153

Telephone: 816-891-0449

FAX: $\quad 816-891-8070$

Member \# 8179

Cathryn F. Pittman

Technologist

TN Dept of Agr Wghts \& Meas

440 Hogan Rd PO Box 40627

Nashville, TN 37204

Telephone: 615-360-0159

FAX: 615-360-0194

Member \# 8671

Douglas Pond

Science Director

IN Commodity Licensing

Ista Street 414150 West Market

Indianapolis, IN 46204

Telephone: $317-232-8770$

FAX: $\quad 317-232-1362$

Member \# 8752

Galen Postier

Agr Inspector III ACAP

KS Dept of Agriculture

2016 SW 37th Street

Topeka, KS 66611-2570

Telephone: 913-267-4641

Member \# 11172

Member \# 28839
Member \# 13794

Member \# 2403

Member \# 25609

Member \# 10620
[Tence Powell

Inspector Spec II

E Div of Wghts \& Meas ox 74757

nciln, NE 68509

lephone: $402-471-4292$

\section{Arati Prabhakar \\ Director}

NIST

Administration Building Rm 1134

Gaithersburg, MD 20899

Telephone: 301-975-2300 
Edwin J. Price

Director for Consumer Programs

TX Dept of Agriculture

PO Box 12847

Austin, TX 78711

Telephone: 512-463-7607

FAX: $\quad 512-475-1618$

David W. Quinn

Vice President Heavy Cap Mkt

Fairbanks Scales

239 69th Avenue

Meridian, MS 39301

Telephone: 601-483-4311

FAX: $601-485-2733$

\section{Myron Rau}

Motor Carrier Commander

SD Highway Patrol

500 East Capitol

Pierre, SD 57501

Telephone: $605-773-3105 \times 4925$

FAX: 605-773-6046

\section{Robert A. Reinfried}

Technical Assistant

Scale Manufacturers Assn

932 Hungerford Drive \#36

Rockville, MD 20850

Telephone: 301-738-2448

FAX: $\quad 301-738-0076$

\section{Robert E. Reynolds}

President

Downstream Alternatives Inc

2982 Dogwood Court, PO Box 10653

Bremen, IN 46506

Telephone: $219-546-4204$

FAX: 219-546-5845

\section{Shawn Rich}

Agr Inspector II

KS Weights \& Measures

$701 \mathrm{~S} 13$ th

Dodge City, KS 67801

Telephone: $913-267-4641$
Member \# 2434

Gale Prince

Manager Regulatory Compliance

Kroger Co

1014 Vine St

Cincinnati, OH 45201

Telephone: 513-762-4209

FAX: $\quad 513-762-4372$

Member \# 11509

James H. Rampton

Physical Scientist

USDA FGIS

10383 N Executive Hills Blvd

Kansas City, MO 64079

Telephone: 816-891-0450

FAX: $\quad 816-891-8070$

Member \# 11378

Michel Raymond

Agr Inspector II

KS Weights \& Measures

RR 1 Box 140 D

Kingman, KS 67068

Telephone: $913-267-4641$

Member \# 9388

Stanley C. Retrum

Staff Engineer

Shell Oil Co

777 Walker-TSP1132

Houston, TX 77002

Telephone: 713-241-1794

FAX: $\quad$ 713-241-7166

Member \# 10653

Sliaron Rlioades

Chief Enforcement Officer

AZ Dept of Wghts \& Meas

9535 E Doubletree Ranch Rd

Scottsdale, AZ 85258-5539

Telephone: 602-255-5211

FAX: $\quad 602-255-1950$

Dean Richards

Member \# 10178

Petroleum Inspector

MO Dept of Agriculture

420 Sanderson Drive

Richmond, MO 64085

Telephone: 816-776-5359
Member \# 106

Member \# 112 .

Member \# 115t

Member \# 4648

Member \# 8157 
a J. Robinson

ssistant Vice President

a of American Railroads

St NW Suite 6200

shington, DC 20001

ephone: 202-639-2204

र: 202-639-2930

n A. Rogers

gram Manager

Weights \& Measures Bureau

Box 1163 Rm 402

amond, VA 23209-1163

ephone: 804-786-2476

x: 804-786-1571

Iter P. Rubert

ervisor Grain Weighing

radian Grain Commission

Main Street

anipeg, R3C 3 G8

ephone: 204-983-7167

sert B. Sabistina

ef Inspector

ional Hardwood Lumber Assn

Box 34518

mphis, TN 38184

ephone: $901-377-1818$

901-382-6419

hard D. Sanne

:cutive Vice President

raska Grain \& Feed Assn

3 Lincoln Mall Ste 200

coln, NE 68508-3911

ephone: 402-476-6174

402-476-3401

ry Saunders

g 101 Room A 603

itherburg, MD 20899

ephone: 301-975-2396

X: $\quad 301-963-2871$
Member \# 743

Juan Rodriguez

Member \# 25462

Secretary Lic Enf \& Comp

PR Dept of Consumer Affairs

PO Box 41059 Minillas Station

San Juan, PR 00940-1059

FAX: $\quad 809-723-2715$

Member \# 9374

Tim Rogers

Member \# 10182

Petroleum Inspector

MO Dept of Agriculture

Route 1 Box 229

Billings, MO 65610

Telephone: 417-744-2046

Member \# 25529

Thomas E. Runyon

Member \# 1530

Executive Vice President

Seedburo Equip Co

1022 W Jackson Blvd

Chicago, IL 60607-2990

Telephone: $312-738-3700$

FAX: $\quad 312-738-3544$

Member \# 1854

Albert E. Salerno

President

Syracuse Scale Co Inc

158 Solar St

Syracuse, NY 13204

Telephone: $315-476-9696$

FAX: $\quad 315-476-3743$

Member \# 2000

Mike P. Sargent

Sales Manager

Beowulf Corporation

345 Nick Fitcheard Road

Huntsville, AL 35806

Telephone: 205-859-0004

FAX: 205-859-0008

Member \# 25608

Member \# 12232

Member \# 5358
Roger D. Schaefer

Member \# 25562

Application

Intersystems Inc

13300 I Street

Omaha, NE 68137

Telephone: 402-330-1500

FAX: $\quad 402-330-3350$ 
Dennis Schaffer

Marketing Product Manager

TEC America Inc

19300 Hamilton Ave Suite 200

Gardena, CA 90248

Telephone: $310-329-9600$

FAX: $\quad 310-329-1490$

Fred Seeber

Shore Sales

RR2 Box 7A

Paxton, IL 60957

Telephone: $217-379-4702$

FAX: 217-379-3995

Herbert Sehgel

Supervisor of Tech Services

NJ Weights and Measures

1261 US Route 1 \& 9 South

Avenel, NJ 07001

Telephone: 908-815-4840

\section{George S. Shefcheck}

Field Op Mgr Measurement Stds

Oregon Dept of Agriculture

635 Capitol St NE

Salem, OR 97310-0010

Telephone: 503-378-4689

FAX: $\quad 503-378-6525$

\section{Joseph Silvestro}

Superintendent

Consumer Protection/Wgts \& Msr

152 N Broad St Box 337

Woodbury, NJ 08096

Telephone: $609-853-3358$

FAX: $\quad 609-853-2770$

\section{Galen Simon}

Agricultural Inspector

KS Weight \& Measures

2024 NW 50th

Topeka, KS 66618

Telephone: 913-267-4641
Member \# 3911

Timothy W. Scott

Member \# 3780

Engineering Manager

Brooks Instrument

PO Box 450

Statesboro, GA 30458

Telephone: 912-764-5471

FAX: $\quad$ 912-764-2538

Member \# 5177

Cliris Seested

Member \# 2554

SGS Control Services Inc

20 Lafayette Street

Carteret, NJ 07008

Telephone: 908-541-7200

FAX: $\quad$ 908-541-1336

Member \# 6043

Don Slieets

Agr Inspector III ACAP

KS Dept of Agriculture

2016 SW 37th Street

Topeka, KS 66611-2570

Telephone: 913-267-4641

Member \# 6241

Jolın Slieplıard

Member \# 1063

nspector

MO Dept of Agriculture

2904 N 3 Ter

Blue Springs, MO 64015

Telephone: $314-751-4278$

Member \# 2809

Kendrick J. Simila

Adm Meas Stds Div

OR Dept of Agriculture 635 Capitol Street N E

Salem, OR 97310-0110

Telephone: 503-373-0964

FAX: $\quad 503-378-6525$

Curtis E. Simpkins

Inspector

Grant Co Wghts \& Meas

401 South Adams St

Marion, IN 46952

Telephone: $317-668-8871$ x170 
y Skinner

spector

O Dept of Agriculture

Box 881

imdenton, MO 65020

lephone: $314-346-4718$

\section{David Smith}

rector Standards Division

¿ Dept of Agriculture

D. Box 27647

aleigh, NC 27611

lephone: 919-733-3313

IX: $\quad 919-715-0524$

vain Snider

ogram Administrator

issouri Weights \& Measures

Box 630

fferson City, MO $65102-0630$

lephone: 314-751-5639

IX: 314-751-0281

\section{Sperling}

eneral Counsel

atural Gas Coalition

15 Wilson Blvd Ste 1030

slyn, VA 22209

lephone: 703-527-3022

1omas M. Stabler

ur Environmental \& Reg Affair ettler-Toledo Inc

) Box 1705

Jumbus, OH 43216

lephone: $614-438-4548$

IX: $\quad 614-438-4646$

chard Stair

zricultural Inspector III

Dept of Agriculture

$16 \mathrm{SW} 37$ th Street

speka, KS 66611-2570

elephone: 913-267-4641
Member \# 9810

John C. Skuce

Manager Mechanical Engineering

Member \# 10442

Smith Meter Inc

PO Box 10428

Erie, PA 16514-0428

Telephone: 814-898-5405

FAX: $\quad 814-899-3414$

Member \# 2391

Robert M. Smith

Sr. Electronic Engineer

Smith Meter Inc

1602 Wagner Avenue

Erie, PA 16514

Telephone: $814-898-5000$

FAX: $\quad 814-899-3414$

Member \# 28852

Louis F. Sokol

President Emeritus

US Metric Association

255 Mountain Meadows Rd

Boulder, CO 80302-9256

Telephone: 303-443-9728

Member \# 25575

Kirk Sponsler

Weights \& Measures Insp I

MO Dept of Agriculture

PO Box 630

Jefferson City, MO 65102-0630

Telephone: $314-751-3440$

FAX: $\quad 314-751-0281$

Member \# 3119

Don E. Stagg

Member \# 3317

Director Wghts \& Meas

AL Dept of Agr \& Industry

PO Box 3336

Montgomery, AL 36109-0336

Telephone: $205-242-2613$ or 2614

FAX: 205-240-3135

Member \# 10789

Rex Stapel

Member \# 28416

Member \# 4449

Member \# 1021

Member \# 25563

Agriculture Inspector

KS Weights \& Measures

Box 14

Meriden, KS 66512

Telephone: 913-267-4641 
John J. Steinberger

Chief Weights and Measures

OH Dept of Agriculture

8995 East Main Street Bldg \#5

Reynoldsburg, OH 43068-3399

Telephone: 614-866-6361

FAX: $\quad 614-866-4174$

\section{Fred Stone}

Executive Director

Nebraska Petroleum Marketers

1320 Lincoln Mall

Lincoln, NE 68508

Telephone: 402-474-6691

FAX: $\quad 402-474-2510$

\section{Chuck Strawn}

Director of Marketing

Schlumberger

1310 Emerald Road

Greemwood, SC 29646-8800

Telephone: 803-942-2247

Billy W. Sullivant

Laboratory Supervisor

AR Bureau of Standards

4608 West $61 \mathrm{St}$

Little Rock, AR 72209

Telephone: 501-324-9680

FAX: $\quad 501-562-7605$

\section{Chester Szyndrowski}

Inspector

East Chicago Wghts \& Meas

1102 W 151 Street

East Chicago, IN 46312

Telephone: 219-397-3409

\section{Larry E. Thomas}

Chief Inspector

Terre Haute Wghts \& Meas

3010 North 5 th St

Terre Haute, IN 47804

Telephone: $812-466-1546$
Member \# 5178

Gerald E. Stitt

AVP Transportation

Member \# 2

Archer Daniels Midland Co

PO Box 1470

Decatur, IL 62525

Telephone: 217-424-5951

FAX: $\quad 217-424-5381$

Member \# 25556

Louis E. Straub

Chief Weights \& Measures

MD Dept of Agriculture

50 Harry S Truman Parkway

Annapolis, MD 21401

Telephone: $410-841-5790$

FAX: $\quad 410-841-2765$

Member \# 22148

Richard C. Suiter

Agr Inspector Supervisor

NE Div of Wghts \& Meas PO Box 94757

Lincoln, NE 68509

Telephone: 402-471-4292

FAX: $402-471-3252$

Member \# 2466

Dale W. Swafford

PMEP Inspector

KS Weights \& Measures

1417 Starkey

Augusta, KS 67010

Telephone: 913-267-4641

Member \# 10302

Ellen Thomas

Mgr Corp QA and Compliance

Borden Inc

1105 Schrock Road

Columbus, $\mathrm{OH} 43229$

Telephone: 614-431-6625

FAX: 614-431-6611

Aves D. Thompson

Chief

AK Div of Measurement Stds

12050 Industry Way Bldg O

Anchorage, AK 99515

Telephone: $907-345-7750$

FAX: $\quad 907-345-6835$
Member \# 2

Member \# 6

Member \# 9

Member \# 5

Member \# 11: 
* airman Thompson

suth Point Ethanol

Id US 52, Cnty Rd. 1, PO Box 1004

buth Point, $\mathrm{OH} 45680$

slephone: $614-377-2765$

\section{athleen A. Thuner}

घr Comm Sealer Wghts \& Meas

in Diego Co Dept of Agr

i55 Overland Ave Bldg 3

in Diego, CA 92123-1292

elephone: 619-694-2741

4X: $\quad 619-565-7046$

\section{Imes E. Tipton}

spector

O Dept of Agriculture

R 1 Box 43

ewtown, MO 64667

elephone: $314-751-3117$

aryl E. Tonini

echnical Director

ale Manufacturers Assn

12 Hungerford Drive \#36

ockville, MD 20850

elephone: 703-821-0766

4X: $\quad 703-821-0766$

\section{obert M. Traettino}

ice President of Quality

iquid Controls Corp

15 Albrecht Drive

ake Bluff, IL 60044

elephone: 708-295-1056

4X: $\quad 708-295-1089$

imes C. Truex

ispection Mgr Wghts \& Meas

$\mathrm{H}$ Dept of Agriculture

$95 \mathrm{E}$ Main St

eynoldsburg, $\mathrm{OH}$ 43068-3399

elephone: $614-866-6361$

AX: $\quad 614-866-4174$
Member \# 28614

Merrill S. Thompson

Member \# 590

Attorney

Arnold \& Porter

PO Box 8500 Main Street

Bridgeton, IN 47836

Telephone: $317-548-2211$

FAX: $\quad 317-548-2214$

Member \# 5869

Ken Tichota

Member \# 7165

Agr Inspector Spec II

NE Div of Wghts \& Meas

Box 94757

Lincoln, NE 68509

Telephone: 402-471-4292

Member \# 10185

Allen Tolbers

Member \# 10632

Inspector

MO Dept of Agriculture

1000 South Madison

Sedalia, MO 65301

Telephone: $314-751-4278$

Member \# 1336

David E. Torska

Purchasing Manager

Georgia-Pacific

233 Peachtree Street

Atlanta, GA 30303

Telephone: 404-220-6912

FAX: 404-527-0070

Member \# 8923

Ron Troutt

Inspector

MO Dept of Agriculture

R R 1

Knox City, MO 63446

Telephone: $816-434-5230$

Member \# 2178

Richard Tucker

Member \# 9070

Member \# 25567

Member \# 9931

Manager Dept of Authorities

Tokheim Corporation

10501 Corporate Drive

Ft Wayne, IN 46845

Telephone: 219-423-2552 Ext2410

FAX: $\quad 219-482-5030$ 
Ann H. Turner

Weights \& Measures Coordinator

Natl Conf on Wts \& Meas

PO Box 4025

Gaithersburg, MD 20885

Telephone: 301-975-4012

FAX: $\quad 301-926-0647$

David E. Varner

Technical Specialist

Dow Chemical Co

Bldg OC-1120 2301 Brazosport Blvd

Freeport, TX 77541-3257

Telephone: 409-238-3041

FAX: $\quad 409-238-0265$

\section{Robert Voltmann}

Director of Policy Development

Natl Industrial Trans League

1700 N Moore Street \#1900

Arlington, VA 22209

Telephone: 703-524-5011

FAX: 703-524-5017

Steve Wadley

Petroleum Inspector

MO Dept of Agriculture

4664 Henwick Lane

Jefferson City, MO 65109

Telephone: $314-893-2315$

David J. Wall

Reg Customer \& Tech Service

Saybolt Inc

400 Swenson Drive

Kenilworth, NJ 07033

Telephone: 908-245-3100

FAX: $\quad 908-245-2747$

Eddie R. Walsh

Manager

Memphis Weights \& Measures

590 Washington St

Memphis, TN 38105

Telephone: 901-528-2905
Member \# 236

Gary R. Vanblarcum

Member \# 255

Marketing Specialist

USDA AMS Market Administrator 14827 W 95th Street

Lenexa, KS 66215-5520

Telephone: 913-599-0630

FAX: $\quad 913-599-0614$

Member \# 1118

Gilles Vinet

Program Officer

Canada Legal Metrology Branch

307 Laurier Ave West 5th Floor

Ottawa, K1A 0C9

Telephone: 613-952-2628

FAX: 613-952-1736

Member \# 28853

Terry Voss

Asst VP Rail Transportation

AG Processeing Inc

PO Box 2047

Omaha, NE 68103-2047

Telephone: 402-498-5579

FAX: $\quad 402-498-5504$

Member \# 13426

William G. Walker

Trade District Manager

Ross Laboratories

37 Clifford Road

Sudbury, MA 01776-3410

Telephone: 508-443-3089

FAX: $\quad 508-443-0069$

Member \# 4635

David R. Wallace

Chief Meas Standards Section

CO Dept of Agriculture

3125 Wyandot St

Denver, CO 80211

Telephone: 303-866-2845

FAX: $\quad 303-480-9236$

Member \# 3519

William D. Waltman

Member \# 8182

Agr Inspector II

KS Weights \& Measures

PO Box 87

Paxico, KS 66526

Telephone: 913-267-4641
Member \# 255

Member \# 119

Member \# 235 .

Member \# 447: 
rry Wang

irector of Engineering

\& $D$ Engineering Inc

55 McCandless Drive

ilpitas, CA 95035

lephone: 408-263-5333

AX: $\quad 408-263-0119$

tto K. Warnlof

IST

Jmin Bldg A625

aithersburg, MD 20899

slephone: 301-975-4026

4X: $\quad 301-926-0647$

anley I. Warshaw

irector Office of Stds Serv

IST

503 Admin Bldg

aithersburg, MD 20899

slephone: 301-975-4001

1X: 301-963-2871

obert A. Webb

easurement Coordinator arathon Oil Company

9 South Main Street

ndley, $\mathrm{OH} 45840$

lephone: 419-422-2121

AX: $\quad 419-421-2509$

Jnald J. Weick

onsumer Protection

speka Weights \& Measures

5 East 7th Rm 353

opeka, KS 66603

lephone: 913-295-3883

IX: $\quad 913-295-3850$

ary D. West

rector Stds \& Consumer Serv

Member \# 8345

Member \# 3996

Raymond R. Wells

President

Sensitive Measurement Inc

200 S Westhampton St PO Box 72

Pemberton, NJ 08068

Telephone: 609-894-2292

FAX: 609-894-0387

Richard L. Whipple

W \& M Coordinator

NIST

Admin Bldg $101 \quad$ A617

Gaithersburg, MD 20899

Telephone: 301-975-3990

FAX: $\quad 301-926-0647$

) Box 30005 Dept 3170

5 Cruces, NM 88003-0005

lephone: 505-646-1616

505-646-3303
Member \# 7145

Member \# 9067

Member \# 16558

Member \# 684

Member \# 3484

Member \# 3486 
George Whittaker

Manager, B \& B Budgets \& Weigh CSX Transportation

500 Water Street, P.O. Box 45052

Jacksonville, FL 32232-5052

Telephone: 904-359-1052

FAX: $\quad$ 904-359-7476

Robert E. Williams

Factory Services

Procter \& Gamble Company

PO Box 13220

Sacramento, CA 95813

Telephone: 916-381-9618

FAX: $\quad$ 916-381-9707

\section{Danny Willis}

Director Wghts \& Meas

KY Dept of Agriculture

106 West 2nd Street

Frankfort, KY 40601

Telephone: 502-564-4870

FAX: $\quad$ 502-564-6527

\section{Andrea A. Wing}

Coord of Prod \& New Tech

Texaco Refinging \& Mrkg Inc

10 UCP 10 th Floor

Universal City, CA 91608

Telephone: 818-505-2576

FAX: 818-505-2833

Arthur W. Woodcock

PMEP Inspector I

KS Weights \& Measures

743 Banner Circle

Salina, KS 67401

Telephone: 913-267-4641

Richard W. Wotthlie

Supervising Insp Wghts \& Meas

MD Dept of Agriculture

50 Harry S Truman Parkway

Annapolis, MD 21401

Telephone: 410-841-5790

FAX: $\quad 410-841-2765$

Member \# 28837

\section{Curtis Williams}

Director Fuel Oil Laboratory

GA Dept of Agriculture

State Oil Lab 5235 Kennedy Rd

Forest Park, GA 30050

Telephone: 404-363-7597

Member \# 9941

Member \# 4207

Member \# 25511

Randall Wise

Prog Coordinator Wghts \& Meas KY Dept of Agriculture

106 West 2nd Street

Frankfort, KY 40601

Telephone: 502-564-4870

FAX: $502-564-4669$

Member \# 12837

Larry Woodson

Director Div of Inspections KS State Board of Agriculture 891 S Kansas Avenue

Topeka, KS 66612
Chris W. Wright

Product Manager

Badger Meter Inc

4545 West Brown Deer Road

Milwaukee, WI 53223

Telephone: 414-355-0400

FAX: 414-355-7499 
o Wurdeman

gr Inspector Spec II E Div of Wghts \& Meas ox 94757

ncoln, NE 68509

-lephone: 402-471-4292

Courtney Yelle

nief Sealer

acks Co Wghts \& Meas

North Main Street

oylestown, PA 18901

elephone: $215-348-7442$

AX: $\quad 215-348-2019$

ichard S. Yurek

echnical \& QA Coordinator

ybolt Inc

\O Swenson Drive

enilworth, NJ 07033

elephone: 908-245-3100

4X: $\quad 908-245-2747$

adrew A. Zards

secialist Facilities Engineer moco Oil Co

10 East Randolph Drive

nicago, IL 60601

elephone: $312-856-4073$

IX: $\quad 312-856-3401$

arold Zorlen

egional Supervisor

I Dept of Agriculture

.400 Lahser Rd Room 220

outhfield, MI 48034

elephone: $313-356-1700$

4X: $\quad 313-356-0374$
Member \# 10432

Theodore H. Yaffe

Program Manager

US Postal Service

8403 Lee Highway

Merrifield, VA 22082-8101

Telephone: 703-641-7055

FAX: $\quad 703-280-4541$

Member \# 16354

Lorelle Young

President

US Metric Association

2032 Mendon Drive

San Pedro, CA 90732

Telephone: $310-832-3763$

FAX: $\quad 818-368-7443$

Member \# 3153

Paul Zalon

Director Regulatory Affairs

Nestle USA

100 Manhattanville Rd

Purchase, NY 10577

Telephone: 914-251-3487

FAX: $\quad 914-251-3600$

Member \# 1344

Joel H. Zimmerman

Director of Technical Serv.

Member \# 13225

ConAgra Frozen Foods Co

6 ConAgra Drive

Omaha, NE 68102

Telephone: 402-595-6433

FAX: $\quad 402-595-7660$

Men 


Official Business

Permit No. G195

Penalty for Private Use $\$ 300$

FORWARDING \& RETURN POSTAGE GUARANTEED ADDRESS CORRECTION REQUESTED 